Universitat Politècnica de València

Departamento de Máquinas y Motores Térmicos

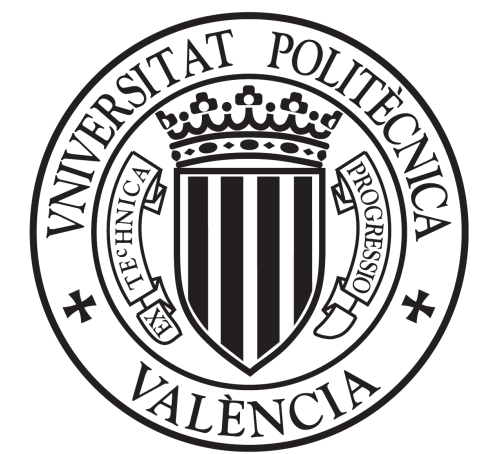

\title{
DUAL-FUEL COMPRESSION IGNITION: TOWARDS CLEAN, HIGHLY EFFICIENT COMBUSTION
}

\author{
Doctoral Thesis \\ Presented by: \\ Javier Monsalve Serrano \\ Directed by: \\ Dr. Antonio García Martínez
}

Valencia, September 2016 



\section{Doctoral Thesis}

\section{DUAL-FUEL COMPRESSION IGNITION: TOWARDS CLEAN, HIGHLY EFFICIENT COMBUSTION}

Presented by: Javier Monsalve Serrano

Directed by: Dr. Antonio García Martínez

Examining Board:

President: $\quad$ Prof. Raúl Payri Marín

Secretary: $\quad$ Prof. Juan José Hernández Adrover

Examiner: $\quad$ Dr. Michele Bardi

Reviewing Board:

Dr. Ezio Mancaruso

Dr. José Rodríguez Fernández

Dr. Michele Bardi

Valencia, September 2016 



\begin{abstract}
The more and more stringent emissions regulations, together with the greater fuel economy demanded by vehicle users, impose a clear objective to researchers and engine manufacturers: look for the maximum efficiency with the minimum pollutant emissions levels.

The conventional diesel combustion is a highly efficient process, but also leads to high levels of NOx and soot emissions that require using aftertreatment systems to reduce the final levels released to the environment. Since these systems incur in higher costs of acquisition and operation of the engine, the scientific community is working on developing alternative strategies to reduce the generation of these pollutants during the combustion process itself.
\end{abstract}

The literature shows that the new combustion modes based on promoting low temperatures during this process, offer high efficiency and very low NOx and soot levels simultaneously. However, after years of investigation, it can be concluded that these techniques cannot be applied in the whole engine operating range due to, among others, factors like the low control of the combustion process. In recent years, it has been demonstrated that the dual-fuel combustion technique allows to overcome this limitation thanks to the additional degree of freedom provided by the capacity of modulating the fuel reactivity depending on the engine operating conditions. This characteristic, together with the near-zero NOx and soot levels obtained with this technique, has encouraged the scientific community to deeply investigate the dual-fuel combustion. In this sense, former works confirm the advantages previously described, concluding that still exist some limitations to be tackled, as well as some margin for improving the potential of this combustion concept.

The general objective of the present doctoral thesis is to contribute to the understanding of the dual-fuel combustion mode, with the particular aim of exploring different ways to improve its efficiency. For this purpose, it has been experimentally evaluated different options such as the modification of the engine operating parameters, specific designs of the piston geometry or the use of alternative fuels.

With the aim of answering some of the questions found in the literature, the first part of each study has been dedicated to perform a detailed analysis of the influence of each particular strategy on the dual-fuel operation at low load. Later, it has been checked the ability of each option to extend the dual-fuel operating range towards higher engine loads. It is interesting to note that the analysis of some results has been supported by CFD calculations, which have allowed to understand some local phenomena occurring during the dual-fuel combustion process, which cannot be confirmed only from the experimental point of view.

Finally, taking into account the knowledge acquired during the different studies performed, the last chapter of results has been devoted to evaluate the ability of the dual-fuel concept to operate over the whole engine map, as well as to identify the possible limitations that this technique presents from the technological point of view. 


\section{Resumen}

Las cada vez más restrictivas normativas anticontaminantes, junto con la demanda de motores con menor consumo de combustible por parte de los usuarios, imponen un claro objetivo a investigadores y fabricantes de motores: la búsqueda de la máxima eficiencia con los mínimos niveles de emisiones contaminantes.

La combustión diésel convencional ofrece una alta eficiencia, pero a su vez da lugar a elevadas emisiones de NOx y hollín que requieren del uso de sistemas de postratamiento para reducir los niveles finales emitidos al ambiente. Dado que estos sistemas incurren en mayores costes de adquisición y operación del motor, la comunidad científica está trabajando en el desarrollo de distintas estrategias para reducir la generación de estos contaminantes durante el propio proceso de combustión.

La literatura demuestra que los nuevos modos de combustión basados en promover bajas temperaturas durante este proceso, ofrecen simultáneamente una elevada eficiencia y muy bajos niveles de NOx y hollín. Sin embargo, tras años de investigación, se puede llegar a la conclusión de que estas técnicas no pueden ser aplicadas en todo el rango de operación del motor debido a, entre otros, factores como el escaso control sobre el proceso de combustión. En los últimos años, se ha demostrado que la técnica de combustión dual-fuel permite superar esta limitación gracias al grado de libertad adicional que supone la capacidad de modular la reactividad del combustible en función de las condiciones de operación del motor. Esta característica, junto con los casi nulos niveles de NOx y hollín que proporciona, ha despertado un gran interés sobre la comunidad científica. En este sentido, trabajos precedentes confirman las ventajas que este modo de combustión ofrece, demostrando a su vez que aún existen una serie de limitaciones por abordar, así como cierto margen por explotar para mejorar el potencial de este concepto.

La presente tesis doctoral plantea como objetivo general el contribuir a la comprensión del modo de combustión dual-fuel, y de manera particular explorar distintas vías con objeto de mejorar su eficiencia. Para ello, se han evaluado de manera experimental diferentes opciones que van desde la modificación de los parámetros de operación del motor, hasta diseños específicos de la geometría del pistón o el uso de combustibles alternativos.

Tratando de responder algunas de las cuestiones encontradas en la literatura, en cada uno de los estudios se ha realizado un análisis detallado de la influencia del parámetro en cuestión sobre la operación del motor a baja carga, y a su vez se ha comprobado la capacidad de cada una de estas opciones de extender la operación del motor hacia cargas más elevadas. Cabe destacar que el análisis de ciertos resultados se ha apoyado en cálculos numéricos CFD, los cuales han permitido entender ciertos fenómenos locales que ocurren durante el proceso de combustión dual-fuel, y que no pueden ser confirmados únicamente desde el punto de vista experimental.

Finalmente, teniendo en cuenta el conocimiento adquirido en los diferentes estudios realizados, el último capítulo de resultados se ha dedicado a evaluar la capacidad de operación del concepto dual-fuel sobre todo el rango de funcionamiento del motor, así como a identificar las posibles limitaciones que esta técnica presenta desde el punto de vista tecnológico. 


\section{Resum}

Les cada vegada més restrictives normatives anticontaminants, juntament amb la demanda de motors amb menor consum de combustible per part dels usuaris, imposen un clar objectiu a investigadors i fabricants de motors: la cerca de la màxima eficiència amb els mínims nivells d'emissions contaminants.

La combustió dièsel convencional ofereix una alta eficiència, però al seu torn dóna lloc a elevades emissions de NOx i sutge que requereixen de l'ús de sistemes de postractament per a reduir els nivells finals emesos a l'ambient. Atès que aquests sistemes incorren en majors costos d'adquisició i operació del motor, la comunitat científica està treballant en el desenvolupament de diferents estratègies per a reduir la generació d'aquests contaminants durant el propi procés de combustió.

La literatura demostra que les noves tècniques de combustió basades a promoure baixes temperatures durant aquest procés, ofereixen simultàniament una elevada eficiència i molt baixos nivells de NOx i sutge. No obstant açò, després d'anys de recerca, es pot arribar a la conclusió que aquestes tècniques no poden ser aplicades en tot el rang d'operació del motor a causa de, entre uns altres, factors com l'escàs control sobre el procés de combustió. En els últims anys, s'ha demostrat que la tècnica de combustió dual-fuel permet superar aquesta limitació gràcies al grau de llibertat addicional que suposa la capacitat de modular la reactivitat del combustible en funció de les condicions d'operació del motor. Aquesta característica, juntament amb els quasi nuls nivells de NOx i sutge que proporciona, ha despertat un gran interès sobre la comunitat científica. En aquest sentit, treballs precedents confirmen els avantatges que aquesta tècnica de combustió ofereix, demostrant al seu torn que encara existeixen una sèrie de limitacions per abordar, així com cert marge per explotar per a millorar el potencial d'aquest concepte.

La present tesi doctoral planteja com a objectiu general el contribuir a la comprensió de la tècnica de combustió dual-fuel, i de manera particular explorar diferents vies a fi de millorar la seua eficiència. Per a açò, s'han avaluat de manera experimental diferents opcions que van des de la modificació dels paràmetres d'operació del motor, fins a dissenys específics de la geometria del pistó o l'ús de combustibles alternatius.

Tractant de respondre algunes de les qüestions trobades en la literatura, en cadascun dels estudis s'ha realitzat una anàlisi detallada de la influència del paràmetre en qüestió sobre l'operació del motor a baixa càrrega, i al seu torn s'ha comprovat la capacitat de cadascuna d'aquestes opcions d'estendre l'operació del motor cap a càrregues més elevades. Cal destacar que l'anàlisi de certs resultats s'ha recolzat en càlculs numèrics CFD, els quals han permès entendre certs fenòmens locals que ocorren durant el procés de combustió dual-fuel, i que no poden ser confirmats únicament des del punt de vista experimental.

Finalment, tenint en compte el coneixement adquirit en els diferents estudis realitzats, l'últim capítol de resultats s'ha dedicat a avaluar la capacitat d'operació del concepte dual-fuel en tot el rang de funcionament del motor, així com a identificar les possibles limitacions que aquesta tècnica presenta des del punt de vista tecnològic. 

a mis padres a Anabel 



\section{Agradecimientos - Acknowledgements}

La realización de esta tesis doctoral ha sido posible gracias a la colaboración, de manera directa o indirecta, de muchas personas a las que me gustaría dedicar unas líneas de agradecimiento.

En primer lugar quisiera agradecer a los responsables de CMT-Motores Térmicos, Francisco Payri y José María Desantes, la oportunidad que me brindaron de incorporarme a su grupo de trabajo, así como por todos los medios facilitados para el desarrollo de esta tesis doctoral. A su vez, quiero expresar mi gratitud a Jesús Benajes por la confianza depositada en mí, permitiéndome formar parte de la línea de investigación de combustión.

En segundo lugar quiero destacar la figura de mi director de tesis, Antonio García. Has guiado mi desarrollo profesional hasta llegar a esta meta, motivándome y contagiándome tu tenacidad. He aprendido mucho durante la gran cantidad de horas que hemos compartido estos 5 años de trabajo. Muchísimas gracias.

Esta tesis doctoral también tiene parte del know-how de todos los profesores integrantes de la línea de combustión de CMT, Jaime Martín, José María García, Ricardo Novella, José Manuel Pastor, José Vicente Pastor, Santiago Molina y Javier López. Siempre habéis tenido la puerta abierta para responder cualquier duda que me ha podido surgir, cosa que siempre os agradeceré. También quiero agradecer a Raúl Payri todos los buenos consejos que me ha dado a lo largo de estos años, los guardo a buen recaudo.

Como no mencionar en estas líneas a buenos compañeros y amigos como son Carlos Micó, Eduardo Belarte, Chris Kolodziej, Johannes Winklinger, Adrián Pandal, Mattia Pinotti, Walter Vera-Tudela, David Villalta y Vicente Boronat. Sin ninguna duda creo que la convivencia con ellos es una de las mejores cosas que me llevo de esta etapa de mi vida. De entre ellos quiero destacar a quien empezó siendo tutor de mi proyecto fin de carrera y ha terminado siendo un gran amigo, Vicent Doménech. Gracias por todo.

Me gustaría extender estos agradecimientos a todo el grupo de técnicos, y especialmente a Gabriel Alcantarilla, por su valiosa ayuda durante todas las horas que hemos compartido delante del motor. Mil gracias. Quisiera mencionar también aquí a Daniel Lérida, con quien he compartido buenos ratos en la sala de ensayos, así como a José Gálvez y José Enrique del Rey por tratar siempre de robarme una sonrisa en esos largos días de ensayos. Agradezco también a todo el personal de secretaría del Departamento, especialmente a Teresa y Amparo, toda su ayuda en los trámites administrativos, así como a Juan A. Yustas por el tiempo dedicado en poner a punto los equipos informáticos.

I would like to switch to English for expressing my gratitude to Volvo Group Trucks Technology for funding the work in this thesis. Thanks to Iyad Balloul and Gérard Pradel for following closely the different projects that we have developed together during all these years. I have really enjoyed this investigation. Thanks also 
to Total for funding the study related to fuels, as well as for supplying the fuels used in that part of the thesis.

I wish to express my sincere gratitude to Ken Friis Hansen for hosting me inside the Advanced Engineering Diesel Department of General Motors Powertrain Europe. My thanks also go to Alberto Vassallo for his effort to make possible my internship in Torino. I cannot forget to acknowledge all the ATW people, in special to the combustion group: Francesco Pesce, Giancarlo Cifali, Michele Dematteis and Vincenzo Ottria. I really appreciate your effort for welcoming me in your team and spending with me your valuable time during my internship.

Finalmente, quiero dar las gracias a mi familia y amigos por animarme cada día. De manera más especial quiero dar las gracias a mis padres por haberme guiado y ayudado no solo en este periodo, sino durante todo el transcurso de mi vida. Nunca podré agradeceros todo lo que me habéis dado, solo espero poder estar algún día a vuestra altura. Gracias por vuestro apoyo, paciencia y comprensión. Os quiero. También a Anabel, quien ha sufrido de manera directa esta tesis. Espero poder devolverte este tiempo a lo largo de todo el camino que nos queda juntos. Te quiero.

This doctoral thesis has been partially supported by the Universitat Politècnica de València through the predoctoral contract of the author (FPI-S2-2015-1531), which is included within the framework of Programa de Apoyo para la Investigación y Desarrollo (PAID). 


\section{Table of Contents}

1 Introduction 1

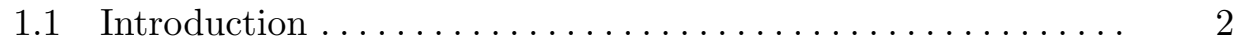

1.2 Technological framework of compression ignition engines .... 2

1.3 New combustion strategies..................... 10

1.4 Document content and structure $\ldots \ldots \ldots \ldots \ldots \ldots \ldots \ldots$

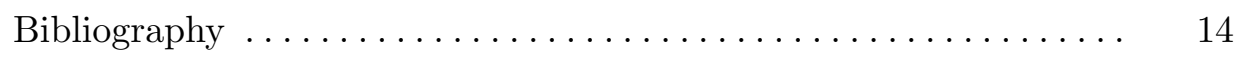

2 Advanced combustion strategies in compression ignition $\begin{array}{ll}\text { engines } & 17\end{array}$

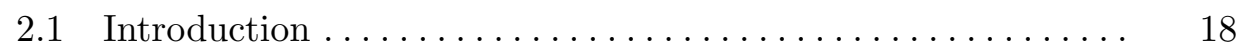

2.2 Conventional diesel emissions dilemma .............. 18

2.3 Low Temperature Combustion approaches ............. 21

2.3.1 Mixing-controlled LTC $\ldots \ldots \ldots \ldots \ldots \ldots \ldots \ldots .21$

2.3.2 Homogeneous Charge Compression Ignition ........ 24

2.4 Strategies for expanding the HCCI operating limits ....... 25

2.4.1 Charge preparation ...................... 25

2.4.2 Fuel stratification using direct injection ......... 27

2.4.3 Fuel autoignition qualities modification .......... 31

2.4.4 Spark assistance ........................ 33

2.4.5 Dual-fuel operation..................... 35

2.5 Reactivity Controlled Compression Ignition ............. 38

2.5.1 Description of RCCI combustion process ......... 38 
2.5.2 Direct comparison of RCCI vs HCCI .......... 40

2.5.3 Effects of engine variables on RCCI combustion ...... 42

2.6 Approach of the study ....................... 51

2.6.1 Motivation of the study .................. 51

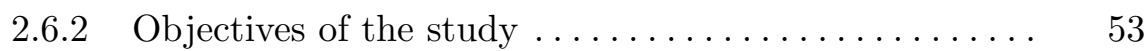

2.6.3 General methodology and research development..... 53

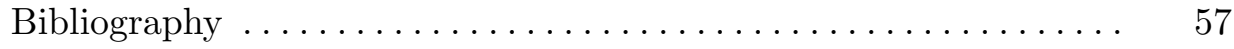

3 Tools and methodology $\quad 63$

3.1 Introduction . . . . . . . . . . . . . . . . . . . . . . . . . . 65

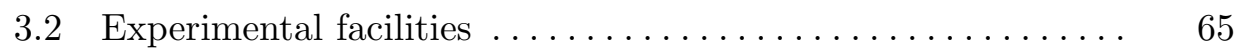

3.2.1 Single-cylinder research engine .............. 65

3.2.1.1 Engine description . . . . . . . . . . . . 66

3.2.1.2 Variable valve actuation system $\ldots \ldots \ldots \ldots \quad 67$

3.2.1.3 Fuel injection systems . . . . . . . . . . . 68

3.2.1.4 Baseline fuel properties .............. 71

3.2.2 Test cell characteristics . . . . . . . . . . . . . . 71

3.2.2.1 Engine speed and torque regulation ....... 72

3.2.2.2 Air supply and exhaust systems . . . . . . 73

3.2.2.3 Exhaust Gas Recirculation loop ......... 74

3.2.2.4 Lubrication and cooling systems ......... 75

3.2.2.5 Fuel conditioning system ............. 76

3.2.2.6 Data acquisition systems . . . . . . . . $\quad 76$

3.2.3 Instrumentation and measuring equipment ....... 78

3.2.3.1 Torque and engine speed measurement .... 78

3.2.3.2 Mean pressure and temperature measurement $\quad 78$

3.2.3.3 Instantaneous pressure transducers . . . . . . $\quad 79$

3.2.3.4 Mass flow measurement............... 79

3.2.3.5 Horiba gas analyzer . . . . . . . . . . . $\quad 80$

3.2.3.6 AVL Smoke meter ................... 81 
3.2.3.7 Blow-by meter . . . . . . . . . . . . 83

3.2.4 Experimental procedure considerations $\ldots \ldots \ldots \ldots .83$

3.3 Theoretical tools . . . . . . . . . . . . . . . . . . . . . . . . . . 85

3.3.1 0-D Combustion diagnosis model............. 85

3.3.2 3-D Computational fluid dynamics model ......... 88

3.3.2.1 General features . . . . . . . . . . . . . . 89

3.3.2.2 Modeling methodology . . . . . . . . . . . . 90

3.3.2.3 Model set-up and validation.............. 94

3.4 Summary and conclusions $\ldots \ldots \ldots \ldots \ldots \ldots \ldots \ldots . . \ldots 9$

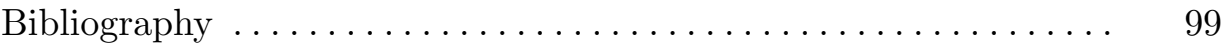

4 Improving RCCI efficiency at low load by combining engine $\begin{array}{ll}\text { settings } & 103\end{array}$

$4.1 \quad$ Introduction . . . . . . . . . . . . . . . . . . . . . . . . . . . . . . 104

4.2 Operating conditions and test methodology definition ....... 104

4.2.1 Baseline injection strategy selection ............ 105

4.2.2 Influence of main injection timing on NOx and soot emissions . . . . . . . . . . . . . . . . . . . . . 109

4.3 Strategy 1: Effect of oxygen concentration and gasoline fraction 112

4.4 Strategy 2: Effect of intake charge temperature and gasoline fraction .................................. 117

4.5 Comparison of both strategies...................... 122

4.6 Summary and conclusions . ..................... 125

Bibliography .................................. 127

5 Piston bowl geometry effects on RCCI combustion 129

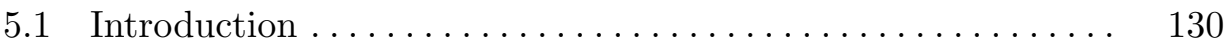

5.2 Sources of heat transfer losses in RCCI combustion ........ . 131

5.3 Piston bowl geometries definition . . . . . . . . . . . . . . . 135

5.3.1 Approaches in piston design to reduce heat transfer .. 135

5.3.1.1 Thermal barrier coatings . . . . . . . . . 136

5.3.1.2 Piston geometry modification ......... 138 
5.3.2 Description of the piston bowl geometries studied ... 141

5.4 Effect of piston bowl geometry at low load ............ 144

5.4.1 Experimental results . . . . . . . . . . . . . . . . . . 144

5.4.2 Understanding the differences between geometries .... 151

5.4.2.1 Heat transfer analysis . . . . . . . . . . . . 152

5.4.2.2 Combustion losses ................ 155

$5.4 .2 .3 \quad$ Efficiency ...................... 156

5.5 Evaluation of the suitable geometry for extended load operation 157

5.5 .1 Medium load results . . . . . . . . . . . . . . . 157

5.5.2 High load results . . . . . . . . . . . . . . . . . . 162

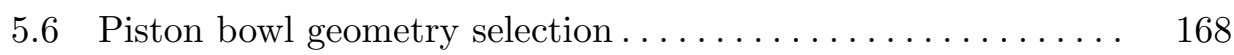

5.7 Summary and conclusions . . . . . . . . . . . . . . . 170

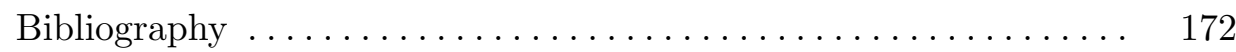

6 Effect of intermediate ethanol-gasoline blends on RCCI combustion

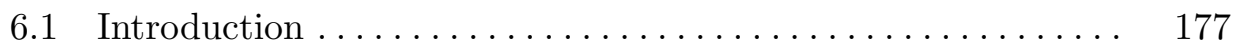

6.2 Background and conditions of the study ............ 178

6.2.1 Alternative fuels for internal combustion engines .... 178

6.2.2 Fuels used and methodology considerations......... 182

6.3 Low load study $\ldots \ldots \ldots \ldots \ldots \ldots \ldots \ldots \ldots \ldots \ldots \ldots \ldots \ldots$

6.3.1 Effect of low reactivity fuel properties on RCCI ..... 183

6.3.1.1 Test conditions .................... 184

6.3.1.2 Results . . . . . . . . . . . . . . . 185

6.3.2 Gas properties modification for improved reactivity .. 190

6.3.2.1 Test conditions ................... 191

6.3.2.2 Combustion development comparison...... 192

6.3.2.3 Engine-out emissions results........... 197

6.3.2.4 Discussion . . . . . . . . . . . . . . . . . . . 199

6.4 Evaluation of the suitable LRF for extended load operation .. 202

6.4.1 Medium load results ....................... 202 
6.4.1.1 Test conditions .................... 202

6.4.1.2 Results .......................... 203

6.4.2 High load results....................... 208

6.4.2.1 Test conditions . . . . . . . . . . . . . . 208

6.4.2.2 Results ......................... 209

6.5 Low reactivity fuel selection $\ldots \ldots \ldots \ldots \ldots \ldots \ldots \ldots \ldots . \ldots \ldots$

6.6 Summary and conclusions ........................ 219

Bibliography ................................... 222

7 RCCI operating limits assessment 225

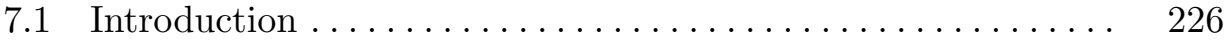

7.2 RCCI operation over the whole engine map ........... 227

7.2.1 Experimental procedure definition. . . . . . . . . . . . 227

7.2.2 Results with nominal compression ratio .......... 232

7.2.3 Results with reduced compression ratio ........... 235

7.2.4 Technological challenges of RCCI concept ......... 238

7.3 Dual-mode RCCI/CDC capabilities ................. 243

7.3.1 Engine description ........................... . 244

7.3.2 RCCI operating limits . . . . . . . . . . . . . . . 246

7.3.2.1 Low and high reactivity fuels selection..... 246

7.3.2.2 Results . . . . . . . . . . . . . . . . . 247

7.3.3 Dual-mode engine operation approach ........... 249

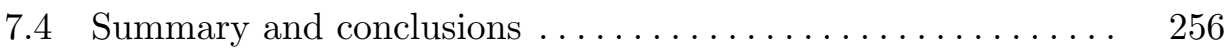

Bibliography .................................... 259

8 Conclusions and suggestions for future work 261

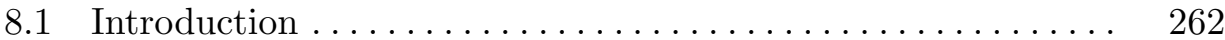

8.2 Summary and conclusions ..................... 262

8.3 Suggestions for future work . . . . . . . . . . . . . . . . . . . . 269

$\begin{array}{ll}\text { Bibliography } & 275\end{array}$ 


\section{Index of Figures}

1.1 Evolution of the energy consumption of petroleum products in Europe between 1990 and 2012 by sector (left) and breakdown of transport energy consumption in 2012 by modes (right) ...

1.2 Typical EURO VI emissions control layout and its operating

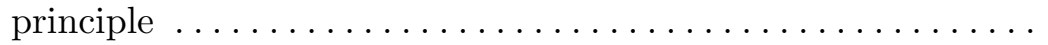

1.3 Sketch of the different subsystems used in the VOLVO D13K460 engine to fulfill the EURO VI emissions standard .........

1.4 Cumulative costs to reach each regulatory stage (left) and cost of each aftertreatment system used for EURO VI (right). The costs are referred to a 12 liter engine ................

1.5 Line of argument followed to develop the work presented in this thesis

2.1 Different phases occurring during conventional diesel combustion. The injection rate, in-cylinder pressure and temperature, and the RoHR are represented $\ldots \ldots \ldots \ldots \ldots \ldots \ldots$

2.2 Schematic of the diesel combustion conceptual model presented

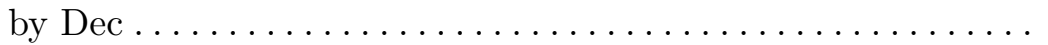

$2.3 \phi$-T diagram showing the soot and NO formation regions. The operating zones of conventional diesel combustion, LTC, HCCI

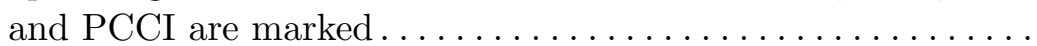

2.4 Comparison of the apparent heat release rate (AHRR) for typical CDC $\left(18 \% \mathrm{XO}_{2}\right)$ with that of EGR-diluted LTC $(12.6 \%$ $\mathrm{XO}_{2}$ ) engine operation at low load $\ldots \ldots \ldots \ldots \ldots \ldots \ldots$

2.5 Comparison of the conceptual model for the conventional diesel combustion with that for LTC combustion 
2.6 Natural luminosity imaging of spark ignition, compression

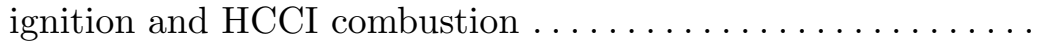

2.7 Two examples of chemiluminescence imaging of the main combustion event for HCCI (SOI: -320 CAD ATDC) and PPC (SOI: -70 CAD ATDC) $\ldots \ldots \ldots \ldots \ldots \ldots \ldots \ldots \ldots \ldots$

2.8 Computed pressure (left) and HRR (right) for homogeneous and fuel-stratified operation with PRF50 and gross IMEP $=7.9$ bar

2.9 Stable operational load window as a function of fuel type (left) and soot-NOx trade-off for different fuels types from 5 to 25 bar

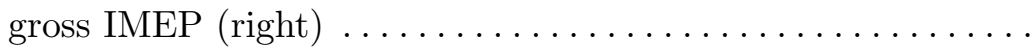

2.10 Coefficient of variation of IMEP (left) and Ringing intensity (right) versus engine load for 200 engine cycles with and without

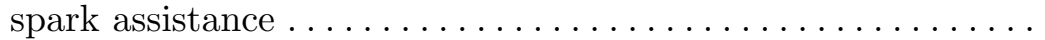

2.11 Performance and engine-out emissions from the gasoline SAPPC combustion using a single (-9 CAD) and double (-16/-9 CAD) injection strategy . . . . . . . . . . . . . . . . .

2.12 Constant-volume ignition delay times for three different fuels calculated using a reduced PRF mechanism ............

2.13 Scheme of the lean-boosted dual-fuel stratified PCI engine proposed by Inkagaki et al. using iso-octane and diesel fuel ..

2.14 Comparison of heat release rate between HCCI and dual-fuel stratified PCI (total $\phi=0.35) \ldots \ldots \ldots \ldots \ldots \ldots \ldots$

2.15 Engine parameters and performance of dual-fuel stratified PCI operation at $1400 \mathrm{rpm} \ldots \ldots \ldots \ldots \ldots \ldots \ldots \ldots \ldots$

2.16 In-cylinder evolution of several key combustion species for dualfuel PCCI operation at 6 bar IMEP. Also shown are the heat release rate and the average temperature $\ldots \ldots \ldots \ldots \ldots$.

2.17 Comparison of pressure and apparent rate of heat release traces for HCCI and RCCI at the conditions depicted in table 2.1 (left). Comparison of fuel energy breakdown between RCCI and HCCI

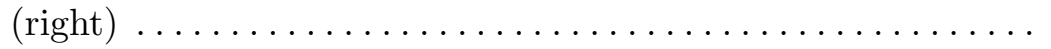

2.18 RCCI performance compared to HCCI, CDC in a 2007 engine and CDC in a modern engine

2.19 Effect of diesel injection timing on CA50 (left) and effect of EGR at constant CA50 of +8 CAD ATDC for an early and late

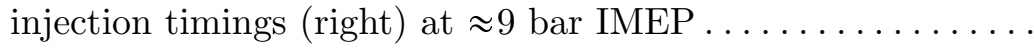


2.20 Effect of diesel pilot injection timing on cylinder pressure, HRR, NOx and soot emissions using a fixed late main injection timing at $\approx 9$ bar IMEP $\ldots \ldots \ldots \ldots \ldots \ldots \ldots \ldots \ldots \ldots \ldots \ldots \ldots$

2.21 Effect of main injection timing on cylinder pressure, HRR, NOx and soot emissions using a fixed early pilot injection timing at

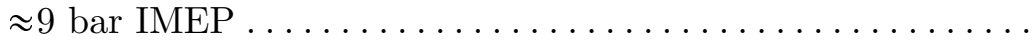

2.22 Effect of SOI1 fuel percentage on cylinder pressure and HRR (left). Effect of gasoline fraction on cylinder pressure and HRR (right) at $\approx 9$ bar IMEP . . . . . . . . . . . . . . . .

2.23 Effect of EGR rate on RoHR and engine-out emissions using a

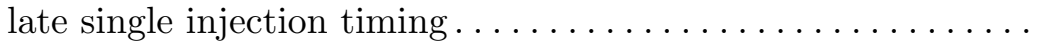

2.24 Effect of EGR rate on RoHR and engine-out emissions using an early double injection timing $\ldots \ldots \ldots \ldots \ldots \ldots \ldots \ldots$

2.25 Effect of intake temperature on RoHR and engine-out emissions using an early double injection timing.............. 46

2.26 Additive impact on PRF of base 96 RON gasoline ........ 47

2.27 Combustion trends of $3.5 \%, 1.75 \%$, and $0.75 \%$ DTBP addition to direct-injected gasoline at 9 bar IMEP compared to dual-fuel cases.........................................

2.28 Average combustion phasing (CA50) as a function of DI SOIc (left) and PFI gasoline percentage (right) for the various fuel combinations investigated

2.29 Comparison of combustion and emission characteristics for all the loads and fuels tested in the work of Splitter et al. .....

2.30 Sketch of the general methodological approach employed in this thesis

3.1 Isometric and cross sectional views of the piston $\ldots \ldots \ldots \ldots$

3.2 Valve lift profiles for the standard production camshaft and the HVA 4 A system ............................ 68

3.3 Scheme of the diesel fuel circuit . . . . . . . . . . . . . . . 69

3.4 Scheme of the gasoline fuel circuit $\ldots \ldots \ldots \ldots \ldots \ldots \ldots . \quad 70$

3.5 Test cell scheme. The location of the different auxiliary systems, measuring equipment and the most important sensors

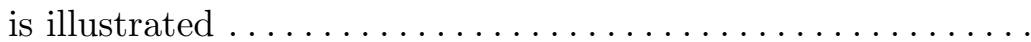


3.6 Scheme of the measurement principle of the gravimetric fuel balance AVL 733S used for measuring the fuel mass flow .... 80

3.7 Experimental methodology carried out during the engine tests

3.8 Definition of the main combustion metrics and parameters

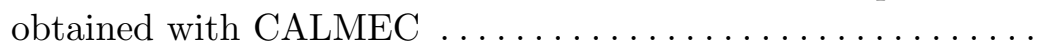

3.9 Different grid refinements using the adaptive mesh refinement (AMR) by CONVERGE $\ldots \ldots \ldots \ldots \ldots \ldots \ldots \ldots \ldots$

3.10 Comparison of different grid configurations for a highly premixed case of $25 \%$ load and $1200 \mathrm{rpm}$ (A25 HPC) ......

3.11 Comparison of different reaction mechanisms for a partially premixed case of $25 \%$ load and $1200 \mathrm{rpm}$ (A25 PPC) ......

3.12 Comparison of different discretization levels of the multi-zone model for a highly premixed case of $50 \%$ load and $1200 \mathrm{rpm}$ (A50 HPC) . . . . . . . . . . . . . . . . . . . . .

3.13 Influence of the blow-by model for a highly premixed case of $50 \%$ load and $1200 \mathrm{rpm}(\mathrm{A} 50 \mathrm{HPC}) \ldots \ldots \ldots \ldots \ldots \ldots$

4.1 Influence of diesel injection pattern (single or double), main and pilot injection timing, main and pilot fuel quantity, gasoline fraction and injection pressure on RCCI performance and emissions at low load

4.2 Diesel fuel (in lines) and PRF stratification at a radial plane located in the crevice region for three different injection strategies . . . . . . . . . . . . . . . . . . . .

4.3 Evolution of the iso-octane mass fraction at the crevice region for the three injection strategies studied $(-24,-60 /-35$ and $-60 /-$

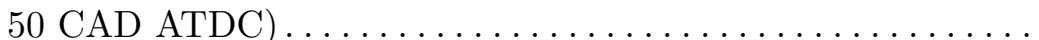

4.4 Engine-out emissions and combustion parameters as a function of the main injection timing for the two operating conditions studied ..................................

4.5 Engine-out emissions and combustion parameters as a function of GF. The EGR rate of each case is shown in the upper part of the figure. The dashed lines denote the emissions limits for

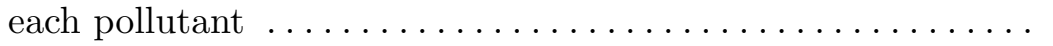

4.6 Evolution of key combustion species, mean temperature and simulated RoHR for the cases of maximum (left) and minimum (right) combustion efficiency $\ldots \ldots \ldots \ldots \ldots \ldots \ldots \ldots \ldots$ 
4.7 Cut planes coincident with the spray axis, squish and crevice regions colored by temperature, $\mathrm{CO}$ mass fraction, n-heptane mass fraction of and iso-octane mass fraction for the case: $43 \%$ EGR, $70.8 \%$ GF ....................... 116

4.8 Cut planes coincident with the spray axis, squish and crevice regions colored by temperature, mass fraction of $\mathrm{CO}$, mass fraction of n-heptane and mass fraction of iso-octane for the

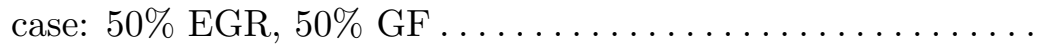

4.9 Engine-out emissions and combustion parameters as a function of GF. The intake temperature corresponding each case is shown in the upper part of the figure. The dashed lines denote the emissions limits for each pollutant $\ldots \ldots \ldots \ldots \ldots \ldots \ldots$

4.10 Evolution of key combustion species, mean temperature and simulated RoHR for the cases of the maximum (left) and minimum (right) combustion efficiency ...............

4.11 Cut planes coincident with the spray axis, squish and crevice regions colored by temperature, mass fraction of $\mathrm{CO}$, mass fraction of n-heptane and mass fraction of iso-octane for the

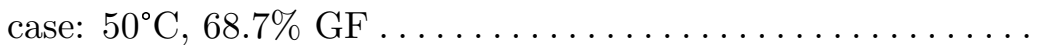

4.12 Cut planes coincident with the spray axis, squish and crevice regions colored by temperature, mass fraction of $\mathrm{CO}$, mass fraction of $n$-heptane and mass fraction of iso-octane for the

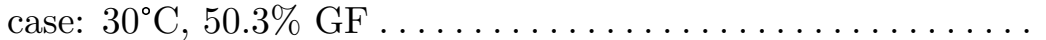

4.13 Relationships between GF with intake charge temperature and oxygen concentration to maintain constant CA50 at +5.5 CAD

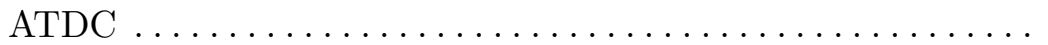

4.14 Merit function results for both strategies taking into account EURO VI limits for regulated emissions and RI $<5 \mathrm{MW} / \mathrm{m}^{2}$

4.15 Comparison of the regulated emissions and GIE for CDC, baseline RCCI point and the best results for the two optimization strategies studied in this chapter $(\mathrm{EGR}+\mathrm{GF}$ and

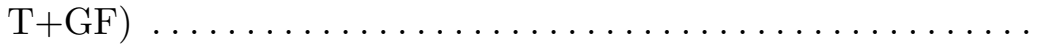

5.1 Typical energy flow path experienced in compression ignition engines working under conventional diesel operation ........ 
5.2 Comparison of the temperature distribution between low, medium and high load using the stock piston. A cut plane coincident with the spray axis, an iso-surface of $\mathrm{T}=1500 \mathrm{~K}$ and the HT coefficient are represented at each instant.........

5.3 Comparison of the heat transfer breakdown and total heat transfer energy between low, medium and high load using the

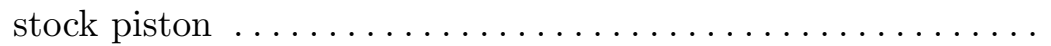

5.4 Comparison of the brake specific fuel consumption between stock

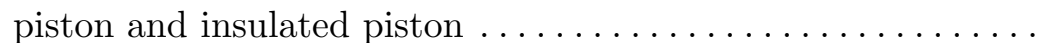

5.5 Several bowl concepts considered for the combustion system optimized in ref. 25. The bowls are all scaled to the same volume .................................

5.6 Shape of piston bowl and distribution of in-cylinder gas velocity

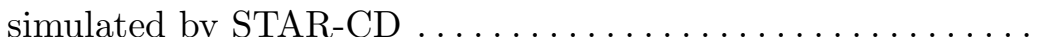

5.7 Comparison of apparent rate of heat release and heat flux at the squish region (left) and fuel consumption (right) between the standard and the tapered shallow-dish pistons .........

5.8 Predicted gross indicated efficiency (left) and combustion and heat transfer losses (right) as a function of bowl depth ......

5.9 Cross sectional view of the stock, tapered and bathtub piston

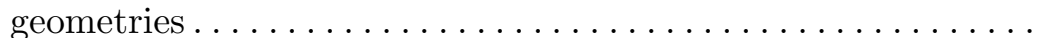

5.10 Velocity vectors at +13 CAD ATDC (left) and evolution of the mean heat transfer coefficient (right) for the stock and tapered pistons at the low load condition described in table $5.2 \ldots \ldots$.

5.11 Temperature distribution at +13 CAD ATDC for the stock and tapered pistons at the low load condition described in table 5.2

5.12 Experimental RoHR and bulk gas temperature of the different sweeps with single (left) and double injection (right) for the stock piston at low load conditions ................

5.13 Engine-out emissions and fuel consumption for the three single injection conditions represented in figure 5.12 (left). The results correspond to the stock piston $\ldots \ldots \ldots \ldots \ldots \ldots \ldots$

5.14 Engine-out emissions and fuel consumption for the three double injection conditions represented in figure 5.12 (right). The results correspond to the stock piston ............... 
5.15 Experimental RoHR and bulk gas temperature of the most interesting tests with single (left) and double injection (right) for the three piston geometries at low load conditions .......

5.16 Engine-out emissions and fuel consumption for the three piston geometries at the representative condition of double injection strategy: $-60 /-35$ CAD ATDC and GF $75 \% \ldots \ldots \ldots \ldots \ldots$

5.17 Engine-out emissions and fuel consumption for the three piston geometries at the representative condition of single injection strategy: -24 CAD ATDC and GF $75 \% \ldots \ldots \ldots \ldots \ldots$

5.18 Comparison of the RoHR, $\mathrm{HC}$ and $\mathrm{CO}$ emissions for the experimental and computational results at low load conditions with the three piston geometries. Double injection set at -60/-35 CAD ATDC, EGR rate of $45 \%$ and intake temperature of $40^{\circ} \mathrm{C}$

5.19 Global heat flux and breakdown between piston, cylinder and cylinder head for the stock, tapered and bathtub pistons at low load ....................................

5.20 Comparison of the temperature distribution between the stock, tapered and bathtub pistons at low load. A cut plane coincident with the spray axis, an iso-surface of $\mathrm{T}=1500 \mathrm{~K}$ and the heat transfer coefficient are represented in each case ...........

5.21 Comparison of the heat transfer breakdown and total heat transfer energy between the stock, tapered and bathtub pistons

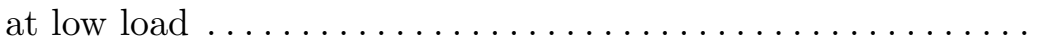

5.22 Temporal evolution of the HC and CO emissions, instantaneous iso-octane mole fraction and bulk gas temperature predicted by the model. The experimental measurements of $\mathrm{HC}$ and $\mathrm{CO}$ emissions are also included in the figure $\ldots \ldots \ldots \ldots \ldots \ldots$

5.23 Comparison of the fuel energy usage between the stock, tapered

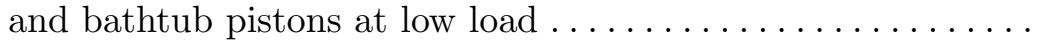

5.24 Experimental RoHR and bulk gas temperature of the different sweeps with double (left) and single injection (right) for the stock piston at medium load conditions ..............

5.25 Engine-out emissions and fuel consumption for the three double injection conditions represented in figure 5.24 (left). The results correspond to the stock piston $\ldots \ldots \ldots \ldots \ldots \ldots \ldots \ldots$ 
5.26 Engine-out emissions and fuel consumption for the three single injection conditions represented in figure 5.24 (right). The results correspond to the stock piston ...............

5.27 Experimental RoHR and bulk gas temperature of the most interesting tests with double (left) and single injection (right) for the three piston geometries at medium load conditions ...

5.28 Engine-out emissions and fuel consumption for the three piston geometries at the representative condition of double injection strategy: $-50 /-12$ CAD ATDC and GF $70 \% \ldots \ldots \ldots \ldots \ldots$

5.29 Engine-out emissions and fuel consumption for the three piston geometries at the representative condition of single injection strategy: -15 CAD ATDC and GF $60 \% \ldots \ldots \ldots \ldots \ldots$

5.30 Experimental RoHR and bulk gas temperature of the different sweeps with double (left) and single injection (right) for the stock piston at high load conditions................

5.31 Engine-out emissions and fuel consumption for the three double injection conditions represented in figure 5.30 (left). The results correspond to the stock piston $\ldots \ldots \ldots \ldots \ldots \ldots \ldots$

5.32 Engine-out emissions and fuel consumption for the three single injection conditions represented in figure 5.30 (right). The results correspond to the stock piston $\ldots \ldots \ldots \ldots \ldots \ldots$.

5.33 Experimental RoHR and bulk gas temperature of the most interesting tests with double (left) and single injection (right) for the three piston geometries at high load conditions ......

5.34 Engine-out emissions and fuel consumption for the three piston geometries at the representative condition of double injection strategy: $-40 /-13$ CAD ATDC and GF $70 \% \ldots \ldots \ldots \ldots \ldots .166$

5.35 Engine-out emissions and fuel consumption for the three piston geometries at the representative condition of single injection strategy: +0 CAD ATDC and GF $60 \% \ldots \ldots \ldots \ldots \ldots \ldots$

5.36 Merit function results for three constrained values: $\mathrm{NOx}=0.4$ $\mathrm{g} / \mathrm{kWh}$, soot $=0.01 \mathrm{~g} / \mathrm{kWh}$ and maximum $\mathrm{PRR}=15 \mathrm{bar} / \mathrm{CAD}$. Marked operating conditions are the ones that provide minimum MF values and lowest $\mathrm{BSFC} \ldots \ldots \ldots \ldots \ldots \ldots \ldots \ldots$

$5.37 \mathrm{NOx}$, soot, combustion efficiency, maximum PRR, gross indicated efficiency and relative BSFC to CDC versus engine load for the best points of the different pistons .......... 
6.1 Influence of fuel properties and PER on some combustion tracers as a function of diesel $\mathrm{SOI}_{\text {main }} \ldots \ldots \ldots \ldots \ldots \ldots \ldots \ldots$

6.2 Influence of fuel properties and PER on heat release evolution at two injection timing scenarios . . . . . . . . . . . . 187

6.3 Influence of fuel properties and PER on NOx and soot emissions as a function of diesel $\mathrm{SOI}_{\text {main }} \ldots \ldots \ldots \ldots \ldots \ldots \ldots \ldots$

6.4 Influence of fuel properties and PER on NOx, gross indicated efficiency (GIE) and maximum pressure rise rate (MPRR) as a function of combustion phasing (CA50) ..............

6.5 Influence of fuel properties and PER on $\mathrm{HC}$ and $\mathrm{CO}$ emissions and combustion efficiency as a function of diesel $\mathrm{SOI}_{\text {main }} \ldots .$. .

6.6 RoHR traces for the different PERs and fuels ............

6.7 EGR rate needed to maintain CA50 at +5 CAD ATDC for the different PERs and fuels........................

6.8 Maximum heat release peak and energy released during the low temperature combustion phase for the different PERs and fuels

6.9 Ignition delay accounted as the difference between the SOC and the end of the main diesel injection for the different PERs and

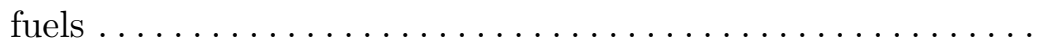

6.10 Maximum heat release peak and energy released during the main combustion stage for the different PERs and fuels .........

6.11 Combustion duration (CA90-SOC) and ringing intensity (RI) for the different PERs and fuels . . . . . . . . . . . . . . . . 196

6.12 Summary of the effects of PER (left) and fuel composition

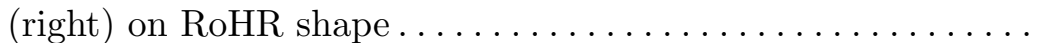

6.13 NOx emissions and maximum combustion temperature for the different PERs and fuels.........................

6.14 Engine-out soot emissions and ID/DOI ratio for the different PERs and fuels

6.15 Engine-out $\mathrm{HC}$ and $\mathrm{CO}$ emissions for the different PERs and fuels

6.16 Gross indicated efficiency (GIE), exhaust losses, heat transfer losses and combustion losses as a percentage of the fuel energy for the different PERs and fuels . 
6.17 Comparison between the results of the baseline and modified

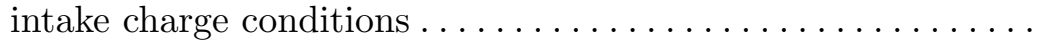

6.18 Influence of fuel properties and PER on some combustion tracers

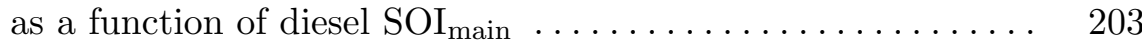

6.19 Influence of fuel properties and PER on heat release evolution at two injection timing scenarios $\ldots \ldots \ldots \ldots \ldots \ldots \ldots$

6.20 Effect of ethanol content on intake charge temperature. Results correspond to E10-95 and E20-95 fuels at different PERs ....

6.21 Influence of fuel properties and PER on NOx, gross indicated efficiency (GIE) and maximum pressure rise rate (MPRR) as a function of combustion phasing (CA50) ..............

6.22 Influence of fuel properties and PER on soot emissions and

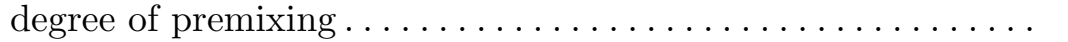

6.23 Influence of fuel properties and PER on $\mathrm{HC}$ and $\mathrm{CO}$ emissions and combustion efficiency as a function of diesel $\mathrm{SOI}_{\text {main }} \ldots .$.

6.24 Influence of fuel properties and PER on some combustion tracers as a function of diesel $\mathrm{SOI}_{\text {main }} \ldots \ldots \ldots \ldots \ldots \ldots \ldots \ldots$

6.25 Influence of fuel properties and PER on heat release evolution at two injection timing scenarios $\ldots \ldots \ldots \ldots \ldots \ldots \ldots$

6.26 Influence of fuel properties and PER on NOx, gross indicated efficiency (GIE) and maximum pressure rise rate (MPRR) as a function of combustion phasing (CA50) ..............

6.27 Influence of fuel properties and PER on soot emissions and degree of premixing $\ldots \ldots \ldots \ldots \ldots \ldots \ldots \ldots \ldots \ldots \ldots \ldots$

6.28 Influence of fuel properties on the normalized degree of premixing and bulk gas temperature $\ldots \ldots \ldots \ldots \ldots \ldots$

6.29 Influence of fuel properties and PER on $\mathrm{HC}$ and $\mathrm{CO}$ emissions and combustion efficiency as a function of diesel $\mathrm{SOI}_{\text {main }} \ldots$.

6.30 Merit function results for three constrained values: $\mathrm{NOx}=0.4$ $\mathrm{g} / \mathrm{kWh}$, soot $=0.01 \mathrm{~g} / \mathrm{kWh}$ and maximum $\mathrm{PRR}=15 \mathrm{bar} / \mathrm{CAD}$. Marked operating conditions are the ones that provide minimum MF values and lowest $\mathrm{BSFC} \ldots \ldots \ldots \ldots \ldots \ldots \ldots \ldots$

6.31 Engine-out emissions ( $\mathrm{NOx}$, soot, combustion efficiency) and performance (maximum PRR, GIE and BSFC) versus engine load for the selected engine operating conditions........... 
6.32 Comparison of the results from RCCI combustion using biofuels and petroleum-based fuels. The best results of B7+E10-95 and those obtained with regular pump fuels in chapter 5 are represented. In both cases, the stock piston geometry was used

7.1 Steps of the experimental procedure followed to reach the three imposed constraints over a wide range of engine speed and loads

7.2 Experimental procedure to reach stable RCCI conditions at a desired engine load (Step 1) $\ldots \ldots \ldots \ldots \ldots \ldots \ldots \ldots \ldots$

7.3 Experimental procedure to introduce the stable RCCI operating points from step 1 under the NOx and soot limits (Step 2)...

7.4 Experimental procedure to minimize $\mathrm{HC}$ and $\mathrm{CO}$ emissions and BSFC while maintaining NOx and soot emissions under the

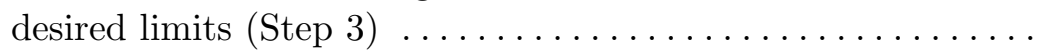

7.5 Effect of EGR rate on RCCI engine-out emissions at $75 \%$ load

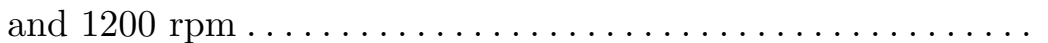

7.6 Effect of the combined modification of the EGR rate and diesel SOI on RCCI engine-out emissions at $50 \%$ load and $1200 \mathrm{rpm}$

7.7 Maps of gasoline fraction and different parameters derived from the in-cylinder pressure processing operating with a compression

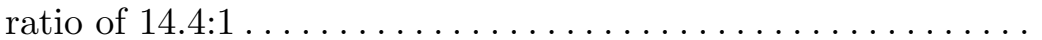

7.8 Engine-out emissions mapping for RCCI operation with the nominal compression ratio of $14.4: 1 \ldots \ldots \ldots \ldots \ldots \ldots .234$

7.9 Maps of gasoline fraction and different parameters derived from the in-cylinder pressure processing operating with a compression

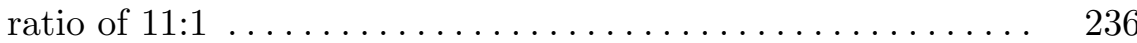

7.10 Engine-out emissions mapping for RCCI operation with a compression ratio of $11: 1 \ldots \ldots \ldots \ldots \ldots \ldots \ldots \ldots \ldots \ldots$

7.11 NOx, soot and gross indicated efficiency as a function of engine load at $1200 \mathrm{rpm}$ for RCCI with CR 11:1 and CDC .........

7.12 Engine-out $\mathrm{CO}$ and $\mathrm{HC}$ emissions, and exhaust temperatures as a function of engine load at $1200 \mathrm{rpm}$ for RCCI and CDC ...

7.13 $\mathrm{HC}$ and $\mathrm{CO}$ conversion efficiency as a function of inlet exhaust temperature for three types of DOCs working under RCCI operation (left). Exhaust temperature map for the operating points of CR 11:1 (right) 
7.14 Exhaust temperature for the stock and bathtub pistons at the same engine operating conditions from low to high load at 1200

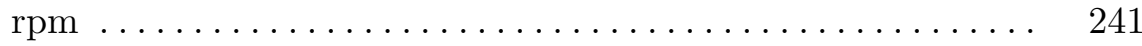

7.15 Combustion noise level for the RCCI operating points of CR 11:1 (left). Combustion noise level limit as a function of engine load used in ref. 7 and 8 for developing the GDCI combustion mode (right) . . . . . . . . . . . . . . . . . . .

7.16 Boost pressure and EGR maps for the RCCI operating points of CR $11: 1 \ldots \ldots \ldots \ldots \ldots \ldots \ldots \ldots \ldots \ldots \ldots \ldots \ldots \ldots \ldots \ldots \ldots$

7.17 Test cell scheme. The RCCI cylinder is fully isolated and governed by means of a full-pass controller.............

7.18 Comparison of RCCI and CDC emissions, maximum in-cylinder pressure and PRR at $25 \%$ and $35 \%$ load in the whole engine

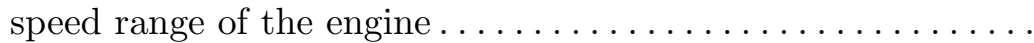

7.19 Different engine settings corresponding to the RCCI tests at $25 \%$ and $35 \%$ load in the whole engine speed range .......... 249

7.20 RCCI emissions mapping in the high compression ratio EURO VI engine. The maximum operable load under RCCI conditions is limited by the excessive PRR and maximum in-cylinder

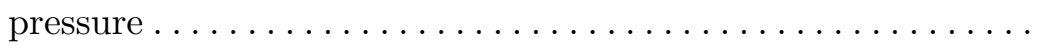

7.21 Exhaust temperature and combustion noise levels experienced during RCCI operation in the high compression ratio EURO VI engine

7.22 Scheme of the exhaust line of the VOLVO D5K240 engine used

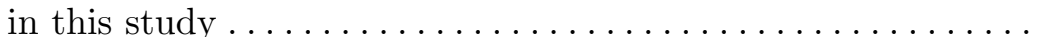

7.23 Reduction in GIE for CDC at different engine speeds and loads when considering the urea consumption $\ldots \ldots \ldots \ldots \ldots \ldots$

7.24 GIE map for RCCI and GIE difference between RCCI and corrected CDC ............................

7.25 Reduction in soot emissions promoted by RCCI compared to CDC operation . . . . . . . . . . . . . . . . . . .

7.26 Tests proposed in the world harmonized stationary cycle (WHSC) and tests experimentally measured with RCCI and $\mathrm{CDC}$

8.1 General view of the different studies and main results of this thesis . . 


\section{Index of Tables}

1.1 European emission standards for heavy-duty diesel engines in steady-state operation $\ldots \ldots \ldots \ldots \ldots \ldots \ldots \ldots \ldots \ldots \ldots$

2.1 HCCI and RCCI conditions and PPRR for fixed operation at 9 bar gross IMEP, $\phi^{\prime}=0.29$ and $45 \%$ EGR $\ldots \ldots \ldots \ldots \ldots .40$

3.1 Main characteristics of the engine used in this research ..... 66

3.2 Main characteristics of the diesel fuel injector . . . . . . . . 69

3.3 Main characteristics of the gasoline fuel injectors ........ 70

3.4 Main characteristics of the fuels used in chapters 4 and $5 \ldots \quad 71$

3.5 Characteristics of the dynamometer brake ............. 73

3.6 Location of the instantaneous parameters recorded during the

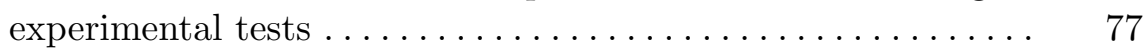

3.7 Boundary conditions types and values............. 93

3.8 Calculation time and processors required depending on the mesh

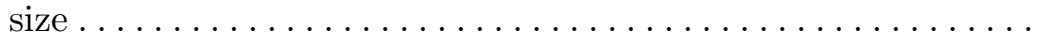

4.1 Engine operating conditions set to evaluate the effect the combined modification of EGR and GF on combustion efficiency

4.2 Engine operating conditions set to evaluate the effect of the main injection strategy on NOx and soot emissions .......... 113

4.3 Engine operating conditions set to evaluate the combined effect of temperature and GF modification on combustion efficiency

5.1 Energy balance for RCCI and conventional diesel combustion with and without heat transfer ................. 13 
5.2 Detail of the engine settings used for the parametric studies at

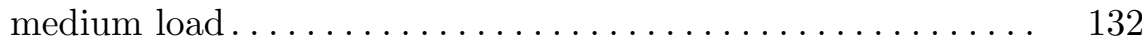

5.3 Main specifications of the three combustion chambers studied 144

5.4 Detail of the engine settings used for the parametric studies at low load ................................ 145

5.5 Detail of the engine settings used for the parametric studies at medium load ................................ 158

5.6 Detail of the engine settings used for the parametric studies at high load .............................. 163

6.1 Physical and chemical properties of the fuels used in this chapter 182

6.2 Constant engine settings at low load conditions ......... 184

6.3 Operating parameters at low load conditions. Diesel main injection timing sweep for the different fuels and PERs ..... 185

6.4 Diesel and LRF mass per blend delivered to the cylinder for each

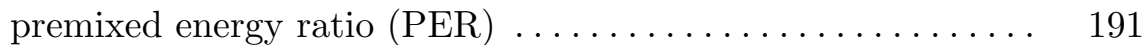

6.5 Constant engine settings to evaluate the effect of the gas properties modification ......................... 192

6.6 Constant engine settings at medium load conditions ....... 202

6.7 Operating parameters at medium load conditions. Diesel main injection timing sweep for the different fuels and PERs ..... 203

6.8 Constant engine settings at high load conditions........... 209

6.9 Operating parameters at high load conditions. Diesel injection timing sweep for the different fuels and PERs ........... 209

6.10 Injection settings for the best results of B7+E10-95 and those obtained with regular fuels in chapter $5 \ldots \ldots \ldots \ldots \ldots .218$

7.1 Main specifications of the medium-duty engine used in this study 244

7.2 Physical and chemical properties of the fuels used in this section 247

7.3 CDC and dual-mode conditions considered to calculate the soot emissions from the engine cycle proposed ........... 255 



\section{Nomenclature}

$\begin{array}{ll}\text { Latin } & \\ A / F & \text { Air fuel ratio } \\ C_{p} & \text { Specific heat capacity at constant pressure } \\ \mathrm{CO} & \text { Carbon Monoxide } \\ \mathrm{CH}_{2} \mathrm{O} & \text { Formaldehyde } \\ \mathrm{CO}_{2} & \text { Carbon Dioxide } \\ h & \text { Hours } \\ \bar{h} & \text { Enthalpy } \\ \mathrm{HC} & \text { Hydrocarbon } \\ \mathrm{H}_{2} \mathrm{O} & \text { Water } \\ i \mathrm{C}_{8} \mathrm{H}_{18} & \text { Iso-octane } \\ m & \text { Mass } \\ \dot{m} & \text { Mass flow } \\ n & \text { Engine speed } \\ n C_{7} H_{16} & \text { N-heptane } \\ \mathrm{N}_{2} & \text { Nitrogen } \\ \mathrm{NH}_{3} & \text { Ammonia } \\ \mathrm{NO}_{\mathrm{NO}} & \text { Nitrogen monoxide } \\ \mathrm{NO}_{2} & \text { Nitrogen dioxide } \\ \mathrm{NO}_{x} & \text { Nitrogen oxides }\left(\mathrm{NO} \text { and } \mathrm{NO}_{2}\right) \\ \mathrm{O}_{2} & \text { Oxygen } \\ p & \text { Pressure } \\ Q_{w} & \text { Teat transfer to the walls } \\ t & \\ \mathrm{~T} & \text { Temperature } \\ & \end{array}$




$\begin{array}{ll}u & \text { Internal energy } \\ V & \text { Volume } \\ X & \text { Molar fraction } \\ Y & \text { Mass fraction }\end{array}$

Greek

$\Delta$

$\eta$

$\rho$

$\phi$

\section{Superscripts}

\section{Subscripts}

$\begin{array}{ll}\text { ad } & \text { Relative to adiabatic conditions } \\ \text { air } & \text { Relative to air } \\ b b & \text { Relative to blow-by } \\ \text { cyl } & \text { Relative to in-cylinder conditions } \\ \text { evap } & \text { Relative to evaporation conditions } \\ \text { exh } & \text { Relative to exhaust conditions } \\ f & \text { Relative to fuel } \\ g & \text { Relative to gas } \\ \text { inj } & \text { Relative to fuel injection } \\ \text { int } & \text { Relative to intake conditions } \\ \text { max } & \text { Maximum value } \\ u b & \text { Relative to unburned conditions } \\ s t & \text { Relative to stoichiometric conditions }\end{array}$

Adiabatic exponent

Variation / Increment

Efficiency

Density

Equivalence ratio

\section{Standard conditions}

Initials and acronyms

$\begin{array}{ll}\text { AMR } & \text { Adaptive Mesh Refinement } \\ \text { ASC } & \text { Ammonia Slip Catalyst } \\ \text { ASTM } & \text { American Society for Testing and Materials } \\ \text { ATDC } & \text { After Top Dead Center } \\ \text { BDC } & \text { Bottom Dead Center }\end{array}$




\begin{tabular}{|c|c|}
\hline BMEP & Brake Mean Effective Pressure \\
\hline BSFC & Brake Specific Fuel Consumption \\
\hline BTDC & Before Top Dead Center \\
\hline BTE & Brake Thermal Efficiency \\
\hline $\mathrm{CAD}$ & Crank Angle Degree \\
\hline CA50 & Crank Angle at $50 \%$ mass fraction burned \\
\hline $\mathrm{CDC}$ & Conventional Diesel Combustion \\
\hline CFD & Computational Fluid Dynamics \\
\hline $\mathrm{CI}$ & Compression Ignition Engine \\
\hline $\mathrm{CN}$ & Cetane Number \\
\hline CNL & Combustion Noise Level \\
\hline $\mathrm{COV}$ & Coefficient of Variation \\
\hline $\mathrm{CR}$ & Compression Ratio \\
\hline DI & Direct Injection \\
\hline DOC & Diesel Oxidation Catalyst \\
\hline DOI & Duration of Injection \\
\hline $\mathrm{DPF}$ & Diesel Particulate Filter \\
\hline EGR & Exhaust Gas Recirculation \\
\hline EOC & End of Combustion \\
\hline EOI & End of Injection \\
\hline $\mathrm{EVC}$ & Exhaust Valve Closing angle \\
\hline EVO & Exhaust Valve Opening angle \\
\hline FSN & Filter Smoke Number \\
\hline GF & Gasoline Fraction \\
\hline GIE & Gross Indicated Efficiency \\
\hline $\mathrm{HCCI}$ & Homogeneous Charge Compression Ignition \\
\hline $\mathrm{HD}$ & Heavy Duty \\
\hline $\mathrm{HF}$ & Heat Flux \\
\hline $\mathrm{HOV}$ & Heat (or Enthalpy) of Vaporization \\
\hline $\mathrm{HPC}$ & Highly Premixed Combustion \\
\hline $\mathrm{HRF}$ & High Reactivity Fuel \\
\hline HRL & Heat Release Law \\
\hline HRR & Heat Release Rate \\
\hline HT & Heat Transfer \\
\hline
\end{tabular}




\begin{tabular}{|c|c|}
\hline HTHR & High Temperature Heat Release \\
\hline $\mathrm{ICE}$ & Internal Combustion Engine \\
\hline ID & Ignition Delay \\
\hline IEGR & Internal Exhaust Gas Recirculation \\
\hline IMEP & Indicated Mean Effective Pressure \\
\hline IP & Injection Pressure \\
\hline ISFC & Indicated Specific Fuel Consumption \\
\hline IVC & Intake Valve Closing angle \\
\hline IVO & Intake Valve Opening angle \\
\hline LHV & Lower Heating Value \\
\hline LHR & Low Heat Rejection \\
\hline LRF & Low Reactivity Fuel \\
\hline LTC & Low Temperature Combustion \\
\hline LTHR & Low Temperature Heat Release \\
\hline MCE & Multi Cylinder Engine \\
\hline MF & Merit Function \\
\hline $\mathrm{MON}$ & Motor Octane Number \\
\hline MPRR & Maximum Pressure Rise Rate \\
\hline $\mathrm{NCT}$ & Number of Compliant Tests \\
\hline OEM & Original Equipment Manufacturer \\
\hline $\mathrm{ON}$ & Octane Number \\
\hline PCI & Premixed Compression Ignition \\
\hline PCCI & Premixed Charge Compression Ignition \\
\hline PER & Premixed Energy Ratio \\
\hline PFI & Port Fuel Injection \\
\hline $\mathrm{PM}$ & Particulate Matter \\
\hline PPC & Partially Premixed Charge \\
\hline PPM & Parts Per Million \\
\hline PRF & Primary Reference Fuel \\
\hline PRR & Pressure Rise Rate \\
\hline $\mathrm{RC}_{e f f}$ & Effective Compression Ratio \\
\hline RCCI & Reactivity Controlled Compression Ignition \\
\hline RI & Ringing Intensity \\
\hline RoHR & Rate of Heat Release \\
\hline
\end{tabular}




$\begin{array}{ll}\text { RON } & \text { Research Octane Number } \\ \text { SCE } & \text { Single Cylinder Engine } \\ \text { SCR } & \text { Selective Catalytic Reduction } \\ \text { SI } & \text { Spark Ignition } \\ \text { SOC } & \text { Start of Combustion } \\ \text { SOF } & \text { Soluble Organic Fraction } \\ \text { SOI } & \text { Start of Injection } \\ \text { TBC } & \text { Thermal Barrier Coating } \\ \text { TDC } & \text { Top Dead Center } \\ \text { VVA } & \text { Variable Valve Actuation } \\ \text { WHSC } & \text { World Harmonized Stationary Cycle } \\ \text { WHTC } & \text { World Harmonized Transient Cycle } \\ \text { 0-D } & \text { Zero Dimensional } \\ \text { 1-D } & \text { One Dimensional } \\ \text { 3-D } & \text { Three Dimensional }\end{array}$





\section{Chapter 1}

\section{Introduction}

\section{Contents}

1.1 Introduction ..................... 2

1.2 Technological framework of compression ignition engines...................... 2

1.3 New combustion strategies $\ldots \ldots \ldots \ldots \ldots \ldots \ldots$

1.4 Document content and structure .......... 10

Bibliography ........................ 14 


\subsection{Introduction}

This initial chapter presents the general framework within which this investigation is developed. The chapter shows first the impact of on-road transportation on global energy consumption and pollutant emissions. Then, the most common technological solution and the main in-cylinder strategies adopted by the engine manufacturers to fulfill the current emissions legislation are described. Later, the general scope of this work is contextualized by summarizing the main characteristics of the novel combustion concepts based on low temperature combustion. Finally, the structure of the document is described in order to provide an overview of all the work performed.

\subsection{Technological framework of compression igni- tion engines}

Since decades, internal combustion engines (ICE) play a fundamental role in the lifestyle of modern societies [1]. The capability of ICEs to cover fundamental requirements such as people and goods transportation and power generation has resulted in their mass production. However, the massive use of ICEs has contributed to the global energy consumption and pollutant emissions increase.
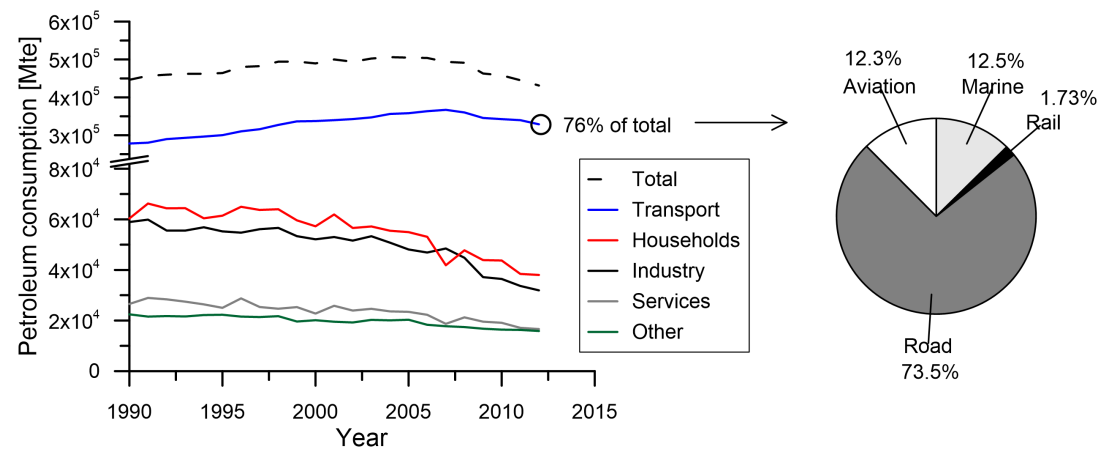

Figure 1.1. Evolution of the energy consumption of petroleum products in Europe between 1990 and 2012 by sector (left) and breakdown of transport energy consumption in 2012 by modes (right). Adapted from [2].

As seen in figure 1.1, consumption of petroleum products in the European Union (EU) increased by $13 \%$ between 1990 and 2005. It can be seen that this trend was mainly driven by the fuel consumption of transportation sector. 
Between 2005 and 2012, the oil consumption decreased in all sectors due to the recession, but transport sector experienced the smallest decrease by only $8 \%$. In fact, in 2012 the transport industry had $76 \%$ share of the petroleum consumption in the EU, of which near $74 \%$ belonged to road transport [2]. These data evidence that ICEs are responsible of near $60 \%$ of the energy consumption of petroleum products in Europe.

Historically, the higher efficiency of compression ignition (CI) engines than spark ignition (SI) engines has led them to lead heavy-duty transportation. Moreover, the share of CI engines in the EU car fleet is gradually increasing during the last years [3]. However, in spite of offering improved fuel economy, CI engines are considered one of the first sources of environmental pollution. The main pollutants associated to their operation are described next:

- Nitrogen oxides (NOx) cause a wide variety of health and environmental impacts. In particular, they contribute to acid deposition and eutrophication, which can lead to potential changes occurring in soil and water quality. Also, NOx react with the volatile organic compounds forming ozone at ground level, which causes respiratory illness and other health problems [4]. Since NOx formation is benefited from high temperatures and lean combustion environments, they suppose a major concern of compression ignition engines.

- Particulate matter (PM) is a complex aggregate formed by soot, hydrocarbons (HC) resulting from fuel and lubrication, and other minor products. Major concerns for human health from exposure to PM are related to damaging in the breathing and respiratory systems. Transportation sector, monopolized by ICEs, is responsible of $11 \%$ of the particles with diameter of $10 \mu \mathrm{m}$ or less $\left(\mathrm{PM}_{10}\right)$ and $16 \%$ of the $\mathrm{PM}_{2.5}$ emitted to the atmosphere [5].

- Carbon monoxide (CO) is a dangerous colorless, odorless and tasteless gas. This emission is produced from the partial oxidation of the fuel when there is not enough oxygen to produce carbon dioxide $\left(\mathrm{CO}_{2}\right)$. The human health risks are explained because $\mathrm{CO}$ enters the bloodstream and reduces oxygen delivery to the body's organs and tissues. However, $\mathrm{CO}$ emissions are not a major concern of CI engines due to the excess of oxygen in the ambient during combustion development.

- Hydrocarbons (HC) are a product of an incomplete combustion of the injected fuel due to rich conditions and low temperatures that can locally be achieved inside the cylinder. Partially oxidized HC and non-burnt HC 
are usually included inside this group. As the case of carbon monoxide, $\mathrm{HC}$ emissions are of less importance than NOx and PM in diesel engines.

Since engine-out emissions are harmful to both humans and the environment, stringent regulations have been introduced along the years to reduce progressively the negative impact of CI engines. Table 1.1 shows the evolution of the European emissions standards for heavy-duty vehicles under steady-state operation. It can be seen that NOx and PM emissions have had the strongest reduction along the years, with a total reduction of $95 \%$ and 98\%, respectively, between 1992 and 2013. In this sense, the EURO VI regulation is the most stringent and the most effective in reducing these emissions, imposing a reduction of $80 \%$ and $50 \%$, respectively, compared to the predecessor regulation [6]. It is interesting to remark that the EURO VI standard establishes also a limit for particle number $(\mathrm{PN})$, and a maximum concentration of ammonia $\left(\mathrm{NH}_{3}\right)$ in the exhaust gas of 10 parts per million (ppm). Moreover, since $\mathrm{NO}_{2}$ emissions aggravate ozone and $\mathrm{PM}_{2.5}$ pollution problems, it is expected that a maximum limit for the $\mathrm{NO}_{2}$ component of $\mathrm{NOx}$ emissions will be defined at later stages of the emissions regulation.

Table 1.1. European emission standards for heavy-duty diesel engines in steady-state operation. Data from [7].

\begin{tabular}{lllllll}
\hline \hline Regulation & Year & $\begin{array}{l}\mathrm{CO} \\
{[\mathrm{g} / \mathrm{kWh}]}\end{array}$ & $\begin{array}{l}\mathrm{HC} \\
{[\mathrm{g} / \mathrm{kWh}]}\end{array}$ & $\begin{array}{l}\text { NOx } \\
{[\mathrm{g} / \mathrm{kWh}]}\end{array}$ & $\begin{array}{l}\text { PM } \\
{[\mathrm{g} / \mathrm{kWh}]}\end{array}$ & $\begin{array}{l}\text { PN } \\
{[1 / \mathrm{kWh}]}\end{array}$ \\
\hline \multirow{2}{*}{ EURO I } & $1992,(<85 \mathrm{~kW})$ & 4.5 & 1.1 & 8.0 & 0.612 & - \\
& $1992,(>85 \mathrm{~kW})$ & 4.5 & 1.1 & 8.0 & 0.36 & - \\
\multirow{2}{*}{ EURO II } & $10 / 1996$ & 4.0 & 1.1 & 7.0 & 0.25 & - \\
& $10 / 1998$ & 4.0 & 1.1 & 7.0 & 0.15 & - \\
EURO III & $10 / 2000$ & 2.1 & 0.66 & 5.0 & 0.1 & - \\
EURO IV & $10 / 2005$ & 1.5 & 0.46 & 3.5 & 0.02 & - \\
EURO V & $10 / 2008$ & 1.5 & 0.46 & 2.0 & 0.02 & - \\
EURO VI & $10 / 2013$ & 1.5 & 0.13 & 0.4 & 0.01 & $8.0 \times 10^{11}$ \\
\hline
\end{tabular}

In addition to the regulated emissions shown in table 1.1, heavy-duty vehicles are responsible for about $25 \%$ of $\mathrm{CO}_{2}$ emissions from road transport in the $\mathrm{EU}$ and for some $6 \%$ of total $\mathrm{CO}_{2}$ emissions in Europe [8]. Thus, because of the great environmental impact of $\mathrm{CO}_{2}$, the European Commission is working on future legislation which would limit the $\mathrm{CO}_{2}$ emissions from newly-registered heavy-duty vehicles, as is already done for cars and vans [9]. 
Since $\mathrm{CO}_{2}$ emissions are proportional to fuel consumption, the development of future heavy-duty diesel engines will require the improvement of the existing technologies, or the evolution towards new strategies for achieving not only clean operation, but also high efficiency [10]. This new scenario brings new challenges to the engine research community and manufacturers.

\section{The technological response to EURO VI standard}

The different engine manufacturers have responded with a quite standard technological solution for moving from EURO V to EURO VI regulation [11]. It consist of a two-stage NOx reduction; exhaust gas recirculation (EGR) first, followed by selective catalytic reduction (SCR) exhaust aftertreatment, and diesel particulate filter (DPF) to remove particulates [12]. Unburned hydrocarbons $(\mathrm{HC})$ and carbon monoxide $(\mathrm{CO})$ emissions are reduced using a diesel oxidation catalyst (DOC). The layout and the operating principle of the different aftertreatment systems is illustrated in figure 1.2.

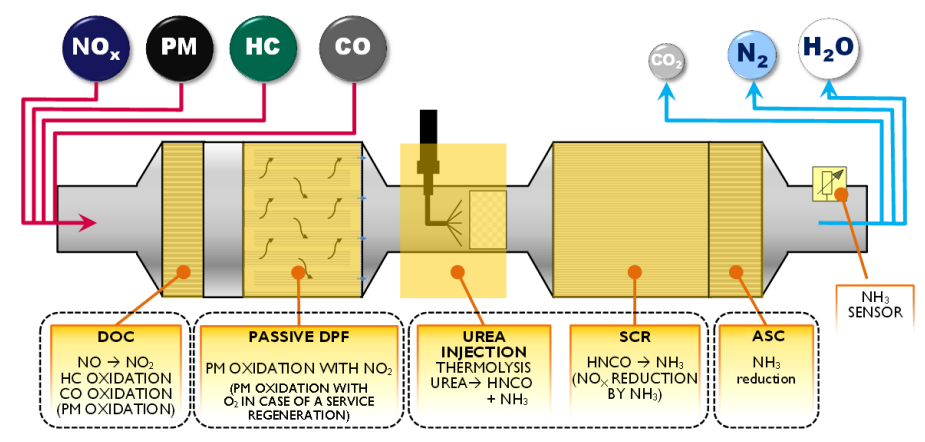

Figure 1.2. Typical EURO VI emissions control layout and its operating principle. Adapted from [13].

The exhaust gas passes first through the DOC, where $\mathrm{CO}$ and $\mathrm{HC}$ are oxidized. The oxidation process provokes the heating of the exhaust gas, which is convenient to improve the global efficiency of the system. Another important reaction that occurs in the DOC is the oxidation of $\mathrm{NO}$ to $\mathrm{NO}_{2}$. This reaction is fundamental for the operation of the current emission control systems because $\mathrm{NO}_{2}$ is required for the regeneration of the DPF and also to enhance the performance of the SCR catalysts. After that, particulate matter $(\mathrm{PM})$ is removed from the exhaust stream by the DPF through chemical mechanisms that induce its storage on the substrate materials located in this aftertreatment device. When necessary, the accumulated PM is oxidized through $\mathrm{NO}_{2}$ to avoid the blocking of the DPF. This operation is known as 
regeneration. Before the exhaust gas reaches the SCR, urea fluid is injected into the exhaust stream to enhance the NOx conversion efficiency of this device. In the SCR, the ammonia produced by the hydrolysis of the urea reacts with NOx forming nitrogen $\left(\mathrm{N}_{2}\right)$ and water $\left(\mathrm{H}_{2} \mathrm{O}\right)$. Later, the ammonia slip catalyst (ASC) prevents that the possible excess of $\mathrm{NH}_{3}$ be emitted to the atmosphere. This situation mainly occurs with low exhaust temperatures, where higher quantity of urea than the ideal ratio is used to compensate the low efficiency of the SCR. Finally, $\mathrm{N}_{2}, \mathrm{CO}_{2}$, water and minor quantities of the regulated emissions are emitted to the atmosphere.

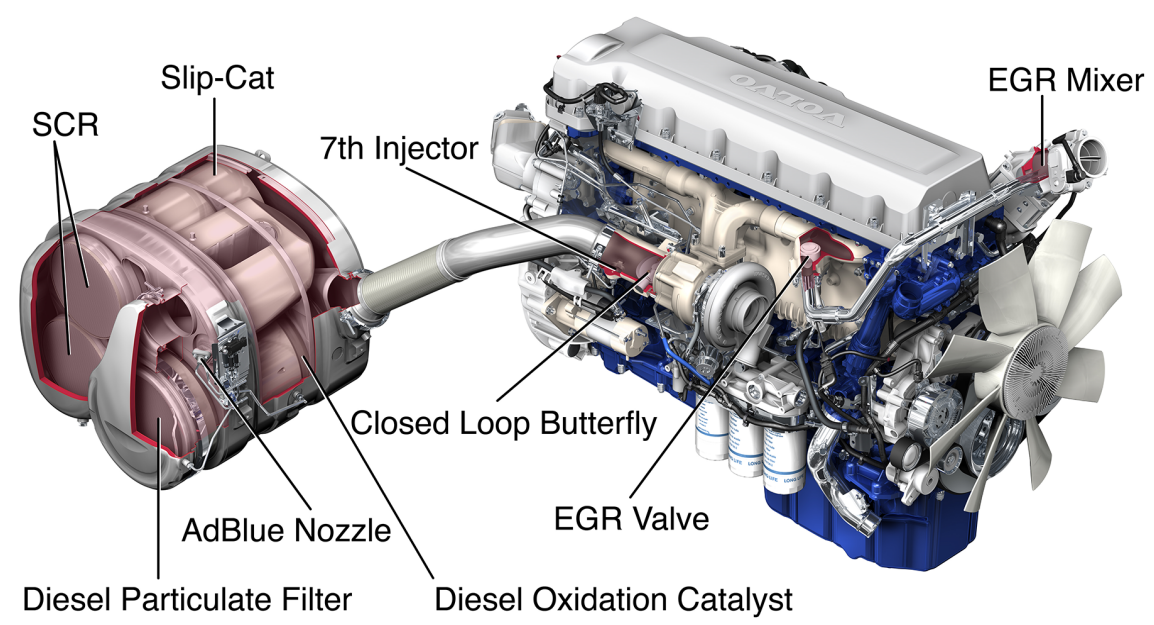

Figure 1.3. Sketch of the different subsystems used in the VOLVO D13K460 engine to fulfill the EURO VI emissions standard [14].

The disposition of those systems in a real engine is shown in figure 1.3. As can be seen, the complete emissions control system includes a DOC, wallflow DPF, urea (AdBlue) nozzle and mixer, twin parallel SCR catalysts, twin parallel ASC and the EGR system. Moreover, an additional diesel injector

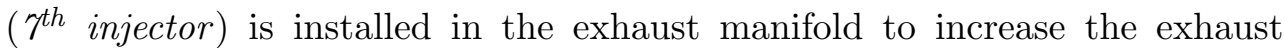
gas temperature during the cold operating conditions and DPF regeneration intervals. To monitor the different subsystems, additional instrumentation is needed. In particular, NOx sensors are required upstream and downstream the SCR catalysts, the pressure drop across the DPF is controlled for regeneration purposes and the gas temperature is measured all the way up to the catalysts. Since NOx-conversion efficiency of SCR catalysts and the possibility of injecting urea depend on the exhaust gas temperature, the thermal management has also became a major concern. To minimize the 
heating-up period of the exhaust aftertreatment equipment, all devices and the silencer are enclosed in a single insulated box. As can be inferred from figure 1.3, the addition of aftertreatment systems supposes a considerable extra volume to the vehicle, which has also repercussion on the total weight.

As figure 1.4 shows, the different measures taken for fulfilling the emissions standards have led to a progressive increase of the base cost of the engine. As a result, a EURO VI heavy-duty vehicle equipped with a 12 liter engine has experienced an increase of approximately $6000 €$ as compared to its EURO II equivalent [15]. Moreover, it is clear that the main cause of that increase is the addition of aftertreatment technologies to the engine. Among the different systems, the SCR catalyst is the most expensive so far, accounting for about $63 \%$ of the aftertreatment costs and for some $46 \%$ of the total.
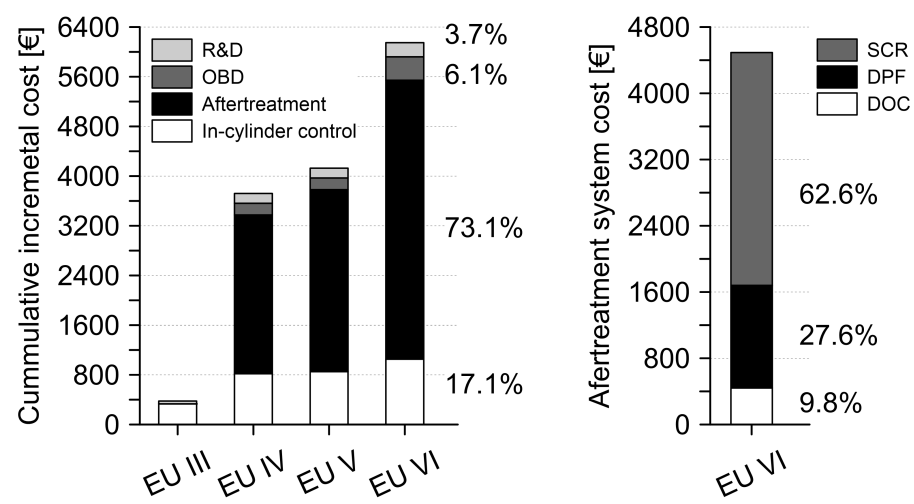

Figure 1.4. Cumulative costs to reach each regulatory stage (left) and cost of each aftertreatment system used for EURO VI (right). The costs are referred to a 12 liter engine. Data from [15].

From figure 1.4, it can be inferred that the aftertreatment technologies have experimented the greater incremental cost as the emissions standards have evolved from EURO IV to EURO VI. Again, this fact is well related with the evolution of the SCR catalysts to face the strong reduction imposed on NOx emissions in this period (from 3.5 to $0.4 \mathrm{~g} / \mathrm{kWh}$ ). EURO IV NOx levels were achieved by using open-loop control urea dosing, thus avoiding the use of the costly NOx sensors $(\approx 160 € /$ unit). For moving to EURO V limits, the catalyst volume was increased and a closed-loop control had to be implemented. This fact contributed to rise the engine price due to the greater precious metal loading and the addition of extra NOx sensors. Currently, the SCR catalysts used to reach the EURO VI NOx levels have similar size to those used for EURO V. However, in order to increase the NOx conversion 
efficiency, the modern SCR catalysts use zeolite as base precious metal instead of vanadium, which increases their cost. Finally, it is interesting to remark that, aside from the higher base cost, the addition of aftertreatment systems to heavy-duty vehicles entails an extra fluid consumption in the exhaust (diesel and urea) and higher maintenance costs $[16,17]$.

As confirmed in figure 1.4, in parallel to the aftertreatment systems development, the automotive scientific community and engine manufacturers are investing considerable efforts in investigating different in-cylinder strategies to minimize the generation of NOx and soot emissions during combustion. In this way, the requirements demanded to their respective aftertreatment systems can be minimized, which contributes to reduce their base price due to the lower size and also their operational costs due to the saving of extra fluids. The main in-cylinder strategies used in the current engines are briefly explained next.

\section{In-cylinder strategies for NOx emissions control}

Exhaust gas recirculation (EGR) is the most effective method to reduce in-cylinder NOx emissions. This technique relies on reducing the combustion flame temperatures by diluting the charge with gaseous combustion products. The temperature reduction occurs due to the less oxygen availability during combustion and the greater heat absorbing capacity of the non-reacting gas [18]. However, the displacement of part of the fresh air by exhaust gas causes the equivalence ratio to increase, leading to a trade-off ${ }^{1}$ between NOx and soot emissions. Moreover, the increase of the intake charge temperature when using conventional EGR leads to substantial decrease in ignition delay, rising also soot emissions [19]. To avoid this effect, the exhaust gas is cooled before being recirculated to combustion chamber, which provides additional benefits by lowering NOx emissions to a greater extent. In addition, the use of cooled EGR improves the volumetric efficiency and therefore increases the power density of the engine as compared to non-cooled EGR.

The progressive reduction of the NOx limit imposed by the emissions regulations has resulted in a continuous increase of the EGR rates and EGR cooling capacity. This actuation demands higher levels of boost pressure if it is wanted to achieve suitable air-fuel ratios to control PM emissions. Ladommatos et al. [20] demonstrated that the increase of EGR rate while keeping constant the air-fuel ratio can promote a substantial decrease in NOx emissions with little penalty in PM emissions. However, the high

\footnotetext{
${ }^{1} \mathrm{~A}$ trade-off is a situation that involves losing one quality or aspect of something in return for gaining another quality or aspect.
} 
boosting requirements led to lower brake engine efficiency. In addition, better performance of the vehicle cooling systems is needed to reduce the temperature of the greater EGR mass flow, which also increases the power loss for driving these auxiliary systems. Other researchers have shown that simultaneous reduction of soot and NOx can be achieved at several low to moderate load conditions by using ultra-high EGR rates, but this strategy significantly deteriorates the engine performance and fuel economy [21]. Moreover, at very high EGR levels, combustion becomes incomplete and unacceptable levels of $\mathrm{HC}$ emissions are released in the exhaust. These disadvantages justify the combined use of EGR and SCR aftertreatment to reach the EURO VI NOx levels.

\section{In-cylinder strategies for soot emissions control}

As literature demonstrates, engine-out soot emissions in conventional direct-injection diesel engines are the result of the balance between the soot formation and oxidation processes [22]. As such, the soot emissions reduction can be addressed by improving the mixture formation to prevent local overrich portions of in-cylinder mixture, or accelerating the oxidation of the formed soot by promoting high temperature conditions.

With respect to soot formation, the identification of the key parameters governing this process have allowed to improve several engine subsystems for contributing to reduce the final emissions [23]. In particular, the great evolution of the injection systems has enabled the use of higher injection pressures, lower nozzle holes diameters, higher number of orifices and multiple injections, which have had a key role on improving the mixture formation $[24,25]$. Also, the optimization of the piston shape for improving the spraybowl interaction and the air flow movement inside the combustion chamber has contributed greatly to soot formation reduction $[26,27]$.

Another strategy typically used to reduce soot emissions is the use of post injections. The use of post injections is thought to have influence on both soot oxidation and soot formation processes [28, 29]. Thus, the different theories suggested by the authors attribute the reduction of engine-out soot emissions to different reasons such as the extra energy for mixing introduced in the chamber by the post injection pulse [30], the high temperature in the chamber prompted by the post injection reactions [31] and the lower soot produced by the main pulse due to the lower fuel mass injected [32]. In any case, all the studies in literature conclude that the use of post injections is a very effective method to reduce engine-out soot emissions for a wide variety of engine sizes and range of operating conditions. 


\subsection{New combustion strategies}

More recently, the pursuit for achieving a simultaneous reduction in NOx and soot emissions while maintaining high efficiency, has led the research community to investigate new combustion strategies based on low temperature combustion (LTC) [33]. In these combustion strategies, a premixed combustion environment is achieved by injecting the fuel in the early instants of the compression stroke, such that an extended ignition delay period is obtained. These conditions allow the fuel-air mixture to reach relatively lean equivalence ratios prior to the start of combustion, which minimizes the soot formation process [34]. Moreover, the high EGR levels typically used result in lower combustion temperature peaks, which reduces the NOx formation [35]. The thermal efficiency is also improved because of two main reasons; the fast heat release occurring when the proper in-cylinder conditions are reached and the heat transfer (HT) reduction because of the lower in-cylinder temperature peaks [36].

Although literature demonstrates remarkable benefits of LTC concepts versus conventional diesel combustion, they still present some limitations that unfit their use in the whole engine operating range. Thus, as it will be described in chapter 2, more understanding is needed before their practical implementation in compression ignition engines.

Following the LTC pathway as method to reduce the NOx and soot aftertreatment requirements, the work presented in this thesis intends to improve the understanding of a novel dual-fuel combustion concept known as Reactivity Controlled Compression Ignition (RCCI), pretending to answer some of the current limitations of this combustion technique. For this purpose, the methodological approach proposed combines the use of a heavyduty single-cylinder research engine, a zero-dimensional model and CFD calculations. This methodology allows to evaluate the performance and engineout emissions with the required level of control and precision during the experimental studies, while the CFD results are used to complement the missing aspects that are unattainable by experimentation.

\subsection{Document content and structure}

This thesis is organized in eight chapters including the present introduc-

tion. A brief outline of the contents of the following chapters is provided next: 
Chapter 2 presents a detailed literature review about the evolution of the novel combustion strategies applied in compression ignition engines to overcome the conventional diesel combustion (CDC) dilemma. According to that, the objectives, justification and methodology of this investigation are defined.

Chapter 3 describes the two complementary sources of information used in this work, the experimental and computational tools. The most important tool is the single-cylinder research engine, so that an exhaustive explanation of their characteristics is provided. Moreover, the different subsystems of which the test cell is composed, such as instrumentation and measuring equipment, are described. In a second part, the combustion diagnosis code used to perform the combustion analysis from the experimental data is presented. Finally, the fundamentals and validation of the CFD code used to perform the computational calculations shown in chapters 4 and 5 are detailed.

Chapter 4 illustrates how the engine settings can be managed simultaneously to maximize the efficiency of RCCI concept at low load. There, experiments and computational calculations are used to give a complete description of the effects of the intake charge temperature and oxygen concentration on combustion propagation at the same time that the fuel blending ratio is varied.

Chapter 5 proposes the modification of the piston bowl geometry as a way for improving the efficiency of this novel combustion concept. The first part of the chapter presents a detailed computational analysis to identify the main sources of heat transfer losses with RCCI. In addition, the influence of the piston shape on heat transfer and combustion losses at low load is discussed. The second part of the chapter focuses on presenting the experimental results of two new geometries at medium and high load, which helps to verify if the conclusions extracted at low load are valid in a greater engine operating range.

Chapter 6 aims to understand the role of the fuel reactivity gradient on RCCI combustion development. For this purpose, some alternative fuels based on ethanol-gasoline blends with different ethanol content and gasoline octane number are used in substitution of the regular gasoline. Moreover, a biodiesel blend, instead of regular diesel, is used as high reactivity fuel. In this sense, the potential of each of these fuels for promoting clean and efficient operation from low to high load is evaluated. Finally, the most potential biofuels found in the study are directly compared versus the regular fuels used in previous chapters.

Chapter 7 explores the operational limits of RCCI over the whole engine map using the piston and fuels selected from chapters 5 and 6 . To do so, an 
experimental methodology to allow stable RCCI operation at different engine speeds and loads under certain restrictions is defined. After that, the relevance of the engine compression ratio on the operational limits of RCCI concept is pointed out. Finally, according to these results, the capabilities of the dualmode RCCI/CDC operation are evaluated.

Chapter 8 summarizes all the results obtained and draws the main conclusions of this work. Moreover, some suggestions for future works on this research topic are provided.

The line of argument followed to define and reach the objectives of this thesis is shown in figure 1.5. 


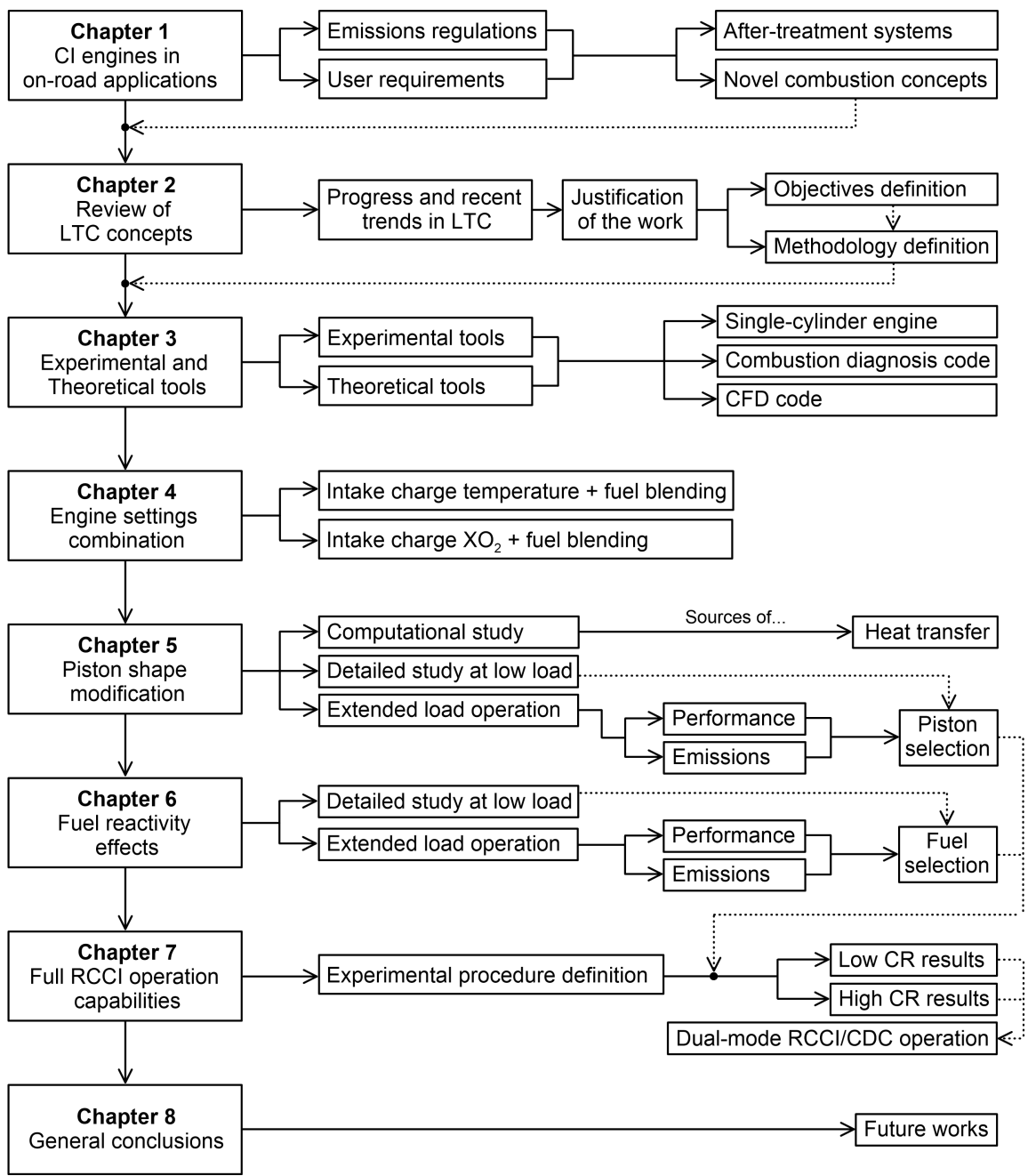

Figure 1.5. Line of argument followed to develop the work presented in this thesis. 


\section{Bibliography}

[1] Dargay J. and Gately D. "Income's effect on car and vehicle ownership, worldwide: 1960-2015". Transportation Research Part A: Policy and Practice, Vol. $33 \mathrm{n}^{\circ}$ 2, pp. 101$138,1999$.

[2] The European Commission. "Energy, Transport and Environment Indicators". Technical report, 2014.

[3] European Automobile Manufacturers' Association. "The Automobile Industry Pocket Guide 2014-2015". Technical report.

[4] Environmental Protection Agency. "Nitrogen Oxides (NOx), Why and How They Are Controlled". Technical report, 1999.

[5] Environmental European Agency. "Emissions of primary PM2.5 and PM10 particulate matter". Technical report.

[6] "Regulation (EC) No 595/2009 of the European Parliament and of the Council of 18 June 2009 on type-approval of motor vehicles and engines with respect to emissions from heavy duty vehicles (Euro VI) and on access to vehicle repair and maintenance information and amending Regulation (EC) No 715/2007 and Directive 2007/46/EC and repealing Directives 80/1269/EEC, 2005/55/EC and 2005/78/EC. Official Journal of the European Union, Vol. 52 no L275, pp. 1-14, 2009". http://eur-lex.europa.eu.

[7] European Emission Standards: Heavy-Duty Truck and Bus Engines. More information available at www.dieselnet.com.

[8] Ricardo. "Report to the European Commission: Reduction and Testing of GHG emissions from Heavy Duty Vehicles - Lot 1: Strategy". Technical report, February 2011.

[9] European Commission. "Strategy for reducing Heavy-Duty Vehicles' fuel consumption and $\mathrm{CO}_{2}$ emissions". Technical report, 2014.

[10] Johnson T.V. "Review of $\mathrm{CO}_{2}$ Emissions and Technologies in the Road Transportation Sector". SAE Int. J. Engines, Vol. 3, pp. 1079-1098, 2010.

[11] Engineer Commercial Vehicle. "Euro 6 the inside story". Technical report, March 2012.

[12] Johnson T.V. "Vehicular Emissions in Review". SAE Int. J. Engines, Vol. 7, pp. 12071227, 2014.

[13] Maritati M. "EURO VI Technologies and Strategies". Technical report, IVECO Body Builders.

[14] VOLVO D13K engine features. Technical information available at http://www.volvotrucks.com.

[15] Posada F., Chambliss S. and Blumberg K. "Costs of emission reduction technologies for heavy-duty diesel vehicles". ICCT White paper, 2016.

[16] Johnson T.V. "Vehicular Emissions in Review". SAE Int. J. Engines, Vol. 5, pp. 216$234,2012$.

[17] Gense N.L.J., Riemersma, Such C. and Ntziachristos L. "Euro VI technologies and costs for Heavy Duty vehicles". Technical report, Delft: TNO Science and Industry report 06.OR.PT.023.2/NG, 2006. p. 56.

[18] Payri F., Benajes J., Molina S. and Riesco J.M. "Reduction of Pollutant Emissions in a HD Diesel Engine by Adjustment of Injection Parameters, Boost Pressure and EGR". SAE Technical Paper, $\mathrm{n}^{\circ}$ 2003-01-0343, 2003. 
[19] Idicheria C.A. and Pickett L.M. "Soot Formation in Diesel Combustion under HighEGR Conditions". SAE Technical Paper, no 2005-01-3834, 2005.

[20] Ladommatos N., Abdelhalim S. and Zhao H. "The effects of exhaust gas recirculation on diesel combustion and emissions". International Journal of Engine Research, Vol. 1 $\mathrm{n}^{\circ} 1$, pp. 107-126, 2000.

[21] Wagner R.M., Green J.B., Dam T.Q., Edwards K.D. and Storey J.M. "Simultaneous Low Engine-Out NOx and Particulate Matter with Highly Diluted Diesel Combustion". SAE Technical Paper, $\mathrm{n}^{\circ}$ 2003-01-0262, 2003.

[22] Tao F., Foster D.E. and Reitz R.D. "Soot Structure in a Conventional Non-Premixed Diesel Flame". SAE Technical Paper, no 2006-01-0196, 2006.

[23] Pickett L.M. and Siebers D.L. "Soot in diesel fuel jets: effects of ambient temperature, ambient density, and injection pressure". Combustion and Flame, Vol. $138 \mathrm{n}^{\circ}$ 1-2, pp. 114-135, 2004.

[24] Zhang W., Tian J-P. and Nishida K. "Effects of Nozzle Hole Diameter and Injection Pressure on Flame Lift-Off and Soot Formation in D.I. Diesel Combustion". $S A E$ Technical Paper, $\mathrm{n}^{\circ}$ 2011-01-1813, 2011.

[25] Dronniou N., Lejeune M., Balloul I. and Higelin P. "Combination of High EGR Rates and Multiple Injection Strategies to Reduce Pollutant Emissions". SAE Technical Paper, $\mathrm{n}^{\circ}$ 2005-01-3726, 2005.

[26] Lee J., Lee S., Kim J. and Kim D. "Bowl Shape Design Optimization for Engine-Out PM Reduction in Heavy Duty Diesel Engine". n ${ }^{\circ}$ 2015-01-0789, 2015.

[27] Wickman D.D., Senecal P.K. and Reitz R.D. "Diesel Engine Combustion Chamber Geometry Optimization Using Genetic Algorithms and Multi-Dimensional Spray and Combustion Modeling". SAE Technical Paper, $\mathrm{n}^{\circ}$ 2001-01-0547, 2001.

[28] O'Connor J. and Musculus M. "Post Injections for Soot Reduction in Diesel Engines: A Review of Current Understanding". SAE Int. J. Engines, Vol. 6 n $^{o}$ 2013-01-0917, pp. 400-421, 2013.

[29] O'Connor J. and Musculus M. "In-Cylinder Mechanisms of Soot Reduction by CloseCoupled Post-Injections as Revealed by Imaging of Soot Luminosity and Planar LaserInduced Soot Incandescence in a Heavy-Duty Diesel Engine". SAE Int. J. Engines, Vol. 7, pp. 673-693, 2014.

[30] Molina S., Desantes J.M., García A. and Pastor J.M. "A Numerical Investigation on Combustion Characteristics with the use of Post Injection in DI Diesel Engines". SAE Technical Paper, $\mathrm{n}^{\circ}$ 2010-01-1260, 2010.

[31] Bakenhus M. and Reitz R.D. "Two-Color Combustion Visualization of Single and Split Injections in a Single-Cylinder Heavy-Duty D.I. Diesel Engine Using an EndoscopeBased Imaging System". SAE Technical Paper, $\mathrm{n}^{\circ}$ 1999-01-1112, 1999.

[32] Desantes J.M., J. Arrègle J.J., López and García A. "A Comprehensive Study of Diesel Combustion and Emissions with Post-injection". SAE Technical Paper, $\mathrm{n}^{\circ}$ 2007-010915, 2007.

[33] Caton J.A. "Thermodynamic Advantages of Low Temperature Combustion (LTC) Engines Using Low Heat Rejection (LHR) Concepts". SAE Technical Paper, $\mathrm{n}^{\circ} 2011$ 01-0312, 2011.

[34] Jung Y., Qi D. and Bae C. "Assessment of Soot Particles in an Exhaust Gas for Low Temperature Diesel Combustion with High EGR in a Heavy Duty Compression Ignition Engine". SAE Technical Paper, $\mathrm{n}^{\circ}$ 2013-01-2572, 2013. 
[35] Brijesh P., Chowdhury A. and Sreedhara S. "Effect of Ultra-Cooled EGR and Retarded Injection Timing on Low Temperature Combustion in CI Engines". SAE Technical Paper, ${ }^{o}$ 2013-01-0321, 2013.

[36] Bittle J.A., Knight B.M. and Jacobs T.J. "Heat Release Parameters to Assess Low Temperature Combustion Attainment". SAE Technical Paper, ${ }^{\circ}$ 2011-01-1350, 2011. 


\section{Chapter 2}

\section{Advanced combustion strategies in compression ignition engines}

\begin{tabular}{|c|c|c|}
\hline $\mathbf{S}$ & & \\
\hline 2.1 & Introduction $\ldots \ldots \ldots \ldots \ldots \ldots \ldots \ldots \ldots$ & 18 \\
\hline 2.2 & Conventional diesel emissions dilemma ........ & 18 \\
\hline 2.3 & Low Temperature Combustion approaches ...... & 21 \\
\hline & 2.3.1 Mixing-controlled LTC $\ldots \ldots \ldots \ldots \ldots \ldots \ldots$ & 21 \\
\hline & 2.3.2 Homogeneous Charge Compression Ignition ...... & 24 \\
\hline 2.4 & $\begin{array}{l}\text { Strategies for expanding the HCCI operating } \\
\text { limits } \ldots \ldots \ldots \ldots \ldots \ldots \ldots \ldots \ldots \ldots \ldots \ldots\end{array}$ & 25 \\
\hline & 2.4.1 Charge preparation $\ldots \ldots \ldots \ldots \ldots \ldots \ldots \ldots$ & 25 \\
\hline & 2.4.2 Fuel stratification using direct injection .......... & 27 \\
\hline & 2.4.3 Fuel autoignition qualities modification & 31 \\
\hline & 2.4.4 Spark assistance $\ldots \ldots \ldots \ldots \ldots \ldots \ldots \ldots \ldots$ & 33 \\
\hline & 2.4.5 Dual-fuel operation..................... & 35 \\
\hline 2.5 & Reactivity Controlled Compression Ignition ..... & 38 \\
\hline & 2.5.1 Description of RCCI combustion process ......... & 38 \\
\hline & 2.5.2 Direct comparison of RCCI vs HCCI & 40 \\
\hline & 2.5.3 Effects of engine variables on RCCI combustion... & 42 \\
\hline 2.6 & Approach of the study $\ldots \ldots \ldots \ldots \ldots \ldots$ & 51 \\
\hline & 2.6.1 Motivation of the study & 51 \\
\hline & $2.6 .2 \quad$ Objectives of the study $\ldots \ldots \ldots \ldots \ldots \ldots \ldots$ & 53 \\
\hline & 2.6.3 General methodology and research development... & 53 \\
\hline Bibl & liography & 57 \\
\hline
\end{tabular}




\section{$2.1 \quad$ Introduction}

This chapter contains two main pieces of information, a literature review to describe the progress and recent trends of the low temperature combustion (LTC) modes, and the overall thesis approach.

The literature review begins describing the diesel emissions dilemma. In particular, a brief description of the conventional diesel combustion process is presented, which allows to understand the reasons governing the classical trade-off between NOx and soot emissions experienced during conventional diesel operation. This fact introduces the necessity of studying new combustion strategies to reduce the emissions of compression ignition engines. In particular, the LTC concepts and the evolution of the different strategies used for expanding their operating limits are reviewed. This review starts from the most widely studied premixed LTC strategy, homogeneous charge compression ignition (HCCI), and arrives up to the dual-fuel combustion, which is the LTC concept most intensively studied nowadays.

Finally, after reviewing some interesting results obtained under dual-fuel conditions up to the date, the chapter closes presenting the thesis approach. It contains the motivation of the study, the detailed objectives of the thesis and the description of the general methodology used to reach the objectives proposed.

\subsection{Conventional diesel emissions dilemma}

The combustion process in conventional direct-injected diesel engines is very complex, involving a wide variety of events and phenomena, such as fuel injection, spray atomization, evaporation, droplet-wall interactions, and combustion and flame-wall interactions. This leads to a turbulent, unsteady, multiphase and three-dimensional event, whose evolution in time can be summarized as follows:

Air, and trapped exhaust gases (internal and external EGR) in the combustion chamber are compressed by the upwards moving piston. At the end of this compression stroke, at around top dead center (TDC), liquid fuel is injected at high velocity through the orifices of the injector nozzle into the combustion chamber. The injected fuel atomizes, vaporizes and mixes with air. Due to the high pressure and high temperature in the combustion chamber, a spontaneous ignition of the air-fuel mixture occurs after a short delay, during which the first pre-reactions happen. At these moments, the 
fuel is partially oxidized, leading to the so-called "cool flames" (see figure 2.1). The air-fuel mixture accumulated during this delay burns fast in a premixed combustion. While the injection is on-going, the flame stabilizes and the fuel is burnt in a diffusion combustion at the edge of the spray. Due to the reaction of fuel with oxygen, both the temperature and pressure increase in the combustion chamber, which enhances the combustion. When the injection is over, the remaining fuel burns slowly in a fading away diffusion combustion. The different temporal stages of the combustion event can be identified in figure 2.1 .

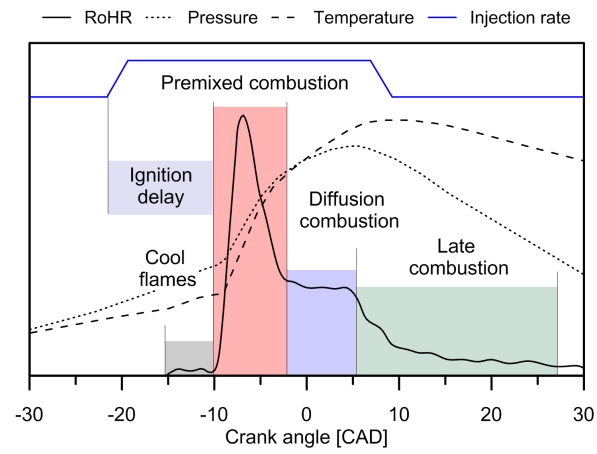

Figure 2.1. Different phases occurring during conventional diesel combustion. The injection rate, in-cylinder pressure and temperature, and the RoHR are represented.

As stated in the phenomenological description presented by Dec [1], the burning process in conventional diesel engines resembles turbulent diffusion combustion with both fuel rich and fuel lean zones that burn simultaneously. The fuel lean zones tend to burn at high temperature, forming considerable amounts of NOx. The fuel rich zones tend to form a lot of soot, which is later partially oxidized when further mixing occurs. The formation locations of both pollutants during the diffusion combustion period can be seen in the scheme of the Dec's conceptual model, which is shown in figure 2.2. As can be seen, the soot formation takes place in the inner part of the diffusion flame, where rich regions are found due to the lack of oxygen. By contrast, the NOx production occurs at the outer reaction zone due to the high temperature and oxygen availability.

Kamimoto and Bae [2] mapped the soot formation region on a $\phi$-T diagram by combining the results obtained in their experiments with data from literature. In addition, the NO formation region determined by the Zeldovich equations was plotted on the same diagram. Finally, the $\phi$ and $\mathrm{T}$ time histories of the flame in a DI diesel engine, which were obtained by 


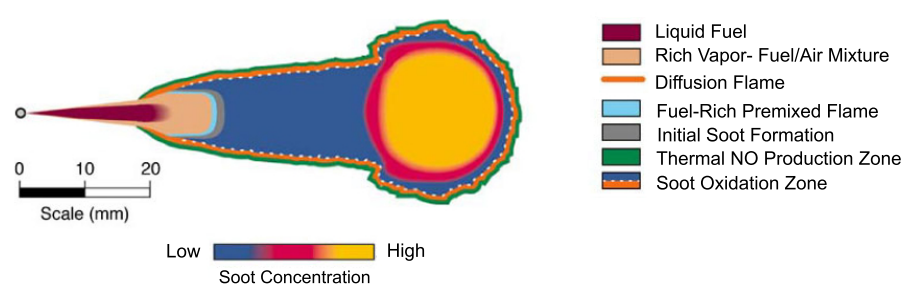

Figure 2.2. Schematic of the diesel combustion conceptual model presented by Dec [1].

means of a gas sampling study, were also plotted on the $\phi$-T diagram to form a trajectory. As can be seen in figure 2.3, the conventional diesel combustion (CDC) regime encompasses both the NOx and soot formation peninsulas.

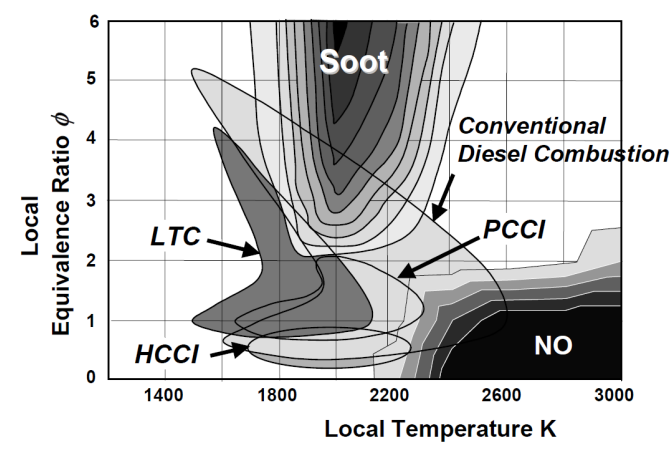

Figure 2.3. $\phi$-T diagram showing the soot and $N O$ formation regions. The operating zones of conventional diesel combustion, LTC, HCCI and PCCI are marked [3].

Many strategies have been studied by the engine researchers to reduce the formation of these two pollutants during conventional diesel operation, all them concluding that exists a trade-off between both emissions, where a strategy to decrease one, leads to an increase in the other [4]. This is commonly known as conventional diesel emissions dilemma.

Taking into account the toxicity of these two emissions and the increasingly stringent regulations for these pollutants, in recent years it have been proposed different advanced combustion strategies to escape from the classical NOx-soot trade-off. A brief review of these combustion strategies, which will serve as a base for defining the objectives of the present thesis, is performed next. 


\subsection{Low Temperature Combustion approaches}

The advanced combustion concepts are based on promoting low local combustion temperatures to avoid the interaction with the NOx formation peninsula. By this reason, this type of combustion strategies are commonly known as low temperature combustion (LTC) modes. These techniques also rely on extending the mixing time prior to the start of combustion to avoid rich regions and inhibit soot formation. These combustion characteristics can be inferred from the $\phi$-T space proposed by Neely et al. [3], which overlaid the operating region of some LTC concepts in the original $\phi$-T space proposed by Kamimoto and Bae [2], as sketched in figure 2.3.

As can be seen in figure 2.3, the mixing-controlled LTC pathway has similar shape than that of CDC. This LTC concept is based on promoting low local flame temperatures, for which, very high EGR levels are typically used. This need for reducing the oxygen concentration, results in similar equivalence ratios $(\phi)$ than $\mathrm{CDC}$ operation. However, the reduced flame temperatures due to lower oxygen concentration enables to avoid the interaction with the NOx formation peninsula. Moreover, as it can be seen following the LTC pathway, this strategy also reduces significantly the soot formation versus CDC.

Aside from the mixing-controlled LTC pathway, figure 2.3 shows the operating region of two different premixed LTC strategies; homogeneous charge compression ignition (HCCI) and premixed charge compression ignition (PCCI). Here appears the first classification inside the LTC combustion concepts; mixing-controlled and premixed. The premixed LTC strategies enable greater air-fuel mixing time prior to combustion than the mixingcontrolled LTC concepts, decoupling the injection-combustion processes and promoting much leaner local in-cylinder equivalence ratios. Inside the premixed LTC concepts, different approaches can be found depending on the air-fuel mixing degree achieved before the start of combustion. This can be confirmed in figure 2.3 by comparing the $\phi$ range through which the combustion process evolves in the case of HCCI (homogeneous or fully premixed) and PCCI (premixed). More details about the different LTC approaches will be provided in next sections.

\subsubsection{Mixing-controlled LTC}

Pickett et al. [5] reported three different alternatives to attain non-sooting, low flame temperature mixing-controlled diesel combustion. The different methods were investigated in an optically accessible, quiescent constant- 
volume combustion vessel. The first method is based on the use of reduced nozzle hole diameters; the second one consists of sharply decrease the ambient gas temperature; and the third needs the use of extensive exhaust gas recirculation (EGR) to reduce the ambient gas oxygen concentration.

Figure 2.4 compares the apparent heat release rate (AHRR) for typical CDC with that of EGR-diluted LTC engine operation at low load [6]. Some remarkable differences between both combustion processes can be appreciated. As occurs in CDC, LTC combustion starts with the partial oxidation of the diesel fuel, which leads to the first small bump in the AHRR profile. Because of the higher dilution levels and higher ignition delay, more prominent cool flames are observed for LTC. After the first reactions, a second-stage combustion occurs. This corresponds to the premixed combustion phase, where contrarily to CDC, the majority of the fuel is consumed. This occurs due to the higher ignition delay from the start of injection to the start of second-stage combustion. In spite of that, due to the highly EGR-diluted ambient, less spiky AHRR is observed for LTC. Finally, the second-stage combustion event is followed by a mixing-controlled burn that is less pronounced than for CDC.

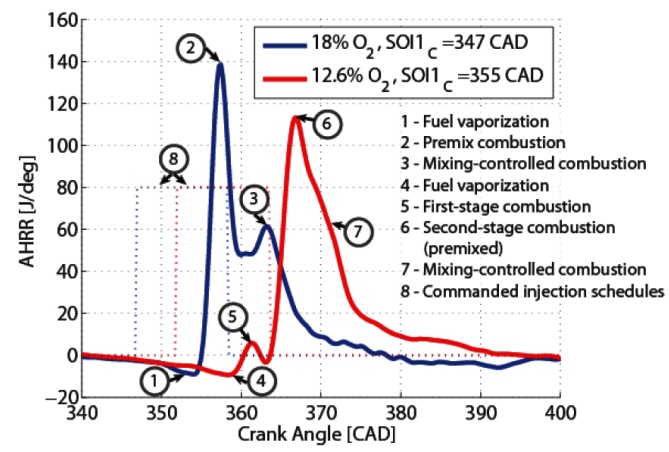

Figure 2.4. Comparison of the apparent heat release rate (AHRR) for typical CDC $\left(18 \% \mathrm{XO}_{2}\right)$ with that of EGR-diluted LTC $\left(12.6 \% \mathrm{XO}_{2}\right)$ engine operation at low load $[6]$.

Further study performed by Musculus [7], provided a comprehensive knowledge for typical low sooting, low NOx, early-injection EGR-diluted diesel combustion conditions. For this purpose, multiple laser and imaging techniques were applied in an optically accessible heavy-duty engine. Based on the findings of this study, a conceptual model, similar to that proposed by Dec for CDC, was developed [8]. A comparison between both conceptual models is shown in figure 2.5. 


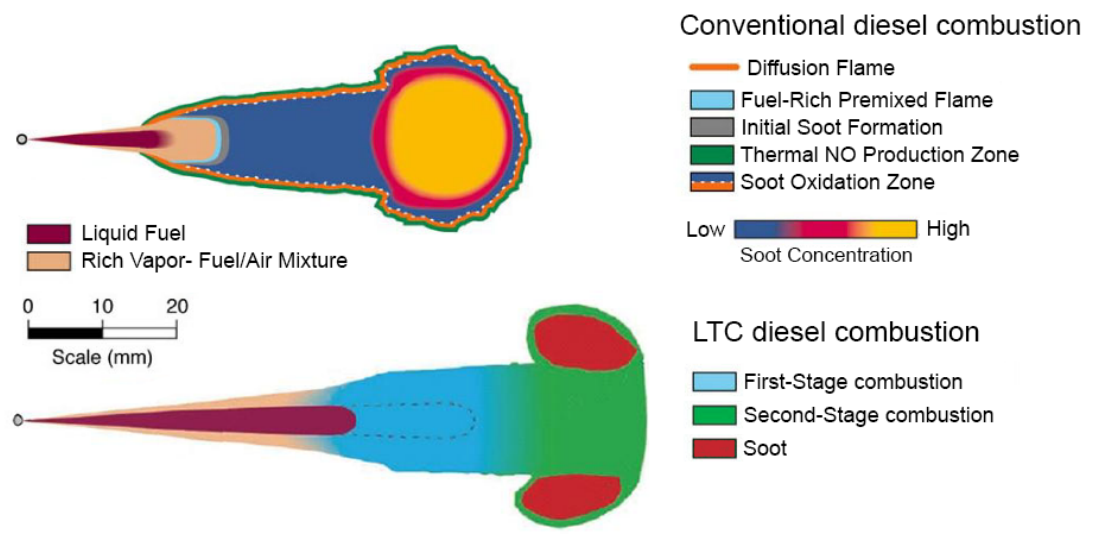

Figure 2.5. Comparison of the conceptual model for the conventional diesel combustion with that for LTC combustion [1, 8].

As it can be seen, the low ambient temperature and density for the earlyinjection condition of LTC, lead to longer penetration of the liquid fuel than CDC. This promotes that liquid fuel may impinge on and wet in-cylinder surfaces, potentially degrading combustion efficiency and emissions. After vaporization of the liquid fuel (blue), the subsequent premixed burn initiates. Based on $\mathrm{OH}$ measurements, Musculus [7] reported that the majority of the heat release of premixed burn (green), evolves throughout near-stoichiometric mixtures. By contrast, a conventional diesel jet is typically fuel-rich, and $\mathrm{OH}$ in the diffusion flame is confined to a stoichiometric shell on the perimeter of the jet. Finally, another substantial difference versus CDC is the spatial location of the soot formation. For LTC, soot forms exclusively at the head vortex region of the jet (green), which indicates that mixing is least complete in this zone. This observation is in contrast with typical soot formation for CDC conditions, where soot is still formed within the head vortex of the flame, but it was also formed within the upstream regions of the jet cross section.

As demonstrated in literature, the mixing-controlled LTC concepts promote high degree of combustion control. However, the large combustion duration and the relatively delayed combustion phasing lead to low thermal efficiency and higher fuel combustion than CDC [9]. Moreover, achieving the required ignition delay following the methods described by Pickett et al. [5], requires the use of "unconventional" hardware. For example, the use of reduced nozzle hole diameters requires fuel injection systems that provide ultra-high injection pressures, and to achieve a highly diluted ambient (with massive EGR), high-performance boosting systems are needed. 


\subsubsection{Homogeneous Charge Compression Ignition}

Homogeneous charge compression ignition (HCCI) relies on achieving a homogeneous air-fuel mixture in the cylinder prior to be ignited due to the high pressure and temperature experienced during compression stroke. To allow this relatively homogeneous charge, the HCCI concept was originally described using port fuel injection (PFI) of diesel fuel [10].

As shown in figure 2.6, HCCI autoignition differs from that of conventional compression ignition engines as it does not occur at a specific place in the spray. By contrast, a spontaneous ignition occurs almost simultaneously across the combustion chamber. This avoids the appearance of a flame front as in spark ignition engines, which leads to drastically decrease NOx emissions due to the lack of a high temperature region in the chamber. In addition, soot formation is inhibited due to the near homogeneous air-fuel mixture achieved prior to the start of combustion [11].
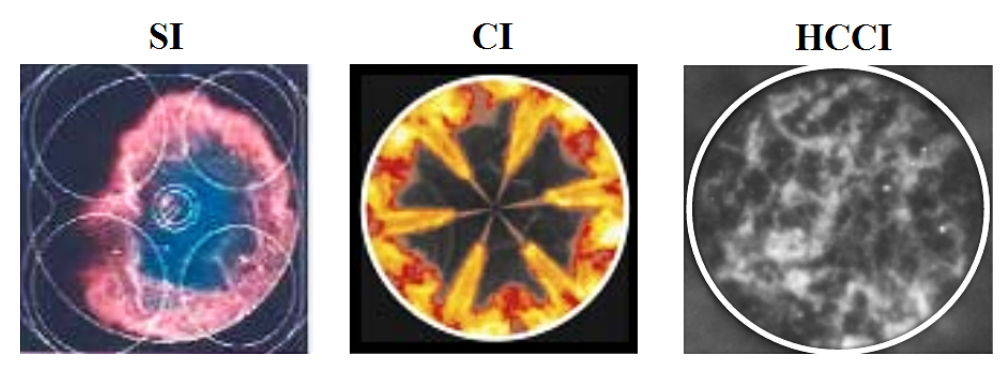

Figure 2.6. Natural luminosity imaging of spark ignition, compression ignition and HCCI combustion. Adapted from [12].

As a result of the simultaneous autoignition of the charge, the heat release rate in HCCI is significantly higher and faster than in SI and diesel engines, which lead to improved fuel-to-work conversion efficiency if a favorable combustion phasing is reached. However, although HCCI combustion appears thermodynamically attractive, it is entirely controlled by chemical kinetics, which means that in-cylinder temperature, pressure, equivalence ratio, and cetane number of the fuel govern when autoignition occurs. This fact arises important challenges when trying to put this concept into practice.

Since combustion control can be only done by managing the charge conditions at intake valve close (IVC), the concept becomes highly dependent on the engine operating conditions. This limits the HCCI operation to the partial load range. At lower loads, the high dilution levels and low in-cylinder temperature make reaching the autoignition conditions too late in the cycle, 
resulting in partial burn, and leading to high $\mathrm{HC}$ and $\mathrm{CO}$ emissions and loss of power [13]. In the extreme case, the misfire occurs. At high loads, the autoignition temperature threshold of diesel fuel is reached too early in the compression stroke. This promotes too advanced combustion phasing, which leads to penalties in thermal efficiency, high noise and eventually engine knocking [14].

Another disadvantage of HCCI is that, even in case of achieving a thermodynamic environment favorable for autoignition of the charge near TDC, the lean operation and low temperature experienced during combustion provoke high levels of $\mathrm{HC}$ and $\mathrm{CO}$ emissions inherently. In addition, a second source of HC with HCCI is the one coming from the portions of the fuel mixture trapped in the cool regions of the chamber, such as the crevices zone. Moreover, due to the low temperature combustion process, catalytic converters are inefficient to oxidize these pollutants [15]. Finally, the fast and high heat release with HCCI leads to greater pressure rise rates and engine noise than CDC. Furthermore, HCCI engines will face more problems than CDC in firing during cold start operation, when temperatures are very low and heat transfer to the cold combustion chamber is high.

\subsection{Strategies for expanding the HCCI operating limits}

As discussed in previous section, the operating range of HCCI is limited to partial loads. This fact has encouraged many researchers to study possible strategies for extending the feasible operation of this concept to greater portion of the engine map. This means that these strategies must be able to extend the ignition delay at high loads, reduce $\mathrm{HC}$ and $\mathrm{CO}$ emissions at low loads and improve combustion control over the load-speed map.

\subsubsection{Charge preparation}

Several techniques have been investigated to modify the intake charge properties to expand the operating limits of PFI diesel-HCCI to some extent.

Despite port fuel injection (PFI) is the simplest method of external mixture preparation, it is not optimal for heavy fuels. In this sense, a major source of $\mathrm{HC}$ and $\mathrm{CO}$ emissions with diesel-HCCI is due to the low volatility of the diesel fuel, which leads to poor vaporization and increased wall impingements in both the intake duct and in-cylinder walls. Ganesh et al. $[16,17]$ used an 
electronically controlled fuel vaporizer to enhance the mixture formation. By this way, they avoided the use of high intake air temperatures, and therefore the additional electric power consumption [18]. The authors reported that wall wetting and soot formation were largely avoided using the fuel vaporizer. Guezennec et al. [19] also confirmed this findings, achieving successful dieselHCCI operation with external mixture formation up to 4.7 bar IMEP load using an engine with compression ratio of 18:1.

With the aim of extending the engine operation towards higher loads, Christensen et al. [20] studied diesel-HCCI in a variable compression ratio (CR) engine. The engine was run with CRs ranging from 9.6:1 to 22.5:1, which allowed the operation with different fuels. They demonstrated that the start of combustion in diesel-HCCI can be delayed by decreasing the CR of the engine. However, excessive decrease of CR compromises the low load operation and reduces thermal efficiency.

The ignition timing can be also modified through the air-fuel ratio variation. As reported by Machrafi et al. [21], the increase of the equivalence ratio leads to decrease the ignition delay at HCCI conditions. However, the equivalence ratio variation also affects the combustion characteristics in other several ways, for instance through the heat release rate, and wall and residual temperatures.

A straightforward method for controlling the start of reaction is by modulating the intake air temperature. Higher intake temperatures advance the start of combustion and vice versa. However, the range of crank angles over which the combustion phasing can be controlled is quite limited and a large penalty in volumetric efficiency accompanies the high intake temperatures [22]. Moreover, this method is generally deemed impractical for mobile applications.

The most practical way to delay the autoignition timing in a PFI dieselfueled HCCI engine was found to be through the addition of high levels of EGR into the intake. In addition, the heat of the recycled exhaust gases can contribute to the evaporation of the fuel, thus reducing wall wetting problems. When cooled EGR is applied, NOx emissions further decrease due to the lower combustion temperature. However, with the increase of the EGR rate, combustion reaction rate reduces, in-cylinder mean temperature decreases and combustion becomes more incomplete, which increases $\mathrm{CO}$ and $\mathrm{HC}$ emissions [16].

The strategies previously described help to solve some isolated problems of HCCI. However, the mentioned techniques require large time scales to achieve cycle-to-cycle control, and therefore cannot provide precise control over combustion phasing. This disadvantage has led to investigate other 
combustion strategies in which the mixture homogeneity is reduced but the start of combustion control is easier, as will be described next.

\subsubsection{Fuel stratification using direct injection}

Promoting certain degree of fuel stratification in the chamber, instead of completely homogeneous mixtures, could reduce the problems found with HCCI combustion. This can be achieved by delaying the injection timing towards the compression stroke, for which, direct injection systems must be used. Depending on the injection timing used, an almost-homogenous, premixed, or partially premixed charge can be achieved before combustion starts. A comparison of the main stage of HCCI and partially premixed combustion (PPC) is shown in figure 2.7. In both cases, a single direct-injected pulse was used [23].
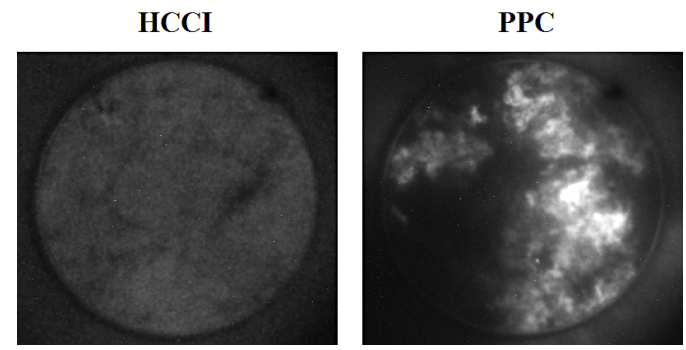

Figure 2.7. Two examples of chemiluminescence imaging of the main combustion event for HCCI (SOI: -320 CAD ATDC) and PPC (SOI: -70 CAD ATDC). Adapted from [23].

The effect of fuel stratification on combustion development is well described in the work performed by Sjöberg et al. [23], Dec et al. [24] and Yang et al. [25-27]. The multizone chemical-kinetics modeling study carried out in [23] demonstrates that, for fuels with sufficient sensitivity to the local $\phi$ (diesel-like fuels), fuel stratification promotes a staged combustion event with reduced pressure rise rates (PRR), which allows increasing the load limits of HCCI operation. This fact is illustrated in figure 2.8 , where a homogeneous and fuel-stratified case (with five different zones of $\phi$ ) are compared.

Figure 2.8a shows the pressure traces for both homogeneous and fuelstratified operation. As it can be seen, the homogeneous case leads to very high $\mathrm{PRR}$, which is explained due to the fast chemical reactions occurring during the main stage of combustion. This can be confirmed looking at the singlezone heat release rate (HRR) profile shown in figure 2.8b. By contrast, each 
$\phi$-zone of the stratified case show different combustion phasing, which creates a staged combustion, and reduces the PRR. This behavior can be inferred looking at the figure 2.7, where different chemiluminescence levels across the combustion chamber are observed for the PPC case.
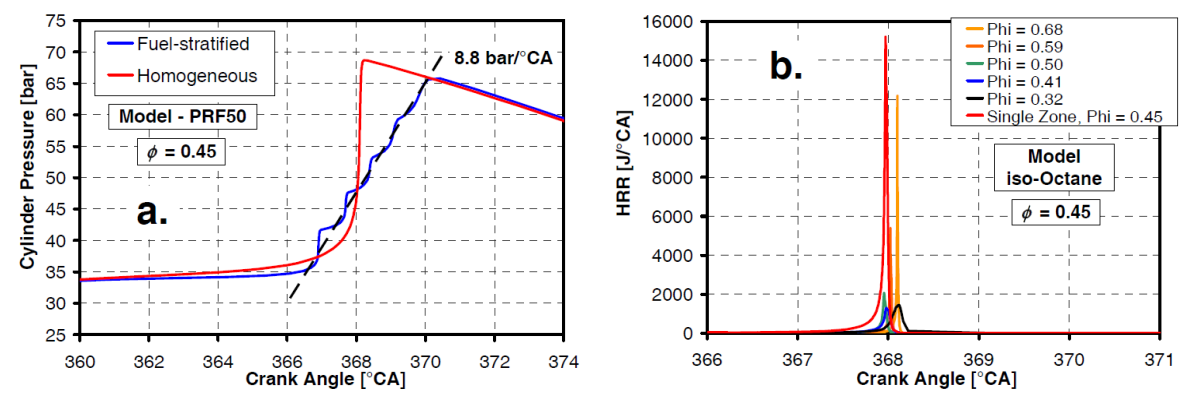

Figure 2.8. Computed pressure (left) and HRR (right) for homogeneous and fuelstratified operation with PRF50 and gross IMEP $=7.9$ bar [23].

During past years, many strategies based on the fuel stratification method have been implemented in diesel-fueled engines. As noted in figure 2.7, the in-cylinder fuel stratification can be created using a single injection of fuel, where the degree of stratification achieved depends on the injection timing used. Some of the concepts developed using a single diesel injection are:

- Premixed lean diesel combustion (PREDIC) $[28,29]$. Requires two side injectors with high number of nozzle holes (x16) of very low diameter $(80 \mu \mathrm{m})$. The compression ratio of the engine was 16.5:1.

- Premixed compression ignition (PCI) [30]. The use of an impinged-spray nozzle realizes low penetration, high-dispersion and high injection rates. A combination of reduced compression ratio (13.5:1) and high amounts of cooled EGR was needed to prevent premature ignition.

In both cases, the fuel is injected during the early compression stroke, promoting a partly homogeneous mixture, and combustion starts closer to TDC. The authors reported a dramatic reduction in NOx and soot emissions compared to $\mathrm{CDC}$, which was accompanied by an increase in $\mathrm{HC}$ and $\mathrm{CO}$ emissions. The high levels of unburned products were explained due to two main reasons. The first one was the combination of the low volatility of the diesel fuel and the low air density during the early timings of the compression stroke, which causes liquid wetting into cylinder walls. This effect 
was minimized in the PCI concept by using the impinged-spray nozzle. The second source of $\mathrm{HC}$ emissions was from the fuel located in quench areas, such as the crevices, due to the early injection timings used. This fuel combustion inefficiency provoked higher fuel consumption than CDC in both operating modes. Moreover, the fuel injection optimization studies performed to provide adequate mixing conditions for achieving the PCI combustion regime, concluded that the effective operating range was restricted to partial loads due to the appearance of misfire and knocking.

To take advantage of the fuel stratification for extending the operational limits of HCCI towards higher loads, it was necessary the use of multiple injections. This allows to distribute the fuel to all parts of the combustion chamber, thus enhancing the air utilization and reducing the pollutant emissions formation. In this sense, the load range of the PCI combustion concept was extended by using a split injection with high injection pressure and small nozzle diameter. While the first injection leads to PCI combustion, the second injection event leads to more conventional combustion [31]. Unfortunately, higher fuel consumption than CDC was still observed in all engine loads. Some other concepts using various fuel injections per cycle are:

- Multiple stage diesel combustion (MULDIC) [32]. This concept uses the PREDIC configuration with an extra injector at the center of the chamber. The first injection occurs during the early compression stroke (side injectors) and the second injection just before TDC (center injector). This allowed to achieve around 50\% load of that achieved in a naturally aspirated diesel engine. However, the second injection event promotes high local temperatures, leading to higher NOx emissions than PREDIC strategy. Fuel consumption was higher than that of CDC because of the premature ignition of the first stage combustion and the extremely late injection for the second stage combustion.

- Homogeneous charge intelligent multiple injection combustion system (HiMICS) [33]. This concept uses a high CR (18:1) and common rail injection system. Two nozzle types were compared: a standard 6-hole nozzle and a 30-hole nozzle with small diameter. The standard nozzle was found better to reduce engine-out soot emissions. The mixture was formed by one or two injections performed during a period from the early stage of the intake stroke to the middle stage of the compression stroke, and a later injection after TDC to oxidize soot. It was found a tradeoff between NOx and fuel consumption. Specifically, retarded injection timings resulted in low NOx emissions but increased fuel consumption. 
- Uniform bulky combustion system (UNIBUS) [34]. The concept was developed on a high CR diesel engine (18.4:1) with common rail system and conventional injector nozzle. As done in HiMICS, an early injection for fuel diffusion and a second injection after TDC to act as ignition trigger of the main combustion stage were used. This system was also found to be limited to low loads, while at high loads conventional diesel combustion was used.

- Multiple injection bumped combustion (MULINBUMP) [35]. Developed on a 15:1 CR diesel engine with common rail system and standard injector nozzle. The concept combines premixed and lean diffusion combustion. Multi-pulse injection (3/4 pulses) is used to premix the early-injected fuel without wall impingements problems. The air-fuel mixing of the main injection near TDC is enhanced due to the specially designed bowl (so-called BUMP combustion chamber). Low soot and moderate NOx emissions were reported under 9 bar IMEP load. At higher loads, appeared the typical NOx-soot trade-off as in CDC.

- Narrow angle direct-injection (NADI) [36]. An engine with conventional flat cylinder head, CR of 16:1 and common rail injection system was used. The concept relied on reducing the angle between the sprays (lower than $100^{\circ}$ ) to prevent fuel deposition on the cold cylinder-liner region. Results with single injection indicated that liquid fuel impinges on the bowl wall, which leads to incomplete combustion and high soot formation for all early injection cases. This was solved using optimized multiple injections, with growing injection quantities according to in-cylinder temperature and pressure [37]. Excellent NOx and soot emissions levels with acceptable $\mathrm{HC}$ and $\mathrm{CO}$ emissions at part load were reported. To extend the concept up to full load conditions, a dual-mode concept switching to CDC at full load was developed.

- Modulated kinetics (MK) [38]. This concept was developed using a high CR engine (18:1) and common rail injection to perform a single injection event after TDC. To accelerate the mixing process, high swirl ratios were used (3.6 10). It was found that retarded injection timings resulted in higher fuel consumption. This was compensated by lower cooling losses due to the high swirl ratios, which reduced efficiently the mean heat flux by modifying the in-cylinder flow structures and therefore the spatial progression of the combustion. To extend the concept to medium loads, the use of reduced CR (16:1), cooled EGR and high injection pressures was required [39]. To minimize wall impingement, a wider piston bowl was also used. At high loads, the impossibility of injecting all the fuel 
quantity before the start of combustion leads to unacceptable soot levels. Compared to $\mathrm{CDC}$, the MK concept performed better in terms of noise [40], while the main advantage over the early direct injection systems was the greater combustion control achieved with the late injection timing.

As general conclusion, it can be stated that combustion control is still a problem using early single direct injections. Moreover, high levels of HC and CO emissions were reported due to wall impingement of liquid fuel. To partially solve this problem, unconventional injection hardware had to be used, and even in that case, the concepts were limited to part load (PREDIC, PCI). Due to the high reactivity of diesel fuel, the use of multiple injections was necessary to increase the load range and enhance combustion control (split-PCI, MULDIC, HiMICS, UNIBUS, MULINBUMP). However, since the second injection takes place just before or after TDC, NOx problems and fuel consumption penalties were found. NADI concept is one of the most potential LTC concepts, however a switch to conventional diesel combustion is needed to cover the full operating range of the engine. Finally, late injection strategies such as MK were studied. This strategy improves the combustion control versus the early injection strategies and noise levels versus CDC. However, the concept shows lower thermal efficiency and is limited to partial loads.

\subsubsection{Fuel autoignition qualities modification}

As can be inferred from previous section, the ability to achieve controlled autoignition at high loads continues to be a problem with diesel-fueled stratified operation. This limitation arises due to the chemical nature of diesel fuel, which does not allow extending the ignition delay sufficiently as in-cylinder thermodynamic conditions become more reactive.

To overcome this problem, Kalghatgi et al. [41] introduced the concept of gasoline partially premixed combustion (PPC) in 2006. They demonstrated that the use of a fuel with higher resistance to autoignition than diesel, allows extending the ignition delay without the need of high EGR fractions, too early injection timings, too low compression ratios or unconventional hardware. Moreover, the larger mixing time provides a well-mixed charge prior to combustion, which leads to lower NOx and soot emissions as compared to conventional diesel operation [42]. By using double injection strategies and $25 \%$ of EGR in a SCE of 2.0 liters displaced volume and CR 14:1, Kalghatgi al. [42] were able to extend the PPC operation with commercial $95 \mathrm{RON}$ gasoline up to $\sim 16$ bar IMEP at $1200 \mathrm{rpm}$ with low smoke (FSN <0.07), low NOx $(0.58 \mathrm{~g} / \mathrm{kWh})$ and low ISFC $(179 \mathrm{~g} / \mathrm{kWh})$. 
Several works developed at Lund University obtained similar results to those reported by Kalghatgi et al. A very illustrative work was developed by Manente et al. [43], who studied PPC operation with different tailor-made fuels with boiling point in the range of gasoline, but very different octane number. All fuels were tested from idle (2.5 bar IMEP, $600 \mathrm{rpm}$ ) to 26 bar gross IMEP at $1250 \mathrm{rpm}$ in a 2.1 liters SCE engine of CR 17.3:1. The EGR was fixed at $50 \%$ and the inlet pressure varied from 1 to near 3.7 bar at full load. The authors found that, while full load operation was achieved with all the fuels, the lowest achievable load (limited by ignitibility limits) was strongly dependent on the fuel octane number. The feasible operable region as a function of the fuel type is depicted in figure 2.9 (left). On the other hand, the authors stated that gross indicated efficiency remained at roughly $53.5 \%$ throughout the whole load sweep, independently on fuel composition.

As can be seen from the figure 2.9 (right), most of the operating conditions studied fulfilled simultaneously the EURO VI and US10 legislations in terms of NOx and soot emissions. In particular, at 25 bar gross IMEP, the soot levels for all the gasoline fuels studied were below $0.05 \mathrm{~g} / \mathrm{kWh}$, while the same tests with diesel fuel arrived up to $0.4 \mathrm{~g} / \mathrm{kWh}$ (not shown in figure 2.9). At partial load conditions, the tests exceeding soot emissions correspond to the most reactive gasoline fuels. Finally, it is interesting to note that all the studies in literature concluded that gasoline PPC combustion leads to high $\mathrm{HC}$ and $\mathrm{CO}$ emissions levels as a consequence of the incomplete oxidation of the fuel.
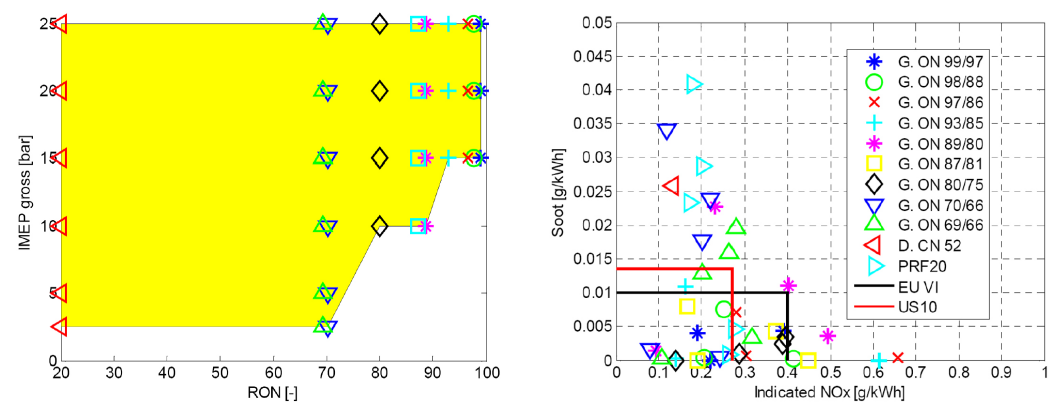

Figure 2.9. Stable operational load window as a function of fuel type (left) and sootNOx trade-off for different fuels types from 5 to 25 bar gross IMEP (right). Adapted from [43].

The results previously described demonstrate that the use of gasolinelike fuels offers notable benefits for extending the operating range of the PPC concept, providing NOx and soot emissions and high thermal efficiency simultaneously. However, as done by Manente et al. [43], many other 
researchers have confirmed the ignitability problems at low load and idle conditions with gasolines of RON greater than 80 [44, 45]. A method to enhance the autoignition of gasoline fuel at these operating conditions is to increase the in-cylinder temperature. Ciatti et al. [46, 47] used uncooled EGR as a way to increase the intake charge temperature and demonstrated stable gasoline compression ignition operation $\left(3 \% \mathrm{COV}_{\text {IMEP }}\right)$ down to idle conditions using $93 \mathrm{RON}$ gasoline. However, the use of uncooled EGR does not allow the operating range extension to upper loads due to the appearance of knocking. Alternatively, the charge heating can be done by trapping hot residuals from the previous combustion cycle. This is commonly known as internal EGR (iEGR). To achieve the required iEGR levels, the two main approaches discussed in literature are the negative valve overlap (NVO) and the rebreathing strategies [48]. From the technological point of view, both strategies can be implemented using a variable valve actuation (VVA) system, which allows modifying the valve lift and duration as needed.

Several studies concluded that NVO is an effective method to extend the minimum load limit of gasoline PPC [45, 49, 50], but this technique has the disadvantage of low net indicated efficiency due to the greater heat losses promoted by the recompression of the hot residual gases [51]. An alternative to using NVO is to rebreathe the exhaust gas during the intake stroke. The rebreathing strategy can be done in different ways, for example by delaying the exhaust valve closing or by reopening the exhaust valves later during the intake stroke. As concluded by many authors, rebreathing also allows stable PPC operation at low load with the advantage of a higher net indicated efficiency than NVO [51]. It is interesting to note that, while in heavy-duty engines the thermal load in the exhaust stream is high, in smaller engines these strategies may have less effectiveness because of the lack of sufficient heat in the exhaust gases in some operating conditions. In addition, the feasible operating range of a production engine using the rebreathing strategy will be very sensitive to variations of the engine thermal conditions during the load and speed transients, which reduces the effectiveness of this technique [52].

\subsubsection{Spark assistance}

Alternatively to using trapped or reinducted residual gases, several researchers have studied the capabilities of the spark assistance as method to improve the combustion stability and cycle-to-cycle control of gasoline PPC at low load conditions $[53,54]$. 
Benajes et al. [55] demonstrated that the spark assistance can provide spatial and temporal control to the PPC combustion process, extending the stable operation towards lower loads even using 98 RON gasoline. Figure 2.10 (left) shows that spark assistance leads to an almost constant $5 \%$ coefficient of variation $(\mathrm{CoV})$ of IMEP in all the load range tested. Moreover, it can be seen that the best improvement versus the PPC tests is obtained in the range from 1.5 to 3 bar IMEP, where values ranging from $10 \%$ to $18 \%$ are observed without the spark assistance.

On the other hand, the figure 2.10 (right) shows that the spark assistance promotes a reduction of the ringing intensity as load is increased. This reduction is achieved due to the consumption of part of the charge during the premixed flame growth, which promotes softer heat release rates and peak PRR. Thus, the maximum achievable load for a given PRR limit can be increased. Unfortunately, the authors reported that the staged combustion provoked by the spark assistance reduces the thermal efficiency of the concept.
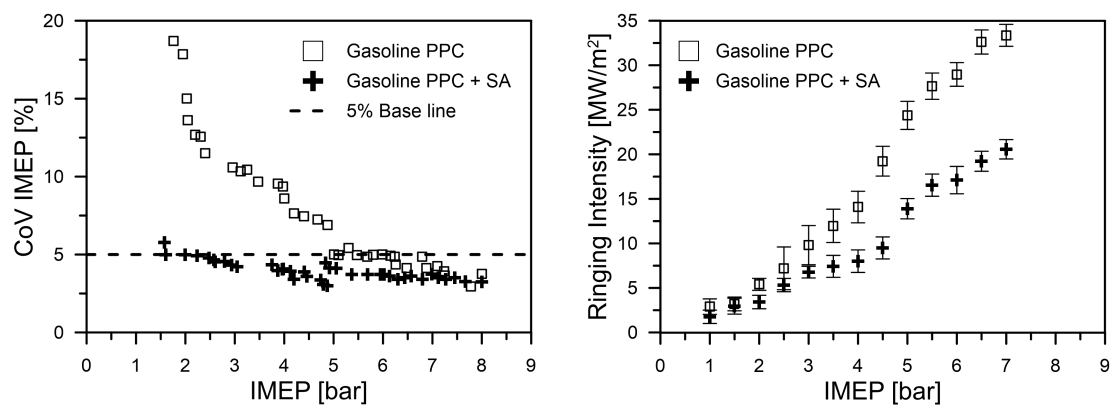

Figure 2.10. Coefficient of variation of IMEP (left) and Ringing intensity (right) versus engine load for 200 engine cycles with and without spark assistance.

Further studies [56] carried out to evaluate the engine-out emissions from this combustion concept in a wide range of engine operating conditions $(\phi$, EGR, SOI, $\mathrm{P}_{\mathrm{inj}}$ ), demonstrated that the use of the spark assistance led to unacceptable NOx and soot emissions, as can be confirmed in figure 2.11.

The excessive emissions levels were thought to be related to the rich equivalence ratios needed between the spark plug electrodes at the time of the spark discharge to avoid misfire, which contributes to increase NOx emissions during the flame propagation phase. In addition, it was confirmed that the use of double injection strategies is a suitable strategy to improve the unburned $\mathrm{HC}$ and $\mathrm{CO}$ emissions, but still does not solve the unacceptable NOx and soot emission levels [57]. 

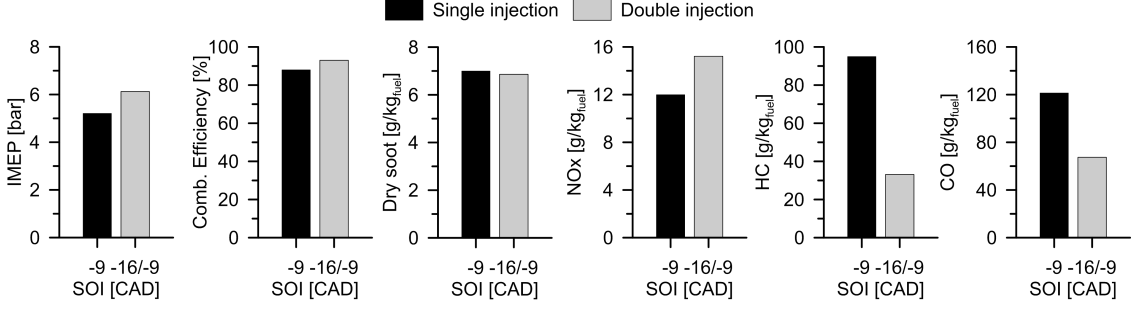

Figure 2.11. Performance and engine-out emissions from the gasoline SA-PPC combustion using a single (-9 CAD) and double (-16/-9 CAD) injection strategy.

\subsubsection{Dual-fuel operation}

Recent experiments performed by Bessonette et al. [58] in a heavy-duty engine of 12:1 compression ratio (CR) suggested that, to achieve proper HCCI operation, the fuel characteristics must vary depending on the engine operating conditions. Specifically, they were able to extend the HCCI operating range up to 16 bar BMEP using a fuel with a derived cetane number of $\sim 27$ (i.e., a gasoline boiling range fuel with an octane number of 80.7). This represented a $60 \%$ increase in the maximum achievable load compared to the operation using regular diesel fuel. By contrast, to achieve successful operation at engine loads near 2 bar BMEP, it was required the use of a fuel with a derived cetane number of $\sim 45$ (i.e., regular diesel fuel).

These results are explained looking at the figure 2.12, which shows the ignition delay times for three fuels with different RON $(0,50$ and 100) at equal initial pressure and $\phi[59]$.

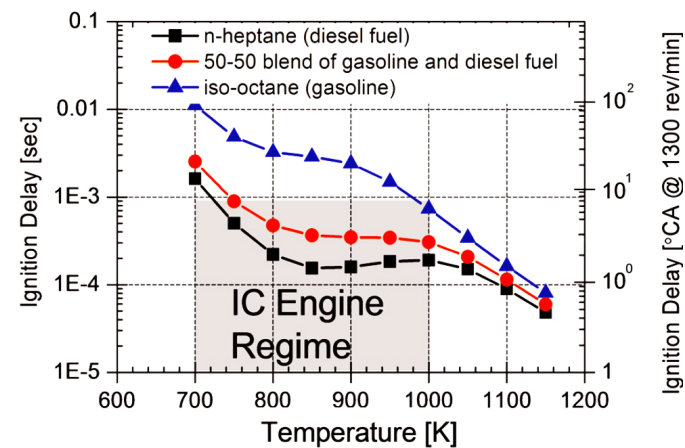

Figure 2.12. Constant-volume ignition delay times for three different fuels calculated using a reduced PRF mechanism [59]. 
The ignition delay curve of each fuel governs the CA50 in a kineticallycontrolled combustion as HCCI. This entails that, depending on the charge gas temperature, which varies with engine speed, load and in-cylinder conditions, only one fuel can provide the optimum combustion phasing that allows maximizing the thermal efficiency. As it can be inferred from figure 2.12, the use of net iso-octane will lead to excessive delayed CA50 at low temperature conditions, while at high temperatures, n-heptane would provide excessive advanced combustion phasing. Moreover, it is seen that the use of intermediate fuel mixtures is a potential method to optimize the engine operation depending on the in-cylinder thermodynamic conditions.

With the aim of exploiting this ability on a cycle-to-cycle basis, Inagaki et al. [60] introduced a dual-fuel stratified PCI combustion concept combining the port fuel injection of iso-octane and direct injection of diesel fuel. This engine configuration allows to manage efficiently the fuel blending to adjust the proper in-cylinder fuel reactivity depending on the engine operating conditions. A scheme of this combustion concept is shown in figure 2.13 .

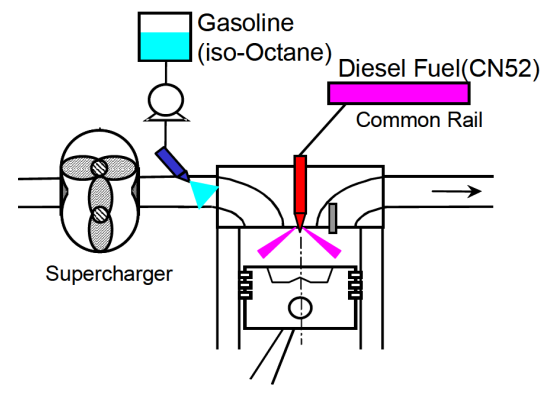

Figure 2.13. Scheme of the lean-boosted dual-fuel stratified PCI engine proposed by Inkagaki et al. [60] using iso-octane and diesel fuel.

The authors compared the heat release rate between dual-fuel HCCI of nheptane/iso-octane (both port fuel injected with separate injectors) and dualfuel stratified PCI of diesel/iso-octane operating with an engine CR of 14:1. In both cases, the intake air temperature was regulated at $60^{\circ} \mathrm{C}$, the average RON was 30 and the total $\phi$ was 0.35 . As shown in figure 2.14 , the dual-fuel stratified PCI operation provides more advanced ignition timing than dual-fuel HCCI. Moreover, the stratified operation also results in broader combustion duration and significantly reduced peak heat release rate, which allows to decrease the noise from $85 \mathrm{~dB}$ to $75 \mathrm{~dB}$. As the figure shows, NOx emissions increased from $3 \mathrm{ppm}$ to $9 \mathrm{ppm}$ because of the more locally-richer mixtures formed in the dual-fuel stratified PCI than with HCCI. 


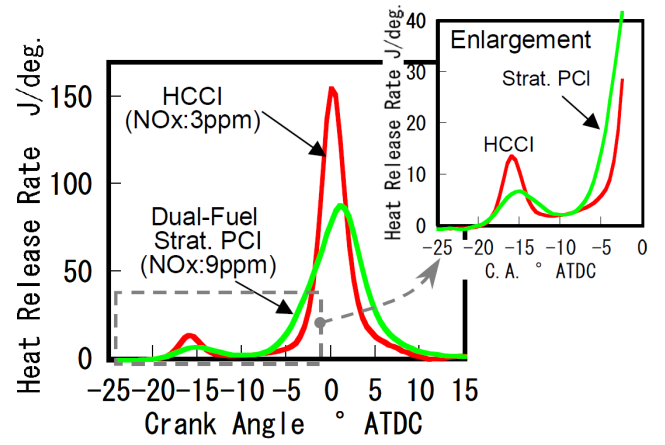

Figure 2.14. Comparison of heat release rate between HCCI and dual-fuel stratified PCI (total $\phi=0.35)$ [60].

In the same work, the authors examined the effects of the ignitability distribution (local $\phi$ of both fuels and RON) on the PCI combustion characteristics. To do so, the ignitability distribution profile was changed actuating on the diesel injection timing and the PFI/DI fuel ratio over the total quantity injected. As can be seen in figure 2.15, the ratio of diesel fuel was decreased as engine load increased, which is consistent with the findings reported by Bessonete at al. [58]. The results shown in figure 2.15 also demonstrate that dual-fuel stratified PCI combustion provides very low NOx and soot emissions, even without using EGR. Moreover, greater $\mathrm{HC}$ and $\mathrm{CO}$ levels than those of conventional diesel engines were observed, however, they were smaller than those resulting from a conventional PCI combustion using a large amount of EGR. Lastly, the authors reported that boosted operation (for tests with IMEP $>6$ bar) caused an important increase in thermal efficiency, with peak values above $50 \%$ at 12 bar IMEP.

The causes for the high thermal efficiency in the lean boosted dual-fuel PCI operation were summarized as follows:

- Increase of the expansion work due to the higher specific heat ratio $\left(\gamma=C_{p} / C_{v}\right)$ promoted by the leaner mixture and the absence of EGR.

- Decrease of heat transfer losses due to the lower combustion temperature with intake air boosting.

- Optimally-timed and near constant volume-like combustion development controlled by the diesel fuel fraction. 

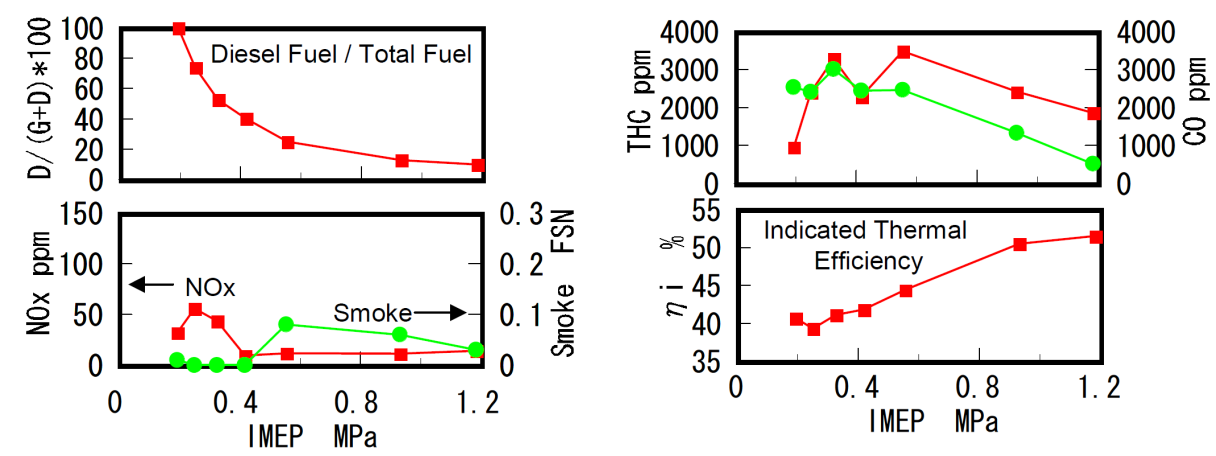

Figure 2.15. Engine parameters and performance of dual-fuel stratified PCI operation at 1400 rpm. Adapted from [60].

\subsection{Reactivity Controlled Compression Ignition}

More recently, Kokjohn et al. [61] reinforced the promising results found in the pioneering investigation performed by Inagaki et al. [60]. In their work, the authors numerically and experimentally investigated PCCI dualfuel combustion at low and medium load conditions (6 and 11 bar IMEP) and achieved engine-out emissions levels below EPA 2010 heavy-duty limits, without the need for aftertreatment, and maintaining low PRR and thermal efficiencies above $50 \%$. In this case, the experiments were conducted using gasoline and diesel fuel, thus providing a more realistic approach than using iso-octane as low reactivity fuel (LRF).

Since PCCI dual-fuel concept relies on the fuel reactivity stratification for controlling the combustion process (i.e., combustion phasing and rate of heat release), the authors re-baptized this strategy as Reactivity Controlled Compression Ignition (RCCI).

\subsubsection{Description of RCCI combustion process}

Based on the results from the CFD modeling work performed in [61], a first description of the RCCI combustion process was presented. In particular, the authors provided a detailed description of the RCCI combustion phenomenon by means of the evolution of several key combustion species. The computations used reference fuels, n-heptane (diesel surrogate) and iso-octane (gasoline surrogate). The results of the low load case (6 bar IMEP) are described next. 


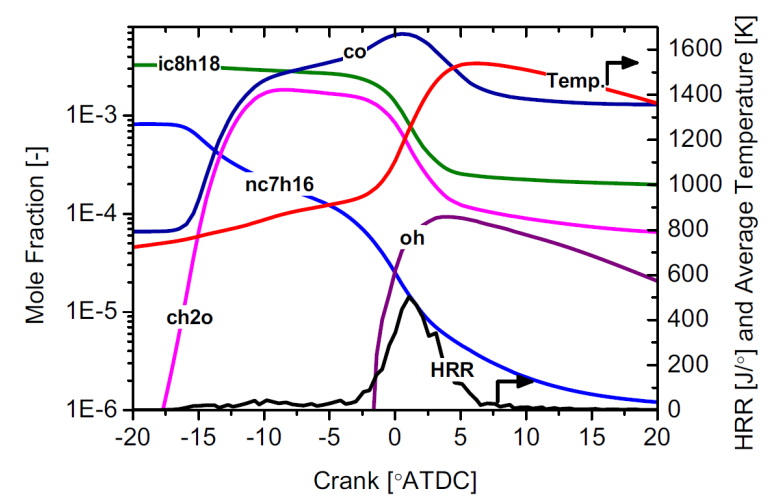

Figure 2.16. In-cylinder evolution of several key combustion species for dual-fuel PCCI operation at 6 bar IMEP. Also shown are the heat release rate and the average temperature [61].

As commented by the authors, figure 2.16 suggests that n-heptane starts to be consumed significantly earlier in the cycle than iso-octane. It can be confirmed by comparing the trend of both species. As it can be seen, by $5{ }^{\circ} \mathrm{BTDC}$ the mole fraction of n-heptane is reduced by nearly an order of magnitude, while iso-octane remains near its IVC concentration. The consumption of n-heptane also appears to coincide with the appearance of formaldehyde $\left(\mathrm{CH}_{2} \mathrm{O}\right)$, which denotes the presence of low temperature oxidation [62]. Formaldehyde consumption and $\mathrm{OH}$ accumulation (i.e., a transition from thermal preparation to thermal ignition of the n-heptane) appears to track with iso-octane consumption. This suggests significant iso-octane consumption does not occur until the thermal ignition of the nheptane is reached. Once the thermal ignition of the n-heptane is reached, CO oxidation is present; thus, energy is released, cylinder temperature rises, and fuel series reactions of iso-octane accelerate. These computational predictions were supported by a subsequent optical investigation performed by Splitter et al. [63], which studied the natural thermal emission from some species to identify the combustion intermediates and fuel decomposition mechanisms that control the RCCI ignition process.

The results of both studies confirmed that the extended heat release period as compared with HCCI combustion is promoted by a staged consumption of the more reactive diesel fuel followed by the less reactive gasoline. These observations are consistent with the hypothesis proposed by Inagaki [60], which suggested that the rate of heat release peaks were reduced due to fuel reactivity stratification. 


\subsubsection{Direct comparison of RCCI vs HCCI}

As stated by Inagaki [60] and Kokjohn [61], to overcome the main drawbacks found with HCCI combustion, RCCI relies on two sources of reactivity stratification; the local fuel reactivity $(\mathrm{PRF})$ and the equivalence ratio. Thus, to evaluate the differences in the operational parameters and performance of the two strategies, Splitter et al. [64] performed a dedicated work comparing both combustion strategies in the same heavy-duty engine platform.

The first part of the study focused on the comparison at matched conditions of 9 bar gross IMEP, charge-based $\phi$ ' of 0.29, 45\% EGR and CA50 of 5 CAD ATDC. In both cases the port-injected fuel was 91 PON gasoline, with RCCI being additionally fueled by early multiple direct-injections of ultra-low sulfur diesel (ULSD). The CR was held constant at 14.8:1. The differences in operational parameters required to achieve the matched conditions for both combustion concepts are summarized in table 2.1. As shown in the table, the HCCI case required $66^{\circ} \mathrm{C}$ in the intake manifold due the low reactivity of gasoline fuel. By contrast, the intake temperature needed to maintain constant combustion phasing with RCCI was lower, and it was reduced as the injected quantity of ULSD increased.

Table 2.1. HCCI and RCCI conditions and PPRR for fixed operation at 9 bar gross $I M E P, \phi^{\prime}=0.29$ and $45 \%$ EGR [64].

\begin{tabular}{lccc}
\hline \hline Operation & Intake temp. $\left[{ }^{\circ} \mathrm{C}\right]$ & ULSD $[\%]$ & PPRR [bar/CAD $]$ \\
\hline HCCI & 66 & 0 & 14.7 \\
RCCI & 57 & 3.0 & 9.6 \\
RCCI & 42 & 6.4 & 7.5 \\
\hline
\end{tabular}

The results shown in figure 2.17 (left) demonstrate that RCCI enables to smooth the heat release rate, leading to lower PRR peaks, combustion noise and pressure-based ringing after the heat release event. Moreover, as depicted in figure 2.17 (right), these differences have a direct impact on engine performance. From the figure, it is stated that pumping and exhaust losses are nearly identical in all cases. This is explained because both strategies were operated with the same intake and exhaust pressures, and only differ in exhaust losses due to changes in intake temperature. However, significant differences in combustion losses and heat transfer are seen, both having a direct effect on net efficiency. In particular, the higher pressure (and temperature) in HCCI allows reducing the incomplete combustion losses, but also increase heat 
transfer. In RCCI, the heat transfer reduction outweighs the increase observed in combustion loss, increasing the net efficiency. Thus, the comparison of the net efficiency between the three cases states that both RCCI conditions enhance the fuel-to-work conversion over HCCI operation, also improving the combustion features.
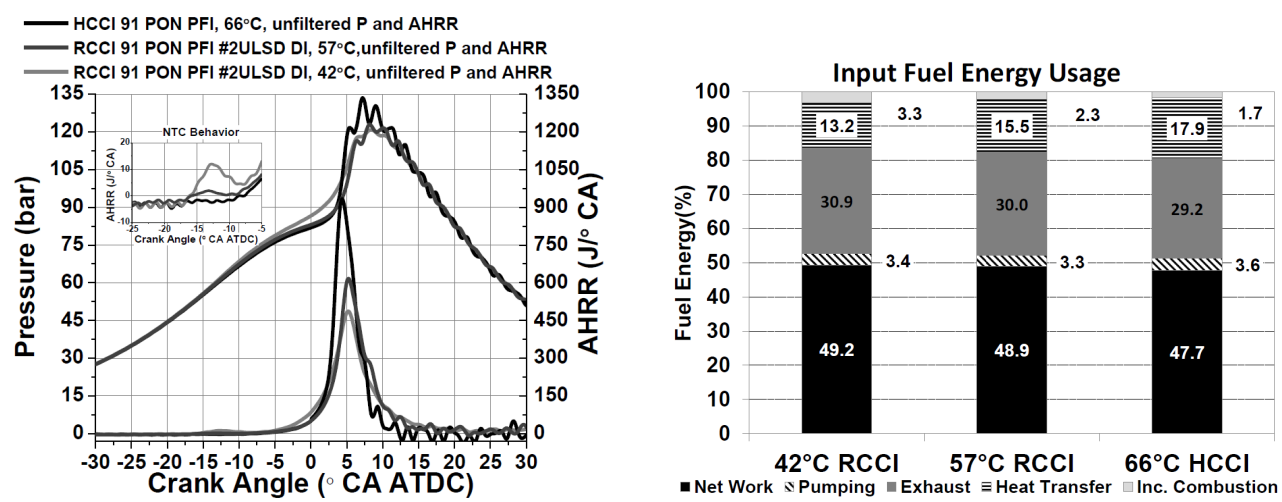

Figure 2.17. Comparison of pressure and apparent rate of heat release traces for HCCI and RCCI at the conditions depicted in table 2.1 (left). Comparison of fuel energy breakdown between RCCI and HCCI (right). Adapted from [64].

The second part of the study performed by Splitter et al. [64] aimed at evaluating the impact of the differences between HCCI and RCCI combustion processes on the engine load limits. The results of brake thermal efficiency (BTE) for RCCI, HCCI and CDC are depicted in figure 2.18. Note that the operating conditions are not the same than in previous study. In this case, the HCCI results came from [65], in which HCCI was operated with ULSD and a reduced compression ratio of 8:1 to mitigate knocking problems. As explained in [65], HCCI operation had engine-out NOx emissions below EPA 2010 mandate with levels of PM slightly above the limit, and maximum PRR around 20 bar/CAD at 20 bar BMEP. The maximum PRR of RCCI at the highest load was also near $20 \mathrm{bar} / \mathrm{CAD}$. However, the increased stratification of RCCI enabled higher compression ratio operation than HCCI, which allowed to increase significantly the BTE in all the engine load range. The values reported were similar to that of modern diesel engines. 


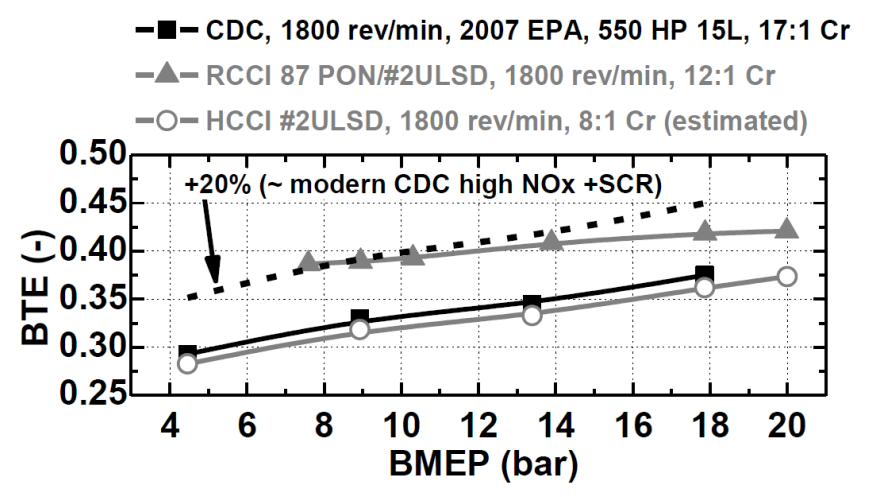

Figure 2.18. RCCI performance compared to HCCI, CDC in a 2007 engine and CDC in a modern engine [64].

\subsubsection{Effects of engine variables on RCCI combustion}

The promising results described in the initial studies motivated an increasing interest on the research community to further investigate RCCI combustion. Thus, several studies have confirmed that this dual-fuel concept is a more potential LTC technique than HCCI and PPC, allowing more effective control of the combustion process while achieving ultra-low NOx and soot emissions together with better fuel consumption than CDC in a wide range of operating conditions. The most interesting findings from the available RCCI literature are summarized next.

\section{Influence of injection parameters}

Diesel injection timing (single injection): figure 2.19 (left) confirms the authority that diesel injection timing has on RCCI combustion process under single injection conditions. With advancing SOI, CA50 is initially advanced and reaches the earliest value at SOI timing of -27 CAD ATDC, and then is retarded. Too late or too early injection timings will retard the CA50 far away from top dead center (TDC), resulting in potentially unstable combustion. Comparing the emissions values for the two injection strategies (early and late) in figure 2.19 (right), it is seen that the early diesel injection allows reducing considerably NOx and soot emissions in all the EGR range tested. Moreover, as reported by the authors, hydrocarbon emissions, CO and ISFC were very similar between both strategies. 

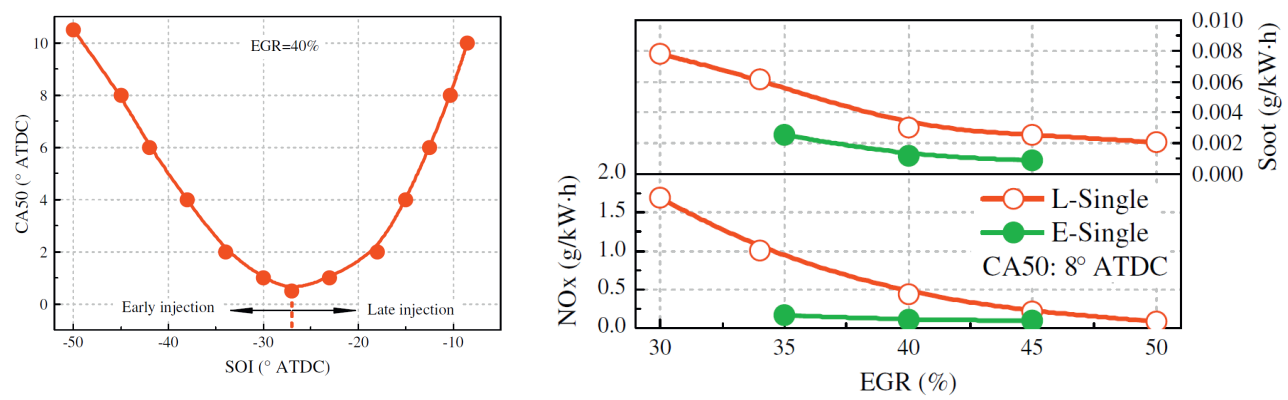

Figure 2.19. Effect of diesel injection timing on CA50 (left) and effect of EGR at constant CA50 of $+8 C A D A T D C$ for an early and late injection timings (right) at $\approx 9$ bar IMEP. Adapted from [66].

Diesel injection timing (double injection): figure 2.20 shows the effect of pilot injection timing on cylinder pressure, heat release rate (HRR), NOx and soot emissions using a fixed late main injection. The advance of the first injection (SOI1) with constant second injection timing (SOI2) results in a progressive decrease of cylinder pressure and peak heat release rate (PHRR) and more retarded combustion phasing. The decreased cylinder temperature and PHRR explain the decreasing NOx emissions. On the other hand, soot emissions are ultra-low and almost uninfluenced by varying the SOI1 timing.
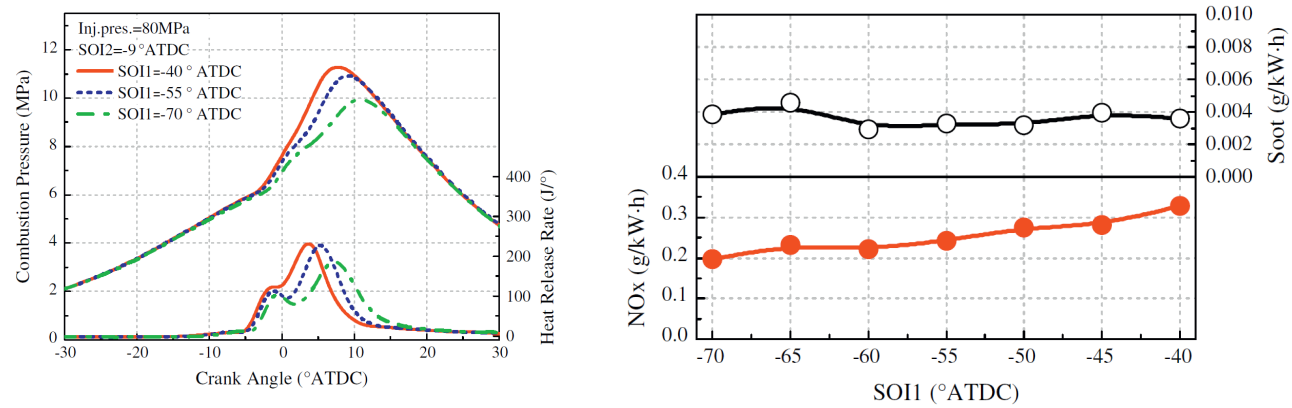

Figure 2.20. Effect of diesel pilot injection timing on cylinder pressure, HRR, NOx and soot emissions using a fixed late main injection timing at $\approx 9$ bar IMEP. Adapted from [66].

Figure 2.21 shows the effect of main injection timing variation on cylinder pressure, HRR, NOx and soot emissions using a fixed early pilot injection. As SOI2 is retarded towards TDC, cylinder pressure and PHRR are decreased, and combustion phasing is retarded, resulting in decreased cylinder temperature and NOx emissions. Again, soot emissions remain unaffected as 
SOI2 timing is varied. As described by the authors, as SOI2 is delayed, the maximum PRR decreases and the $\mathrm{HC}, \mathrm{CO}$ emissions increase.
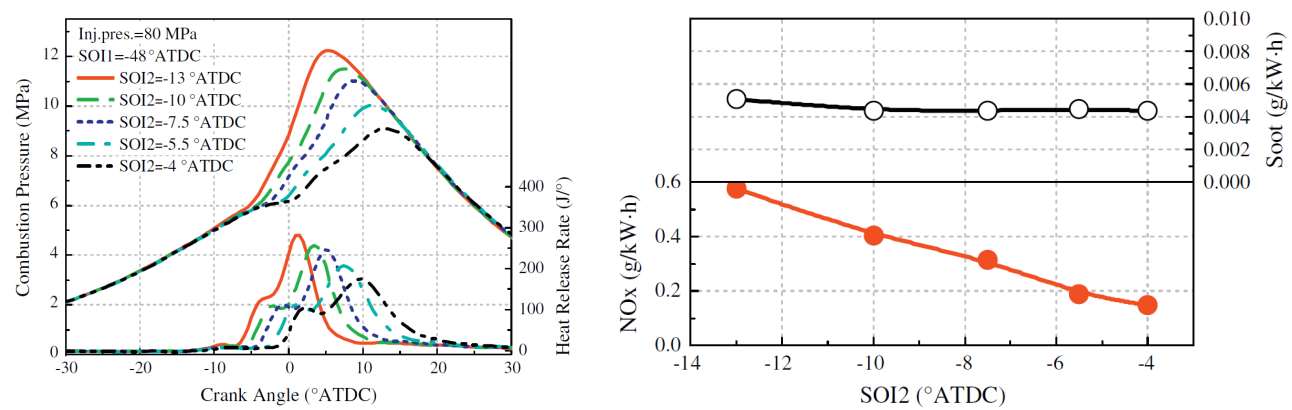

Figure 2.21. Effect of main injection timing on cylinder pressure, $H R R, N O x$ and soot emissions using a fixed early pilot injection timing at $\approx 9$ bar IMEP. Adapted from [66].

Diesel fuel percentage between injections (double injection): figure 2.22 (left) shows the effect of the fuel percentage between both injection events at two scenarios; E-SOI2: -58/-35 CAD and L-SOI2: -48/-9 CAD. In the case of using an early main injection (E-SOI2), the start of combustion and combustion phasing are retarded as the fuel mass injected in SOI1 is increased. In addition, the values of in-cylinder pressure and PHRR decrease. By contrast, in the case of delayed main injection (L-SOI2), the in-cylinder pressure and PHRR increase, while the ignition timing and combustion phasing keep almost constant. Regarding engine-out emissions, the authors stated that the trends of $\mathrm{CO}$ and $\mathrm{HC}$ emissions in both scenarios were opposite due to different combustion behaviors. In addition, NOx and soot emissions were not notably affected by the modification in the fuel apportionment. In this sense, only a clear decrease of NOx emissions was observed for the E-SOI2 strategy as SOI1 mass increased.

Gasoline fraction: figure 2.22 (right) shows measured cylinder pressure and HRR data for several gasoline percentage (Rg) at the same two scenarios of diesel injection timing (E-SOI2 and L-SOI2). As it can be seen, the increase in gasoline percentage promotes a delayed combustion phasing, with reduced cylinder pressure and PHRR. This combustion behavior promotes lower NOx and soot, with higher $\mathrm{HC}$ and $\mathrm{CO}$ emissions. In addition, the slowed HRR prolongs the combustion duration and decreases the maximum PRR [66]. In the case of L-SOI2, the ISFC increases as gasoline fraction increases, while in the case of E-SOI2, the trend of the ISFC is well associated with the CA50, showing a $u$-shaped trend with the minimum value at $\mathrm{Rg}=76 \%$. 

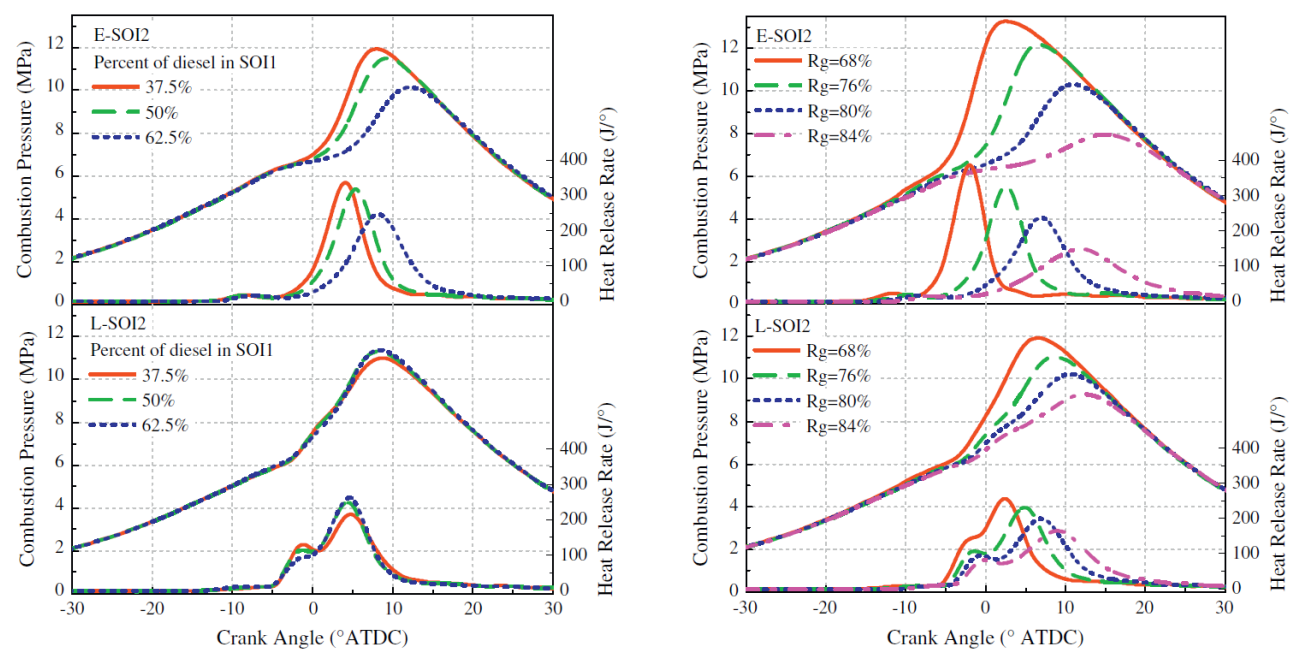

Figure 2.22. Effect of SOI1 fuel percentage on cylinder pressure and HRR (left). Effect of gasoline fraction on cylinder pressure and HRR (right) at $\approx 9$ bar IMEP. Adapted from [66].

\section{Influence of gas charge properties}

Exhaust gas recirculation: figure 2.23 shows the effect of EGR rate on RoHR and engine-out emissions using a late single injection timing. Figure 2.24 shows the same results for an early double injection timing. In both cases, the EGR increase promotes lower NOx levels, with higher CO and $\mathrm{HC}$ emissions. Moreover, all cases show ultra-low soot emissions and remain unaffected by the EGR variation. Regarding combustion development, in the case of the late single injection, the increase of EGR rate decreases the first premixed peak and smooths the second combustion stage, delaying both the start of combustion and combustion phasing. For the highest EGR rate, a degraded combustion with a long diesel-like tail is observed, which explains the rise of $\mathrm{CO}$ and $\mathrm{HC}$ emissions. In the case of the early double injection, the effect of EGR is much more remarkable. This is expected to occur, since the charge is well-mixed at earlier timings, making it more sensitive to chemical kinetics. Thus, as EGR increases, it is seen that the HRR peak reduces notably, CA50 delays and combustion duration increases.

Intake temperature: The effect of intake charge temperature variation on heat release rate and engine-out emissions is shown in figure 2.25. It can be seen that, for a fixed gasoline fraction and diesel injection timing, as the intake temperature varies from $31^{\circ} \mathrm{C}$ to $41^{\circ} \mathrm{C}$, the combustion phasing advances 
towards earlier timings in the compression stroke. This results in higher NOx emissions and lower $\mathrm{HC}$ and $\mathrm{CO}$ levels. Again, soot emissions remain at ultralow levels for all the intake temperatures.
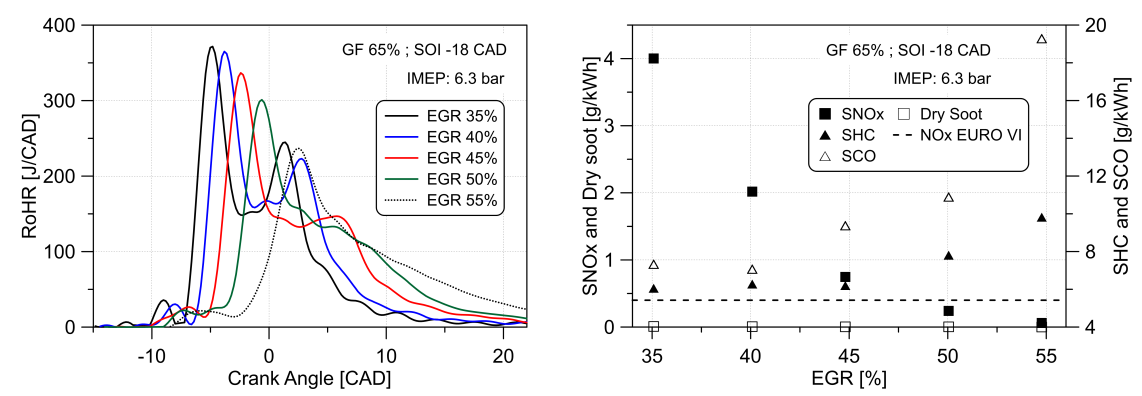

Figure 2.23. Effect of EGR rate on RoHR and engine-out emissions using a late single injection timing. Data from [67].
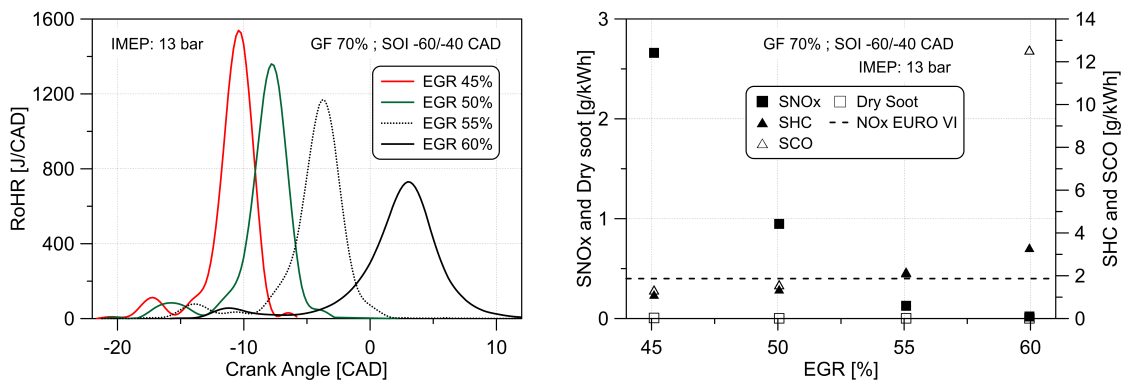

Figure 2.24. Effect of EGR rate on RoHR and engine-out emissions using an early double injection timing. Data from [67].
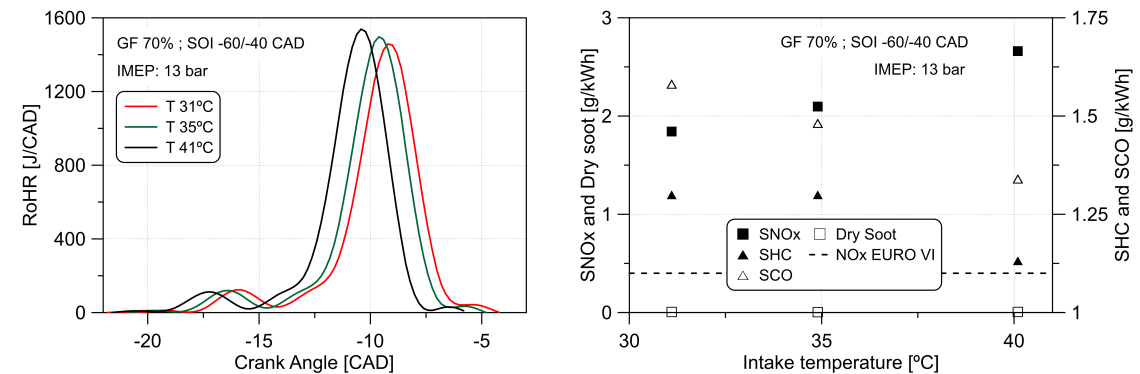

Figure 2.25. Effect of intake temperature on RoHR and engine-out emissions using an early double injection timing. Data from [67]. 


\section{Influence of fuel type}

The physicochemical fuel properties play a fundamental role on local reactivity, and therefore are expected to have a direct impact on RCCI combustion characteristics. This has motivated some authors to study the operation with different fuel combinations than conventional diesel/gasoline as a method to extend the operational range of the concept. Since, as noted by Kokjohn et al. [61] and Splitter et al. [63], the majority of the RCCI heat release comes from the LRF, this fuel source has received the major interest to be investigated. The studies found in literature have followed two differentiated paths: increase the fuel base reactivity to improve RCCI performance at low load, and use higher-octane fuels to enable widest range of operating conditions at high load.

Use of cetane improvers: One interesting approach to increase the base fuel reactivity is the use of cetane number (CN) improvers. Two common $\mathrm{CN}$ improvers are 2-ethylhexyl nitrate (2-EHN) and di-tertiary butyl peroxide (DTBP). As can be seen in figure 2.26, only a small percentage of either of these chemicals is required to achieve significant increase in the $\mathrm{CN}$ of gasoline fuel. Moreover, Higgens et al. [68] demonstrated that the addition of CN improvers lowers the activation energy of the base fuel, but otherwise does not affect to other fuel chemistry.

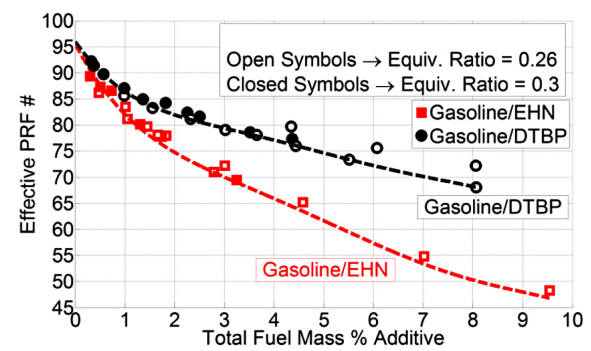

Figure 2.26. Additive impact on PRF of base 96 RON gasoline [69].

Splitter et al. [70] studied the concept of single-fuel RCCI at 6 and 9 bar BMEP using CN improvers. In this work, experiments using port injection of un-additized gasoline and direct injection of DTBP-additized gasoline were conducted. The use of the same base fuel as low and high reactivity fuel avoids the necessity of using two separate fuel tanks, which must favor the market acceptance of RCCI concept. The DTBP percentage was varied at addition levels of $3.5 \%, 1.75 \%, 0.75 \%$ and $0 \%$. As the DTBP percentage was decreased the combustion became more volumetric, reducing the combustion duration 
and increasing the maximum PRR and COV. Operation without DTBP was not realizable, demonstrating the necessity of a reactivity gradient to achieve RCCI combustion. The comparison versus dual-fuel RCCI at 9 bar BMEP showed that single-fuel RCCI can yield similar performance to gasoline/diesel dual-fuel operation, while meeting NOx and PM mandates in-cylinder. By contrast, $\mathrm{HC}$ and $\mathrm{CO}$ levels were considerably higher than gasoline/diesel operation, mainly $\mathrm{HC}$ emissions. The main results are summarized in figure 2.27, in which dual-fuel results from [71] are also included. The authors explained the near $1 \%$ gain in gross indicated efficiency by the decreased compression work due to the lower magnitude of the low temperature heat release exhibited by the additized gasoline as compared to diesel fuel.

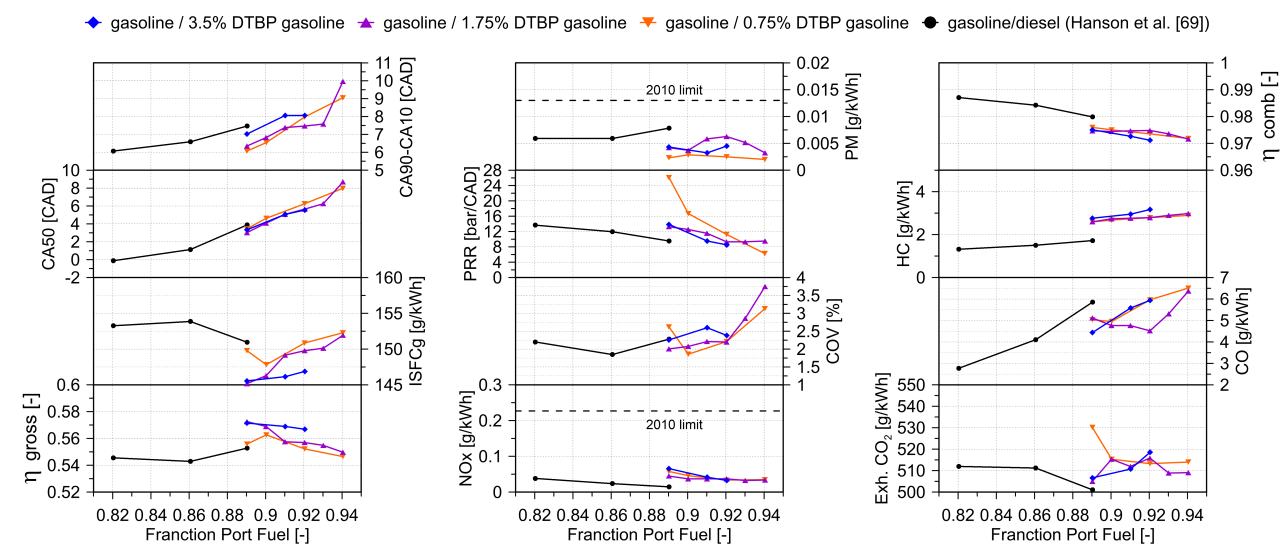

Figure 2.27. Combustion trends of 3.5\%, 1.75\%, and 0.75\% DTBP addition to direct-injected gasoline at 9 bar IMEP, compared to dual-fuel cases of Hanson et al. [71]. Adapted from [70].

To cover the low load operational range, Hanson et al. [72] investigated the single-fuel RCCI operation at 2 and 4.5 bar IMEPg. In this case, the CN improver used for the direct injected gasoline was 2-EHN, which was selected because is most commonly used in the market than DTBP. However, since 2 -EHN is a nitrogen-containing compound, it could increase engine-out NOx emissions [69]. The authors compared the single-fuel operation using gasoline and $3.5 \%$ by volume of 2 -EHN versus gasoline/diesel dual-fuel. The highest thermal efficiencies were obtained with the single-fuel strategy, which obtained maximum peaks of $54 \%$ at 4.5 bar IMEPg and $44 \%$ at 2 bar IMEPg. In addition, for particular cases, NOx and PM were below US 2010 EPA levels. The increase in thermal efficiency was thought to be related with the lower reactivity gradient between both fuels, which promoted the air-fuel mixture 
to ignite more volumetrically. Unfortunately, this characteristic limits the capabilities of the single-fuel RCCI concept to operate at high load conditions.

More recently, Dempsey et al. [73] studied the influence of several parameters on the controllability of single-fuel RCCI operation using gasoline and 2-EHN as CN improver at $\approx 4$ bar BMEP. As shown in figure 2.28, the authors observed that the authority to control combustion phasing (CA50) through the DI timing for the gasoline/EHN fuel blends was fairly constant and not strong function of the DI fuel reactivity. This was thought to be related with the rapid evaporation and mixing of the gasoline/EHN blends, which promotes more well-mixed charge than diesel fuel. Thus, the lack of equivalence ratio stratification due to the high volatility of the fuel overrides one of the main mechanisms to control RCCI combustion. Moreover, it was demonstrated that the sensitivity of CA50 to PFI gasoline percentage was more similar to that of diesel/gasoline operation, but it was essentially constant for the different gasoline/EHN fueling combinations. This is consistent with the work performed by Schwab et al. [74], which evidenced that, despite $\mathrm{CN}$ improvers have great impact on ignition delay, their overall effect on fuel oxidation is negligible.
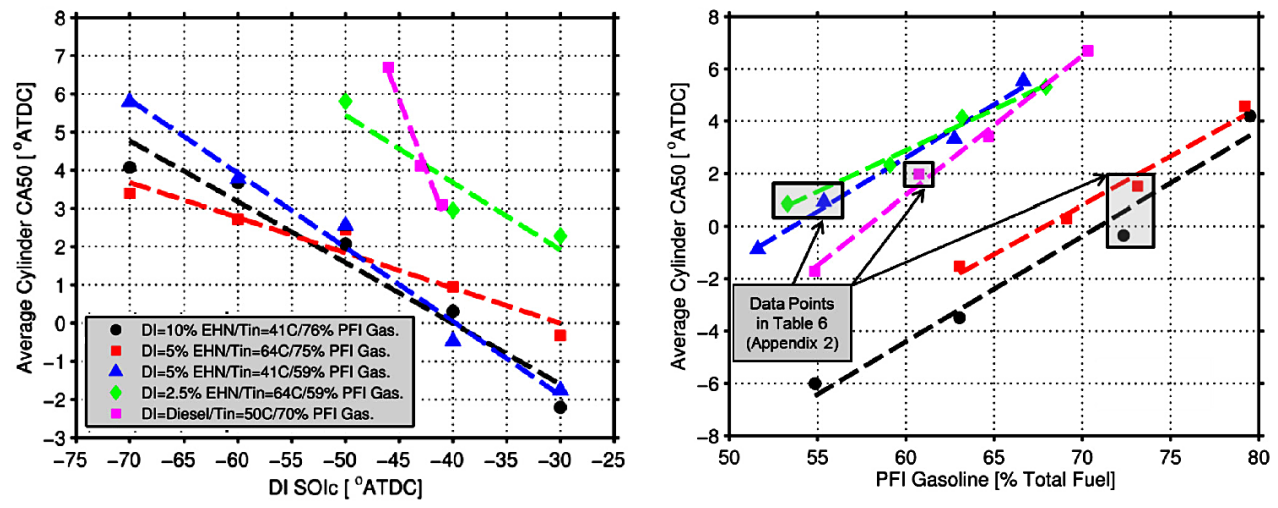

Figure 2.28. Average combustion phasing (CA50) as a function of DI SOIc (left) and PFI gasoline percentage (right) for the various fuel combinations investigated. Adapted from [73].

Use of biofuels: To enable widest operational range at high engine loads, the LRF used must have low sensitivity to thermodynamic conditions. This behavior is not guaranteed by only having a high octane number, but also some additional fuel properties are desirable. Dec and Yang [75] demonstrated that intake pressure has an important effect on real gasoline fuels in the intermediate temperature range, which tends to cause knocking problems at 
high loads. Moreover, they confirmed that ethanol fuel (which has higher octane number than gasoline) does not exhibits this pressure-dependence during the early stages of autoignition. Further chemical kinetic simulations performed by Mehl et al. [76] allowed to understand the chemistry underlying this phenomenon, which showed that the formation of certain intermediate species and the reduction of the branching reactions rate were the reasons of the extended ignition delay with ethanol.

The unique characteristics of ethanol and the public availability of E85 in the fuel distribution network of many countries, have motivated the extensive study of this fuel grade in the field of RCCI combustion. Splitter et al. [77] compared the dual-fuel E85/diesel operation versus some other fueling strategies. As shown in figure 2.29, the direct comparison at 9.5 bar IMEP reveals higher gross indicated efficiency for E85/diesel and gasoline/gasoline+DTBP than gasoline/diesel. Moreover, all the fueling strategies allowed NOx and soot emissions operation below EPA 2010 HD limits.

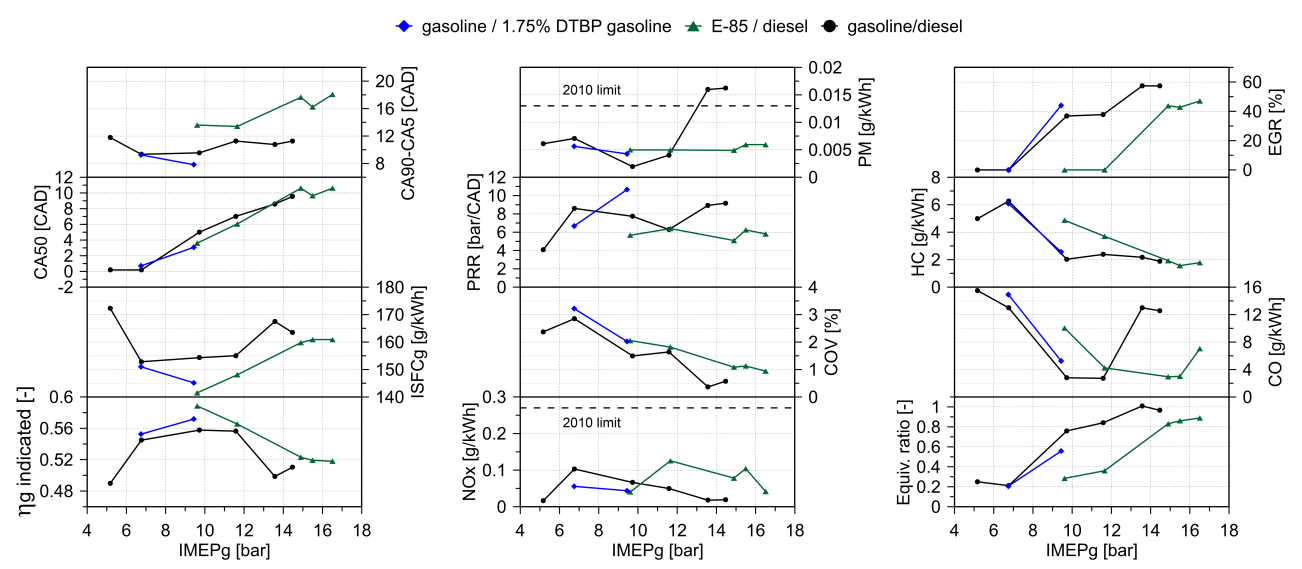

Figure 2.29. Comparison of combustion and emission characteristics for all the loads and fuels tested in the work of Splitter et al. [7r]].

From the figure, it can be inferred that the efficiency of RCCI concept at low load can be increased by reducing the reactivity gradient between the LRF and HRF, but this action limits the opportunities of the concept to be extended towards high load conditions. On the other hand, it is also observed that the increase of the reactivity gradient between both fuels, using ethanol as LRF, allows extending the maximum achievable load while improving the efficiency, but compromises the operation towards lower engine loads. 
Many other authors have studied the impact of the dual-fuel E85/diesel strategy on RCCI performance and emissions. All the studies concluded that the use of E85 allows extending the operating range to high loads [78]. Moreover, it was observed that the increase of E85 rate led to decrease NOx and soot emissions below those of gasoline/diesel operation [79], but increases notably the emissions of $\mathrm{CO}$ and $\mathrm{HC}[80]$. With the aim of minimizing the unburned products, Sarjovaara et al. [81] studied how the charge air temperature affects E85 dual-fuel combustion at different load conditions. The authors found that, by means of the intake temperature increase and the diesel injection optimization, $\mathrm{CO}$ and $\mathrm{HC}$ emissions could be minimized to some extent. However, unacceptable levels were still observed, thus suggesting that more research would be required in this direction in the future.

\subsection{Approach of the study}

\subsubsection{Motivation of the study}

During last years, many new combustion strategies have been proposed to simultaneously improve the engine efficiency and reduce the most harmful emissions of compression ignition engines, NOx and soot.

Homogeneous charge compression ignition (HCCI) demonstrated great potential to produce virtually no soot and NOx emissions while maintaining high efficiency. By contrast, new challenges regarding combustion control, HC and $\mathrm{CO}$ emissions and mechanical engine stress were identified. With the aim of improving the controllability and reduce the knocking levels experienced with HCCI, different partially premixed combustion (PPC) strategies have been widely investigated. However, the application of these strategies was found to be confined to low-medium load conditions due to the high reactivity of diesel fuel. To extend the PPC operation towards higher loads, gasoline-like fuels were explored. The investigations confirmed gasoline PPC as a promising method to extend the ignition delay while providing a simultaneous reduction in NOx and soot emissions. However, the concept demonstrated difficulties at low load conditions using high octane number gasolines. The spark assistance was found to be an effective method to provide temporal and spatial control over the gasoline PPC operation at low load, but led to unacceptable NOx and soot emissions.

Some authors suggested that, for this type of premixed combustion, different in-cylinder fuel reactivity is required to achieve a proper operation under different operating conditions. In particular, high-cetane fuels are 
required at low load and low-cetane fuels are necessary at medium and high loads. To exploit this idea, a dual-fuel combustion concept combining two fuels of different reactivity was developed. The use of two separated injection systems allows tailoring the in-cylinder fuel reactivity according to the engine operating conditions, which confers greater control of the combustion process. By this reason, this combustion concept it is known as reactivity controlled compression ignition (RCCI), and it has been demonstrated to be capable of providing ultra-low $\mathrm{NOx}$ and soot emissions over a wide engine operating range.

In recent years, a substantial progress has been made in the understanding of the RCCI combustion strategy. However, the literature review suggested that there are some gaps to be studied to further increase the potential and understanding of the concept. This requires additional research in several areas:

- RCCI achieves very high GIE at medium load conditions; however, the combustion efficiency can be poor at low load conditions. The poor combustion efficiency at low load limits the efficiency advantages over CDC operation. Thus, an optimization work at low load is recommended to improve the combustion efficiency and reduce $\mathrm{HC}$ and $\mathrm{CO}$ emissions of RCCI.

- The comparison versus HCCI combustion revealed that heat transfer reduction is the main source of RCCI efficiency gain. Thus, understanding the main source of HT process with RCCI would help to determine pathways for further increasing the thermal efficiency of the concept.

- Decreasing the reactivity gradient between LRF and HRF seems to be effective for increasing the engine efficiency at low load, but does not enable the operation at high load. On the other hand, ethanol can be utilized to expand the load range towards higher loads, but leads to poor efficiency at low load. Thus, investigate low reactivity fuels that combine both properties may be beneficial to take advantage of these characteristics in a greater operating range. Similarly, instead of regular diesel, biofuels could be used as direct-injected fuels.

- Finally, more experiments are needed at higher speeds and loads to evaluate the capabilities of the concept to be implemented in real automotive applications. 


\subsubsection{Objectives of the study}

Taking into account the information available in the literature, the general objective of this work is to contribute to the understanding of the reactivity controlled compression ignition (RCCI) combustion process, analyzing different sources of efficiency gain and evaluating the potential of the concept to be applied in compression ignition engines representative of those used in on-road applications.

In order to achieve this general objective, the following specific objectives are established:

- Improve the understanding of the relationships among the main variables governing the RCCI combustion and their capabilities for increasing the efficiency of the concept at low load. This study aims to exploit the potential of the engine settings looking for suitable combinations to minimize one of the main drawbacks found in literature with this combustion concept: the low combustion efficiency at low load.

- Analyze the potential of different sources for increasing the efficiency of RCCI concept. For this purpose, several modifications on the baseline engine configuration will be evaluated. The first study will investigate the piston geometry modification as a method for increasing the thermal efficiency through the heat transfer reduction. The second study will explore the fuel reactivity effects, not only by changing the mass ratio between the two fuels injected, but also by modifying the fuel properties. In this sense, the potential of different mid-level ethanol-gasoline blends will be studied in detail.

- Identify the operational limits of the RCCI combustion mode. This objective aims to assess the capabilities of this combustion mode to cover the full operating range of the engine (speed and load), thus identifying the technological challenges that would appear when moving to a real application.

\subsubsection{General methodology and research development}

The general methodology followed to reach the objectives proposed in this work is based on the combination of two complementary information sources: the experimental facility and theoretical tools.

The main information source is the single-cylinder heavy-duty research diesel engine. During the experimental tests, aside from the performance 
and emissions values, some other outputs are recorded to feed the theoretical models. These tools are used to perform the subsequent combustion analysis, which helps to understand the results obtained in the engine tests. As sketched in figure 2.30, the main theoretical tool employed to perform the combustion analysis is a thermodynamic (zero-dimensional) model, whose results are based on the classical analysis derived from the in-cylinder pressure signal. In a second place, a computational fluid dynamics (CFD) tool has been used as support information source. This tool allows to complement the analysis with some additional data that cannot be obtained neither from the experimental tests nor from the combustion diagnosis code.

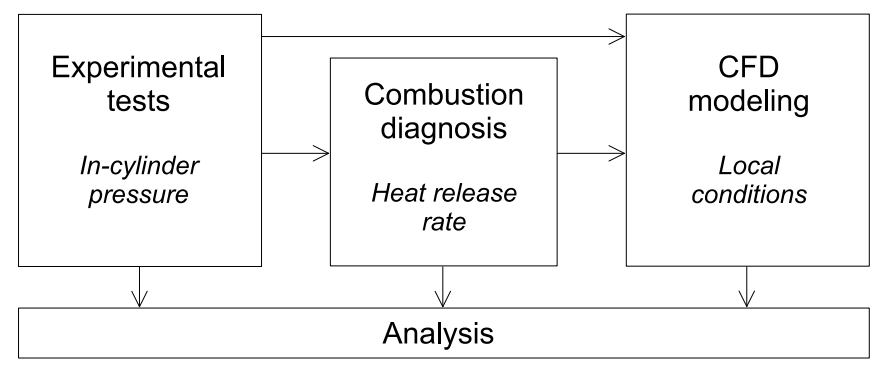

Figure 2.30. Sketch of the general methodological approach employed in this thesis.

Regarding the research development, it consists of three differentiated but related steps, each of whom respond to a specific objective defined in section 2.6.2. Since the three steps are developed sequentially, the knowledge acquired in the earlier steps can be applied at the same time that the investigation progresses. The specific studies and the tools used in each step of the investigation are described next.

To respond to the first specific objective, chapter 4 will explain the advantages of combining different engine settings to promote the proper incylinder conditions for RCCI combustion at low load. It will help to identify the engine settings range that allow improving the thermal efficiency of the concept while keeping the emissions levels under the desired limits ( $\mathrm{NOx}<0.4$ $\mathrm{g} / \mathrm{kWh}$ and soot $<0.01 \mathrm{~g} / \mathrm{kWh}$ ). For this purpose, the studies will combine the three sources of information previously described. Thus, aside from the data obtained through the pressure signal processing, the results from the 3D-CFD modeling tool will be used to gain insight the local conditions.

The experimental tests will be developed at a constant combustion phasing, which will be selected considering the different trade-offs between engine performance and emissions. After that, the influence of different engine 
settings that have direct impact on ignitability and reactivity stratification will be studied. On one hand, the intake charge properties will be tuned through the oxygen concentration (EGR) and temperature variation. Moreover, the diesel/gasoline ratio (GF) in the chamber will be managed as a second source to modify the local reactivity. During the experiments, each pair of settings $(\mathrm{EGR}+\mathrm{GF}$ and Temperature+GF) will be varied simultaneously to analyze their effects on performance and emissions, while keeping constant the combustion phasing. After the campaign of engine tests, detailed CFD simulations will be used to understand the local phenomena governing the results obtained. In particular, the simulation results of the tests with best and worst performance will be compared for each of the two studies.

Aiming at responding the second specific objective, chapters 5 and 6 will study two different ways to improve the efficiency of the concept; minimize heat transfer losses and modify fuel properties. Chapter 5 will discuss first the main sources of HT losses in RCCI using results from CFD modeling. Considering the findings from this preliminary study, the modification of the piston bowl geometry will be evaluated as a method to reduce the heat transfer to the coolant. Thus, after a dedicated literature review, two alternative pistons will be defined and compared experimentally against the stock piston.

Chapter 6 will propose the modification of the fuel reactivity gradient using biofuels. Taking into account the findings from literature, several fuel blends of gasoline and ethanol will be used as LRF. Specifically, the gasoline octane number and the ethanol content in the blend will be varied to analyze their effect on performance and emissions. Moreover, biodiesel will be used as direct injected fuel. This study will allow to prove if such near-term available biofuels can promote higher efficiency than the regular 98 ON gasoline, which is interesting taking into account future regulations.

Both studies will be carried out following the same general methodology. In a first stage, a batch of parametric sweeps aimed at finding the most potential engine settings at low load will be performed. Later, the effects of each strategy (modify piston shape or fuel properties) on low load results will be studied in detail. After that, the potential of each strategy to be applied at higher loads will be evaluated considering two mandatory constraints: to keep NOx and soot emissions under $0.4 \mathrm{~g} / \mathrm{kWh}$ and $0.01 \mathrm{~g} / \mathrm{kWh}$, respectively, and ensure maximum PRRs below 15 bar/CAD.

To tackle the last specific objective, chapter 7 will focus on giving a first overview about the capabilities of RCCI combustion to be applied in a real engine platform. To achieve this, two main tasks must be addressed. First, the evaluation of the operational limits of the concept considering the whole 
engine map of the production engine, and second, the identification of the main technological challenges of this novel combustion concept. Methodologically it will be carried out in two stages, which will entail:

- The development of a dedicated experimental procedure that allows obtaining RCCI engine maps efficiently and under well-defined criteria. This methodology should synthesize the knowledge acquired in previous steps of the investigation.

- A specific study about the influence of different compression ratios on the operational limits of the concept (speed and load). The experiments will be carried out following the procedure previously developed, thus ensuring that the operational limits in each case are defined in base of the same restrictions. 


\section{Bibliography}

[1] Dec J.E. "A Conceptual Model of DI Diesel Combustion Based on Laser-Sheet Imaging*". SAE Technical Paper, $\mathrm{n}^{\circ}$ 970873, 1997.

[2] Kamimoto T. and Bae M. "High Combustion Temperature for the Reduction of Particulate in Diesel Engines". SAE Technical Paper, n $^{\circ}$ 880423, 1988.

[3] Neely G.D., Sasaki S., Huang Y., Leet J.A. and Stewart D.W. "New Diesel Emission Control Strategy to Meet US Tier 2 Emissions Regulations". SAE Technical Paper, $\mathrm{n}^{\circ}$ 2005-01-1091, 2005.

[4] Li T. and Ogawa H. "Analysis of the Trade-off between Soot and Nitrogen Oxides in Diesel-Like Combustion by Chemical Kinetic Calculation”. SAE Int. J. Engines, Vol. 5 , pp. 94-101, 2011.

[5] Pickett L.M. and Siebers D.L. "Non-Sooting, Low Flame Temperature MixingControlled DI Diesel Combustion". SAE Technical Paper, n ${ }^{\circ}$ 2004-01-1399, 2004.

[6] O'Connor J. and Musculus M. "Optical Investigation of Multiple Injections for Unburned Hydrocarbon Emissions Reduction with Low-Temperature Combustion in a Heavy-Duty Diesel Engine". $8^{\text {th }}$ US National Combustion Meeting, May 19-22, 2013.

[7] Musculus M. "Multiple Simultaneous Optical Diagnostic Imaging of Early-Injection Low-Temperature Combustion in a Heavy-Duty Diesel Engine". SAE Technical Paper, $\mathrm{n}^{\circ}$ 2006-01-0079, 2006.

[8] "Sandia laboratories CFR Newsletter: Imaging of advanced low-temperature diesel combustion". Technical report, Combustion Research facility, Sandia Laboratories, 2005, Livermore, CA, USA, Vol. 25, n 5 , Page 2.

[9] Benajes J., Molina S., Novella R. and Belarte E. "Evaluation of massive exhaust gas recirculation and Miller cycle strategies for mixing-controlled low temperature combustion in a heavy duty diesel engine". Energy, Vol. 71, pp. 355-366, 2014.

[10] Alperstein M., Swim W.B. and Schweitzer P.H. "Fumigation kills smoke - improves diesel performance". SAE Technical Paper, $\mathrm{n}^{\circ}$ 580058, 1958.

[11] Iorio S. Di, Mancaruso E. and Vaglieco B.M. "Characterization of Soot Particles Produced in a Transparent Research CR DI Diesel Engine Operating with Conventional and Advanced Combustion Strategies". Aerosol Science and Technology, Vol. $46 \mathrm{n}^{\circ} 3$, pp. 272-286, 2012.

[12] Mueller C.J. and Upatnieks A. "Dilute clean diesel combustion achieves low emissions and high efficiency while avoiding control problems of HCCI.". Proceedings of $11^{\text {th }}$ diesel engine emission reduction conference, 2005, Chicago, USA.

[13] Stanglmaier R.H. and Roberts C.E. "Homogeneous Charge Compression Ignition (HCCI): Benefits, Compromises, and Future Engine Applications". SAE Technical Paper, n $^{\circ}$ 1999-01-3682, 1999.

[14] Willand J., Nieberding R-G., Vent G. and Enderle C. "The Knocking Syndrome - Its Cure and Its Potential". SAE Technical Paper, nº 982483, 1998.

[15] Bartley G.J. "Identifying Limiters to Low Temperature Catalyst Activity". SAE Technical Paper, $\mathrm{n}^{\circ}$ 2015-01-1025, 2015.

[16] Ganesh D., Nagarajan G. and Mohamed Ibrahim M. "Study of performance, combustion and emission characteristics of diesel homogeneous charge compression ignition (HCCI) combustion with external mixture formation". Fuel, Vol. $87 \mathrm{n}^{\circ} 17-18$, pp. 3497-3503, 2008. 
[17] Ganesh D. and Nagarajan G. "Homogeneous charge compression ignition (HCCI) combustion of diesel fuel with external mixture formation". Energy, Vol. $35 \mathrm{n}^{\circ} 1$, pp. 148-157, 2010.

[18] Liu H., Zheng Z., Yao M., Zhang P., Zheng Z., He B. and Qi Y. "Influence of temperature and mixture stratification on HCCI combustion using chemiluminescence images and CFD analysis". Applied Thermal Engineering, Vol. 33-34, pp. 135-143, 2012.

[19] Guezennec Y., Midlam-Mohler S. and Rizzoni G. "A mixed mode HCCI/DI engine based on a novel heavy fuel atomizer". Proceedings of $8^{\text {th }}$ diesel engine emission reduction conference, 2002, San Diego, USA.

[20] Christensen M., Hultqvist A. and Johansson B. "Demonstrating the Multi Fuel Capability of a Homogeneous Charge Compression Ignition Engine with Variable Compression Ratio". SAE Technical Paper, n ${ }^{\circ}$ 1999-01-3679, 1999.

[21] Machrafi H. and Cavadiasa S. "An experimental and numerical analysis of the influence of the inlet temperature, equivalence ratio and compression ratio on the HCCI autoignition process of Primary Reference Fuels in an engine". Fuel Processing Technology, Vol. $89 \mathrm{n}^{\circ}$ 11, pp. 1218-1226, 2008.

[22] Midlam-Mohler S., Guezennec Y. and Rizzoni G. "Mixed-mode diesel HCCI with external mixture formation". Deer 2003 Newport, August 26 ${ }^{\text {th }}, 2003$.

[23] Sjöberg M. and Dec J.E. "Smoothing HCCI Heat-Release Rates Using Partial Fuel Stratification with Two-Stage Ignition Fuels". SAE Technical Paper, ${ }^{\circ}$ 2006-01-0629, 2006.

[24] Dec J.E. and Sjöberg M. "Isolating the Effects of Fuel Chemistry on Combustion Phasing in an HCCI Engine and the Potential of Fuel Stratification for Ignition Control". SAE Technical Paper, no 2004-01-0557, 2004.

[25] Yang Y., Dec J.E., Dronniou N., Sjöberg M. and Cannella W. "Partial Fuel Stratification to Control HCCI Heat Release Rates: Fuel Composition and Other Factors Affecting Pre-Ignition Reactions of Two-Stage Ignition Fuels". SAE International Journal of Engines, Vol. $4 \mathrm{n}^{\circ}$ 1, pp. 1903-1920, 2011.

[26] Yang Y., Dec J.E., Dronniou N. and Sjöberg M. "Tailoring HCCI heat-release rates with partial fuel stratification: Comparison of two-stage and single-stage-ignition fuels". Proceedings of the Combustion Institute, Vol. $33 \mathrm{n}^{\circ}$ 2, pp. 3047-3055, 2011.

[27] Yang Y., Dec J.E., Dronniou N. and Cannella W. "Boosted HCCI Combustion Using Low-Octane Gasoline with Fully Premixed and Partially Stratified Charges". SAE International Journal of Engines, Vol. $5 \mathrm{n}^{\circ}$ 3, pp. 1075-1088, 2012.

[28] Takeda Y., Keiichi N. and Keiichi N. "Emission Characteristics of Premixed Lean Diesel Combustion with Extremely Early Staged Fuel Injection". SAE Technical Paper, $\mathrm{n}^{\circ}$ 961163, 1996.

[29] Nishijima Y., Asaumi Y. and Aoyagi Y. "Impingement Spray System with Direct Water Injection for Premixed Lean Diesel Combustion Control". SAE Technical Paper, $\mathrm{n}^{\circ}$ 2002-01-0109, 2002.

[30] Iwabuchi Y., Kawai K., Shoji T. and Takeda Y. "Trial of New Concept Diesel Combustion System - Premixed Compression-Ignited Combustion". SAE Technical Paper, $\mathrm{n}^{\circ}$ 1999-01-0185, 1999.

[31] Okude K., Mori K., Shiino S. and Moriya T. "Premixed Compression Ignition (PCI) Combustion for Simultaneous Reduction of NOx and Soot in Diesel Engine". SAE Technical Paper, no 2004-01-1907, 2004. 
[32] Hashizume T., Miyamoto T., Hisashi A. and Tsujimura K. "Combustion and Emission Characteristics of Multiple Stage Diesel Combustion". SAE Technical Paper, ${ }^{\circ}$ 980505, 1998.

[33] Yokota H., Kudo Y., Nakajima H., Kakegawa T. and Suzuki T. "A New Concept for Low Emission Diesel Combustion". SAE Technical Paper, no 970891, 1997.

[34] Hasegawa R. and Yanagihara H. "HCCI Combustion in DI Diesel Engine". SAE Technical Paper, $\mathrm{n}^{\circ}$ 2003-01-0745, 2003.

[35] Wanhua S., Tiejian L. and Yiqiang P. "A Compound Technology for HCCI Combustion in a DI Diesel Engine Based on the Multi-Pulse Injection and the BUMP Combustion Chamber". SAE Technical Paper, no 2003-01-0741, 2003.

[36] Walter B. and Gatellier B. "Development of the High Power NADI ${ }^{\mathrm{TM}}$ Concept Using Dual Mode Diesel Combustion to Achieve Zero NOx and Particulate Emissions". SAE Technical Paper, ${ }^{\circ}$ 2002-01-1744, 2002.

[37] Reveille B., Kleemann A., Knop V. and Habchi C. "Potential of Narrow Angle Direct Injection Diesel Engines for Clean Combustion: 3D CFD Analysis". SAE Technical Paper, $\mathrm{n}^{\circ}$ 2006-01-1365, 2006.

[38] Kimura S., Aoki O., Ogawa H., Muranaka S. and Enomoto Y. "New Combustion Concept for Ultra-Clean and High-Efficiency Small DI Diesel Engines". SAE Technical Paper, ${ }^{\circ}$ 1999-01-3681, 1999.

[39] Kimura S., Aoki O., Kitahara Y. and Aiyoshizawa E. "Ultra-Clean Combustion Technology Combining a Low-Temperature and Premixed Combustion Concept for Meeting Future Emission Standards". SAE Technical Paper, no 2001-01-0200, 2001.

[40] Kondo M., Kimura S., Hirano I., Uraki Y. and Maeda R. "Development of noise reduction technologies for a small direct-injection diesel engine". Society of automotive engineers of Japan, Vol. 21, Page 327-333, 2000.

[41] Kalghatgi G.T., Risberg P. and Ångström H-E. "Advantages of Fuels with High Resistance to Auto-ignition in Late-injection, Low-temperature, Compression Ignition Combustion". SAE Technical Paper, $\mathrm{n}^{\circ}$ 2006-01-3385, 2006.

[42] Kalghatgi G.T., Risberg P. and Ångström H-E. "Partially Pre-Mixed Auto-Ignition of Gasoline to Attain Low Smoke and Low NOx at High Load in a Compression Ignition Engine and Comparison with a Diesel Fuel". SAE Technical Paper, n ${ }^{\circ}$ 2007-01-0006, 2007.

[43] Manente V., Zander C-G., Johansson B., Tunestål P. and Cannella W. "An Advanced Internal Combustion Engine Concept for Low Emissions and High Efficiency from Idle to Max Load Using Gasoline Partially Premixed Combustion". SAE Technical Paper, $\mathrm{n}^{\circ}$ 2010-01-2198, 2010 .

[44] Tunèr M., Johansson T., Aulin H., Tunestål P., Johansson B. and Cannella W. "Multi Cylinder Partially Premixed Combustion Performance Using Commercial Light-Duty Engine Hardware". no 2014-01-2680, 2014.

[45] Borgqvist P., Tunestål P. and Johansson B. "Gasoline Partially Premixed Combustion in a Light Duty Engine at Low Load and Idle Operating Conditions". SAE Technical Paper, ${ }^{\circ}$ 2012-01-0687, 2012.

[46] Kolodziej C., Kodavasal J., Ciatti S., Som S., Shidore N. and Delhom J. "Achieving Stable Engine Operation of Gasoline Compression Ignition Using 87 AKI Gasoline Down to Idle". SAE Technical Paper, no 2015-01-0832, 2015. 
[47] Kolodziej C., Ciatti S., Vuilleumier D., Adhikary B. Das and Reitz R.D. "Extension of the Lower Load Limit of Gasoline Compression Ignition with 87 AKI Gasoline by Injection Timing and Pressure". SAE Technical Paper, $\mathrm{n}^{\circ}$ 2014-01-1302, 2014.

[48] Borgqvist P., Tunestål P. and Johansson B. "Investigation and Comparison of Residual Gas Enhanced HCCI using Trapping (NVO HCCI) or Rebreathing of Residual Gases". SAE Technical Paper, $\mathrm{n}^{\circ}$ 2011-01-1772, 2011.

[49] Koopmans L. and Denbratt I. "A Four Stroke Camless Engine, Operated in Homogeneous Charge Compression Ignition Mode with Commercial Gasoline". $\mathrm{n}^{\circ}$ 200101-3610, 2001.

[50] Persson H., Agrell M., Olsson J., Johansson B. and Ström H. "The Effect of Intake Temperature on HCCI Operation Using Negative Valve Overlap". SAE Technical Paper, $\mathrm{n}^{\circ}$ 2004-01-0944, 2004.

[51] Borgqvist P., Tunestål P. and Johansson B. "Comparison of Negative Valve Overlap (NVO) and Rebreathing Valve Strategies on a Gasoline PPC Engine at Low Load and Idle Operating Conditions". SAE Int. J. Engines, Vol. 6 n ${ }^{o}$ 2013-01-0902, pp. 366-378, 2013.

[52] Chang K., Babajimopoulos A., Lavoie G.A., Filipi Z. and Assanis D.N. "Analysis of Load and Speed Transitions in an HCCI Engine Using 1-D Cycle Simulation and Thermal Networks". SAE Technical Paper, no 2006-01-1087, 2006.

[53] Reuss D.L., Kuo T.W., Silvas G., Natarajan V. and Sick V. "Experimental metrics for identifying origins of combustion variability during spark-assisted compression ignition". International Journal of Engine Research, Vol. $9 \mathrm{n}^{\circ}$ 5, pp. 409-434, 2008.

[54] Persson H., Johansson B. and Remón A. "The Effect of Swirl on Spark Assisted Compression Ignition (SACI)". SAE Technical Paper, $\mathrm{n}^{\circ}$ 2007-01-1856, 2007.

[55] Benajes J., García A., Domenech V. and Durrett R. "An investigation of partially premixed compression ignition combustion using gasoline and spark assistance". Applied Thermal Engineering, Vol. $52 \mathrm{n}^{\circ}$ 2, pp. 468-477, 2013.

[56] Desantes J.M., Payri R., García A. and Monsalve-Serrano J. "Evaluation of Emissions and Performances from Partially Premixed Compression Ignition Combustion using Gasoline and Spark Assistance". SAE Technical Paper, no 2013-01-1664, 2013.

[57] Benajes J., Molina S., García A., Monsalve-Serrano J. and Durrett R. "Performance and engine-out emissions evaluation of the double injection strategy applied to the gasoline partially premixed compression ignition spark assisted combustion concept". Applied Energy, Vol. 134, pp. 90-101, 2014.

[58] Bessonette P.W., Schleyer C.H., Duffy K.P., Hardy W.L. and Liechty M.P. "Effects of Fuel Property Changes on Heavy-Duty HCCI Combustion". SAE Technical Paper, $\mathrm{n}^{\circ}$ 2007-01-0191, 2007.

[59] Kokjohn S., Hanson R., Splitter D. and Reitz R.D. "Fuel reactivity controlled compression ignition (RCCI): a pathway to controlled high-efficiency clean combustion". International Journal of Engine Research, Vol. $12 \mathrm{n}^{\circ}$ 3, pp. 209-226, 2011.

[60] Inagaki K., Fuyuto T., Nishikawa K., Nakakita K. and Sakata I. "Dual-Fuel PCI Combustion Controlled by In-Cylinder Stratification of Ignitability". SAE Technical Paper, ${ }^{\circ}$ 2006-01-0028, 2006.

[61] Kokjohn S., Hanson R., Splitter D. and Reitz R.D. "Experiments and Modeling of Dual-Fuel HCCI and PCCI Combustion Using In-Cylinder Fuel Blending". SAE Int. J. Engines, Vol. 2, pp. 24-39, 2009. 
[62] Ando H., Sakai Y. and Kuwahara K. "Universal Rule of Hydrocarbon Oxidation". SAE Technical Paper, ${ }^{o}$ 2009-01-0948, 2009.

[63] Splitter D., Kokjohn S., Rein K., Hanson R., Sanders S. and Reitz R.D. "An Optical Investigation of Ignition Processes in Fuel Reactivity Controlled PCCI Combustion". SAE Int. J. Engines, Vol. 3, pp. 142-162, 2010.

[64] Splitter D., Wissink M.L., Hendricks T.L., Ghandhi J.B. and Reitz R.D. "Comparison of RCCI, HCCI, and CDC Operation from Low to Full Load". THIESEL Conference on Thermo- and Fluid Dynamic Processes in Direct Injection Engines, 2012.

[65] Millam D. "Final Report for Caterpillar/DOE Heavy Truck Clean Diesel Cooperative Research Program". Technical report, Heavy Truck Engine Program, March 31 ${ }^{\text {st }}, 2007$.

[66] Ma S., Zheng Z., Liu H., Zhang Q. and M.Yao. "Experimental investigation of the effects of diesel injection strategy on gasoline/diesel dual-fuel combustion". Applied Energy, Vol. 109, pp. 202-212, 2013.

[67] Belarte E. Estudio del proceso de combustión premezclada controlada por la reactividad del combustible en un motor de encendido por compresión. Doctoral Thesis, Universitat Politècnica de València, Departamento de Máquinas y Motores Térmicos, 2015.

[68] Higgins B., Siebers D., Mueller C. and Aradi A. "Effects of an ignition-enhancing, dieselfuel additive on diesel-spray evaporation, mixing, ignition, and combustion". Symposium (International) on Combustion, Vol. $27 \mathrm{n}^{\circ}$ 2, pp. 1873-1880, 1998.

[69] Dempsey A.B., Walker N.R. and Reitz R.D. "Effect of Cetane Improvers on Gasoline, Ethanol, and Methanol Reactivity and the Implications for RCCI Combustion". SAE International Journal of Fuels and Lubricants, Vol. 6 n 1, pp. 170-187, 2013.

[70] Splitter D., Reitz R.D. and Hanson R. "High Efficiency, Low Emissions RCCI Combustion by Use of a Fuel Additive". SAE International Journal of Fuels and Lubricants, Vol. $3 \mathrm{n}^{\circ} 2$, pp. 742-756, 2010.

[71] Hanson R., Kokjohn S., Splitter D. and Reitz R.D. "An Experimental Investigation of Fuel Reactivity Controlled PCCI Combustion in a Heavy-Duty Engine". SAE Int. J. Engines, Vol. 3, pp. 700-716, 2010.

[72] Hanson R., Kokjohn S., Splitter D. and Reitz R.D. "Fuel Effects on Reactivity Controlled Compression Ignition (RCCI) Combustion at Low Load". SAE International Journal of Engines, Vol. $4 \mathrm{n}^{\circ}$ 1, pp. 394-411, 2011.

[73] Dempsey A.B., Curran S. and Reitz R.D. "Characterization of Reactivity Controlled Compression Ignition (RCCI) Using Premixed Gasoline and Direct-Injected Gasoline with a Cetane Improver on a Multi-Cylinder Engine". SAE International Journal of Engines, Vol. 8 n $^{\circ}$ 2, pp. 859-877, 2015.

[74] Schwab S.D., Guinther G.H., Henly T.J. and Miller K.T. "The Effects of 2-Ethylhexyl Nitrate and Di-Tertiary-Butyl Peroxide on the Exhaust Emissions from a Heavy-Duty Diesel Engine". SAE Technical Paper, no 1999-01-1478, 1999.

[75] Dec J.E. and Yang Y. "Boosted HCCI for High Power without Engine Knock and with Ultra-Low NOx Emissions - using Conventional Gasoline”. SAE Int. J. Engines, Vol. 3, pp. $750-767,2010$.

[76] Mehl M., Pitz W., Sarathy M., Yang Y. and Dec J.E. "Detailed Kinetic Modeling of Conventional Gasoline at Highly Boosted Conditions and the Associated Intermediate Temperature Heat Release". SAE Technical Paper, no 2012-01-1109, 2012. 
[77] Splitter D., Hanson R., Kokjohn S. and Reitz R.D. "Reactivity Controlled Compression Ignition (RCCI) Heavy-Duty Engine Operation at Mid-and High-Loads with Conventional and Alternative Fuels". SAE Technical Paper, ${ }^{\circ}$ 2011-01-0363, 2011.

[78] Curran S., Hanson R. and Wagner R. "Effect of E85 on RCCI Performance and Emissions on a Multi-Cylinder Light-Duty Diesel Engine". SAE Technical Paper, $\mathrm{n}^{o}$ 2012-01-0376, 2012.

[79] Tutak W. "Bioethanol E85 as a fuel for dual fuel diesel engine". Energy Conversion and Management, Vol. 86, pp. 39-48, 2014.

[80] Sarjovaara T. and Larmi M. "Dual fuel diesel combustion with an E85 ethanol/gasoline blend". Fuel, Vol. 139, pp. 704-714, 2015.

[81] Sarjovaara T., Larmi M. and Vuorinen V. "Effect of charge air temperature on E85 dual-fuel diesel combustion". Fuel, Vol. 153, pp. 6-12, 2015. 


\section{Chapter 3}

\section{Tools and methodology}

\section{Contents}

3.1 Introduction .................... 65

3.2 Experimental facilities................ 65

3.2.1 Single-cylinder research engine ............ 65

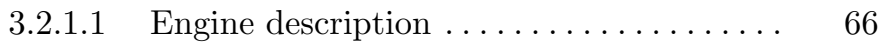

3.2.1.2 Variable valve actuation system ...... 67

3.2.1.3 Fuel injection systems . . . . . . . . 68

3.2.1.4 Baseline fuel properties ........... 71

3.2 .2 Test cell characteristics $\ldots \ldots \ldots \ldots \ldots \ldots \ldots \ldots .71$

3.2.2.1 Engine speed and torque regulation .... 72

3.2.2.2 Air supply and exhaust systems ...... 73

3.2.2.3 Exhaust Gas Recirculation loop ....... 74

3.2.2.4 Lubrication and cooling systems ...... 75

3.2.2.5 Fuel conditioning system......... 76

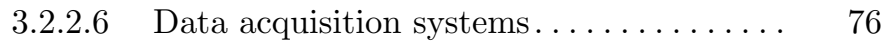

3.2.3 Instrumentation and measuring equipment ..... 78

3.2.3.1 Torque and engine speed measurement . . 78

3.2.3.2 Mean pressure and temperature measurement . . . . . . . . . . . . . . . . . . . . . 78

3.2.3.3 Instantaneous pressure transducers..... $\quad 79$

3.2.3.4 Mass flow measurement............ 79

3.2.3.5 Horiba gas analyzer ............ 80

3.2.3.6 AVL Smoke meter ............. 81 
3.2.3.7 Blow-by meter $\ldots \ldots \ldots \ldots \ldots \ldots \ldots \ldots$

3.2.4 Experimental procedure considerations ........ 83

3.3 Theoretical tools .................. 85

3.3.1 0-D Combustion diagnosis model........... 85

3.3.2 3-D Computational fluid dynamics model ....... 88

3.3.2.1 General features . . . . . . . . . . 89

3.3.2.2 Modeling methodology ............ 90

3.3.2.3 Model set-up and validation .......... 94

3.4 Summary and conclusions ............. 98

Bibliography ....................... 99 


\subsection{Introduction}

As detailed in chapter 2, the methodological approach proposed to address the objectives of this work combines two information sources, the experimental and theoretical tools. The current chapter provides an accurate description of these tools, presenting also the particular methodologies followed to obtain the final data.

The chapter is divided in two main sections. The section 3.2 explains the most relevant characteristics of the experimental facility, giving a detailed description of the single-cylinder engine and all the auxiliary systems used for its operation and control. Moreover, the methodology used in the experiments is discussed. Later, the fundamentals of the theoretical tools used to perform the analysis of the combustion process are given in section 3.3.

\subsection{Experimental facilities}

The strong experimental nature of the present investigation requires the use of adequate experimental tools to obtain precise, repetitive and reliable results. Thus, the description of the experimental equipment provided in the current section is strictly necessary because it gives to the reader valuable information about the different systems and procedures used in the experiments.

This section is structured in four subsections. The first one presents the main characteristics of the single-cylinder heavy-duty research diesel engine. The second subsection details all the auxiliary systems required for the engine operation and control. The third subsection addresses the description of the instrumentation and measuring equipment used in the research. Finally, the last subsection points out the most significant aspects of the experimental methodology followed to carry out the engine tests.

\subsubsection{Single-cylinder research engine}

This subsection describes the main characteristics of the engine unit and the different systems of which is equipped, such as the variable valve actuation system and the different fuel injection systems. Moreover, the main properties of the baseline fuels used in the present investigation are detailed here. 


\subsubsection{Engine description}

A 1.806 liter single-cylinder (SCE) heavy-duty (HD) diesel engine has been used in the experiments performed in this work. Despite some parts of the engine have been designed specifically as a research tool to investigate the combustion and engine-out emissions phenomena, it can be considered representative of those used in on-road applications.

The SCE engine has been built taking as a base a standard unit manufactured by the Austrian company AVL, in particular, the 5300 model. This basic unit is composed of the engine block, oil pan and counter-masses system to ensure the proper engine balance. This configuration allows to perform efficient structural modifications during the research. Thus, to reproduce the geometrical characteristics of the equivalent production-type multi-cylinder engine, the connecting rod, crank, piston and cylinder-head mounted on the basic unit correspond to the MD11US07 model manufactured by Volvo Group Trucks Technology. The total displaced volume of the inline 6 cylinder production engine is 10.836 liter, offering $2200 \mathrm{Nm}$ peak torque at rated speed of $1245 \mathrm{rpm}$ and $315 \mathrm{~kW}$ peak power at $1775 \mathrm{rpm}$. A summary of the main specifications of the single-cylinder research engine is given in table 3.1.

Table 3.1. Main characteristics of the engine used in this research.

\begin{tabular}{ll}
\hline \hline Style & SCE diesel engine, 4 valves, \\
& 4 stroke, direct injection \\
Manufacturer & AVL (basic unit) \\
Equivalent engine & VOLVO MD11US07 \\
Maximum engine speed [rpm] & 2100 \\
Maximum in-cylinder pressure [bar] & 250 \\
Bore x Stroke [mm] & $123 \times 152$ \\
Connecting rod length $[\mathrm{mm}]$ & 225 \\
Crank length [mm] & 76 \\
Displaced volume $\left[\mathrm{cm}^{3}\right]$ & 1806 \\
Compression ratio $[-]$ & $14.4: 1$ \\
Bowl diameter $[\mathrm{mm}]$ & 87.5 \\
Bowl depth $[\mathrm{mm}]$ & 21.2 \\
Bowl volume $\left[\mathrm{cm}^{3}\right]$ & 110.7 \\
Swirl ratio $[-]$ & 0.3 \\
\hline
\end{tabular}


The piston bowl shape and its particular dimensions are shown in the isometric and cross sectional views presented in figure 3.1. It is worthy to note that the great bore-to-bowl diameter ratio (0.71) together with the low swirl ratio restrict the rotational air motion inside the combustion chamber during the injection-combustion process.
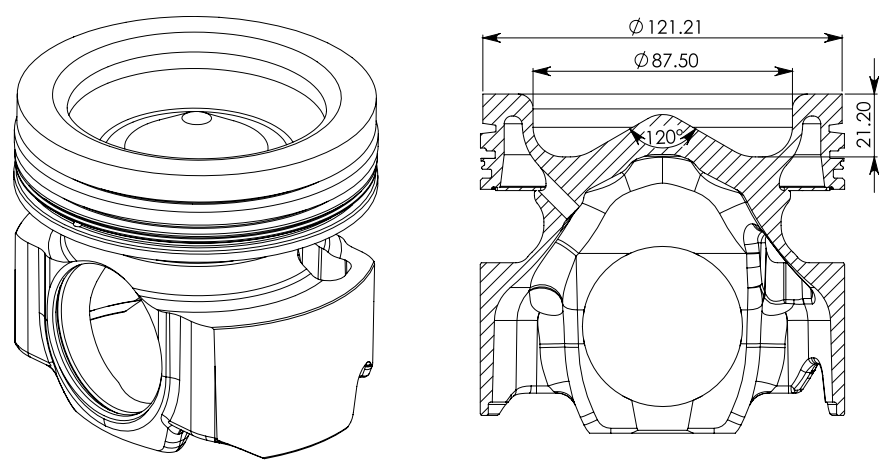

Figure 3.1. Isometric and cross sectional views of the piston.

\subsubsection{Variable valve actuation system}

In the present work, the engine's standard production camshaft has been replaced by a fully-variable valve actuation (VVA) system. Specifically, a hydraulic camless system patented by Sturman Industries as HVA 4A has been used $[1,2]$. This system uses custom valves with longer valve stems than the stock configuration, but otherwise the valve geometry is unchanged.

The VVA system allows fully independent control on each of the four valves. In particular, the valve timing, duration and lift can be electronically controlled for each valve during the engine tests. This confers great flexibility to the research, allowing to get the proper in-cylinder thermodynamic conditions for the different engine operating conditions [3]. Figure 3.2 shows the valve lift profiles for the standard production camshaft and the VVA system. It is possible to see that the VVA valve lifts are more abrupt and square wave-like as compared to the cam based profiles. This occurs due to the absence of direct mechanical actuators. Another difference is that the maximum valve lift for the VVA system is limited to $10 \mathrm{~mm}$ by manufacturer's design. 


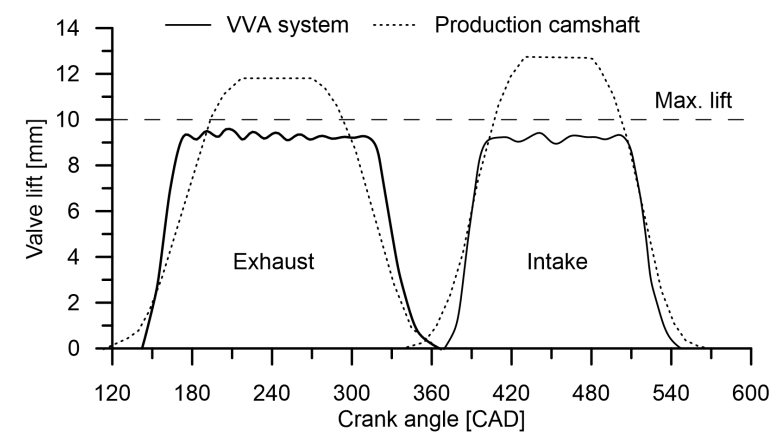

Figure 3.2. Valve lift profiles for the standard production camshaft and the $H V A 4 A$ system.

Lombard et al. [4] tested the HVA 4A system in a multi-cylinder engine equivalent to the single-cylinder engine used in the present investigation. In this work, an analysis of the accuracy and repeatability of the HVA 4A system was performed. The results concerning the main parameters associated to the intake and exhaust valves are summarized as follows:

- Valve opening angle: The precision of this parameter is $\pm 2 \mathrm{CAD}$, with a repeatability of $3 \mathrm{CAD}$.

- Maximum valve lift: The precision of this parameter is $\pm 0.2 \mathrm{~mm}$ if the reference value is below $3.5 \mathrm{~mm}$ and $\pm 0.5 \mathrm{~mm}$ for greater valve lifts. The repeatability in these cases is $0.8 \mathrm{~mm}$. During the valves overlap period, when the valve lifts for the intake valves are around $1 \mathrm{~mm}$, the repeatability is $0.5 \mathrm{~mm}$.

- Valve closing angle: The precision of this parameter is $\pm 3 \mathrm{CAD}$, with a repeatability of $3 \mathrm{CAD}$.

\subsubsection{Fuel injection systems}

To enable RCCI operation, the engine was equipped with two separate fuel injection systems. A port fuel injection system is used to inject gasoline (low reactivity fuel) and a common rail direct injection system is used to inject the diesel fuel (high reactivity fuel). This configuration enables to vary the in-cylinder fuel blending ratio and the fuel mixture properties according to the engine operating conditions. The layout of the fuel circuits and their different components are described in detail next. 


\section{Common rail injection system}

The scheme of the diesel circuit is illustrated in figure 3.3, which shows the different components needed to define the low and high pressure circuits. In this case, the software used to command the electronic control unit of the diesel injector was INCA (version 5), commercialized by ETAS.

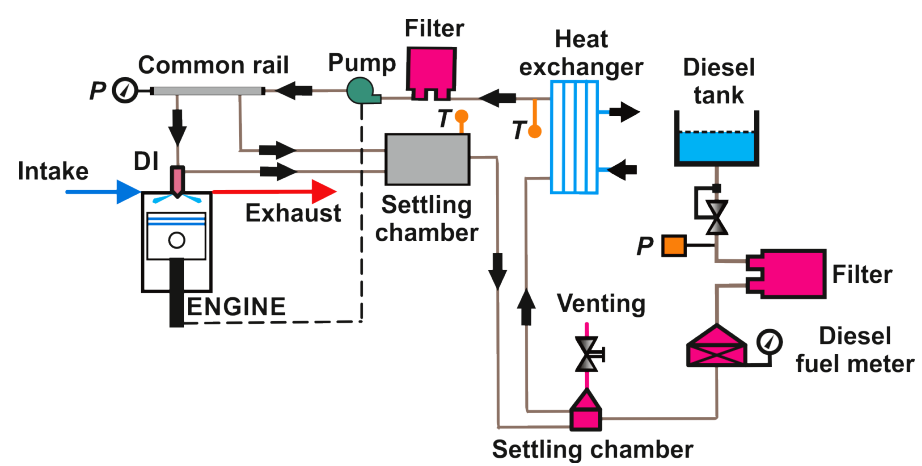

Figure 3.3. Scheme of the diesel fuel circuit.

To inject the diesel fuel, the engine is equipped with a Bosch CRSN4.2 common-rail injection hardware [5], which is able to perform up to five injections per engine cycle. The main characteristic of this hardware is the capability of amplifying the common-rail pressure by a factor of 2.1 for one of the injection pulses. This pressure amplification is done by means of a hydraulic piston located inside the injector body. To allow this, the fuel injector has two control solenoids, one for controlling the needle movement and other that governs the amplifier piston.

In this work, a 7 holes Bosch injector nozzle with $194 \mu \mathrm{m}$ holes diameter and included spray angle of $142^{\circ}$ has been used. The steady flow rate is $857 \mathrm{~cm}^{3} / 30 \mathrm{~s} / 100 \mathrm{bar}$. The main characteristics of the diesel injector are summarized in table 3.2 .

Table 3.2. Main characteristics of the diesel fuel injector.

\begin{tabular}{ll}
\hline \hline Actuation Type & Solenoid \\
Steady flow rate @ 100 bar $\left[\mathrm{cm}^{3} / 30 \mathrm{~s}\right]$ & 857 \\
Number of Holes [-] & 7 \\
Hole diameter $[\mu \mathrm{m}]$ & 194 \\
Included Spray Angle $\left[^{\circ}\right]$ & 142 \\
\hline
\end{tabular}




\section{Port fuel injection system}

The fuel circuit dedicated to inject gasoline is shown in figure 3.4. The system includes a reservoir, fuel filter, fuel meter, electrically driven pump, heat exchanger and two commercially available port fuel injectors, whose main characteristics are depicted in table 3.3 .

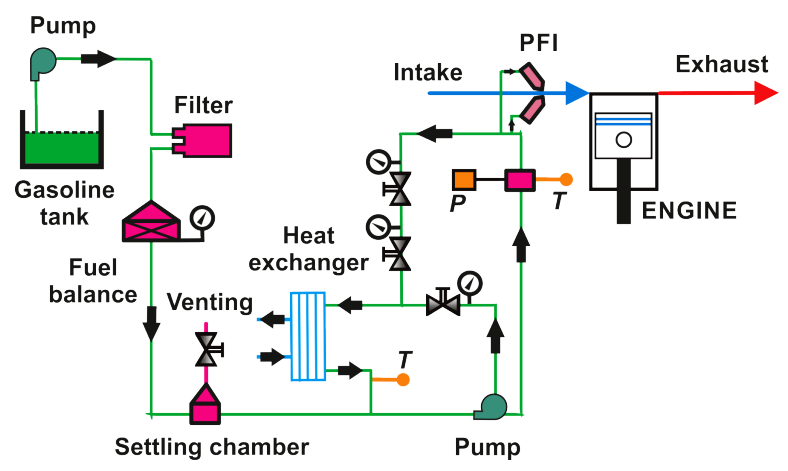

Figure 3.4. Scheme of the gasoline fuel circuit.

The injection system was designed to allow feeding the engine at full load conditions from 1200 to $1800 \mathrm{rpm}$ with a safety factor of $20 \%$. For this purpose, two Bosch injectors (model EV14 KxT) were installed at the intake manifold in a radially opposite position. The electronic control unit used to command the PFIs was Genotec MIV2, which allows to manage both injectors simultaneously in a flexible manner. To be able to introduce all the gasoline amount into the cylinder during the intake stroke, the gasoline injection timing was fixed $10 \mathrm{CAD}$ after the IVO. This injection timing allows the fuel to flow along the $160 \mathrm{~mm}$ length that separates the PFI location and the intake valves seats without causing fuel pooling over the intake valves, which would cause a undesirable variability in the combustion process.

Table 3.3. Main characteristics of the gasoline fuel injectors.

\begin{tabular}{ll}
\hline \hline Injector Style & Saturated \\
Steady flow rate @ $3 \mathrm{bar}\left[\mathrm{cm}^{3} / \mathrm{min}\right]$ & 980 \\
Included Spray Angle [ $\left.{ }^{\circ}\right]$ & 30 \\
Injection Pressure [bar] & 5.5 \\
Injection Strategy [-] & Single \\
Start of Injection timing [CAD ATDC] & 385 \\
\hline
\end{tabular}




\subsubsection{Baseline fuel properties}

The experimental tests of chapters 4 and 5 were carried out using commercially available diesel (EN590) and 98 octane number gasoline as high and low reactivity fuels, respectively. The main physicochemical properties of both fuels, obtained following ASTM standards, are listed in table 3.4. For convenience, the properties of the fuels used in chapters 6 and 7 will be presented there.

Table 3.4. Main characteristics of the fuels used in chapters 4 and 5.

\begin{tabular}{lll}
\cline { 2 - 3 } & Diesel & Gasoline \\
\hline Density $\left(\mathrm{T}=15^{\circ} \mathrm{C}\right)\left[\mathrm{kg} / \mathrm{m}^{3}\right]$ & 824 & 735 \\
Viscosity $\left(\mathrm{T}=40^{\circ} \mathrm{C}\right)\left[\mathrm{mm}^{2} / \mathrm{s}\right]$ & 2.8 & 0.45 \\
Surface tension $[\mathrm{N} / \mathrm{m}]$ & 0.0275 & 0.0216 \\
Reid vapor pressure $[\mathrm{bar}]$ & 0.0132 & 0.547 \\
Stoichiometric equivalence ratio $[-]$ & $1 / 14.56$ & $1 / 14.88$ \\
Cetane number [-] & 46.6 & - \\
Octane number [-] & - & 98 \\
Lower heating value $[\mathrm{MJ} / \mathrm{kg}]$ & 42.92 & 43.95 \\
Reduced formula [-] & $\mathrm{C}_{14.8} \mathrm{H}_{29.53}$ & $\mathrm{C}_{7.42} \mathrm{H}_{12.6}$ \\
\hline
\end{tabular}

\subsubsection{Test cell characteristics}

The test cell used to develop the present research is located in the laboratories of the Instituto Universtario de Investigación (IUI) CMT-Motores Térmicos, headquartered in the Universitat Politècnica de València.

Figure 3.5 shows a scheme of the test cell, which contains the engine as well as all the auxiliary systems for its operation and control. From the scheme, the different auxiliary systems such as the torque and speed regulation unit, the intake and exhaust systems, the EGR loop, and the engine lubrication and cooling systems are identified. In addition, the location of the different measuring equipment and sensors can be checked in the scheme. A detailed description of each subsystem will be done in next subsections. 


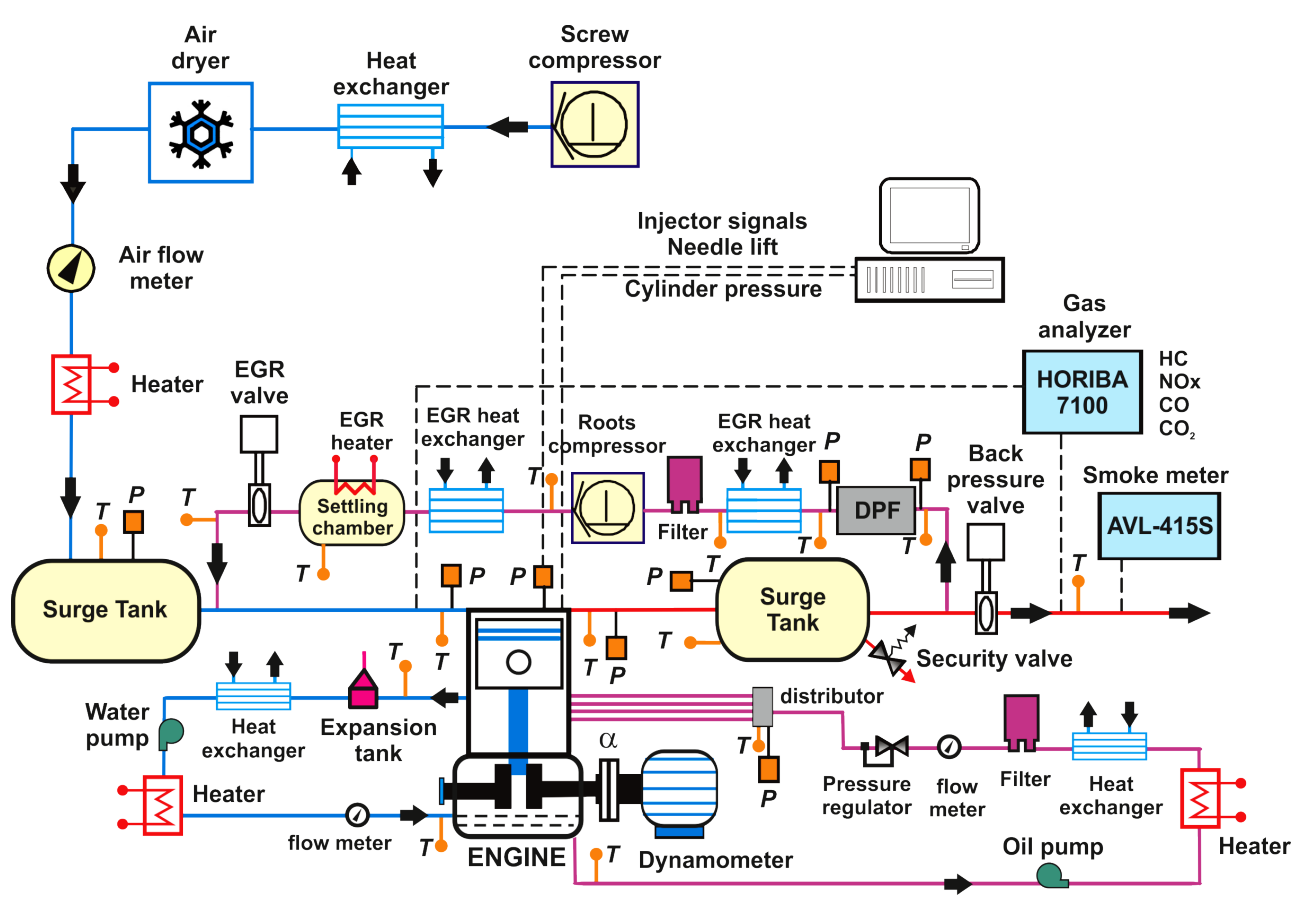

Figure 3.5. Test cell scheme. The location of the different auxiliary systems, measuring equipment and the most important sensors is illustrated.

\subsubsection{Engine speed and torque regulation}

A dynamometer brake is used to stabilize the engine at a desired operating point. This element allows to control the engine speed and torque at the time that dissipates the power generated by the engine. In addition, it can be used as motoring dynamometer to run the engine in motored conditions, e.g. during the engine start up or to perform the motored tests needed to characterize the engine.

To provide the required precision during the experiments, the dynamometer equips a dedicated control based on a variable-frequency drive and a proportional-integrator (PI) regulator, which gives a precision of $\pm 1 \mathrm{rpm}$. The more relevant characteristics of the dynamometer brake are depicted in table 3.5. 
Table 3.5. Characteristics of the dynamometer brake.

\begin{tabular}{ll}
\hline \hline Type & 4 poles dynamometer brake \\
Manufacturer & Wittur Electric Drives GmbH \\
Model & DSB3-16.3-B0I.41-M1KN \\
Nominal power $[\mathrm{kW}]$ & 65 \\
Nominal torque $[\mathrm{Nm}]$ & 414 \\
Nominal speed $[\mathrm{rpm}]$ & 1500 \\
Maximum speed $[\mathrm{rpm}]$ & 6500 \\
\hline
\end{tabular}

\subsubsection{Air supply and exhaust systems}

As depicted in figure 3.5, the single-cylinder engine is not equipped with a turbocharger. Alternatively, a series of auxiliary systems are used to achieve the intake and exhaust conditions representative of the equivalent multicylinder engine, which are described next.

\section{Air supply system}

The purpose of the air supply system (or intake system) is to tailor the properties of the fresh air before being introduced into the engine during the intake event. The capability of managing the intake conditions independently on the engine operating point provides high flexibility during the experiments. The different components of the intake system can be appreciated in the upperleft part of the figure 3.5.

To ensure that the intake system is capable of reproducing the turbocharged conditions experienced in the real engine, the air supply system equips two screw compressors. One of those works from 1 to 3.7 bar, and the other one from 3.7 to 9 bar. The use of one or the other depends on the conditions proposed in the experimental tests. The air coming from each compressor passes through an air dryer, which removes the humidity from the air by means of a cooling process. The specific humidity of the air (saturated) at the outlet of the dryer is determined by the pressure and dew temperature of the cooler, which is $3.0^{\circ} \mathrm{C}$. After the dryer, the exact air mass flow is measured by means of a volumetric flow meter. Next, the air arrives to a surge tank, which is intended to attenuate the pressure waves generated due to the pulsating nature of the flow during the intake event. For this purpose, the volume should be sized according to certain criteria. In particular, the volume 
of the surge tank used is 500 liters, which exceeds the minimum required value proposed by Kastner's (477 liters) and SAE J244 (418 liters) methods [6, 7].

The air pressure in the intake surge tank is controlled by a PID controller, which actuates on the variable frequency drive of the electrical engine coupled with the screew compressor. The precision provided is \pm 0.001 bar for the compressor which operates from 1 to 3.7 bar and \pm 0.005 bar for the high pressure compressor (from 3.7 to 9 bar). Moreover, the temperature inside the intake surge tank is controlled by means of a PID controller, which governs an electrical heater located upwards the tank with a precision of $\pm 0.5^{\circ} \mathrm{C}$. Finally, the instantaneous pressure and mean temperature are monitored in the intake manifold, as close as possible to the cylinder-head.

\section{Exhaust system}

The main purpose of this subsystem is to evacuate the high pressure and temperature gases from the cylinder after the combustion event. As figure 3.5 shows, the exhaust system is significantly simpler than the air supply system.

This subsystem integrates a surge tank in order to attenuate the pressure waves associated to the pulsating flow through the exhaust lines. The exhaust pressure and temperature are monitored twice, at the intake manifold and in the surge tank. A security valve is installed there to prevent overpressures in the system. To reproduce the backpressure conditions of the real engine, the exhaust pressure is controlled with a pneumatic valve downwards the surge tank, which is governed by a PID controller. This controller provides a precision of \pm 0.01 bar.

\subsubsection{Exhaust Gas Recirculation loop}

A dedicated low pressure EGR system, shown in figure 3.5, is used to produce EGR taking exhaust gases downwards the exhaust settling chamber. First of all, the exhaust gases are filtered by a DPF, whose differential pressure is controlled to avoid its blocking. Later, the temperature of the EGR flow is lowered using an air-water heat exchanger. After that, to prevent damaging the supercharger, water steam and condensate are separated from the gas by means of a centrifugal filter, and the resulting gas passes through a secondary filter. Then, a roots-type supercharger is used to provide the desired EGR mass flow rate to the engine. With the aim of lowering the gas temperature increase caused by the compression process in the supercharger, a second airwater heat exchanger is used before the arrival of the EGR gas to the 100 liter settling chamber. As in the cases of the air supply and exhaust systems, 
the large volume of the settling chamber aims to attenuate the pulsating flow, providing a constant EGR flow in the intake manifold. The EGR surge tank is equipped with an electric heater governed by a PID controller, whose actuation depends on the intake charge temperature demand, which is registered with a temperature sensor located in the intake manifold near the cylinder-head. Finally, the exhaust gas is introduced into the intake pipe, closing the external EGR loop. The determination of the EGR rate is carried out using the experimental measurement of intake and exhaust $\mathrm{CO}_{2}$ concentration and the exact EGR rate is controlled by means of a manual pneumatic valve between the EGR settling chamber and the intake pipe with precision of $\pm 0.2 \%$.

To ensure the desired conditions during the different tests, several parameters are acquired at various points of the EGR circuit. In particular, the mean temperature of the gas is recorded at the inlet of the DPF, at the inlet and outlet of the heat exchangers, at the EGR surge tank and before mixing with the fresh air. In addition, the EGR pressure is controlled by means of a PID controller, which modifies as required the variable frequency drive of the electrical engine of the roots compressor. The PID controller is feed by a pressure transducer installed in the EGR surge tank.

\subsubsection{Lubrication and cooling systems}

Considering the low effective power generated by a single-cylinder engine, the use of conventional lubrication and cooling systems, in which their respective pumps are driven by the engine, would cause an unacceptable rise of mechanical losses. Moreover, the heat flux generated by only one cylinder is far below of that generated by the equivalent multi-cylinder engine, leading to unacceptable engine heating-up periods until reaching the desired steady temperature.

These facts make necessary that both the cooling water and oil circuits have to be driven by electric pumps governed by electrical engines independent on the single-cylinder engine. As shown in figure 3.5, the oil and water are cooled by means of heat exchangers. Additionally, both circuits are equipped with electric heaters to accelerate the heating-up of the engine. For this purpose, the coolant and lubricant temperatures are acquired at the inlet and outlet of the engine, being the last ones used as control variables. The oil pressure is also monitored for safety purposes and it is regulated at $5 \pm 0.2$ bar. With the aim of avoiding variability during the experiments, the oil and water temperatures are maintained constant at $90 \pm 1^{\circ} \mathrm{C}$ and $80 \pm 1^{\circ} \mathrm{C}$, respectively, by means of PID controllers. This values are the ones defined for the equivalent multicylinder engine at standard operation. 


\subsubsection{Fuel conditioning system}

As will be described later, the injected fuel mass is measured by an AVL $733 \mathrm{~S}$ fuel balance, which gives the results directly in $\mathrm{kg} / \mathrm{h}$. This implies that variations in fuel temperature occurring between the outlet of the fuel balance and the inlet of the fuel injector will lead to errors in the fuel consumption measurement. In their works, de Rudder [8] and Novella [9] studied the sensibility of that error to the fuel temperature in a high-speed diesel engine and heavy-duty diesel engine, respectively. The Novella's study was performed using an engine with the same displaced volume $\left(1.806 \mathrm{~cm}^{3}\right)$ and slightly higher minimum fuel consumption $(\approx 3.2 \mathrm{~kg} / \mathrm{h})$ than the one used in the present work $(\approx 2.52 \mathrm{~kg} / \mathrm{h})$. In that work, it was demonstrated that if the fuel temperature would vary $\pm 1^{\circ} \mathrm{C}$ in eleven minutes and if the circulating volume would be $8 \mathrm{dm}^{3}$, the error committed would be of $0.03 \mathrm{~kg} / \mathrm{h}(10 \%$ in the worst case). Moreover, in the case of diesel fuel, the variation in fuel temperature (and density) would also affect the spray morphology during the injection-combustion process, and therefore to the engine-out emissions.

To avoid these undesirable variations in fuel temperature, two independent fuel conditioning systems for diesel and gasoline fuels are installed in the test cell. The different elements of the fuel circuits are aimed at ensuring the constant pressure and temperature required by their respective fuel injection systems. As shown in figure 3.3, the diesel fuel drained from the injector, common rail and high pressure pump is cooled to a constant temperature before being returned back to the intake of the high-pressure fuel pump. This is also done in the case of gasoline to prevent false fuel consumption measurements (figure 3.4). In both circuits, the fuel temperature is acquired at the inlet and outlet of the engine, and a PID controller governs a heat exchanger fluid-fuel to ensure the desired temperature. The constant temperatures used for gasoline and diesel were $45 \pm 1^{\circ} \mathrm{C}$ and $50 \pm 1^{\circ} \mathrm{C}$, respectively.

\subsubsection{Data acquisition systems}

The data acquisition systems are used to collect the information from the different measuring equipment and sensors. Due to the high amount and different nature of the data acquired during the engine tests, the test cell is equipped with two types of acquisition systems. They can be classified depending on their sampling frequency. 


\section{High sampling frequency}

The high frequency data acquisition is carried out by means of a Yokogawa DL716E oscilloscope, which enables recording up to 16 variables. The oscilloscope is connected to a PC, which stores the data transferred from the Yokogawa. Regarding its sampling frequency, the angle encoder installed on the crankshaft of the engine sends a pulse to a control box every 0.5 CAD. Nevertheless, via interpolation, a pulse is obtained every 0.2 CAD. This pulse serves as the clock timer for the oscilloscope. Additionally, this crank angle encoder sends one reference pulse every revolution, which serves to reference the top dead center (TDC) of the engine. With the pulses every 0.2 $\mathrm{CAD}$ acting as clock timer and the reference pulse as trigger, the oscilloscope acquires the data from the sensors at a sampling frequency of $36 \mathrm{kHz}$ (at engine speed of $1200 \mathrm{rpm}$ ). Due to the high speed sampling, these parameters are referred to as instantaneous parameters. The main instantaneous parameters acquired during the investigation are depicted in table 3.6.

Table 3.6. Location of the instantaneous parameters recorded during the experimental tests.

\begin{tabular}{ll}
\hline \hline Location & Variable \\
\hline Cylinder-head & In-cylinder pressure \\
Crankshaft & Trigger signal \\
Direct injection system & Injection pulse \\
Port fuel injection system & Amplifier piston pulse \\
Variable valve actuation system & Injection pulse \\
Intake system & Valve lift \\
Exhaust system & Pressure \\
\hline
\end{tabular}

\section{Low sampling frequency}

The low frequency data acquisition is carried out using hardware from National Instruments together with the in-house developed software SAMARUC, programmed in Labview. This package acquires the data obtained from the sensors, measuring equipment and emissions analyzers at a frequency of $1 \mathrm{~Hz}$ over a typical period of 40 seconds, providing an average value for each variable recorded. Based on the nature of the sampling frequency of this data, these parameters are referred to as mean parameters. At an engine speed of $1200 \mathrm{rpm}$, this system allows to record 400 engine cycles, thus ensuring enough statistical significance for each parameter acquired. 


\subsubsection{Instrumentation and measuring equipment}

Once the single-cylinder engine and the test cell have been described, the present section aims to explain briefly the main instrumentation and measuring equipment used in the experimental facility. In addition, the measuring range as well as the precision of the different sensors and equipment are provided here.

\subsubsection{Torque and engine speed measurement}

The engine torque is measured by means of a load cell mounted in the torque shaft between the engine flywheel and the dynamometer. In particular, the load cell is a T10F-001R-KF1 model, patented by Hottinger Baldwin Messtechnik. The nominal torque for this load cell is $1000 \mathrm{Nm}$, far above of the typical values measured in the present investigation. The precision of this transducer is $\pm 0.2 \%$.

The engine speed is measured by means of an AVL 364 optical angle encoder installed on the crankshaft of the engine. The native resolution of the encoder is $0.5 \mathrm{CAD}$, but it has been increased up to $0.2 \mathrm{CAD}$ via interpolation. The maximum precision of this sensor is $\pm 0.02 \mathrm{CAD}$. In addition, the encoder provides a synchronism signal (one signal per engine revolution), which allows to positioning the top dead center (TDC). As commented before, this synchronism signal is used as trigger for the acquisition system.

\subsubsection{Mean pressure and temperature measurement}

In order to measure the mean pressure of the fluids in the necessary locations of the experimental facility (intake, exhaust and lubrication systems), several piezoresistive transducers by PMA (P40 model) have been used. The most remarkable characteristics of these transducers are the great thermal stability and the reduced measurement drift. The measuring range of these sensors is from 0 to 10 bar.

Regarding mean temperature acquisition, several thermocouples type $\mathrm{K}$ without covering (in the case of the clean gas) and covered (in the case of the exhaust gas and EGR), have been installed. The measuring range of those thermocouples is from 0 to $1100^{\circ} \mathrm{C}$, with a precision of $\pm 2.5^{\circ} \mathrm{C}$. The upper temperature limit is far above of that experienced in the engine tests.

On the other hand, several thermoresistances Pt100 type have been used to measure the oil and water temperatures. The measuring range of those 
sensors is from -200 to $+850^{\circ} \mathrm{C}$, with a precision of $\pm 0.3^{\circ} \mathrm{C}$. The main benefits of this type of thermoresistances are the great sensibility and linearity in all the measuring range.

\subsubsection{Instantaneous pressure transducers}

The in-cylinder pressure signal is the most important data needed to perform the combustion analysis. To acquire this signal, a non-cooled piezoelectric transducer Kistler $6125 \mathrm{C}$ with measuring range from 0 to 250 bar is used. The upper limit of the transducer coincides with the maximum in-cylinder pressure allowed by the engine mechanical specifications, which is not expected to be reached during the experiments. The signal generated from the pressure sensor is conditioned by a Kistler 5011B10 charge amplifier before arriving to the high frequency acquisition system.

On the other hand, the instantaneous pressure at the intake and exhaust manifolds are acquired by means of water-cooled piezoresistive transducers manufactured by Kistler (4045A10), whose measuring range is from 0 to 10 bar. The pressure signal is conditioned before its acquisition by means of a Kistler 4603A10 charge amplifier.

\subsubsection{Mass flow measurement}

An Elster RVG G100 rotary meter is located upwards the intake surge tank to measure the volumetric air flow. This device operates according to the positive displacement principle with a measuring range from 0.05 to $160 \mathrm{~m}^{3} / \mathrm{h}$ and a precision of $\pm 0.1 \%$. The measurement output, in $\mathrm{m}^{3} / \mathrm{h}$, is transferred to $\mathrm{kg} / \mathrm{h}$ by measuring the temperature and pressure of the intake air. Both sensors are integrated in the rotary meter and are similar to those described in subsection 3.2.3.2.

The fuel mass flow is measured by an AVL 733S fuel balance. The scheme presented in figure 3.6 illustrates the measurement principle of this device. As seen in the scheme, the fuel balance performs the measurement by means of a capacitive sensor, providing a signal which depends on the instantaneous fuel mass located inside the measuring vessel. The measuring range of the model used in this work ranges from 0 to $160 \mathrm{~kg} / \mathrm{h}$, with a precision of $\pm 0.2 \%$. 


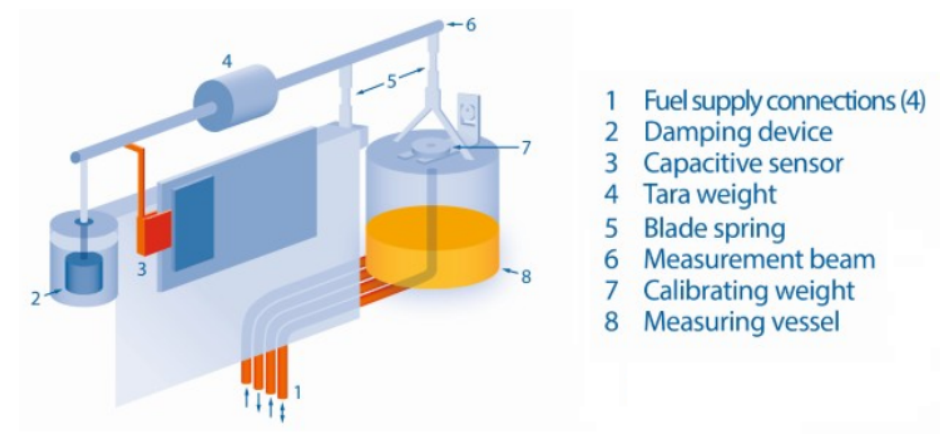

Figure 3.6. Scheme of the measurement principle of the gravimetric fuel balance AVL $733 S$ used for measuring the fuel mass flow [10].

\subsubsection{Horiba gas analyzer}

The exhaust gas is analyzed by a Horiba MEXA-7100 DEGR gas analyzer. In particular, the molar fraction of several species such as $\mathrm{NO}, \mathrm{NO}_{2}, \mathrm{CO}$, total hydrocarbons ( $\mathrm{HC}), \mathrm{CO}_{2}$ and $\mathrm{O}_{2}$ are accounted. As shown in figure 3.5, the gas analyzer test probe is connected in the exhaust line downwards the backpressure valve. The exhaust gas sample flows towards the measuring system through a heated line, which is maintained at $192^{\circ} \mathrm{C}$ to avoid the condensation of hydrocarbon species. The analysis of the different species contained in the exhaust gas sample relies on different principles, so that several analyzers are used. The full details of the complex working principles of each analyzer can be found in the references [11-14]. In this regard, a short summary of the measure principles is presented next.

- The $\mathrm{CO}$ and $\mathrm{CO}_{2}$ are quantified by means of a NDIR (Non Dispersive InfraRed detector). Both $\mathrm{CO}$ and $\mathrm{CO}_{2}$ absorb a specific wavelength of infrared light, which is transferred into concentration values. $\mathrm{CO}$ emissions up to $10 \%$ and $\mathrm{CO}_{2}$ up to $20 \%$ can be measured with a precision of $\pm 4 \%$.

- NOx is determined based on the chemiluminescence principle. First NOx is reduced to $\mathrm{NO}$, second the exhaust gas with $\mathrm{NO}$ is mixed with ozone $\left(\mathrm{O}_{3}\right)$. This reaction creates activated $\mathrm{NO}_{2}^{*}$ which luminesces broadband visible to infrared light as it reverts to its lower energy state $\left(\mathrm{NO}_{2}^{*} \rightarrow\right.$ $\mathrm{NO}_{2}+$ light). This light is detected and converted to NOx concentration. The NOx can be measured in the range of 0 to $5000 \mathrm{ppm}$ with a precision of $\pm 4 \%$. 
- The HC concentration is measured using the flame ionization principle. A hot sample of the exhaust gas is burned in combination with a mixture of hydrogen, helium and synthetic air. When the hydrocarbons burn, they produce ions which in presence of an electric field, produce an ionization current proportional to the quantity of carbon atoms. The $\mathrm{HC}$ emissions can be measured up to $10000 \mathrm{ppm}$ with a precision of $\pm 4 \%$.

- The $\mathrm{O}_{2}$ concentration is measured considering the paramagnetic properties of oxygen. The range of oxygen concentration that can be measured is between 0 and $25 \%$ with a precision of $\pm 4 \%$.

The $\mathrm{CO}_{2}$ concentration is measured both in the intake gas (air + EGR) and the exhaust gas. Thus, the EGR rate is obtained through the comparison of the $\mathrm{CO}_{2}$ contained in the intake and the exhaust gas, according to equation 3.1.

$$
E G R=\frac{C_{2} \text { intake }_{d r y}-400}{C_{2} \text { exhaust }_{d r y}-400}
$$

where $\mathrm{CO}_{2}$ intake $_{d r y}$ and $\mathrm{CO}_{2}$ exhaust $_{d r y}$ are the amount of carbon dioxide in parts per million ( $\mathrm{ppm})$ in the dried intake and exhaust gas respectively, and 400 represents the parts per million of $\mathrm{CO}_{2}$ contained in the ambient air.

Before starting each test session, a calibration procedure for each analyzer is carried out using reference gases. These reference gases have a composition that is representative for the typical emissions range observed for several engines.

The AF ratio (air/fuel ratio) and lambda are calculated by the Horiba equipment based on the composition of the exhaust gas [15].

The NOx, $\mathrm{CO}, \mathrm{CO}_{2}$ and $\mathrm{O}_{2}$ measurements are corrected to consider the humidity in the exhaust gas. HC measurements are not corrected since the samples are not previously dried. The NOx sample is corrected again to take into account the humidity introduced to the engine by means of the intake air. These corrections, together with the conversion from ppm or percentage into $\mathrm{g} / \mathrm{h}$ are done according to the European Directive 2007/46/EC [16], which was in force during the development of the present research.

\subsubsection{AVL Smoke meter}

The soot content of the exhaust gas is measured with an AVL 415S smoke meter. In this filter-type smoke meter, a defined quantity of exhaust gas passes 
through a clean filter paper. In particular, three samples of a 1 liter volume each, with paper-saving mode off, were collected for each engine test recorded.

The smoke meter utilizes an optical reflectometer to determine the amount of blackening of filter paper by the soot contained in the fixed volume of exhaust gas. The blackening on the filter paper is detected by a photoelectric measuring head and translated to FSN (Filter Smoke Number) on a scale from 0 (filter without blackening) to 10 (filter completely blacked). The detection limit of this device is $0.002 \mathrm{FSN}$ and the resolution is $0.001 \mathrm{FSN}$. Soot measurements in FSN are transformed to soot concentration $\left(\mathrm{mg} / \mathrm{m}^{3}\right)$ considering the correlation proposed by Christian et al. [17] (equation 3.2). Later, soot concentration on mass basis $(\mathrm{mg} / \mathrm{kg})$ can be obtained considering a constant exhaust gas density of $1.165 \mathrm{~kg} / \mathrm{m}^{3}$.

$$
\text { Soot }=\frac{1}{0.405} \cdot 4.95 \cdot F S N \cdot e^{(0.38 \cdot F S N)}
$$

The soot readings using the smoke meter are not a direct measurement of particulate matter mass. Since the smoke meter relies on an optical measurement, it may not accurately account for condensable organics contained in particulate matter (PM), and hence may underestimate gravimetric PM measurements. However, since PM emitted by conventional diesel combustion (CDC) are composed of around $60 \%$ of soot, the estimate of PM emissions at a given steady-state engine condition through soot measurements is generally accepted. By contrast, condensable organic hydrocarbons have been shown to be the primary mode of PM with RCCI operation [18], and therefore this estimation entails greater deviation than with CDC. In this sense, the accuracy of the soot-to-PM estimation for RCCI will be affected by several parameters, such as the low reactivity fuel fraction and the low reactivity fuel type, which will strongly determine the portion of condensable organic hydrocarbons contained in PM.

In this investigation, it has been measured only the soot content. As will be seen along the next chapters, a limit of $0.01 \mathrm{~g} / \mathrm{kWh}$ has been imposed for this pollutant, which corresponds to that imposed by the EURO VI regulation for PM emissions. Since soot measurements underestimate the gravimetric PM measurements with RCCI, this limit ensures that tests with soot content above $0.01 \mathrm{~g} / \mathrm{kWh}$ will be also out of EURO VI in terms of PM. However, for engine tests with soot levels below this limit, the compliance of EURO VI in terms of PM cannot be ensured, because their relationship depends on the engine operating conditions. A dedicated work, which is out of the scope of this thesis, is necessary to examine further the characteristics of the PM emitted with RCCI to understand the relationship between soot and PM. 


\subsubsection{Blow-by meter}

During the closed cycle ${ }^{1}$, some part of in-cylinder charge can be lost through the gap between the piston rings and the cylinder-liner, which is known as blow-by phenomenon. In spite of that blow-by is supposed to be minimum in heavy-duty engines, knowing its value allows to calculate more accurately the in-cylinder instantaneous mass, which increases considerably the precision of the theoretical models used for the combustion diagnosis.

In this research, the flow of the blow-by gas is monitored using an AVL 442 blow-by meter, which works under the orifice plate measurement principle. This specific model allows to measure a maximum flow of $4.5 \mathrm{~m}^{3} / \mathrm{h}$ with a precision of $\pm 1.5 \%$. For each engine test, the volumetric blow-by flow is converted to mass flow taking into account the atmospheric pressure and temperature values.

The blow-by measurement is also used to detect possible sealing problems associated to the wearing of the piston rings. The high in-cylinder pressure reached in this work, over 200 bar in some cases, implies an important mechanical loads and therefore the control of this variable becomes important.

\subsubsection{Experimental procedure considerations}

The use of a variable valve actuation system and two different injection systems increases the complexity of the experimental facility. Therefore, the probability of the appearance of experimental errors rises. In order to be able to detect possible errors during the engine tests, the methodology defined by Molina [11] and adapted by Novella [9], has been applied in the present investigation. The fundamentals of this methodology are also found in the work performed by Benajes et al. [19]. A sketch of the methodology is illustrated in the figure 3.7, from which can be observed that the main control mechanism consist of two types of complementary verifications.

The static verification consist of selecting a reference engine operating point with the aim of checking the correct operation of the different systems integrated in the experimental facility every testing day. For this purpose, the values of different parameters such as engine-out emissions (NOx, soot, $\mathrm{CO}$ and $\mathrm{HC}$ ), engine torque, maximum in-cylinder pressure, air mass flow and fuel mass flow are compared to the values measured in previous days. This verification is carried out once the engine has been heated-up. All the

\footnotetext{
${ }^{1}$ The term closed cycle refers to the period of the engine cycle during which the intake and exhaust valves remain closed simultaneously.
} 


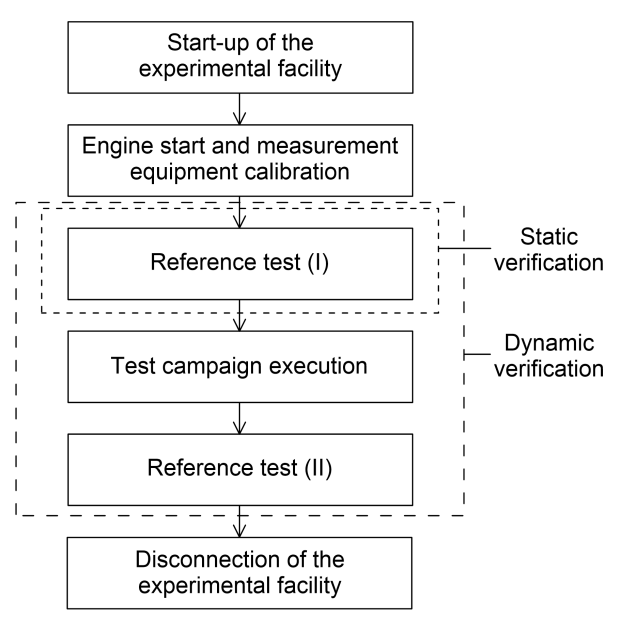

Figure 3.7. Experimental methodology carried out during the engine tests. Adapted from Novella [9].

variables should be inside a confidence interval before proceeding with the tests campaign of the day.

This type of verification is very useful to know how the experimental facility works under steady state conditions. However, the different studies carried out during the tests campaign may imply strong variations in the engine operating conditions, and therefore the static verification may not ensure the reliability of the results. Thus, an additional verification was considered necessary to detect the possible errors during the engine tests.

The dynamic verification aims to detect measuring errors of air mass flow, fuel mass flow, EGR rate and intake oxygen concertation. For this purpose, the checking is done after each test recorded. On one hand, the verification is based on the linear relationship between the intake oxygen concentration and the equivalence ratio. On the other hand, it is also checked the total intake mass flow (air + EGR), which should be constant if the intake temperature is held constant, as it is done in this research.

If the verifications are inside the control limits, the test recorded is considered as correct. Otherwise, the work performed by Benajes et al. [19] gives some protocols to detect the parameter which is the source of error to proceed to its correction. 


\subsection{Theoretical tools}

The theoretical tools are used to process the raw experimental data, improving its quality and generating additional information that contribute to better comprehend the combustion process. To select the suitable theoretical tools, it is necessary to consider several aspects such as the necessary inputs for the models, the hypothesis of the theoretical approaches and the matching between their output information and the objectives of the study.

This section comments the main characteristics of the two theoretical tools used in this investigation. Specifically, the general hypotheses and principles of the 0-D combustion diagnosis code are described in subsection 3.3.1. Later, the main details about the modeling methodology, set-up and validation of the computational fluid dynamic (CFD) code are provided in subsection 3.3.2.

\subsubsection{0-D Combustion diagnosis model}

The use of thermodynamic models to obtain parameters derived from the in-cylinder pressure measurement, such as the heat release law (HRL) and the rate of heat release (RoHR), is fundamental to perform the study of the combustion event. These models are usually zero-dimensional, and their theoretical principles are based on the application of the thermodynamics' first law to a control volume during the closed cycle. The main differences between the different thermodynamic models found in literature are related to the precision of the hypotheses assumed and the grade of simplifications done during the calculations.

The combustion diagnosis code used in the present investigation was developed at CMT-Motores Térmicos and is called CALMEC [20]. The general hypotheses of the model are briefly described and discussed next:

- The pressure is supposed homogeneous in the combustion chamber. This hypothesis is generally accepted since the fluid and the flame propagation velocity are lower than the speed of sound.

- The fluid that evolves inside the combustion chamber is considered as a mixture of air, gaseous fuel and burned products. Despite that in this model a uniformity of charge composition and mixture temperature are taken into account, it is important to remark that a maximum of three species (air, gaseous fuel and burned products) are considered to evaluate the thermodynamic conditions of the mass trapped in the cylinder. 
- An ideal gas behavior is assumed for the mixture that evolves in the combustion chamber. It is reasonable to accept this assumption for the air and burned products, however, it could seem not adequate for the gaseous fuel. In this sense, Lapuerta [21] compared the results from the combustion analysis model using different state equations for the gaseous fuel. The results confirmed that the differences in mean temperature and HRL are small enough to accept the hypothesis.

Taking into account the previous hypotheses, CALMEC raises the first law of thermodynamics to open systems considering the fuel injection and blow-by flow. Thus, the equation 3.3 is solved in steps of time defined by the resolution of the in-cylinder pressure measurement.

$\Delta H R L=m_{c y l} \cdot \Delta u_{c y l}+\Delta Q_{w}+p \cdot \Delta V-\left(\bar{h}_{f, i n j}-u_{f, g}\right) \cdot \Delta m_{f, e v a p}+R_{c y l} \cdot T_{c y l} \cdot \Delta m_{b b}$

The different terms of the equation are explained below:

- $\triangle H R L$ : This term corresponds to the thermal energy released by the fuel assuming a constant heat power along the combustion event.

- $m_{c y l} \cdot \Delta u_{c y l}$ : This is the sensible internal energy variation of the gas trapped in the control volume. As detailed by Lapuerta [20], this term is calculated by means of a specific correlation for each specie. For each temporal step, these correlations are solved as a function of the mean temperature in the control volume while pondering by the mass fraction of each specie.

- $\Delta Q_{w}$ : This term accounts the heat transfer from the gas trapped in the control volume to the surrounding surfaces of the piston, liner, cylinderhead and valves. The model does not consider the possibility of fuel impinged in the wall. The instantaneous heat transfer coefficient between the gas and the different surfaces is based on Woschni [22] with some improvements detailed in Payri et al. [23]. For the calculation of the different wall temperatures a nodal heat transfer model is implemented $[24,25]$.

- $p \cdot \Delta V$ : This term represents the total work made by the gas trapped in the control volume during the calculation period. For the instantaneous calculation of the combustion chamber volume, a mechanical deformations model is considered. This submodel takes into 
account both the pressure made by the gas on the piston head and the inertial forces generated by the alternative movement of the masses.

- $\left(\bar{h}_{f, i n j}-u_{f, g}\right) \cdot \Delta m_{f, e v a p}$ : This term includes all the energetic considerations associated to the fuel injection process [26], i.e. the flow work, the heat needed to reach the evaporation temperature and the heating-up process of the vapor fuel until reaching the combustion chamber temperature.

- $R_{c y l} \cdot T_{c y l} \cdot \Delta m_{b b}$ : Finally, the energy lost due to the blow-by through the piston rings is also considered. The blow-by mass is calculated using an isentropic nozzle model to simulate the gas evolution from the combustion chamber to the oil sump.

Figure 3.8 shows the kind of data obtained from CALMEC that will be used to perform the combustion analysis. In particular, the figure shows the instantaneous evolution of the heat release law (HRL), rate of heat release (RoHR), mean temperature, in-cylinder pressure and simulated fuel injection rate. Based on this results, it can be obtained several metrics to describe the injection and combustion events. The combustion metrics that will be typically used in next chapters are defined below:

- Start of injection (SOI): Defined as the instant in which the injection event begins. This parameter is based on a simulated injection rate, which takes into account the hydraulic and electric delay of the injector after the start of energizing (SOE).

- CA10, CA50, CA75 and CA90: Crank angle degree in which the 10\%, $50 \%, 75 \%$ and $90 \%$ of the total heat release has been released during the combustion process, respectively. The crank angle is referred to the top dead center (TDC).

- Start of combustion (SOC): Defined as the crank angle position in which the cumulative heat release has reached $5 \%$.

- Ignition delay: Defined as the time elapsed from the diesel start of injection (SOI) up to the start of combustion (SOC).

- Combustion duration: Defined as the time elapsed from the start of combustion (SOC) up to the CA90. 


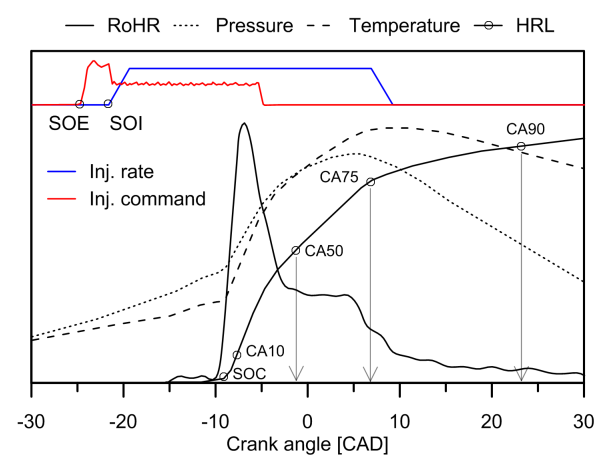

Figure 3.8. Definition of the main combustion metrics and parameters obtained with CALMEC.

\subsubsection{3-D Computational fluid dynamics model}

The 0-D combustion diagnosis code provides a lot of accurate information about the combustion event with very low computational cost. However, this theoretical tool is not able to capture some fundamental details of the combustion phenomenon that are necessary to reach the objectives of the present research. As literature demonstrates, in order to study the local conditions that allow deeper understanding of the combustion process, the researchers typically follow two main pathways.

The first one is the application of optical techniques, which provide information based on the visualization of the combustion process using complex optical equipment. These techniques are considered intrusive since they require the structural modification of the engine to have optical access. Moreover, the heavy-duty engine used in this work is not adapted to allow optical investigations on it, which suppressed this possibility.

An alternative pathway to obtain detailed information about the combustion process are the three-dimensional computational fluid dynamic (CFD) models. By means of numerical methods, these tools allow to solve the equations that govern the fluid flow to describe accurately the structure of the fuel spray and the combustion process, spatially and temporally. The numerical methods are based on discretize the space in small control volumes, where the equations are solved considering the initial state of the fluid and certain boundary conditions.

Taking into account the objectives of the present work, a 3-D CFD model has been used to understand some details of the RCCI combustion process 
that cannot be explained with only the information from the experimental tests. From the different codes available at CMT-Motores Térmicos, the model CONVERGE showed the best performance for simulating the RCCI combustion through detailed chemical reactions. The next subsections present a brief description of the modeling methodology, highlighting its different steps and the submodels used in the code. Nevertheless, the reader is invited to consult the literature to deepen on this computational code [27].

\subsubsection{General features}

The computational tool CONVERGE [28] allows the generation of the mesh during its execution, which enables adapting its topology to the computational economy instead of to the geometry. The embedding option permits to refine the mesh in the zone where more precise calculations are needed, while maintaining a greater mesh size in the rest of the computational domain. These options increase notably the computational efficiency. In addition, the adaptative mesh refinement (AMR) allows to refine the mesh automatically as a function of the local variation of certain variables such as temperature or velocity. This option makes possible to simulate complex phenomena without incurring into the computational cost associated to the whole mesh refinement. Looking for maximizing the computational economy, CONVERGE solves the velocity and pressure matching by means of the modified PISO algorithm by Issa et al. [29].

In addition, compared to other computational models that incorporated the required tools to model internal combustion engines some years after its appearance, CONVERGE was conceived with all the necessary submodels and tools for modeling reciprocating internal combustion engines. Thus, the different numerical resolution tools and updated submodels of turbulence, spray, combustion, heat transfer and cavitation are integrated in the model and validated for their application in internal combustion engines.

The general combustion model, named SAGE [28], is based on a set of basic reactions that describe in detail a more general chemical reaction. This model allows its adaptation to model the combustion of different fuels. By means of this mechanism, the solver SAGE calculates the reaction rates of the different basic reactions, while the transport equations are solved by CFD. Moreover, CONVERGE solves the mass and energy conservation equations in each temporal step, updating the cell temperature once the detailed chemical calculation have converged to the result. 


\subsubsection{Modeling methodology}

After the brief description of the main features of the model, this section points out the most important considerations about the hypotheses, mesh topology, main submodels and boundary conditions used to perform the calculations.

\section{Hypotheses}

The next fundamental hypotheses have been used to simplify the approach and resolution of the problem:

- Sector-type mesh with cyclic contours: With the aim of reducing the computational costs, the calculation domain corresponds only to one sector of $\approx 52^{\circ}$ of the combustion chamber, which is associated to the 7 orifices nozzle used in this study. The reduction in the calculation domain with a cyclic boundary conditions ${ }^{2}$ imposed at its both sides allows reducing considerably the calculation time while maintaining a high precision [30, 31].

- Closed loop calculation: The calculations are limited to the period in which the valves (intake and exhaust) are closed. This consideration allows to avoid the intake and exhaust processes modeling, whose evolution in terms of local conditions inside the cylinder are not in the scope of the present research.

- Gasoline mass completely evaporated: For the calculations it is assumed that all the gasoline mass is completely evaporated and homogeneously mixed with the air when the calculation begins. This is a reasonable hypothesis due to the high volatility of the gasoline and the early injection timing used (10 CAD after IVO).

\footnotetext{
${ }^{2}$ The cyclic (or periodic) boundary condition treats two boundary regions as if they were physically connected, thus sharing the values of the bulk properties. This type of boundary is used for geometries that have a repeated pattern in flow distribution more than twice, in which the symmetric boundary condition cannot be applied.
} 


\section{Mesh topology}

The mesh geometry was defined taking into account the main dimensions of the single-cylinder engine used in this investigation: bore, stroke, sector angle, squish, compression ratio, and piston and cylinder-head profiles.

A structured Cartesian grid with base cell size of $1.6 \mathrm{~mm}$ was used to generate the mesh. Moreover, an adaptive mesh refinement, with two levels, was considered during the closed cycle for the velocity, temperature and the species representative of the gasoline and diesel fuels. An embedding operation, with also two refinement levels, was done in the spray zone from the beginning of the fuel injection until the exhaust valve opening. In addition, embedding operations were also done in the cylinder-head and piston (with only one refinement level) from the temporal instants near the start of combustion until the exhaust valve opening. The maximum cells number was limited to 250000 .
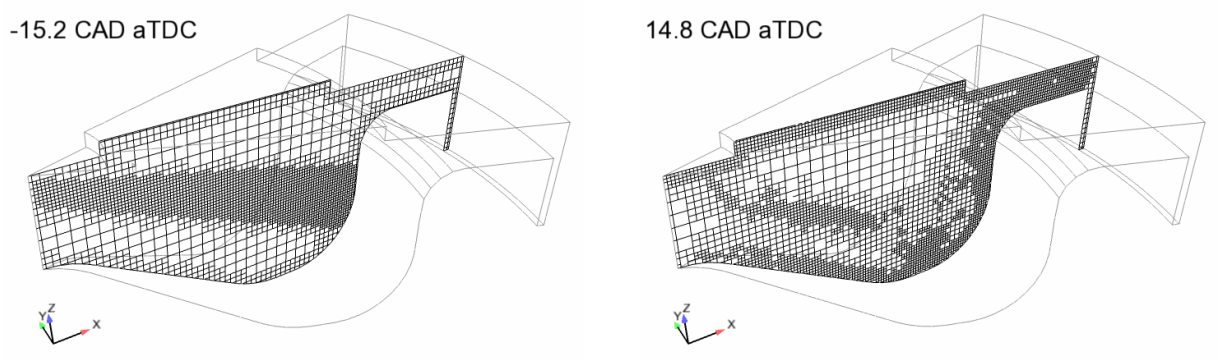

Figure 3.9. Different grid refinements using the adaptive mesh refinement (AMR) by CONVERGE.

Figure 3.9 shows the computational domain, with a radial plane located in the spray axis, at two temporal instants of the engine cycle near TDC. The comparison of both instants denotes the advantages of using the embedding and the adaptative mesh refinement (AMR) options. In addition, it can be stated that the cylinder-head is not plane. In this sense, an additional volume has been added to adjust the compression ratio to the value obtained experimentally.

\section{Main submodels}

As commented above, the port fuel injected gasoline is considered to be homogeneously mixed and vaporized at IVC. Regarding diesel fuel, its injection process is simulated by the standard Droplet Discrete Model [32]. The physical 
properties of diesel fuel used to simulate the mixing process, are represented by the diesel2 fuel surrogate available in the CONVERGE database. Spray atomization and break-up processes are modeled using the hybrid KH-RT model [33] with random parcels distribution in a solid cone, the O'Rourke's model [34] for turbulent dispersion of the droplets and the droplet evaporation model by Frossling [35]. The interaction between the droplets and walls has been solved by means of a wall film model [36].

The turbulent flow is modeled by means of a RANS approach using a RNG $\mathrm{k}-\epsilon$ model [37]. In order to account the wall heat transfer, a wall-functions model by Han and Reitz has been included [38].

Concerning combustion modeling, a direct integration of detailed chemistry approach was used by means of SAGE solver. In order to speed-up the chemistry calculations, a multi-zone model from Babajimopoulos et al. [39] is used to solve the detailed chemistry in zones, i.e. groups of cells that have similar thermodynamic state. The cells are grouped based on two variables, temperature and equivalence ratio. The calculations performed in the thesis used a $5 \mathrm{~K}$ bin size for temperature and 0.01 bin size for equivalence ratio zones.

A reduced PRF reaction mechanism [40] made up of 45 species and 142 reactions including $\mathrm{NOx}$ formation (thermal, $\mathrm{N}_{2} \mathrm{O}$ and $\mathrm{NO}_{2}$ pathways) describes the combined oxidation of n-heptane (PRF 0) and iso-octane (PRF 100). The use of these PRF as surrogate fuels to represent the combustion characteristics of diesel and gasoline, respectively, is widely used in literature $[30,31,41]$.

\section{Calculation initialization}

To initialize the calculations it is necessary to stablish the boundary conditions of the computational domain, define the calculation conditions, determine the initial conditions of the engine load and propose the injection strategy.

Regarding the boundary conditions, it is interesting to remark that the mesh used in the calculations is delimited by five contours, each of which has a certain boundary condition type defined. In particular, the piston has been defined as a wall-type contour with translational movement; the cylinderhead and liner have been also defined as wall-type contour but stationary, and finally both sector sides are defined as cyclic, specifying that one side should be equal to the other with periodic pattern for the whole computational domain. The boundary conditions used for the piston, cylinder-head and liner are summarized in table 3.7. 
Table 3.7. Boundary conditions types and values.

\begin{tabular}{lll}
\hline \hline Variable & Boundary condition & Value \\
\hline Velocity & Wall law & 0 \\
Pressure & Neumann & Zero gradient \\
Temperature & Wall law & - \\
Species & Neumann & Zero gradient \\
Passives & Neumann & Zero gradient \\
Turbulent kinetic energy & Neumann & Zero gradient \\
Turbulent energy dissipation rate & Dirichlet & 0 \\
\hline
\end{tabular}

Regarding the calculation conditions, the temporal step at the beginning of the simulation has been defined at $1 \mathrm{e}^{-07} \mathrm{~s}$, with a maximum and minimum temporal steps of $1 \mathrm{e}^{-04} \mathrm{~s}$ and $1 \mathrm{e}^{-08} \mathrm{~s}$. On the other hand, the maximum number of iterations to solve the transport equations and pressure has been defined in 30 and 500, respectively. The tolerance to the pressure convergence is $1 \mathrm{e}^{-08}$, while the corresponding one for the velocity, specific internal energy, density, species, passives, turbulent kinetic energy and turbulent kinetic energy dissipation rate is $1 \mathrm{e}^{-04}$. Finally, the convergence criteria for the algorithm PISO has been fixed in 10, with a maximum and minimum number of iterations of 9 and 2, respectively.

To complete the calculation initialization, it is necessary to determine the in-cylinder conditions at the beginning of the calculation (pressure, temperature and mass fractions of $\mathrm{N}_{2}, \mathrm{O}_{2}, \mathrm{CO}_{2}, \mathrm{H}_{2} \mathrm{O}$ y iC $\mathrm{iC}_{8} \mathrm{H}_{18}$ ) at the intake valve closing (IVC). These parameters are provided to CONVERGE after processing the experimental tests with the combustion diagnosis code, CALMEC.

Since the gasoline is considered to be homogeneously mixed and vaporized at IVC, and considering that its mass fraction is defined during the calculation initialization, only rests to introduce the diesel injection rate. The computational calculations have been carried out taking into account only one sector of the combustion chamber, which contains one injector orifice. Thus, the simulated injection rate by CALMEC code has been rescaled to account only the mass of one orifice. 


\subsubsection{Model set-up and validation}

This section analyzes the influence of different aspects on the velocity and precision of the computational calculations. These aspects are related to the mesh size, reaction mechanism, multi-zone combustion model and blow-by model.

\section{Influence of mesh size}

The initial mesh proposed had a $1.6 \mathrm{~mm}$ cell size, with two adaptive refinement levels and two embedding levels in the spray zone. In order to check if this type of mesh offers a good trade-off between accuracy and computational cost, two additional configurations were evaluated at different engine operating conditions. In particular, the two proposed configurations hold the same base cell size than the inital mesh, but increasing the AMR or the embedding level to 3 .
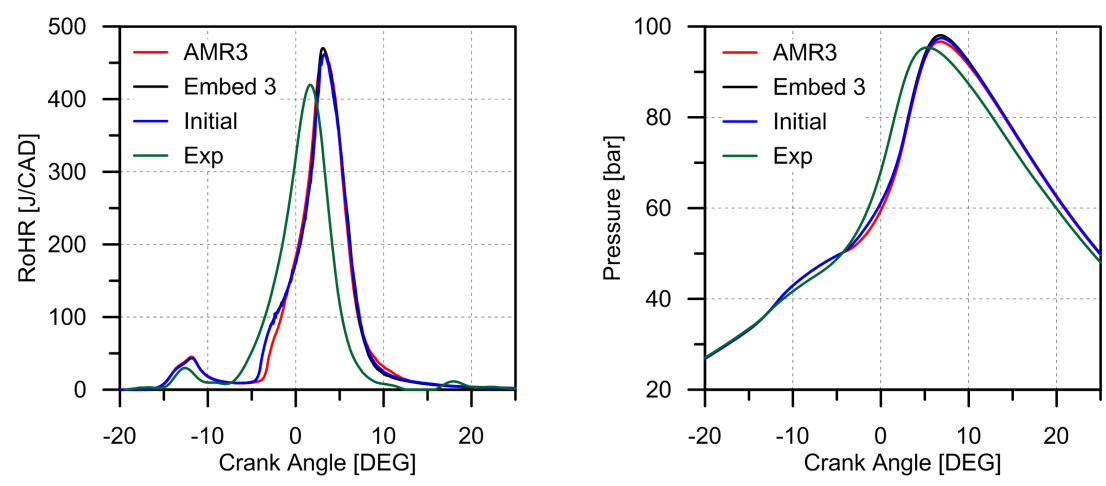

Figure 3.10. Comparison of different grid configurations for a highly premixed case of $25 \%$ load and $1200 \mathrm{rpm}$ (A25 HPC).

Figure 3.10 shows the results obtained for the different mesh configurations at low engine load with a highly premixed injection strategy (A25 HPC). The results denote that the initial mesh proposed gives acceptable accuracy. In addition, the mesh with 3 embedding levels offers very similar results compared to the initial mesh. By contrast, the use of three levels of adaptive refinement (AMR 3) shows notable differences. These differences are mainly explained by the more precise mixing simulation, which results in a slightly higher ignition delay and also a decrease in the maximum in-cylinder pressure.

On the other hand, table 3.8 depicts the calculation time and computer processing units required to carry out the simulations with the different mesh 
configurations proposed. It can be stated that the increase in the accuracy of the results achieved with the two adaptive meshes (AMR 3 and Embedding 3 ) does not justify the computational overrun, mainly in the case of AMR 3. Thus, the initial mesh, with two adaptive refinement levels and embedding has been used to develop the calculations.

Table 3.8. Calculation time and processors required depending on the mesh size.

\begin{tabular}{|c|c|c|c|}
\hline Case & \multicolumn{3}{|c|}{ [hours@processors] } \\
\hline $\mathrm{A} 25 \mathrm{PPC}$ & $16.5 @ 6$ & $45 @ 8$ & $24 @ 8$ \\
\hline A $25 \mathrm{HPC}$ & $18 @ 6$ & $53.5 @ 4$ & $16.4 @ 8$ \\
\hline A50 HPC & $13.5 @ 6$ & $56.5 @ 4$ & $20 @ 8$ \\
\hline A75 HPC & $36 @ 6$ & $76 @ 6$ & $33.5 @ 8$ \\
\hline A75 PPC & $24 @ 6$ & $36 @ 12$ & $27.5 @ 12$ \\
\hline
\end{tabular}

\section{Influence of reaction mechanism}

With the aim of reproducing the RCCI combustion process with a reasonable computational costs, it have been tested two different versions of the oxidation mechanism proposed by Reiz et al. [40].

Figure 3.11 shows an example of the results obtained for the different versions of the oxidation mechanism, under the same operating conditions.
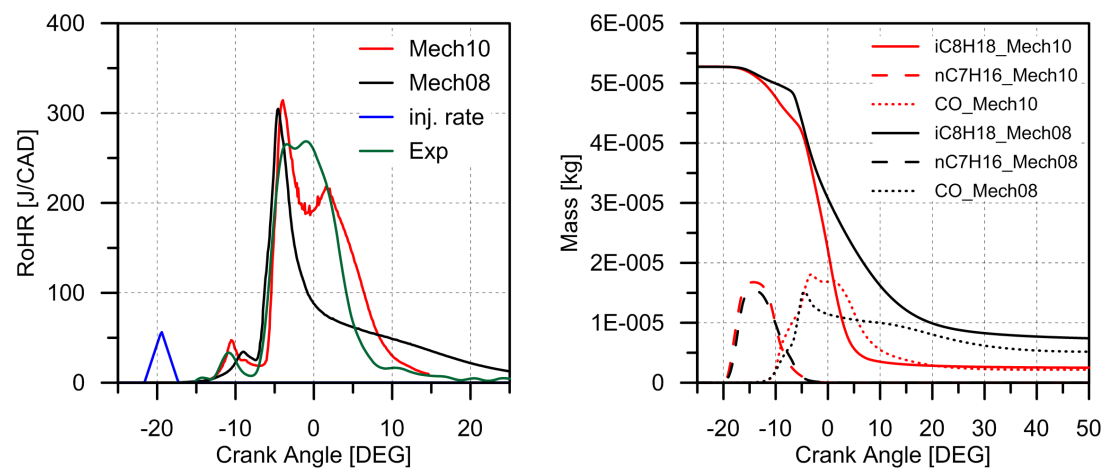

Figure 3.11. Comparison of different reaction mechanisms for a partially premixed case of $25 \%$ load and $1200 \mathrm{rpm}$ (A25 PPC).

As seen from the figure, both reaction mechanisms are able to capture the start of combustion and the first reactions, which imply the initial n-heptane 
oxidation with some minor part of the surrounding iso-octane. Following the evolution of the species, it can be seen that the updated mechanism (Mech10) is capable of reproducing the iso-octane oxidation after the start of combustion. This can be also appreciated in the third peak of the rate of heat release profile. By contrast, the initial mechanism promotes great amount of unburned isooctane, which results in rates of heat release far from the experimental ones.

\section{Influence of multi-zone combustion modeling}

As described previously, the combustion calculation has been performed with a multi-zone model, which relies on grouping cells with similar characteristics in terms of temperature and equivalence ratio, in order to solve them jointly and speed-up the chemistry calculations.

A multi-zone model with a discretization level of $5 \mathrm{~K}$ for temperature and two different discretization levels for equivalence ratio, 0.05 and 0.01 , have been tested under different operating conditions. Figure 3.12 shows the results at medium load conditions with a highly premixed injection strategy.
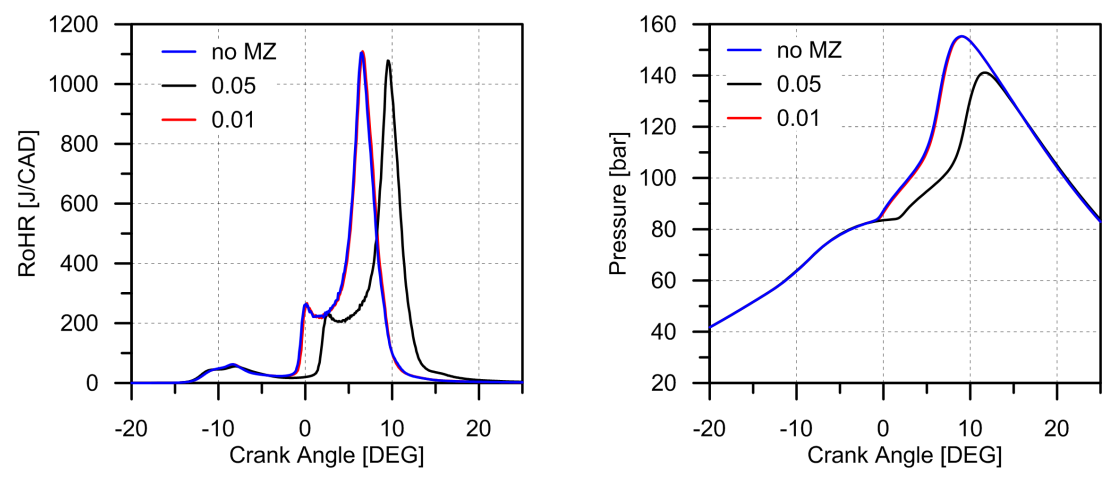

Figure 3.12. Comparison of different discretization levels of the multi-zone model for a highly premixed case of $50 \%$ load and $1200 \mathrm{rpm}$ (A50 HPC).

The results show that a 0.05 discretization in equivalence ratio does not offer an acceptable accuracy in the calculations. In this sense, the low temperature heat release onset is well captured, but the subsequent oxidation of the n-heptane is delayed, promoting a wrong combustion phasing (CA50). With a 0.01 discretization, the model provides better results, showing also a significant improvement in calculation time (13.39 vs 46.81 hours using 6 computer processor units). Thus, it will be applied a multi-zone model with $5 \mathrm{~K}$ bin size for temperature and 0.01 bin size discretization for equivalence ratio. 


\section{Influence of blow-by model}

The use of port fuel injection allows the gasoline to be mixed homogeneously with the air during the compression stroke, but this fact also favors the fuel accumulation in the crevices zones (volume defined between the upper piston ring and liner). Since the blow-by phenomenon can cause the loss of certain quantity of hydrocarbons during the gas leakage towards the oil pan, it arises the necessity of using a proper blow-by model to capture accurately this phenomenon.

In order to evaluate the importance of the blow-by model usage in the computational calculations, a comparison under different operating conditions has been carried out. The results at medium load conditions with a highly premixed injection strategy, with and without using the blow-by model, are represented in figure 3.13 .
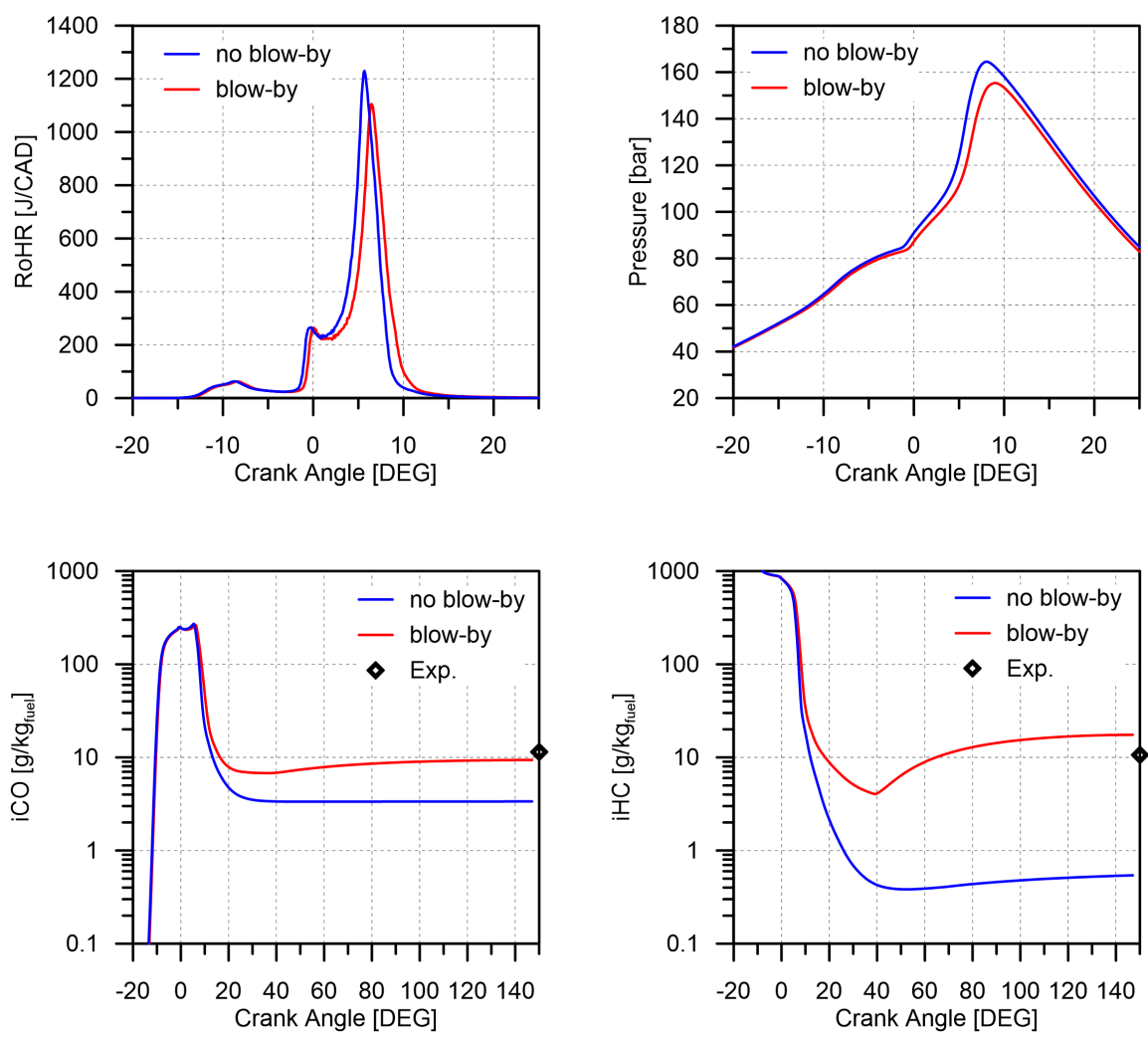

Figure 3.13. Influence of the blow-by model for a highly premixed case of 50\% load and $1200 \mathrm{rpm}(\mathrm{A} 50 \mathrm{HPC})$. 
All the cases show the same trend when using the blow-by model. Regarding combustion process, the in-cylinder pressure becomes slightly reduced and consequently the ignition delay increases. The main effect of the blow-by model is appreciated in $\mathrm{HC}$ and $\mathrm{CO}$ emissions predictions, which are noticeably improved considering the experimental results. In the light of these results it has been considered necessary to include the blow-by model in the calculations.

\subsection{Summary and conclusions}

This chapter has presented the different tools used to develop this Doctoral Thesis. First, the experimental resources have been described, paying special attention on the single-cylinder engine, test cell characteristics and the accuracy of each sensor and measuring equipment. In addition, some considerations about the experimental procedure followed during the engine tests were provided. Later, the two theoretical tools used to analyze the experimental data have been presented. Specifically, the general hypotheses, principles and main parameters obtained with the combustion diagnosis code CALMEC were defined. Finally, the chapter ended by presenting the general features of the CFD tool, the modeling methodology as well as the set-up and validation of the computational code. 


\section{Bibliography}

[1] Turner C.W., Raimao M.A. and Babbitt G.R. "Hydraulic valve actuation systems and methods". US Patent App. 10/164,046, Patent Number 6739293, 2002.

[2] Turner C.W., Babbitt G.R., Balton C.S., Raimao M.A. and Giordano D.D. "Design and Control of a Two-stage Electro-hydraulic Valve Actuation System". SAE Technical Paper, $\mathrm{n}^{o}$ 2004-01-1265, 2004.

[3] Payri F. and Desantes J.M. Motores de combustión interna alternativos. Editorial Reverté, 2011.

[4] Lombard B. and Le Forrestier R. "Advanced combustion and engine integration of a Hydraulic Valve Actuation system (camless)". Proceedings of the SIA Conference on Variable Valve Actuation, 2006.

[5] Albrecht W., Dohle U., Gombert R., Krauss J., Leonhard R. and Wannenwetsch P. "Innovative BOSCH common rail injection system CRSN4.2 for the new generation of Daimler-Chrysler heavy duty diesel-engines". $28^{\text {th }}$ International Vienna Motor Symposium, $200 \%$.

[6] Kastner L.J. "An investigation of the airbox method of measuring the air consumption of internal combustion engines". Proceedings of the Institution of Mechanical Engineers, Vol. $157 \mathrm{n}^{\circ} 1$, pp. 387-404, 1947.

[7] "Measurement of intake air or exhaust gas flow of Diesel engines". SAE Standards J244, 1992.

[8] de Rudder K. An approach to low-temperature combustion in a small HSDI diesel engine. Doctoral Thesis, Universitat Politècnica de València, Departamento de Máquinas y Motores Térmicos, 2007.

[9] Novella R. Estudio de la influencia de los ciclos Atkinson y Miller sobre el proceso de combustión y la formación de emisiones contaminantes en un motor Diesel. Doctoral Thesis, Universitat Politècnica de València, Departamento de Máquinas y Motores Térmicos, 2009.

[10] AVL 733S fuel balance. Technical information available at http://www.avl.com.

[11] Molina S. Estudio de la influencia de los parámetros de inyección y la recirculación de gases de escape sobre el proceso de combustión, las prestaciones y las emisiones de un motor diesel de 1.8 litros de cilindrada. Doctoral Thesis, Universitat Politècnica de València, Departamento de Máquinas y Motores Térmicos, 2003.

[12] Sherman M.T., Chase R., Mauti A., Rauker Z. and Silvis W. "Evaluation of Horiba MEXA 7000 Bag Bench Analyzers for Single Range Operation". SAE Technical Paper, $\mathrm{n}^{\circ}$ 1999-01-0147, 1999.

[13] Sherman M.T., Mauti A., Rauker Z. and Dageforde A. "Evaluation of Mass Flow Controller Gas Divider For Linearizing Emission Analytical Equipment". SAE Technical Paper, no 1999-01-0148, 1999.

[14] Degobert P. Automobiles and pollution. SAE International, 1995.

[15] Silvis W.M. "An Algorithm for Calculating the Air/Fuel Ratio from Exhaust Emissions". SAE Technical Paper, no 2016-04-05, 1997.

[16] "Regulation (EC) No 595/2009 of the European Parliament and of the Council of 18 June 2009 on type-approval of motor vehicles and engines with respect to emissions 
from heavy duty vehicles (Euro VI) and on access to vehicle repair and maintenance information and amending Regulation (EC) No 715/2007 and Directive 2007/46/EC and repealing Directives 80/1269/EEC, 2005/55/EC and 2005/78/EC. Official Journal of the European Union, Vol. 52 no L275, pp. 1-14, 2009". http://eur-lex.europa.eu.

[17] Christian R., Knopf F., Jasmek A. and Schindler W. "A new method for the filter smoke number measurement with improved sensitivity". MTZ Motortechnische Zeitschift, Vol. 54, pp. 16-22, 1993.

[18] Prikhodko V., Curran S., Barone T., Lewis S., Storey J., Cho K., Wagner R. and Parks J. "Emission characteristics of a diesel engine operating with in-cylinder gasoline and diesel fuel blending". Technical report, SAE Technical Paper, 2010.

[19] Benajes J., López J.J. and R. Novella A. García. "Advanced methodology for improving testing efficiency in a single-cylinder research diesel engine". Experimental Techniques, Vol. $32 \mathrm{n}^{\circ}$ 6, pp. 41-47, 2008.

[20] Lapuerta M., Armas O. and Hernández J.J. "Diagnosis of DI Diesel combustion from in-cylinder pressure signal by estimation of mean thermodynamic properties of the gas". Applied Thermal Engineering, Vol. 19 n ${ }^{\circ}$ 5, pp. 513-529, 1999.

[21] Lapuerta M., Ballesteros R. and Agudelo J.R. "Effect of the gas state equation on the thermodynamic diagnostic of diesel combustion". Applied Thermal Engineering, Vol. 26 $\mathrm{n}^{\circ}$ 14-15, pp. 1492-1499, 2006.

[22] Woschni G. "A Universally Applicable Equation for the Instantaneous Heat Transfer Coefficient in the Internal Combustion Engine". SAE Technical Paper, $\mathrm{n}^{\circ}$ 670931, 1967.

[23] Payri F., Margot X., Gil A. and Martín J. "Computational Study of Heat Transfer to the Walls of a DI Diesel Engine". SAE Technical Paper, no 2005-01-0210, 2005.

[24] Degraeuwe B. Contribution to the thermal management of DI Diesel engines. Doctoral Thesis, Universitat Politècnica de València, Departamento de Máquinas y Motores Térmicos, 2007.

[25] Torregrosa A., Olmeda P., Degraeuwe B. and Reyes M. "A concise wall temperature model for DI Diesel engines". Applied Thermal Engineering, Vol. $26 \mathrm{n}^{\circ} 11-12$, pp. 13201327, 2006.

[26] Martín J. Aportación al diagnóstico de la combustión en motores Diesel de inyección directa. Doctoral Thesis, Universitat Politècnica de València, Departamento de Máquinas y Motores Térmicos, 2007.

[27] Converge CFD software. Technical information available at http://www.convergecfd.com.

[28] Senecal P.K., Richards K.J., Pomraning E., Yang T., Dai M.Z., McDavid R.M., Patterson M.A., Hou S. and Shethaji T. "A New Parallel Cut-Cell Cartesian CFD Code for Rapid Grid Generation Applied to In-Cylinder Diesel Engine Simulations". SAE Technical Paper, $\mathrm{n}^{\circ}$ 2007-01-0159, 2007.

[29] Issa R.I., Ahmadi-Befrui B., Beshay K.R. and Gosman A.D. "Solution of the implicitly discretised reacting flow equations by operator-splitting". Journal of Computational Physics, Vol. 93 n $^{\circ}$ 2, pp. 388-410, 1991.

[30] Kokjohn S., Hanson R., Splitter D. and Reitz R.D. "Experiments and Modeling of Dual-Fuel HCCI and PCCI Combustion Using In-Cylinder Fuel Blending". SAE Int. J. Engines, Vol. 2, pp. 24-39, 2009. 
[31] Kokjohn S., Hanson R., Splitter D. and Reitz R.D. "Fuel reactivity controlled compression ignition (RCCI): a pathway to controlled high-efficiency clean combustion". International Journal of Engine Research, Vol. 12 n 3, pp. 209-226, 2011.

[32] Dukowicz J.K. "A particle-fluid numerical model for liquid sprays". Journal of Computational Physics, Vol. $35 \mathrm{n}^{\circ}$ 2, pp. 229-253, 1980.

[33] Reitz R.D. and Beale J.C. "Modeling spray atomization with the KelvinHelmholtz/Rayleigh-Taylor hybrid model". Atomization and Sprays, Vol. $9 \mathrm{n}^{o} 6$, pp. 623-650, 1999.

[34] O'Rourke P.J. "Statistical properties and numerical implementation of a model for droplet dispersion in a turbulent gas". Journal of Computational Physics, Vol. $83 \mathrm{n}^{\circ} 2$, pp. 345-360, 1989.

[35] Amsden A.A., O'Rourke P.J. and Butler T.D. "KIVA-II: A Computer Program for Chemically Reactive Flows with Sprays". Los Alamos National Laboratory Report, Vol. $L A-11560-M S$ no UC-96, May 1989.

[36] O'Rourke P.J. and Amsden A.A. "A Spray/Wall Interaction Submodel for the KIVA-3 Wall Film Model". SAE Technical Paper, $\mathrm{n}^{\circ}$ 2000-01-0271, 2000.

[37] Han Z. and Reitz R.D. "Turbulence Modeling of Internal Combustion Engines Using RNG $k-\epsilon$ Models". Combustion Science and Technology, Vol. 106 n $^{\circ}$ 4-6, pp. 267-295, 1995.

[38] Han Z. and Reitz R.D. "A temperature wall function formulation for variabledensity turbulent flows with application to engine convective heat transfer modeling". International Journal of Heat and Mass Transfer, Vol. $40 \mathrm{n}^{\circ}$ 3, pp. 613-625, 1997.

[39] Babajimopoulos A., Assanis D.N., Flowers D.L., Aceves S.M. and Hessel R.P. "A fully coupled computational fluid dynamics and multi-zone model with detailed chemical kinetics for the simulation of premixed charge compression ignition engines". International Journal of Engine Research, Vol. $6 \mathrm{n}^{\circ}$ 5, pp. 497-512, 2005.

[40] Ra Y. and Reitz R.D. "A reduced chemical kinetic model for IC engine combustion simulations with primary reference fuels". Combustion and Flame, Vol. $155 \mathrm{n}^{\circ} 4$, pp. 713-738, 2008.

[41] Ra Y., Yun J.E. and Reitz R.D. "Numerical simulation of gasoline-fuelled compression ignition combustion with late direct injection". International Journal of Vehicle Design, Vol. $50 \mathrm{n}^{o}$ 1, pp. 3, 2009. 



\section{Chapter 4}

\section{Improving RCCI efficiency at low load by combining engine settings}

\begin{tabular}{|c|c|c|}
\hline \multicolumn{3}{|l|}{ Contents } \\
\hline 4.1 & Introduction $\ldots \ldots \ldots \ldots \ldots \ldots \ldots \ldots \ldots \ldots$ & 104 \\
\hline 4.2 & $\begin{array}{l}\text { Operating conditions and test methodology defini- } \\
\text { tion } \ldots \ldots \ldots \ldots \ldots \ldots \ldots \ldots \ldots \ldots \ldots \ldots\end{array}$ & 104 \\
\hline & 4.2.1 Baseline injection strategy selection $\ldots \ldots \ldots \ldots$ & 105 \\
\hline & $\begin{array}{l}\text { Influence of main injection timing on NOx and soot } \\
\text { emissions } \ldots \ldots \ldots \ldots \ldots \ldots \ldots \ldots \ldots \ldots \ldots \ldots \ldots \ldots \ldots \ldots \ldots \ldots \ldots\end{array}$ & 109 \\
\hline 4.3 & $\begin{array}{l}\text { Strategy 1: Effect of oxygen concentration and } \\
\text { gasoline fraction } \ldots \ldots \ldots \ldots \ldots \ldots \ldots \ldots \ldots\end{array}$ & 112 \\
\hline 4.4 & $\begin{array}{l}\text { Strategy 2: Effect of intake charge temperature } \\
\text { and gasoline fraction } \ldots \ldots \ldots \ldots \ldots \ldots \ldots \ldots\end{array}$ & 117 \\
\hline 4.5 & Comparison of both strategies $\ldots \ldots \ldots \ldots \ldots$ & 122 \\
\hline 4.6 & Summary and conclusions $\ldots \ldots \ldots \ldots \ldots \ldots$ & 125 \\
\hline Bib & liography $\ldots . \ldots \ldots$ & 127 \\
\hline
\end{tabular}




\subsection{Introduction}

As described in chapter 2, the thermal efficiency advantage of RCCI versus conventional diesel combustion (CDC) is consequence of two main factors. First, the capability of achieving shorter and optimally timed combustion than CDC allows maximizing the work extraction from the engine cycle. Second, Kokjohn et al. [1] proved that heat transfer (HT) reduction is the major source of efficiency improvement with RCCI. The reduced HT is explained due to the leaner and more uniform global equivalence ratio than CDC operation, which results in lower local peak gas temperatures [2].

In spite of these characteristics, which confer great benefits to RCCI combustion, literature demonstrates that one of the largest sources of efficiency loss with RCCI is the fuel combustion inefficiency. In this sense, depending on the operating conditions, the in-cylinder equivalence ratio and fuel reactivity stratification existing during combustion can promote under- or over-mixing in-cylinder regions, which results in higher $\mathrm{HC}$ and $\mathrm{CO}$ emissions than $\mathrm{CDC}$ operation. Moreover, experimental and modeling results have confirmed that this source of inefficiency is more evident at low loads $[1,3]$.

Considering previous statements, this chapter explores the influence of different engine settings that could improve the RCCI combustion process, and therefore the thermal efficiency of this combustion concept. In particular, the combined effect of the main parameters governing in-cylinder reactivity, i.e. gasoline fraction, intake temperature and oxygen concentration, has been studied as method to raise RCCI combustion efficiency at low load. The different combinations of settings will be aimed at fulfilling three simultaneous constraints: NOx $<0.4 \mathrm{~g} / \mathrm{kWh}$, soot $<0.01 \mathrm{~g} / \mathrm{kWh}$ and ringing intensity $<5$ $\mathrm{MW} / \mathrm{m}^{2}$, which was established by Dec and Yang [4] as proper upper limit to achieve an acceptable combustion noise and knock-free operation.

\subsection{Operating conditions and test methodology definition}

This section justifies the specific conditions selected to perform the main studies of the current chapter (sections 4.3 and 4.4). Firstly, the injection pattern for diesel fuel (single or double) is selected considering the experimental background. In a second step, the proper injection timing for diesel fuel is defined by means of a specific study. Finally, the test methodology is defined based on these results. 


\subsubsection{Baseline injection strategy selection}

As literature demonstrates, the direct injection parameters such as injection timing and number of injections govern the mixture reactivity stratification, which determines RCCI combustion development and emissions characteristics $[5,6]$. Since achieving EURO VI NOx levels and ultra-low soot emissions is the primary objective of this study, it is important to select a proper injection strategy for the diesel fuel prior to evaluate the influence of other settings on RCCI combustion efficiency.

A previous work developed at CMT-Motores Térmicos, investigated the isolated effect of several engine settings on RCCI performance and emissions using the same SCE platform than in the current study [7]. The most relevant results from the parametric studies performed at low load have been represented in simplified way to highlight the main effects of each variable analyzed. In particular, figure 4.1 shows trade-offs of the regulated gaseous emissions, soot and fuel consumption for tests varying the injection pattern (single or double), main and pilot injection timing, main and pilot injected fuel quantity, gasoline fraction (GF) and diesel injection pressure. The dashed lines across the different subfigures denote the emissions limits established for each pollutant and the fuel consumption target at low load, which was defined based on CDC results using the original engine manufacturer (OEM) settings. Thus, the potential points are located in the region defined under the horizontal restriction-line and at the left of the vertical one. It is interesting to remark that the experiments were conducted at fixed engine speed of 1200 rpm, EGR rate of $45 \%$ and intake temperature of $40^{\circ} \mathrm{C}$.

The experimental results represented in figure 4.1 confirm that this combustion mode has the capability of achieving lower fuel consumption than CDC with near zero NOx and soot emissions. As can be seen, delayed single injection strategies with low GF push NOx emissions far from the limit due to the diesel-like combustion events attained in these cases (triangles-right). By contrast, advanced single injection strategies with high GF allow minimizing NOx emissions, but at the expense of producing very high quantities of $\mathrm{HC}$ and $\mathrm{CO}$ emissions (triangles-left). This fact can be explained due to the over dilution of the diesel injection.

The application of double injection strategies (empty circles) allows a simultaneous improvement in $\mathrm{NOx}, \mathrm{HC}$ and $\mathrm{CO}$ emissions compared to single injection. In addition, slight variations of injection pressure and pilot injection quantity in the points with the best pilot injection timings (-60 to $-40 \mathrm{CAD}$ ATDC) lead to an additional improvement of BSFC, soot, $\mathrm{HC}$ and $\mathrm{CO}$ emissions (filled circles). However, only one test (-60/-15) attains to the NOx 


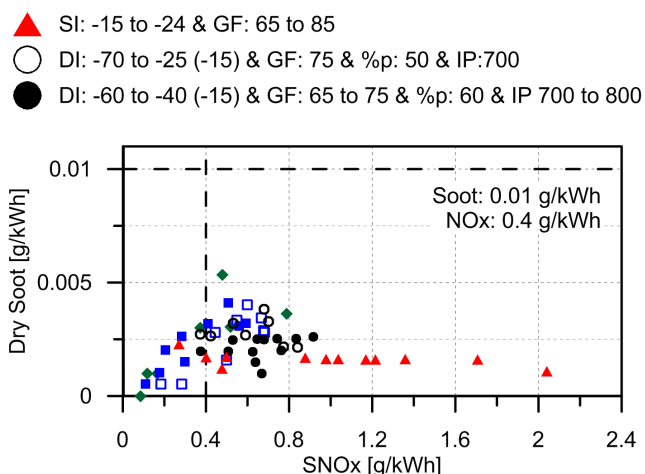

DI: -60 to -40 (-15) \& GF: $75 \& \%$ p: 40 to $60 \% \& I P=700$

DI: -60 to -40 (-15) \& GF: $75 \& \%$ p: 60 to $80 \% \&$ IP $=600$

DI: $(-60)-15$ to $-50 \&$ GF: $75 \& \%$ : $60 \& I P=700$
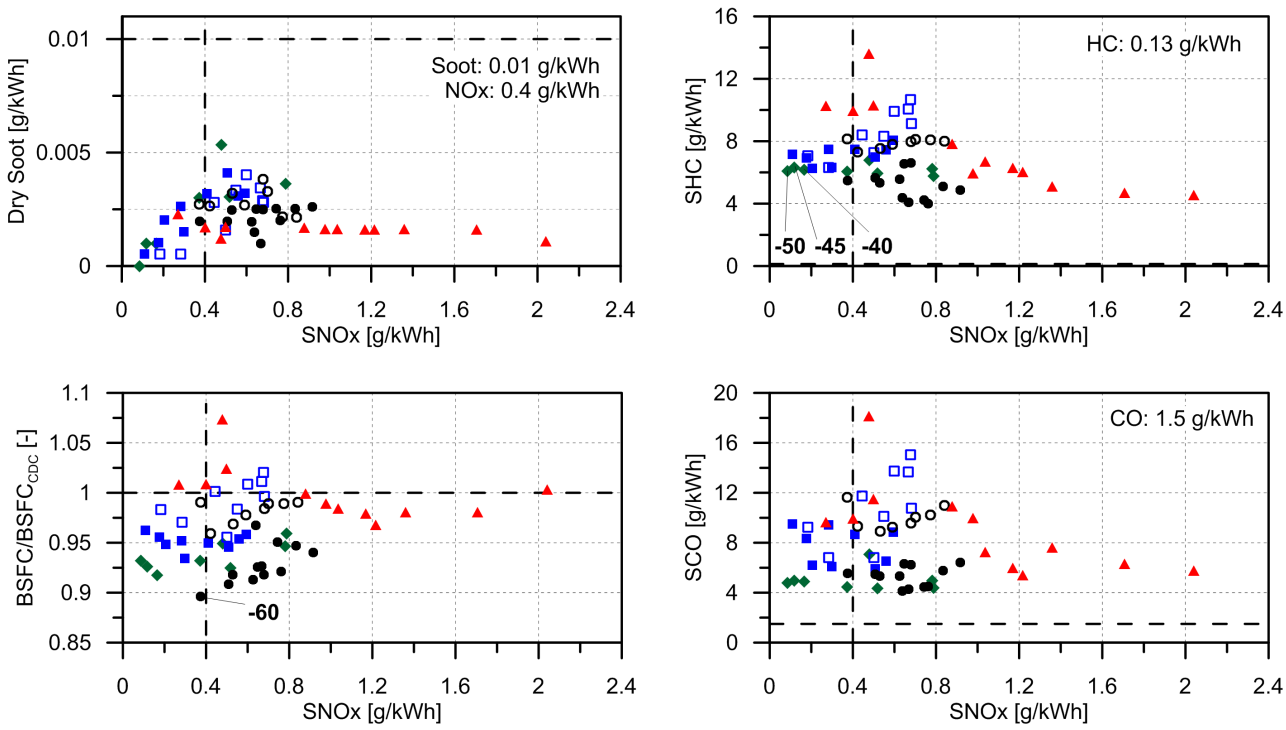

Figure 4.1. Influence of diesel injection pattern (single or double), main and pilot injection timing, main and pilot fuel quantity, gasoline fraction and injection pressure on RCCI performance and emissions at low load. Data from [7].

limitation region. In this sense, the pilot injection quantity reduction does not solve this situation (empty squares). By contrast, more promising results are obtained when increasing the pilot injection quantity while reducing the injection pressure to prevent wall impingement (filled squares). Finally, it is possible to see that advancing the main injection timing up to -50 CAD ATDC while maintaining the pilot injection at -60 CAD ATDC (diamonds), provides considerable amount of tests inside the NOx-soot and NOx-BSFC potential areas with moderated $\mathrm{HC}$ and $\mathrm{CO}$ emissions.

The computational calculations shown in figure 4.2 allow to understand one of the reasons why the double injection strategies contribute to the notable reduction in combustion losses. For this purpose, three cases with equal intake conditions and different diesel injection strategies have been simulated. The injection timing of each case is depicted in the top of the figure, while the timing shown in the bottom side refers to the instant of the cycle represented. The figure shows the diesel fuel injection (in lines) and a radial plane located 
at the crevice region colored by $\mathrm{PRF}$, which has been calculated as stated in equation 4.1 .

$$
P R F=100 \cdot \frac{y I C_{8} H_{18}}{y I C_{8} H_{18}+y N C_{7} H_{16}}
$$

As it can be seen, in the case of single injection with SOI at -24 CAD ATDC, all the diesel fuel remains inside the piston bowl, which makes the combustion propagating towards the center of the cylinder. Since the diesel fuel does not arrive to the outer region of the piston, where great amount of premixed gasoline is located, low fuel reactivity is reached, and therefore high levels of unburned hydrocarbons are emitted. By contrast, the use of a double injection strategy with an early pilot injection allows raising the fuel reactivity in the vicinities of the cylinder liner and top ring land, which enhances the combustion of premixed gasoline. Later, the main injection closer to top dead center (-35 CAD ATDC) increases the reactivity in the center of the cylinder, which generates a relatively high reactivity region to act as an ignition source. As can be seen in the figure, when the main injection is advanced up to -50 CAD ATDC, greater part of diesel fuel reaches the crevices region, which increases much more the fuel reactivity at this zone. Similar conclusions regarding the suitable direct injection strategy for proper RCCI operation were found in $[1,8,9]$.
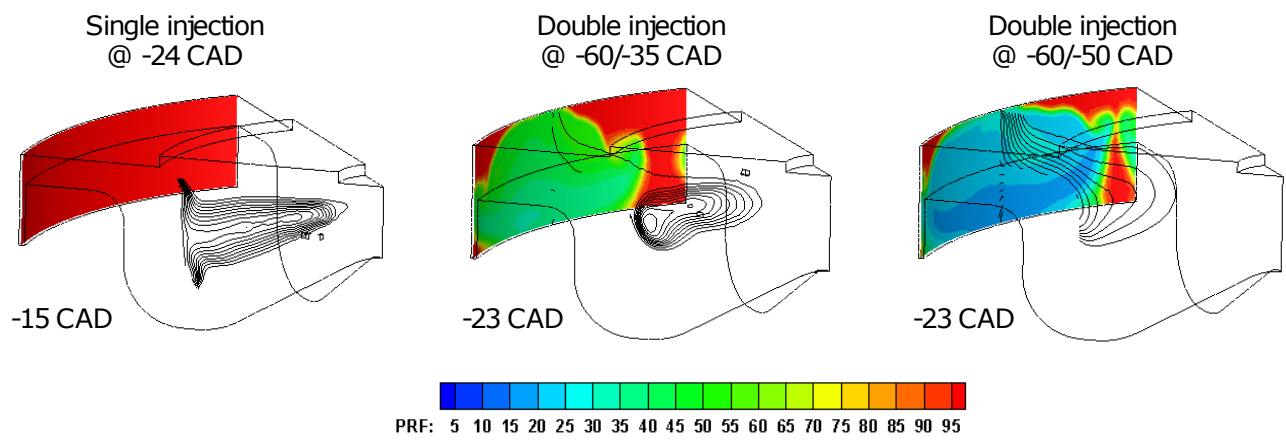

Figure 4.2. Diesel fuel (in lines) and PRF stratification at a radial plane located in the crevice region for three different injection strategies.

To evaluate how the local fuel reactivity affects the burning of the gasoline located at the crevices region, figure 4.3 shows the evolution of the iso-octane mass fraction $\left(y \mathrm{IC}_{8} \mathrm{H}_{18}\right)$ at this particular zone. The vertical dashed lines denote the injection timings for the different injection strategies. The height of the integration volume was defined between the fire deck plane and the upper 
surface of the top piston ring, as illustrated in the radial planes represented in figure 4.2. Thus, the effect of volume variation with crank angle must be taken into account to interpret the results. This effect can be seen during the first crank angle timings shown in the figure, where the monotonic decrease of $y \mathrm{IC}_{8} \mathrm{H}_{18}$ is merely associated to the movement of the piston towards TDC. This is more evident in the single injection case, taking place up to $-20 \mathrm{CAD}$ ATDC.

At around -50 CAD ATDC, in which the piston is still performing the upwards movement towards TDC, an increase in $y \mathrm{IC}_{8} \mathrm{H}_{18}$ profile can be seen for both double injection strategies. This is due to the diesel jet entrainment, which pushes and drags part of the premixed iso-octane located in the center of the cylinder towards the squish and crevice regions. This effect is more striking at $-60 /-50 \mathrm{CAD}$ ATDC because of the proximity of both injection events, which promotes the momentum flux of both injections to interact. In the case of main injection at -35 CAD ATDC, this effect is less pronounced because great part of the second injection pulse is interfered by the piston.

In spite of the greatest $y \mathrm{IC}_{8} \mathrm{H}_{18}$ contained in the integration volume for $-60 /-50$ CAD ATDC, the higher fuel reactivity in this case allows more efficient and rapid iso-octane oxidation than -60/-35 CAD ATDC. This can be confirmed by comparing the falling slope and minimum levels of both profiles. Finally, regarding single injection strategy, a negligible iso-octane oxidation is observed. In this sense, after seen the effect associated to diesel injection at around - $20 \mathrm{CAD}$ ATDC, the $y \mathrm{IC}_{8} \mathrm{H}_{18}$ profile shows a progressive increase as the piston initiates the expansion stroke.

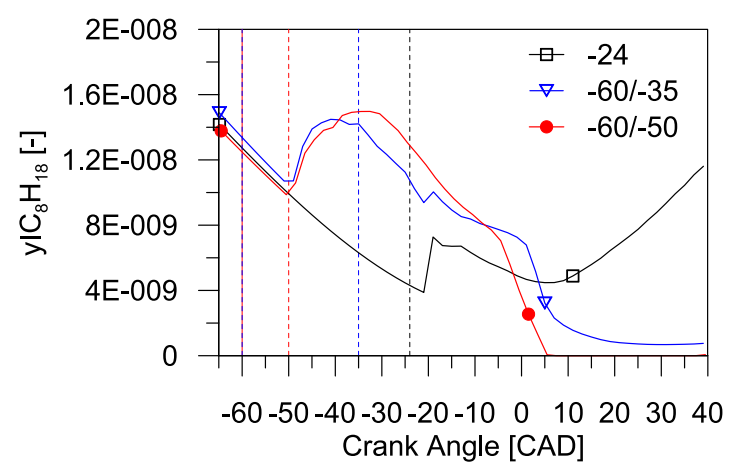

Figure 4.3. Evolution of the iso-octane mass fraction at the crevice region for the three injection strategies studied (-24, -60/-35 and -60/-50 CAD ATDC). 


\subsubsection{Influence of main injection timing on $\mathrm{NOx}$ and soot emissions}

Previous section demonstrated that double injection strategies provide better trade-off between emissions and fuel consumption than single injection. Moreover, it was found that the use of highly advanced injection timings for both injection events offers greater opportunities to operate inside the potential areas defined by the emissions and fuel consumption targets.

The results presented in section 4.2.1 were obtained at fixed EGR rate $(45 \%)$ and intake temperature $\left(40^{\circ} \mathrm{C}\right)$ conditions. However, since these two parameters have great impact on in-cylinder reactivity and engine-out emissions, they will be varied in next sections to evaluate their potential for improving the efficiency of RCCI concept at low load. Thus, first of all it is necessary to confirm that the knowledge acquired in section 4.2 .1 is also valid for a relatively wide range of EGR and intake temperature conditions.

The trade-off between NOx and soot emissions presented in figure 4.1 shows that soot emissions are far below the limit in all tests, while NOx emissions are more sensitive to the different parameters varied. The ultra-low soot emissions are consequence of the low amount of diesel fuel injected, which together with a relatively early injection timing, provides enough mixing time prior to the start of combustion to minimize soot formation. By contrast, the figure shows great amount of tests exceeding the EURO VI NOx limit. So, this pollutant may lead to not fulfilling the constraint imposed under certain conditions.

As described in chapter 2, when using double injection strategies for diesel fuel, the main injection acts as an ignition source, and therefore governs the pollutant emissions formation [10]. For this reason, this section aims at finding a proper main injection timing that provides NOx and soot emissions levels below 0.4 and $0.01 \mathrm{~g} / \mathrm{kWh}$, respectively, under different operating environments. To do so, a main injection timing sweep considering two different operating conditions is proposed. The first case, from now on referred to as baseline condition, has the same engine settings than those used in section 4.2.1 (GF 75\%, EGR $45 \%$ and $\mathrm{T}_{\text {intake }} 40^{\circ} \mathrm{C}$ ). The second case proposes more favorable NOx formation conditions (lower EGR rate and higher intake temperature) to evaluate the acceptable limits of the injection strategy. The improved in-cylinder reactivity in the last case allows increasing the GF, which was demonstrated as suitable strategy to increase RCCI efficiency [11]. Finally, the pilot injection was fixed at $-60 \mathrm{CAD}$ ATDC since that timing provided the best results for all conditions shown in figure 4.1. The engine settings of the two operating conditions investigated are summarized in table 4.1. 
Table 4.1. Engine operating conditions set to evaluate the effect the combined modification of EGR and GF on combustion efficiency.

\begin{tabular}{ll}
\hline \hline Engine speed [rpm] & 1200 \\
Piston Bowl [-] & Open crater \\
Compression ratio [-] & $14.4: 1$ \\
Injector Nozzle & $7 \times 194 \mu \mathrm{m}-142^{\circ}$ \\
EGR [\%] & $45 / 30$ \\
Intake temperature [ $\left.{ }^{\circ} \mathrm{C}\right]$ & $40 / 55$ \\
Diesel pilot inj. timing [CAD ATDC] & -60 \\
Fuel mass in pilot Diesel inj. [\%] & 50 \\
Diesel main inj. timing [CAD ATDC] & -25 to -50 \\
Diesel injection pressure [bar] & 700 \\
Low reactivity fuel inj. timing [CAD ATDC] & 385 \\
Total fuel mass [mg/cycle] & 70 \\
\hline
\end{tabular}

Figure 4.4 shows the regulated gaseous emissions, soot and combustion efficiency [12] (equation 4.2) versus the main injection timing for the two operating conditions studied. In addition, some additional parameters derived from the combustion event CA50, CA90-SOC, ringing intensity (RI) and gross indicated efficiency (GIE) are presented. The dashed lines across the figures denote the emissions limits for the different pollutants.

$$
\text { Comb.Eff. }=1-\frac{H C}{\dot{m}_{f}}-\frac{C O}{4 \cdot \dot{m}_{f}}
$$

For both operating conditions studied, NOx emissions show an increasing trend as main injection timing is delayed. This behavior is related to the increase in combustion temperatures as combustion phasing shifts closer to TDC (see CA50 trend). Thus, the higher combustion temperatures enhance the NO formation reactions, and therefore the engine-out NOx emissions. On the other hand, it is seen that the more reactive ambient promoted by the low EGR and high temperature operating condition (square symbols) results in advanced CA50 and higher in-cylinder temperature in all the range, leading to higher sensitivity of NOx emissions to the injection timing. In this case, only the two most advanced main injection timings are valid to reach the EURO VI NOx limit. Regarding soot emissions, all tests resulted in levels near the minimum detection limit of the AVL 415S Smoke Meter. 
Focusing on $\mathrm{HC}$ and $\mathrm{CO}$ emissions evolution, it is clear that their trend versus main injection is similar in both operating conditions, denoting poor oxidation process as injection timing is delayed. Whereas, opposite effects on $\mathrm{HC}$ and $\mathrm{CO}$ emissions are found when the operating conditions are changed. In particular, $\mathrm{HC}$ emissions increase as $\mathrm{GF}$ increases from $75 \%$ to $85 \%$, while $\mathrm{CO}$ emissions decrease. In this case, the increase in $\mathrm{HC}$ levels is associated to the lower in-cylinder fuel mixture reactivity, which makes more difficult to burn the greater amount of premixed gasoline located in the crevices and squish regions. By contrast, the increase in temperature and intake oxygen concentration at this operating condition, enhances the $\mathrm{CO}$ to $\mathrm{CO}_{2}$ conversion leading to lower $\mathrm{CO}$ levels in all the range tested. Finally, since $\mathrm{HC}$ emissions affects the combustion efficiency four times more than $\mathrm{CO}$ emissions, higher combustion efficiency values are obtained in the case with lower GF.
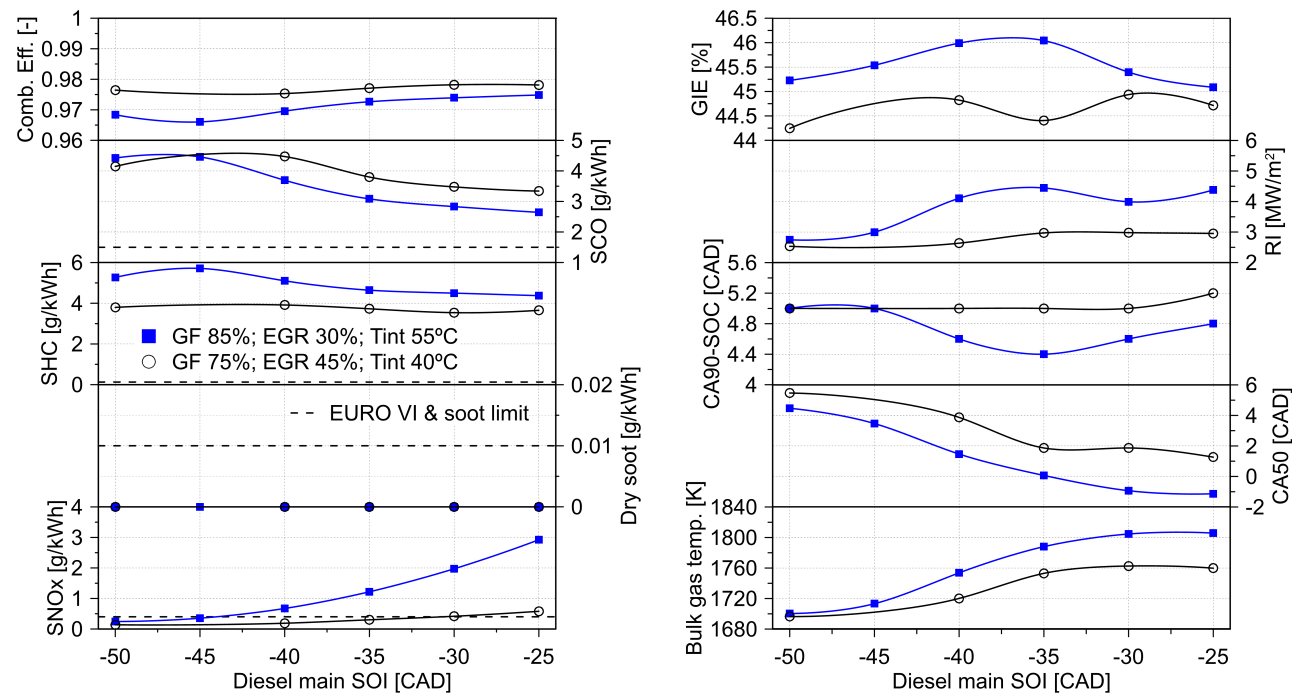

Figure 4.4. Engine-out emissions and combustion parameters as a function of the main injection timing for the two operating conditions studied.

Regarding GIE, it is possible to see that the high GF operating condition shows better results in all the range, with maximum values near $46 \%$ at -40 and -35 CAD ATDC. Comparing GIE values at the potential injection timings ( -45 and -50 CAD TDC) it is confirmed that the operating condition with higher GF allows an improvement of around 1\% versus the baseline condition. Finally, it is seen that RI remains below $5 \mathrm{MW} / \mathrm{m}^{2}$ in all the range tested, even when combustion phasing is closer to TDC. 
In the light of these results, it can be stated that the effect of main injection timing on RCCI combustion development and emissions is greatly conditioned by the three main variables governing in-cylinder reactivity. In this sense, the variation of these parameters for promoting more reactive conditions revealed that only some main injection timings ( -45 and $-50 \mathrm{CAD}$ ATDC) allow achieving NOx values below the EURO VI limit. At these two conditions, combustion efficiency was very similar for both strategies, but 60/-50 CAD ATDC offered greater margin of NOx versus the EURO VI limit. Thus, this injection strategy will be used to carry out the main studies of the present chapter. The analysis of the CA50 trend suggests that, under the range of operating conditions tested, values around +5.5 CAD ATDC are needed to keep ultra-low NOx emissions with acceptable GIE. By this reason, CA50 will be kept constant at this value in the next studies.

\subsection{Strategy 1: Effect of oxygen concentration and gasoline fraction}

The direct injection strategy selected from previous study, -60/-50 CAD ATDC, leads to ultra-low NOx levels with no soot emissions. However, CO and $\mathrm{HC}$ emissions are unacceptable considering the limits stablished by the EURO VI regulation. To enhance the fuel burning, several strategies such as the EGR reduction, intake temperature increase or gasoline fraction decrease can be applied. However, all these methods provoke an advance of combustion phasing, leading to NOx emissions increase.

Alternatively, this section proposes the simultaneous variation of EGR rate and GF as strategy to increase the baseline combustion efficiency. In the range of operating conditions tested in figure 4.4, NOx emissions have shown to be directly related to combustion phasing. Thus, simultaneous variations of EGR and GF will be done to maintain CA50 at $+5.5 \mathrm{CAD}$, which was confirmed as potential value for achieving NOx $<0.4 \mathrm{~g} / \mathrm{kWh}$, soot $<0.01 \mathrm{~g} / \mathrm{kWh}$ and RI $<5 \mathrm{MW} / \mathrm{m}^{2}$ at the same time. The rest of engine settings were held constant as summarized in table 4.2 .

Figure 4.5 shows the regulated gaseous emissions, soot and combustion efficiency as a function of GF. In addition, the values of gross indicated efficiency (GIE), ringing intensity (RI), CA90-SOC and CA50 are also depicted in the figure. The EGR rate used in each case is shown in the upper part of the figure, and the limits imposed for each pollutant are denoted by the horizontal dashed lines. 
Table 4.2. Engine operating conditions set to evaluate the effect of the main injection strategy on NOx and soot emissions.

\begin{tabular}{ll}
\hline \hline Combustion phasing (CA50) [CAD ATDC] & $+5.5 \pm 0.5$ \\
Intake temperature $\left[{ }^{\circ} \mathrm{C}\right]$ & 40 \\
Diesel pilot inj. timing [CAD ATDC] & -60 \\
Fuel mass in pilot Diesel inj. [\%] & 50 \\
Diesel main inj. timing [CAD ATDC] & -50 \\
Diesel injection pressure [bar] & 700 \\
Low reactivity fuel inj. timing [CAD ATDC] & 385 \\
Total fuel mass [mg/cycle] & 70 \\
\hline
\end{tabular}

As can be seen from figure 4.5, in order to keep the CA50 at the desired value, the EGR rate was decreased as GF increased. In this way, the lower fuel reactivity due to the higher amount of gasoline injected is compensated by the more favorable intake charge conditions for autoignition.
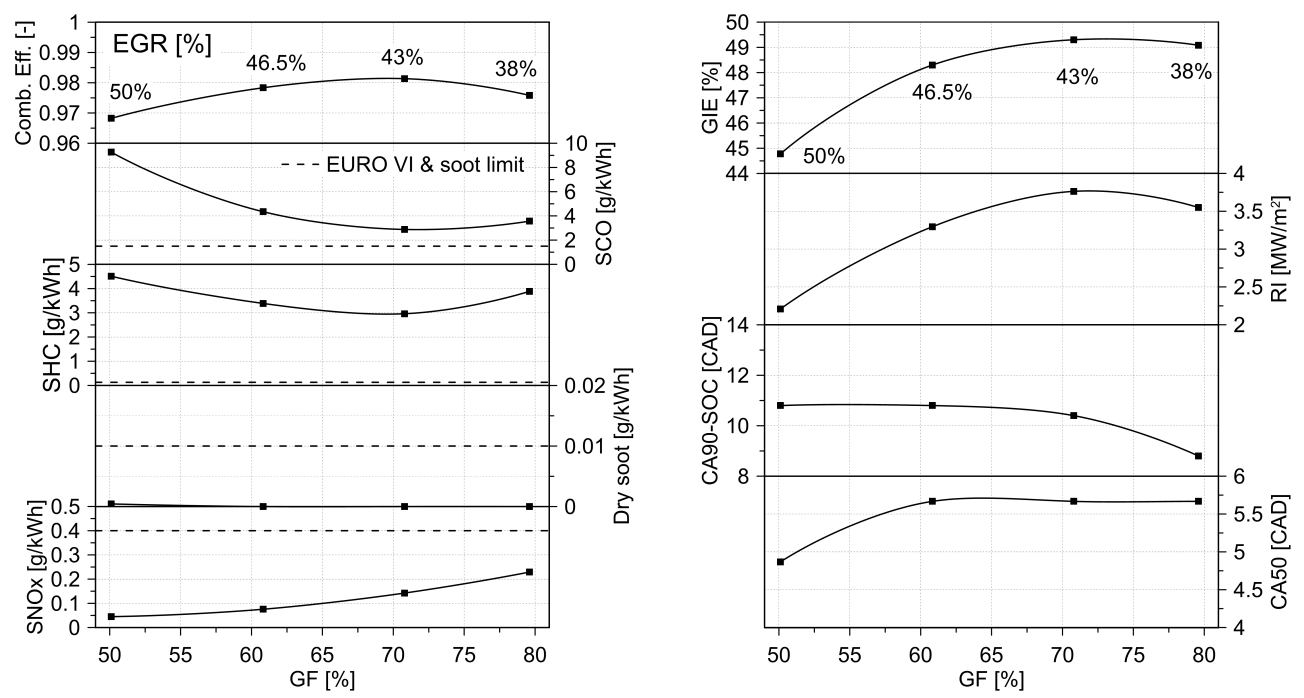

Figure 4.5. Engine-out emissions and combustion parameters as a function of GF. The EGR rate of each case is shown in the upper part of the figure. The dashed lines denote the emissions limits for each pollutant.

Combustion efficiency shows a maximum peak of $98.2 \%$ in the test which combines $43 \%$ of EGR and $70.8 \%$ of GF. This supposes an improvement of 
$1.4 \%$ if compared to the worst case (50\% EGR). Specifically, a reduction of 6.5 $\mathrm{g} / \mathrm{kWh}(\approx 70 \%)$ of $\mathrm{CO}$ and $1.6 \mathrm{~g} / \mathrm{kWh}(\approx 36 \%)$ of $\mathrm{HC}$ emissions is achieved. This suggests that $\mathrm{CO}$ has greater dependence than $\mathrm{HC}$ to the engine settings variation.

The highly premixed strategy used for the diesel fuel leads to soot levels below the minimum detection limit of the smoke meter in all tests. NOx emissions show a growing trend as EGR rate is reduced, but otherwise all the operating conditions proposed are EURO VI compliant. In addition, RI also remains below the target level, which was expected considering the results from previous section.

Gross indicated efficiency (GIE) shows similar trend than combustion efficiency, increasing up to the test of $43 \%$ EGR and then decreasing. In fact, the maximum GIE peak of $49.3 \%$ corresponds to the case with lowest combustion losses. However, the comparison of the tests with maximum and minimum GIE ( $43 \%$ and $50 \%$ EGR) reveals a difference of $4.5 \%$, while the combustion efficiency difference is $1.4 \%$. This suggests substantial differences of heat transfer and exhaust losses between both cases.

To better understand the phenomena governing the combustion efficiency trends observed in figure 4.5, an analysis of the computational results obtained by means of the CFD code is presented next. In particular, the experimental conditions with maximum and minimum combustion efficiency ( $43 \%$ and $50 \%$ EGR) have been simulated and compared. Figure 4.6 presents the temporal evolution of the mole fraction of several key combustion species, as well as the mean temperature and rate of heat release predicted by the computational model. The simulated mass flow rate profile for the direct injected fuel is also depicted in the upper part of the figure.

Comparing both subfigures, it is possible to see that the low temperature reactions trigger the first $n$-heptane consumption at almost the same instant of the cycle in both cases. These low temperature reactions are clearly denoted by the appearance of formaldehyde $\left(\mathrm{CH}_{2} \mathrm{O}\right)$. In addition, a first $\mathrm{OH}$ accumulation is observed, reaching similar values in the two operating conditions. At this moment, the iso-octane molar fraction still remains near its intake valve closing (IVC) concentration for the two operating points. After the first reactions, the thermal ignition of the $\mathrm{n}$-heptane is reached when favorable chemical kinetics are attained. As it can be seen, the n-heptane slope shows more abrupt change in the $43 \%$ EGR condition (left), which explains the faster and higher rate of heat release in this case. The in-cylinder average temperature rise during the thermal ignition of the n-heptane provokes the most noticeable isooctane consumption, which also drives the formaldehyde consumption. In the 

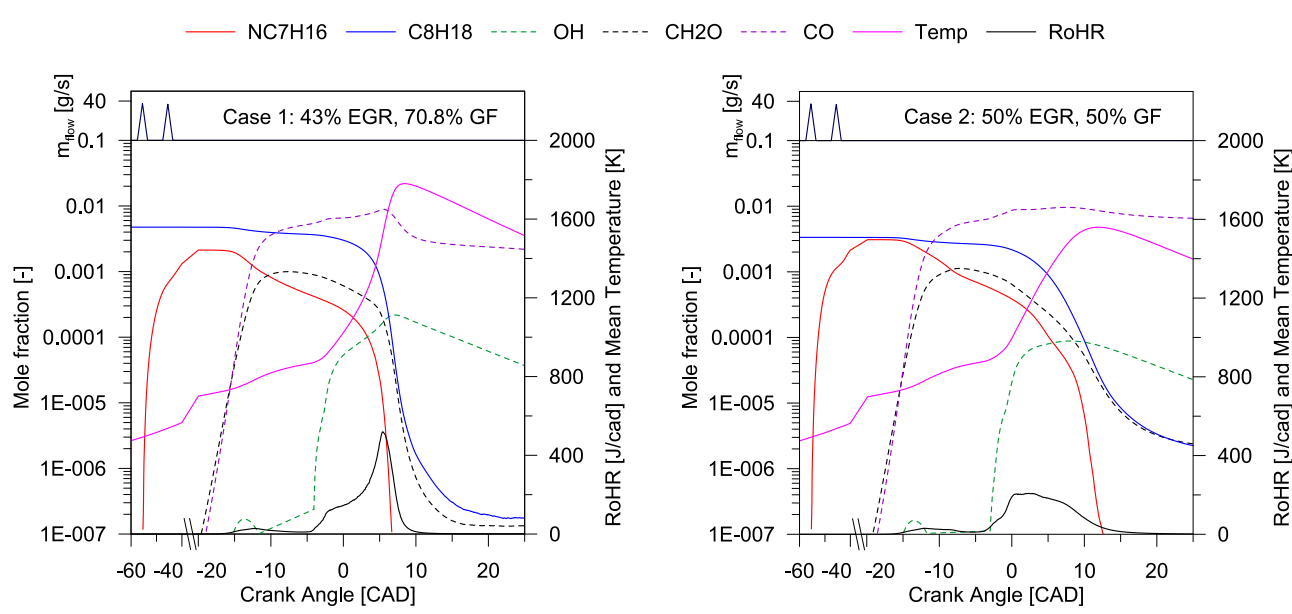

Figure 4.6. Evolution of key combustion species, mean temperature and simulated RoHR for the cases of maximum (left) and minimum (right) combustion efficiency.

case of $50 \%$ EGR, the low in-cylinder temperature slows down the iso-octane oxidation reactions, reaching values an order of magnitude higher than the case of $43 \%$ EGR at the end of the cycle. This fact explains the higher unburned $\mathrm{HC}$ values registered for this condition during the experiments (figure 4.5). Regarding $\mathrm{CO}$ oxidation, which is linked with the $\mathrm{OH}$ consumption, is also clearly enhanced in the case of $43 \%$ EGR. This is confirmed by a noticeable fall in $\mathrm{CO}$ and $\mathrm{OH}$ profiles, while a smooth descent is noted in the case of $50 \%$ EGR. Finally, the improved iso-octane burning in the case of $43 \%$ EGR results in higher mean temperature peak during the combustion event (1742 $\mathrm{K}$ vs $1540 \mathrm{~K}$ ), which explains the NOx emissions trend shown in figure 4.5.

The comparison of the key species evolution between both cases has denoted substantial differences during combustion development, which results in different levels of combustion losses. To better understand the spatial dependencies of these losses, in-cylinder images from the modeling work are presented in figure 4.7 (43\% EGR, 70.8\% GF) and figure 4.8 (50\% EGR, 50\% $\mathrm{GF}$ ). The figures show three cut planes coincident with the spray axis, squish and crevice regions, which are colored by temperature, mass fraction of $\mathrm{CO}$, mass fraction of $n$-heptane and mass fraction of iso-octane.

The temperature plot at the first instant of both figures shows that the region near the cylinder liner has lower temperature than the rest of the cylinder. This is consequence of the n-heptane impact in vapor phase due to the highly advanced injection strategy used (-60/-50 CAD ATDC), as was 


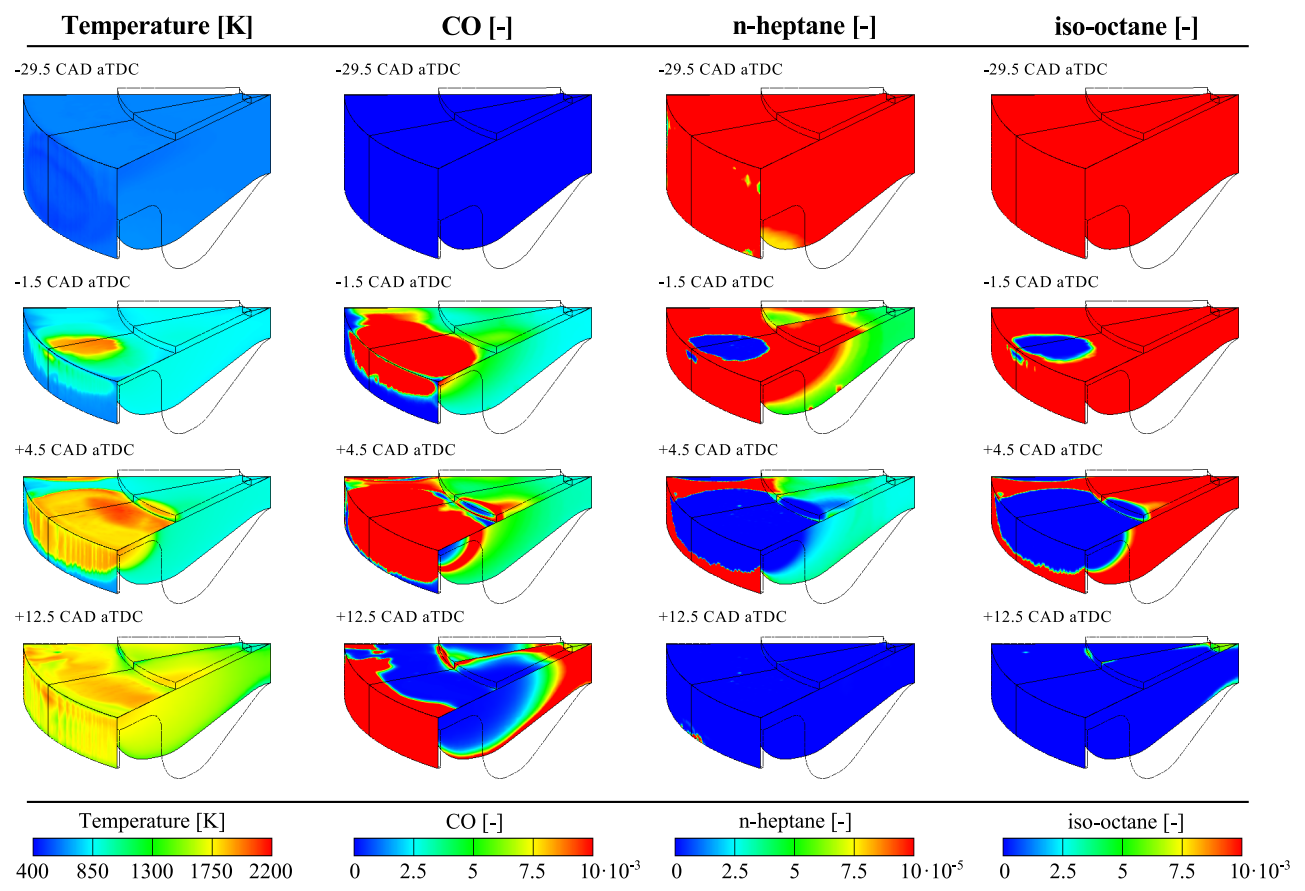

Figure 4.7. Cut planes coincident with the spray axis, squish and crevice regions colored by temperature, CO mass fraction, $n$-heptane mass fraction of and iso-octane mass fraction for the case: $43 \%$ EGR, $70.8 \%$ GF.

illustrated in figure 4.2. During compression, flow tends to move part of the fuel from the crevice zone towards the fire deck and squish regions. Due to the high fuel reactivity, the ignition occurs in the squish zone in both cases, as can be seen in the second instant represented. Then, the charge is sequentially consumed from more-to-less reactive regions, with relatively fast burning in the crevice region and slower progression towards the center of the cylinder, as confirmed by looking at the third and fourth instants shown in the figure.

The major difference between both operating conditions is found during the late cycle evolution. Comparing the last row of images represented in figures 4.7 and 4.8 , it can be noted the greater iso-octane mass fraction around the centerline in the case of $50 \%$ EGR. In this case, the low concentration of n-heptane around the centerline of the cylinder together with the highly EGRdiluted ambient, slow down the combustion progression up to this zone. This fact results in rapid fall in temperature, avoiding the complete $\mathrm{CO}$ oxidation in this region. 


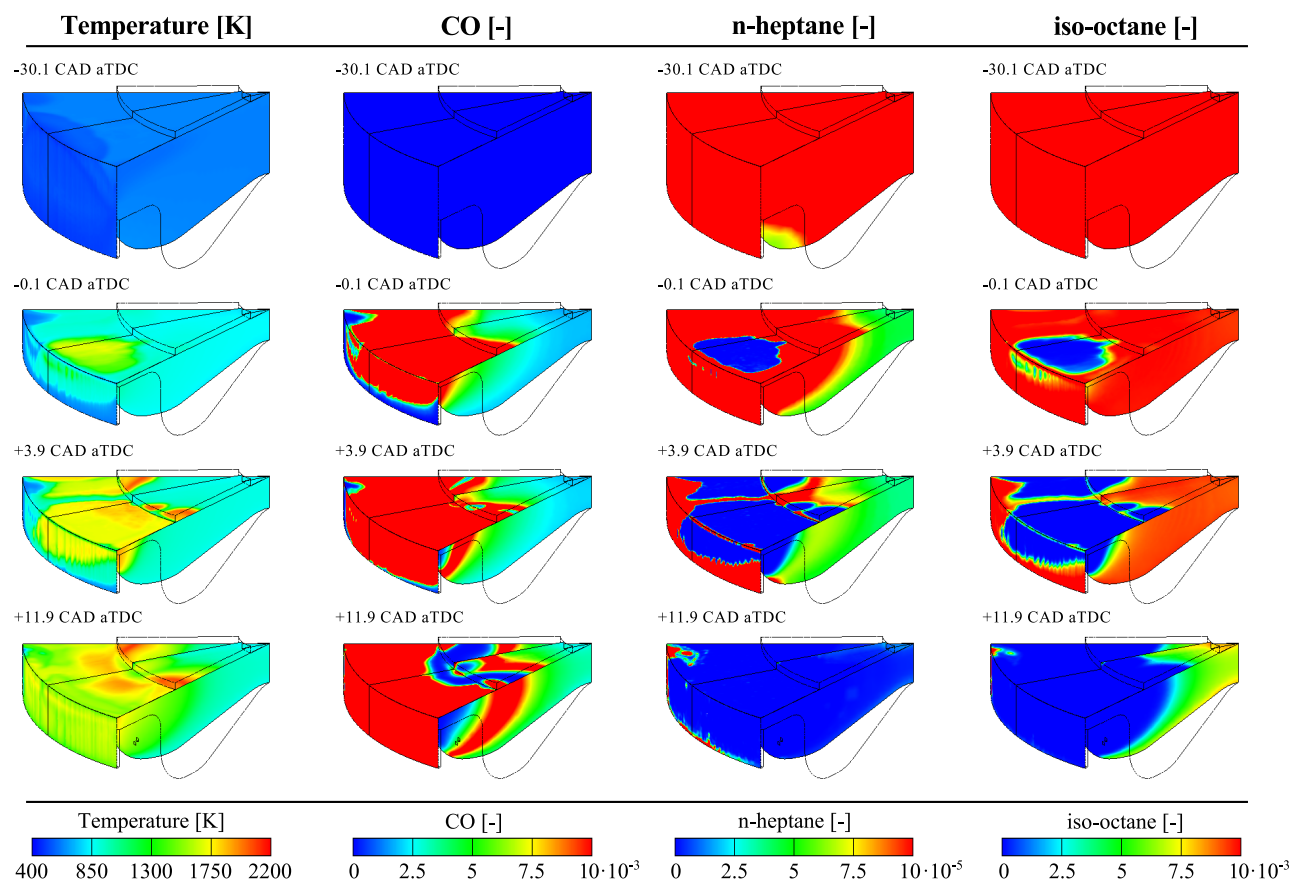

Figure 4.8. Cut planes coincident with the spray axis, squish and crevice regions colored by temperature, mass fraction of $C O$, mass fraction of n-heptane and mass fraction of iso-octane for the case: 50\% EGR, 50\% GF.

\subsection{Strategy 2: Effect of intake charge temperature and gasoline fraction}

As demonstrated in previous section, the slow progression of the combustion towards the center of the cylinder due to the poor n-heptane stratification, leads to a low in-cylinder temperature during the last phase of the combustion. This low temperature promotes high amount of $\mathrm{CO}$ and $\mathrm{HC}$ emissions in the late combustion cycle.

In order to assess the role of in-cylinder temperature in reducing combustion losses, this section proposes simultaneous variations of intake charge temperature and GF to attain the desired combustion phasing. Moreover, the same limit values for NOx, soot and RI than in previous section have been considered. The specific engine operating conditions of this study are shown in table 4.3 , and figure 4.9 presents the experimental results in the same way than figure 4.5. In this case, the intake charge temperature 
corresponding to each operating point is depicted in the upper part of the figure.

Table 4.3. Engine operating conditions set to evaluate the combined effect of temperature and GF modification on combustion efficiency.

\begin{tabular}{ll}
\hline \hline Combustion phasing (CA50) [CAD ATDC] & $+5.5 \pm 0.5$ \\
EGR [\%] & 45 \\
Diesel pilot inj. timing [CAD ATDC] & -60 \\
Fuel mass in pilot Diesel inj. [\%] & 50 \\
Diesel main inj. timing [CAD ATDC] & -50 \\
Diesel injection pressure [bar] & 700 \\
Low reactivity fuel inj. timing [CAD ATDC] & 385 \\
Total fuel mass [mg/cycle] & 70 \\
\hline
\end{tabular}

Figure 4.9 shows that both parameters, GF and intake temperature, can be managed effectively to maintain an almost constant combustion phasing. As noted from the figure, the increase in GF requires an increase of intake temperature to compensate the lower fuel reactivity.
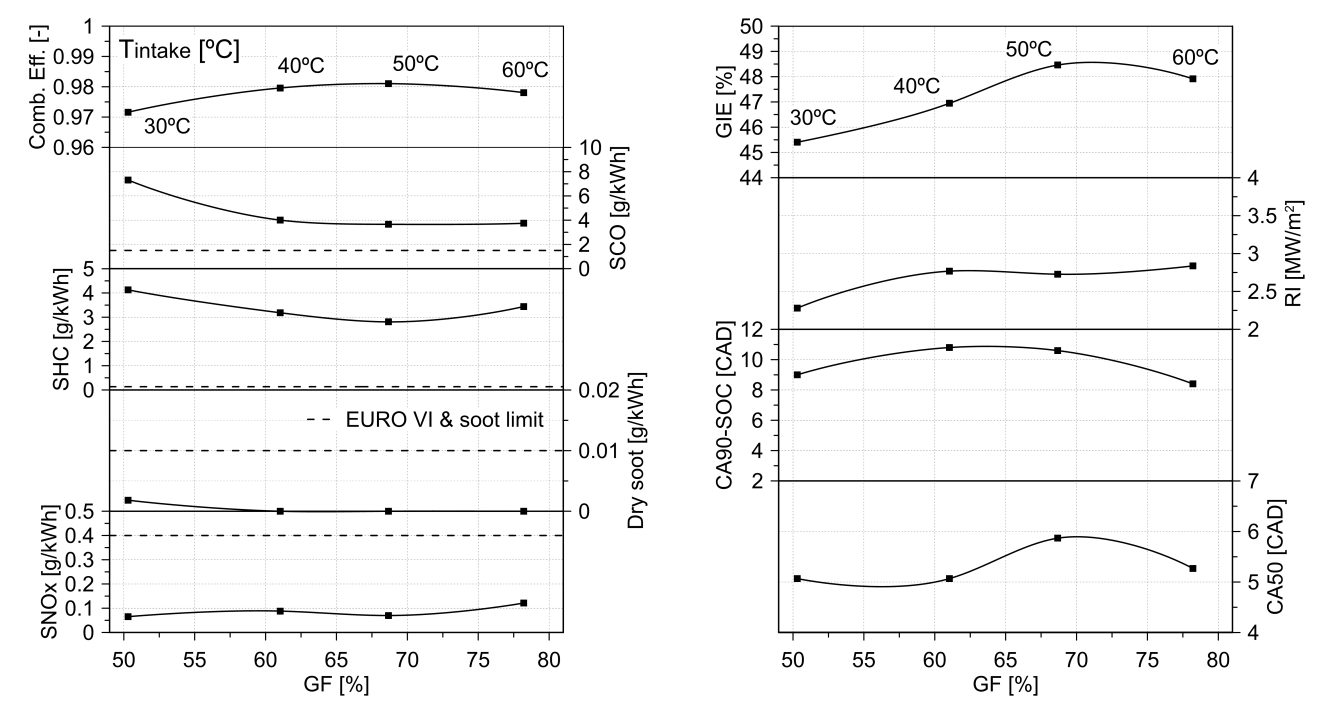

Figure 4.9. Engine-out emissions and combustion parameters as a function of GF. The intake temperature corresponding each case is shown in the upper part of the figure. The dashed lines denote the emissions limits for each pollutant. 
The combustion efficiency profile shows a maximum peak of $98.1 \%$ for the test with $50^{\circ} \mathrm{C}$ of intake temperature and $68.7 \% \mathrm{GF}$. At this point, values of $2.8 \mathrm{~g} / \mathrm{kWh}$ and $3.7 \mathrm{~g} / \mathrm{kWh}$ are seen for unburned $\mathrm{HC}$ and $\mathrm{CO}$ emissions, respectively. The comparison of this point with the one of lowest combustion efficiency $\left(30^{\circ} \mathrm{C}\right)$ denotes a $1 \%$ improvement, which corresponds to a reduction of $3.6 \mathrm{~g} / \mathrm{kWh}(50 \%)$ and $1.3 \mathrm{~g} / \mathrm{kWh}(32 \%)$ in $\mathrm{CO}$ and unburned $\mathrm{HC}$, respectively. The highest reduction is observed for $\mathrm{CO}$ emissions, and it is achieved in the first step of temperature increase. After that intake temperature exceeds $40^{\circ} \mathrm{C}$, the levels of this emission remain almost constant.

As in previous section, all the operating conditions are EURO VI NOx compliant, with higher emission levels as intake temperature rises. Moreover, ultra-low soot levels and reduced RI values were found in all cases.

The gross indicated efficiency (GIE) follows again the combustion efficiency trend. Specifically, a peak of $48.5 \%$ GIE is observed for the test with maximum combustion efficiency $\left(50^{\circ} \mathrm{C}\right)$. This supposes a difference of $3.1 \%$ versus the case of lowest GIE $\left(30^{\circ} \mathrm{C}\right)$. Since the improvement in combustion efficiency is $1 \%$, additional differences in heat transfer and exhaust losses are expected.

The computational analysis of the tests achieving the maximum and minimum combustion efficiency $\left(50^{\circ} \mathrm{C}\right.$ and $\left.30^{\circ} \mathrm{C}\right)$ is presented in figure 4.10 . As in previous section, the temporal evolution of the mole fraction of several key combustion species, mean temperature, diesel injection rate and the rate of heat release predicted by the model are shown.

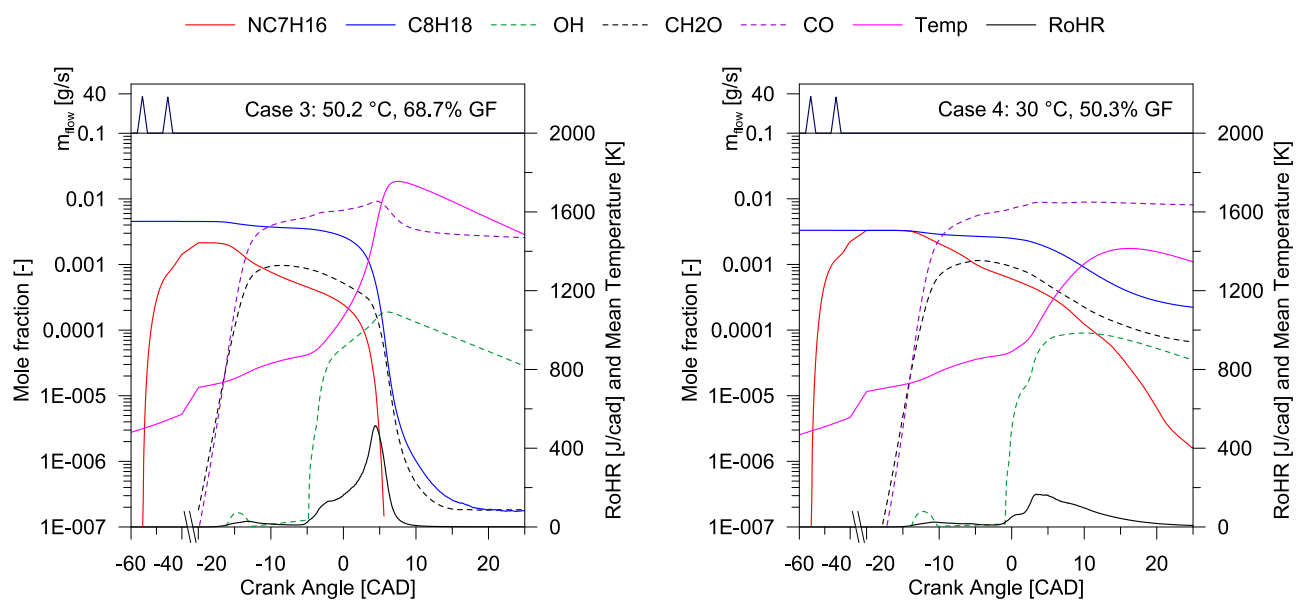

Figure 4.10. Evolution of key combustion species, mean temperature and simulated RoHR for the cases of the maximum (left) and minimum (right) combustion efficiency. 
Comparing the two cases shown in figure 4.10, it is possible to see that the low temperature reactions start earlier in the case of $50^{\circ} \mathrm{C}$, which reveals the great influence of intake temperature on the first $n$-heptane reactions. These reactions are denoted by the first n-heptane consumption as well as the appearance of formaldehyde $\left(\mathrm{CH}_{2} \mathrm{O}\right)$. In particular, the first n-heptane consumption in the case of $30^{\circ} \mathrm{C}$ takes place around -15 CAD ATDC, while in the case of $50^{\circ} \mathrm{C}$ occurs at $-18 \mathrm{CAD}$ ATDC. Note that the starting level of n-heptane mole fraction is different due to the different GF used.

The first $\mathrm{OH}$ accumulation during the LTHR phase reaches similar values in both operating conditions. This suggests similar amounts of n-heptane consumed from the start of combustion up to the thermal ignition of the n-heptane. In detail, $21.3 \%$ and $24 \%$ n-heptane is consumed in this period for the case of $30^{\circ} \mathrm{C}$ and $50^{\circ} \mathrm{C}$ intake temperature, respectively. By contrast, iso-octane remains near its IVC concentration in both cases at this moment.

The thermal ignition of $n$-heptane occurs in both cases when the mean temperature reaches around $1200 \mathrm{~K}$. This combustion phase is identified as a remarkable change in the slope of the n-heptane profile, which is more noticeable in the case of $50^{\circ} \mathrm{C}$. Also of note is that formaldehyde consumption is linked to the iso-octane consumption. In this regard, it is possible to appreciate that iso-octane consumption is slowed down in the case of $30^{\circ} \mathrm{C}$, reaching values various orders of magnitude higher than the case of $50^{\circ} \mathrm{C}$ at the end of the cycle. This fact explains the higher unburned $\mathrm{HC}$ values registered in this case (figure 4.9).

Regarding carbon monoxide, its oxidation is clearly enhanced in the case of $50^{\circ} \mathrm{C}$. Moreover, as described in previous section, $\mathrm{CO}$ oxidation is linked to the $\mathrm{OH}$ consumption, whose evolution in the case of $50^{\circ} \mathrm{C}$ shows a noticeable fall at the time the peak of $\mathrm{CO}$ consumption is observed. By contrast, in the case of $30^{\circ} \mathrm{C}$, a smooth falling of the $\mathrm{OH}$ profile is identified.

As done in the previous study, to explain the spatial dependencies of combustion losses, in-cylinder images from the modeling work are presented in figure $4.11\left(50^{\circ} \mathrm{C}, 68.7 \% \mathrm{GF}\right)$ and figure $4.12\left(30^{\circ} \mathrm{C}, 50.3 \% \mathrm{GF}\right)$. The figures show three cut planes coincident with the spray axis, squish and crevice regions colored by temperature, mass fraction of $\mathrm{CO}$, mass fraction of n-heptane and mass fraction of iso-octane. 


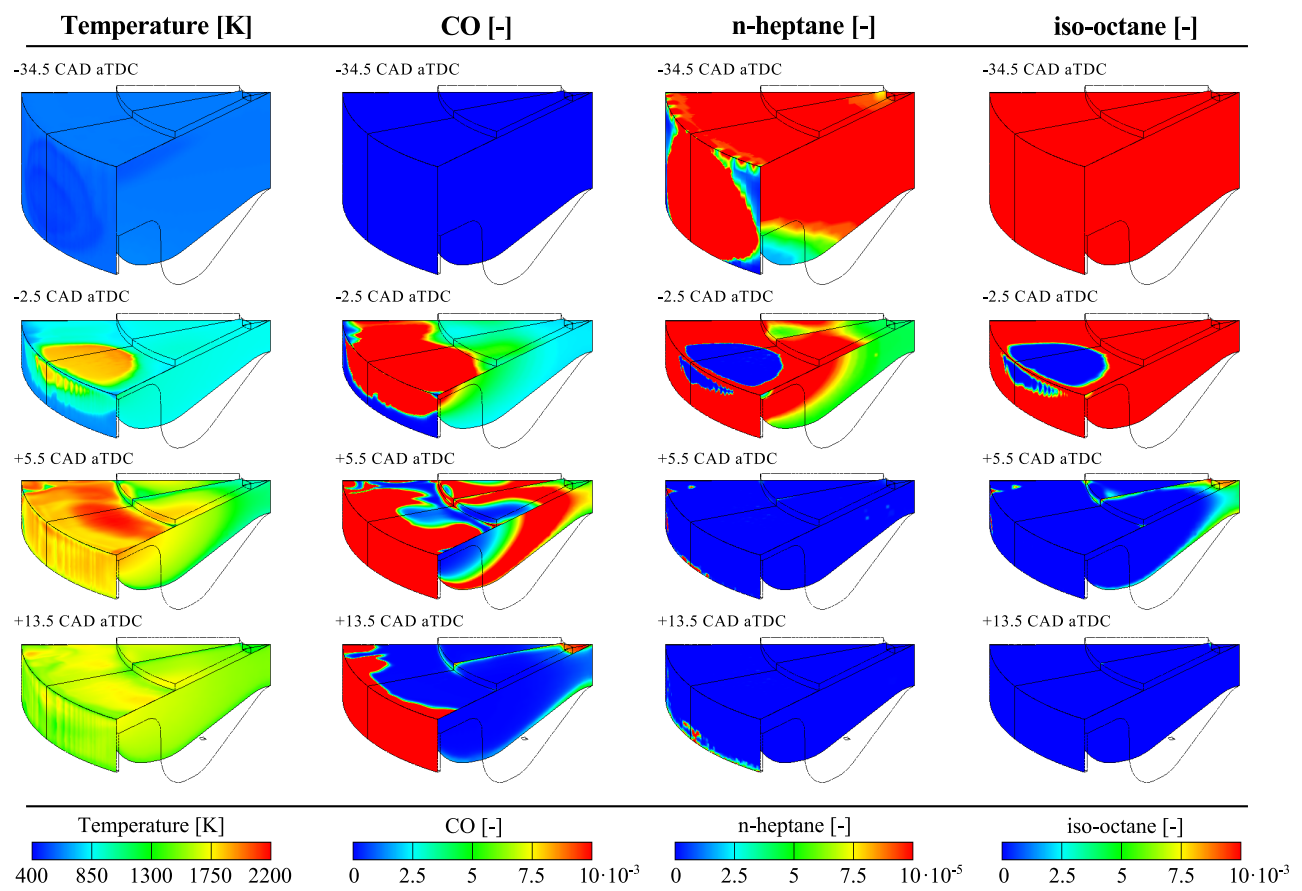

Figure 4.11. Cut planes coincident with the spray axis, squish and crevice regions colored by temperature, mass fraction of CO, mass fraction of $n$-heptane and mass fraction of iso-octane for the case: $50^{\circ} \mathrm{C}, 68.7 \% \mathrm{GF}$.

Considering the n-heptane plot at the second instant in both figures, it is possible to state that the ignition pattern in both cases is equal to the one described in previous section, with the first peak of n-heptane consumption occurring in the squish region. This behavior was demonstrated to be consequence of the highly advanced injection strategy, which promotes high reactivity at this zone due to the air flow movement during compression stroke.

Temporally, the start of combustion (SOC) shows certain differences between both conditions. In the case of $50^{\circ} \mathrm{C}$, the $\mathrm{SOC}$ is found at $-2.5 \mathrm{CAD}$ ATDC, while in the case of $30^{\circ} \mathrm{C}$ it is found at +1.1 CAD ATDC. After that, the charge is sequentially consumed from more-to-less reactive regions. As observed in the comparison performed for the EGR+GF strategy, the more noticeable difference between both operating conditions is the combustion evolution during the late cycle. In the case of $30^{\circ} \mathrm{C}$, a greater mass fraction of unburned n-heptane is located around the centerline region. The unburned n-heptane does not trigger the iso-octane combustion, which contributes to increase $\mathrm{CO}$ and $\mathrm{HC}$ emissions. 


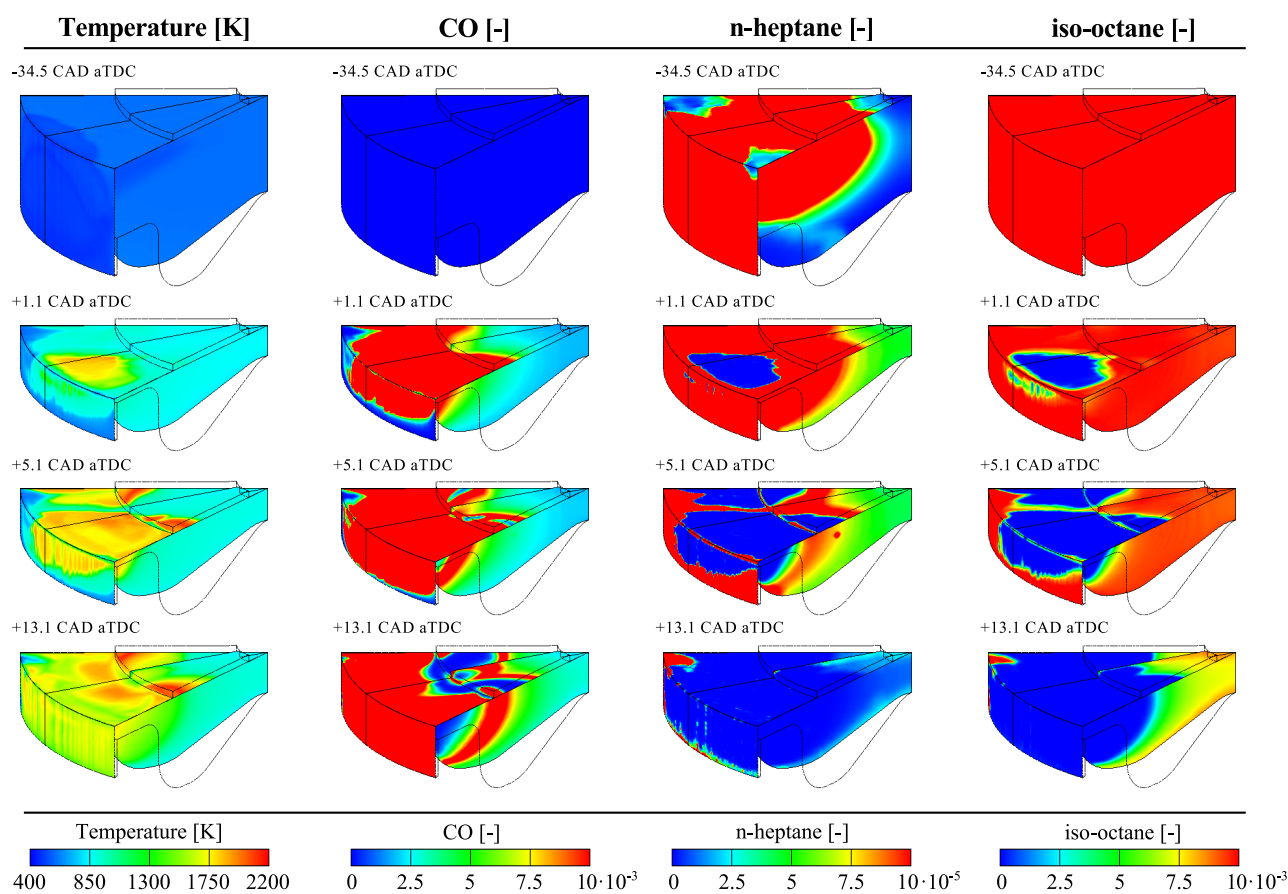

Figure 4.12. Cut planes coincident with the spray axis, squish and crevice regions colored by temperature, mass fraction of CO, mass fraction of $n$-heptane and mass fraction of iso-octane for the case: $30^{\circ} \mathrm{C}, 50.3 \% \mathrm{GF}$.

\subsection{Comparison of both strategies}

Figure 4.13 shows the relationships of GF with intake temperature and with oxygen content to maintain a constant CA50 of +5.5 CAD ATDC. As it can be seen, both strategies show linear response in the range of the operating conditions tested, which is advantageous to be used as an input for a control algorithm for RCCI combustion. This is an important benefit of the dual-fuel RCCI combustion process over a single-fuel HCCI process.

To determine which strategy provides the best global results considering the constraints imposed in the study, a merit function was used [13]. This mathematical function is defined as follows:

$$
M F=\sum_{i} \max \left(0, \frac{x_{i}}{x_{i}^{*}}-1\right)
$$




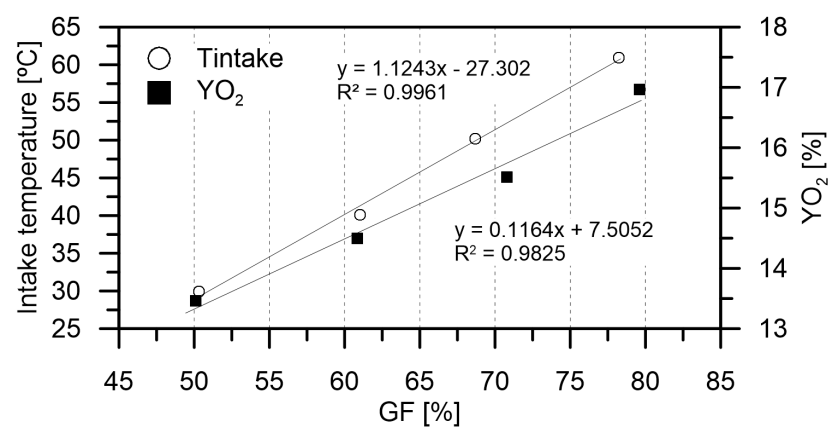

Figure 4.13. Relationships between GF with intake charge temperature and oxygen concentration to maintain constant CA50 at +5.5 CAD ATDC.

where MF is the merit function, $x_{i}$ is the value of the $i^{t h}$ constrained parameter at the given conditions, $x_{i}^{*}$ is the constraint of the $i^{t h}$ parameter and $i$ is the index over all the constraints.

The contribution to the MF from a given variable will be zero if only the measured value is less than or equal to the specified limit. When MF is non-zero, the contribution from each constrained parameter can be examined separately to quantify the severity of its non-compliance. The constraints taken into account in the MF calculation are the EURO VI limits for regulated gaseous emissions ( $\mathrm{NOx}<0.4 \mathrm{~g} / \mathrm{kWh}, \mathrm{CO}<1.5 \mathrm{~g} / \mathrm{kWh}, \mathrm{HC}<0.13 \mathrm{~g} / \mathrm{kWh}$ ), soot $<0.01 \mathrm{~g} / \mathrm{kWh}$, and $\mathrm{RI}<5 \mathrm{MW} / \mathrm{m}^{2}$. Considering that $\mathrm{NOx}$, soot and RI constraints are fulfilled in all tests, the MF trend will be merely defined by $\mathrm{CO}$ and $\mathrm{HC}$ emissions evolution.

Figure 4.14 shows the MF values for the two strategies (EGR+GF and $\mathrm{T}+\mathrm{GF}$ ) as a function of the GF. Note that, for the shake of clarity, the GF values in the $\mathrm{x}$-axis have been rounded (see the actual values in figure 4.13). As can be seen from figure 4.14, independently on the strategy used and GF level, the contribution of $\mathrm{HC}$ emissions to the $\mathrm{MF}$ is higher than that of $\mathrm{CO}$ emissions. This fact reveals the great difficulty of reducing this pollutant up to the EURO VI value by modifying only the engine settings. By contrast, the figure suggests that the operating parameters are able to strongly influence the $\mathrm{CO}$ emissions, which supposes an opportunity of reducing combustion losses. However, since this parameter considers that CO emissions account for the minor energy fraction of the unburned products (note the dividing factor of equation 4.2), no strong influence on combustion efficiency due to $\mathrm{CO}$ emissions reduction is observed. 
Looking at figure 4.14, it is seen that MF trend is equal for both strategies, decreasing up to $\mathrm{GF} \approx 70 \%$ and later increasing. The starting point at $\mathrm{GF} \approx 50 \%$ presents the highest combustion losses. In this case, the low reactive ambient (high EGR and low intake temperature) prevails over the improved fuel reactivity. Later, up to $\mathrm{GF} \approx 70 \%$, the increase of the charge reactivity allows reducing both pollutants in spite of the lower amount of diesel fuel injected. Lastly, it is clear that the raise of $\mathrm{MF}$ with $\mathrm{GF} \approx 80 \%$ is driven by the increase of $\mathrm{HC}$ emissions, while engine-out $\mathrm{CO}$ remains at near same levels than GF $70 \%$ and $60 \%$. In this case, the low fuel reactivity together with the worse diesel fuel stratification deteriorate the combustion progression to all premixed regions, which results in high amount of unburned gasoline even using lower EGR rates or higher intake temperatures. The comparison of both strategies reveals that $\mathrm{T}+\mathrm{GF}$ method provides lower MF values than EGR+GF in all cases.

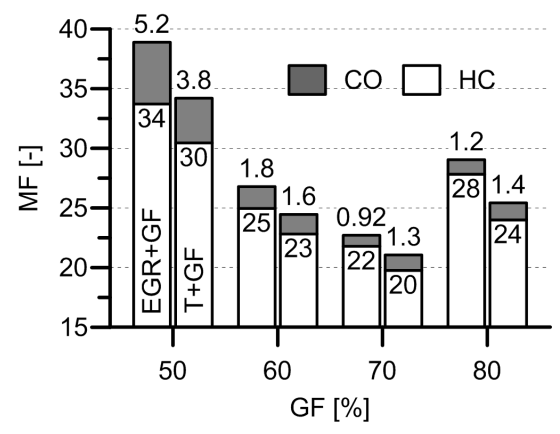

Figure 4.14. Merit function results for both strategies taking into account EURO $V I$ limits for regulated emissions and $R I<5 \mathrm{MW} / \mathrm{m}^{2}$.

Finally, figure 4.15 shows a comparison of the regulated emissions and GIE for CDC operation, the baseline RCCI condition defined from section 4.2.1 (diesel injection timing -60/-50 CAD ATDC, GF 75\%, EGR $45 \%$ and $\mathrm{T}_{\text {intake }}$ $40^{\circ} \mathrm{C}$ ) and the best operating points of both optimization strategies (minimum $\mathrm{MF}$ values). It is worthy to note that all cases, including CDC, resulted in zero soot emissions, so that this pollutant is not presented in the figure.

The results show that all RCCI conditions provide ultra-low NOx with very high $\mathrm{HC}$ and $\mathrm{CO}$ emissions compared to $\mathrm{CDC}$ operation. Moreover, it is demonstrated that the two strategies proposed in this chapter allow reducing these pollutants with respect to the baseline RCCI condition. In particular, EGR+GF strategy provides the lowest $\mathrm{CO}$ emissions and $\mathrm{T}+\mathrm{GF}$ leads to the lowest $\mathrm{HC}$ emissions. In terms of GIE, both strategies show improved efficiency 
than CDC operation, with the greatest increase found for EGR+GF strategy $(+0.9 \%)$.
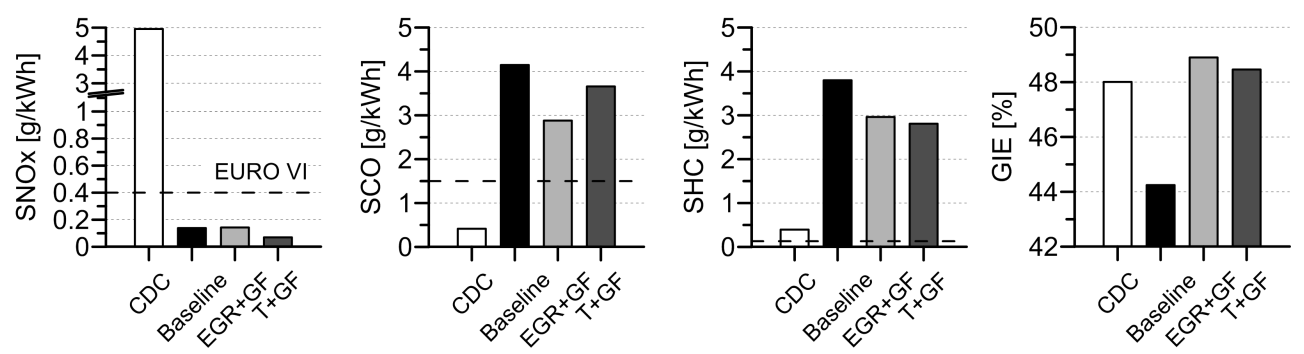

Figure 4.15. Comparison of the regulated emissions and GIE for CDC, baseline RCCI point and the best results for the two optimization strategies studied in this chapter $(E G R+G F$ and $T+G F)$.

\subsection{Summary and conclusions}

This chapter has demonstrated that engine settings combination is an effective method to decrease combustion losses and increase the thermal efficiency of RCCI concept. The results have confirmed that fuel reactivity (PRF and equivalence ratio stratification) and intake charge conditions are key factors for controlling this type of combustion. Also, the ability of RCCI concept to modulate the combustion event has been proved, which exhibited a linear relationship between the intake temperature and EGR rate with GF. To reach these conclusions, three main studies has been addressed along the current chapter.

The first study showed that the use of a highly premixed injection strategy (-60/-50 CAD ATDC) for the high reactivity fuel allows achieving NOx emissions under EURO VI limits, ultra-low soot levels and ringing intensity below the target value. In addition, the CA50 was identified as decisive setting for ensuring low NOx emissions in a relatively wide range of operating conditions (intake temperature, GF and EGR). In this sense, the most promising results were found for CA50 values around +5.5 CAD ATDC.

In the second and third study, the combined effect of the intake temperature and EGR with GF were examined separately by performing different experimental tests at fixed CA50 conditions. Later, the role of each parameter was explained by means of CFD simulations in the tests with the maximum and minimum experimental combustion efficiency. The results 
showed a very similar combustion pattern for both strategies, with the spatial location of the ignition occurring at the squish region. This was consequence of the high reactive region resulted from the early diesel injection together with the air flow movement during compression stroke. Moreover, in both strategies (EGR+GF and $\mathrm{T}+\mathrm{GF})$, the lowest combustion efficiency was identified to be consequence of the great mass fraction of unburned iso-octane located around the centerline. This fact was found to be consequence of the poor n-heptane spatial stratification, which worsens the combustion progression towards this zone of the combustion chamber.

Finally, the direct comparison of the best results of both optimization strategies versus the baseline condition revealed that both methods allow to increase notably the combustion efficiency and GIE. Compared to CDC operation, very high $\mathrm{CO}$ and $\mathrm{HC}$ levels were found. However, both strategies provide NOx emissions under the EURO VI regulation with around 1\% better gross indicated efficiency than CDC. 


\section{Bibliography}

[1] Kokjohn S., Hanson R., Splitter D. and Reitz R.D. "Fuel reactivity controlled compression ignition (RCCI): a pathway to controlled high-efficiency clean combustion". International Journal of Engine Research, Vol. 12 nº 3, pp. 209-226, 2011.

[2] Kokjohn S., Musculus M. and Reitz R.D. "Evaluating temperature and fuel stratification for heat-release rate control in a reactivity-controlled compression-ignition engine using optical diagnostics and chemical kinetics modeling". Combustion and Flame, Vol. $162 \mathrm{n}^{\circ}$ 6, pp. 2729-2742, 2015.

[3] Hanson R., Kokjohn S., Splitter D. and Reitz R.D. "Fuel Effects on Reactivity Controlled Compression Ignition (RCCI) Combustion at Low Load". SAE International Journal of Engines, Vol. $4 \mathrm{n}^{\circ}$ 1, pp. 394-411, 2011.

[4] Dec J.E. and Yang Y. "Boosted HCCI for High Power without Engine Knock and with Ultra-Low NOx Emissions - using Conventional Gasoline”. SAE Int. J. Engines, Vol. 3, pp. 750-767, 2010.

[5] Splitter D., Hanson R., Kokjohn S., Wissink M. and Reitz R.D. "Injection Effects in Low Load RCCI Dual-Fuel Combustion". SAE Technical Paper, no 2011-24-0047, 2011.

[6] Ma S., Zheng Z., Liu H., Zhang Q. and M.Yao. "Experimental investigation of the effects of diesel injection strategy on gasoline/diesel dual-fuel combustion". Applied Energy, Vol. 109, pp. 202-212, 2013.

[7] Belarte E. Estudio del proceso de combustión premezclada controlada por la reactividad del combustible en un motor de encendido por compresión. Doctoral Thesis, Universitat Politècnica de València, Departamento de Máquinas y Motores Térmicos, 2015.

[8] Hanson R., Kokjohn S., Splitter D. and Reitz R.D. "An Experimental Investigation of Fuel Reactivity Controlled PCCI Combustion in a Heavy-Duty Engine". SAE Int. J. Engines, Vol. 3, pp. 700-716, 2010.

[9] Kokjohn S.L. and Reitz R.D. "A modeling study of charge preparation in an HCCI engine using a variable pressure pulse (VPP) injection system and optimized PRF Blends". The $11^{\text {th }}$ International Conference on Liquid Atomization and Spray Systems, Vail, Colorado, July $30^{\text {th }}, 2009$.

[10] Leermakers C.A., Somers L.M. and Johansson B. "Combustion Phasing Controllability with Dual Fuel Injection Timings". SAE Technical Paper, no 2012-01-1575, 2012.

[11] Curran S., Prikhodko V., Cho K., Sluder C.S., Parks J., Wagner R., Kokjohn S. and Reitz R.D. "In-Cylinder Fuel Blending of Gasoline/Diesel for Improved Efficiency and Lowest Possible Emissions on a Multi-Cylinder Light-Duty Diesel Engine". SAE Technical Paper, n ${ }^{\circ}$ 2010-01-2206, 2010.

[12] Agarwal A.K., Pandey A., Gupta A.K., Aggarwal S.K. and Kushari A. Novel Combustion Concepts for Sustainable Energy Development. Springer, p.122, 2014.

[13] Cheng A.S. (Ed), Upatnieks A. and Mueller C.J. "Investigation of Fuel Effects on Dilute, Mixing-Controlled Combustion in an Optical Direct-Injection Diesel Engine". Energy \& Fuels, Vol. 21 n $^{\circ}$ 4, pp. 1989-2002, 2007. 



\section{Chapter 5}

\section{Piston bowl geometry effects on RCCI combustion}

\section{Contents}

$5.1 \quad$ Introduction $\ldots \ldots \ldots \ldots \ldots \ldots \ldots \ldots \ldots \ldots \ldots, 130$

5.2 Sources of heat transfer losses in RCCI combustion 131

5.3 Piston bowl geometries definition .......... 135

5.3.1 Approaches in piston design to reduce heat transfer 135

5.3.1.1 Thermal barrier coatings $\ldots \ldots \ldots \ldots .136$

5.3.1.2 Piston geometry modification ......... 138

5.3.2 Description of the piston bowl geometries studied . 141

5.4 Effect of piston bowl geometry at low load ..... 144

5.4.1 Experimental results .................... 144

5.4.2 Understanding the differences between geometries . 151

5.4.2.1 Heat transfer analysis ............... 152

5.4.2.2 Combustion losses ............... 155

5.4.2.3 Efficiency .................... 156

5.5 Evaluation of the suitable geometry for extended load operation $\ldots \ldots \ldots \ldots \ldots \ldots \ldots \ldots \ldots .157$

5.5 .1 Medium load results...................... 157

5.5.2 High load results ..................... 162

5.6 Piston bowl geometry selection ........... 168

5.7 Summary and conclusions $\ldots \ldots \ldots \ldots \ldots \ldots \ldots, 170$

Bibliography $\ldots \ldots \ldots \ldots \ldots \ldots \ldots \ldots \ldots \ldots \ldots, 172$ 


\subsection{Introduction}

Traditionally, the work output of an internal combustion engine has been divided into three outgoing energy flows; work, exhaust enthalpy and heat transfer, being the largest and most significant contribution from the heat transfer (HT) process experienced during the combustion and expansion events [1]. From figure 5.1, which shows the typical energy flow path experienced in compression ignition engines operating under conventional diesel combustion (CDC), it can be inferred that the most interesting research areas for increased engine efficiency are engine heat transfer and exhaust losses, as they are dominant in the global energy balance.

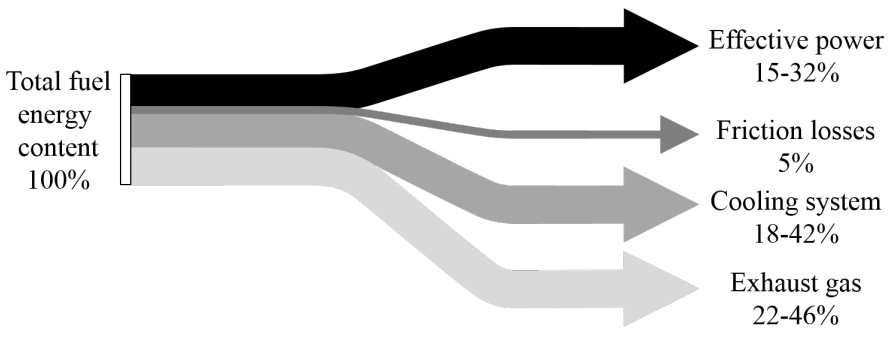

Figure 5.1. Typical energy flow path experienced in compression ignition engines working under conventional diesel operation.

As illustrated in the figure, around one-third of the input energy is converted into mechanical work, around one-third is lost as heat in the exhaust gas, and around one-third is lost as heat to the cooling system through mechanical friction and heat transfer losses within the engine. Approximately half of the latter (which equates to between $15 \%$ and $20 \%$ of the fuel input energy) is lost to in-cylinder heat transfer, i.e. heat transfer from the hot gas to the combustion chamber surface area. If this heat loss could be reduced and utilized either directly as piston work, or via increased exhaust gas enthalpies in a bottoming cycle [2], the fuel to work conversion efficiency of compression ignition engines would improve.

These prospects of improving the engine performance have generated impetus to active research on adiabatic, or more appropriately, low heat rejection (LHR) engines [3]. Thus, although total avoiding of heat transfer during heat to work conversion process will be in violation of the second law of thermodynamics [4], according to the first law, it should be possible to obtain a reduction in the heat losses in order to increase the engine efficiency further. 
In this sense, Kokjohn et al. [5] used detailed CFD modelling to compare the potential of RCCI and CDC concepts for increasing engine efficiency when reducing HT losses. For this purpose, the study considered an ideal adiabatic operation at 9 bar IMEP in both cases. The results showed that, since the HT is eliminated, the apparent heat release rate (AHRR) peak for the RCCI case increases significantly, together with much more rapid end of combustion associated to the elimination of cool regions near the cylinder liner. However, since the rate of heat release for CDC is controlled by transport, the combustion rate for the conventional diesel case was found to be relatively insensitive to the elimination of HT. The main results from that work are summarized in table 5.1.

Table 5.1. Energy balance for RCCI and conventional diesel combustion with and without heat transfer [5].

\begin{tabular}{lcccc} 
& \multicolumn{2}{c}{ RCCI } & \multicolumn{2}{c}{ CDC } \\
& With HT & Adiabatic & With HT & Adiabatic \\
\hline Gross indicated efficiency [\%] & 54.3 & 61.9 & 47.6 & 56 \\
Combustion losses [\%] & 1.3 & 0.0 & 0.3 & 0.3 \\
HT [\%] & 10.9 & 0.0 & 19.1 & 0.0 \\
Exhaust energy [\%] & 33.4 & 38.1 & 33.0 & 43.7 \\
\hline
\end{tabular}

The results shown in the table state that, under adiabatic operation, the gross indicated efficiency (GIE) of each combustion mode increases by approximately 8 per cent of the fuel energy. In spite of the similarity of this value, it is worthy to recall that the percentage of removed HT from RCCI is almost half than that of CDC ( $10.9 \%$ vs $19.1 \%)$, because of the lower HT of RCCI in the baseline condition. Thus, the relative gain in GIE with respect to removed HT in the case of RCCI is around $70 \%$, while for CDC is near $44 \%$. In the last case, reducing in-cylinder heat loss tends to increase exhaust energy more than piston work. Specifically, the 19.1\% removed HT resulted in $8.4 \%$ increase in GIE and $10.7 \%$ increase in exhaust energy.

\subsection{Sources of heat transfer losses in RCCI combus- tion}

As identified in the introduction section, heat transfer reduction offers great potential for increasing the efficiency of RCCI concept. Thus, with the 
aim of understanding the main sources of HT losses in this combustion mode, three operating conditions corresponding to low, medium and high load have been studied by means of the computational code described in chapter 3 . The different engine settings used for running the simulations, which were selected as representative conditions based on the previous experimental background, are summarized in table 5.2.

Table 5.2. Detail of the engine settings used for the parametric studies at medium load.

\begin{tabular}{lccc}
\hline \hline Engine load [-] & Low & Medium & High \\
IMEP [bar] & 8.4 & 14.2 & 19.8 \\
\hline \multicolumn{4}{c}{ Constant engine settings } \\
\hline Speed [rpm] & 1200 & 1200 & 1200 \\
Air mass flow [kg/h] & 53.3 & 86 & 118 \\
Effective CR [-] & $14.4: 1$ & $11: 1$ & $11: 1$ \\
Intake pressure [bar] & 1.35 & 2.96 & 3.4 \\
Intake temperature [ $\left.{ }^{\circ} \mathrm{C}\right]$ & 40 & 40 & 32 \\
YO ${ }_{2}$ at IVC [\%] & 15.1 & 15.1 & 16.3 \\
\hline \multicolumn{4}{c}{ Injection settings } \\
Diesel IP [bar] & 700 & 800 & 1890 \\
Gasoline IP [bar] & 5.5 & 5.5 & 5.5 \\
Total fuel mass [mg/cycle] & 70 & 119 & 175 \\
Gasoline fraction [\%] & 75 & 80 & 70 \\
Diesel SOI [CAD ATDC] & $-60 /-35$ & $-60 /-40$ & -6 \\
Diesel ratio [\% pilot/\%main] & $60 / 40$ & $70 / 30$ & $0 / 100$ \\
\hline
\end{tabular}

From the data depicted in the table, it is interesting to remark that, in order to prevent excessive pressure rise rate peaks and preserve the engine mechanical integrity during the experimental tests at medium and high load, the effective compression ratio was lowered from the nominal value (14.4:1) to 11:1 by means of advancing the intake valves closing event (early Miller cycle). With the same purpose, at high load, it was necessary to establish single injection patterns instead of double ones as well as reducing the intake charge temperature. In addition, the intake oxygen concentration was increased (via EGR reduction) to prevent excessive rise in soot emissions at this load. As can be seen, the highest rate of gasoline fraction (GF) was reached at medium load. At low load, greater diesel amount was necessary for increasing the mixture 
reactivity, while at high load a reduction in GF was needed due to increased knocking tendency. Finally, the injection pressure at low and medium load was maintained relatively low to prevent wall impingement, while at high load it was increased to more than double to be able to inject the greater amount of diesel fuel needed in a reasonable period of time.

In order to assess the spatial dependences of HT losses during combustion progression, the figure 5.2 shows a comparison of the temperature distribution at the three operating conditions described above. For this purpose, a cut plane coincident with the spray axis and an iso-surface of temperature are represented. In particular, $\mathrm{T}=1500 \mathrm{~K}$ was selected as representative value of the high temperature regions in the chamber. In addition, the value of the HT coefficient together with the instant of the engine cycle represented are depicted in each subfigure. In this regard, it is interesting to note that the higher values of HT coefficient at high load compared to the other cases are related to the momentum flux introduced by the diesel injection near TDC, which results in very high velocities inside the combustion chamber.

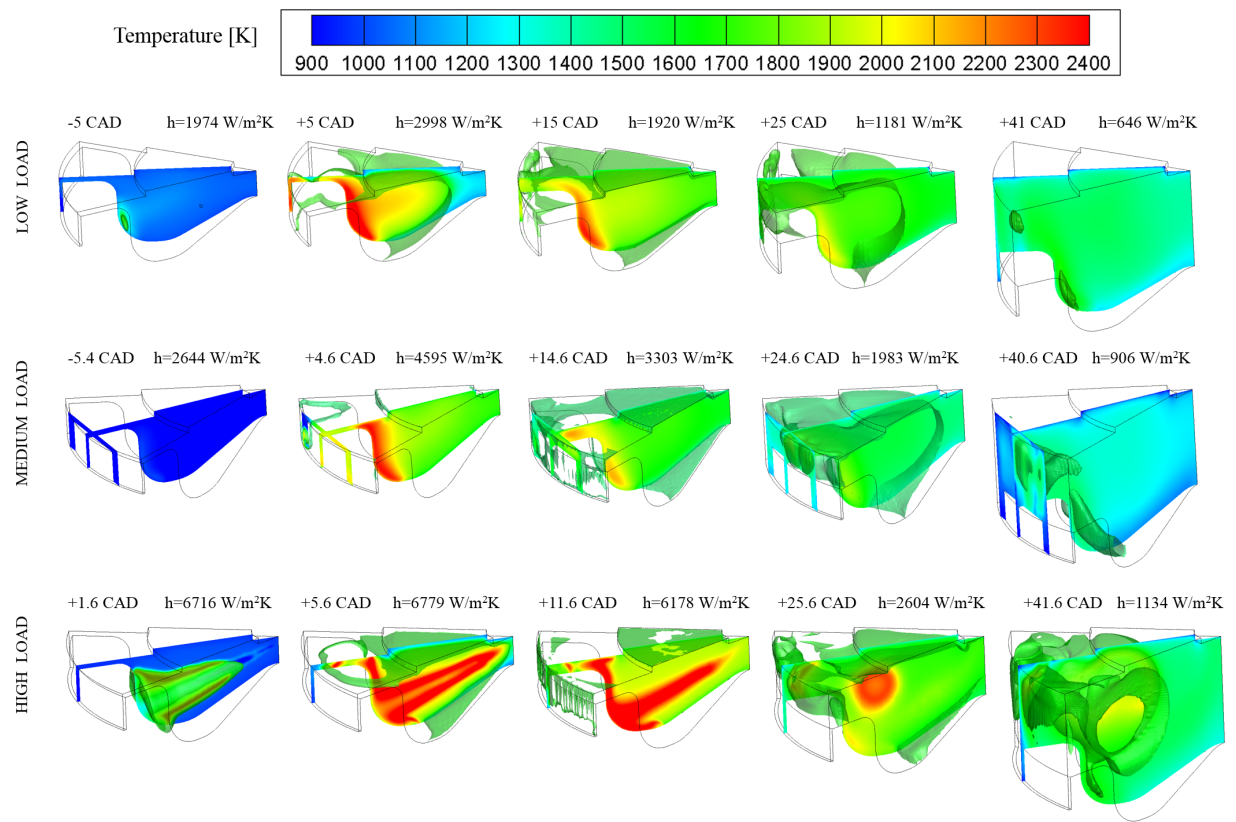

Figure 5.2. Comparison of the temperature distribution between low, medium and high load using the stock piston. A cut plane coincident with the spray axis, an isosurface of $T=1500 \mathrm{~K}$ and the $H T$ coefficient are represented at each instant. 
A first look at the figure reveals that combustion patterns at low and medium load conditions are almost equal. This similitude is explained due to the minor differences among the injection strategies proposed. In both cases, the first spot of the high temperature combustion appears in the piston surface (first instant represented), where the most reactive equivalence ratios are found due to the impact of the main diesel injection with the piston wall. After that, the combustion propagates over the piston surface consuming the charge sequentially from more-to-less reactive regions, as shown in the second and third instants represented in the figure. This promotes the appearance of the highest temperature regions in that zone. Finally, the comparison between low and medium load conditions from the fourth to the last instant shown, suggests that the propagation of the high temperature gas until the center of the cylinder is worse in the case of medium load. This fact can be explained by the more advanced main injection timing than that used at low load (40 instead of -35 CAD ATDC), which promotes that higher amount of diesel fuel mass reaches the outer region of the piston, and therefore, the mixture becomes leaner around center line of the cylinder.

At high load, the fuel spray remains inside the piston bowl. The ignition takes place close to the boundaries of the spray plumes, where the most reactive local equivalence ratios are reached due to the oxygen availability $(+1.6 \mathrm{CAD}$ ATDC). It is worthy to note that the end of injection event takes place at +2.2 CAD ATDC, which suggests that certain portion of diesel fuel is burned as traditional mixing-controlled combustion. This fact can be confirmed in the first subfigure by the coexistence of a colder region near piston center due to the fuel injection, together with the high temperature regions associated to combustion. Following the cycle, at +5.6 CAD ATDC, a combustion progression from the outside of the spray plume to the centerline of the spray is confirmed. It is also observed an in-axis propagation of the high temperature towards the injector nozzle. Also of note is that the fuel spray does not have enough momentum to penetrate far into the squish zone, which avoids the high temperature gas propagating until the crevice region. At +11.6 CAD ATDC it is confirmed that combustion process continues developing through the piston wall. Finally, during the late cycle (+41.6 CAD ATDC), it is seen that the high temperature gas advances until the cylinder walls.

To quantify the differences in HT losses between the three operating conditions, figure 5.3 shows the HT breakdown and total HT energy for the cases studied. The figure states that total HT energy increases as engine load increases. This is presumably due to the greater total energy delivered at higher loads. In addition, it is seen that the apportionment of HT energy between the different parts on which combustion occurs is the same for all 
the engine loads, with greater heat flux through the piston wall, followed by cylinder head and cylinder liner. Moreover, the percentages at low and medium load conditions are very similar, while an increase in HT through the piston surface is computed at high load. This behavior is explained by the combustion pattern described in figure 5.2. In addition, it is seen that the use of a single diesel injection pattern (high load) reduces the HT amount through the cylinder liner.

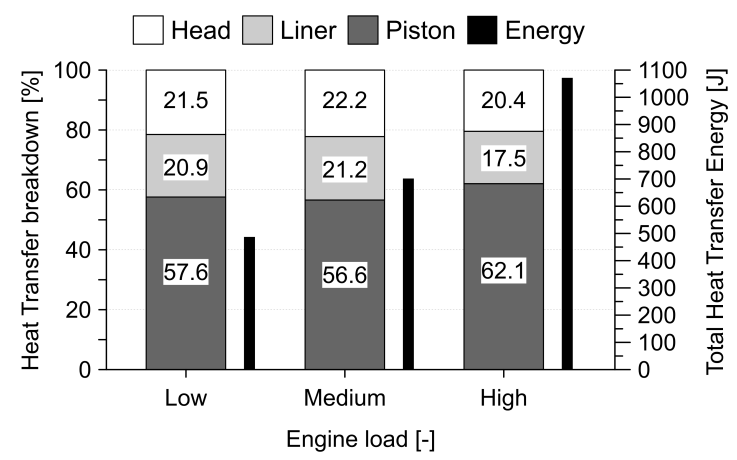

Figure 5.3. Comparison of the heat transfer breakdown and total heat transfer energy between low, medium and high load using the stock piston.

\subsection{Piston bowl geometries definition}

The computational calculations presented in previous section demonstrated that heat flux through the piston wall is the dominant mechanism of HT losses of RCCI concept. Thus, if the energy normally rejected to the coolant could be recovered as useful work on the crankshaft, then a substantial improvement in fuel economy would result. With this purpose, a series of bowl geometries aimed at reducing the wall heat transfer has been designed and evaluated by means of computational calculations and experimental tests.

\subsubsection{Approaches in piston design to reduce heat transfer}

Prior to define the piston geometries studied in this research (section 5.3.2), a literature review about the main tendencies in piston design to reduce heat transfer losses of compression ignition engines was carried out, whose main conclusions are presented next. 


\subsubsection{Thermal barrier coatings}

The concept of thermal barrier coatings (TBC) for diesel engines arose in the mid 1970's by Kvernes as solution for the hot-corrosion experienced in marine diesel engines attributed to the reduced quality of residual fuel used. In the late 70's, Kamo and Bryzik introduced TBC with the aim of reducing the heat energy rejected to the engine coolant during the operation of internal combustion engines. Thus, by insulating different surfaces of the combustion chamber, they reported an improvement in engine performance near 7\% [6]. The pioneering work done by Kamo and Bryzik [7] stimulated that many governments, industries and research institutes worldwide begun to work in the area of adiabatic engine technology. Thus, in the 1980's, the concept of using TBC to insulate the combustion chamber of the diesel engine was widely investigated by well-known researchers as Prof. Woschni [8] among many others.

Results from simulations consistently reported a considerable potential for increasing the thermal efficiency of insulated engines compared to that of baseline engine at all loads and speeds. The percentage of improvements varied depending on the engine type, insulation materials and the degree of insulation. Thus, the benefits claimed in thermal efficiency and fuel consumption ranged from $2 \%$ [9] to $17 \%$ [10] and from $16 \%$ to $37 \%$ [11], respectively.

The gains in fuel consumption and thermal efficiency predicted by simulations were confirmed by means of several experimental investigations. In addition, many researchers claimed that the LHR engines (based on the use of different TBC configurations) offered increased availability of energy in the exhaust together with overall reduction in engine-out emissions. In particular, benefits in thermal efficiency up to $10 \%$ [12] were found and improved fuel consumption ranging from $4 \%$ [13] to $9 \%$ [14]. However, contrary to the above, some other experimental investigations indicated almost no improvement in thermal efficiency [8] and concluded that exhaust emissions [15] and BSFC [16] deteriorated as compared to those of the conventional water-cooled engines. The conflicting results are probably due to the large number of possible LHR engine configurations, test conditions and analysis techniques used [17].

In the early 1990's several drawbacks of LHR engines were determined. From the mechanical point of view, it was found that the piston side wall stresses produced by the conventional piston crank designs compromise the integrity of the ceramic coatings. In addition, it was confirmed that the higher temperatures of the combustion chamber surfaces of LHR engine deteriorate the properties of lubricating oil. Regarding pollutant emissions, the issue 
was related to the elevated combustion chamber temperatures, which resulted in undesired high NOx levels as well as higher soot emissions due to the reduced volumetric efficiency. Thus, in spite of that the coating and lubricating materials can still be improved, the focus on achieving near zero emissions engines eliminated the interest of using TBCs in the diesel engines [18].

Nowadays, the use of aftertreatment systems becomes imperative to reach the levels imposed by the emissions standards, which suggests that the increase in NOx and soot emissions in benefit of increased efficiency should not be as dramatic as in the early 1990's. Thus, although some of the stated works showed only small benefits of the LHR strategies, the idea of developing more adiabatic engines could be a valid alternative to reduce $\mathrm{CO}_{2}$ emissions through the reduction of BSFC. In this sense, recent work developed at CMT-Motores Térmicos using the multi-cylinder version of the SCE used in the current thesis, investigated the impact of the barrier coating application to different engine parts on performance, emissions and heat rejection [19]. The coating material used was agglomerated-sintered $\mathrm{Y}_{3} \mathrm{O}_{2}-\mathrm{ZrO}_{2}$ and its total thickness was about $1 \mathrm{~mm}$ [20]. The results showed that, under CDC conditions from 1260 (mode A) to $1840 \mathrm{rpm}$ (mode C) and 25\% to 100\% load, the use of an insulated piston increases the BSFC compared to the operation with the stock piston (see figure 5.4). Moreover, after performing an optimization work, the best operating condition for the insulated piston resulted in about $3 \%$ more BSFC than the standard configuration, which was associated to a slowing down of the diffusion phase of the combustion process due to a lack of oxygen induced by the worse volumetric efficiency. Thus, the study concluded that even if reasonable coating price can be found in the context of large volume production, no economic advantage is foreseen because of the increase in fuel consumption and pollutant emissions [21].

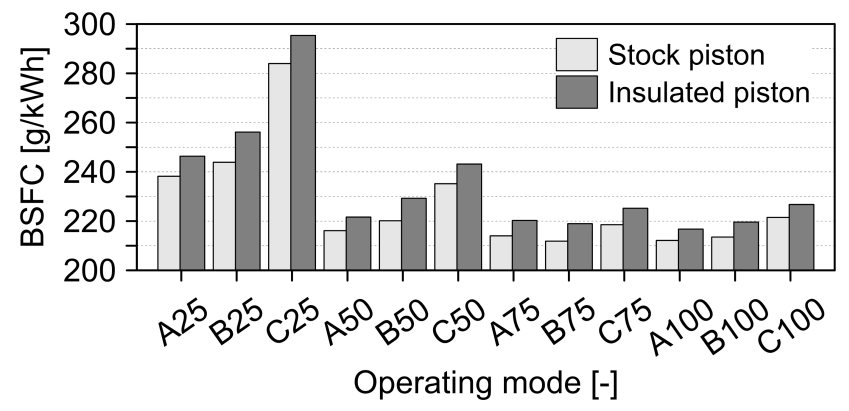

Figure 5.4. Comparison of the brake specific fuel consumption between stock piston and insulated piston. Data from [19]. 
More recently, Toyota introduced the concept of "Temperature Swing Heat Insulation" [22]. This concept is based on coating the combustion chamber walls with a low-heat-conductivity and low-heat-capacity materials that can follow the transient gas temperature during the different strokes of the engine cycle. By this method, the constantly high temperature on combustion wall surface experienced with ceramic coatings is avoided, thus reducing the problems of NOx, soot and knock, and increasing the volumetric efficiency. Thus, despite that the optimum configuration only has a reduced portion of the piston crown coated, this method hints a promising application of the TBCs on the market.

Within the frame of low temperature combustion (LTC) concepts, the application of TBC has not been widely investigated in literature. A couple of recent works in the field of HCCI engines investigated the impact of a magnesium zirconate $(\mathrm{MgZr})$ thermal barrier coating on HCCI ignition operational variability [23] and operational limits [24]. The authors concluded that the use of TBCs increases the stability of the engine at low load conditions, but shifts the maximum operating range towards lower loads due to the higher pressure rise rates experienced. In this sense, the higher combustion wall temperatures of the engine provide elevated compression charge temperatures with consequent reduction of ignition delay. Short ignition delay is conducive to reduced controllability, which is a primary drawback to be overcame in the LTC modes (see chapter 2). This fact questions the potential of using the TBC technique in novel combustion concepts, and therefore an alternative solution has been explored in the present thesis.

\subsubsection{Piston geometry modification}

Alternatively to the application of thermal barrier coatings, in the literature can be found several approaches about piston geometry definition for reducing HT losses occurring during conventional mixing-controlled combustion. One example is the study presented in [25], where the chamfered and wide re-entrant geometries shown in figure 5.5 were optimized using CFD calculations and fractional-factorial design of experiments. Simulations and experiments demonstrated that, with equal compression ratio, the chamfered re-entrant bowl shape offers efficiency advantages than the wide re-entrant bowl geometry. The analysis of heat flux along the engine cycle revealed that the chamfered re-entrant bowl promotes leaner regions along the liner, thus reducing significantly the heat loss to the cylinder walls. Moreover, the less bowl surface area of this design provides better area-to-volume ratio, which greatly contributes to reduce the amount of heat rejected to the engine coolant. 
Thus, it was concluded that the tendency to minimize heat losses of this geometry led to increase the thermal efficiency. Similar findings were found in [26], where a stepped piston similar to the chamfered re-entrant bowl shown in figure 5.5 promoted a reduction in fuel consumption from $3 \%$ to $3.5 \%$ versus the conventional design. This gain was also attributed to the lower amount of heat transferred through the piston wall due to the lower surface area.

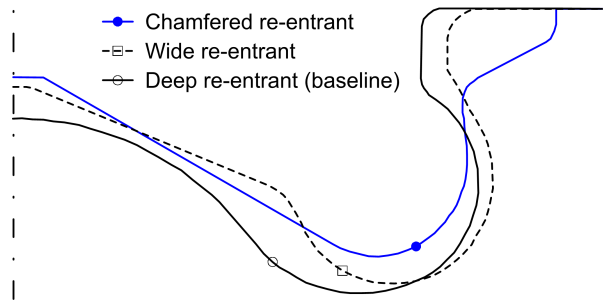

Figure 5.5. Several bowl concepts considered for the combustion system optimized in [25]. The bowls are all scaled to the same volume. Adapted from [25].

With the aim of further decrease the fuel consumption of diesel engines, Toyota developed a new combustion concept based on the combination of PCCI concept with conventional diesel combustion. In particular, this concept operates combining PCCI combustion at low load with diffusive diesel combustion at high load conditions [27]. The authors of that work found that this type of combustion process allows reducing cooling losses from the typical values of $35 \%$ [28] up to only $20 \%$ of the total fuel energy.

Additionally, the same authors claimed that the development of additional technologies to reduce cooling losses can allow further decrease in fuel consumption versus conventional diesel engines. For this purpose, both convective and radiant heat transfer were measured first in a rapid compression machine (RCM), concluding that the primary factor in cooling losses was convective heat transfer. Later, 3D simulations and local heat flux measurements on a multi-cylinder engine were used to determine the cooling loss behavior over the entire combustion chamber, identifying where cooling losses were significant and when these heat losses occurred. The results stated that the area along the side wall of the cavity to the squish region is where the most cooling losses occur. Thus, in order to reduce the convective heat transfer, several piston designs aimed at suppressing reversed squish flow, which promotes the high temperature gas flowing along the side wall of the cavity to the squish region during the descent of the piston, were explored. The different approaches studied in [27] are shown in figure 5.6. 

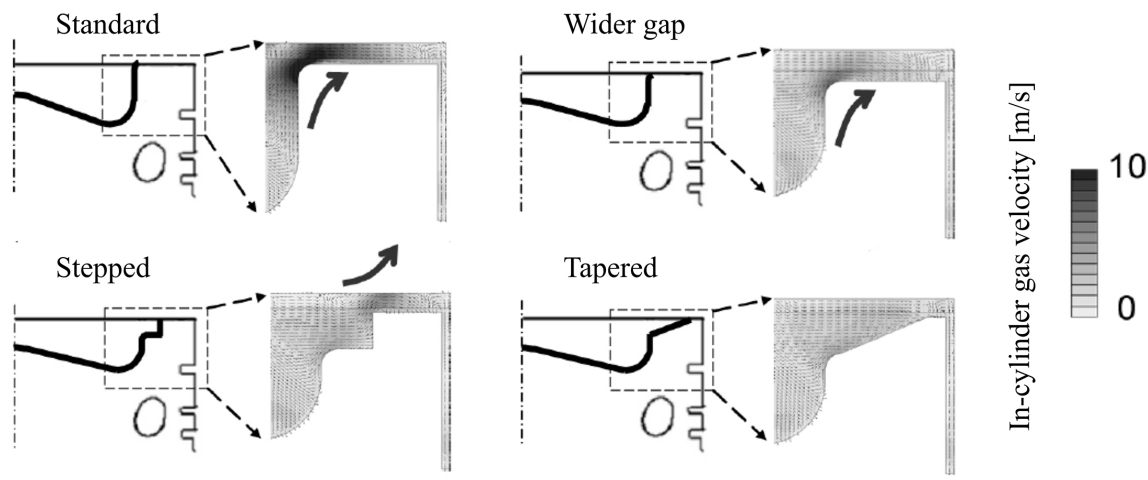

Figure 5.6. Shape of piston bowl and distribution of in-cylinder gas velocity simulated by STAR-CD. Adapted from [27].

As can be seen, the stepped geometry proposed by Toyota is similar to the chamfered re-entrant bowl resulting from the CFD optimization work performed in $[25,26]$. This stepped bowl shape performed better than the standard geometry and also than the one named as "wider gap", in which the squish volume was increased with respect to the standard configuration to diminish the reversed squish flow. Finally, the simulations suggested that the cavity shape referred to as a "tapered" promoted even further reduction in the reversed squish flow velocity. The experimental measurement of the instantaneous heat flux to the squish region with this geometry, shown in figure 5.7 (left), demonstrated the effectiveness of the tapered geometry on reducing cooling losses, which resulted in decreased indicated specific fuel consumption as confirmed in figure 5.7 (right).

The main conclusions from the studies about piston design for reducing HT losses under mixing controlled combustion; i.e. to promote reduced surface area and more quiescent combustion chamber, were also found to be effective for increasing RCCI efficiency. In particular, Splitter et al. [29] evaluated theoretically the effects of the piston bowl depth and squish height on RCCI efficiency using a simplified flat piston geometry. In the simulations, the piston bowl width was held fixed at $2.57 \mathrm{~cm}$ and the piston bowl depth was swept from $0.25 \mathrm{~cm}$ to $1.50 \mathrm{~cm}$. As the piston bowl depth was changed, the squish height was also changed to hold the compression ratio constant. As figure 5.8 (left) shows, thermal efficiency was maximum for the minimum bowl depth. Moreover, the results shown in figure 5.8 (right) suggest that the dominant factors behind this trend were the combustion efficiency and heat transfer, 
reaching the maximum in gross indicated efficiency (figure 5.8 left) at the point of lowest HT and minimum combustion losses.
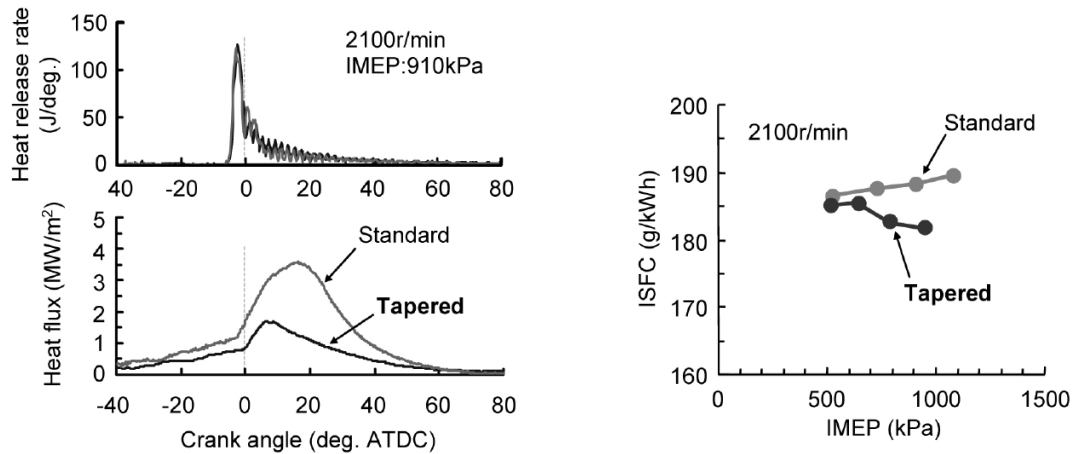

Figure 5.7. Comparison of apparent rate of heat release and heat flux at the squish region (left) and fuel consumption (right) between the standard and the tapered shallow-dish pistons [27].
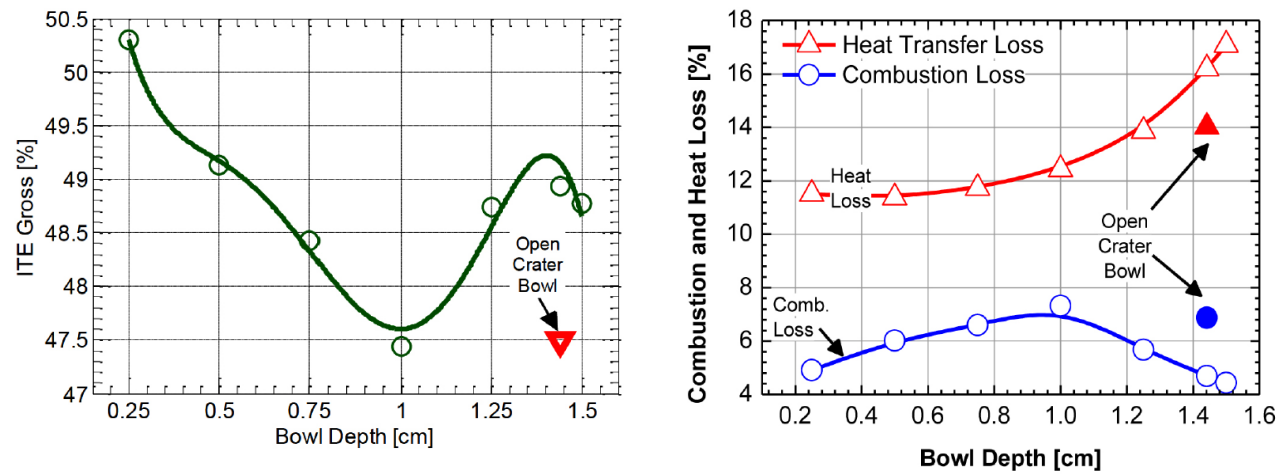

Figure 5.8. Predicted gross indicated efficiency (left) and combustion and heat transfer losses (right) as a function of bowl depth [29].

\subsubsection{Description of the piston bowl geometries studied}

Bearing in mind the findings of the studies described in the previous section, in the current study it has been considered to modify the piston geometry for reducing global heat transfer of RCCI combustion. As suggested by Splitter et al. [29], the baseline hardware may not be optimum to be directly applied to RCCI concept and thereby the modification in piston geometry 
could provide an additional improvement to the concept, for instance on the oxidation of the unburned products located in crevice regions. Thus, two additional piston bowl geometries to the baseline used in the Volvo MD11 engine (from now on, stock piston) were defined. The volumes of the designed combustion bowl geometries were matched to keep the same geometric compression ratio than with the stock piston, which is 14.4:1. The three geometries are illustrated in the cross sectional view presented in figure 5.9.

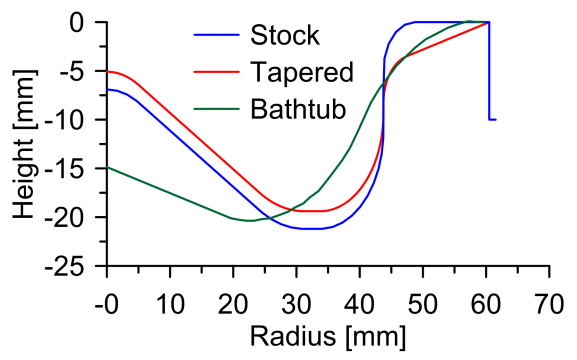

Figure 5.9. Cross sectional view of the stock, tapered and bathtub piston geometries.

The first of the two designed geometries was named as "tapered" and, compared to the stock piston, introduces a notable modification in the transition zone between the bowl and the outer region of the piston, as shown in figure 5.9. In addition, the tapered piston maintains the same central geometry than the stock piston, with slightly higher height necessary to keep the same compression ratio. As described previously, the aim of this geometry is to limit heat transfer in the squish region by increasing the squish height, which reduces the squish flow velocities and therefore the heat transfer coefficient. This effect is illustrated in figure 5.10, where the velocity vectors and the evolution of the mean HT coefficient in the cylinder are shown for the stock and tapered pistons at the low load condition described in table 5.2. As can be seen, the tapered geometry reduces considerably the heat transfer coefficient during the descent moving of the piston, when the heat flux to the squish region becomes more important.

In addition, the high squish height of the tapered geometry would facilitate the high temperature arriving to the squish zone, which is confirmed in figure 5.11. However, the heat flux progression from the squish land up to crevice region seems not being greatly affected by the modified geometry, showing only a slight increase in the temperature of that region with respect to the stock piston. This is related to the reduced reversed squish flow, which diminishes the entrainment of the hot gases to near the top ring land. Finally, 
it is interesting to remark that the designed geometry resulted in $5.7 \%$ reduced piston surface versus the stock piston, which will contribute to minimize the total heat transfer.
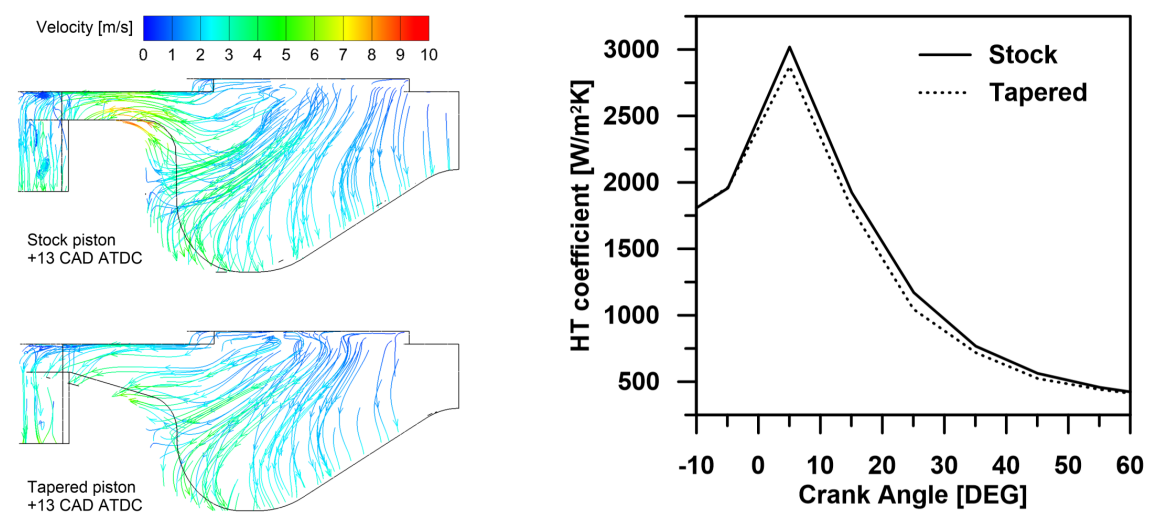

Figure 5.10. Velocity vectors at +13 CAD ATDC (left) and evolution of the mean heat transfer coefficient (right) for the stock and tapered pistons at the low load condition described in table 5.2.
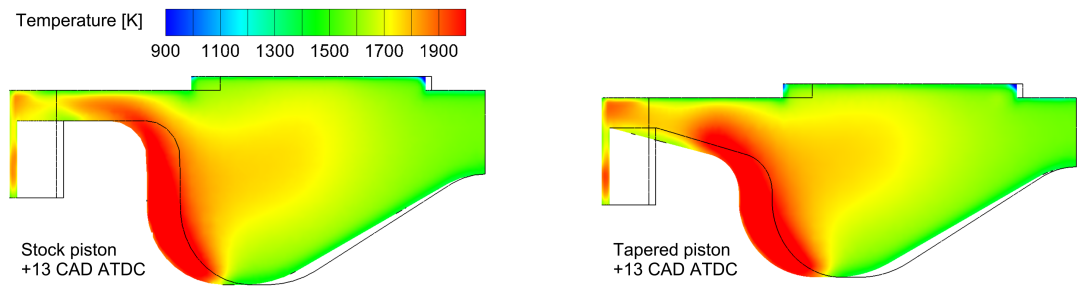

Figure 5.11. Temperature distribution at +13 CAD ATDC for the stock and tapered pistons at the low load condition described in table 5.2.

The second geometry was named as "bathtub" as it follows some of the design guidelines provided in $[29,30]$. Using detailed CFD modeling, the cited works demonstrated that, for fixed compression ratio, the gross indicated efficiency of RCCI increases as the piston bowl radius increases and the piston bowl depth decreases. Thus, the main increase in efficiency was caused by a reduction in heat transfer losses due to the reduced surface area of the wider bowl. The application of these findings to the piston blanks available for performing the current work, resulted in a piston bowl geometry with near $16 \%$ less piston surface area than the stock piston. This reduction in surface 
area, in combination with the more quiescent combustion chamber created by the resulting flatter bowl geometry (see figure 5.9), should contribute significantly to reduce the heat transfer losses. In addition, as demonstrated with the tapered piston, the flatter geometry would improve the penetration of high temperature gas into the squish and near-liner regions [29]. The main specifications of the three combustion chambers are summarized in table 5.3.

Table 5.3. Main specifications of the three combustion chambers studied.

\begin{tabular}{lccc}
\hline \hline Piston & Stock & Tapered & Bathtub \\
\hline Area $\left[\mathrm{mm}^{2}\right]$ & 15895 & $14977(\downarrow 5.7 \%)$ & $13383(\downarrow 15.8 \%)$ \\
Volume $\left[\mathrm{mm}^{3}\right]$ & 110705 & 110705 & 110705 \\
Area/volume $\left[\mathrm{mm}^{-1}\right]$ & 0.143 & 0.135 & 0.121 \\
Squish cavity shape $[-]$ & flat & tapered & rounded \\
Min. squish height $[\mathrm{mm}]$ & 13.1 & 13.1 & 13.1 \\
\hline
\end{tabular}

\subsection{Effect of piston bowl geometry at low load}

As seen before, the piston geometry modification can effectively diminish heat transfer losses. However, this method would affect not only to the HT process, but also to the in-cylinder flow structures, and therefore to the engine performance and emission levels. Thus, in this section, the two bowl geometries previously defined are evaluated and compared to the stock one by means of experimental tests at low load conditions.

\subsubsection{Experimental results}

Due to the notable differences in the geometry of the three combustion chambers studied, the optimal combination of engine settings for one piston may not be valid for the other two. Thus, with the aim of acquiring knowledge about the behavior of the two new geometries at low load, a series of parametric sweeps has been proposed. The operating conditions fixed and swept in the parametric studies are shown in table 5.4. As can be seen, variations of the injection pattern (single or double), gasoline fraction and diesel injection timing (main and pilot) were performed. In the case of double injection strategy, the injection settings fixed during the pilot and main injection sweeps are shown in parentheses. 
Table 5.4. Detail of the engine settings used for the parametric studies at low load.

\begin{tabular}{lc}
\hline \hline \multicolumn{2}{c}{ Constant engine settings } \\
\hline Speed [rpm] & 1200 \\
Air mass flow [kg/h] & 53 \\
Total fuel mass [mg/cycle] & 70 \\
Effective CR [-] & $14.4: 1$ \\
Intake pressure [bar] & 1.35 \\
Intake temperature [ $\left.{ }^{\circ} \mathrm{C}\right]$ & 40 \\
$\mathrm{YO}_{2}$ at IVC [\%] & 15.5 \\
\hline \multicolumn{1}{c}{ Single injection } \\
\hline Diesel IP [bar] \\
Gasoline fraction [\%] \\
Diesel SOI [CAD ATDC] & 1000 \\
\hline \multicolumn{1}{c}{ Double injection } \\
\hline Diesel IP [bar] & -15 to -24 \\
Gasoline fraction [\%] & 700 \\
Diesel pilot SOI [CAD ATDC] & -40 to $-60(-15)$ \\
Diesel main SOI [CAD ATDC] & $(-60)-25$ to -40 \\
Diesel ratio [\%pilot/\%main] & $60 / 40$ \\
\hline
\end{tabular}

The comparison between pistons will be performed at the most potential tests in terms of performance and emissions resulting from the sweeps proposed in table 5.4, for both single and double injection strategies. In order to clarify the operating conditions selected to perform the comparison, the main effects of the two variables studied (injection timing and GF) are presented in figure 5.12, which shows the RoHR and bulk gas temperature for some specific cases of double and single injection strategies. For the sake of clarity, only the results of stock piston are presented, while the explanation is also valid for the other two geometries.

With respect to single injection results (left), it is seen that combustion pattern does not experience a great change when advancing diesel injection timing from $-15 \mathrm{CAD}$ to $-24 \mathrm{CAD}$ with the same GF. In both cases, two main combustion stages can be identified. The first RoHR peak is associated with the burning of premixed diesel fuel with certain portion of the entrained gasoline, while the second stage entails the burning of the majority of gasoline 

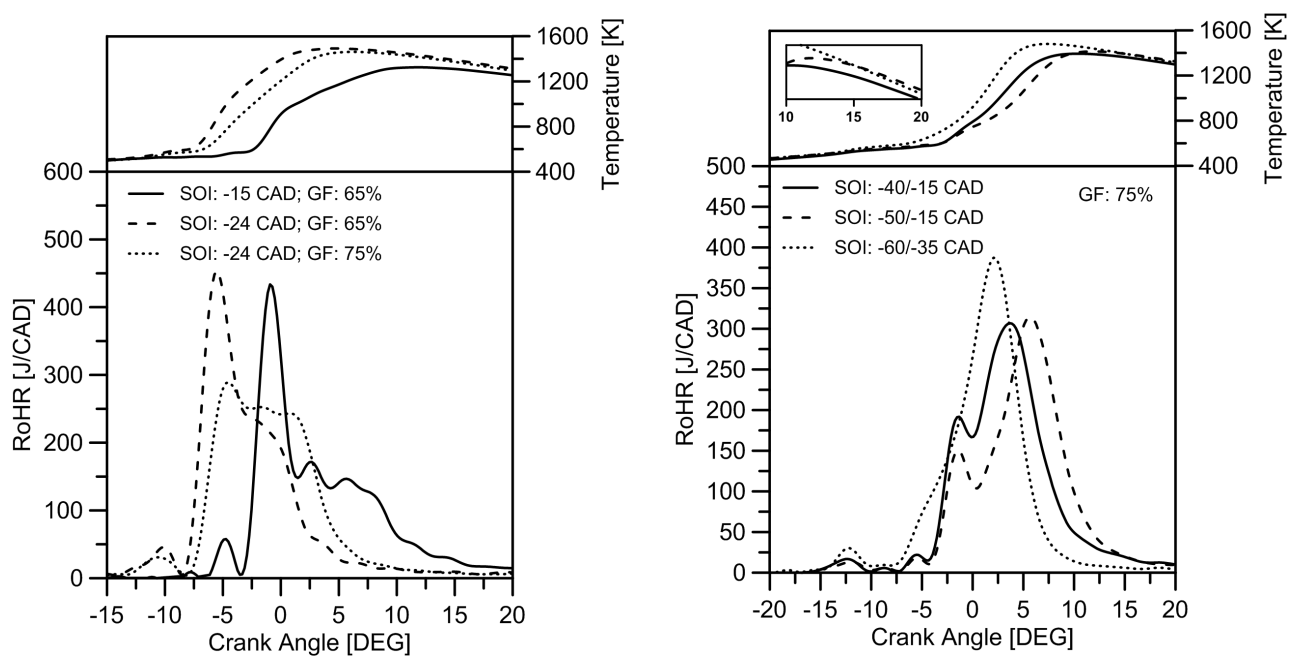

Figure 5.12. Experimental RoHR and bulk gas temperature of the different sweeps with single (left) and double injection (right) for the stock piston at low load conditions.

fuel. It is observed that the advance in diesel SOI promotes more advanced combustion development, which results in higher temperature, and therefore, in remarkable higher NOx emissions (figure 5.13). However, the improved reactivity through the increase in temperature allows reducing considerably the duration of the second combustion period, leading to lower $\mathrm{CO}$ and $\mathrm{HC}$ emissions. In this sense, a great reduction of $\mathrm{CO}$ emissions is observed, while $\mathrm{HC}$ emissions were not found to be as sensitive to combustion temperature as CO. From figure 5.13, it is also inferred that the low amount of diesel fuel used at these conditions (35\% of total) results in soot levels below the minimum detection limit of the smoke meter in both cases. Finally, despite SOI -24 CAD allows improving considerably the combustion process, this strategy only offers slight improvement in BSFC because the majority of the combustion event takes place during the compression stroke. The increase in GF from $65 \%$ to $75 \%$ at $-24 \mathrm{CAD}$ resulted in almost equal combustion duration with greater portion of the combustion event evolving just after TDC, which improves much more the BSFC. In addition, the increase in GF promotes a reduction of $\mathrm{NOx}$ emissions. In this sense, the lower amount of diesel fuel injected in the case of GF $75 \%$ together with the higher mixing time observed (shorter injection duration and equal start of combustion) should promote leaner equivalence ratio distribution at SOC. This reduces significantly the temperature peak at the first instants, when the combustion evolves through richer equivalence ratios, and thus reduces NOx emissions. Finally, it is interesting to remark 
that $\mathrm{CO}$ emissions remain almost constant between $\mathrm{GF} 65 \%$ and $75 \%$, which is explained by the near equal temperature experienced during the expansion period. However, HC increases as GF increases, again suggesting they are mainly a function of unburned fuel escaping combustion in the engine crevices.
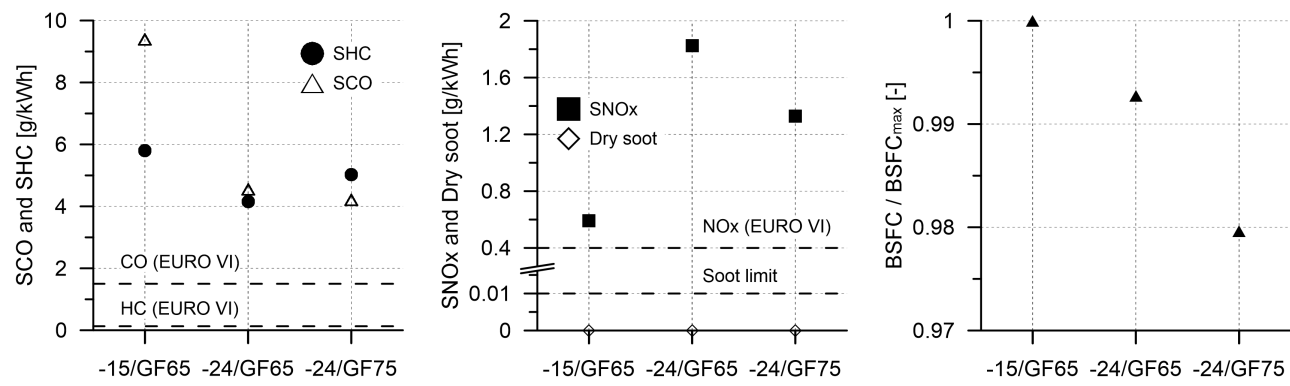

Figure 5.13. Engine-out emissions and fuel consumption for the three single injection conditions represented in figure 5.12 (left). The results correspond to the stock piston.

Focusing on the double injection results presented in figure 5.12 (right), it is stated that the advance in pilot injection timing while keeping constant the main injection does not have a strong effect on the morphology of combustion development. The start of combustion (SOC) is equal in both cases, which denotes that combustion onset is governed by the main diesel injection. However, the most advanced strategy (-50/-15 CAD) provides a lower first RoHR peak and delayed combustion progression. This fact is thought to be related to the higher mixing time available for the pilot injection, which results in leaner equivalence ratios at SOC. The leaner equivalence ratio distribution together with the lower temperature during the main autoignition stage promote NOx emissions under the EURO VI limit for this injection strategy (figure 5.14). Moreover, the increase in temperature during the late combustion stage in the expansion period (see detailed view) allows reducing $\mathrm{CO}$ and $\mathrm{HC}$ emissions. This is supposed to be related to the better spatial stratification of diesel fuel around the squish and crevice regions. Finally, the moderated increase of BSFC observed in the case of - $-50 /-15$ is due to the slightly worse combustion phasing and larger combustion duration, which penalizes the work extraction from the combustion cycle. As the main injection is advanced together with the pilot one (-60/-35 CAD), the combustion pattern moves from two-staged to one stage Gaussianshaped heat release. This combustion shape results in improved $\mathrm{HC}$ and $\mathrm{CO}$ emissions due to the enhanced RoHR and temperature peaks. Also, as was demonstrated in chapter 4 , the advance of the pilot injection timing up to 
-60 CAD ATDC improves notably the reactivity in crevice and squish regions, which enhances burning the gasoline trapped in this zones of the combustion chamber. Regarding NOx emissions, further reduction is observed while soot levels remain below the EURO VI limit. Since the combustion temperature peak increases in this case, the reduction in NOx emissions should be driven by the much leaner in-cylinder equivalence ratio distribution as consequence of the highly advance injection strategy used. Lastly, the advance in CA50 experienced in this case results in minimum increase of fuel consumption than $-50 /-15$ CAD ATDC.
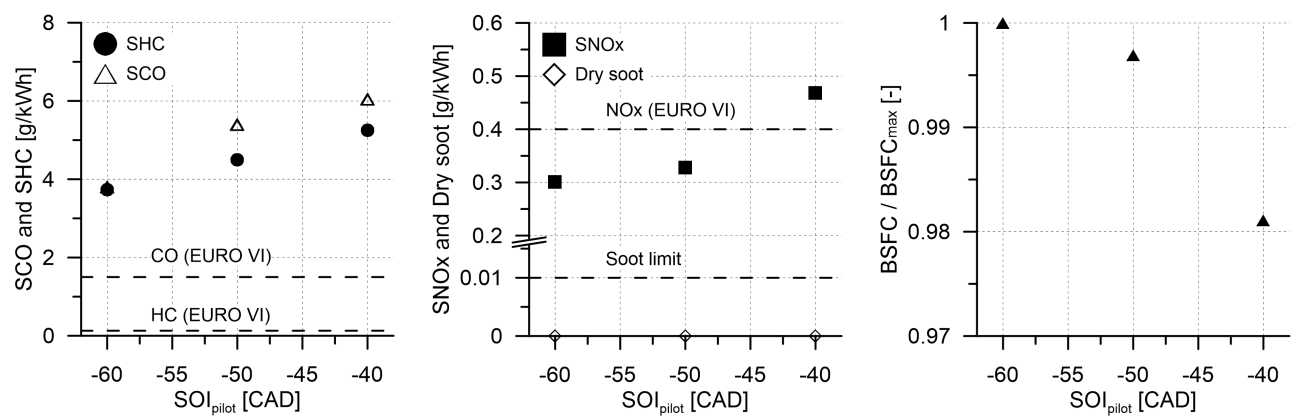

Figure 5.14. Engine-out emissions and fuel consumption for the three double injection conditions represented in figure 5.12 (right). The results correspond to the stock piston.

To assess the main differences in combustion development between pistons, which is the main purpose of the current section, the figure 5.15 shows the RoHR traces obtained at the most potential settings from the results described before. In particular, the strategy of - 24 CAD with GF $75 \%$ has been selected as representative of the single injection strategy because these settings provide the lowest fuel consumption and none of the single injection strategies allowed the EURO VI NOx compliance. In the case of double injection, -60/-35 CAD with GF $75 \%$ has been considered as proper strategy as it showed lower NOx, $\mathrm{CO}$ and $\mathrm{HC}$ emissions and not much higher fuel consumption than those of $-50 /-15$ CAD.

The double injection results shown in figure 5.15 (left), state that the stock piston provides earlier SOC than the other geometries. This is thought to be related to differences in the main diesel injection stratification in the combustion chamber. Thus, the deeper bowl of the stock piston seems to retain more diesel fuel from the main injection (-35 CAD ATDC) resulting in more reactive equivalence ratios, which enhances the autoignition process. The remarkable higher RoHR peak further confirms this thought. 

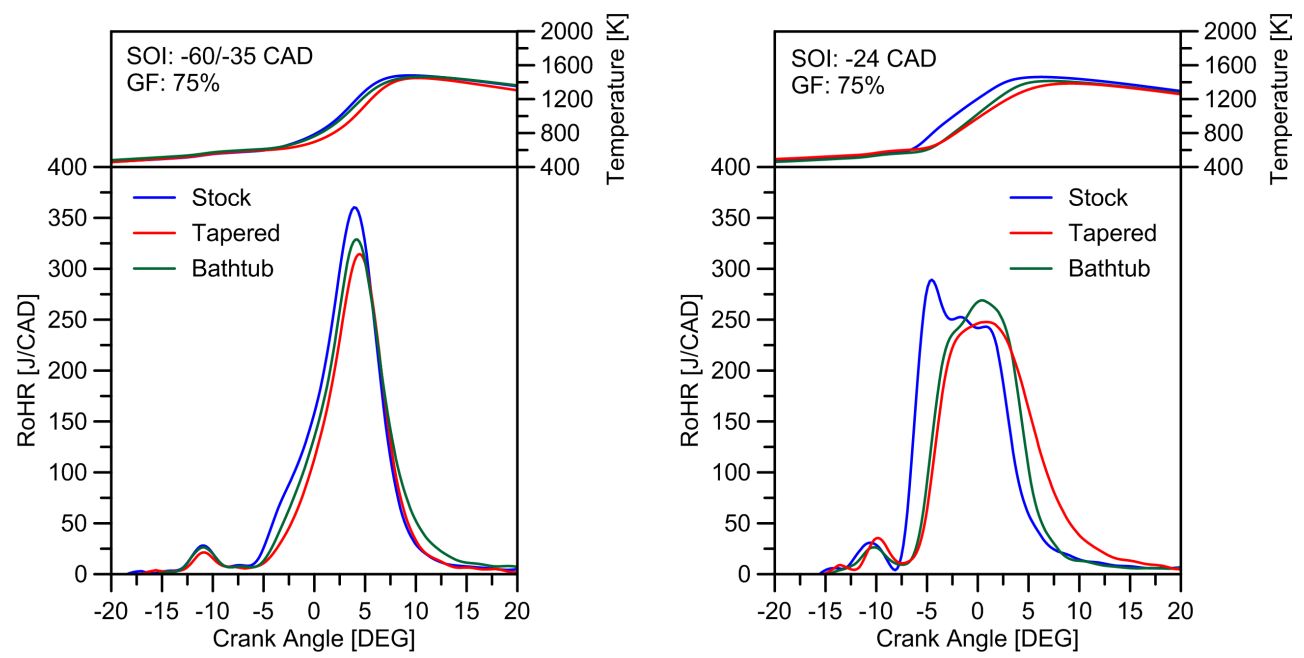

Figure 5.15. Experimental RoHR and bulk gas temperature of the most interesting tests with single (left) and double injection (right) for the three piston geometries at low load conditions.

Nevertheless, nearly half of the combustion event develops during the compression stroke, which penalizes the fuel consumption for this geometry (figure 5.16). Moreover, it is interesting to remark that the maximum combustion temperatures for the two designed geometries are very similar to the one reached with the stock piston, which should be directly related to the reduced heat transfer losses due to the minimized piston surface area. Regarding engine-out emissions, the results shown in figure 5.16 reveal that the use of double injection strategy allows to meet the EURO VI NOx and soot limitations for the three piston geometries. Thus, the main differences between pistons are found in $\mathrm{CO}$ and $\mathrm{HC}$ emissions levels. As can be seen, bathtub and stock piston provide similar $\mathrm{HC}$ emissions with slightly improved levels in the case of the tapered geometry. Moreover, $\mathrm{CO}$ emissions are worsened in the case of bathtub piston, which is consequence of the smoother expansion period.

In the case of single injection strategy, it is also confirmed that the stock piston leads to more advanced SOC than bathtub and tapered geometries. In addition, steeper RoHR with slightly higher maximum peak is observed. Under single injection strategy conditions, the spray-bowl interaction has a key role on combustion process, and then, the differences in mixture formation due to differences in bowl geometry have a greater impact on combustion development than in case of using double injection patterns with advanced 
injection timings. Thus, it seems that the more pronounced bowl of the stock geometry enhances the charge motion, which results in faster mixing and earlier autoignition. The higher peak and steeper growth of the RoHR is thought to be related to differences in the equivalence ratio stratification at SOC.
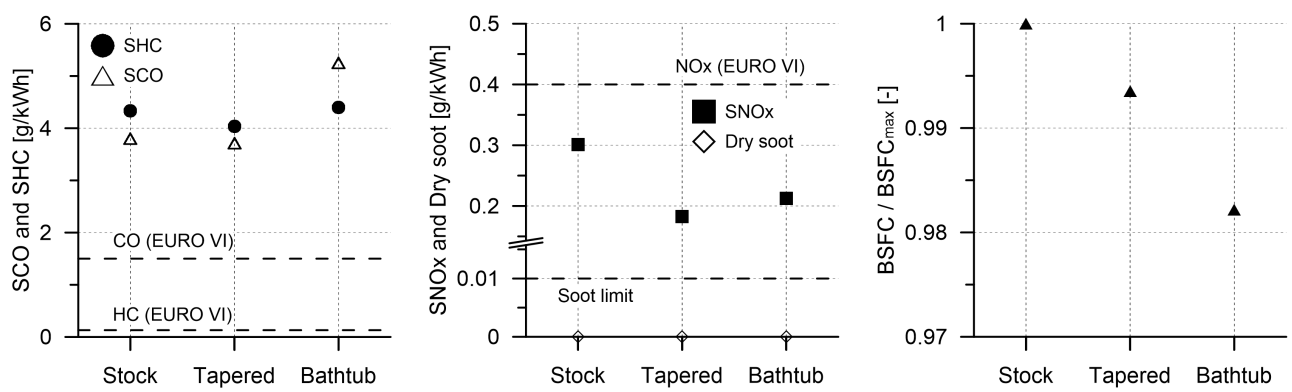

Figure 5.16. Engine-out emissions and fuel consumption for the three piston geometries at the representative condition of double injection strategy: -60/-35 CAD $A T D C$ and $G F 75 \%$.
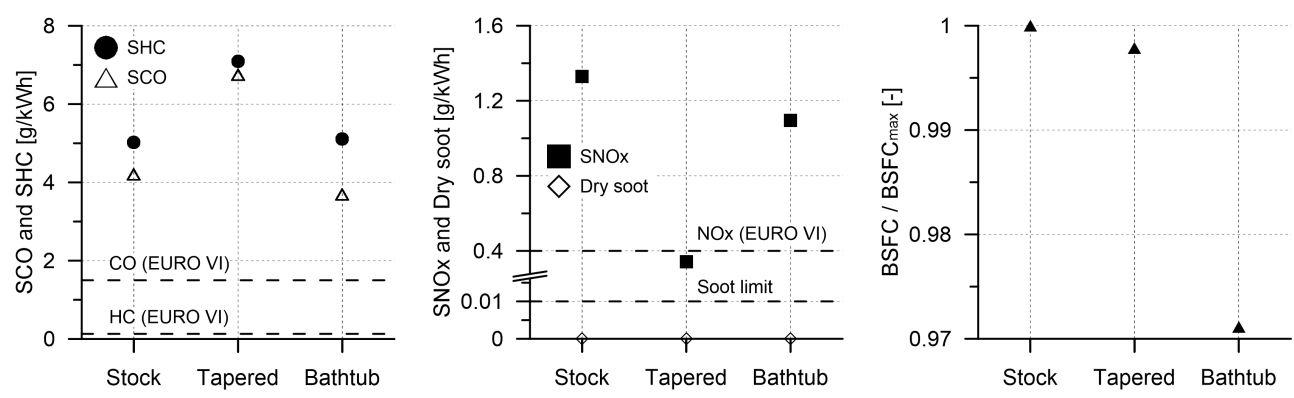

Figure 5.17. Engine-out emissions and fuel consumption for the three piston geometries at the representative condition of single injection strategy: -24 CAD ATDC and GF $75 \%$.

Regarding fuel consumption, shown in figure 5.17, it is seen that tapered and bathtub pistons allow improved BSFC than the stock geometry, which must be related to the slight delay in combustion process. In this sense, the bathtub piston allows greater reduction in BSFC than tapered geometry due to the shorter combustion duration together with the slightly higher maximum RoHR peak. Focusing on the emissions levels, it is highlighted that only the tapered piston reaches the EURO VI limits for NOx emissions. However, their $\mathrm{HC}$ and $\mathrm{CO}$ emissions levels are greater than those obtained with the other 
geometries, as could be expected attending to the late burning period during the expansion stroke. It is interesting to see that $\mathrm{CO}$ emissions for bathtub piston are lower than with the stock geometry, which suggests better oxidation during the expansion period. Finally, as was found in chapter 4, at this engine load, soot levels are negligible for all the pistons.

\subsubsection{Understanding the differences between geometries}

Experimental results from previous section denoted certain differences during combustion development as well as notable variations in engine-out emissions and fuel consumption between the stock and the two alternative piston geometries. Thus, the current section focuses on understanding phenomena governing these variations. For this purpose, both heat transfer and combustion losses have been studied by means of detailed CFD simulations. Later, their repercussion on thermal efficiency is presented.

The analysis has been performed at the most potential operating condition considering the results of the previous parametric sweeps, which corresponds to double injection strategy at -60/-35 CAD ATDC and GF 75\%. In particular, this strategy allowed simultaneous reduction in engine-out emissions and BSFC versus the single injection strategy. The rest of engine settings belonging to this operating condition are the ones depicted in table 5.4.
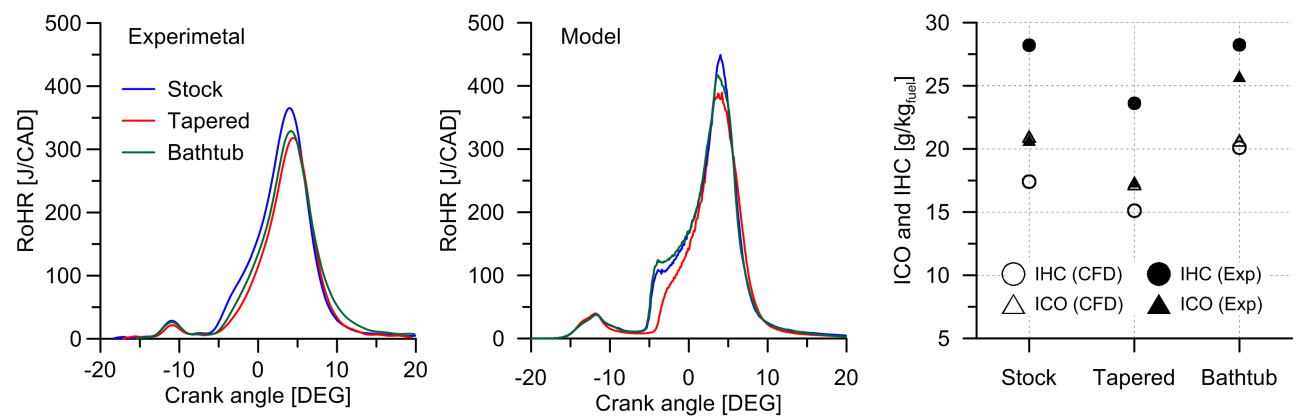

Figure 5.18. Comparison of the RoHR, HC and CO emissions for the experimental and computational results at low load conditions with the three piston geometries. Double injection set at -60/-35 CAD ATDC, EGR rate of $45 \%$ and intake temperature of $40^{\circ} \mathrm{C}$.

In order to confirm the validity of the computational code with the two new piston geometries, figure 5.18 compares the RoHR for the experimental and computational results at the operating condition selected. In addition, 
the experimental measurements and model-predicted $\mathrm{HC}$ and $\mathrm{CO}$ emissions for the three piston geometries are shown in the figure. As can be seen, the computational model shows enough accuracy capturing the combustion characteristics for the three geometries, as well as the trends of $\mathrm{HC}$ and $\mathrm{CO}$ emissions when comparing with the experimental results. However, in spite of reproducing quite well the emissions trend, the simulations tend to underestimate the $\mathrm{HC}$ emissions, which must be taken into account to interpret the results in terms of absolute values. These differences are related to the variations in the maximum RoHR peaks among the modeling and experimental results.

\subsubsection{Heat transfer analysis}

Improving the engine thermal efficiency by means of the in-cylinder heat transfer reduction is the key objective of the current study. Thus, figure 5.19 shows the global instantaneous heat flux (HF) as well as its breakdown among piston, cylinder liner and cylinder head for the three piston geometries.
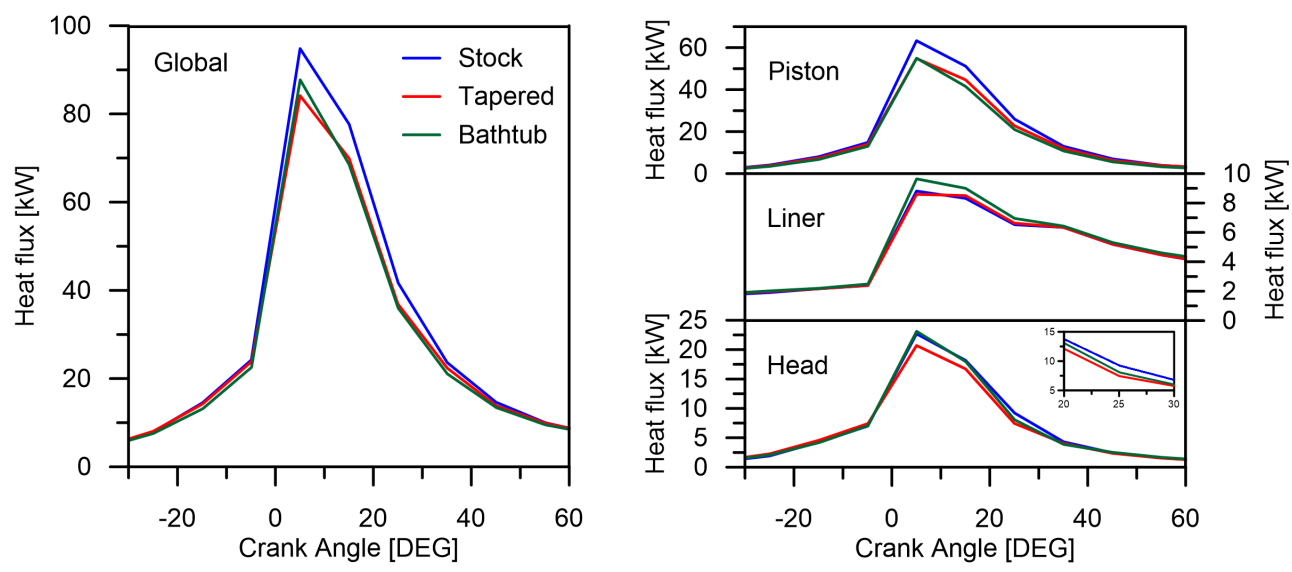

Figure 5.19. Global heat flux and breakdown between piston, cylinder and cylinder head for the stock, tapered and bathtub pistons at low load.

As can be seen, the stock piston leads to higher global HF than tapered and bathtub pistons during the whole combustion cycle. Looking at the HF apportionment, it is clear that this fact is mainly consequence of the greater HF through the piston surface, which represents more than $50 \%$ of the total. Moreover, in the case of stock geometry, it is also observed higher HF through the cylinder head from +20 to +40 CAD ATDC. This is explained by the 
stronger reversed squish flow during the descent of the piston promoted by the lower squish height (see figure 5.10). The comparison between tapered and bathtub pistons reveals minimum differences in global HF. Analyzing the apportionment, it seems that the reduced piston HF for bathtub geometry during the whole cycle was balanced by the increase in the HF through the liner and cylinder head. This spatial evolution of the high temperature regions towards colder zones, as the cylinder liner, might account for the increase in CO emissions observed for bathtub piston in the figure 5.16. Finally, the reduced HF through the cylinder head in the case of the tapered piston is explained by its higher squish height, which reduces more effectively the incylinder velocity in this zone, and therefore the HT coefficient.

The spatial evolution of the high temperature regions during the combustion event for the three piston geometries is shown in figure 5.20. The cut plane represented is coincident with the spray axis and the iso-surface of temperature $1500 \mathrm{~K}$ was selected as representative for tracing the evolution of the high temperature regions in the chamber.

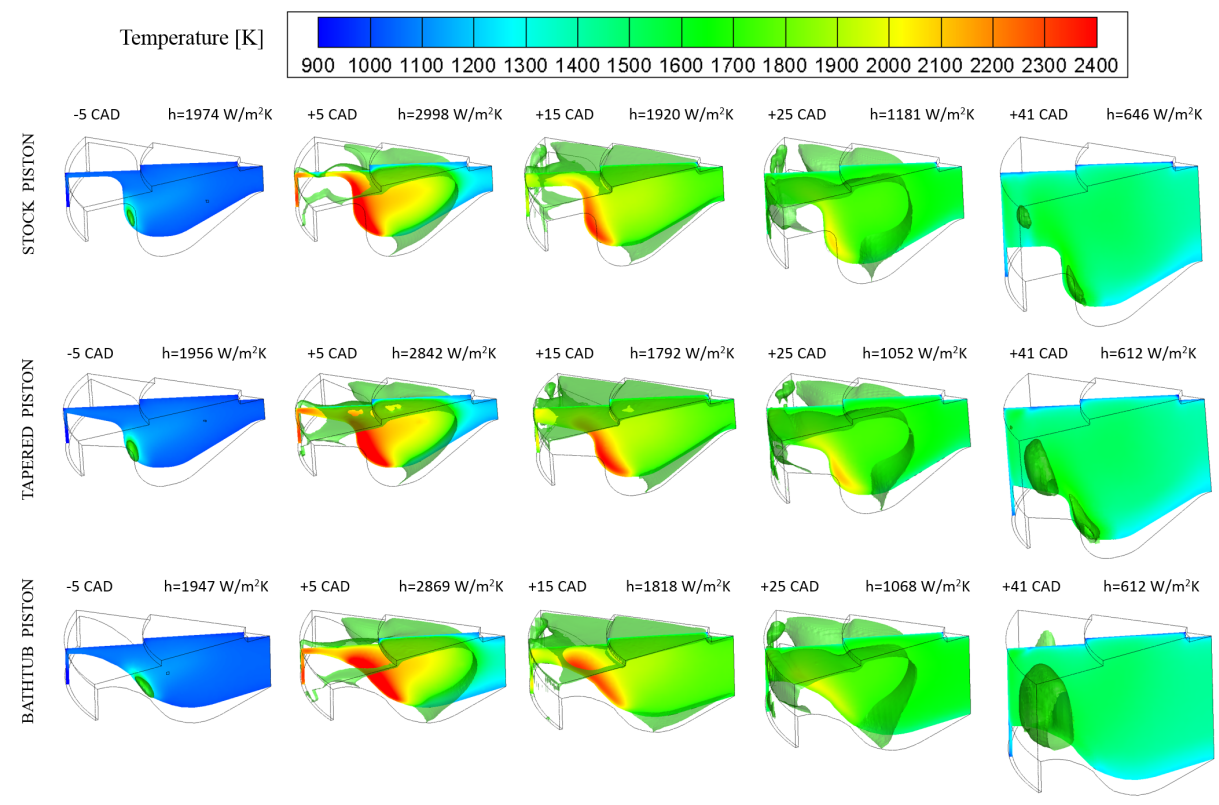

Figure 5.20. Comparison of the temperature distribution between the stock, tapered and bathtub pistons at low load. A cut plane coincident with the spray axis, an isosurface of $T=1500 \mathrm{~K}$ and the heat transfer coefficient are represented in each case. 
Looking the first instant (-5 CAD ATDC), it is clear that the ignition pattern is equal for the three pistons. In all cases, the autoignition onset occurs on the piston surface, propagating later over the walls of the piston bowl ( +5 CAD ATDC). This is consequence of the more reactive equivalence ratio stratification promoted by the impact of the main diesel injection with the piston bowl. Thus, the greater area of the stock piston together with the higher HT coefficient, explain the significantly higher piston HF depicted in figure 5.19. Also of note is that the smoother transition from the piston center to the squish region for tapered and bathtub pistons enhances the high temperature propagation until that zone. This can be confirmed looking at the instants of +15 and +25 CAD ATDC, were it is seen that the high temperature regions near the cylinder head are more evident for tapered and bathtub pistons than for stock geometry. Finally, comparing the late combustion period $(+41$ CAD ATDC) it is found that the flatter geometry of bathtub piston enhances the propagation of the high temperature region until the cylinder liner, which results in a peak of HF in this zone (see figure 5.19).

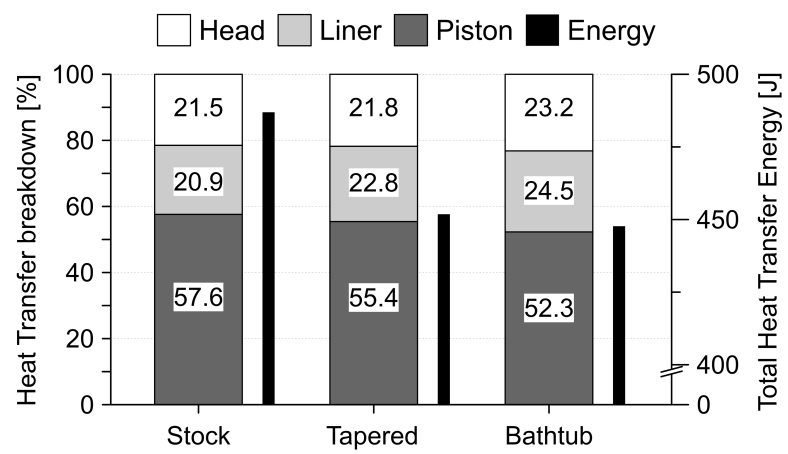

Figure 5.21. Comparison of the heat transfer breakdown and total heat transfer energy between the stock, tapered and bathtub pistons at low load.

To summarize and compare numerically the differences in HT, figure 5.21 shows the HT breakdown and total HT energy for the three pistons. As can be seen, bathtub piston allows the greatest reduction in the total HT energy when compared to the stock geometry. Taking into account the combustion pattern explained above, this fact is well related to the notable reduction in piston area coupled with lower heat transfer coefficient. On the other hand, it is observed that the modification in piston geometry changed the ratio between the HT through the cylinder liner and cylinder head. Thus, the less prominent bowl of the new geometries enhanced the propagation of the high temperature until the cylinder walls, which causes a significant increase of HT in this zone. In 
this sense, the flatter geometry of bathtub piston magnifies this effect versus the tapered piston, which rests part of the gain promoted by the reduction in piston surface area.

\subsubsection{Combustion losses}

In order to understand the main sources of combustion losses as well as their differences when comparing the three pistons, figure 5.22 (left) shows the temporal evolution of the $\mathrm{CO}$ and $\mathrm{HC}$ emissions predicted by the model as well as their corresponding experimental measurements. In addition, the evolution of the bulk gas temperature and the iso-octane mole fraction predicted by the CFD simulations are shown in the right subfigure.
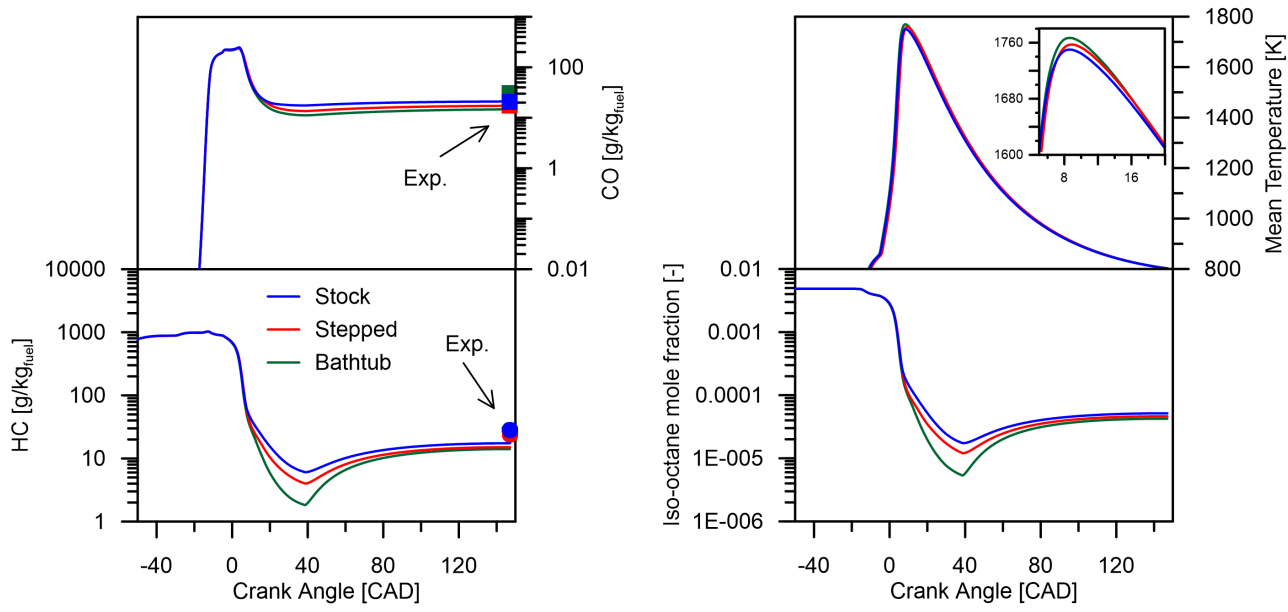

Figure 5.22. Temporal evolution of the $\mathrm{HC}$ and $\mathrm{CO}$ emissions, instantaneous iso-octane mole fraction and bulk gas temperature predicted by the model. The experimental measurements of $\mathrm{HC}$ and $\mathrm{CO}$ emissions are also included in the figure.

The differences in $\mathrm{CO}$ emission levels between geometries are related to changes in the temperature of both gases and combustion chamber walls as the heat rejection is reduced. Thus, the higher bulk gas temperature for bathtub and tapered pistons together with the enhancement of the spatial propagation of the high temperature region through the chamber, resulted in improved $\mathrm{CO}$ oxidation. The trend of $\mathrm{HC}$ emissions between the pistons is equal than that observed for $\mathrm{CO}$ emissions, but in this case the differences between pistons are more remarkable. This indicates that $\mathrm{HC}$ emissions are more sensitive to changes in geometry, while $\mathrm{CO}$ emissions mainly follow the 
peak temperature in the chamber. On the other hand, it can be seen that the temporal evolution of the hydrocarbon emissions follows that of the iso-octane mole fraction, which reinforces that the main cause of the combustion losses at low load is the poor oxidation of the gasoline fuel. Finally, the comparison of the iso-octane oxidation between the three pistons reveals some differences, which are related to the spatial differences during combustion progression. It seems that the geometrical modification of the two proposed pistons assist in permitting the iso-octane oxidation, proceeding to more complete combustion.

\subsubsection{Efficiency}

Thermal efficiency indicates the efficiency with which the chemical energy input in the form of fuel is converted into useful work. To account the thermal efficiency gain obtained with each piston due to differences in heat transfer and combustion losses, figure 5.23 shows a comparison of the fuel energy usage between the stock, tapered and bathtub pistons at the low load case analyzed.

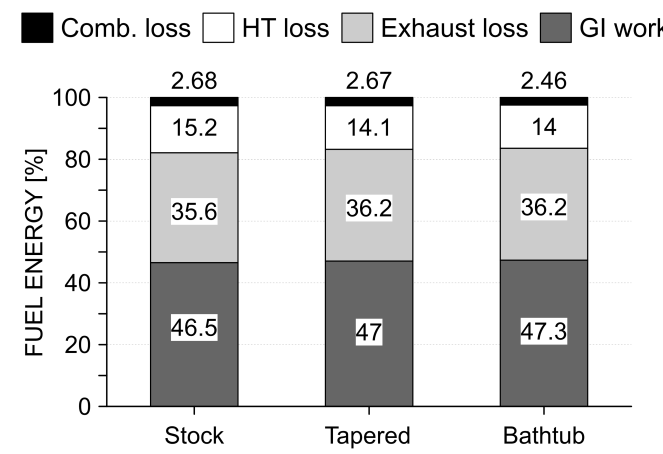

Figure 5.23. Comparison of the fuel energy usage between the stock, tapered and bathtub pistons at low load.

Again, it is seen that tapered and bathtub pistons reduce significantly the heat transfer losses compared to the stock piston. However, only a portion of this recovered energy is extracted as additional gross work, while the rest is merely rejected as thermal exhaust loss due to the higher exhaust temperature. In any case, rising the exhaust temperature presents also benefits with respect to rejecting the heat to the coolant, e.g. for increasing conversion efficiency in the aftertreatment systems. Comparing the gross indicated efficiency between the three pistons, it is seen that the trend follows the experimental findings, which demonstrated improved fuel economy for bathtub and tapered piston versus the stock geometry. Finally, it is observed that the model predicts that 
bathtub piston promotes a slight reduction of combustion losses compared to the stock piston, which does not follow the experimental results. This discrepancy is consequence of the underestimation of $\mathrm{CO}$ emissions for bathtub piston (see figure 5.18). In spite of that, this error supposes only a $0.2 \%$ of the total energy balance, which does not disturb the general conclusions extracted.

\subsection{Evaluation of the suitable geometry for ex- tended load operation}

This section aims at evaluating experimentally the potential of the two new piston geometries for promoting improved operation than the stock piston at medium and high load conditions. For this purpose, similar parametric studies than those presented in section 5.4.1 are performed here.

\subsubsection{Medium load results}

The engine settings established for performing the parametric studies are summarized in table 5.5. As commented before, in order to prevent excessive PRR peaks and preserve the mechanical integrity of the engine, the effective compression ratio was lowered to 11:1 by means of advancing the intake valves closing event (early Miller cycle). In particular, this strategy was applied when using double injection strategies, and the boost pressure was increased from 2.2 to 2.96 bar to keep the air mass flow constant between both strategies.

The rate of heat release profiles and bulk gas temperature of some representative settings for single and double injections are shown in figure 5.24. The analysis of these data will allow to identify the strategy that provides the best trade-off between emissions and engine performance. As done in section 5.4.1, in this first part of the analysis, only the profiles of stock piston are depicted.

Concerning the double injection strategy, the same effects found at low load conditions are appreciated. Thus, equal SOC is obtained when advancing the pilot injection from -50 to -60 CAD ATDC with fixed main injection. Nonetheless, at this load, greater differences in the first RoHR peak are observed. Specifically, the pilot injection set at -50 CAD ATDC improves notably the RoHR in the middle instants of the combustion cycle, leading to improved fuel consumption with lower $\mathrm{CO}$ and $\mathrm{HC}$ levels (figure 5.25). These differences should be related to changes in mixing time, and hence, in the equivalence ratio stratification at SOC. In particular, the shorter mixing 
Table 5.5. Detail of the engine settings used for the parametric studies at medium load.

\begin{tabular}{lc}
\hline \hline \multicolumn{2}{c}{ Constant engine settings } \\
\hline Speed [rpm] & 1200 \\
Air mass flow $[\mathrm{kg} / \mathrm{h}]$ & 86 \\
Total fuel mass $[\mathrm{mg} / \mathrm{cycle}]$ & 119 \\
Intake temperature $\left[{ }^{\circ} \mathrm{C}\right]$ & 40 \\
YO $_{2}$ at IVC [\%] & 15.1 \\
\hline \multicolumn{1}{c}{ Single injection } \\
\hline Effective CR [-] & $14.4: 1$ \\
Intake pressure [bar] & 2.2 \\
Diesel IP [bar] & 1175 \\
Gasoline fraction [\%] & 60 to 70 \\
Diesel SOI [CAD ATDC] & -9 to -21 \\
\hline \multicolumn{1}{c}{ Double injection } \\
\hline Effective CR [-] \\
Intake pressure [bar] & $11: 1$ \\
Diesel IP [bar] & 2.96 \\
Gasoline fraction [\%] & 800 \\
Diesel pilot SOI [CAD ATDC] & -40 to $-60(-12)$ \\
Diesel main SOI [CAD ATDC] & $(-60)-9$ to -40 \\
Diesel ratio [\%pilot/\%main] & $70 / 30$ \\
\hline
\end{tabular}

for the pilot injection would provide richer mixture distribution at SOC, which explains the higher RoHR observed in the first stage. On the other hand, the advance in main injection from -12 to -21 CAD ATDC results in advanced combustion development, with almost the complete combustion cycle occurring during the compression stroke. This promotes considerably higher in-cylinder temperatures, which leads to notably higher NOx and lower $\mathrm{HC}$ and $\mathrm{CO}$ emissions. Soot emissions are also reduced below the limit of $0.01 \mathrm{~g} / \mathrm{kWh}$, which must be consequence of the higher mixing time and better oxidation process. Finally, from figure 5.25, it is seen that the excessive advanced combustion development at $-60 /-21$ CAD reduces the thermodynamic efficiency and penalizes the fuel consumption. 

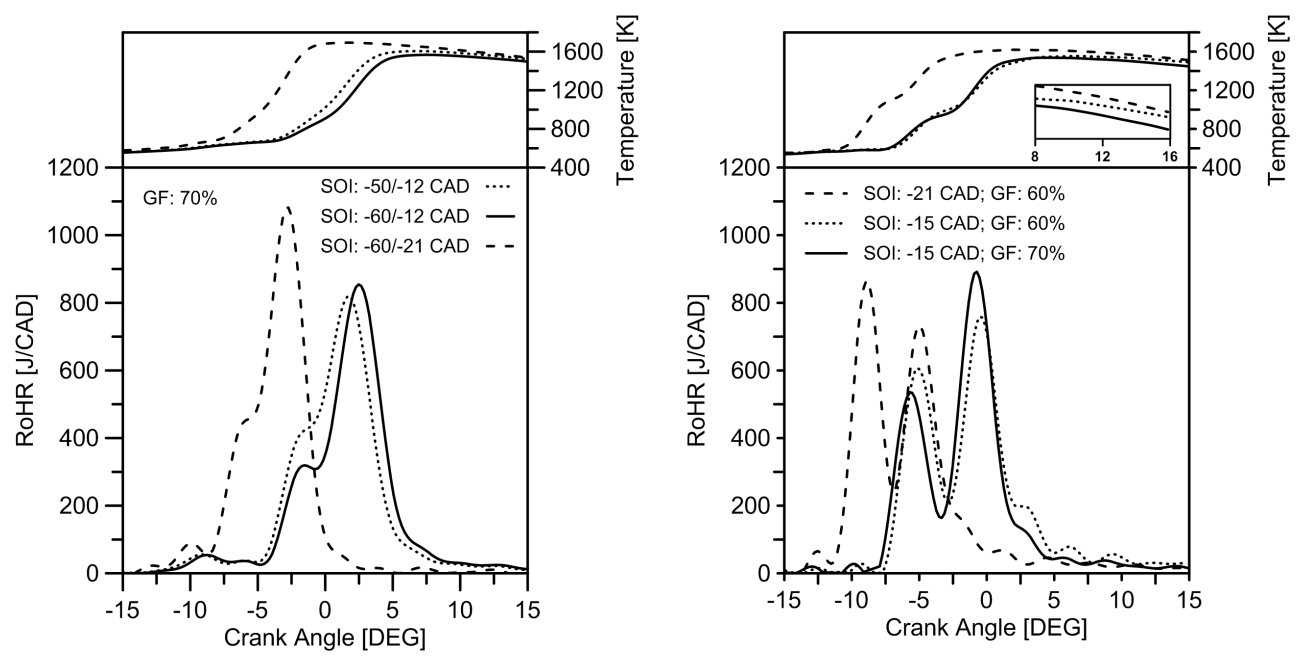

Figure 5.24. Experimental RoHR and bulk gas temperature of the different sweeps with double (left) and single injection (right) for the stock piston at medium load conditions.
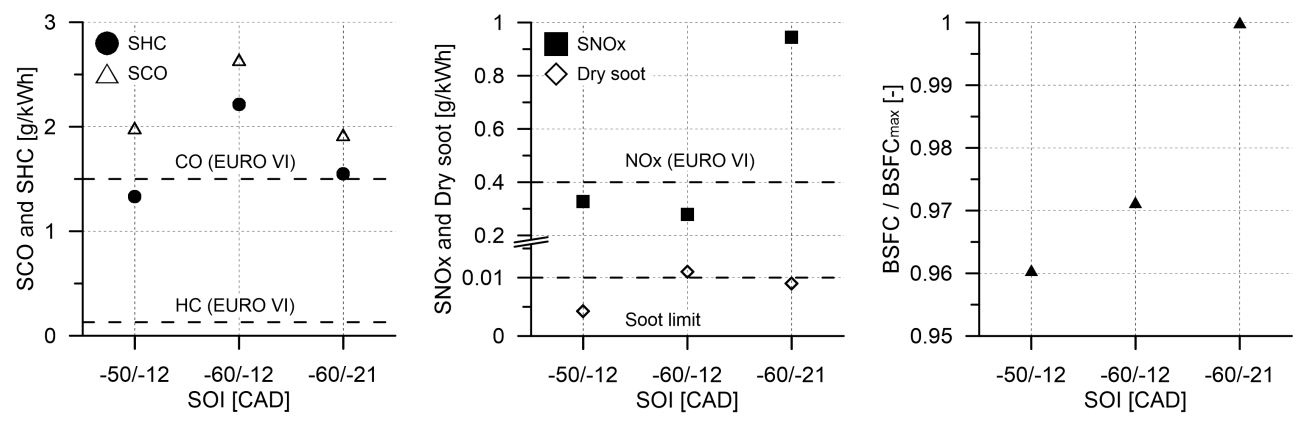

Figure 5.25. Engine-out emissions and fuel consumption for the three double injection conditions represented in figure 5.24 (left). The results correspond to the stock piston.

The single injection results depicted in figure 5.24 (right), show welldefined two-staged RoHR profiles in all the cases. The variation of diesel SOI while keeping constant the GF, results in opposite behavior for the maximum RoHR peaks of the first and second combustion stages. Thus, at the most advanced case (-21 CAD ATDC), an enhancement of the first premixed phase is appreciated. Moreover, the second RoHR peak becomes lower since great part of the fuel has been already combusted. By contrast, 
as diesel SOI is delayed (-15 CAD ATDC), the first RoHR peak becomes lower, which provokes an increase in temperature and pressure resulting in a more powerful autoignition during the second combustion stage. The delay in combustion phasing observed as diesel SOI is delayed promotes a simultaneous reduction in NOx emissions and fuel consumption with slightly higher emission of unburned products (figure 5.26). Finally, the increase in GF from $60 \%$ to $70 \%$ at the same SOI enhances the second combustion stage without affecting the combustion phasing, which results in increased NOx and lower CO due to the higher in-cylinder temperature (figure 5.24 right). On the other hand, as has been already remarked, $\mathrm{HC}$ emissions increase as gasoline fraction increases.
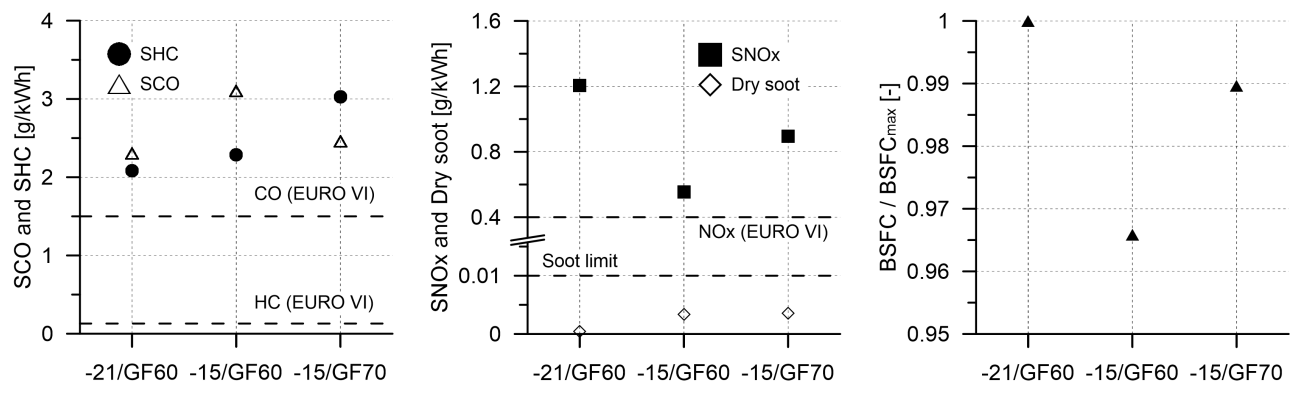

Figure 5.26. Engine-out emissions and fuel consumption for the three single injection conditions represented in figure 5.24 (right). The results correspond to the stock piston.

Figure 5.27 presents the influence of piston geometry on RCCI combustion at medium load. The double injection strategy selected to perform the comparison was -50/-12 CAD with GF $70 \%$. This strategy promoted NOx and soot emissions under EURO VI limits with the best fuel consumption. In the case of single injection, - 15 CAD with GF $60 \%$ showed the lowest BSFC and, in spite of not reaching the EURO VI limit, this strategy also led to the lowest NOx levels.

As can be seen from figure 5.27 (left), under double injection conditions, bathtub and stock pistons shows nearly identical heat release rate. Moreover, bathtub geometry leads to slightly higher RoHR peak than the stock piston. This gain in combustion should be related to its reduced piston surface area and modified geometry. By contrast, in the case of the tapered piston, a singular behavior is observed. This geometry shows an equal RoHR evolution up to the time of the main autoignition, but later, it provides a smoother and larger combustion propagation than the other geometries. Since the 

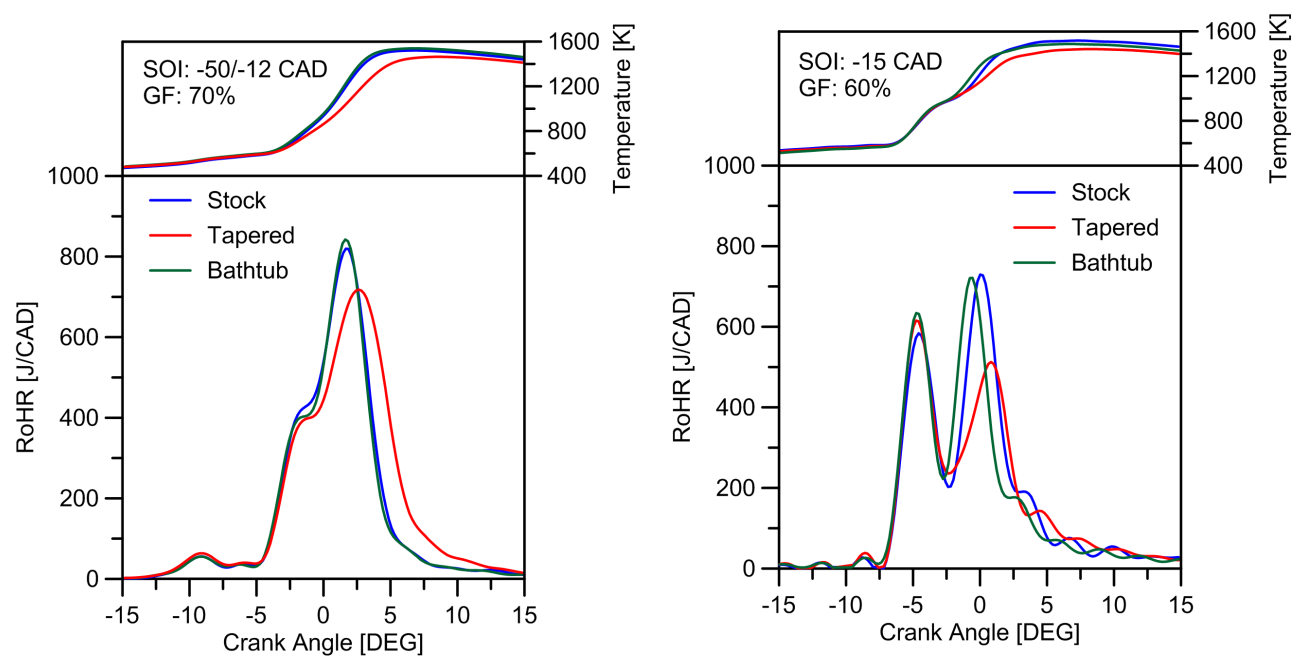

Figure 5.27. Experimental RoHR and bulk gas temperature of the most interesting tests with double (left) and single injection (right) for the three piston geometries at medium load conditions.

air management conditions are fixed between tests, this notable change in combustion pattern should be governed by the differences in the in-cylinder flow structures induced by the the piston geometry modifications. Concerning performance and emissions, all the pistons provide ultra-low NOx and soot emissions, with both pollutants below the limits imposed (figure 5.28). As expected, the poor combustion with the tapered piston results in higher HC and $\mathrm{CO}$ emissions, but as will be shown later, the levels are much lower than those with single injection. Finally, the BSFC values confirm that only the bathtub geometry improves slightly the operation versus the stock one.

Looking at the RoHR profiles corresponding to single injection, it is seen again a nearly equal evolution during the first combustion stage for the three pistons. Moreover, the two new geometries provide higher RoHR peaks than the stock one in this period. Later, bathtub piston promotes more advanced second combustion stage that the stock geometry, while the tapered piston degrades notably the combustion event. This behavior causes again the HC and $\mathrm{CO}$ levels to rise for this geometry, with lower NOx emissions and higher fuel consumption (see figure 5.29). By contrast, bathtub piston leads to higher NOx and lower BSFC than the stock geometry. In all cases, the end of injection takes place at -5 CAD ATDC, which reveals a certain period of diffusive diesel combustion. In spite of that, soot levels remain below $0.01 \mathrm{~g} / \mathrm{kWh}$ in all 
cases, which confirms the ability of RCCI to promote near zero soot levels when higher GFs are used.
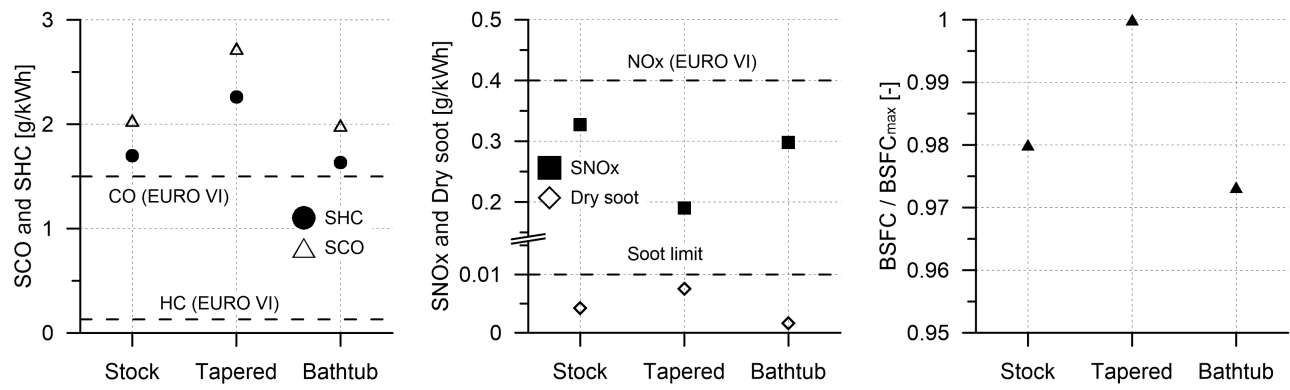

Figure 5.28. Engine-out emissions and fuel consumption for the three piston geometries at the representative condition of double injection strategy: -50/-12 CAD $A T D C$ and GF $70 \%$.
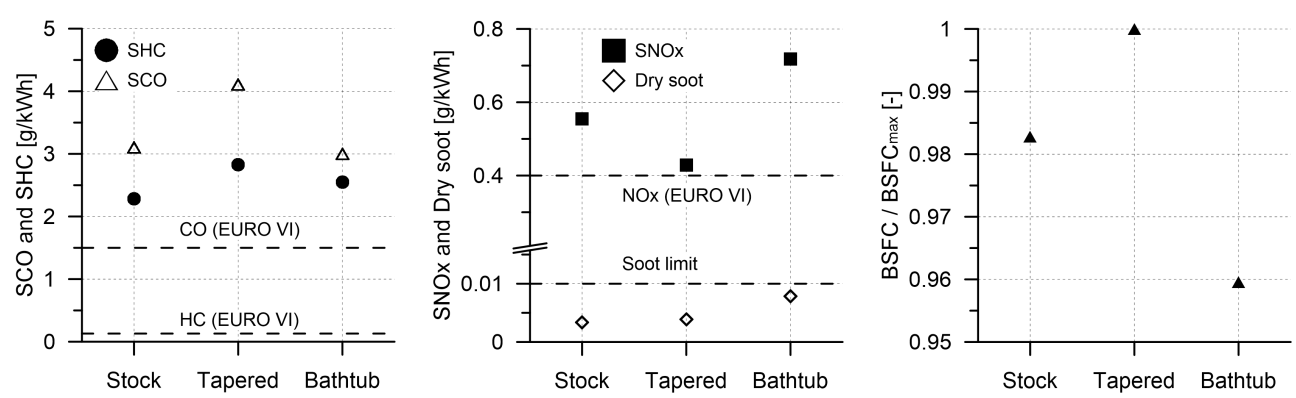

Figure 5.29. Engine-out emissions and fuel consumption for the three piston geometries at the representative condition of single injection strategy: -15 CAD ATDC and GF $60 \%$.

\subsubsection{High load results}

The different engine settings tested during the parametric studies at high load are detailed in table 5.6. As described in section 5.2, additionally to reduce the effective compression ratio to $11: 1$, it was necessary to reduce the intake charge temperature due to the knocking tendency. Thus, the intake oxygen concentration was increased (via EGR reduction) to prevent excessive rise in soot emissions. The injection pressure was increased in both injection strategies (single and double) to reduce the injection duration due to the great 
amount of diesel fuel. The increase of injection pressure in the case of double injection strategy was more moderated to avoid excessive wall impingement.

Table 5.6. Detail of the engine settings used for the parametric studies at high load.

\begin{tabular}{lc}
\hline \hline \multicolumn{2}{c}{ Constant engine settings } \\
\hline Speed [rpm] & 1200 \\
Air mass flow [kg/h] & 118 \\
Total fuel mass [mg/cycle] & 175 \\
Effective CR [-] & $11: 1$ \\
Intake pressure [bar] & 3.4 \\
Intake temperature $\left[{ }^{\circ} \mathrm{C}\right]$ & 32 \\
$\mathrm{YO}_{2}$ at IVC [\%] & 16.3 \\
\hline \multicolumn{1}{c}{ Single injection } \\
\hline Diesel IP [bar] \\
Gasoline fraction [\%] \\
Diesel SOI [CAD ATDC] & 1890 \\
\hline \multicolumn{1}{c}{ Double injection } \\
\hline Diesel IP [bar] \\
Gasoline fraction [\%] & -6 to +6 \\
Diesel pilot SOI [CAD ATDC] & -40 to $-60(-10)$ \\
Diesel main SOI [CAD ATDC] & $(-40)-4$ to -16 \\
Diesel ratio [\%pilot/\%main] & $50 / 50$ \\
\hline
\end{tabular}

To explore the main effects of the different variables on combustion process, figure 5.30 shows the rate of heat release profiles and bulk gas temperature for the stock piston at some cases of single and double injection. As seen in table 5.6, the pilot injection sweep proposed was intended to reach -60 CAD ATDC, but in practice the most advanced achievable value for pilot injection was -40 CAD ATDC due to the unacceptable knocking levels (greater than 25 bar/CAD). Therefore, only the effect of $\mathrm{SOI}_{\text {main }}$ is presented in figure 5.30.

The comparison of the RoHR profiles for the double injection cases represented in figure 5.30 (left) suggests that, as $\mathrm{SOI}_{\text {main }}$ is delayed, the combustion development becomes delayed and weaker, but otherwise the RoHR shape remains unchanged. At the most delayed SOI (-40/-4 CAD ATDC), the injection event takes place at the end of the combustion process, and then, has a negligible contribution to the RoHR. Since the diesel fuel 
amount injected at this instant is not burned during the main combustion event, a great increase of soot, $\mathrm{CO}$ and $\mathrm{HC}$ emissions occurs (figure 5.31). In turn, the poor combustion experienced leads to lower NOx levels than the other strategies. In spite of the worse combustion efficiency, the shift of combustion towards TDC allows improving the fuel consumption. Finally, it is seen that the high in-cylinder temperature of the most advanced case (-40/-13 CAD ATDC) provides CO emissions inside the EURO VI limits and ultra-low soot levels.
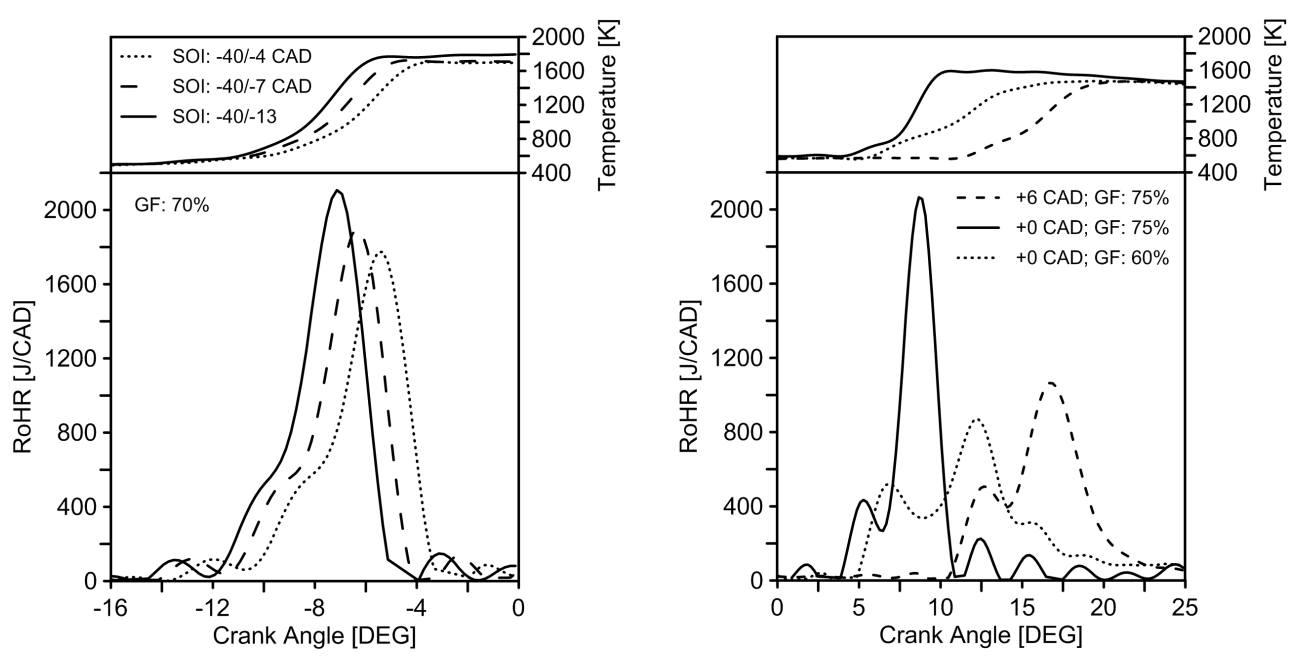

Figure 5.30. Experimental RoHR and bulk gas temperature of the different sweeps with double (left) and single injection (right) for the stock piston at high load conditions.
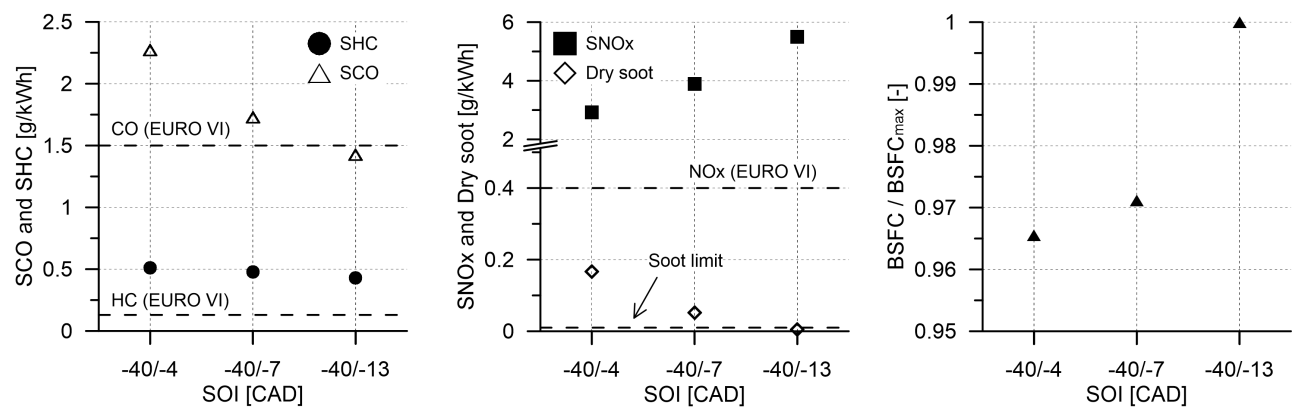

Figure 5.31. Engine-out emissions and fuel consumption for the three double injection conditions represented in figure 5.30 (left). The results correspond to the stock piston. 
Regarding single injection results, a double staged RoHR with higher peak in the second stage is observed in all cases. As can be seen, the advance of diesel SOI from +6 to +0 CAD ATDC with constant GF provokes a substantial improvement in the second combustion phase. This is explained due to the enhanced gasoline burning promoted by the higher pressure and temperature at these instants of the engine cycle. As seen in figure 5.32, this causes a reduction of BSFC in around 5\% while maintaining ultra-low soot levels, but makes the NOx emissions to exceed the EURO VI limitation. In addition, the in-cylinder PRR peaks were unacceptable in this case, reaching values greater than 25 bar/CAD. Finally, the reduction of GF to $60 \%$ with the same SOI diminished the PRR near 10 bar/CAD, and also lowered NOx and soot emissions below the limits imposed. In addition, only a slight increase in $\mathrm{CO}$ and $\mathrm{HC}$ versus $\mathrm{GF} 75 \%$ was observed, with very similar BSFC.
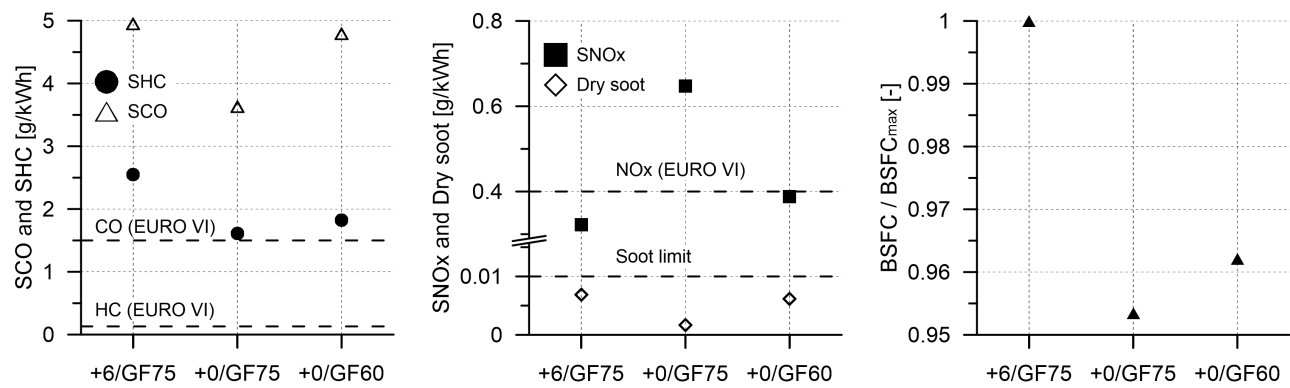

Figure 5.32. Engine-out emissions and fuel consumption for the three single injection conditions represented in figure 5.30 (right). The results correspond to the stock piston.

Figure 5.33 shows the direct comparison between the three geometries at the most potential conditions from the single and double injection strategies described previously. Considering the emissions levels and fuel consumption, these conditions are: + +0 CAD ATDC with GF $60 \%$ and $-40 /-13$ CAD ATDC with GF $70 \%$. Despite the double injection strategy selected provides the highest BFSC and NOx emissions, it has been selected because it leads to very low $\mathrm{CO}$ and soot levels, and no other strategy allow the simultaneous compliance of NOx and soot limits.

The use of double injection pattern (left) provides very similar evolution during the first instants of the high temperature heat release. Just before the main autoignition stage, the tapered geometry shows slightly higher heat release rate than the stock and bathtub pistons. But after that, its autoignition stage becomes slower and less energetic than the other two geometries, which 
show nearly equal evolution. This behavior was also observed at medium load conditions. In spite of the differences, the three pistons show almost equal combustion phasing and duration. The engine-out emissions from the three cases are shown in figure 5.34. The results show similar emissions levels and fuel consumption for the stock and bathtub geometries. As expected, the poor combustion with tapered piston minimizes NOx emissions and increases the unburned products and fuel consumption. In all cases, soot emissions remain under $0.01 \mathrm{~g} / \mathrm{kWh}$.
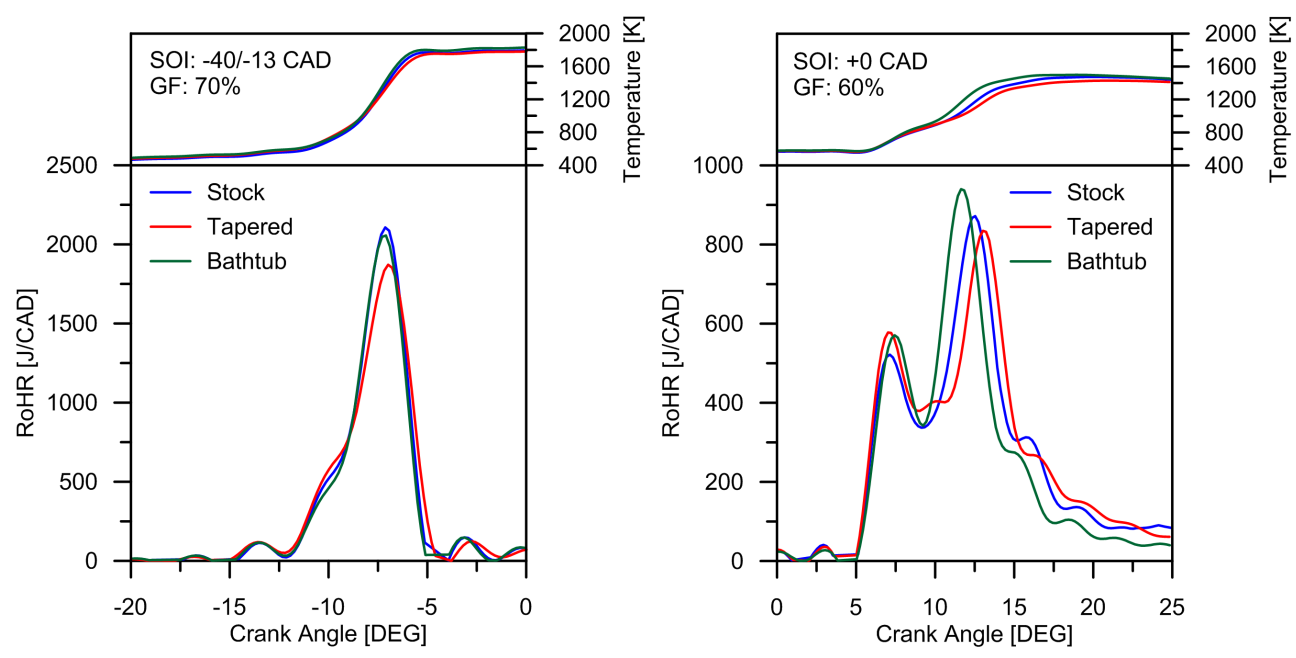

Figure 5.33. Experimental RoHR and bulk gas temperature of the most interesting tests with double (left) and single injection (right) for the three piston geometries at high load conditions.
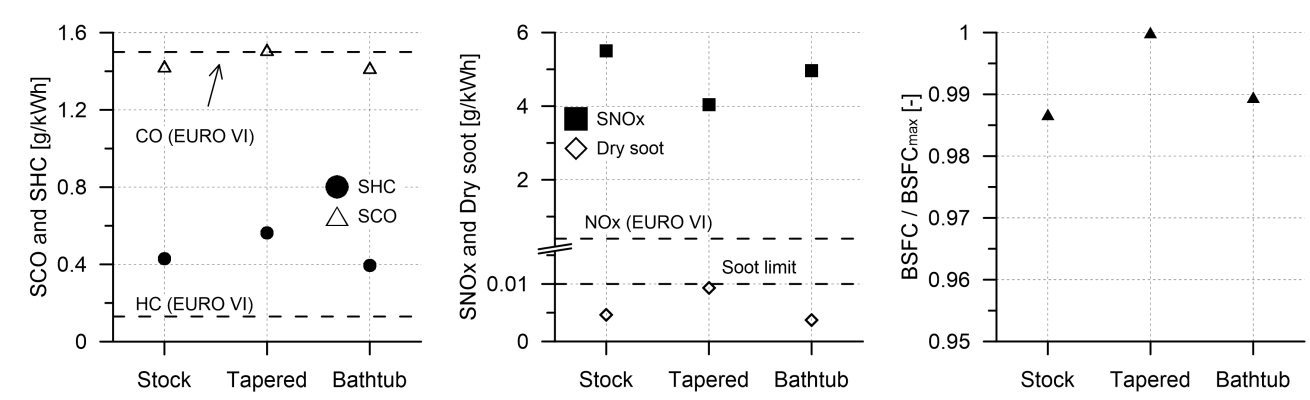

Figure 5.34. Engine-out emissions and fuel consumption for the three piston geometries at the representative condition of double injection strategy: $-40 /-13$ CAD $A T D C$ and $G F$ 70\%. 
Finally, it is worthy to note that, contrarily to the findings at low and medium load, the double injection is not a suitable strategy to achieve ultralow NOx and soot emissions simultaneously. In addition, the unacceptable knocking levels (PRR $>25$ bar/CAD) experienced with all the pistons discard the use of this injection strategy.

Focusing on the RoHR profiles for single injection depicted in figure 5.33, it is seen that the two new geometries provide very similar heat release during the first combustion stage, with higher peak than the stock piston. The subsequent evolution of the RoHR suggests differences in the combustion development between both geometries. Again, bathtub piston shows similar behavior than the stock geometry, with notable enhancement of the second combustion stage. This causes lower HC and CO levels, but NOx and soot emissions exceed the limits imposed (figure 5.35). The increase in NOx emissions is explained due to higher combustion temperature, while the rise in soot emissions should be related to the shallow bowl geometry, which worsens the charge motion and difficult the air-fuel mixing process. Regarding the tapered geometry, it shows an intermediate stage between both combustion phases with lower second RoHR peak than the other two geometries. Moreover, this piston shows a less steep expansion period, which explains the slightly higher HC and $\mathrm{CO}$ emissions. In spite of that, the tapered geometry allows fulfilling the limits imposed for NOx and soot with the best fuel consumption. At these delayed injection timings, the changes in combustion pattern between pistons must be related to the interaction of diesel spray with the piston geometry.
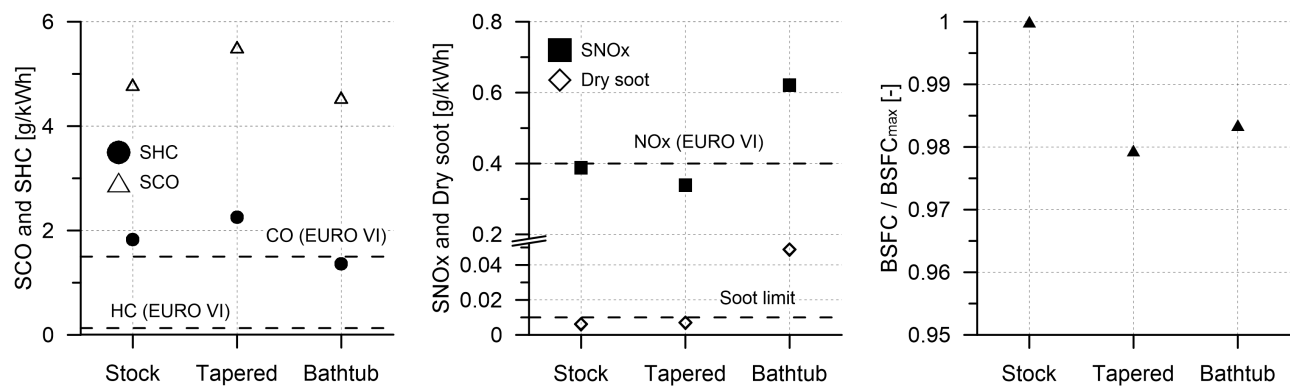

Figure 5.35. Engine-out emissions and fuel consumption for the three piston geometries at the representative condition of single injection strategy: $+0 C A D A T D C$ and GF $60 \%$. 


\subsection{Piston bowl geometry selection}

As done in chapter 4, a merit function [31] was applied to all the tests defined in the tables 5.4, 5.5 and 5.6. This method allows to identify the most suitable engine settings for each piston geometry at the different engine loads, according to certain criteria. In particular, the constrained values for the different variables used for calculating the merit function (MF) are: $\mathrm{NOx}=0.4 \mathrm{~g} / \mathrm{kWh}$, soot $=0.01 \mathrm{~g} / \mathrm{kWh}$ and maximum $\mathrm{PRR}=15 \mathrm{bar} / \mathrm{CAD}$. These limitations were aimed to fulfill the EURO VI limits while preserving the mechanical integrity of the engine.

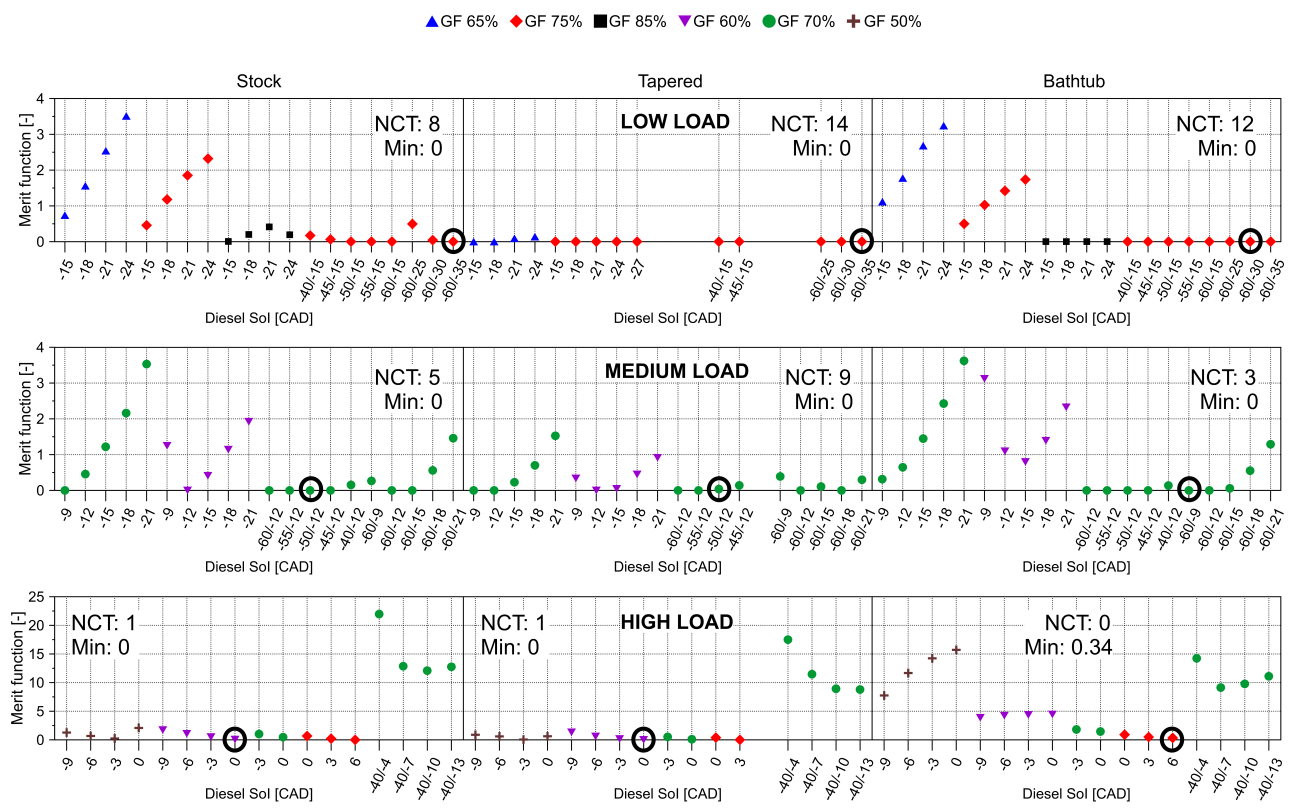

Figure 5.36. Merit function results for three constrained values: $N O x=0.4 \mathrm{~g} / \mathrm{kWh}$, soot $=0.01 \mathrm{~g} / \mathrm{kWh}$ and maximum $P R R=15 \mathrm{bar} / C A D$. Marked operating conditions are the ones that provide minimum MF values and lowest BSFC.

Figure 5.36 shows the merit function results for all the tests carried out in the current study, where each row correspond to the different engine loads and each column refers to the piston type. As it can be seen, for the same piston and load, several conditions provide MF values equal to zero, which indicates their compliance with all the constraints imposed. To account this, the number of compliant tests (NCT) for each fuel and engine load is included in the graph. The best condition among these cases was considered the one 
that minimized the brake specific fuel consumption (BSFC), and is marked in the figure with a round symbol. The specific MF values for the tests selected are shown below the $\mathrm{NCT}$ value.

The results show that, at low and medium load, all the piston geometries allow fulfilling the three constraint imposed $(\mathrm{MF}=0)$. Moreover, at low load, the two new geometries provide greater number of compliant tests than the stock piston. As engine load increases, the NCT decreases for any piston, which reveals the difficulty of achieving proper RCCI conditions. Thus, at high load conditions only one test is valid in the case of stock and tapered pistons, while no compliant condition is obtained with bathtub geometry. As will be shown later, the general increase of the MF values for bathtub piston at high load are consequence of its high sooting tendency.
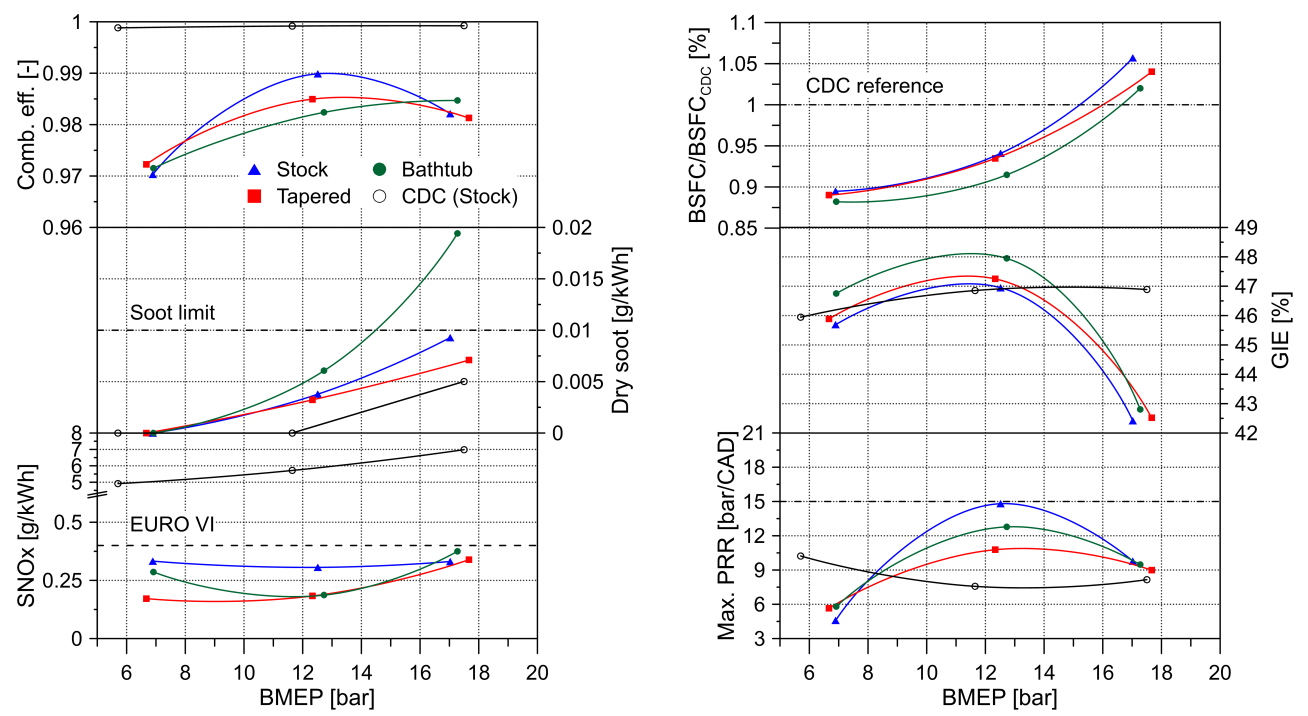

Figure 5.37. NOx, soot, combustion efficiency, maximum PRR, gross indicated efficiency and relative BSFC to CDC versus engine load for the best points of the different pistons.

To summarize and compare the best operating conditions for each piston, figure 5.37 represents the engine-out emissions (left) and performance results (right) of the tests previously selected. The results state that stock and tapered pistons lead to NOx and soot emissions under the EURO VI levels for all the engine loads. By contrast, bathtub geometry exceeds considerably the soot limitation at high load. This fact is consequence of the poor air-fuel mixing process due to the excessive shallow bowl, which becomes more evident 
when single injection strategies near TDC are used. Regarding combustion efficiency, the new geometries provide a slight increase at low and high load, while the stock geometry shows the best results at medium load conditions.

Focusing on engine performance, it is seen that bathtub piston allows the lowest BSFC in all the load range. Moreover, the stock and tapered geometries show near equal results from low to medium load, with slightly lower BSFC of tapered piston at high load. The gain in fuel economy diminishes as engine load increases for all the pistons due to the optimization of the OEM settings for CDC combustion. Another reason for this behavior is the decay of GIE at high load conditions for the three geometries, which is explained by the delayed single injection strategy used in all cases. Finally, the figure shows that the three pistons allow working under the maximum PRR limitation, showing greater values than CDC only at medium load conditions.

\subsection{Summary and conclusions}

The current chapter has proved that the heat transfer reduction by means of the piston bowl geometry modification is a suitable method for improving the efficiency of RCCI concept. For this purpose, two piston bowl geometries were proposed to be studied following the main guidelines found in literature:

- To reduce the surface-to-volume ratio

- To promote more quiescent combustion chamber

The first geometry evaluated was named as tapered, as its main modification versus the stock piston was done in the squish cavity. In particular, a tapered shape was conferred in the piston head to reduce the heat transfer coefficient in this zone. This modification also reduced the bowl surface area in around 6\%. The second geometry, named as bathtub, was focused on achieving the greatest reduction possible in piston surface area versus the stock geometry, which was found to be $16 \%$ considering the available blank pistons. Both geometries were tested experimentally and compared versus the stock piston from low to high load conditions.

The parametric sweeps at low load showed great differences between the combustion pattern of the three pistons. To understand the different behavior, a detailed analysis of the heat transfer process and combustion losses was performed by means of CFD calculations. The results showed that the more pronounced bowl of the stock piston enhanced the mixing process providing 
earlier SOC than bathtub and tapered geometries. In spite of these differences, all pistons allowed ultra-low NOx and soot emissions whatever the injection strategy used. Also, the new geometries resulted in equal or slightly increased $\mathrm{CO}$ and $\mathrm{HC}$ levels due to the smoother combustion process. By contrast, at medium load, the reduced heat transfer losses due to the remarkable lower surface-to-volume ratio of bathtub piston promoted higher combustion temperature peaks, which contributed to reduce combustion losses and fuel consumption. At these conditions only the double injection strategy was found adequate to maintain NOx and soot emissions under the imposed levels. At this engine load, the tapered geometry showed singular combustion behavior, with smoother and larger second combustion stage. Finally, at high load, a delayed single injection pattern was required to reach low NOx and soot emissions with moderated pressure rise rates. In this case, the tapered piston showed more promising results than the stock and bathtub geometries, with low emissions and fuel consumption.

The direct comparison of the best conditions for the three pistons suggested that the two new geometries provide greater efficiency to RCCI concept than the stock geometry. In particular, the bathtub piston showed the greatest efficiency in all the load range, but unfortunately the flat geometry of the bowl resulted in unacceptable soot emissions using single injection strategies at high load. Since the use of single injection was found to be mandatory to reach moderated PRR at high load, this implies that bathtub geometry would not be suitable for extending the RCCI concept up to full load. In terms of BSFC, the tapered and stock geometries showed very similar results, with only minor differences at high load conditions. Thus, since the rest of the constrained parameters remained below the limits in both cases, it is not possible to ensure which one of these two geometries performs better without doing a dedicated optimization work. 


\section{Bibliography}

[1] Payri F. and Desantes J.M. Motores de combustión interna alternativos. Editorial Reverté, 2011.

[2] Giakoumis E.G. "Cylinder wall insulation effects on the first- and second-law balances of a turbocharged diesel engine operating under transient load conditions". Energy Conversion and Management, Vol. $48 \mathrm{n}^{\circ}$ 11, pp. 2925-2933, 2007.

[3] Shabir M.F., Authars S., Ganesan S., Karthik R. and Kumar Madhan S. "Low Heat Rejection Engines - Review". SAE Technical Paper, no 2010-01-1510, 2010.

[4] Cengel Y. and Boles M. Thermodynamics: An Engineering Approach Sixth Edition (SI Units). McGraw-Hill, 2007.

[5] Kokjohn S., Hanson R., Splitter D. and Reitz R.D. "Fuel reactivity controlled compression ignition (RCCI): a pathway to controlled high-efficiency clean combustion". International Journal of Engine Research, Vol. 12 n 3, pp. 209-226, 2011.

[6] Kamo R. and Bryzik W. "Adiabatic Turbocompound Engine Performance Prediction". SAE Technical Paper, $\mathrm{n}^{\circ}$ 780068, 1978.

[7] Kamo R. and Bryzik W. "Cummins/TACOM Advanced Adiabatic Engine". SAE Technical Paper, $\mathrm{n}^{\circ}$ 840428, 1984.

[8] Woschni G., Spindler W. and Kolesa K. "Heat Insulation of Combustion Chamber Walls - A Measure to Decrease the Fuel Consumption of I.C. Engines?". SAE Technical Paper, $\mathrm{n}^{\circ} 870339,1987$.

[9] Miyairi Y. "Computer Simulation of an LHR DI Diesel Engine". SAE Technical Paper, $\mathrm{n}^{\circ} 880187,1988$.

[10] French C.C.J. "Ceramics in Reciprocating Internal Combustion Engines". SAE Technical Paper, $\mathrm{n}^{\circ}$ 841135, 1984.

[11] Bruns L., Bryzik W. and Kamo R. "Performance Assessment of US. Army Truck with Adiabatic Diesel Engine". SAE Technical Paper, no 890142, 1989.

[12] Assanis D.N., Wiese K., Schwarz E. and Bryzik W. "The Effects of Ceramic Coatings on Diesel Engine Performance and Exhaust Emissions". SAE Technical Paper, n ${ }^{\circ} 910460$, 1991.

[13] Wade W.R., Havstad P.H., Ounsted E.J., Trinkler F.H. and Garwin I.J. "Fuel Economy Opportunities with an Uncooled DI Diesel Engine". C432, pp.11-24, ImechE/SAE 1984, 1984 .

[14] Havstad P.H., Garwin I.J. and Wade W.R. "A Ceramic Insert Uncooled Diesel Engine". SAE Technical Paper, $\mathrm{n}^{\circ}$ 860447, 1986.

[15] Dickey D.W. "The Effect of Insulated Combustion Chamber Surfaces on DirectInjected Diesel Engine Performance, Emissions and Combustion". SAE Technical Paper, $\mathrm{n}^{\circ} 890292,1989$.

[16] Cheng W.K., Wong V.W. and Gao F. "Heat Transfer Measurement Comparisons in Insulated and Non-Insulated Diesel Engines". SAE Technical Paper, nº 890570, 1989.

[17] Jaichandar S. and Tamilporai P. "Low Heat Rejection Engines - An Overview". SAE Technical Paper, $\mathrm{n}^{\circ}$ 2003-01-0405, 2003.

[18] Saad D., Saad P., Kamo L., Mekari M., Bryzik W., Schwarz E. and Tasdemir J. "Thermal Barrier Coatings for High Output Turbocharged Diesel Engine". SAE Technical Paper, n ${ }^{\circ}$ 2007-01-1442, 2007. 
[19] Serrano J.R., Arnau F.J., Martín J., Hernández M. and Lombard B. "Analysis of Engine Walls Thermal Insulation: Performance and Emissions". no 2015-01-1660, 2015.

[20] Tricoire A., Bjellman B., Wigren J., Vanvolsem M., Aixala L. and Serrano J.R. "Insulated piston fire face for diesel engines". International Thermal Spray Conference ITSC.

[21] Tricoire A., Bjellman B., Wigren J., Vanvolsem M. and Aixala L. "Insulated Piston Heads for Diesel Engines". Journal of Thermal Spray Technology, Vol. 18 n $^{\circ}$ 2, pp. $217-$ 222,2009

[22] Kosaka H., Wakisaka Y., Nomura Y., Hotta Y., Koike M., Nakakita K. and Kawaguchi A. "Concept of "Temperature Swing Heat Insulation" in Combustion Chamber Walls, and Appropriate Thermo-Physical Properties for Heat Insulation Coat". SAE Int. J. Engines, Vol. 6, pp. 142-149, 2013.

[23] Hoffman M.A., Lawler B.J., Güralp O.A., Najt P.M. and Filipi Z.S. "The impact of a magnesium zirconate thermal barrier coating on homogeneous charge compression ignition operational variability and the formation of combustion chamber deposits". International Journal of Engine Research, Vol. 16 n 8, pp. 968-981, 2015.

[24] Hoffman M.A. Characterization of combustion chamber deposits formed during homogeneous charge compression ignition and the impact of a thermal barrier coating on deposit accumulation and HCCI operability. Doctoral Thesis, The University of Michigan, 2012.

[25] Styron J., Baldwin B., Fulton B., Ives D. and Ramanathan S. "Ford 2011 6.7L Power Stroke ${ }^{\circledR}$ Diesel Engine Combustion System Development”. SAE Technical Paper, $\mathrm{n}^{\circ}$ 2011-01-0415, 2011.

[26] Dolak J.G., Shi Y. and Reitz R.D. "A Computational Investigation of Stepped-Bowl Piston Geometry for a Light Duty Engine Operating at Low Load". SAE Technical Paper, no 2010-01-1263, 2010.

[27] Kono M., Basaki M., Ito M., Hashizume T., Ishiyama S. and Inagaki K. "Cooling Loss Reduction of Highly Dispersed Spray Combustion with Restricted In-Cylinder Swirl and Squish Flow in Diesel Engine". SAE Int. J. Engines, Vol. 5, pp. 504-515, 2012.

[28] Heywood J.B. Internal Combustion Engine Fundamentals. McGraw-Hill, Inc., p.674, 1988.

[29] Splitter D., Wissink M., Kokjohn S. and Reitz R.D. "Effect of Compression Ratio and Piston Geometry on RCCI Load Limits and Efficiency". SAE Technical Paper, $\mathrm{n}^{\circ}$ 2012-01-0383, 2012.

[30] Hanson R., Curran S., Wagner R., Kokjohn S., Splitter D. and Reitz R.D. "Piston Bowl Optimization for RCCI Combustion in a Light-Duty Multi-Cylinder Engine". SAE International Journal of Engines, Vol. 5 n ${ }^{\circ}$ 2, pp. 286-299, 2012.

[31] Cheng A.S. (Ed), Upatnieks A. and Mueller C.J. "Investigation of Fuel Effects on Dilute, Mixing-Controlled Combustion in an Optical Direct-Injection Diesel Engine". Energy \& Fuels, Vol. 21 n $^{\circ}$ 4, pp. 1989-2002, 2007. 



\section{Chapter 6}

\section{Effect of intermediate ethanol-gasoline blends on RCCI combustion}

Contents

6.1 Introduction..................... 177

6.2 Background and conditions of the study ...... 178

6.2.1 Alternative fuels for internal combustion engines . 178

6.2.2 Fuels used and methodology considerations...... 182

6.3 Low load study $\ldots \ldots \ldots \ldots \ldots \ldots \ldots \ldots \ldots \ldots . \quad 183$

6.3.1 Effect of low reactivity fuel properties on RCCI ... 183

6.3.1.1 Test conditions ................... 184

6.3.1.2 Results ...................... 185

6.3.2 Gas properties modification for improved reactivity 190

6.3.2.1 Test conditions ................... 191

6.3.2.2 Combustion development comparison.... 192

6.3.2.3 Engine-out emissions results . ........ 197

6.3.2.4 Discussion ....................... 199

6.4 Evaluation of the suitable LRF for extended load operation....................... 202

6.4.1 Medium load results..................... 202

6.4.1.1 Test conditions ................... 202

6.4.1.2 Results ...................... 203

6.4 .2 High load results........................ 208 


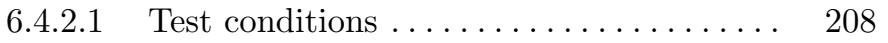

6.4.2.2 Results ................... 209

6.5 Low reactivity fuel selection .............. 214

6.6 Summary and conclusions . . . . . . . . . . 219

Bibliography $\ldots \ldots \ldots \ldots \ldots \ldots \ldots \ldots \ldots \ldots \ldots \ldots \ldots \ldots \ldots$ 


\subsection{Introduction}

As described in chapter 2, RCCI concept relies on ignitability stratification to overcome the main drawbacks found in literature with respect to other LTC strategies. To achieve this, RCCI combustion mode allows actuating on several degrees of freedom.

As demonstrated in chapter 4 and chapter 5 , an effective solution to modulate the in-cylinder reactivity stratification is by controlling the diesel injection settings, which allows the equivalence ratio and reactivity stratification inside the combustion chamber. However, considering the results presented in chapter 4 , the diesel injection pattern (single or double) and timing are limited to a certain range if simultaneous reduction in NOx and soot emissions is desired, while keeping a proper combustion phasing to maximize gross indicated efficiency.

Another variable to modify the local reactivity in RCCI concept is the fuel blending ratio, which must be managed depending on the engine operating conditions to obtain the maximum efficiency of the concept. In this sense, previous chapters demonstrated that in order to achieve high efficiency while reducing NOx and soot emissions, the higher portion of the fuel mass should come from the low reactivity fuel. Thus, it is expected that not only the low reactivity fuel (LRF) amount injected, but also its physicochemical properties, may play a fundamental role on local reactivity and RCCI combustion characteristics. To assess this effect, the present chapter proposes the use of four different LRFs, thus providing different reactivity gradients between the low and high reactivity fuels.

Following the objectives of this thesis, the results presented in this chapter are divided in three main blocks:

- First, a specific study at low load to understand the main differences observed in RCCI combustion and emissions due to the LRF modification is presented. In this case, the isolated effect of the fuel properties as well as the potential of modifying the intake charge characteristics for improving the baseline results are investigated.

- Later, the capabilities for extending the use of the different fuels from low to high load are studied and discussed.

- Finally, the chapter closes with the selection of the most suitable LRF for extended load operation. This selection is made based on their potential for improving RCCI combustion efficiency, performance and emissions. 


\subsection{Background and conditions of the study}

This section briefly reviews the main alternative fuels used in internal combustion engines (ICEs). First of all, the motivation of their usage from the environmental point of view is presented. In a second subsection, the particular fuels used in the current study and some considerations about the methodology followed to perform the experimental tests are introduced.

\subsubsection{Alternative fuels for internal combustion engines}

As described in chapter 1, ICEs are responsible of near $60 \%$ of the energy consumption of petroleum products in Europe [1]. This data proves that, in addition to the need of developing advanced combustion strategies looking for high efficiency and ultra-low emissions, it is necessary that alternative fuels be investigated in parallel to reduce the dependence on petroleum and minimize the environmental impact of transport sector. For this purpose, the Renewable Energy Directive (RED) establishes that all EU countries must ensure that at least $10 \%$ of their transport fuels come from renewable sources by 2020 [2]. Considering that the use of renewable liquid fuels would only demand a moderate evolution of both the vehicle technology and fuel distribution infrastructure, they are claimed as the most potential route to decarbonizing transportation.

Within the group of renewable liquid fuels, bioethanol and biodiesel have shown great potential as automotive fuels because they allow a successful reduction of engine-out emissions from conventional combustion processes, and can be made from a wide variety of feedstocks [3]. By these reasons, these two biofuels represent the most significant volume share in the future biofuels marketing scenarios considered to meet the 2020 target [4]. Thus, despite the maximum content currently allowed in the regular fuels in Europe is limited to $7 \%$ of biodiesel (in diesel) and $10 \%$ of ethanol (in gasoline) by volume [5], the use of higher blending ratios will be necessary to reach the objectives imposed by the RED.

Taking into account the key role that biofuels will play in road transport, the addition of ethanol to gasoline has been considered as the way of modifying the LRF characteristics to perform the current study. Thus, it is useful to summarize the fuel property effects of blending ethanol with gasoline:

- The lower heating value (LHV) of pure ethanol is approximately $33 \%$ less than that of gasoline on a volumetric basis. Thus, the energy content of the blend decreases as the ethanol content is increased. 
- The enthalpy of vaporization (HoV) of pure ethanol is about 2.5 times greater than gasoline per unit mass of fuel, which increases the amount of energy required to evaporate the liquid blend.

- The research octane number (RON) and motored octane number (MON) of pure ethanol are higher than those of gasoline. Thus, the chemical reactivity of the blend decreases as ethanol content is increased.

- The addition of ethanol shows a non-intuitive behavior on the Reid vapor pressure (RVP) of the blend. In particular, the RVP of the mixture remains higher than that of the base gasoline as ethanol is increased up to $45 \%$ by volume, but further increase in ethanol content results in lower RVP than gasoline [6].

The impact of ethanol properties when used as fuel in conventional and advanced combustion concepts are briefly commented next:

\section{Spark ignition engines}

Ethanol has been widely studied as direct substitute of gasoline fuel for spark ignition (SI) engines, showing promising results in terms of performance and engine-out emissions [7]. In particular, it was shown that the faster flame speed of alcohol fuels enhances the fuel conversion efficiency [8], thus reducing $\mathrm{HC}$ and $\mathrm{CO}$ emissions compared to gasoline $[9,10]$. Moreover, the charge cooling effect associated to the great $\mathrm{HoV}$ of ethanol leads to higher volumetric efficiency than gasoline [11], which also contributes to decrease the combustion temperatures and therefore the NOx emissions.

In spite of these benefits, the direct burning of ethanol in conventional SI engines is not optimal for several reasons. First, despite ethanol provides a substantial increase in knock resistance due to its high values of RON and sensitivity (RON-MON), the typical SI engines are limited by peak cylinder pressure at high loads and thus this advantage cannot be fully utilized. Second, the high HoV and low RVP compared to gasoline lead to poor vaporization, which results in ignition and emissions problems at low ambient temperatures, especially during cold start [12]. Finally, the lower LHV reduces the energy content per volume, which in turn decreases the volumetric fuel economy and the driving range before refueling, being both important factors for customer satisfaction. Thus, the most effective application of ethanol in spark ignition engines was demonstrated to be as ethanol-gasoline blend, where the use of optimized percentages of ethanol in the blend provided enough improvement 
in thermal efficiency to offset the penalty in volumetric energy density [13].

\section{Compression ignition engines}

The potential of ethanol to be used in CI engines has been also investigated in literature, concluding that the low cetane number of ethanol makes it unsuitable as direct substitute for diesel fuel. Nevertheless, it was found that a possibility for exploiting the autoignition characteristics of ethanol is by blending it with diesel fuel and injecting the mixture of both fuels in the same way as in a conventional diesel engine $[14,15]$.

When emulsified in a proper manner, the higher HoV, higher auto-ignition temperature and higher RON of ethanol permit raising the compression ratio (CR) of the engine [16], which provides higher the thermal efficiency. Moreover, the addition of ethanol to diesel fuel results in a simultaneous reduction of NOx and soot emissions, with deteriorated unburned $\mathrm{HC}$ and CO especially at lower loads but improved at higher loads [17].

In spite of that, several drawbacks were also found. First, due to the high cost of dehydration procedure during the ethanol production process, the commercial grades of ethanol typically have $10 \%$ to $20 \%$ water content, which reduces the solubility and enhances the phenomenon of phase separation. This makes the use of ethanol-diesel blends unsuitable when ethanol contents higher than $5 \%$ by volume are used. In these cases, the utilization of additives is needed to keep the blends in homogeneous and stable state [18]. In addition, under higher amount of diesel substitution, ignition-improving additives are also needed to attain suitable ignition [19], which rest potential to the concept. Finally, it was found that the increase in thermal efficiency through the use of higher CR does not compensate the reduced LHV of ethanol, which results in higher fuel consumption than CDC operation. Moreover, the in-cylinder peak pressure increases at high loads due to prolonged ignition delay, which can compromise the durability of the engine.

\section{Low temperature combustion concepts}

More recently, the pursuit of developing clean burning, high efficiency engines has motivated the use of ethanol in LTC concepts [20-22]. Ethanol was considered as potential fuel for this type of combustion due to its low reactivity, which was found to be the most suitable pathway to achieve the separation between the end of the main injection and the start combustion required in these combustion strategies [23, 24]. In addition, the higher knock resistance of ethanol than gasoline allows operating in CI engines with higher 
compression ratio, which entails efficiency advantages [25]. Moreover, the high oxygen content of ethanol contributes to reduce soot emissions, which is a primary objective of the lean premixed combustion modes [26].

Investigations using ethanol as fuel for HCCI combustion confirmed that its high $\mathrm{HoV}$ and great autoignition resistance have a considerable effect on the combustion event compared to gasoline [27]. In particular, for the same thermodynamic conditions, combustion phasing results delayed and therefore the peak load limit can be increased. In addition, operating under negative valve overlap conditions for promoting more favorable thermodynamic conditions, ethanol can realize HCCI combustion with relatively leaner mixture and can extend the attainable operating range to higher speeds compared to gasoline [28]. By contrast, some disadvantages such as poor volumetric fuel economy due to the reduced LHV, and difficulty in starting due to low volatility at low temperatures were found.

The high flexibility of RCCI concept allows addressing this shortcoming by managing the diesel injection settings to provide more reactive conditions when required. As literature demonstrates, the most extensive research about RCCI operation using ethanol has been developed using E85 as LRF, which is available on some markets in Europe and in America [29-31]. Despite the studies found in literature deliver mixed conclusions on the maximum E85 fraction for successful engine operation, all them concluded that E85 can reduce effectively NOx and soot emissions to ultra-low values [32]. Moreover, it was found that the combination of the higher $\mathrm{ON}$ and the intake charge cooling effect of E85 allowed a significant load expansion compared to the diesel/gasoline operation [33]. By contrast, these properties lead to much higher $\mathrm{HC}$ and $\mathrm{CO}$ emissions than diesel/gasoline operation, showing an abrupt rise in both pollutants and more unstable combustion as E85 fraction increases [32, 34]. Regarding thermal efficiency, E85 showed worse efficiency than diesel/gasoline operation at low loads but better at high loads, affecting in the same way to the BSFC.

Despite many researchers have focused on investigate intensively the E85 fuel grade, ethanol is able to be blended with gasoline in intermediate ratios that typically range from $10 \%$ (E10) to $85 \%$ (E85) by volume, which offers the possibility of performing wide variations in the fuel blend composition. Thus, in addition to E85, this chapter considers three additional intermediate ethanol-gasoline blends as LRF candidates for RCCI operation. Specifically, the blends studied contain a maximum of $20 \%$ ethanol by volume and different octane number gasolines, 95 and 98 . This relatively low ethanol quantity compared to E85 and the variation in gasoline $\mathrm{ON}$ are intended to find 
the proper reactivity gradient between the high and low reactivity fuels that allows exploiting the characteristics of ethanol while minimizing some of the drawbacks related to diesel/E85 operation (high amount of HC and $\mathrm{CO}$ emissions, low thermal efficiency at low load and reduced volumetric fuel economy). The specific fuels used and their detailed properties are presented in the next section.

\subsubsection{Fuels used and methodology considerations}

Considering the mandatory presence of biofuels in the future context of road transport, the ability of ethanol to be blended with gasoline and the main conclusions extracted from RCCI literature regarding E85 fuel, the low reactivity fuels selected to approach the objectives of this chapter are E10-95, E10-98, E20-95 and E85. In addition, a diesel fuel containing the maximum biodiesel percentage currently allowed to be distributed as a regular fuel grade, $7 \%$ by volume, has been used as high reactivity fuel during all the study. This will be referred to as diesel B7. The main characteristics of the five fuels are listed in table 6.1. All the properties were obtained following ASTM standards.

Table 6.1. Physical and chemical properties of the fuels used in this chapter.

\begin{tabular}{llllll} 
& \hline Diesel B7 & E10-95 & E20-95 & E10-98 & E85 \\
\hline Density $\left(\mathrm{T}=15^{\circ} \mathrm{C}\right)\left[\mathrm{kg} / \mathrm{m}^{3}\right]$ & 837.9 & 739 & 745 & 755 & 781 \\
Viscosity $\left(\mathrm{T}=40^{\circ} \mathrm{C}\right)\left[\mathrm{mm}^{2} / \mathrm{s}\right]$ & 2.67 & - & - & - & - \\
RON [-] & - & 98.8 & 99.1 & 103 & 108 \\
MON [-] & - & 85.2 & 85.6 & 90 & 89 \\
Cetane number [-] & 54 & - & - & - & - \\
Biodiesel content by vol. [\%] & 7 & - & - & - & - \\
Ethanol content by vol. [\%] & - & 9.7 & 19.7 & 9.7 & 84.7 \\
Oxygen content by mass [\%] & 0.8 & 3.5 & 6.6 & 3.5 & 29.7 \\
Lower heating value [MJ $/ \mathrm{kg}]$ & 42.61 & 41.32 & 40.05 & 41.29 & 31.56 \\
\hline
\end{tabular}

As demonstrated in previous chapters, to achieve high efficiencies in a wide range of engine loads during RCCI operation, the mass ratio of low reactivity fuel to high reactivity fuel should be changed accordingly. This requirement has been also demonstrated to be necessary when varying the engine speed [35]. The parameter defined in previous chapters for accounting that variation was the gasoline fraction (GF), which was defined as the mass ratio of gasoline to the total fuel. However, due to the significant differences in lower heating 
value (LHV) between E85 and the three remaining low reactivity fuels, the premixed energy ratio (PER) is defined here. Thus, the PER accounts the ratio of energy of the low reactivity fuel to the total energy (equation 6.1), where the low reactivity fuel and the high reactivity one are denoted by the subscripts LRF and HRF respectively.

$$
P E R=\frac{m_{L R F} \cdot L H V_{L R F}}{m_{L R F} \cdot L H V_{L R F}+m_{H R F} \cdot L H V_{H R F}}
$$

\subsection{Low load study}

The spatial results from the computational calculations presented in chapter 4 showed that great part of $\mathrm{HC}$ and $\mathrm{CO}$ emissions were associated to bad burning of iso-octane around the center line of the cylinder, which resulted to be the main cause of efficiency loss at low load $[36,37]$. Thus, this section aims at evaluating the influence of the reactivity gradient between the high and low reactivity fuels and its repercussion on RCCI performance and emissions at low load. In this sense, a suitable combination of both fuels could improve the combustion propagation, thus increasing the completeness of the combustion and the efficiency of the concept.

To address the objective of this section, two different studies have been proposed. In the first part, the isolated effect of the LRF properties on RCCI combustion is studied by keeping the thermodynamic conditions constant at the time of the LRF injection. In the second part, the response of each LRF to variations in gas composition and fuel blending is investigated by performing a batch of experiments at constant combustion phasing (CA50). There, a detailed study of the combustion process by means of the RoHR analysis is presented. Also, the differences in engine-out emissions between fuels and their potential to reduce the $\mathrm{HC}$ and $\mathrm{CO}$ emissions are explored.

\subsubsection{Effect of low reactivity fuel properties on RCCI}

The present section focuses on providing a first approach about the influence of fuel properties on RCCI combustion. Thus, to ensure that the changes observed in emissions and performance are associated only to differences in LRF properties, the thermodynamic conditions at the time of the LRF injection must be equal in all cases. The particular engine test conditions are detailed in the next subsection. 


\subsubsection{Test conditions}

To evaluate the influence of the LRF properties on low load RCCI combustion, a batch of parametric studies of the key variables governing the fuel reactivity stratification (diesel injection timing and PER) are proposed. To isolate the effect of fuel properties, the intake charge conditions were maintained equal between tests. The baseline values for the different engine settings fixed during this study are summarized in table 6.2.

Table 6.2. Constant engine settings at low load conditions.

\begin{tabular}{ll}
\hline \hline Engine speed [rpm] & 1200 \\
Intake charge temperature $\left[{ }^{\circ} \mathrm{C}\right]$ & 40 \\
EGR [\%] & 45 \\
Intake pressure [bar] & 1.35 \\
Exhaust pressure [bar] & 1.15 \\
Piston bowl geometry [-] & Stock \\
Effective CR [-] & $14.4: 1$ \\
Diesel injection pressure [bar] & 700 \\
Low reactivity fuel inj. pressure [bar] & 5.5 \\
Low reactivity fuel inj. timing [CAD ATDC] & 385 \\
\hline
\end{tabular}

On the other hand, table 6.3 shows the different engine settings varied during the parametric studies. In particular, the diesel injection settings (injection timing and total fuel mass) and the injected fuel mass of the different LRFs for the different PERs are depicted. Following the guidelines provided in chapter 4, a highly advanced injection strategy with the pilot event fixed at -60 CAD ATDC was selected for the diesel fuel. Moreover, with the aim of minimizing soot emissions, the diesel fuel mass was distributed 60/40\% between the pilot and main injection.

The most delayed $\mathrm{SOI}_{\text {main }}$ for the sweep was set at -20 CAD ATDC to prevent the combustion event developing during compression stroke, and therefore avoid the subsequent increase in NOx emissions. The most advanced one was defined at -50 CAD ATDC. Nevertheless, this value was limited by the appearance of misfire conditions, which resulted from the too lean diesel distribution at SOC. Thus, only the $\mathrm{SOI}_{\text {main }}$ values shown in the table could be tested experimentally. As can be seen, the misfire effect was more noticeable as PER increased, occurring even at more delayed $\mathrm{SOI}_{\text {main }}$. Finally, the values 
proposed for the PER sweep were selected to provide a wide range of fuel reactivity conditions.

The very low reactivity of E85 made impossible to perform the tests under the baseline conditions proposed, leading to no combustion at all. By this reason, only the results of E20-95, E10-98 and E10-95 are presented here, while the behavior of E85 fuel will be analyzed in next sections.

Table 6.3. Operating parameters at medium load conditions. Diesel main injection timing sweep for the different fuels and PERs.

\begin{tabular}{lllllll}
\hline \hline \multicolumn{3}{c|}{ Diesel } & \multicolumn{4}{c}{ Low reactivity fuels } \\
\hline $\begin{array}{l}\text { SOI }_{\text {pilot }} \\
{[\mathrm{CAD}]}\end{array}$ & $\begin{array}{l}\mathrm{SOI}_{\text {main }} \\
{[\mathrm{CAD}]}\end{array}$ & $\begin{array}{l}\text { Total mass } \\
{[\mathrm{mg}]}\end{array}$ & $\begin{array}{l}\text { PER } \\
{[\%]}\end{array}$ & $\begin{array}{l}\text { E20-95 } \\
{[\mathrm{mg}]}\end{array}$ & $\begin{array}{l}\text { E10-95 } \\
{[\mathrm{mg}]}\end{array}$ & $\begin{array}{l}\text { E10-98 } \\
{[\mathrm{mg}]}\end{array}$ \\
\hline \multirow{4}{*}{-60} & -20 to -35 & 24.5 & 64 & 45.5 & 44.1 & 44.1 \\
& -20 to -35 & 21 & 69 & 49 & 47.5 & 47.5 \\
& -20 to -30 & 17.5 & 74 & 52.5 & 50.9 & 50.9 \\
& -20 & 14 & 79 & 56 & 54.3 & 54.3 \\
\hline
\end{tabular}

\subsubsection{Results}

Figure 6.1 shows the influence of fuel properties on RCCI combustion at low load by means of several combustion tracers. In particular, the maximum RoHR peak, combustion duration (CA90-SOC) and combustion phasing (CA50) are represented as a function of the diesel SOI main for two different PERs. For the sake of clarity, only the results corresponding to PER $64 \%$ and $74 \%$ are depicted to explain the phenomena occurring, being the general findings also valid for the other PERs.

The trend of the results with respect to $\mathrm{SOI}_{\text {main }}$ are similar between fuels, showing lower RoHR peaks and larger combustion events as $\mathrm{SOI}_{\text {main }}$ is delayed. As can be seen, the sensitivity of CA50 to diesel $\mathrm{SOI}_{\text {main }}$ is very similar for all the fuels at each PER. The low sensitivity found is consequence of the highly advanced injection strategy, which produces more homogeneous distributions of in-cylinder equivalence ratio and fuel mixture octane number. This fact tends to make the charge more dependent on initial thermodynamic conditions, thus reducing the effectiveness of the RCCI combustion control mechanisms.

From the figure, it can be seen that the increase in PER provides a great reduction in the heat release peak as well as more delayed and wider 
combustion development, whatever the fuel blend and SOI main conditions. This is due to the reduced in-cylinder global reactivity as the LRF fraction in the mixture is increased.
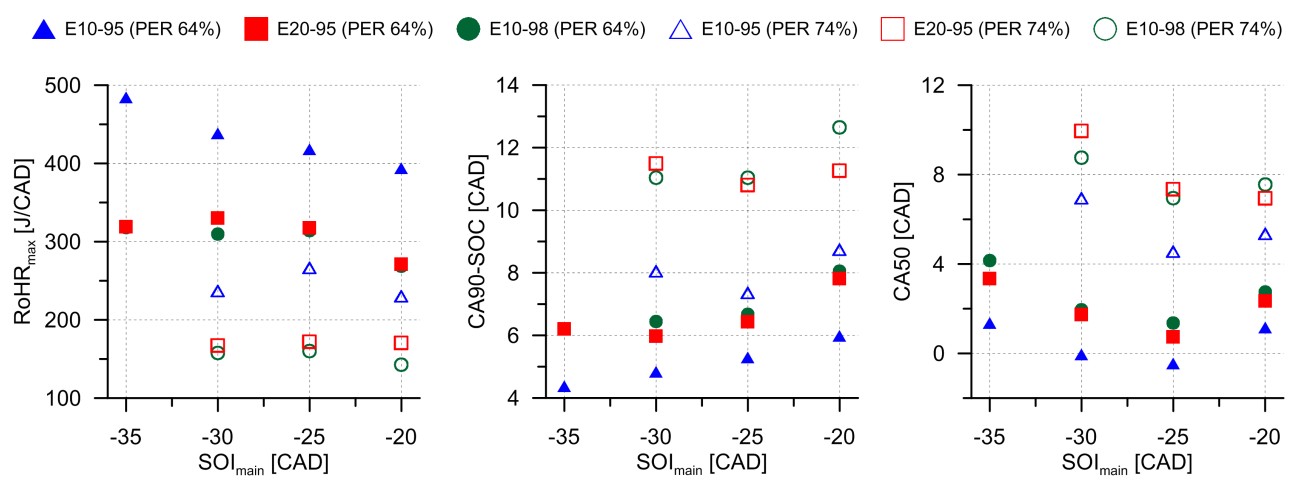

Figure 6.1. Influence of fuel properties and PER on some combustion tracers as a function of diesel SOI main .

Finally, the comparison between fuels at certain PER shows that the more reactive properties of $\mathrm{B} 7+\mathrm{E} 10-95$ result in shorter and advanced combustion development with higher maximum RoHR peaks. In particular, E10-95 with PER 74\% leads to similar combustion durations than E20-95 and E10-98 with PER $64 \%$, in spite of the less favorable thermodynamic conditions because of the more delayed combustion event in the cycle. On the other hand, it is observed that an almost equal combustion development is attained for

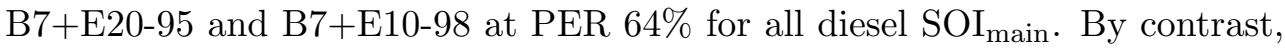
higher differences are found with PER $74 \%$, were the great octane number (ON) of E10-98 provides more degraded combustion.

The effects of each variable described before can be confirmed by comparing the RoHR profiles depicted in figure 6.2. In addition, the figure shows the effect of $\mathrm{SOI}_{\text {main }}$ on RoHR shape, which is not totally described by means of the combustion metrics presented in figure 6.1. As can be seen, the most advanced SOI main (-30 CAD ATDC) provides a well-mixed charge and then, a relatively fast one-staged heat release is attained when the proper thermodynamic conditions are reached. By contrast, the most delayed SOI main (-20 CAD ATDC) results in two-staged heat release events for all fuel blends and PERs. In this case, the lower extra mixing time (SOC-EOI $\left.\mathrm{I}_{\text {main }}\right)$ available as diesel $\mathrm{SOI}_{\text {main }}$ is delayed provides richer equivalence ratio distribution at SOC and enhances the premixed phase, which is mainly related to diesel fuel burning with a minimum amount of entrained LRF. This change in RoHR 
shape partially explains the downward trend of the maximum RoHR peak with $\mathrm{SOI}_{\text {main }}$. Lastly, the effect of the LRF octane number is clearly observed by comparing the maximum peaks of the RoHR profiles between the different fuels, where the greater portion of the LRF is consumed.
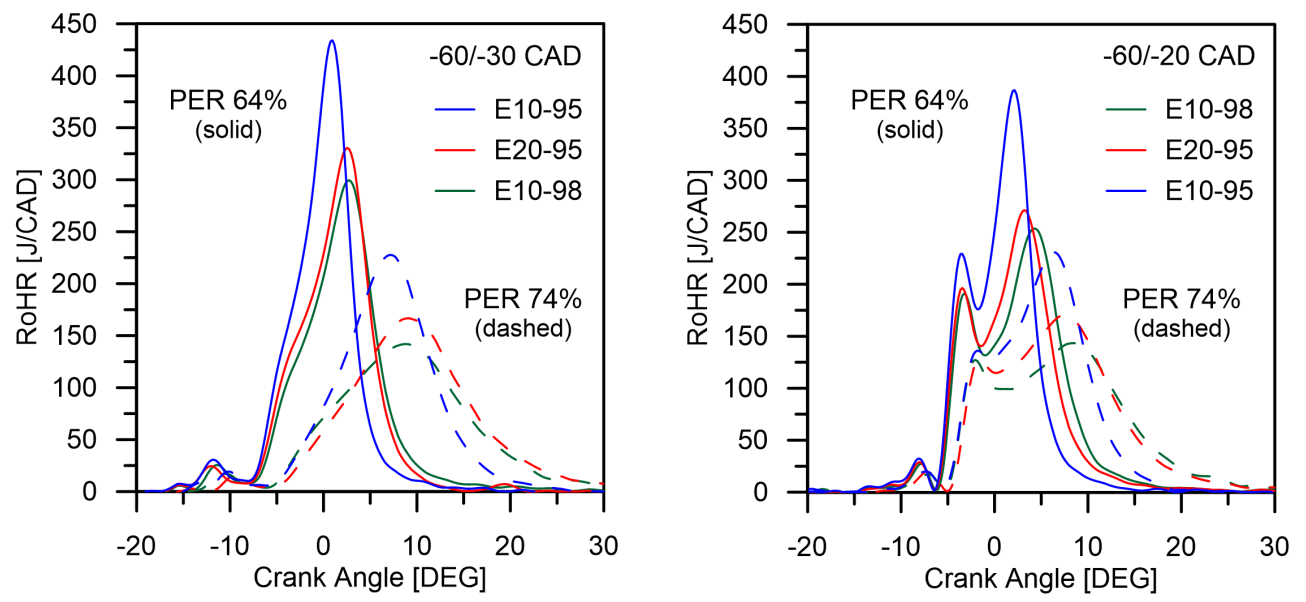

Figure 6.2. Influence of fuel properties and PER on heat release evolution at two injection timing scenarios.

One of the main reasons for developing RCCI combustion is to reduce simultaneously the engine-out NOx and soot emissions. To show the potential of each fuel and PER, figure 6.3 (left) shows NOx emissions results versus $\mathrm{SOI}_{\text {main. }}$. The NOx trend observed for all fuels is explained focusing on the results presented in figure 6.1. First, a reduction in PER enhances the combustion process leading to higher maximum RoHR peaks. Second, a delay in diesel $\mathrm{SOI}_{\text {main }}$ shifts the CA50 to high temperature instants in the cycle, which also contributes to increase NOx emissions. Note that the decrease in NOx emissions at the most delayed $\mathrm{SOI}_{\text {main }}$ for PER $64 \%$ is consequence of the change in CA50 trend (see figure 6.1). Moreover, the importance of using high premixed gasoline fractions is also inferred from the figure, where only the highest PER allows operating inside the area defined by the NOx and soot emissions limits. The comparison between fuels reveals again the great importance of CA50 on NOx emissions. Thus, the slight variations in CA50 between E20-95 and E10-98 found in figure 6.1 are totally reproduced by the NOx trend, with higher values as combustion evolves near TDC.

On the other hand, it is interesting to see how RCCI concept allows avoiding the usual NOx-soot trade-off experienced in conventional diesel combustion. From figure 6.3 (right) it is concluded that, at this relatively 
low load, the combination of high premixed gasoline fraction together with long mixing times for diesel fuel results in zero soot emissions in almost all cases. These ultra-low soot values were also found in chapters 4 and 5 , where a wide variety of engine settings and hardware were explored.
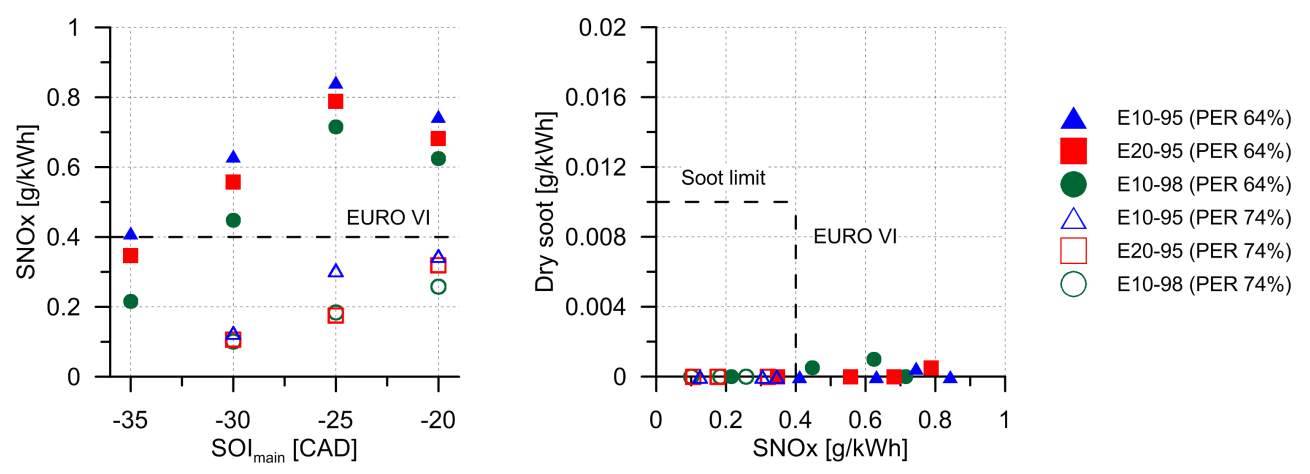

Figure 6.3. Influence of fuel properties and PER on NOx and soot emissions as a function of diesel $S O I_{\text {main }}$.

To better analyze the role played by the combustion phasing on the results obtained, figure 6.4 shows the NOx emissions, gross indicated efficiency (GIE) and maximum pressure rise rate (MPRR) as a function of the CA50 for the different fuels and PERs. As can be seen, the values of CA50 for the NOxcompliant tests are placed from +4 CAD ATDC to more delayed instants in the cycle, which reinforce the findings of the study performed in chapter 4 . Moreover, for these points, it is observed that an excessive delay in CA50 provokes a reduction in gross indicated efficiency.

The figure also shows that the two blends of 95 ON (E10 and E20) allow minimizing the penalty in GIE as PER increased from $64 \%$ to $74 \%$, with E10-95 leading to higher efficiencies than the other two fuels in all cases. By contrast, the low reactivity of E10-98 results in very low GIE when PER 74\% is used. With respect to the maximum pressure rise rate (MPRR), the figure shows that it decreases as CA50 delays, with slightly higher values for E10-95 in both PERs due to the slightly advanced CA50.

Finally, figure 6.5 shows the influence of fuel properties and PER on $\mathrm{HC}$ and $\mathrm{CO}$ emissions as a function of diesel injection timing. The figure states that, for all fuels, $\mathrm{CO}$ emissions presents greater dependency to diesel $\mathrm{SOI}_{\text {main }}$ than $\mathrm{HC}$, which is related to higher sensitivity of $\mathrm{CO}$ to differences in combustion temperature when varying CA50. In fact, the trend of $\mathrm{CO}$ emissions reproduce the same concave shape than that found for CA50 
(figure 6.1), with minimum CO levels as CA50 shifts near TDC. As can be seen, E10-95 allows the highest reduction in $\mathrm{CO}$ emissions at all $\mathrm{SOI}_{\text {main }}$ conditions, providing values near the EURO VI limit when PER 64\% is used. On the other hand, $\mathrm{HC}$ emissions follow the same trend than $\mathrm{CO}$ emissions, but the emission levels are well above the legislated limits for this pollutant.
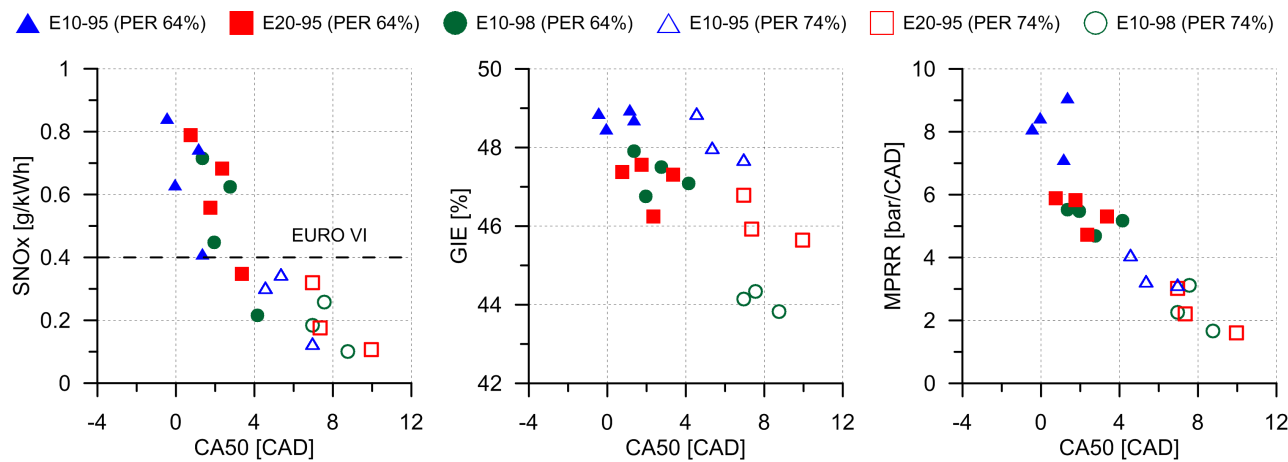

Figure 6.4. Influence of fuel properties and PER on NOx, gross indicated efficiency (GIE) and maximum pressure rise rate (MPRR) as a function of combustion phasing (CA50).
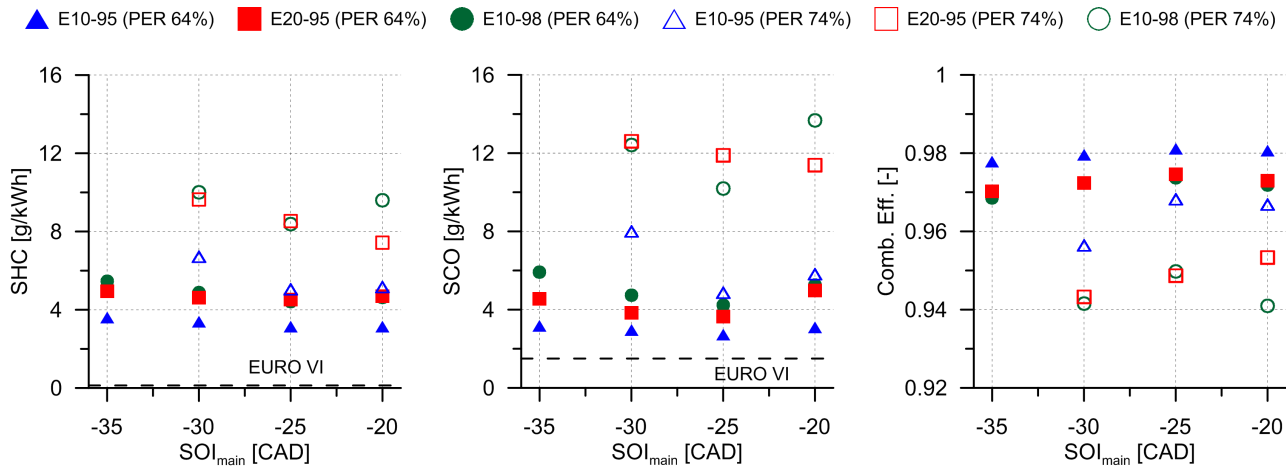

Figure 6.5. Influence of fuel properties and PER on $H C$ and $C O$ emissions and combustion efficiency as a function of diesel SOI main.

The increase in PER has the same effect on $\mathrm{HC}$ and $\mathrm{CO}$ emissions, raising both pollutants due to worsening in combustion process, as was previously demonstrated in figure 6.2. At high PER conditions, which are those required to achieve ultra-low NOx and soot emissions simultaneously, CO emissions are higher in concentration than $\mathrm{HC}$ emissions. This fact is more desirable from 
the combustion efficiency standpoint since the heating value of $\mathrm{HC}$ is typically four times higher than CO.

The combustion efficiency plot states again the benefits of E10-95 with respect to the other fuels. In particular, the results show an increase of around $0.8 \%$ in combustion efficiency compared to the other two fuels at PER $64 \%$. Moreover, for PER $74 \%$ the difference increases to more than $1.5 \%$, where the combustion efficiency values of E20-95 and E10-98 are between $94 \%$ and $95 \%$. These values are far from the $98 \%$ limit found in chapter 4 , which suggests that the intake charge conditions set as baseline values (table 6.2) may not be optimal for all fuels and should be varied to increase combustion efficiency to more acceptable levels. This consideration will be explored in the next section.

\subsubsection{Gas properties modification for improved reactivity}

Previous section demonstrated that the operating conditions which provided results inside the potential region defined by the NOx-soot emissions limits resulted in excessive $\mathrm{HC}$ and $\mathrm{CO}$ emissions, especially in the case of the lowest reactive fuels (E20-95 and E10-98). Also, the greatest combustion efficiency for E10-95 was around 96\%, meaning that there is about $2 \%$ combustion losses that can be recovered considering the limit of $98 \%$ found in chapter 4, and commonly expected in LTC combustion concepts when operating at low load conditions. Taking into account the $48 \%$ indicated efficiency achieved at this condition, it supposes that there is almost $1 \%$ of efficiency which can be theoretically recoverable.

The results presented in chapter 4 proved that the simultaneous improvement of indicated efficiency and $\mathrm{HC}$ and $\mathrm{CO}$ emissions requires variations in both fuel reactivity and in-cylinder thermodynamic conditions. The EGR and intake temperature modification were found to be effective methods for modulating the intake charge properties, leading to very similar results between them in terms of maximum indicated efficiency and minimum combustion losses. Thus, it is expected that the modification in gas properties with respect to the baseline conditions defined in previous section may affect the maximum RCCI efficiency obtained with each LRF. Considering this, the current section aims at evaluating the response of each LRF to variations in gas composition, providing a detailed analysis about their effects on RCCI heat release event and engine-out emissions. 


\subsubsection{Test conditions}

To be able to capture not only the effect of fuel properties but also the influence of the blending ratio when changing the intake gas properties, four different PERs were tested for each pair of fuels $(\mathrm{HRF}+\mathrm{LRF})$. The baseline conditions were selected taking as reference B7+E20-95 fuel combination. In this sense, four different blending ratios were proposed (mass based) and then, the total energy delivered to the cylinder was maintained constant for the three remaining blends by adjusting the LRF mass as required in each case. The diesel fuel mass was kept constant for each PER between the different fuel combinations. Table 6.4 depicts the fuel mass per blend delivered to the cylinder for each PER proposed.

Table 6.4. Diesel and LRF mass per blend delivered to the cylinder for each premixed energy ratio (PER).

\begin{tabular}{lllll} 
& \hline PER 49\% & PER 59\% & PER 69\% & PER 79\% \\
\hline Diesel B7 [mg] & 35 & 28 & 21 & 14 \\
E20-95 [mg] & 35 & 42 & 49 & 56 \\
E10-95[mg] & 33.9 & 40.7 & 47.5 & 54.3 \\
E10-98 [mg] & 33.9 & 40.7 & 47.5 & 54.3 \\
E85 [mg] & 44.4 & 53.3 & 62.2 & 71.1 \\
\hline
\end{tabular}

Table 6.5 depicts the constant engine settings used in this study. All tests were carried out at $1200 \mathrm{rev} / \mathrm{min}$ and constant combustion phasing (CA50) of $5 \pm 0.5$ CAD ATDC, which was demonstrated to be necessary for keeping NOx emissions under EURO VI limitation. In order to fix the CA50 while introducing LRFs with different characteristics, the EGR rate was modified as required in each case, keeping constant the rest of engine settings. At these operating conditions, the mean IMEP value resulted in 7.5 bar, with a maximum value of 7.8 bar (B7+E10-95 and PER 59\%) and minimum value of 6.5 bar (B7+E85 and PER 69\%) due to differences in combustion development between fuels.

Instead of the EGR rate, it could have been modified the intake charge temperature, but this method results in much slower control due to the great time consumed by the thermal transient during the search of the proper combustion phasing. Moreover, this method is generally deemed impractical for mobile applications. 
Table 6.5. Constant engine settings to evaluate the effect of the gas properties modification.

\begin{tabular}{ll}
\hline \hline Engine speed [rpm] & 1200 \\
Combustion phasing (CA50) [CAD ATDC] & +5 \\
Intake charge temperature [ $\left.{ }^{\circ} \mathrm{C}\right]$ & 40 \\
Intake pressure [bar] & 1.35 \\
Exhaust pressure [bar] & 1.15 \\
Diesel pilot inj. timing [CAD ATDC] & -60 \\
Fuel mass in pilot Diesel inj. [\%] & 50 \\
Diesel main inj. timing [CAD ATDC] & -30 \\
Diesel injection pressure [bar] & 700 \\
Low reactivity fuel inj. timing [CAD ATDC] & 385 \\
Piston bowl geometry [-] & Stock \\
\hline
\end{tabular}

\subsubsection{Combustion development comparison}

In order to understand the main differences in combustion process due to variations in LRF characteristics and intake gas conditions, this section presents an analysis of the main parameters derived from in-cylinder pressure signal processing. Figure 6.6 shows the instantaneous RoHR traces for the different PERs and blends together with detailed views of the low temperature heat release (LTHR) profiles. It can be seen that no profile for the case of $\mathrm{B} 7+\mathrm{E} 85$ and $\mathrm{PER}=79 \%$ is represented. In this case, the in-cylinder thermodynamic conditions were not reactive enough to maintain the CA50 at the desired value, which delayed far from +5 CAD ATDC even without using EGR. This seems to be consequence of the remarkable differences in properties compared to the other LRFs studied, e.g. octane number and enthalpy of vaporization, which contribute to reduce the in-cylinder reactivity [38-40].

Figure 6.7 shows the EGR rate needed to maintain CA50 at +5 CAD ATDC for the different fuels and PERs. The results show that, as blend reactivity is deteriorated by both the increase in LRF octane number and PER, lower EGR rates are required. Moreover, the differences in EGR rate between fuels are more remarkable as PER increases, where the LRF characteristics prevail over the total amount of fuel injected.

The LTHR profiles depicted in figure 6.6 show almost equal onset for the different fuel combinations at same PER conditions. This fact suggests that 

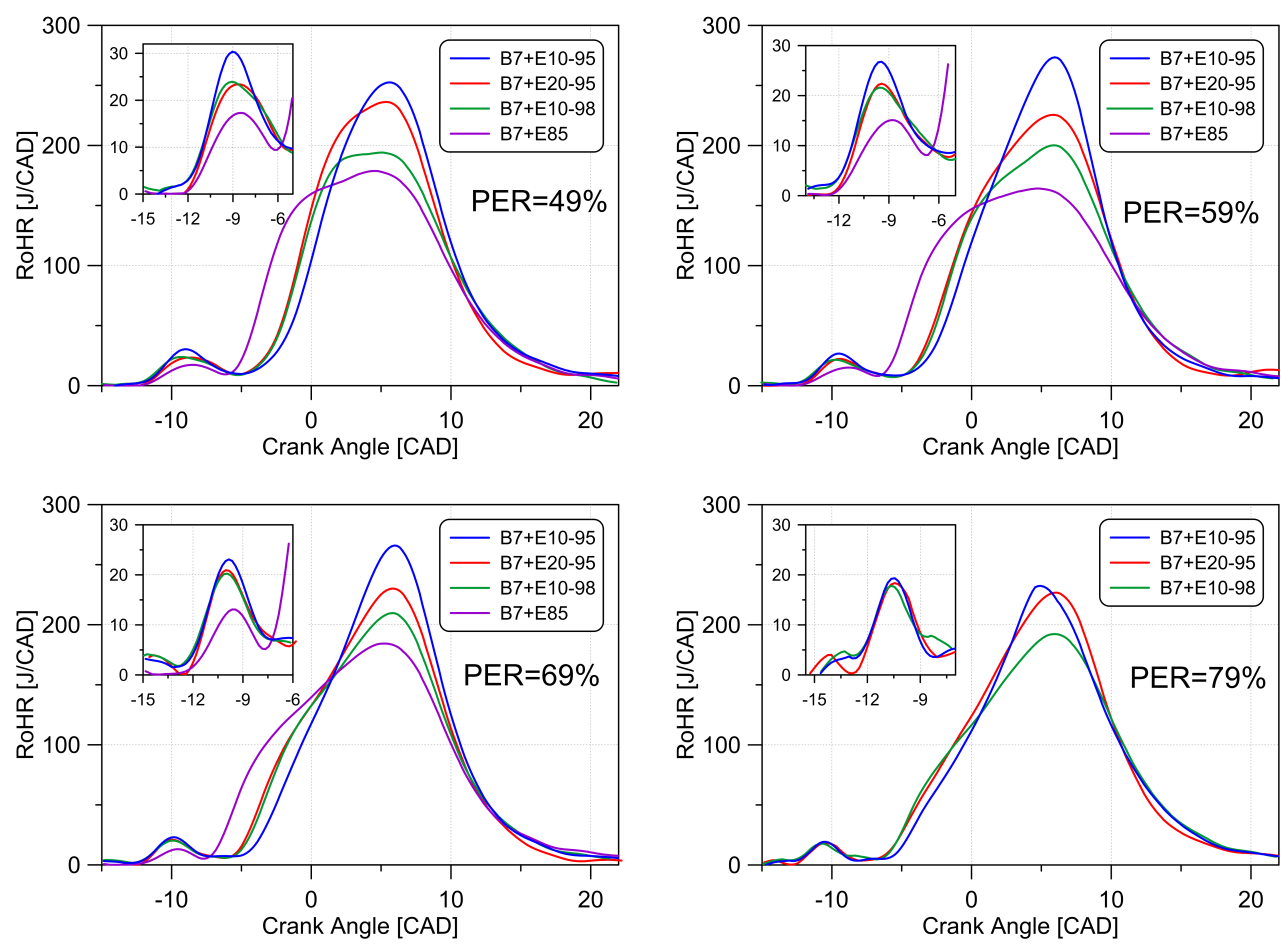

Figure 6.6. RoHR traces for the different PERs and fuels.

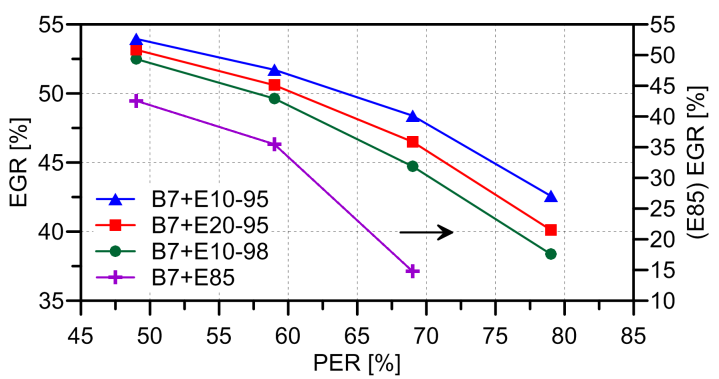

Figure 6.7. EGR rate needed to maintain CA50 at $+5 C A D A T D C$ for the different PERs and fuels.

the low temperature reactions are triggered by the HRF consumption, which was also noted in the analysis of the combustion species presented in chapter 4 . However, since the LRF is well-mixed at this moment, the local increase in temperature due to the HRF ignition makes the surrounding zones start also 
to react. At this point, the amount of energy released is determined by the equivalence ratio stratification and the reactivity gradient between both fuels.

Figure 6.8 shows that, for all fuels, the maximum LTHR peak and the energy released during this combustion phase decrease almost linearly as PER increases. This is consequence of the leaner diesel equivalence ratio stratification. Moreover, the comparison between fuels suggests that both parameters also decrease as the octane number of the LRF increases, as consequence of the greater reactivity gradient between the HRF and LRF. Additionally to reactivity gradient, literature demonstrates that the consumption of $\mathrm{OH}$ radicals by ethanol molecule has great inhibitor effect on the cool flame reactions of heptane [41], which also contributes to explain the high differences found in the case of E85 fuel.
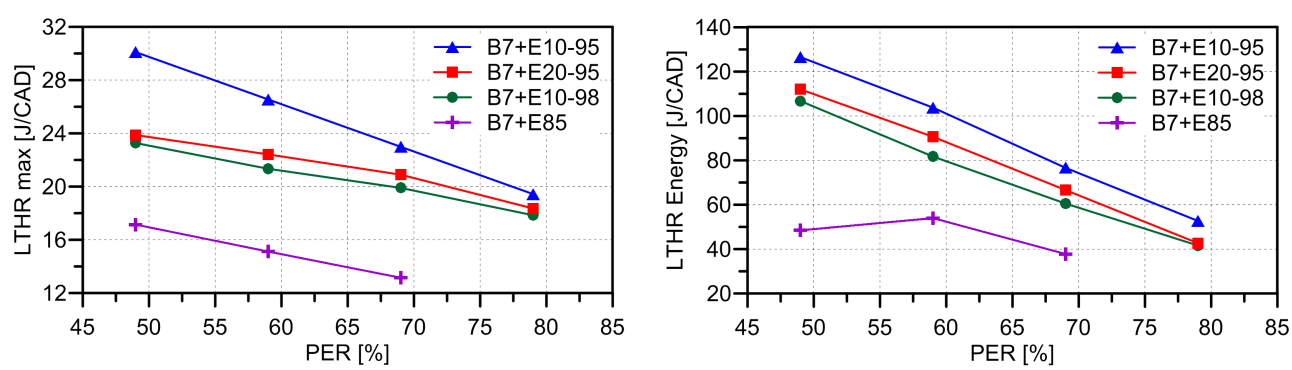

Figure 6.8. Maximum heat release peak and energy released during the low temperature combustion phase for the different PERs and fuels.

The computational calculations shown in chapter 4 demonstrated that the high temperature combustion starts with the thermal autoignition of the HRF, followed by the entrained LRF consumption. This statement is reinforced by comparing the behavior of the main combustion stage for the different cases shown in figure 6.6. It can be seen that LRFs with higher octane number promote earlier high temperature combustion onset. Moreover, the start of the high temperature combustion becomes also advanced as PER is increased. Both effects are clarified in figure 6.9, where the ignition delay is accounted as difference between SOC and the end of main diesel injection (EOI main). Ultimately, both actions (increase of PER and ON) would contribute to reduce in-cylinder reactivity, which opposes to the trend observed in the figure. This fact suggests that the autoignition of the main combustion stage must be governed by the HRF reactions. Thus, the increase in oxygen concentration through the EGR reduction seems to compensate the deterioration in global reactivity due to variations in the LRF characteristics and PER, leading to shorter ignition delay [42]. 


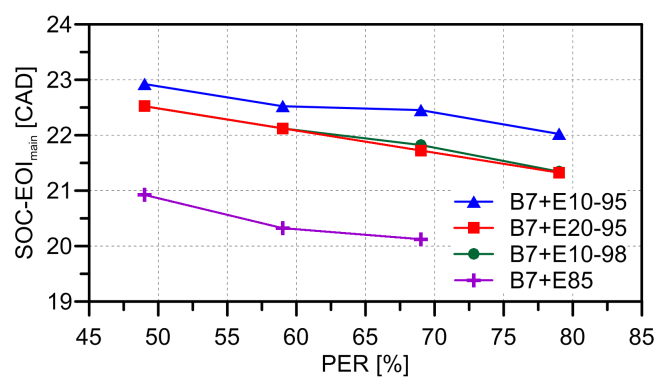

Figure 6.9. Ignition delay accounted as the difference between the SOC and the end of the main diesel injection for the different PERs and fuels.

The subsequent increase in pressure and temperature initiates a reaction zone, which proceeds gradually from high to low reactivity regions of the combustion chamber [43, 44]. The comparison of the RoHR evolution between fuels evidences that combustion propagation strongly depends on LRF characteristics. Looking at the RoHR profiles of PER 49\%, it can be seen that only the case of B7+E10-95 shows a continuous transition between the HTHR onset and the maximum RoHR peak (figure 6.6). The other LRFs show several changes in the RoHR profile during combustion process, which suggests that the energy release between zones of the combustion chamber is slowed down. This behavior is magnified as the difference in reactivity between the HRF and LRF becomes greater. To assess the effect of LRF properties on main autoignition stage, figure 6.10 shows the maximum heat release peak and the energy released during this period. As can be seen, the maximum HTHR peak is not strongly affected by PER conditions, showing all fuels relatively slight variations between their own tests. In addition, all fuels except E85 show similar trends regarding energy released, with increased energy delivery until PER reaches 59\%, followed by progressive decay up to PER $79 \%$.

To account the differences in combustion duration between fuels, figure 6.11 shows the CA90-SOC values for the different PERs and blends. The results prove that combustion event becomes shorter as the octane number of the LRF and PER decrease. Looking at the RoHR profiles in figure 6.6, it can be seen very similar late combustion phases for all fuels, which results in almost equal end of combustion (EOC) in all cases. Thus, differences in combustion duration between fuels are mainly related to the variations in the start of combustion (SOC), which was demonstrated to be governed by the in-cylinder oxygen concentration. 

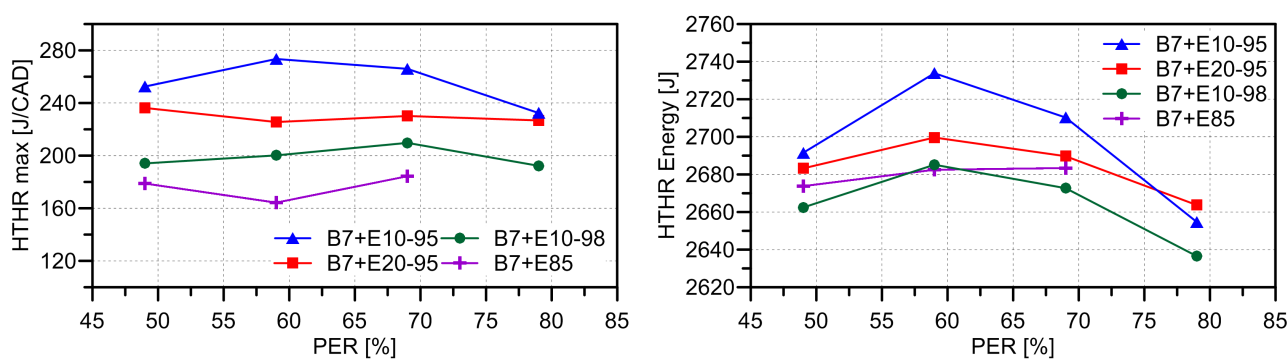

Figure 6.10. Maximum heat release peak and energy released during the main combustion stage for the different PERs and fuels.

The last parameter compared for the fuels is the ringing intensity (RI). From the figure, it is clear that RI shows opposite trend to combustion duration, with higher values as PER and octane number of the LRF decrease. Nevertheless, all values are well below $5 \mathrm{MW} / \mathrm{m}^{2}$, which was established by Dec and Yang as a proper upper limit to achieve an acceptable combustion noise and knock-free operation [45].
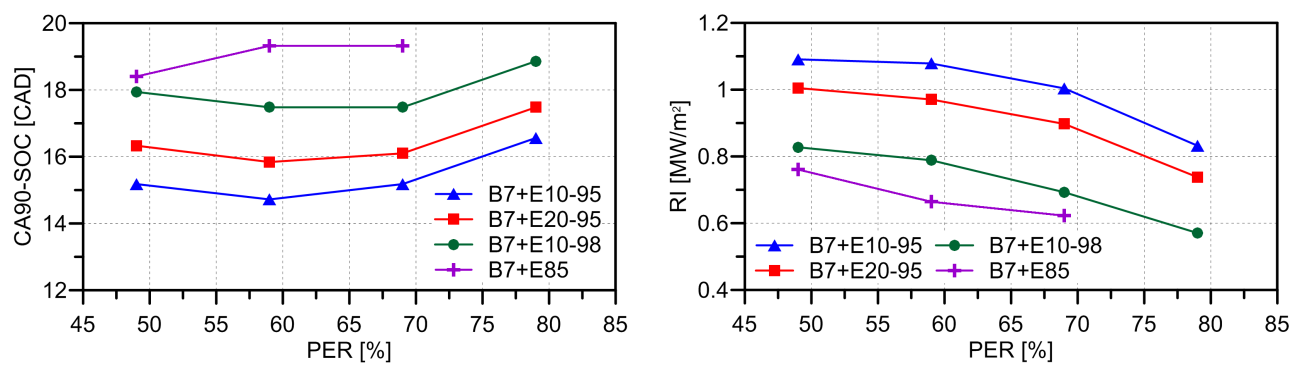

Figure 6.11. Combustion duration (CA90-SOC) and ringing intensity (RI) for the different PERs and fuels.

Finally, in order to provide clear understanding to the reader, figure 6.12 summarizes all the effects previously described. In particular, the influence of PER on combustion development is synthesized using B7+E10-95 fuel combination and the effect of fuel composition on RoHR evolution is summarized using results of PER $69 \%$. 

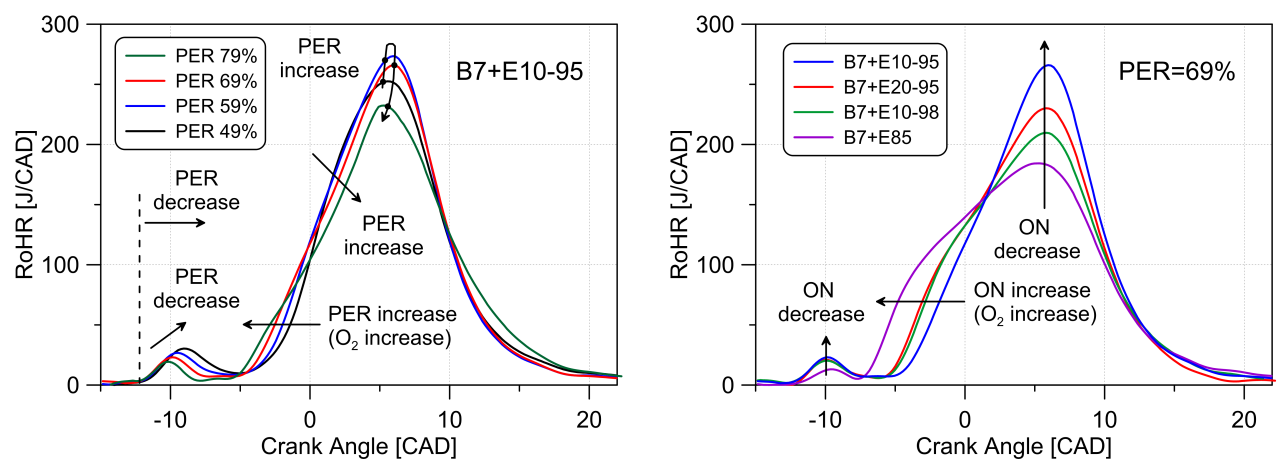

Figure 6.12. Summary of the effects of PER (left) and fuel composition (right) on RoHR shape.

\subsubsection{Engine-out emissions results}

Figures from 6.13 to 6.15 show results of engine-out emissions for the different PERs and fuel blends. Dashed lines across the figures denote the EURO VI limits of the regulated gaseous emissions according to the world harmonized stationary cycle (WHSC) for HD diesel engines, which stablishes the next maximum values: $\mathrm{NOx}=0.4, \mathrm{HC}=0.13$ and $\mathrm{CO}=1.5 \mathrm{~g} / \mathrm{kWh}$. The soot limit, stablished in $0.01 \mathrm{~g} / \mathrm{kWh}$, is also marked in the figures.

From figure 6.13, it is noted that E85 leads to significantly higher NOx levels than the other LRFs. Also of note is that as PER is increased, NOx emissions increase whatever the LRF used. Both trends are explained due to the lower EGR rate required to maintain the proper combustion phasing, which promotes an increase in maximum combustion temperature. It can be seen that NOx emissions follow the trend of the maximum combustion temperature, which was estimated as the maximum adiabatic temperature for the diesel fuel burned under stoichiometric conditions. Since during premixed combustion processes, as RCCI, only a portion of the reaction zone remains at equivalence ratio equal to 1 , this method could overestimate the absolute value of the maximum temperature. Nevertheless, it is a good estimator at least for the maximum local temperature. Thus, it can be inferred that the higher combustion temperature enhances the NO formation reactions promoting an increase in NOx emissions. On the other hand, it is interesting to note that E20-95, E10-98 and E10-95 are valid to fulfill EURO VI NOx limits independently on the PER. In this sense, the greater reactivity of E10-95 
allows using higher EGR rates, leading to NOx levels far below the limit value.
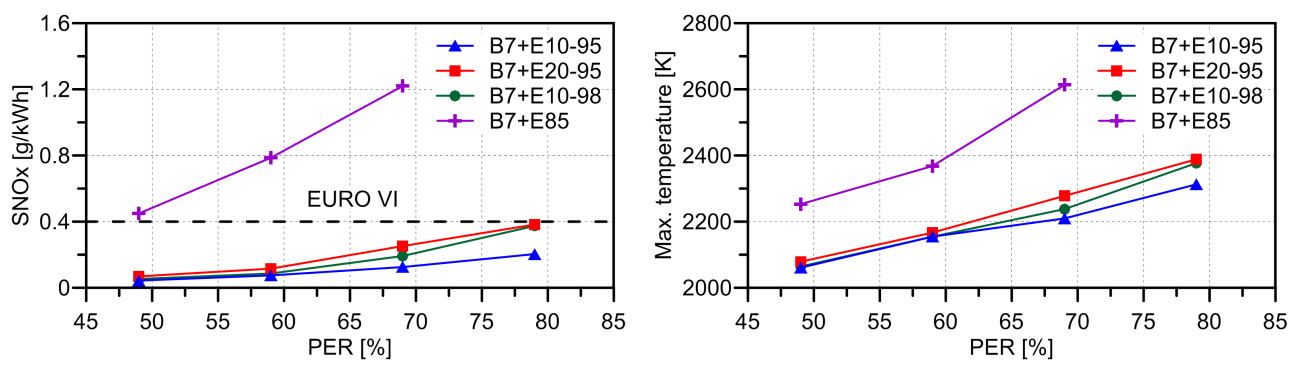

Figure 6.13. NOx emissions and maximum combustion temperature for the different PERs and fuels.

Figure 6.14 shows that soot emissions were below the minimum detection limit of the AVL $415 \mathrm{~S}$ smoke meter in all cases. It is thought that, under these operating conditions, the advanced injection strategy for the HRF allows inhibiting soot formation whatever the LRF used. To confirm this, figure 6.14 (right) shows the ratio between ignition delay (ID) and injection duration (DOI), which accounts for the degree of air and fuel mixing. Thus, ID/DOI ratios greater than 1 denote injection and combustion processes decoupled in time, so that leading to premixed combustion. As can be seen, all ID/DOI ratios are notable greater than 1 in all cases, thus favoring the necessary conditions to avoid soot formation.
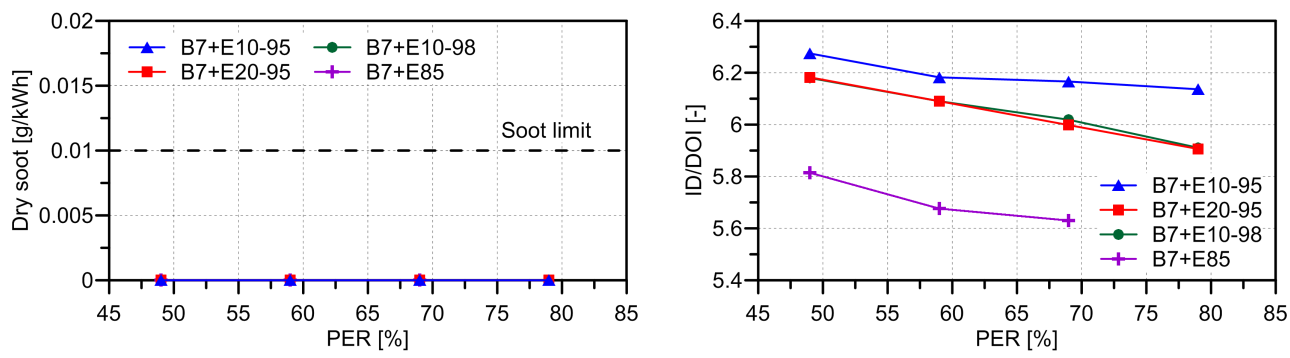

Figure 6.14. Engine-out soot emissions and ID/DOI ratio for the different PERs and fuels.

Figure 6.15 shows that, for all fuels, hydrocarbon emissions increase as PER increases. As explained in chapter 4, the port fuel injection of the LRF during the early instants of the compression stroke results in a homogeneous distribution of the fuel in the chamber. It allows that great quantity of the 
mixture arrives to cold regions such as the cylinder liner. Moreover, the downward movement of the piston near TDC at the beginning of expansion stroke tends to move the charge from the piston bowl to the squish and crevice regions, where great quantity of LRF mass gets also trapped. This issue is enhanced as more quantity of LRF is injected, which explains the increasing trend of measured HC with PER. Finally, the figure shows that LRFs with higher reactivity favor the in-cylinder reactions allowing the $\mathrm{HC}$ emissions reduction.

On the other hand, a minimum in $\mathrm{CO}$ emissions was achieved as PER increased from $49 \%$ to $69 \%$ for all the blends. This trend is explained due to the improvement in the combustion process until this point (see figure 6.6), which enhances the oxidation process of $\mathrm{CO}$. On the contrary, the increase in PER up to $79 \%$ resulted in a deterioration of the combustion process for the three blends, which provoked a raise of the $\mathrm{CO}$ levels. The comparison of $\mathrm{CO}$ emissions between fuels shows the same results as for $\mathrm{HC}$ emissions, confirming that the reduction of the reactivity gradient between the low and high reactivity fuels allows to improve the combustion efficiency of RCCI concept at low load.
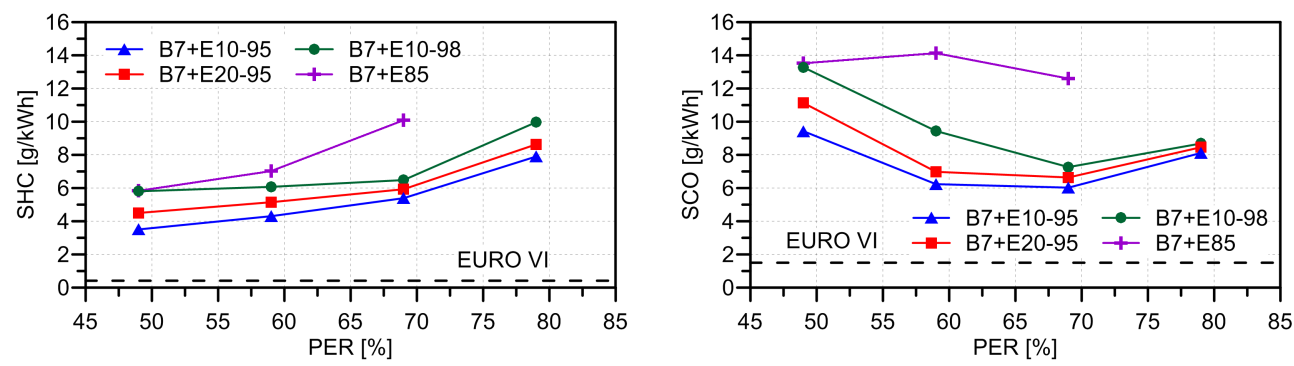

Figure 6.15. Engine-out $H C$ and $C O$ emissions for the different PERs and fuels.

\subsubsection{Discussion}

This section is focused on detailing the influence of the different fuel combinations and blending ratios on RCCI efficiency. For this purpose, figure 6.16 shows distributions of the fuel energy usage over the closed cycle, obtained by means of the combustion diagnosis code described in chapter 3 . Thereby, gross indicated efficiency, heat transfer losses, exhaust losses and combustion losses are depicted as percentage of the input fuel energy for the different PERs and fuel blends. 
The results show that the maximum achievable GIE increases as the reactivity gradient between the HRF and LRF decreases. Comparing the extreme cases, it is seen that the combination of $\mathrm{B} 7+\mathrm{E} 10-95$ provides an improvement in GIE between $4 \%$ and $5.4 \%$ versus B7+E85 operation. In this sense, it is confirmed that combustion losses and HT losses increase as less reactive LRF is used. Moreover, this worsening prevails over the reduction observed in exhaust losses, which reduces the GIE.

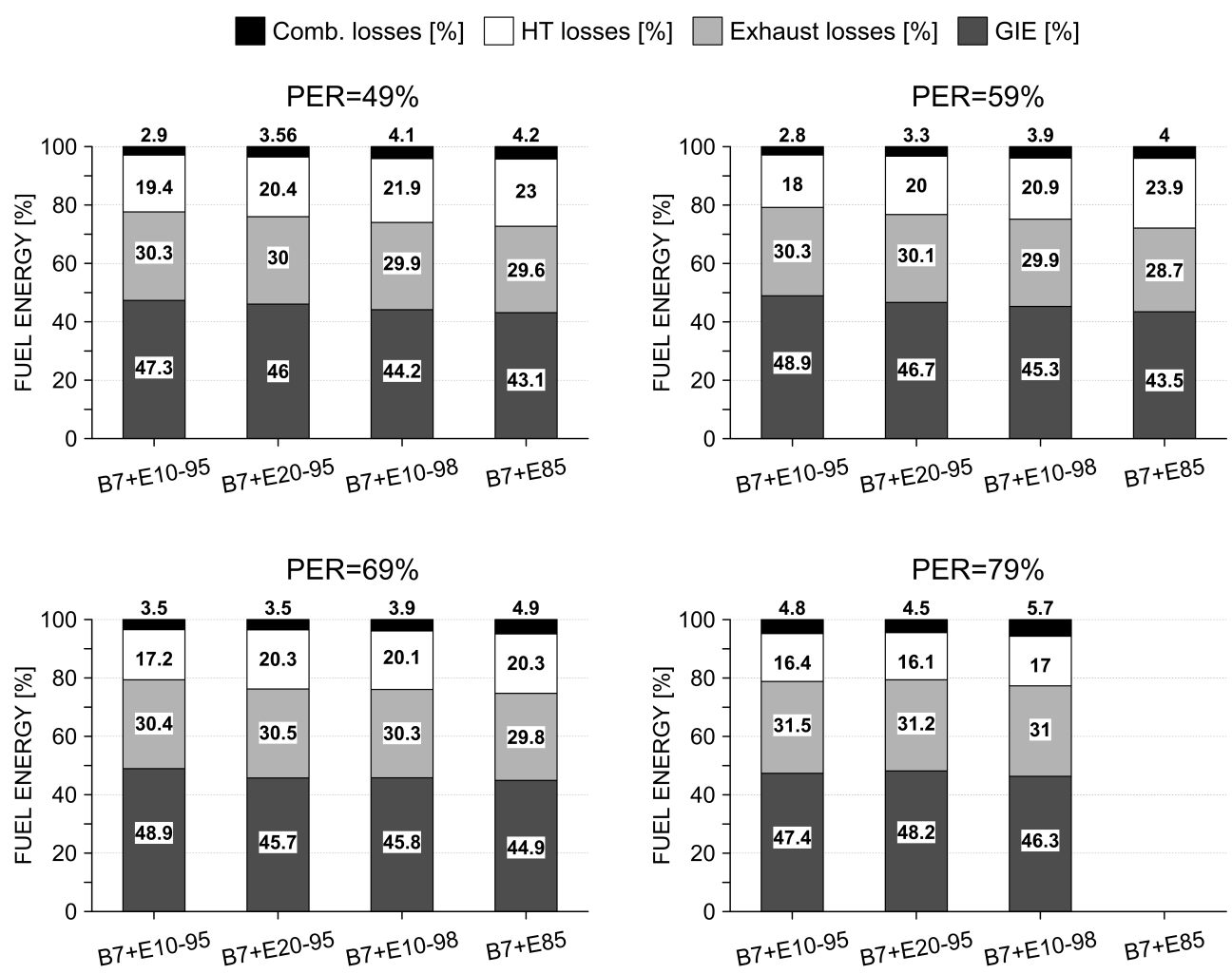

Figure 6.16. Gross indicated efficiency (GIE), exhaust losses, heat transfer losses and combustion losses as a percentage of the fuel energy for the different PERs and fuels.

Figure 6.17 compares the results between the tests developed under baseline conditions (section 6.3.1.2) with the ones obtained in the present section, in which the intake charge conditions have been modified looking for higher efficiency. Specifically, the figure shows the tests of best GIE for each fuel at both operating conditions (baseline and modified), as well as the combustion efficiency corresponding to these cases. A first look at the figure 
reveals a greater improvement achieved for E20-95 and E10-98 than E10-95, which suggests that the baseline conditions proposed in section 6.3.1.2 were more unfavorable for these two fuels. In spite of that, the maximum gross indicated efficiency for both fuels still remains below that of E10-95, which confirms again that, at low load, the reduction in reactivity gradient between the low and high reactivity fuels improves the thermal efficiency of RCCI concept.

The combustion efficiency of the tests with modified conditions show only little improvement versus the ones obtained at baseline conditions. In addition, it is possible to see that no case reaches the $98 \%$ value, which was found as upper limit in chapter 4 . This fact could be explained by the diesel injection strategy used in both studies, which was demonstrated to be a key parameter for improving the oxidation of gasoline trapped in crevice region (figure 4.2, chapter 4$)$. In this sense, the diesel $\mathrm{SOI}_{\text {main }}$ used in the present section was fixed at $-30 \mathrm{CAD}$, which is worse than that used in chapter 4 (-50 CAD) for this purpose.

Another reason for explaining the lower combustion efficiency observed here could be the variation in properties of the LRF fuel used in both chapters. In particular, the results shown in chapter 4 were obtained using regular gasoline of $98 \mathrm{ON}$. By contrast, the most reactive fuel used in the present study (E10-95) has greater RON than 98 and also has $10 \%$ of ethanol content, which has direct impact on intake charge temperature.
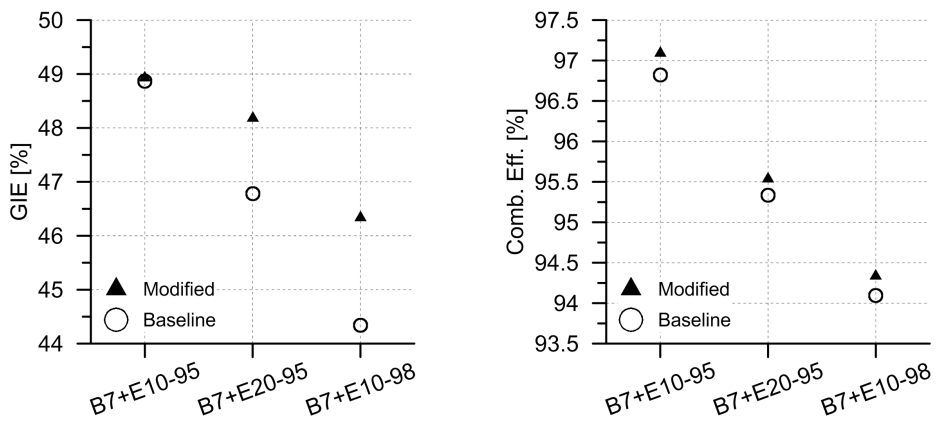

Figure 6.17. Comparison between the results of the baseline and modified intake charge conditions. 


\subsection{Evaluation of the suitable LRF for extended load operation}

This section is devoted to assess the potential of the alternative fuels previously tested for promoting clean and efficient operation from medium to high load. Since the properties of the LRFs are quite different and in-cylinder thermodynamic conditions vary substantially when modifying engine load, similar parametric studies to those presented in section 6.3.1 are performed here. In order to prevent excessive pressure rise rate peaks and preserve the engine mechanical integrity, the effective compression ratio was lowered to 11:1 by means of advancing the intake valves closing event (early Miller cycle).

\subsubsection{Medium load results}

\subsubsection{Test conditions}

Table 6.6 shows the constant engine settings considered for developing the present study. It is interesting to note that, since medium load conditions demand considerably greater fuel mass than low load, the diesel injection settings were slightly modified to minimize soot emissions. First, diesel injected mass was distributed $65 / 35 \%$ between the pilot and main injection. Second, injection pressure was moderately increased (to prevent excessive wall impingement) to 800 bar.

Table 6.6. Constant engine settings at medium load conditions.

\begin{tabular}{ll}
\hline \hline Engine speed [rpm] & 1200 \\
Intake charge temperature $\left[{ }^{\circ} \mathrm{C}\right]$ & 40 \\
EGR [\%] & 45 \\
Intake pressure [bar] & 2.96 \\
Exhaust pressure [bar] & 2.76 \\
Piston bowl geometry [-] & Stock \\
Effective CR [-] & $11: 1$ \\
Diesel injection pressure [bar] & 800 \\
Low reactivity fuel inj. pressure [bar] & 5.5 \\
Low reactivity fuel inj. timing [CAD ATDC] & 385 \\
\hline
\end{tabular}


Table 6.7 depicts the operating parameters at medium load. The diesel $\mathrm{SOI}_{\text {pilot }}$ was also set at $-60 \mathrm{CAD}$ ATDC. In addition, the testing range for diesel main injection timing was delayed compared to low load conditions to avoid excessive pressure rise rates.

Table 6.7. Operating parameters at medium load conditions. Diesel main injection timing sweep for the different fuels and PERs.

\begin{tabular}{lllllll}
\hline \hline \multicolumn{3}{c}{ Diesel } & \multicolumn{4}{c}{ Low reactivity fuels } \\
\hline $\begin{array}{l}\text { SOI }_{\text {pilot }} \\
{[\mathrm{CAD}]}\end{array}$ & $\begin{array}{l}\mathrm{SOI}_{\text {main }} \\
{[\mathrm{CAD}]}\end{array}$ & $\begin{array}{l}\text { Total mass } \\
{[\mathrm{mg}]}\end{array}$ & $\begin{array}{l}\text { PER } \\
{[\%]}\end{array}$ & $\begin{array}{l}\text { E20-95 } \\
{[\mathrm{mg}]}\end{array}$ & $\begin{array}{l}\text { E10-95 } \\
{[\mathrm{mg}]}\end{array}$ & $\begin{array}{l}\text { E10-98 } \\
{[\mathrm{mg}]}\end{array}$ \\
\hline & & 47.6 & 59 & 71.4 & 69.2 & 69.3 \\
\multirow{4}{*}{-60} & \multirow{3}{*}{-9 to -21} & 41.6 & 64 & 77.3 & 74.9 & 75 \\
& & 35.7 & 69 & 83.3 & 80.7 & 80.8 \\
& & 29.7 & 74 & 89.2 & 86.5 & 86.6 \\
\hline
\end{tabular}

\subsubsection{Results}

From the trends in figure 6.18 it is inferred that, for all fuels and PERs, the delay in diesel main injection provides larger and more delayed combustion events. In addition, the more delayed main injection timings than those used at low load, provide great impact on combustion phasing, which is important from the controllability standpoint. In this regard, the results show negligible changes in sensitivity of CA50 to $\mathrm{SOI}_{\text {main }}$ when changing the LRF.
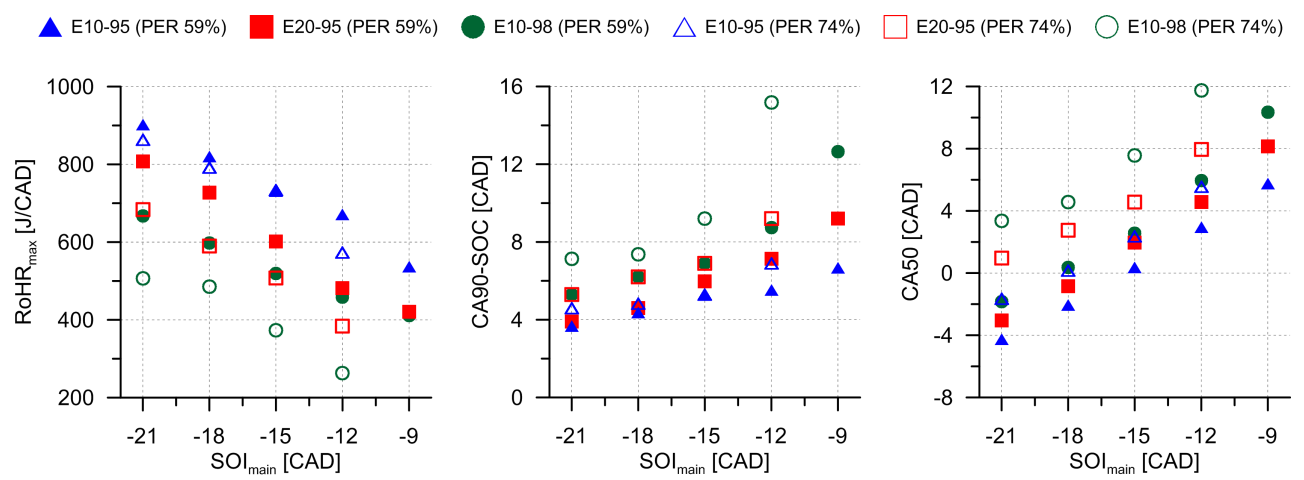

Figure 6.18. Influence of fuel properties and PER on some combustion tracers as a function of diesel $S O I_{\text {main }}$. 
Results between fuels follow the same trend than that observed at low load, with higher RoHR peaks as well as shorter and advanced combustion as the reactivity of the LRF increases. The differences between fuels are more remarkable as $\mathrm{SOI}_{\text {main }}$ is delayed, confirming the greater importance of the LRF chemical characteristics as thermodynamic conditions become more adverse for promoting combustion. On the other hand, it is seen that the lower reactivity of E20-95 and E10-98 compared to E10-95 magnifies the influence of the variations in PER on combustion development.

The influence of the three parameters studied (fuel composition, PER and $\mathrm{SOI}_{\text {main }}$ ) on heat release pattern is shown in figure 6.19. As can be seen, two staged RoHR profiles are obtained in all cases. From the figure, it is seen that the relevance of the combustion stages greatly depends on the LRF properties and diesel injection timing. Thus, in the case of B7+E10-95 fuel, an advanced injection timing (-60/-21 CAD) and PER 59\% lead to first rapid ramp followed by another growth in energy released. The first phase is related to premixed combustion of diesel fuel with entrained LRF, while the second one causes the majority of the LRF consumption. As the reactivity of the LRF reduces, the transition between both phases becomes more evident.
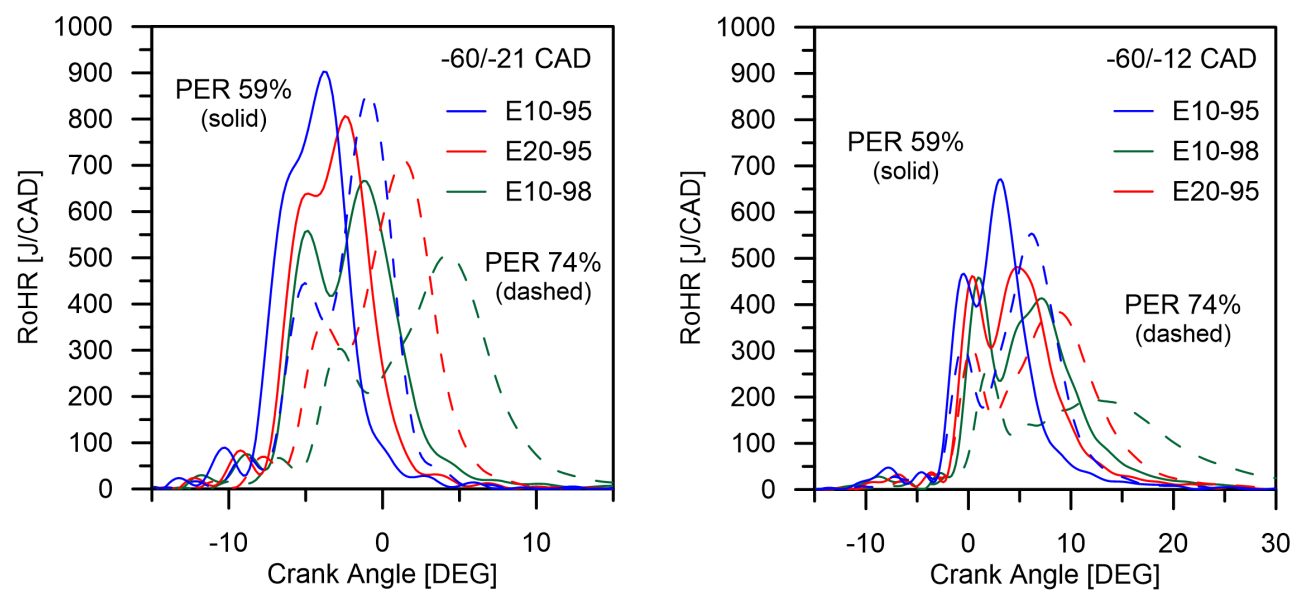

Figure 6.19. Influence of fuel properties and PER on heat release evolution at two injection timing scenarios.

At delayed $\mathrm{SOI}_{\text {main }}(-60 /-12 \mathrm{CAD})$, results also show two-staged combustion profiles, but during the expansion stroke for all PERs and fuel blends. In this case, the heat release profiles show a first premixed phase with more similar $\mathrm{J} / \mathrm{CAD}$ released than in the second stage. The reason is the lower extra mixing time available (SOC-EOI ${ }_{\text {main }}$ ) than in case of $-60 /-21$ 
$\mathrm{CAD}$, which provides richer equivalence ratio distributions at SOC enhancing the reactions during first combustion stage. Moreover, it should be noted that the variations in PER only have appreciable effects on SOC in the case of E10-98.

To illustrate the charge cooling effect of ethanol, figure 6.20 shows the bulk gas temperature profiles of E10-95 and E20-95 for different PERs at the injection timing of $-60 /-21$ CAD ATDC. As can be seen by comparing the different PERs for the same fuel, the evaporation of ethanol in the intake manifold has a great effect on intake charge temperature. Comparing the results of PER $49 \%$ and $79 \%$, it is seen that the cooling effect of both fuels promote a reduction of in-cylinder temperature at the beginning of the diesel injection by $50 \mathrm{~K}$. Moreover, the higher ethanol content of E20-95 than E1095 provides an extra cooling effect of around $10 \mathrm{~K}$ in all cases. This suggests that, additionally to differences in octane number between both fuels, the lower temperature of the charge at the time of diesel injection may also contribute to explain the differences observed in ignition delay time.
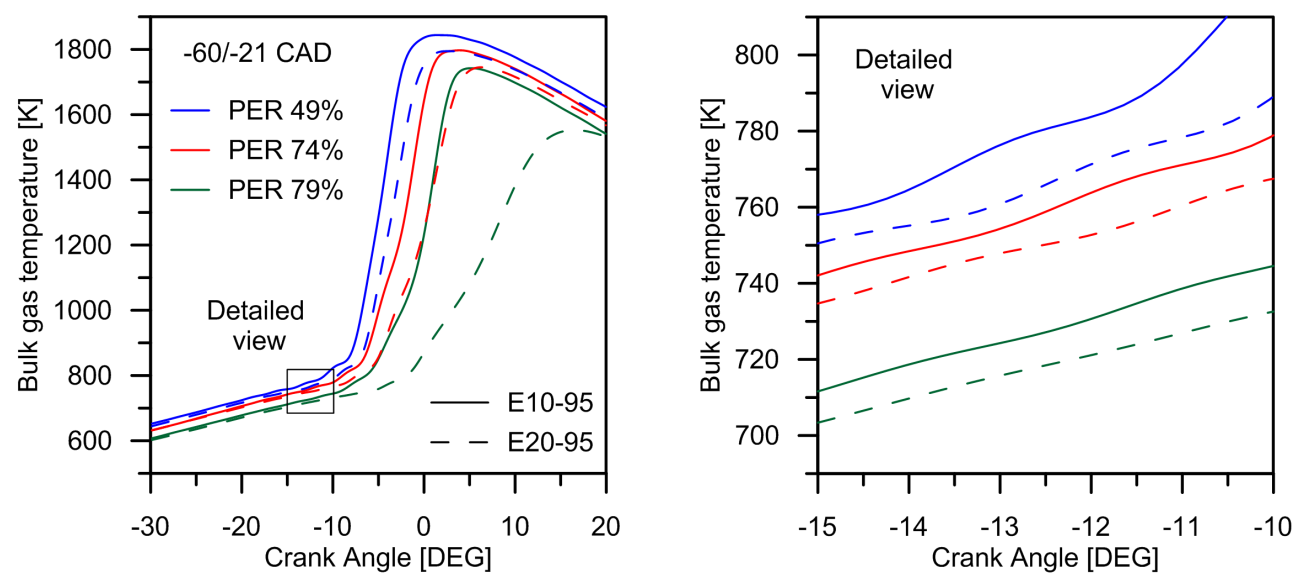

Figure 6.20. Effect of ethanol content on intake charge temperature. Results correspond to E10-95 and E20-95 fuels at different PERs.

The effect of combustion phasing on nitrogen oxides emissions can be clearly seen in figure 6.21. With advancing combustion, peak temperature rises considerably and when combustion is advanced before TDC, the charge remains at high temperature for a longer time. Thus, because of the constant dilution level and oxygen concentration, NOx emissions result increased. In addition, for a given PER, NOx emissions increase while increasing LRF reactivity, which is also explained by the advancing in CA50 (figure 6.18). 
Finally, it is seen that only CA50 values more delayed than +2 CAD ATDC ensure fulfilling the EURO VI limitation for NOx emissions, whatever the fuel and PER used.

The results depicted in figure 6.21 also show that there is a local maximum in gross indicated efficiency (GIE) at CA50 timings between +2 and +4 CAD ATDC, providing maximum PRR values below the limitation of 15 bar/CAD. Nonetheless, the highest brake thermal efficiencies are typically obtained at slightly later combustion phasings, which is desirable in terms of NOx and maximum PRR reduction. After the maximum in GIE, a drop is observed for B7+E20-95 and B7+E10-98, while B7+E10-95 allows maintaining almost constant efficiency at these points. Finally, the trend of maximum PRR shows high dependence on CA50, with expected results when comparing between fuels and PERs.
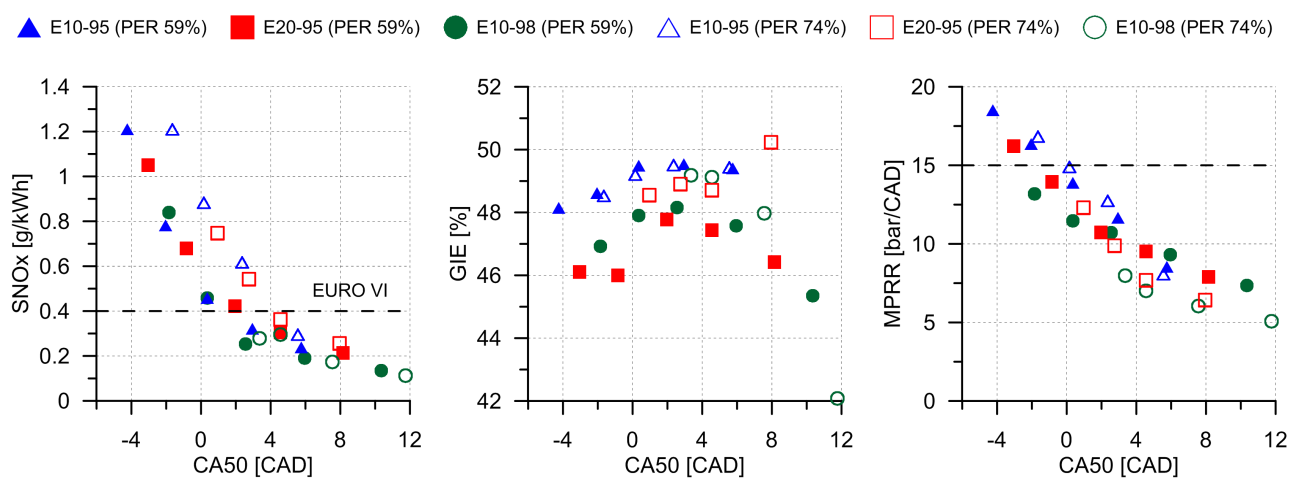

Figure 6.21. Influence of fuel properties and PER on NOx, gross indicated efficiency (GIE) and maximum pressure rise rate (MPRR) as a function of combustion phasing (CA50).

The NOx-soot trade-off represented in figure 6.22 shows that engine-out soot emissions are not as negligible as at low load operation, mainly when relatively high diesel fractions are used. The results at higher diesel fueling conditions (PER 59\%) show the same u-shaped trend for all LRFs, with only three tests performing inside the potential region. Moreover, the figure confirms again the potential of reducing soot emissions by increasing the portion of LRF injected.

As can be seen, the three potential tests with PER 59\% correspond to the lowest reactive fuels (E20-95 and E10-98), which show permanent reduction in soot emissions compared to E10-95. A possible hypothesis for this behavior is the greater degree of premixing allowed for the main injection when using 
E20-95 and E10-98, being this parameter quantified in figure 6.22 as difference between SOC and EOI main. From this figure, it is also concluded that the increase in PER enhances considerably the degree of premixing, which together with the significantly lower diesel mass injected, contributes to the great reduction observed in engine-out soot emissions.

On the other hand, the u-shaped trend observed for all LRFs with PER $59 \%$, seems not explained by only the degree of premixing. In fact, the analysis of the SOC-EOI main trend for a given fuel reveals that the degree of premixing reduces progressively as combustion phasing delays. This fact occurs because the delay experienced in CA50 at each step is lower than that imposed in $\mathrm{SOI}_{\text {main }}$. Thus, the lower mixing time combined with an excessively low incylinder temperature during expansion stroke, could explain the rise of soot emissions after TDC for all fuels (see figure 6.22 right). By contrast, the drop in soot emissions up to TDC seems not having direct explanation, thus requiring further insight into local conditions. In this sense, the effects of variations in dwell time between injections on equivalence ratio distribution and the role of temperature decrease on soot formation/oxidation rates must be more deeply studied.
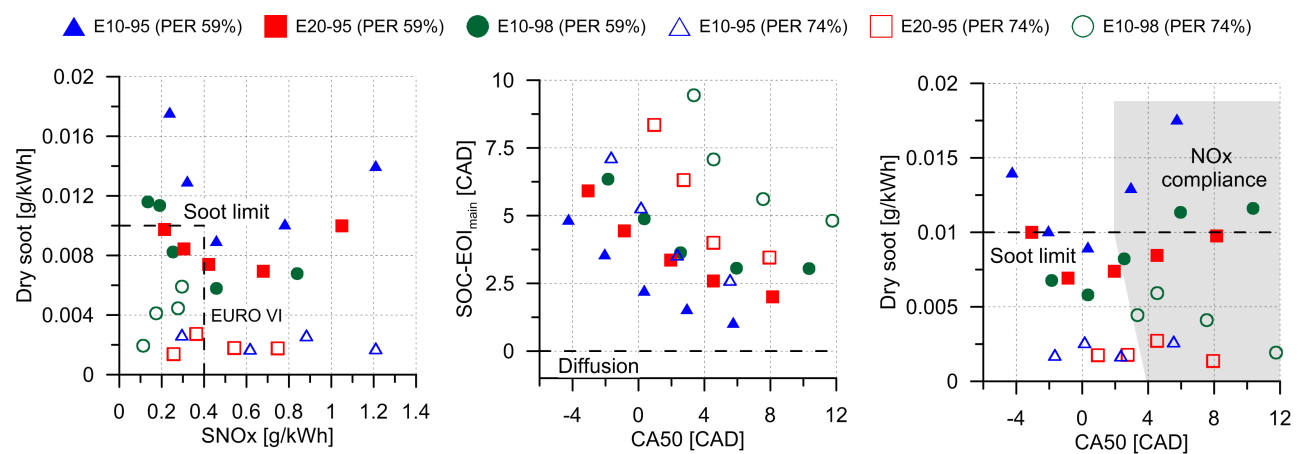

Figure 6.22. Influence of fuel properties and PER on soot emissions and degree of premixing.

Figure 6.23 shows results of $\mathrm{HC}$ and $\mathrm{CO}$ emissions as well as the combustion efficiency computed through their experimental measurements. As can be seen, both emissions show increasing trend as injection timing delays, where combustion event evolves under lower temperature conditions.

Comparing between fuels, the results show similar trends than those explained at low load. For the lowest PER (59\%), E10-95 provides improved results than E20-95 and E10-98, whose results collide in most cases. At higher PER (74\%), the benefits of E10-95 increase and the differences in $\mathrm{HC}$ and 
CO emissions between E20-95 and E10-98 become more noticeable, mainly due to the worsen combustion in the case of E10-98. Finally, it is seen that combustion efficiency shows greater values than those obtained at low load, with values near $99 \%$ at the most advanced injection timings in the case of E10-95. Nevertheless it should be considered that only the most delayed combustion phasings allow operating inside the NOx-soot potential region, where maximum combustion efficiency values drop near $98 \%$ in best cases.
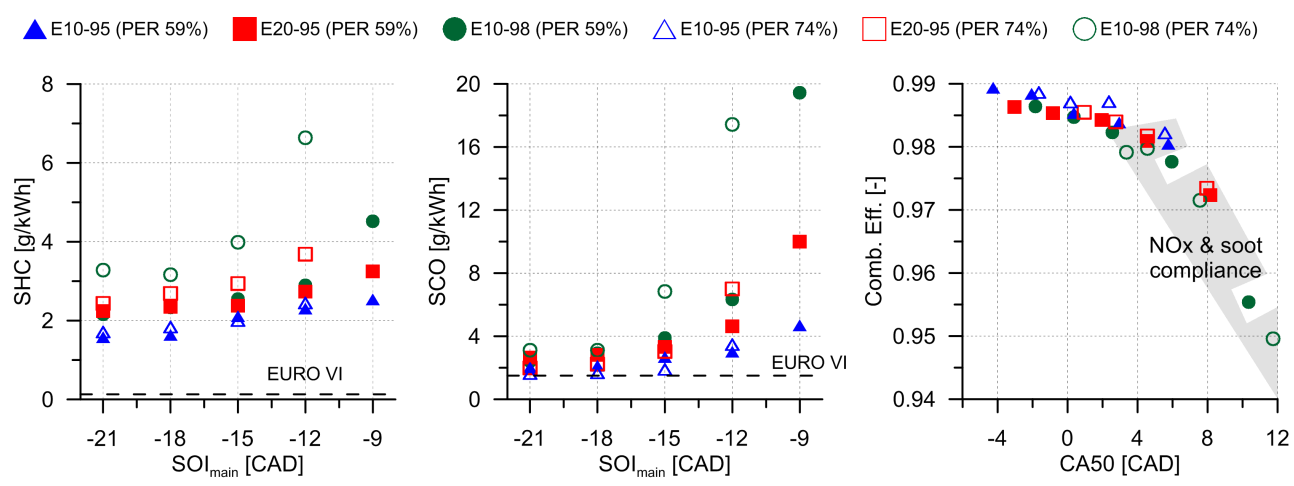

Figure 6.23. Influence of fuel properties and PER on $H C$ and $C O$ emissions and combustion efficiency as a function of diesel SOI main.

\subsubsection{High load results}

\subsubsection{Test conditions}

In order to be able to inject the great amount of diesel fuel needed at this load in a reasonable period of time, diesel injection pressure was increased up to 1890 bar. In addition, the EGR rate was lowered from $45 \%$ to $35 \%$ trying to prevent an excessive rise in soot emissions. As done at medium load, the effective compression ratio was set to 11:1 to keep the maximum PRR below the limit value, which required elevating the boost pressure up to 3.4 bar. Finally, the intake charge temperature and gasoline injection settings were the same than those used in the parametric studies performed at low and medium load. All the fixed engine settings are summarized in table 6.8.

Table 6.9 depicts the values of different parameters varied during the tests performed at high load conditions. The most noticeable modification compared to low and medium load was done on diesel injection strategy, which was switched to single injection pattern at highly delayed timings to avoid excessive pressure rise rates (section 5.5.2 of chapter 5). 
Table 6.8. Constant engine settings at high load conditions.

\begin{tabular}{ll}
\hline \hline Engine speed [rpm] & 1200 \\
Intake charge temperature $\left[{ }^{\circ} \mathrm{C}\right]$ & 40 \\
EGR [\%] & 35 \\
Intake pressure [bar] & 3.4 \\
Exhaust pressure [bar] & 3.2 \\
Piston bowl geometry [-] & Stock \\
Effective CR [-] & $11: 1$ \\
Diesel injection pressure [bar] & 1890 \\
Low reactivity fuel inj. pressure [bar] & 5.5 \\
Low reactivity fuel inj. timing [CAD ATDC] & 385 \\
\hline
\end{tabular}

Table 6.9. Operating parameters at high load conditions. Diesel injection timing sweep for the different fuels and PERs.

\begin{tabular}{|c|c|c|c|c|c|c|}
\hline \multicolumn{3}{|c|}{ Diesel } & \multicolumn{4}{|c|}{ Low reactivity fuels } \\
\hline SOI & Total mass & PER & E20-95 & E10-95 & E10-98 & E85 \\
\hline$[\mathrm{CAD}]$ & {$[\mathrm{mg}]$} & {$[\%]$} & {$[\mathrm{mg}]$} & {$[\mathrm{mg}]$} & {$[\mathrm{mg}]$} & {$[\mathrm{mg}]$} \\
\hline \multirow{4}{*}{-9 to +3} & 87.5 & 49 & 87.5 & 84.8 & 84.9 & 111 \\
\hline & 78.7 & 54 & 78.5 & 93.3 & 93.4 & 122.1 \\
\hline & 70 & 59 & 70 & 101.8 & 101.8 & 133.2 \\
\hline & 61.2 & 64 & 61.2 & 110.2 & 110.3 & 144.3 \\
\hline
\end{tabular}

\subsubsection{Results}

Figure 6.24 shows several combustion tracers to reveal the main differences in combustion development between B7+E10-95, B7+E20-95 and B7+E10-98 at some representative conditions of those depicted in table 6.9. First subfigure shows that, at this engine load, the trend of maximum heat release peak differs from that at low and medium load, where delay of diesel injection timing provoked constant decay in maximum RoHR peaks. The behavior observed here is consequence of the change in combustion pattern as SOI main delays, which tends to induce stronger rise in RoHR once the combustion has started (see figure 6.25). Moreover, as found at low and medium loads, the higher reactivity of E10-95 results in shorter combustion duration with advanced SOC compared to the other LRFs at equal PER conditions. Concerning 
combustion phasing (CA50), the values obtained are very similar for all fuel blends, which denotes more mixing-controlled combustion development than in case of the previously analyzed results at lower engine loads. Finally, although not being illustrated in the figure, it is interesting to note that E10-95 enables combustion propagation even when extremely delayed $\mathrm{SOI}_{\text {main }}$ are used $(+6$ CAD ATDC), while misfire is observed for the other two fuel blends.
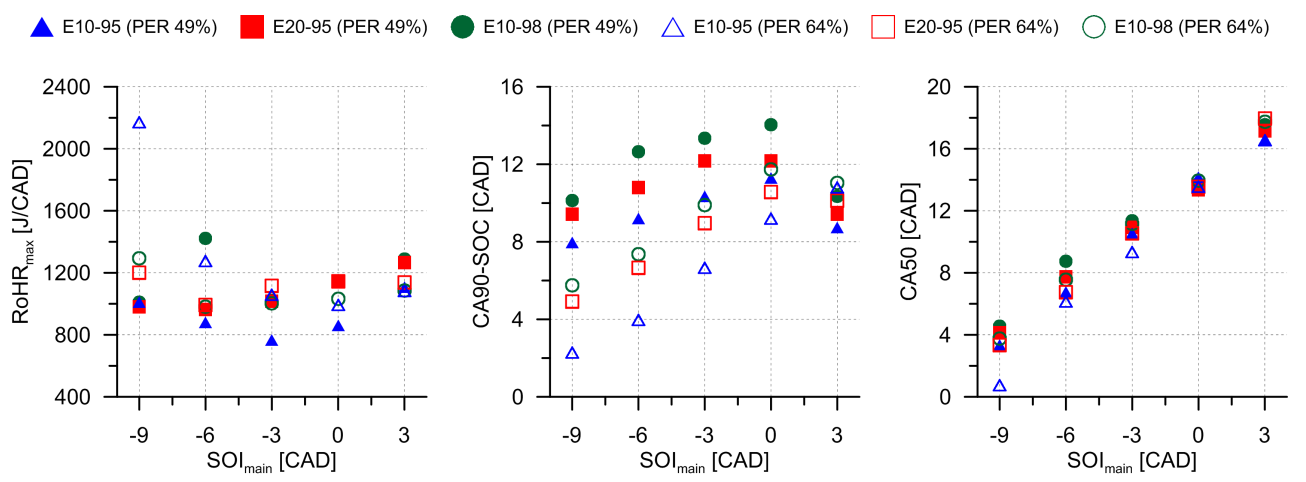

Figure 6.24. Influence of fuel properties and PER on some combustion tracers as a function of diesel SOI $I_{\text {main }}$.

Figure 6.25 presents the effect of PER and fuel properties on combustion pattern at two injection situations. In this way, the effect of injection timing can be also isolated by comparing profiles from both subfigures. As can be seen in left-subfigure, the effect of PER at $\mathrm{SOI}_{\text {main }}=-6$ CAD ATDC is opposite of that observed at low and medium loads under similar CA50 conditions. Specifically, when PER is increased, the first combustion stage remains nearly unaffected (worsened in case of E10-95), while the second one is clearly improved. The enhancement of the second combustion phase is more noticeable for E10-95 due to its more reactive chemical properties. In addition, the early SOC experienced when using E10-95, allows reducing the diesel fuel amount accumulated prior to combustion onset, thus lowering the maximum RoHR peak.

Results at +3 CAD ATDC show diesel-like combustion profiles in all cases, with a strong initial rise of the RoHR slope followed by very late combustion phase. This combustion pattern is explained looking at figure 6.27, which shows the degree of premixing for diesel injection as difference between SOC and EOI. The figure shows negative values in all cases (except two tests), which denote partial overlapping between diesel injection and combustion processes. On the other hand, no remarkable effect of PER on SOC is 
appreciated in figure 6.27 (right), with only minor differences identified for E10-98. Finally, the main difference between fuels is observed at SOC, where E10-95 provides earlier combustion onset due to its higher reactivity. As commented before, this implies lower quantity of diesel fuel burned during the premixed combustion stage, which leads to lower RoHR peaks.
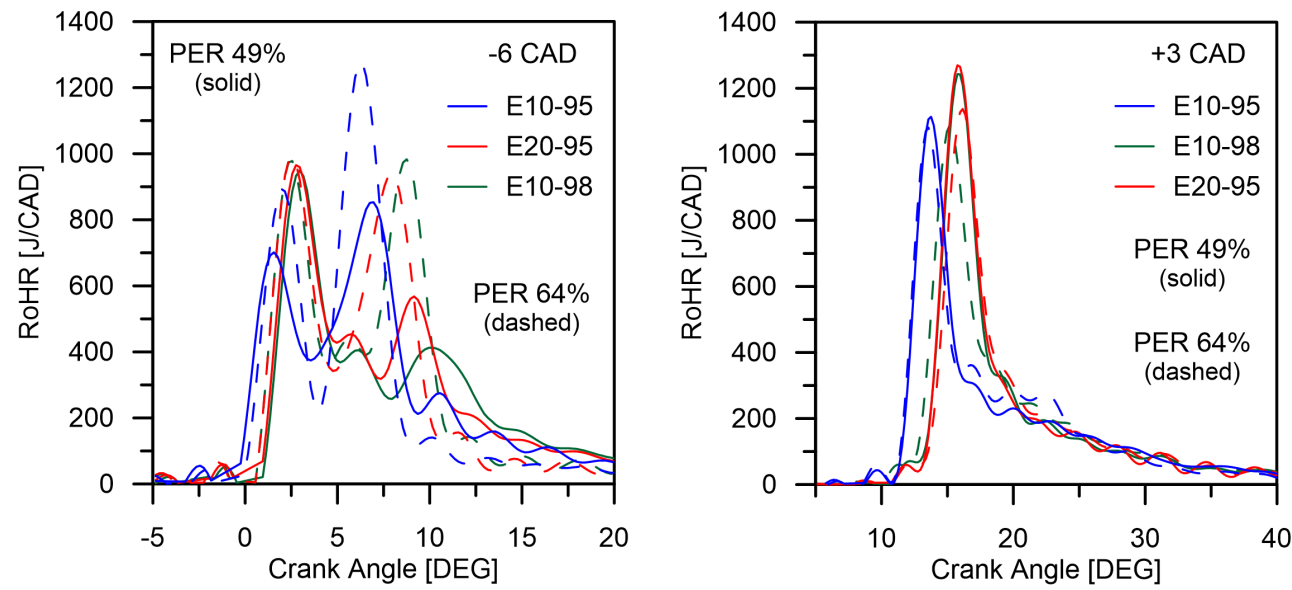

Figure 6.25. Influence of fuel properties and PER on heat release evolution at two injection timing scenarios.

Figure 6.26 shows that the EURO VI limit for NOx emissions is only reached at the more retarded combustion phasings, where low combustion temperatures are experienced (see figure 6.28). In addition, the combustion process enhancement promoted by the increase in PER, leads to higher NOx emissions. From the second subfigure, it is clear that combustion development at these late instants of the cycle penalizes the fuel-to-work extraction, thus showing a continuous decay of gross indicated efficiency as CA50 increases. Finally, contrarily to the expected, the highest reactive fuel (E10-95) performs better than the other fuels in terms of maximum PRR when PER $49 \%$ is used, which is explained by the less steep first combustion phase. For the remaining cases, a decreasing trend of maximum PRR with CA50 is observed, where only some conditions reach MPRR values under 15 bar/CAD.

The NOx-soot trade-off represented in figure 6.27 shows that only one test performs inside the NOx-soot compliance region. This corresponds to E10-95 fuel with PER $64 \%$. In addition, the ability of reducing soot emissions to ultra-low levels when increasing the ratio of premixed fuel can be confirmed again. The trend of soot emissions can be illustrated more clearly if the results are plotted as a function of CA50 (middle subfigure). In this case, 

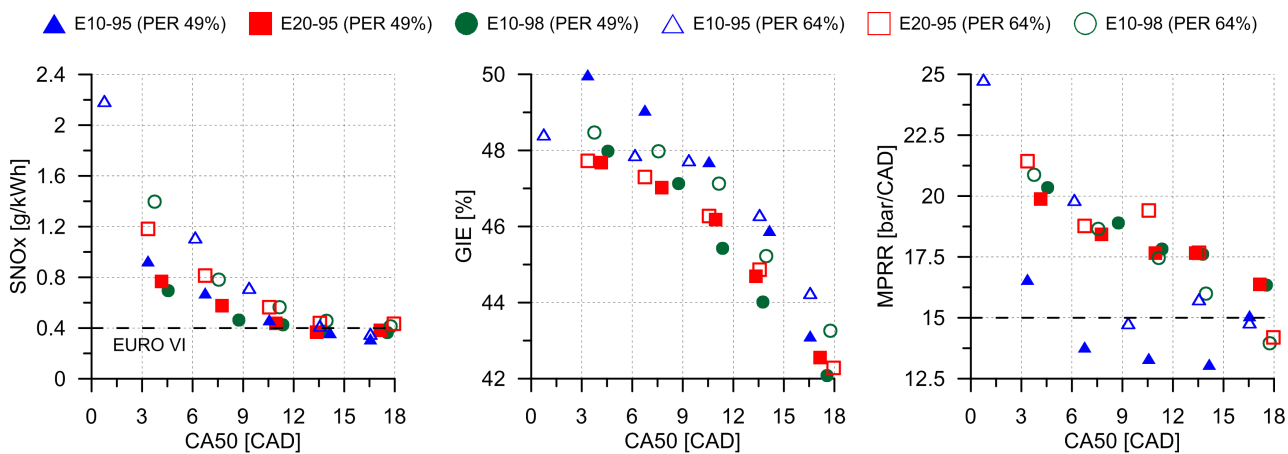

Figure 6.26. Influence of fuel properties and PER on NOx, gross indicated efficiency (GIE) and maximum pressure rise rate (MPRR) as a function of combustion phasing (CA50).

the soot emissions measurements of E20-95 and E10-98 show the same trend, but notably different to that of E10-95. This similitudes and differences may be explained by the degree of premixing for each fuel, which is computed as SOC-EOI in the third subfigure. As can be seen, all cases of PER $49 \%$ show negative mixing time, which infers that certain quantity of diesel fuel is burned in diffusive combustion mode. Moreover, as illustrated before with the RoHR profiles, the figure shows that E10-95 provides constant advance in combustion with respect to E20-95 and E10-98 in all cases.
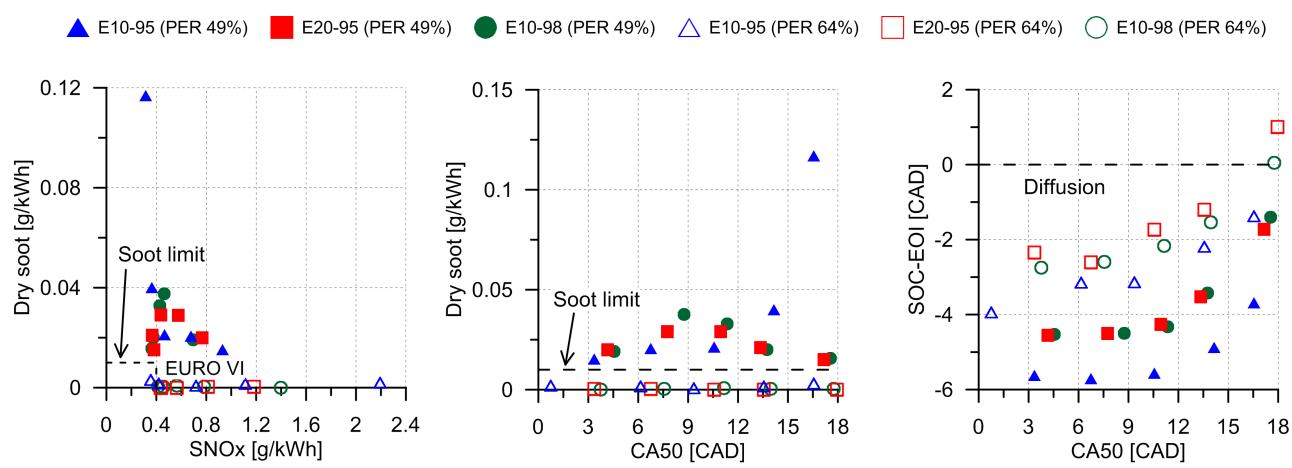

Figure 6.27. Influence of fuel properties and PER on soot emissions and degree of premixing.

To account the relative amount of diesel fuel mass that is burned in diffusion manner, figure 6.28 shows the degree of premixing normalized by the injection duration (DOI). This parameter reveals that in the case of E10- 
95, at the most advanced SOIs, nearly $60 \%$ of total diesel mass is burned as diffusion combustion, which represents an increment of around $12 \%$ with respect to E20-95 and E10-98. When combustion phasing exceeds of +12 CAD ATDC, the fuel/air premixing degree increases considerably in all cases. At these conditions, the difference of diffusion-burned fuel mass between fuels increases up to $20 \%$. Thus, the great quantity of diffusion-burned diesel mass when using E10-95 as LRF, plus the very low combustion temperature, should contribute to the rise observed in soot emissions at latest SOIs. By contrast, in the cases of E20-95 and E10-98, the strong reduction in soot formation when CA50 surpass +12 CAD may compensate the lower soot oxidation rate due to the lower temperature, showing a decrease in engine-out soot emissions. Nonetheless, a dedicated study about the mechanisms governing soot emissions from RCCI combustion is needed to reinforce these thoughts.
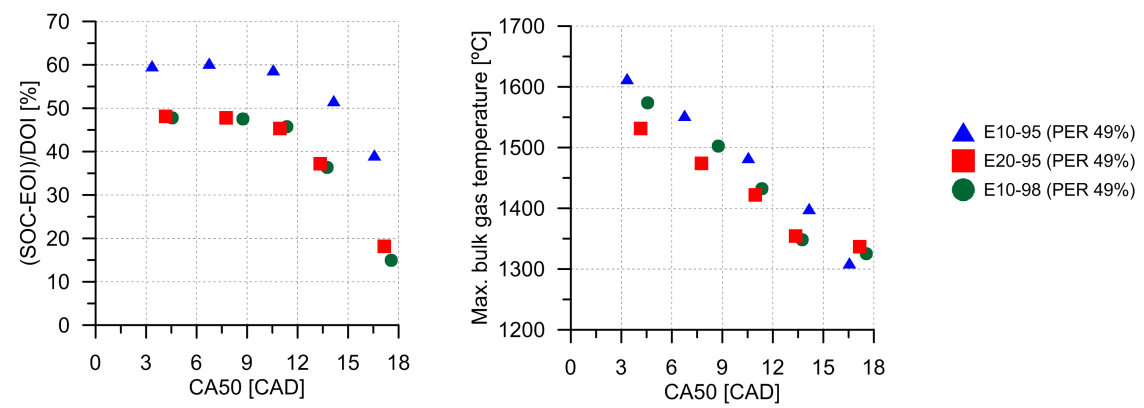

Figure 6.28. Influence of fuel properties on the normalized degree of premixing and bulk gas temperature.

From figure 6.29, it can be seen that unburned $\mathrm{HC}$ and $\mathrm{CO}$ emissions show increasing trend as diesel injection timing is delayed. In this sense, the low temperature associated to the expansion stroke worsens the propagation of the second combustion phase. Moreover, the pronounced rise in $\mathrm{CO}$ emissions for SOI values after TDC confirm the higher sensitivity of CO than $\mathrm{HC}$ to engine settings variation. In these cases, combustion development shows large and delayed combustion tail (figure 6.25), where combustion temperatures are too low for full oxidation of $\mathrm{CO}$ to be completed on engine-cycle time scales. The variation of PER shows opposite effect on both emissions. On one hand, it is seen that the amount of hydrocarbons are increased as PER increases. This is clearly related to the amount of LRF trapped in the crevices. As discussed in chapter 4 , the use of single injection strategy for diesel fuel does not allow to complete the combustion of premixed fuel trapped in the crevice volume, and therefore, the LRF located in this zone results in unburned 
hydrocarbons. In the case of E10-95, the increase in PER improves notably the second combustion phase (well related to gasoline burning), which leads to reduce $\mathrm{HC}$ emissions in some tests.

On the other hand, $\mathrm{CO}$ emissions reduces as PER increases due to the enhancement of combustion event, which is more evident looking at the second combustion stage. This reasoning is not applicable to the last SOI $(+3$ CAD ATDC), where combustion process worsens because of the inappropriate thermodynamic conditions. Finally, the computation of combustion efficiency shows that the unique test which complies simultaneously with EURO VI NOx and soot emissions limits, shows a combustion efficiency value slightly below $98 \%$, which is similar to those obtained at low and medium load.
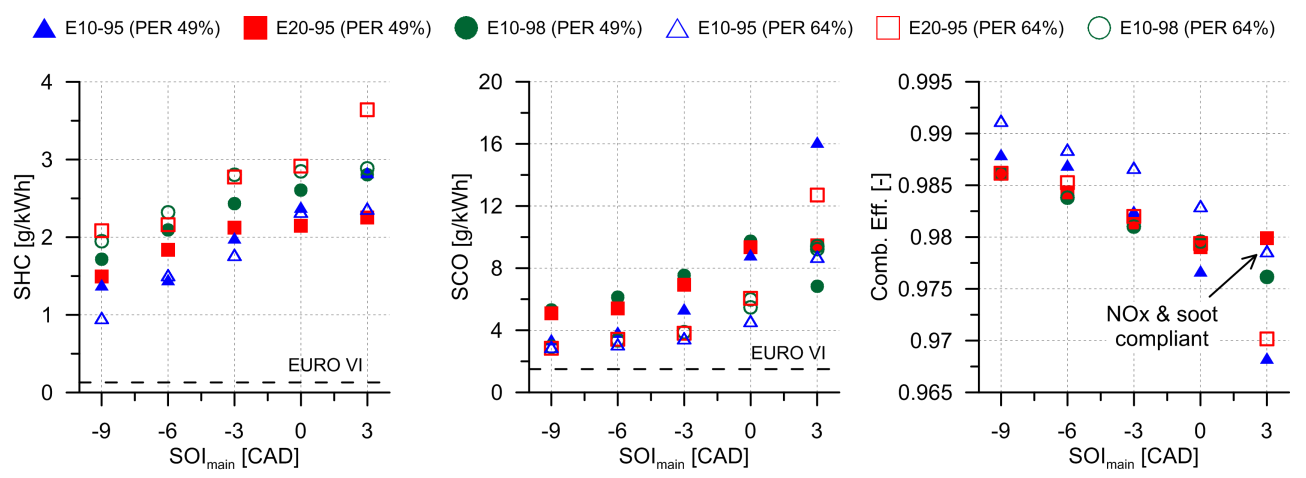

Figure 6.29. Influence of fuel properties and PER on $H C$ and $C O$ emissions and combustion efficiency as a function of diesel SOI main.

\subsection{Low reactivity fuel selection}

After explaining the results obtained from the parametric sweeps, the same merit function [46] than in chapters 4 and 5 has been used to identify the engine settings which provide the most potential results for each LRF at the different engine loads. The constrained values for calculating the merit function (MF) were: $\mathrm{NOx}=0.4 \mathrm{~g} / \mathrm{kWh}$, soot $=0.01 \mathrm{~g} / \mathrm{kWh}$ and maximum $\mathrm{PRR}=15 \mathrm{bar} / \mathrm{CAD}$. These limitations are aimed to achieve ultra-low emissions while preserving the mechanical integrity of the engine.

Figure 6.30 shows the MF values for all the parametric studies developed in this chapter. Results in each row correspond to different engine loads, while each column refers to different fuels. In spite of not being extensively explained 
in the chapter, the MF results concerning E85 fuel have been included here in order to provide wider perspective to the reader. As can be seen in the legend of the figure, the PERs needed to reach stable operation using E85 fuel were notably lower than those of the other LRFs, which explains the great differences observed in MF results. Thus, to provide more clarity to the figure, dedicated ordinate axes have been used at low and medium load conditions for this fuel.

The results show that, for a given fuel and engine load, various operating conditions fulfilled the three constraints mentioned above, which results in MF values equal to zero. The number of compliant tests (NCT) for each fuel and engine load is included in the graph. The best condition from these cases was considered the one that led the lowest brake specific fuel consumption (BSFC). Thus, the selected engine operating conditions for each fuel and their minimum MF values are marked in the figure. As can be seen, all the operating conditions selected, with the exception of E85 at high load, fulfill the three constraints imposed $(\mathrm{MF}=0)$.

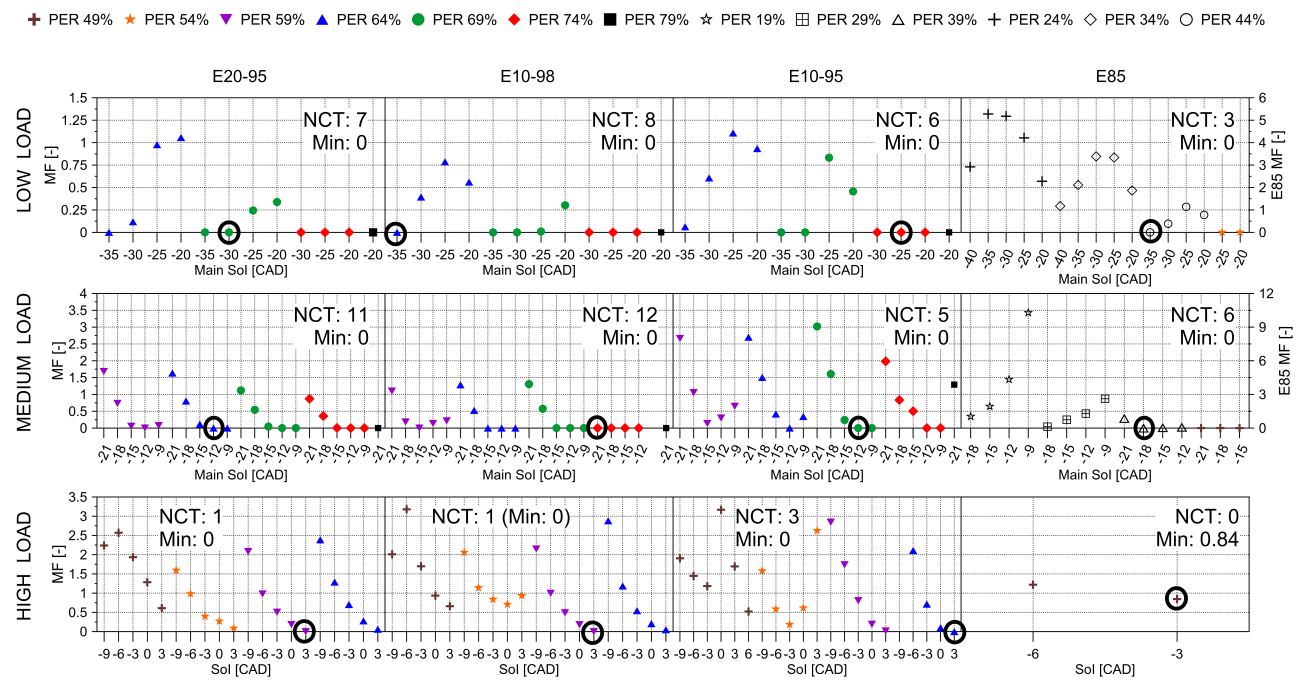

Figure 6.30. Merit function results for three constrained values: NOx=0.4 $\mathrm{g} / \mathrm{kWh}$, soot $=0.01 \mathrm{~g} / \mathrm{k}$ Wh and maximum $P R R=15 \mathrm{bar} / C A D$. Marked operating conditions are the ones that provide minimum MF values and lowest BSFC.

To allow direct comparison between the best tests of each fuel, figure 6.31 represents the engine-out emissions (left) and performance results (right) versus engine load for the tests previously selected. In addition, results from CDC operation with OEM settings have been also included in the figure. 
Because of the reduced LHV of E85, the fuel consumption is presented in grams of diesel energy equivalent (equation 6.2). This method allows the direct comparison of RCCI operation to CDC operation without introducing deviations associated to the LHV of each LRF.

$$
B S F C_{D E}=\frac{m_{B 7}+m_{L R F} \cdot\left(\frac{L H V_{L R F}}{L H V_{B 7}}\right)}{N_{e}}
$$

From the figure, it can be seen that soot levels remain under the limit value whatever the fuel blend and engine load. Moreover, E20-95, E10-98 and E1095 allow operating under the EURO VI NOx limitation in the whole engine load range. By contrast, the lower PER required to ensure stable operation with E85 leads to exceed the NOx limitation. Finally, it can be observed that E10-95 shows the highest combustion efficiency at low and medium load, with similar values than E10-98 at high load.
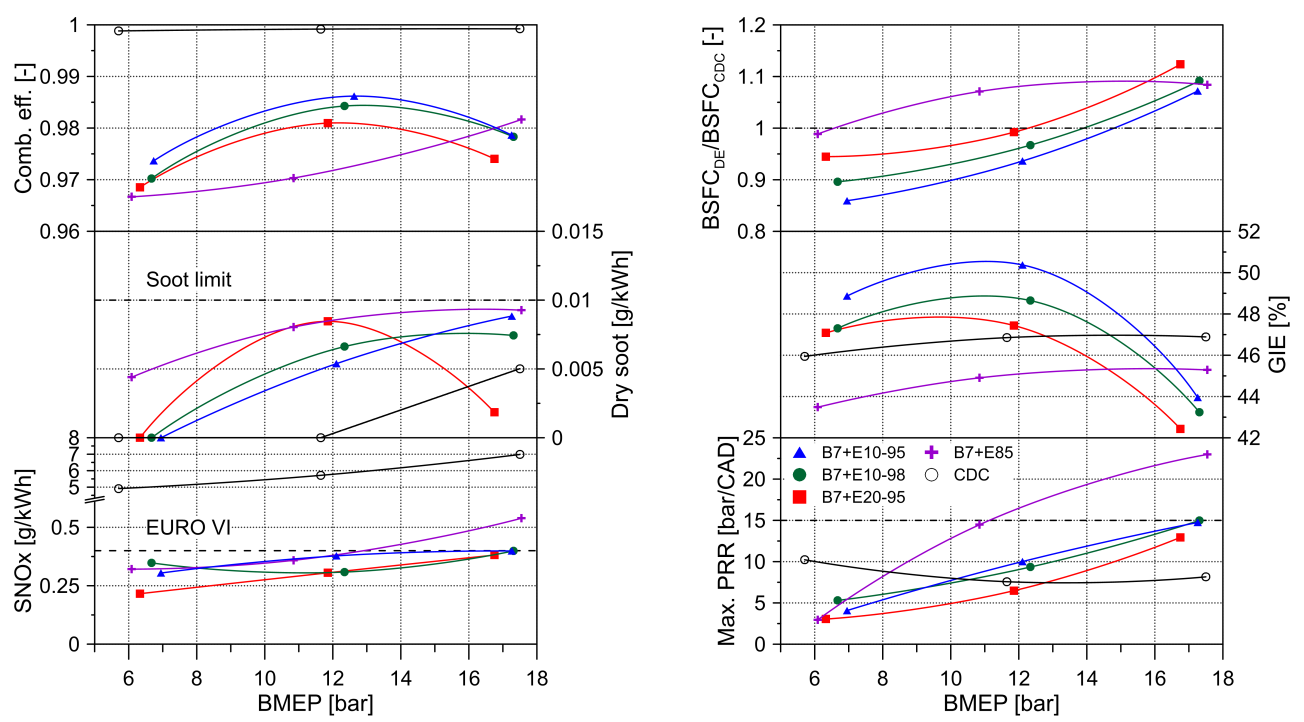

Figure 6.31. Engine-out emissions (NOx, soot, combustion efficiency) and performance (maximum PRR, GIE and BSFC) versus engine load for the selected engine operating conditions.

Regarding engine performance, it is seen that maximum PRR remains below the limitation in the cases of E20-95, E10-98 and E10-95, while E85 leads to values above $15 \mathrm{bar} / \mathrm{CAD}$ at the highest load. Looking at the GIE subfigure it is confirmed that E10-95 fuel is the most suitable LRF to be 
used in all the engine load range, showing a great improvement in GIE at low and medium load versus the other LRFs. The decay in GIE at high load conditions for the three intermediate ethanol-gasoline blends is related to the delayed single injection strategy used to fulfill the three constraints imposed in the $\mathrm{MF}$ (SOI=+3 CAD ATDC). Here, it is worthy to note that, in spite of that E85 shows the best GIE at high load conditions, this operating condition is not valid due to its knocking tendency.

Regarding fuel consumption, it is seen that the higher GIE of E10-95 leads to the greatest fuel saving from low to medium load compared to CDC operation, followed by E10-98 and E20-95. However, at high load, where the OEM settings are optimized for CDC, all the LRFs lead to higher BSFC $\mathrm{DE}_{\mathrm{DE}}$. Finally, the figure shows that E85 does not show potential for reducing fuel consumption versus CDC, which would be even more noticeable if the BSFC were not corrected by the LHV.

B7+E10-95 $\square$ Regular fuels - - EURO VI \& soot limit
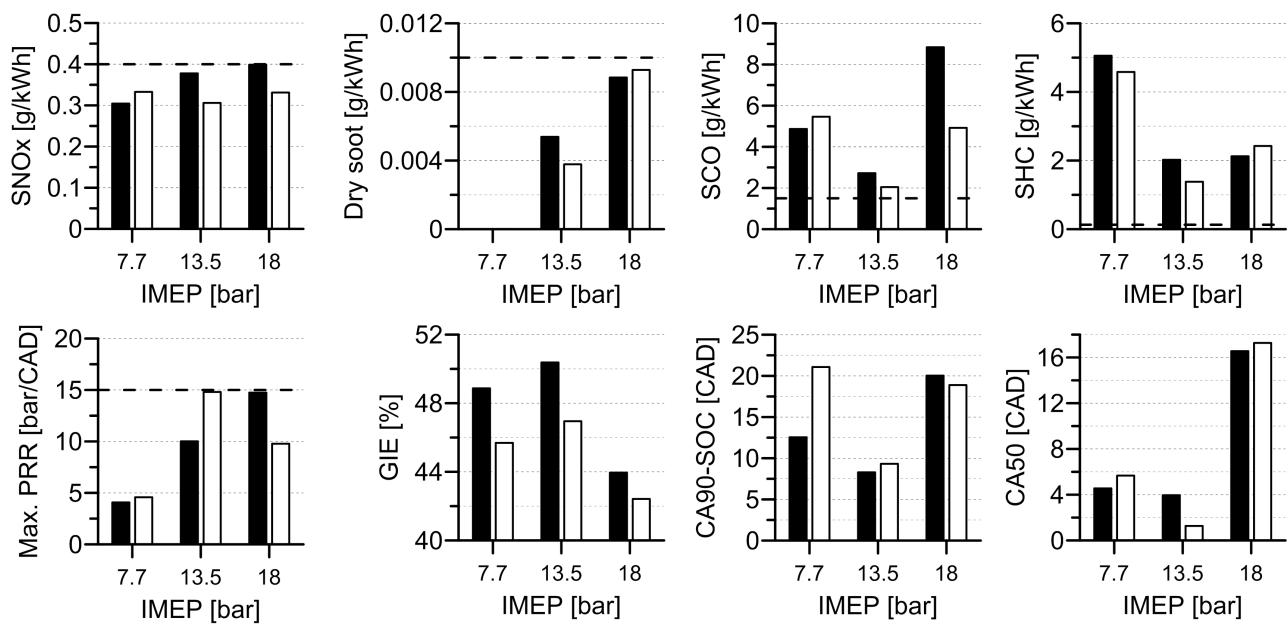

Figure 6.32. Comparison of the results from RCCI combustion using biofuels and petroleum-based fuels. The best results of $\mathrm{B}^{7}+E 10-95$ and those obtained with regular pump fuels in chapter 5 are represented. In both cases, the stock piston geometry was used.

Finally, the figure 6.32 compares the potential of using biofuels versus petroleum-based fuels (regular diesel and gasoline) under RCCI operation. Specifically, the figure shows the best results corresponding to B7+E10-95 (from figure 6.31) together with the best results obtained in chapter 5 with 
the stock piston, which were performed using regular diesel and gasoline fuels (figure 5.31).

Despite the air management settings and other constant parameters used at the different engine loads were equal between the two studies compared, the results show no clear trend in terms of engine-out emissions. This is explained due to the great variations in the injection settings among the best tests selected from both studies, which are summarized in table 6.10.

Table 6.10. Injection settings for the best results of $B 7+E 10-95$ and those obtained with regular fuels in chapter 5.

\begin{tabular}{lllll}
\hline \hline IMEP & \multicolumn{2}{c}{ B7+E10-95 } & \multicolumn{2}{c}{ Regular fuels } \\
[bar] & PER [\%] & Diesel SOI [CAD] & PER [\%] & Diesel SOI [CAD] \\
\hline 7.7 & 74 & $-60 /-25$ & 74 & $-50 /-25$ \\
13.5 & 69 & $-60 /-12$ & 69 & $-50 /-12$ \\
18 & 59 & +3 & 74 & +6 \\
\hline
\end{tabular}

What is interesting to see is that, operating under the same constraints imposed in the merit function, the combination of biofuels allows improving substantially the efficiency of RCCI concept in all the engine loads. As it can be seen, the highest benefit in gross indicated efficiency versus the operation with regular fuels is obtained at low and medium loads. In these cases, the lower reactivity of E10-95 than the regular gasoline and the charge cooling effect introduced by the addition of ethanol to the blend, permit advancing the pilot injection timing for the diesel fuel up to -60 CAD without exceeding the maximum PRR of 15 bar/CAD, which was the limiting factor in the case of using regular fuels. Thus, this injection strategy led to better GIE due to the lower combustion duration (CA90-SOC) and better combustion phasing (CA50).

On the other hand, it is seen that the benefit of using biofuels at high load is lower than that observed at lower loads. At this condition, the lower reactivity of E10-95 and the need of using single injection strategies, demanded a decrease in PER, which reduces the efficiency of the concept. In addition, the high amount of diesel fuel injected at a very delayed instant in the engine cycle provoked an important rise of $\mathrm{CO}$ emissions and maximum PRR. 


\subsection{Summary and conclusions}

This chapter has explained the influence of the low reactivity fuel properties on RCCI combustion characteristics. For this purpose, four different fuel blends varying the ethanol content and gasoline octane number have been investigated.

The initial parametric studies performed at low load denoted that the three fuels selected (E10-95, E20-95 and E10-98) allow reaching ultra-low soot emissions without any limitation in terms of PER. This behavior was explained by the higher advanced injection strategy used and the relatively low diesel fuel mass injected, which unfortunately reduce the effective control on combustion phasing. Moreover, for conditions under investigation, it was shown that only the higher PERs can ensure the EURO VI NOx compliance. At high PER conditions, unburned $\mathrm{HC}$ and $\mathrm{CO}$ emissions were high for all fuels, leading to very low combustion efficiency values. In addition, only the E10-95 fuel provided acceptable gross indicated efficiency with high PERs, mainly because its suitability for maintaining the combustion phasing near the optimal value $(\mathrm{CA} 50 \approx+5 \mathrm{CAD}$ ATDC $)$.

To explore the potential of each fuel for improving the results obtained in the initial parametric studies performed at low load (where the constant settings proposed were not optimal for all fuels), a series of tests keeping constant the combustion phasing at +5 CAD ATDC were carried out. For this purpose, the EGR rate was modified to compensate the differences in chemical reactivity between LRFs. The analysis of the combustion development revealed some differences between fuels, showing that:

- The low temperature combustion initiation is promoted, almost exclusively, by the HRF reactions. Moreover, an inverse linear dependence between the energy released during this stage and the PER was found. In addition, LRFs with more reactive properties promoted higher energy delivered during this combustion phase.

- The in-cylinder oxygen concentration governs the high temperature combustion onset, which was driven by the autoignition of the HRF. It was also found that decreasing PER promotes more rapid RoHR ramps after the main combustion onset, with more progressive transition up to the maximum RoHR peak. Heat release peaks increased as the ON of the LRF decreased, while it was not strongly affected by PER conditions. The energy released in this combustion stage showed similar trend for 
all fuels, with increased energy delivered up to certain PER followed by progressive decay up to highest PER used.

- Combustion duration became shorter as the ON of the LRF and PER decreased. Since late combustion phase was similar between fuels, the differences observed in combustion duration were mainly related to variations in the start of combustion (SOC).

- Ringing intensity showed opposite trend to combustion duration, with higher values as PER and octane number of the LRF decrease. Nevertheless, all values were far below $5 \mathrm{MW} / \mathrm{m}^{2}$.

These variations in combustion behavior affected the engine-out emissions measurements. Comparatively, the LRF with higher autoignition qualities, i.e. E10-95, allowed simultaneous reduction of $\mathrm{NOx}, \mathrm{CO}$ and $\mathrm{HC}$ emissions, keeping also the soot levels below the detection threshold of the smoke meter. This simultaneous reduction was achieved due to two reasons. First, the more reactive properties of this LRF enabled using higher EGR rates, which reduced the maximum combustion temperatures, and in turn, NOx emissions. Second, unburned $\mathrm{HC}$ and $\mathrm{CO}$ emissions were improved due to enhancement of combustion process, showing higher RoHR peaks and lower combustion duration. This fact also led to better gross indicated efficiencies than the rest of LRFs, confirming that E10-95 fuel is the best candidate for low load operation.

The second block of results evaluated the potential of each fuel to operate from medium to high load. In general terms, the findings concerning the influence of fuel properties and PER on combustion process and emissions followed the same trend than those at low load. The main differences found compared to low load results are summarized as follows:

- For preventing excessive PRR at these loads, it was needed to reduce the effective compression ratio up to 11:1. With the same purpose, diesel injection strategy was modified compared to low load. Thus, the range of diesel $\mathrm{SOI}_{\text {main }}$ was delayed to perform the tests at medium load, and single injection strategies were set at high load.

- The more delayed main injection timings used in the tests provided better control on combustion process, showing a linear relationship between diesel SOI and CA50.

- Engine-out soot emissions were not as negligible as at low load conditions, mainly when relatively high diesel fractions were used. Thus, 
engine-out soot emissions were found to be a balance between formation and oxidation processes.

- Contrarily to low load, at high load conditions, the increase of PER improved the second stage of the combustion event.

The direct comparison of the best tests obtained from all the parametric studies showed that the three intermediate ethanol-gasoline blends allow reaching NOx levels under the EURO VI limit and ultra-low soot emissions with acceptable ringing intensity and better fuel consumption than CDC operation from low to medium load. This fact demonstrates the capabilities of RCCI as flexible-fuel concept. From these fuels, E10-95 showed the highest potential to be used in all the engine load range due to its capacity for lowering $\mathrm{HC}$ and $\mathrm{CO}$ emissions together with higher gross indicated efficiency. By contrast, under the conditions investigated, the E85 fuel showed worse BSFC than CDC up to medium load, and exceeded NOx and maximum PRR limits at high load conditions.

Finally, the comparison between the best tests of E10-95 and the best results obtained in chapter 4 using regular diesel and gasoline, showed that the near-term biofuel blends investigated here have the capability of decreasing the petroleum energy consumption, reducing engine-out emissions and increasing the efficiency of RCCI concept. 


\section{Bibliography}

[1] The European Commission. "Energy, Transport and Environment Indicators". Technical report, 2014.

[2] "Directive 2009/28/EC of the European parliament and of the council of 23 April 2009 on the promotion of the use of energy from renewable sources". Technical report, http://eur-lex.europa.eu.

[3] Pearson R.J. and Turner J.W.G. "2 - The role of alternative and renewable liquid fuels in environmentally sustainable transport A2 - Folkson, Richard". In Alternative Fuels and Advanced Vehicle Technologies for Improved Environmental Performance, pp. 19-51. Woodhead Publishing, 2014.

[4] Kampman B., Verbeek R., van Grinsven A., van Mensch P., Croezen H. and Patuleia A. "Bringing biofuels on the market: options to increase EU biofuels volumes beyond the current blending limits". In CE Delft, 2013.

[5] "Directive 2009/30/EC of the European parliament and of the council of 23 April 2009". Technical report, http://eur-lex.europa.eu.

[6] Andersen V.F., Anderson J.E., Wallington T.J., Mueller S.A. and Nielsen O.J. "Vapor Pressures of Alcohol-Gasoline Blends". Energy \& Fuels, Vol. $24 \mathrm{n}^{\circ}$ 6, pp. 3647-3654, 2010 .

[7] Saravana T., Abu A. and Farid A. "Review on bioethanol as alternative fuel for spark ignition engines". Renewable and Sustainable Energy Reviews, Vol. 56, pp. 820-835, 2016.

[8] Owen K., Coley T. and Weaver C.S. Automotive fuels reference book. Society of Automotive Engineers, 1995.

[9] Balki M.K., Sayin C. and Canakci M. "The effect of different alcohol fuels on the performance, emission and combustion characteristics of a gasoline engine". Fuel, Vol. 115, pp. 901-906, 2014.

[10] Celik M.B. "Experimental determination of suitable ethanol-gasoline blend rate at high compression ratio for gasoline engine". Applied Thermal Engineering, Vol. $28 \mathrm{n}^{\circ} 5-6$, pp. 396-404, 2008.

[11] Yoon S.H. and Lee C.S. "Effect of undiluted bioethanol on combustion and emissions reduction in a SI engine at various charge air conditions". Fuel, Vol. 97, pp. 887-890, 2012 .

[12] Chen R-H., Chiang L-B., Chen C-N. and Lin T-H. "Cold-start emissions of an SI engine using ethanol-gasoline blended fuel". Applied Thermal Engineering, Vol. 31 $\mathrm{n}^{\circ}$ 8-9, pp. 1463-1467, 2011.

[13] Stein R.A., Anderson J.E. and Wallington T.J. "An Overview of the Effects of EthanolGasoline Blends on SI Engine Performance, Fuel Efficiency, and Emissions". SAE Int. J. Engines, Vol. 6, pp. 470-487, 2013.

[14] Murcak A., Haşimoğlu C., Çevik İ. and H. Kahraman Hüseyin. "Effect of injection timing to performance of a diesel engine fuelled with different diesel-ethanol mixtures". Fuel, Vol. 153, pp. 569-577, 2015.

[15] Lei J., Bi Y. and Shen L. "Performance and Emission Characteristics of Diesel Engine Fueled with Ethanol-Diesel Blends in Different Altitude Regions". BioMed Research International, Vol. 2011, pp. 417-421, 2010. 
[16] Gnanamoorthi V. and Devaradjane G. "Effect of compression ratio on the performance, combustion and emission of DI diesel engine fueled with ethanol-Diesel blend". Journal of the Energy Institute, Vol. $88 \mathrm{n}^{\circ}$ 1, pp. 19-26, 2015.

[17] Kumar C., Athawe M., Aghav Y.V., Babu M.K. Gajendra and Das L.M. "Effects of Ethanol Addition on Performance, Emission and Combustion of DI Diesel Engine Running at Different Injection Pressures". SAE Technical Paper, n $^{\circ}$ 2007-01-0626, 2007.

[18] Gerdes K.R. and Suppes G.J. "Miscibility of Ethanol in Diesel Fuels". Industrial \& Engineering Chemistry Research, Vol. 40 n ${ }^{\circ}$ 3, pp. 949-956, 2001.

[19] Xing-cai L., Jian-guang Y., Wu-gao Z. and Zhen H. "Effect of cetane number improver on heat release rate and emissions of high speed diesel engine fueled with ethanol-diesel blend fuel". Fuel, Vol. 83 n $^{\circ}$ 14-15, pp. 2013-2020, 2004.

[20] Mancaruso E. and Vaglieco B.M. "UV - Visible imaging of PCCI engine running with ethanol/diesel fuel". SAE Technical Paper, $\mathrm{n}^{\circ}$ 2012-01-1238, 2012.

[21] Mancaruso E. and Vaglieco B.M. "Characterization of PCCI combustion in a single cylinder CI engine fuelled with RME and bio-ethanol". SAE Technical Paper, ${ }^{o}$ 201301-1672, 2013.

[22] Mancaruso E. and Vaglieco B.M. "Spectroscopic analysis of the phases of premixed combustion in a compression ignition engine fuelled with diesel and ethanol". Applied Energy, Vol. 143, pp. 164-175, 2015.

[23] Kalghatgi G.T., Risberg P. and Ångström H-E. "Advantages of Fuels with High Resistance to Auto-ignition in Late-injection, Low-temperature, Compression Ignition Combustion". SAE Technical Paper, ${ }^{\circ}$ 2006-01-3385, 2006.

[24] Kalghatgi G.T., Risberg P. and Ångström H-E. "Partially Pre-Mixed Auto-Ignition of Gasoline to Attain Low Smoke and Low NOx at High Load in a Compression Ignition Engine and Comparison with a Diesel Fuel". SAE Technical Paper, no 2007-01-0006, 2007.

[25] Sjöberg M. and Dec J.E. "Ethanol Autoignition Characteristics and HCCI Performance for Wide Ranges of Engine Speed, Load and Boost". SAE International Journal of Engines, Vol. $3 \mathrm{n}^{o}$ 1, pp. 84-106, 2010.

[26] Asad U., Kumar R., Zheng M. and Tjong J. "Ethanol-fueled low temperature combustion: A pathway to clean and efficient diesel engine cycles". Applied Energy, Vol. 157, pp. 838-850, 2015.

[27] Gnanam G., Sobiesiak A., Reader G. and Zhang C. "An HCCI Engine Fuelled with Iso-octane and Ethanol". SAE Technical Paper, no 2006-01-3246, 2006.

[28] Zhang Y., He B-Q., Xie H. and Zhao H. "The Combustion and Emission Characteristics of Ethanol on a Port Fuel Injection HCCI Engine". SAE Technical Paper, $\mathrm{n}^{\circ}$ 2006-010631, 2006.

[29] Blasio G. Di, Beatrice C. and Molina S. "Effect of Port Injected Ethanol on Combustion Characteristics in a Dual-Fuel Light Duty Diesel Engine". SAE Technical Paper, $\mathrm{n}^{\circ}$ 2013-01-1692, 2013.

[30] Fraioli V., Mancaruso E., Migliaccio M. and Vaglieco B. "Ethanol effect as premixed fuel in dual-fuel CI engines: Experimental and numerical investigations". Applied Energy, Vol. 119, pp. 394-404, 2014.

[31] Sarjovaara T., Larmi M. and Vuorinen V. "Effect of charge air temperature on E85 dual-fuel diesel combustion". Fuel, Vol. 153, pp. 6-12, 2015. 
[32] Tutak W. "Bioethanol E85 as a fuel for dual fuel diesel engine". Energy Conversion and Management, Vol. 86, pp. 39-48, 2014.

[33] Curran S., Hanson R. and Wagner R. "Effect of E85 on RCCI Performance and Emissions on a Multi-Cylinder Light-Duty Diesel Engine". SAE Technical Paper, $\mathrm{n}^{\circ}$ 2012-01-0376, 2012.

[34] Sarjovaara T. and Larmi M. "Dual fuel diesel combustion with an E85 ethanol/gasoline blend". Fuel, Vol. 139, pp. 704-714, 2015.

[35] Curran S., Hanson R., Wagner R. and Reitz R.D. "Efficiency and Emissions Mapping of RCCI in a Light-Duty Diesel Engine". SAE Technical Paper, no 2013-01-0289, 2013.

[36] Kokjohn S., Hanson R., Splitter D. and Reitz R.D. "Fuel reactivity controlled compression ignition (RCCI): a pathway to controlled high-efficiency clean combustion". International Journal of Engine Research, Vol. $12 \mathrm{n}^{\circ}$ 3, pp. 209-226, 2011.

[37] Splitter D., Wissink M., Kokjohn S. and Reitz R.D. "Effect of Compression Ratio and Piston Geometry on RCCI Load Limits and Efficiency". SAE Technical Paper, $\mathrm{n}^{\circ}$ 2012-01-0383, 2012.

[38] Sjöberg M. and Dec J.E. "Smoothing HCCI Heat Release with Vaporization-CoolingInduced Thermal Stratification using Ethanol". SAE International Journal of Fuels and Lubricants, Vol. $5 \mathrm{n}^{\circ}$ 1, pp. 7-27, 2011.

[39] Foong T.M., Morganti K.J., Brear M.J., da Silva G., Yang Y. and Dryer F.L. "The Effect of Charge Cooling on the RON of Ethanol/Gasoline Blends". SAE Int. J. Fuels Lubr., Vol. $6 \mathrm{n}^{\circ}$ 2013-01-0886, pp. 34-43, 2013.

[40] Huang Y., Hong G., Cheng X. and Huang R. "Investigation to Charge Cooling Effect of Evaporation of Ethanol Fuel Directly Injected in a Gasoline Port Injection Engine". SAE Technical Paper, $\mathrm{n}^{\circ}$ 2013-01-2610, 2013.

[41] Hashimoto K. "Inhibition Effect of Ethanol on Homogeneous Charge Compression Ignition of Heptane". SAE Technical Paper, no 2008-01-2504, 2008.

[42] Benajes J., Molina S., Novella R. and Amorim R. "Study on Low Temperature Combustion for Light-Duty Diesel Engines". Energy \& Fuels, Vol. 24 n ${ }^{o}$ 1, pp. 355-364, 2010 .

[43] Kokjohn S., Reitz R.D., Splitter D. and Musculus M. "Investigation of Fuel Reactivity Stratification for Controlling PCI Heat-Release Rates Using High-Speed Chemiluminescence Imaging and Fuel Tracer Fluorescence". SAE Int. J. Engines, Vol. 5, pp. 248-269, 2012.

[44] Kokjohn S., Musculus M. and Reitz R.D. "Evaluating temperature and fuel stratification for heat-release rate control in a reactivity-controlled compression-ignition engine using optical diagnostics and chemical kinetics modeling". Combustion and Flame, Vol. $162 \mathrm{n}^{\circ}$ 6, pp. 2729-2742, 2015.

[45] Dec J.E. and Yang Y. "Boosted HCCI for High Power without Engine Knock and with Ultra-Low NOx Emissions - using Conventional Gasoline". SAE Int. J. Engines, Vol. 3, pp. 750-767, 2010.

[46] Cheng A.S. (Ed), Upatnieks A. and Mueller C.J. "Investigation of Fuel Effects on Dilute, Mixing-Controlled Combustion in an Optical Direct-Injection Diesel Engine". Energy \& Fuels, Vol. 21 n $^{o}$ 4, pp. 1989-2002, 2007. 


\title{
Chapter 7
}

\section{RCCI operating limits assessment}

\author{
Contents \\ $7.1 \quad$ Introduction $\ldots \ldots \ldots \ldots \ldots \ldots \ldots \ldots \ldots \ldots \ldots, 226$ \\ 7.2 RCCI operation over the whole engine map ..... 227 \\ 7.2.1 Experimental procedure definition........... 227 \\ 7.2.2 Results with nominal compression ratio ........ 232 \\ 7.2.3 Results with reduced compression ratio ........ 235 \\ 7.2.4 Technological challenges of RCCI concept ....... 238 \\ 7.3 Dual-mode RCCI/CDC capabilities ......... 243 \\ 7.3.1 Engine description ....................... 244 \\ $7.3 .2 \quad$ RCCI operating limits .................. 246 \\ 7.3.2.1 Low and high reactivity fuels selection... 246 \\ 7.3.2.2 Results ........................ 247 \\ 7.3.3 Dual-mode engine operation approach ......... 249
}

7.4 Summary and conclusions $\ldots \ldots \ldots \ldots \ldots \ldots \ldots, 256$

Bibliography $\ldots \ldots \ldots \ldots \ldots \ldots \ldots \ldots \ldots \ldots \ldots .259$ 


\subsection{Introduction}

Previous chapters demonstrated the potential of RCCI concept to reduce simultaneously NOx and soot emissions while improving the efficiency versus conventional diesel combustion (CDC). So, the use of RCCI concept in engines for transport sector can be claimed as alternative of the costly aftertreatment technologies needed for reducing the engine-out emissions up to the limits imposed by the current regulations. This ultimately means that a vehicle utilizing the RCCI technique must be able to operate over the whole engine speed and load range. If the engine cannot operate in RCCI regime over the whole engine map, then a dual-mode switching between RCCI and CDC could be utilized. In this case, the vehicle would still need to be equipped with aftertreatment systems for CDC operation, turning more unclear the potential of the concept.

According to the previous considerations, the first objective of this chapter is to evaluate the ability of RCCI concept to operate in a wide range of engine speeds and loads. For this purpose, a dedicated experimental procedure will be defined and tested with two different compression ratios. Considering the main findings from previous chapters, this study has been developed using the stock piston geometry and the biofuels combination of B7+E10-95. In particular, these fuels were selected because they showed clear improvements on RCCI efficiency versus the regular fuels in all the engine load range tested at 1200 rpm. Regarding piston selection, the bathtub geometry was discarded due to the unacceptable soot levels observed at high load conditions, which limited the extension of RCCI operation up to high load. Thus, since the tapered piston did not show as clear benefits as bathtub piston, it was decided to perform the study using the stock geometry. By this way, the results obtained here can be directly compared to CDC operation without introducing changes in the baseline hardware of the production engine.

In the second part of the chapter, the capabilities of the dual-mode RCCI/CDC operation are analyzed. For this purpose, a EURO VI mediumduty diesel engine representative of the current transport fleet was used. Considering the high compression ratio of the production engine (17.5:1) and taking into account the capabilities of ethanol to reduce the maximum incylinder pressure rise rates, the low reactivity fuel selected for performing this study was E20-95. In addition, B7 fuel was used as high reactivity fuel. 


\subsection{RCCI operation over the whole engine map}

As a first approach, this section evaluates the possibility of extending the use of the RCCI concept to cover the full operating range of the engine. As in previous chapters, the operating points will be considered valid for RCCI operation only if they fulfill certain restrictions. In this sense, a mandatory constraint is to ensure NOx levels under the EURO VI limit and ultra-low soot emissions, simultaneously. Moreover, looking for the durability and mechanical integrity of the engine, an additional restriction will be imposed limiting the maximum pressure rise rate in the combustion chamber.

\subsubsection{Experimental procedure definition}

Figure 7.1 shows a scheme of the experimental procedure developed and carried out during the experimental tests in order to reach the three imposed constraints over a wide range of engine speed and loads.

\begin{tabular}{|c|c|c|}
\multicolumn{1}{c}{ Step 1 } & Step 2 \\
\cline { 3 - 3 } $\begin{array}{c}\text { Stable operation } 3 \\
\text { at engine load }\end{array}$ & $\rightarrow \begin{array}{c}\text { NOx \& soot } \\
\text { target }\end{array}$ & $\begin{array}{c}\text { Minimize: } \\
\text { CO, HC \& BSFC }\end{array}$ \\
\cline { 3 - 3 } & &
\end{tabular}

Figure 7.1. Steps of the experimental procedure followed to reach the three imposed constraints over a wide range of engine speed and loads.

The first step, detailed in figure 7.2, is aimed at finding potential engine settings to allow stable RCCI operation at a desired engine load. As previous chapters and literature demonstrate [1], the more effective control parameters over RCCI combustion are the diesel injection timing and the gasoline fraction (GF). Thus, for a fixed intake charge properties, the single or the combined modification of these parameters enables the modulation of the combustion development to achieve a stable combustion with a desired combustion phasing. Figure 7.2 illustrates that, starting from the CDC operation at low load, the stable RCCI conditions at a desired load can be reached by gradually increasing the GF and advancing the diesel SOI. Both actions favor lowering the soot emission levels, which is one of the objectives of the global procedure. Nevertheless, it is interesting to remark that the maximum $\mathrm{GF}$ is limited to ensure stable conditions $\left(\mathrm{COV}_{\mathrm{IMEP}}<4 \%\right)$ and the SOI advance is also limited to avoid excessive knocking $\left(\mathrm{PRR}_{\max }<25\right.$ bar/CAD). As it can be seen, the maximum PRR imposed is quite higher than the 15 bar/CAD proposed in previous chapters. This action is intended 
to explore the maximum operational limits of RCCI due to limitations in NOx and soot emissions without being conditioned by the maximum PRR.

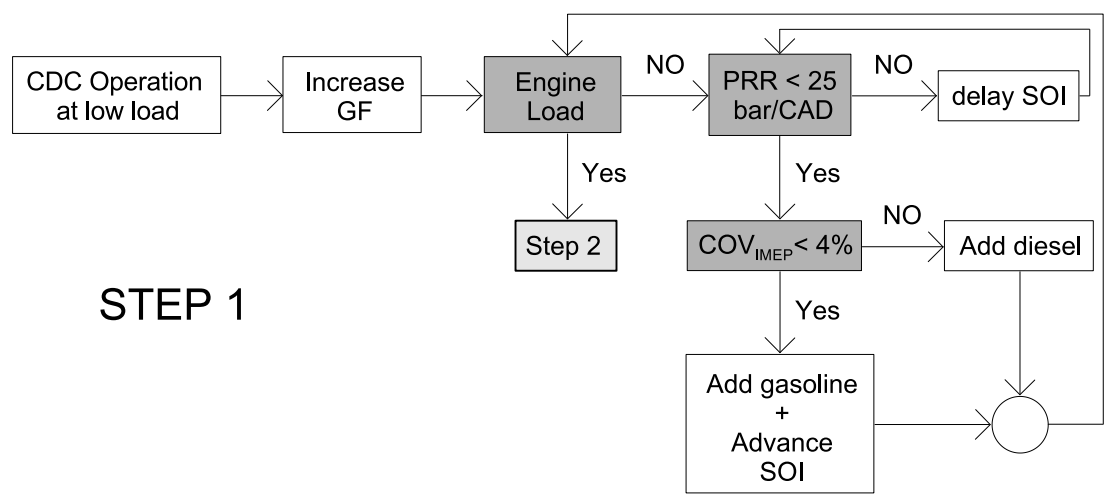

Figure 7.2. Experimental procedure to reach stable RCCI conditions at a desired engine load (Step 1).

In the second step, detailed in figure 7.3, a loop to reach NOx levels below the EURO VI limit and soot emissions lower than $0.01 \mathrm{~g} / \mathrm{kWh}$ is proposed. In this case, additionally to the diesel SOI and GF, the EGR rate was found as a key variable to achieve both emissions targets. It is interesting to remark that no explicit restrictions in terms of $\mathrm{CO}$ and $\mathrm{HC}$ emissions are imposed in this step, but the limitation introduced in the coefficient of variation of the IMEP $\left(\mathrm{COV}_{\text {IMEP }}<4 \%\right)$ is aimed to avoid misfire conditions (with unacceptable $\mathrm{HC}$ and $\mathrm{CO}$ ). As a result of this second step, a NOx and soot compliant engine operating point, but not optimized in terms of $\mathrm{HC}$ and $\mathrm{CO}$ emissions, is achieved (noted as potential setting in the figure).

Finally, a rough optimization step (referred as final tuning in the scheme of figure 7.3) was done. The objective of this final step, illustrated in figure 7.4, is to minimize $\mathrm{HC}$ and $\mathrm{CO}$ emissions as well as to improve the fuel consumption while keeping NOx and soot emissions under the imposed limits (NOx $<0.4$ $\mathrm{g} / \mathrm{kWh}$ and soot $<0.01 \mathrm{~g} / \mathrm{kWh})$. In this case, the EGR rate and diesel SOI were found as the key engine variables.

During the implementation of the third step, two scenarios were identified. The first one entails a progressive reduction of BSFC as well as $\mathrm{CO}$ and $\mathrm{HC}$ emissions by only decreasing the EGR rate, without the need of actuating on the diesel SOI. This occurs at high load, where the starting point (coming from step 2) typically has very delayed diesel injection timings to avoid knocking problems. This procedure is illustrated in figure 7.5, which shows the RoHR profiles and the engine-out emissions at $75 \%$ load ( $\approx 17$ bar BMEP) and 1200 


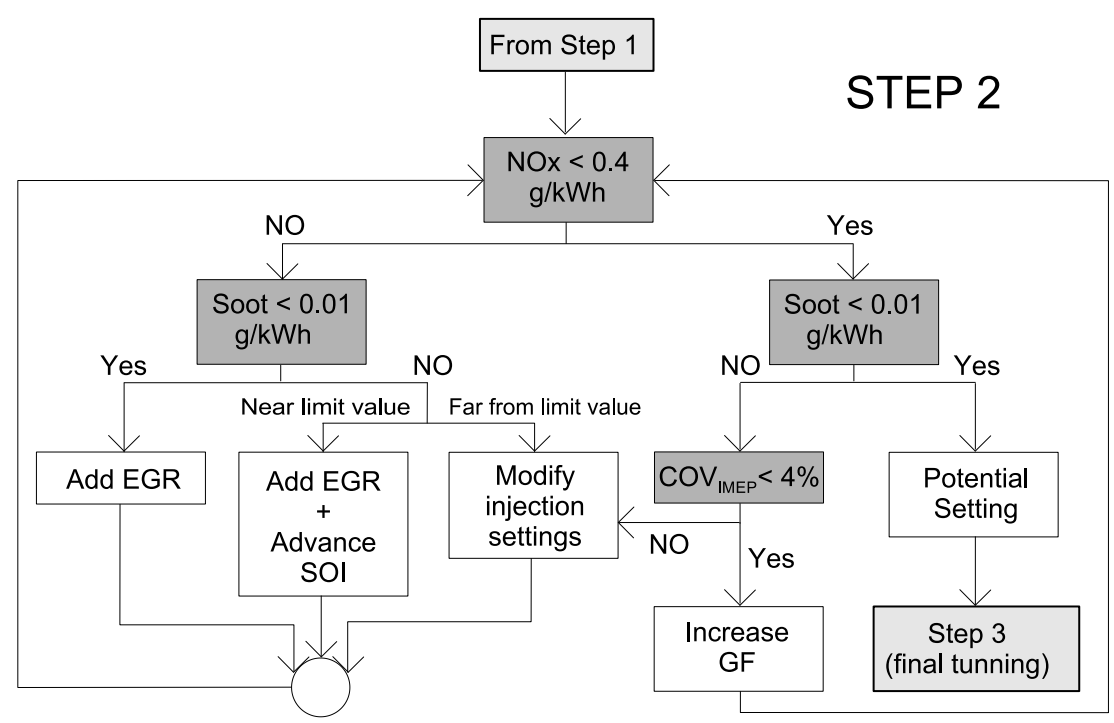

Figure 7.3. Experimental procedure to introduce the stable RCCI operating points from step 1 under the NOx and soot limits (Step 2).

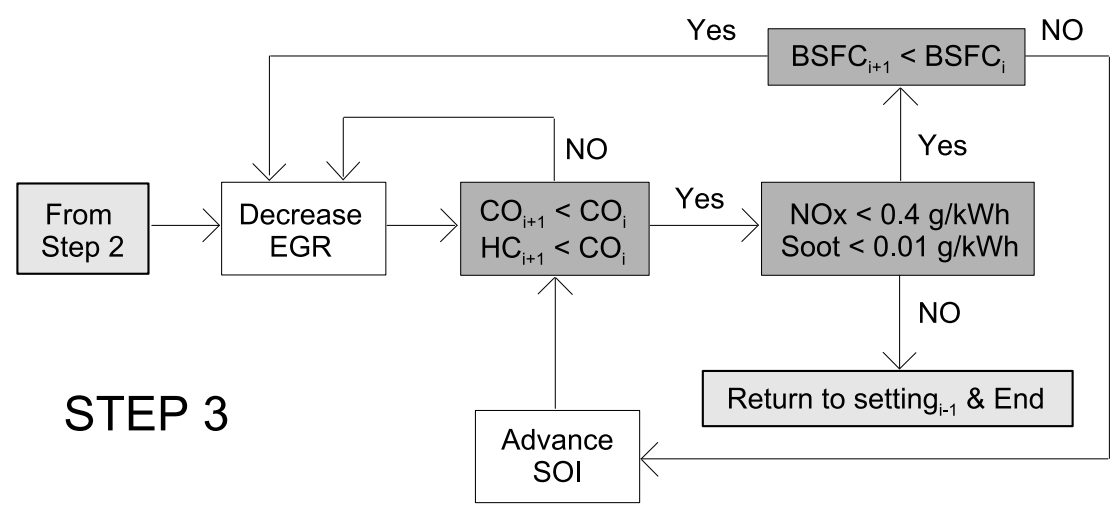

Figure 7.4. Experimental procedure to minimize $\mathrm{HC}$ and $\mathrm{CO}$ emissions and $\mathrm{BSFC}$ while maintaining NOx and soot emissions under the desired limits (Step 3).

rpm. In this case, the operating conditions obtained at the end of the second step (denoted as initial point in the figure) lead to NOx and soot levels considerably lower than the limitations imposed, but with excessive $\mathrm{CO}$ and $\mathrm{HC}$ emissions. It can be seen that the reduction of the EGR rate provides an improvement of around $46 \%$ and $76 \%$ in $\mathrm{HC}$ and $\mathrm{CO}$ emissions, respectively, between the extreme cases. Moreover, soot emissions are decreased as EGR is 
reduced due to the enhancement of the oxidation process, and NOx emissions remain below the limit of $0.4 \mathrm{~g} / \mathrm{kWh}$. Further reduction of EGR rate caused the non-compliance of EURO VI NOx emissions, without showing notable benefits on the unburned products.

From figure 7.5 it is also inferred that $\mathrm{HC}$ and $\mathrm{CO}$ emissions reduction is linked to the enhancement of the second combustion stage, when the majority of gasoline is consumed [2]. This fact can be explained due to the advance of the combustion event towards TDC, which promotes higher combustion temperatures. Thus, a notable increase in the maximum RoHR peak of the second stage is observed, while the first one is progressively reduced and advanced. It is also interesting to remark that combustion phasing is almost unchanged with the EGR modification (CA50 only varies 0.6 CAD between the extremes of the rage).

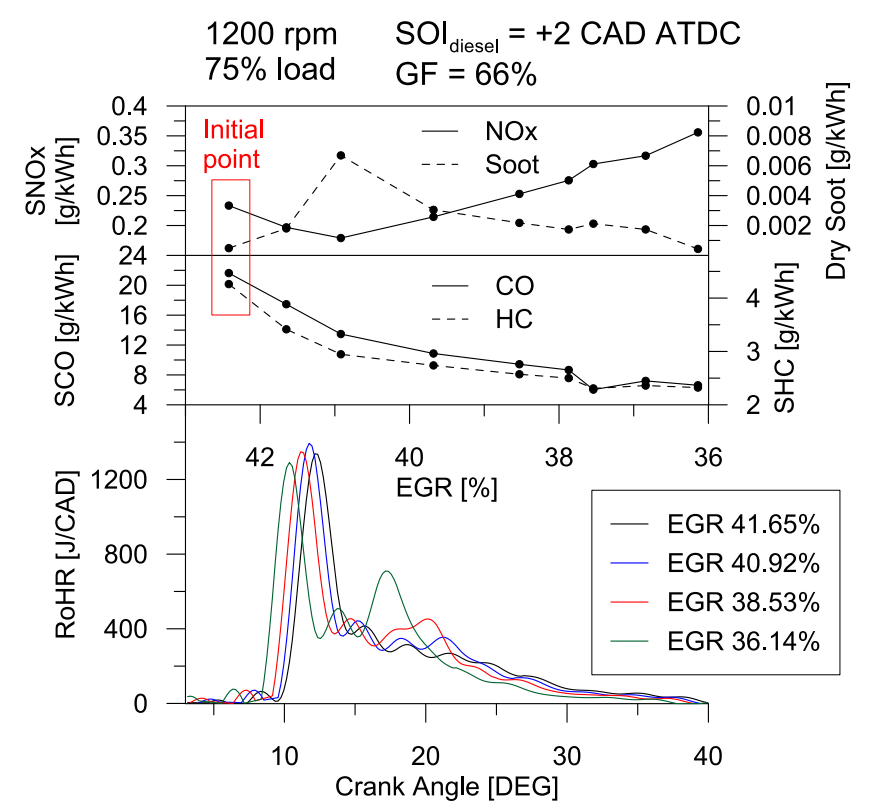

Figure 7.5. Effect of EGR rate on RCCI engine-out emissions at $75 \%$ load and 1200 rpm.

The second scenario was found to occur at low and medium loads. In these cases, the initial point showed an early injection timing and therefore the complete loop could be executed during this final tuning. This step is clarified in figure 7.6. 


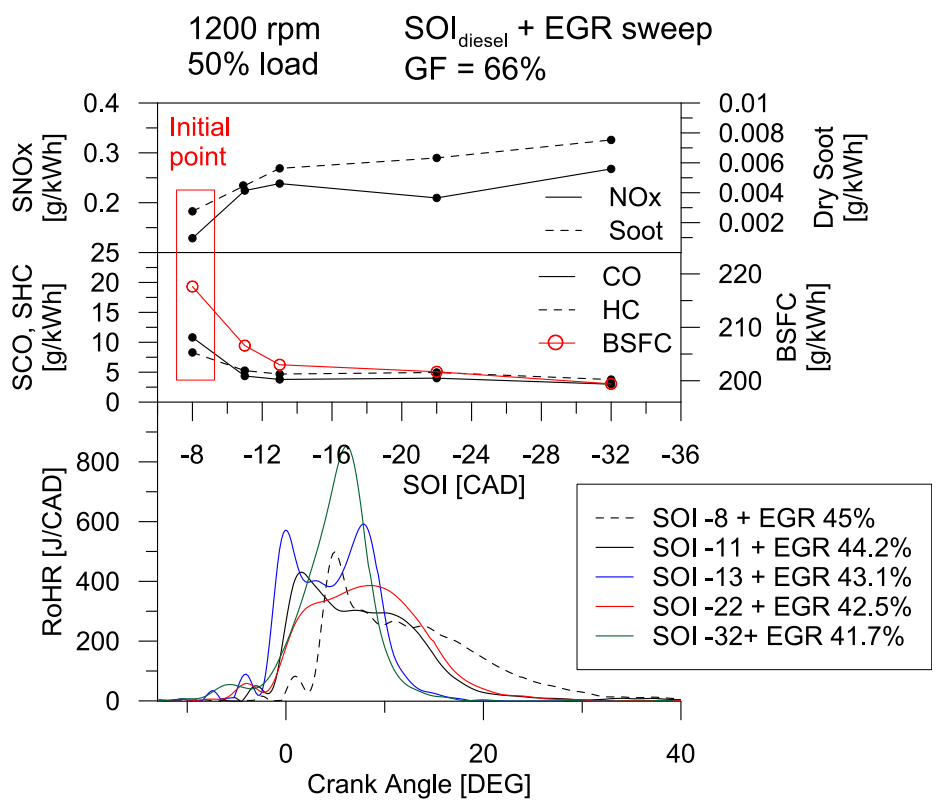

Figure 7.6. Effect of the combined modification of the EGR rate and diesel SOI on RCCI engine-out emissions at 50\% load and $1200 \mathrm{rpm}$.

The figure shows the potential of combining both effects (EGR rate and diesel SOI modification) to reduce $\mathrm{HC}$ and $\mathrm{CO}$ emissions while setting an optimum combustion phasing. It contributes not only to reduce the emission levels, but also to improve the brake specific fuel consumption (BSFC). As seen in the figure, the two firsts advances in diesel SOI (from -8 CAD to -13 CAD ATDC) result in a notable improvement in BSFC. This improvement is related to the better combustion phasing achieved (CA50 moved from +11.1 CAD to +4.7 CAD ATDC), which allows enhancing the fuel to work conversion efficiency. In addition, a great reduction in $\mathrm{HC}$ and $\mathrm{CO}$ emissions is observed. In this sense, as combustion development is shifted towards higher pressure and temperature conditions, the late soft burn (which causes the majority of unburned products) is avoided. Once a desired CA50 is reached, the combined modification of the EGR rate and diesel SOI allows to modulate the combustion development in order to search slight improvements in BSFC and emissions. Comparing the RoHR traces of SOI -13 and $-32 \mathrm{CAD}$, it is possible to appreciate how the combustion shape moves from a two-staged heat release to a one-staged heat release. The advance in diesel SOI without the additional modification of other engine settings results in the over-dilution of the diesel fuel injected, and then lower EGR rate is needed to maintain a 
stable combustion with a desired CA50. Thus, focusing on the RoHR shape of SOI -32 CAD, it is clear that almost the whole combustion development takes place after TDC. In addition, the improved in-cylinder reactivity, due to the EGR reduction, results in a higher RoHR peak. Both factors lead to a reduction of $3.5 \%$ in BSFC. Also of note is that $\mathrm{CO}$ and $\mathrm{HC}$ emissions are not strongly affected with this strategy. It is expected that once achieved certain emission levels, the emissions are mainly governed by geometric factors such as squish flow and crevices and not by the engine settings [2].

\subsubsection{Results with nominal compression ratio}

In a first approach, the nominal compression ratio of 14.4:1 was tested. Figure 7.7 represents different key parameters for the RCCI combustion analysis as a function of the engine speed and load. The full load curve showed in the maps corresponds to CDC operation using the manufacturer's engine settings. In addition, the specific RCCI measured points are remarked with black dots in the maps.

In figure 7.7, it can be observed that RCCI engine mapping was only possible up to 12 bar BMEP load whatever the engine speed. In this regard, it is remarkable that neither the excessive knocking level nor the combustion stability were the limiting factors for extending the RCCI mode to higher loads. Instead, the operation was limited by the high soot emissions.

As confirmed in the figure, the maximum PRRs are below 25 bar/CAD in all the operating points [3], as was imposed in the experimental procedure defined in figure 7.2 to reach stable RCCI conditions. Moreover, higher PRR values are seen as load is increased and engine speed is reduced. In this case, the low engine speed allows higher time to burn and enhances the combustion process, which is confirmed looking at the $\mathrm{CO}$ and $\mathrm{HC}$ trends in figure 7.7. Hence, the greater fuel mass burned leads to higher knocking levels. On the other hand, stable combustion is attained in all the tests with $\mathrm{COV}_{\text {IMEP values }}$ only slightly higher than $4 \%$ at $1800 \mathrm{rpm}$ and idle conditions. Also worth noting is that the comparison of these two parameters confirm their inverse relationship, with lower $\mathrm{COV}_{\text {IMEP }}$ (higher combustion stability) as PRR is increased.

Analyzing the gasoline fraction map, which is defined as the ratio between the LRF and the total fuel mass, it is observed that the maximum GF achievable for fulfilling the imposed combustion stability criteria at low load was around $37 \%$. In addition, for a given engine load, the GF was maintained as the engine speed varied without knocking or stability problems. Thus, the 

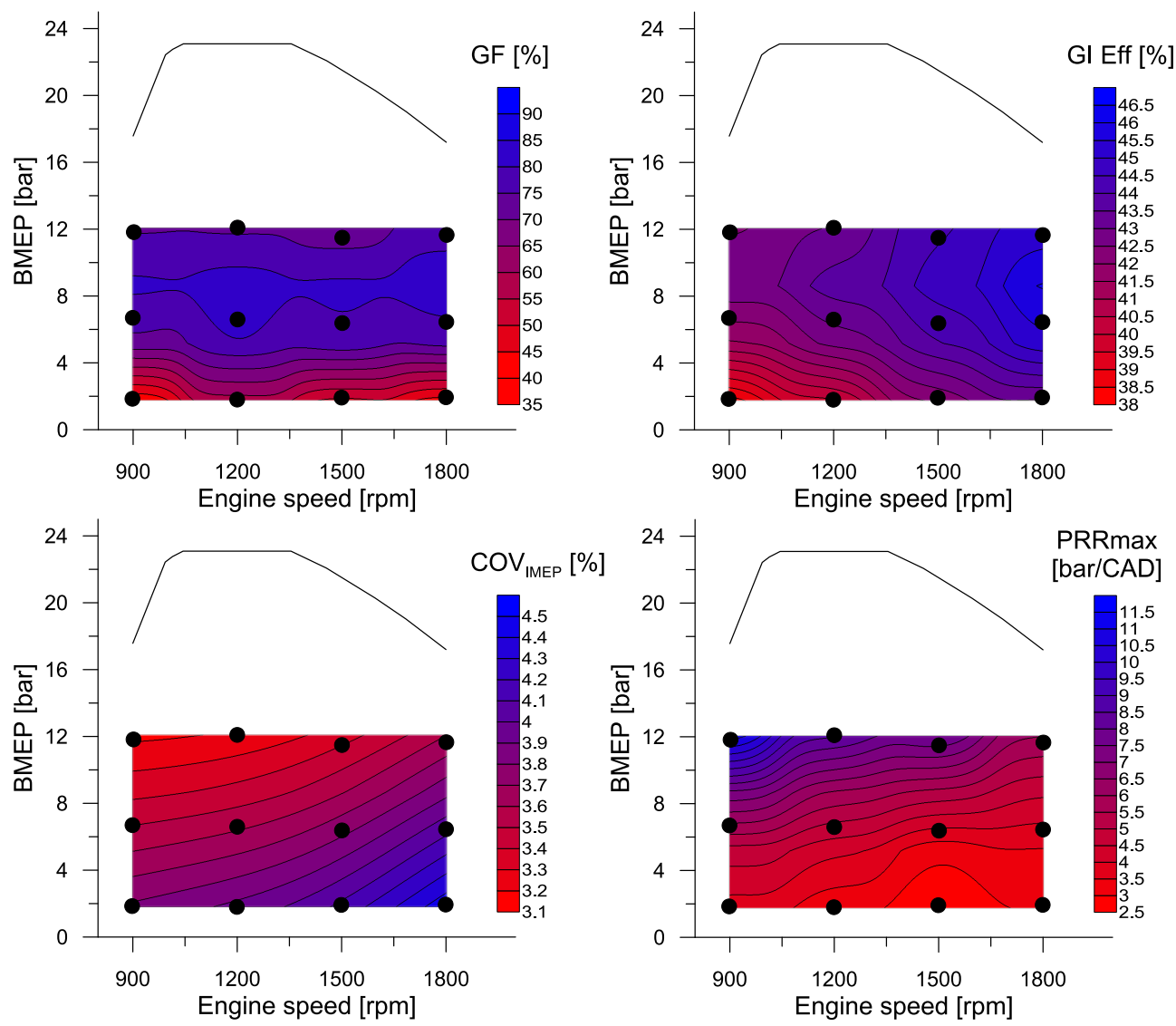

Figure 7.7. Maps of gasoline fraction and different parameters derived from the in-cylinder pressure processing operating with a compression ratio of 14.4:1.

higher GF region is found at 6 bar BMEP, where a maximum GF of $90 \%$ at $1800 \mathrm{rpm}$ was achieved. Finally, focusing on the gross indicated efficiency (GIE) trend, it is clear that it increases as engine speed increases. In addition, the higher value found in this specific study was $47.2 \%$ at $1800 \mathrm{rpm}$ and 6 bar BMEP load, which corresponds to the test with the highest GF. The trend of GIE as a function of the engine load shows a parabolic behavior, with a maximum values between 6 and 12 bar BMEP, which also correspond with the highest GF levels in the map. Thus, it is confirmed that to achieve high efficiency while maintaining low NOx and soot emissions, the higher portion of the energy should come from the low reactivity fuel. 

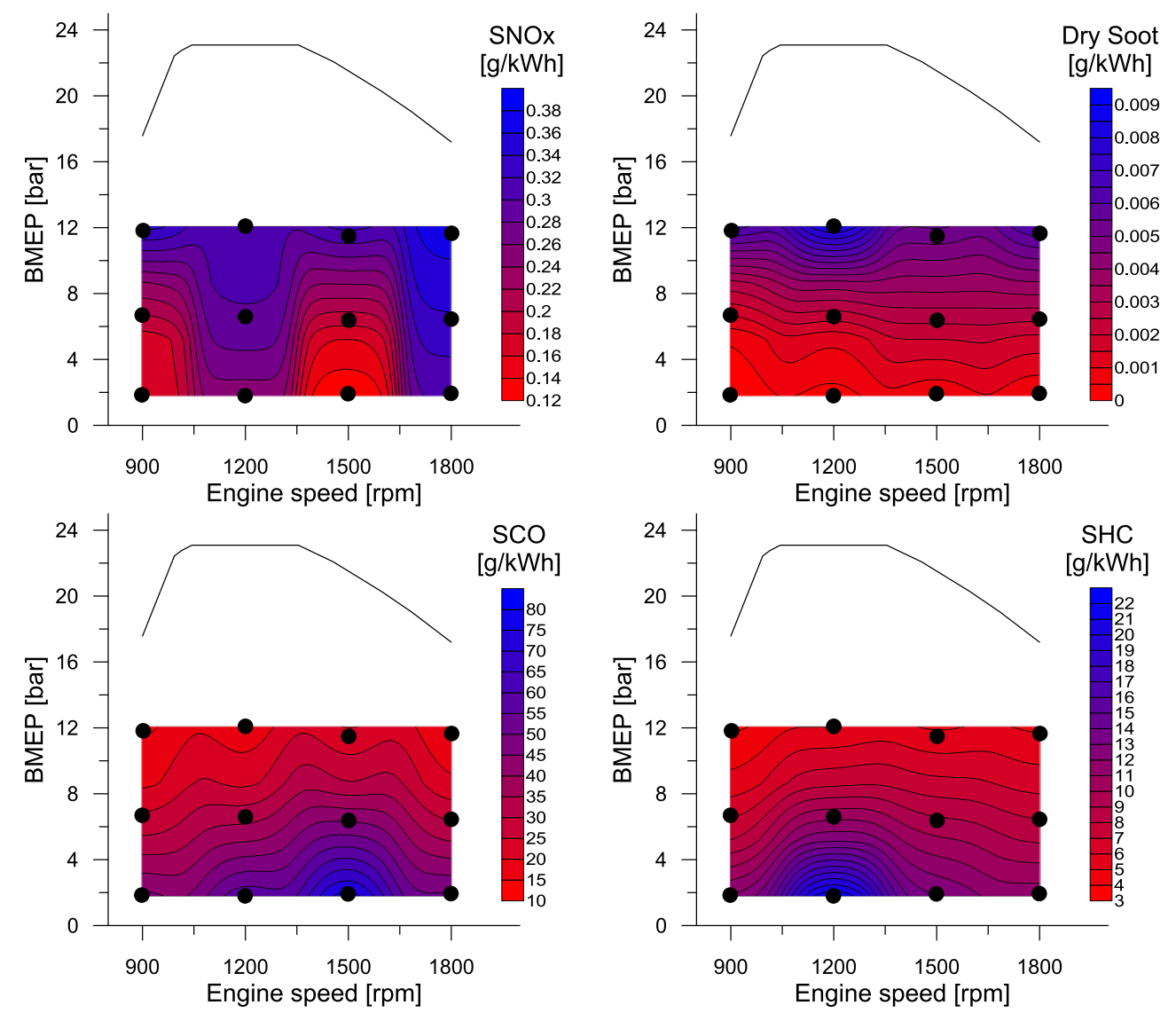

Figure 7.8. Engine-out emissions mapping for RCCI operation with the nominal compression ratio of $14 \cdot 4: 1$.

Figure 7.8 represents the engine-out emissions in the same way as in previous figure. As explained in the experimental procedure, soot emission levels were a key experimental constraint with a limit of $0.01 \mathrm{~g} / \mathrm{kWh}$ to be fulfilled over the whole engine map. As seen from the figure, at 12 bar BMEP soot levels are very close to the limitation (mainly at $1200 \mathrm{rpm}$ ). During the experimental tests, it was confirmed that further increase in load (i.e. in fuel mass) pushed the soot levels over the maximum allowed value, even with GF greater than $90 \%$. These high soot levels are consequence of the required delay in diesel SOI to avoid excessive PRR as load is increased (figure 7.2). As a consequence, the mixing time for diesel injection is reduced and the mixture distribution at SOC becomes richer, which promotes the soot formation. This 
fact limits the RCCI engine map to 12 bar BMEP load with the nominal compression ratio.

Regarding NOx emissions, it is worthy to note that all the values are below the EURO VI limitation $(0.4 \mathrm{~g} / \mathrm{kWh})$. In addition, the trend obtained differs notably to those of the other pollutant emissions. In this case, a greater dependency on the engine speed is observed, with the lowest emission levels found at 900 and $1500 \mathrm{rpm}$. Additionally, a rise in NOx levels is observed as load is increased. This fact is explained due to the enhancement in the combustion development (higher stability and low $\mathrm{HC}$ and $\mathrm{CO}$ emissions).

$\mathrm{HC}$ and $\mathrm{CO}$ emissions were found to decrease as load increased. As expected, the lower $\mathrm{HC}$ and $\mathrm{CO}$ emissions are located in the region of the map with great combustion stability and PRR. Inside this region, the slight differences in the emission values are the result of variations in diesel SOI, stability and GF. Thus, the engine operating condition with the best balance in terms of $\mathrm{HC}$ and $\mathrm{CO}$ emissions achieved in this specific study was found at $1500 \mathrm{rpm}$ and 12 bar BMEP, with 3.9 and $4.4 \mathrm{~g} / \mathrm{kWh}$ respectively.

\subsubsection{Results with reduced compression ratio}

The main limitation found in previous section for extending the RCCI operation towards higher loads was the impossibility of simultaneously reaching soot $<0.01 \mathrm{~g} / \mathrm{kWh}$ and $\mathrm{PRR}_{\max }<25$ bar/CAD. At 12 bar BMEP load, soot levels were just in the limit for all engine speeds, and the PRR $\mathrm{Pax}_{\max }$ was between 7 and 12 bar/CAD. However, further increase in engine fueling to reach the next load step, provoked unacceptable soot emissions. Moreover, the advance of diesel SOI in that point to minimize soot formation led to $\mathrm{PRR}_{\max }>25$ bar/CAD. So that, the maximum feasible load was limited to 12 bar BMEP.

In order to explore the capabilities of RCCI concept to fulfill these constraints in the whole engine map, a more reduced compression than the nominal one is tested in this section. It is thought that the lower CR may let advancing the diesel SOI to minimize soot formation without exceeding the PRR limit. In particular, an effective compression ratio of 11:1 was set by means of advancing the intake valves closing event (early Miller cycle).

Figure 7.9 shows the same parameters than in previous section, but for compression ratio of 11:1. The figure shows that, with this lower compression ratio, the RCCI operation can be extended towards higher BMEP, and almost up to full load at 1200 and $1800 \mathrm{rpm}$. In addition, it is found that the trends in $\mathrm{COV}_{\text {IMEP }}$ and PRR are the same found with high CR, with higher PRR and 

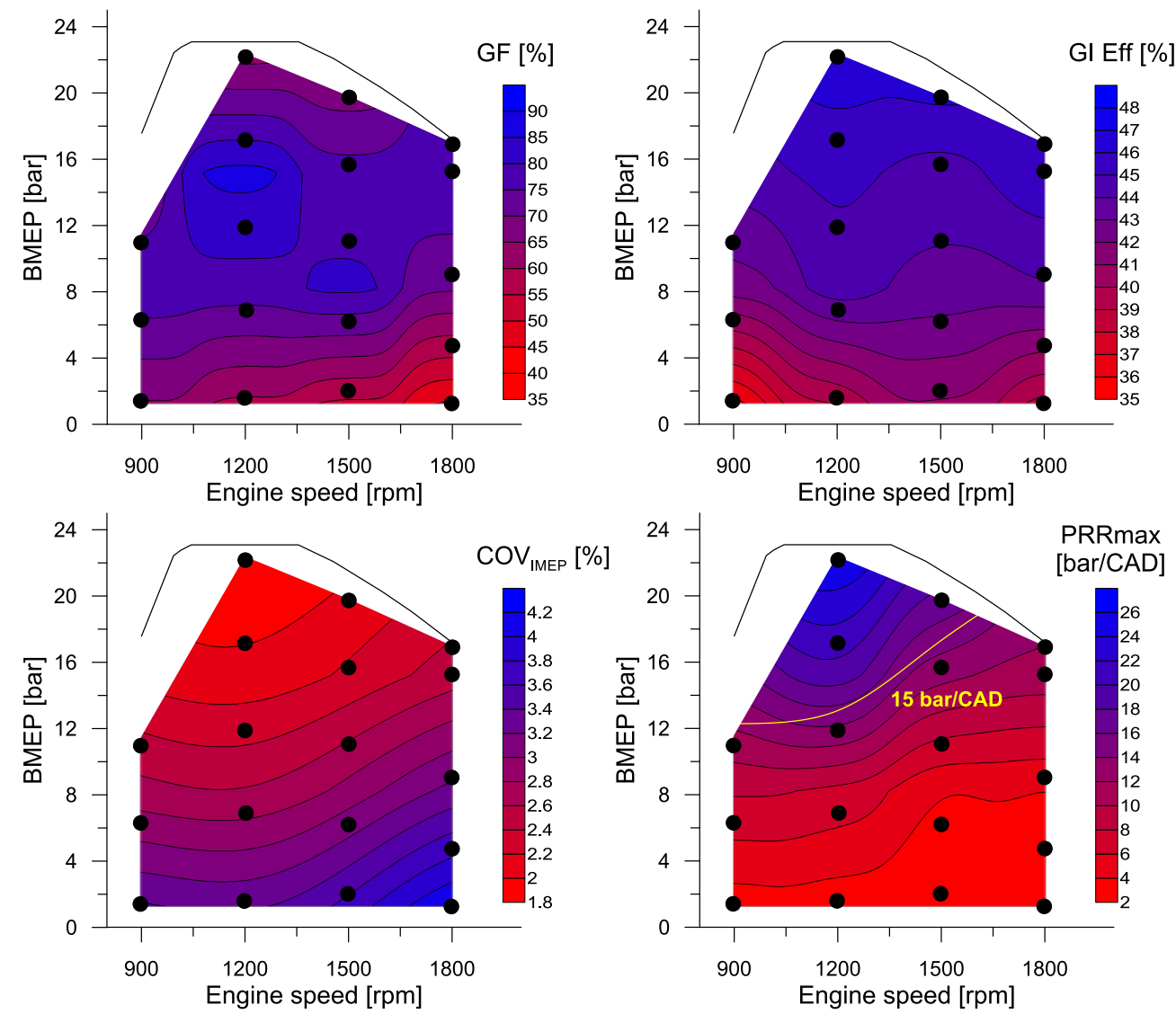

Figure 7.9. Maps of gasoline fraction and different parameters derived from the in-cylinder pressure processing operating with a compression ratio of 11:1.

combustion stability as BMEP is increased and engine speed is reduced. Also of note is that, at 12 bar BMEP, slightly higher maximum PRR values than in the case of CR 14.4:1 were obtained. The lower CR allows to advance the diesel SOI to minimize soot formation, which implies slightly higher maximum PRR than the same operating condition at CR 14.4:1. Consequently, the maximum PRR registered in this study was 25 bar/CAD at $1200 \mathrm{rpm}$ and $96 \%$ load. On the other hand, the maximum $\mathrm{COV}_{\text {IMEP }}$ values are slightly lower than with CR 14.4:1 and the minimum values are lower too, which denotes that the combination of the settings proposed with the low CR provides higher combustion stability in the whole engine map. 
Focusing on the GF results, three different areas are identified. From idle conditions to low load (2 to 6 bar BMEP) the GF varies from 35\% (at high engine speed) to $65 \%$ (at low engine speed). At these engine loads, the increase in the amount of diesel fuel as engine speed increases was necessary to maintain stable operation. In a region between 6 and 16 bar BMEP, the GF varies from $70 \%$ to $78 \%$ with peaks of $88 \%$ at $1200 \mathrm{rpm}$. Finally, at high load, a peninsula with lower GF than at medium load is appreciated. This fact is consequence of a technological limitation. In particular, the high boost pressure required to keep the same air mass flow than CR 14.4:1 while using Miller cycle, does not allow the gasoline injector to introduce as much gasoline as desired, and therefore an increase in diesel injection is needed to reach the target load. Finally, the GIE increases as engine speed and load increase. The higher value found in this case was $48.2 \%$ at $1200 \mathrm{rpm}$ and $96 \%$ load. It is interesting to remark that almost the same value was obtained at the highest load achieved at $1500 \mathrm{rpm}$.

As far as engine-out emissions, figure 7.10 shows that soot levels remain under the limit value in the whole engine map. The peninsula with higher soot levels corresponds to the area of the limited GF at high load. In this sense, since a large total fuel mass has to be supplied to the engine at this operating condition, a GF around $75 \%$ still implies high diesel injected mass, which enhances the soot formation.

The NOx emissions trend suggests a stronger dependency on engine speed than on engine load. Only at $1800 \mathrm{rpm}$ a clear change in NOx emissions levels is observed as a function of the engine load. At this engine speed, a region with values near the limitation is observed between 2 and 6 bar BMEP, with a maximum NOx level of $0.39 \mathrm{~g} / \mathrm{kWh}$. This fact is well related to the low GF used in this case (35\%). In addition, it is demonstrated that all the values remain below the EURO VI limitation.

Finally, as found with CR 14.4:1, HC and CO emissions levels were notably reduced as BMEP increased. The lower $\mathrm{HC}$ and $\mathrm{CO}$ emissions are also located in the zone of the map with the greater combustion stability and PRR. Specifically, values of $\mathrm{HC}=0.17 \mathrm{~g} / \mathrm{kWh}$ and $\mathrm{CO}=1.75 \mathrm{~g} / \mathrm{kWh}$ were attained at $1500 \mathrm{rpm}$ and 19 bar BMEP, which are very near to the EURO VI limits. It represents a $95 \%$ improvement in $\mathrm{HC}$ and $60.2 \%$ in $\mathrm{CO}$ versus the best balanced operating point in terms of these emissions with CR 14.4:1. 

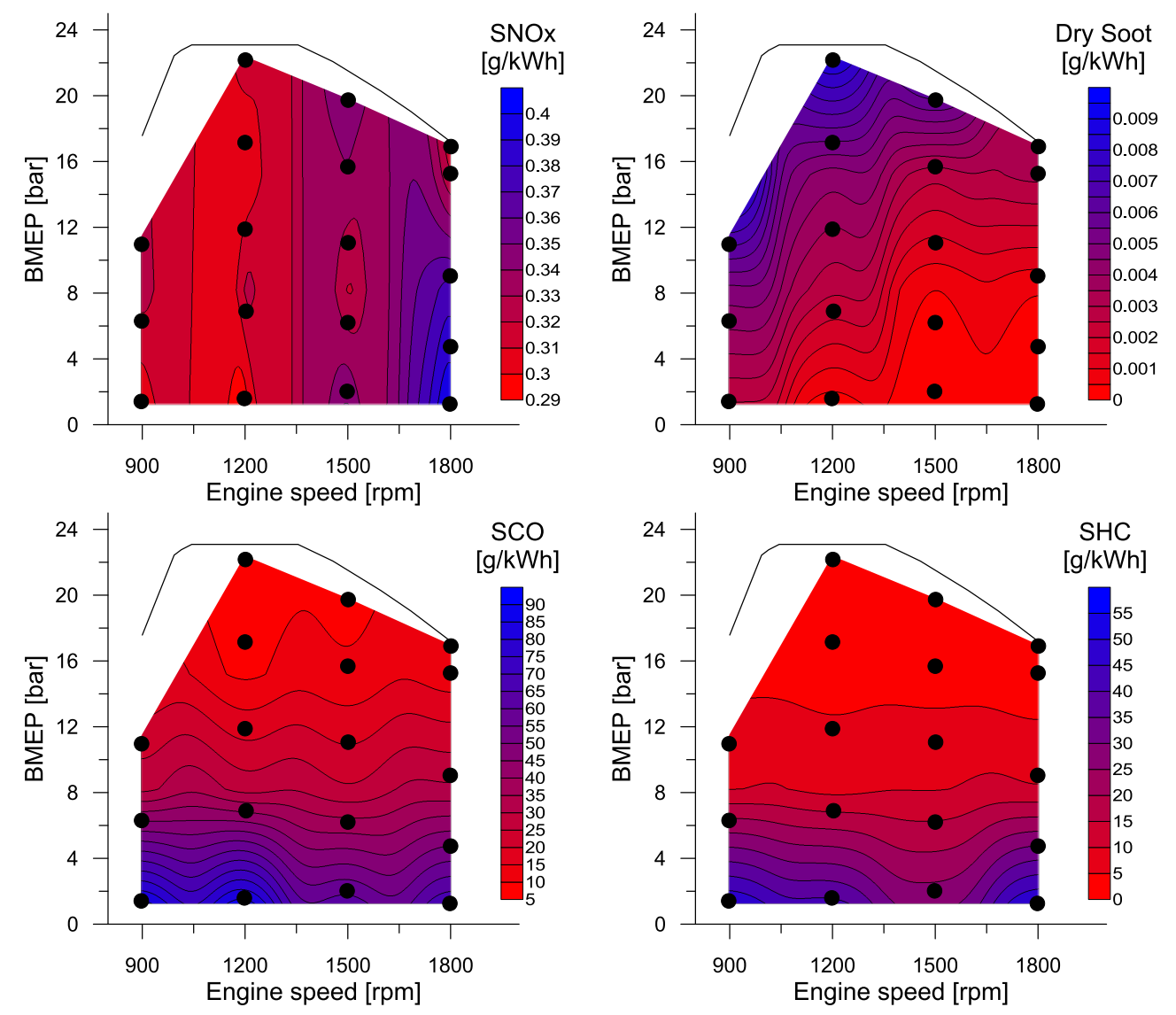

Figure 7.10. Engine-out emissions mapping for RCCI operation with a compression ratio of 11:1.

\subsubsection{Technological challenges of RCCI concept}

Figure 7.11 shows the results of NOx, soot and GIE as a function of engine load at $1200 \mathrm{rpm}$ for RCCI with CR 11:1 and CDC operation. As can be seen, RCCI combustion allows lowering NOx emissions in around 90-96\% with respect to $\mathrm{CDC}$ operation while maintaining soot emissions under the desired value. In terms of GIE, RCCI provides improved results except in the case of $75 \%$ load (17.2 bar BMEP), in which the engine is fully optimized for CDC operation by the manufacturer. However, a significant improvement of around $2 \%$ and $3.5 \%$ is observed at 6.9 and 22.2 bar, respectively. Finally, a moderated improvement of around $0.8 \%$ at 11.9 bar is also appreciated. 

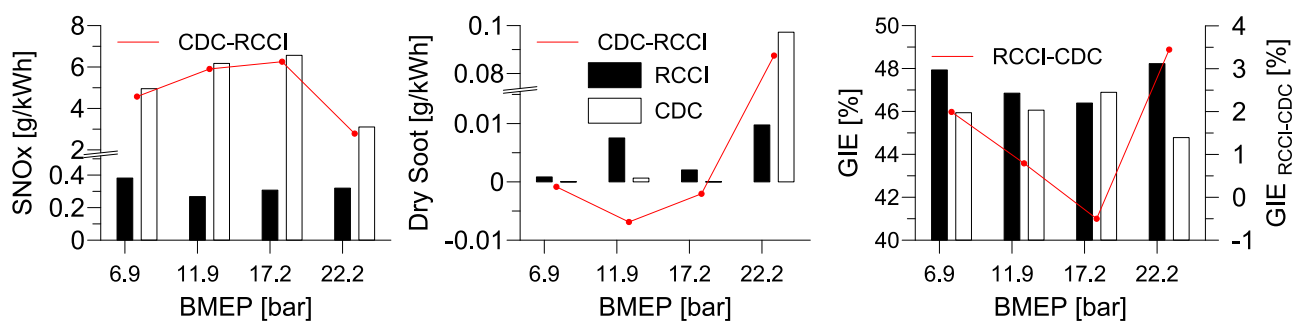

Figure 7.11. NOx, soot and gross indicated efficiency as a function of engine load at 1200 rpm for RCCI with $C R 11: 1$ and $C D C$.

In spite of these promising results, previous section demonstrated that the reduction in NOx emissions at the expense of minimizing the combustion temperatures leads to greater combustion losses. In this sense, figure 7.12 compares $\mathrm{HC}$ and $\mathrm{CO}$ emissions as a function of engine load at $1200 \mathrm{rpm}$ for RCCI and CDC operation. As can be seen, the major differences between both operating modes are identified at low load (6.9 bar BMEP), where around $5 \mathrm{~g} / \mathrm{kWh}$ difference are found for both emissions. This value is reduced progressively as engine load increases, reaching the minimum difference of around -2 and $0.2 \mathrm{~g} / \mathrm{kWh}$ for $\mathrm{CO}$ and $\mathrm{HC}$, respectively, at full load conditions. The high differences in emissions levels between RCCI and CDC could compromise the effectiveness of the conventional diesel oxidation catalysts (DOC) if they were used for RCCI operation. Aside from that, one of the key limitations to reduce engine $\mathrm{HC}$ and $\mathrm{CO}$ emissions using in-exhaust catalysts is the inactivity of these catalysts at low exhaust gas temperatures. In this case, figure 7.12 shows that the exhaust temperatures for RCCI operation range from $26 \%$ to $42 \%$ lower than that of CDC operation. This correlates to around a $50^{\circ} \mathrm{C}$ difference at the lower loads and up to a $130^{\circ} \mathrm{C}$ difference at the higher loads.
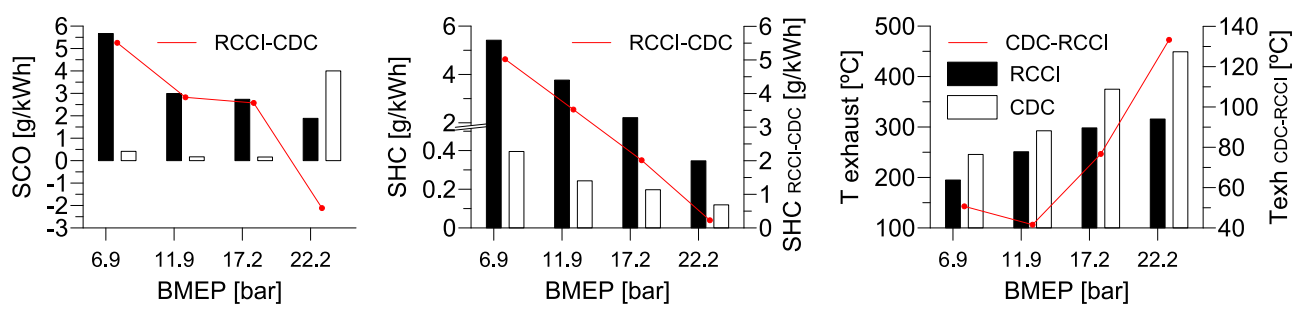

Figure 7.12. Engine-out $C O$ and HC emissions, and exhaust temperatures as a function of engine load at $1200 \mathrm{rpm}$ for RCCI and CDC. 
Prikhodko et al. [4] discussed the effectiveness of several DOCs with different precious metal loadings under RCCI steady-state operation. Figure 7.13 (left) shows the $\mathrm{HC}$ and $\mathrm{CO}$ conversion efficiency of the three DOCs investigated as a function of the inlet gas temperature. The figure shows that all DOCs were effective in oxidizing $\mathrm{CO}$ and $\mathrm{HC}$ from RCCI operation at temperatures greater than $300^{\circ} \mathrm{C}$, with no catalyst activity under $200^{\circ} \mathrm{C}$. The slight differences in light-off temperatures and conversion efficiency peaks between the different DOCs were related to the variations in their composition. It is worthy to note that, for CDC operation all DOCs achieved $80 \%$ and $100 \%$ $\mathrm{HC}$ and $\mathrm{CO}$ conversions, respectively, at $190^{\circ} \mathrm{C}$. So, a shift to higher $\mathrm{HC}$ and CO light-off temperatures was observed during RCCI as compared to CDC.

Figure 7.13 (right) shows the exhaust temperature for the operating points of compression ratio $11: 1$, in which the iso-temperature lines of $200^{\circ} \mathrm{C}$ and $300^{\circ} \mathrm{C}$ are depicted. Based on the previous findings, it is possible to state that only the area from medium to full load at high engine speeds would have a great efficiency in oxidizing $\mathrm{HC}$ and $\mathrm{CO}$ emissions. In addition, this operating region will have the lower aftertreatment demand due to the reduced engineout emission levels at these conditions. From low to medium load, a linear increase in conversion efficiency with engine speed and load is observed. In this region, the higher catalytic demand will be found at low load conditions, where the highest $\mathrm{HC}$ and $\mathrm{CO}$ levels are appreciated independently on engine speed. Finally, no conversion is expected in the low engine speed zone.
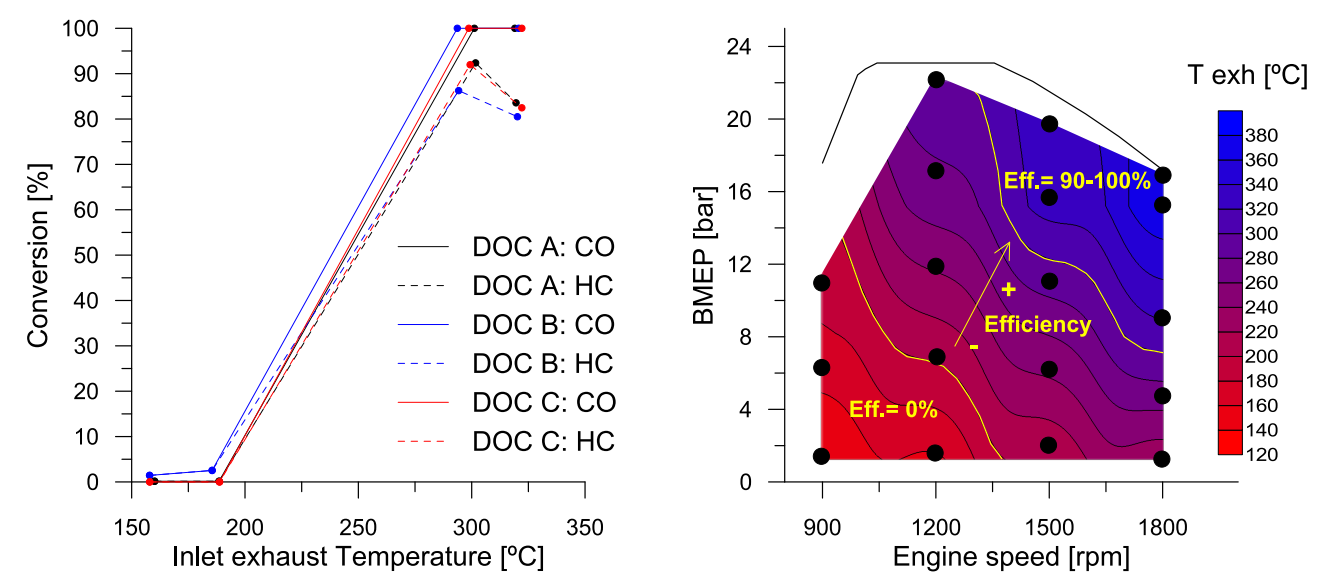

Figure 7.13. $H C$ and $C O$ conversion efficiency as a function of inlet exhaust temperature for three types of DOCs working under RCCI operation (left). Adapted from [4]. Exhaust temperature map for the operating points of CR 11:1 (right). 
These results raise the necessity of improving the understanding of the mechanisms causing the catalytic activity limitation at low temperature conditions, with the ultimate goal of reducing the light-off temperatures [5]. Also worth noting is that the region with no catalytic activity has the greatest margin of NOx versus the EURO VI limit, so that the engine settings should be optimized to increase the exhaust temperature as much as possible at these points. In addition, chapter 5 demonstrated that the reduction in piston area results in lower heat transfer losses and higher exhaust temperatures, which should also benefit the conversion efficiency of the DOC. A comparison of the exhaust temperatures for the stock and bathtub piston (-16\% area) at same engine operating conditions from low to high load at $1200 \mathrm{rpm}$ is shown in figure 7.14. The results show that the exhaust temperatures for bathtub piston range from $30^{\circ} \mathrm{C}$ to $5^{\circ} \mathrm{C}$ higher than that of the stock geometry. The greatest increase is found at low load conditions, which is beneficial to minimize the non-catalytic conversion area. The exhaust temperature differences becomes reduced as engine load increases, reaching very similar values at 17.3 bar $(75 \%$ load).

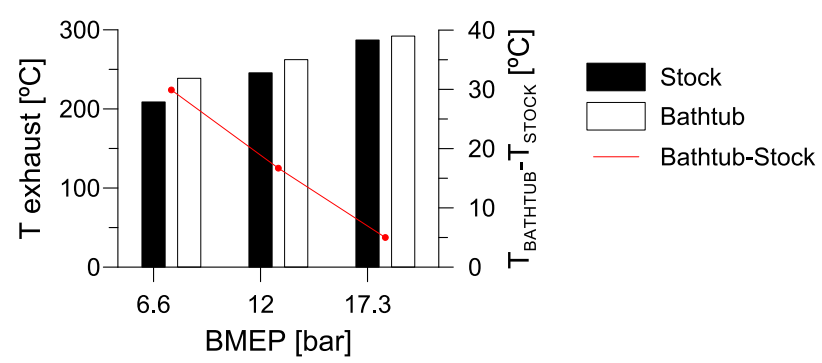

Figure 7.14. Exhaust temperature for the stock and bathtub pistons at the same engine operating conditions from low to high load at $1200 \mathrm{rpm}$.

Aside from pollutant emissions, the noise produced by the engines is currently receiving more and more attention due to the discomfort that it causes on both passengers and pedestrians. In this sense, the alteration of the combustion process towards sharper heat release curves when moving from CDC to RCCI operation, can have a negative effect on the noise level produced by the combustion process [6]. Figure 7.15 shows the combustion noise level (CNL) for the operating points of CR 11:1 (left) as well as the CNL limit as a function of engine load used by other researchers [7, 8] during preliminary studies for developing advanced combustion concepts such as gasoline direct injection compression ignition (GDCI) (right). It can be stated that CNL of the present experiments are in the range of those found in literature [9], 
showing $98 \mathrm{~dB}$ peaks at full load conditions. Nevertheless, the European regulation for homologating on-road vehicles establishes an upper limit of $\approx 80$ $\mathrm{dB}$ for heavy-duty vehicles intended for freight transport $[10,11]$. Thus, with the aim of reducing the engine packaging requirements, more studies should be conducted to reduce the CNL in the region above 12 bar BMEP.
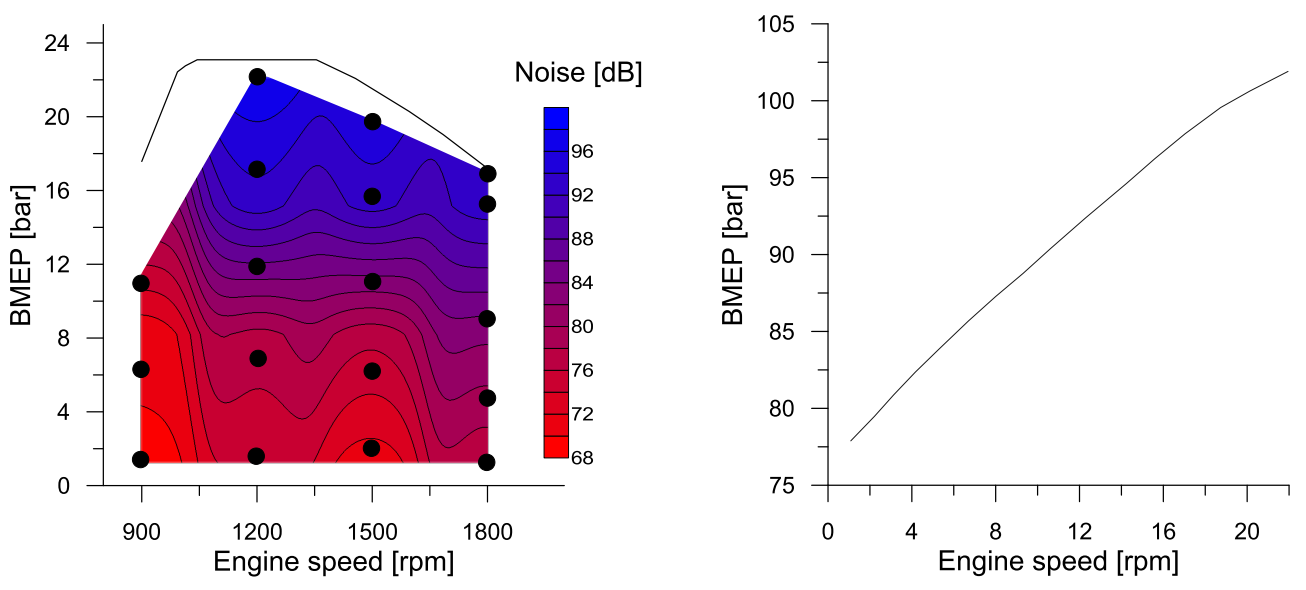

Figure 7.15. Combustion noise level for the RCCI operating points of CR 11:1 (left). Combustion noise level limit as a function of engine load used in [7, 8] for developing the GDCI combustion mode (right).

Another limitation is that the maximum PRRs observed in the engine mapping of figure 7.9 are quite high compared to those experienced in modern diesel engines during combustion (around 6 bar/CAD). As explained in section 7.2.1, the relaxed PRR limitation introduced to develop the experimental procedure was aimed at evaluating the capabilities of RCCI to promote clean combustion in the whole engine map without additional limitations. However, 25 bar/CAD is not an acceptable PRR level from the technological point of view and therefore limit values near 15 bar/CAD are more commonly used in literature. Considering this limit, and looking at the figure 7.9, it is seen that even using a CR of 11:1, the RCCI concept is limited to around $70 \%$ load.

Finally, even if the maximum PRRs could be lowered to more acceptable values, another important challenge to allow RCCI operation in the whole engine map is related to the air management requirements. As figure 7.16 shows, intake pressure peaks of 4.4 bar with $42 \%$ EGR rates are needed to allow full load operation. The stock turbocharger used in the real multicylinder engine version of the SCE used in this research is not capable of 
supplying these high intake pressures, even more taking into account the lower enthalpy in the exhaust stream under RCCI operation, which compromises the turbocharger efficiency. The lack of air supply at high loads will cause the equivalence ratio to increase, leading to higher NOx and soot emissions. Thus, a two-stage turbocharger architecture may be necessary to deliver the required air mass at high loads, which could increase the pumping work and reduce the net indicated efficiency. Regarding the EGR system, the high amount of hydrocarbons in the exhaust line may yield condensate problems if a cooled high pressure (HP) EGR system is used. In this case, a combination of HP and LP EGR could be needed to supply the required rates in the whole engine map. Thus, it is clear that dedicated turbo-machinery and EGR systems should be designed to enable RCCI operation from low to full load.
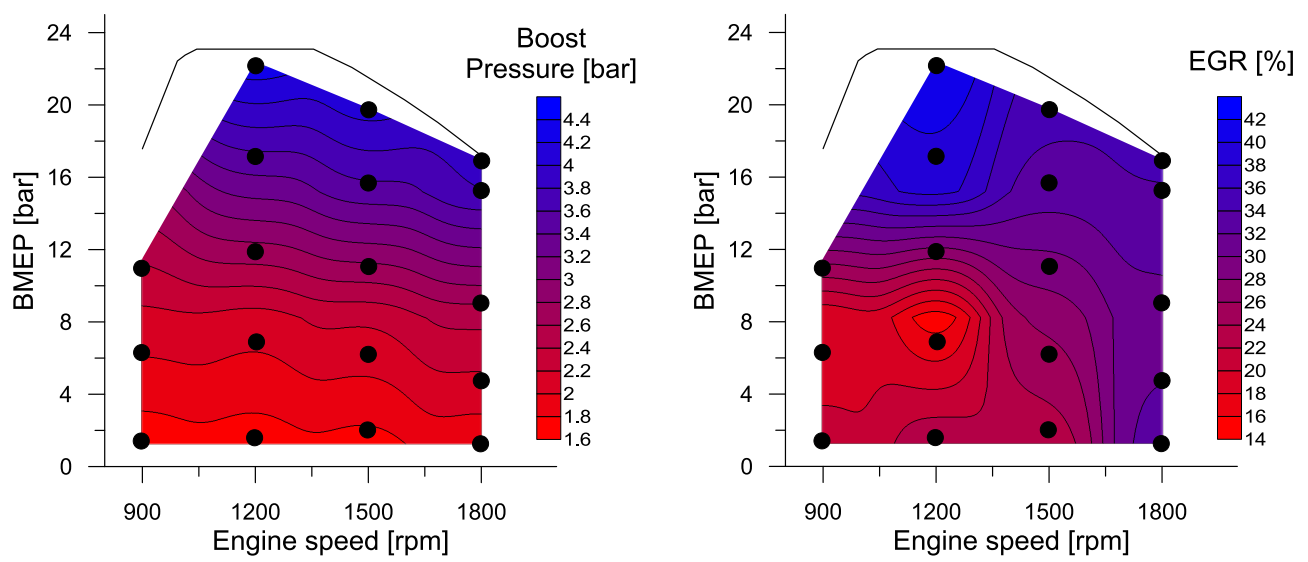

Figure 7.16. Intake pressure and EGR maps for the RCCI operating points of CR 11:1.

Considering the different technological challenges described in this section, namely the poor efficiency of conventional DOCs in reducing $\mathrm{HC}$ and $\mathrm{CO}$ emissions from RCCI, the high combustion noise levels at high engine loads and the strong requirements demanded to the turbocharging and EGR systems, the capabilities of a dual-mode RCCI/CDC engine operating mode are evaluated in next section.

\subsection{Dual-mode RCCI/CDC capabilities}

A possible option for exploiting the benefits that RCCI combustion offers while avoiding great part of the limitations that arise when trying to 
extend this combustion concept up to full load conditions, is the dual-mode $\mathrm{RCCI} / \mathrm{CDC}$ engine operation. This operating concept is based on working under RCCI conditions up to the maximum possible engine load according to the PRR limitation of $15 \mathrm{bar} / \mathrm{CAD}$, and then switch to CDC mode to cover the full operating range of the engine. Despite this mapping strategy does not allow avoiding the use of SCR and DPF aftertreatment systems needed for CDC operation, the higher thermal efficiency of RCCI versus CDC may yield to global fuel savings depending on the drive cycle considered. Moreover, the dual-mode implementation will relieve the aftertreatment systems requirements, which has repercussions on their sizing, durability and exhaust fluids costs. A first approach of the capabilities of this alternative engine operating mode is provided next.

\subsubsection{Engine description}

The experiments presented in this section were conducted using a singlecylinder diesel engine derived from the multi-cylinder production engine, whose main specifications are show in table 7.1. As it can be seen, the engine used in this specific study is a EURO VI medium-duty diesel engine representative of urban freight distribution fleet. This engine has notably higher CR and lower displaced volume than the MD11 engine used in the previous part of the thesis.

Table 7.1. Main specifications of the medium-duty engine used in this study.

\begin{tabular}{ll}
\hline \hline Style & 4 Stroke, DI diesel engine \\
Manufacturer / model & VOLVO / D5K240 \\
OEM ECU calibration & EURO VI \\
Piston bowl geometry & Re-entrant \\
Maximum power & $177 \mathrm{~kW} \mathrm{@} \mathrm{2200} \mathrm{rpm}$ \\
Maximum in-cylinder pressure [bar] & 190 \\
Bore x Stroke [mm] & $110 \times 135$ \\
Connecting rod length [mm] & 212.5 \\
Crank length [mm] & 67.5 \\
Total displaced volume [cm $\left.{ }^{3}\right]$ & 5100 \\
Number of cylinders [-] & 4 \\
Compression ratio [-] & $17.5: 1$ \\
\hline
\end{tabular}


A particularity of the test cell set-up (figure 7.17) is that the engine used is not a conventional SCE research engine, but is a hybrid solution between a MCE and SCE. This engine configuration allows to study an isolated cylinder as conventional SCE engine, while the three remaining cylinders are governed using the OEM ECU to balance the cylinder-to-cylinder maximum pressure and load. Similar test cell configurations are found in $[12,13]$. This approach results in much cheaper solution than using modified SCEs for research purposes, as the one used in the previous part of the thesis. In addition, this test cell layout allows an easy switching to the MCE version to broaden the spectrum of the study. However, as the crankshaft and the dynamometer are shared between both engine sides, it is not possible to obtain isolated torque-based parameters from the cylinder under investigation, which force to study the combustion process using indicated parameters. As expected, when switching to MCE version, this limitation disappears.

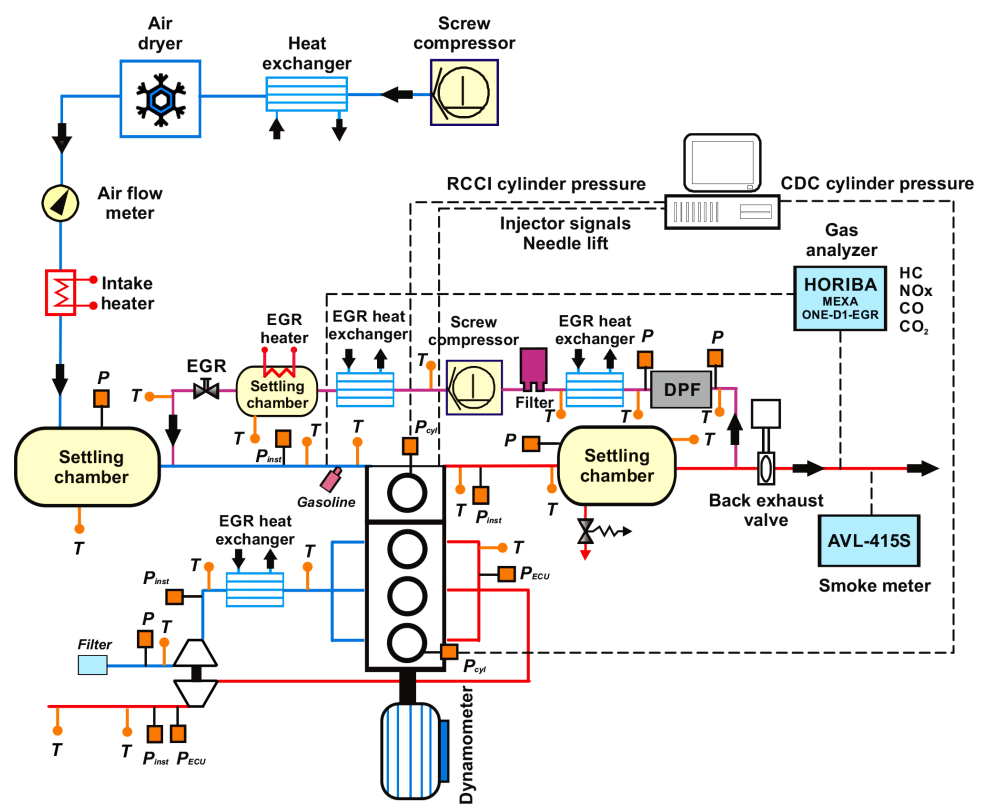

Figure 7.17. Test cell scheme. The RCCI cylinder is fully isolated and governed by means of a full-pass controller.

From the test cell scheme shown in figure 7.17, it can be seen that the modifications done for isolating the cylinder in which the combustion study will be performed (from now on, SCE) are equal to those described in chapter 3 . In particular, the stock turbocharger and EGR systems were replaced by an external compressor and dedicated low pressure EGR loop, respectively. 
Regarding the injection system, a PFI was installed in the intake manifold to allow port fuel injection of the low reactivity fuel. In addition, the OEM ECU was replaced by a Drivven engine controller to allow full access to the injection control parameters of both DI and PFI systems. All the instrumentation used in the SCE side is homologous to the one described in chapter 3, as well as the engine-out emissions analyzers installed in the exhaust line.

As it can be seen, the MCE side is also fully instrumented, which allows monitoring each subsystem during the engine operation. Thus, the in-cylinder pressure signals from both sides (SCE and $\mathrm{MCE}$ ) are monitored in real-time for balancing purposes. In this sense, as the SCE conditions varied during the RCCI studies, the MCE settings were modified to provide similar maximum pressure, engine load and combustion phasing. Finally, it is interesting to note that as the MCE side of the engine is not used for study the combustion process, the EGR rate was annulled to compensate part of the exhaust gas lost in the turbocharger due to the isolated cylinder.

\subsubsection{RCCI operating limits}

This section aims at finding the RCCI operating limits on this new engine platform. This will define the portion of the dual-mode engine map covered by RCCI regime. To do so, the experimental procedure described in section 7.2.1, but with the constraints adapted to the current engine characteristics, has been followed. In particular, the maximum in-cylinder pressure was limited to 190 bar and the MPRR to 15 bar/CAD. The constrained values for NOx and soot emissions were kept constant at $0.4 \mathrm{~g} / \mathrm{kWh}$ and $0.01 \mathrm{~g} / \mathrm{kWh}$, respectively.

\subsubsection{Low and high reactivity fuels selection}

The results of chapter 6 showed the potential of biofuels for increasing the efficiency of RCCI concept. The study was performed using the nominal CR of 14.4:1 at low load and an effective CR of 11:1 at medium and high loads. In all the cases, the most suitable combination of biofuels was B7+E10-95. In addition, the current chapter has shown that this combination of biofuels allows achieving a clean and efficient operation up to very high loads when using an effective CR of 11:1, but practically the RCCI concept is limited to around $70 \%$ load due to excessive in-cylinder PRRs. Although the RCCI operating range can be maximized by lowering the CR of the engine, the dualmode operation needs to be implemented in a high $\mathrm{CR}$ engine to guarantee high efficiency when switching to CDC mode, as is the case of the EURO VI engine used in this study (CR 17.5:1). 
The results of chapter 6 demonstrated that the high ON and cooling effect of ethanol allow reducing effectively the maximum PRR. Thus, taking into account the high $\mathrm{CR}$ of the production engine, it was decided to use E20-95 as LRF fuel for performing the current work. In addition, the HRF selected was diesel B7 as it showed good performance when combined with this intermediate ethanol-gasoline blend. The main characteristics of the fuels are listed in table 7.2 .

Table 7.2. Physical and chemical properties of the fuels used in this section.

\begin{tabular}{lll}
\cline { 2 - 3 } & Diesel B7 & E20-95 \\
\hline Density $\left(\mathrm{T}=15^{\circ} \mathrm{C}\right)\left[\mathrm{kg} / \mathrm{m}^{3}\right]$ & 837.9 & 745 \\
Viscosity $\left(\mathrm{T}=40^{\circ} \mathrm{C}\right)\left[\mathrm{mm}^{2} / \mathrm{s}\right]$ & 2.67 & - \\
RON [-] & - & 99.1 \\
MON [-] & - & 85.6 \\
Cetane number [-] & 54 & - \\
Biodiesel content by vol. [\%] & 7 & - \\
Ethanol content by vol. [\%] & - & 19.7 \\
Oxygen content by mass [\%] & 0.8 & 6.6 \\
Lower heating value [MJ $/ \mathrm{kg}]$ & 42.61 & 40.05 \\
\hline
\end{tabular}

\subsubsection{Results}

The first campaign of RCCI tests performed in this new engine platform was aimed at acquiring knowledge about the engine response to modifications in the main variables governing the combustion process. In particular, the effects of EGR, GF, diesel injection pattern and timing and intake charge temperature were studied. The results from this study showed that the guidance acquired up to now was still valid even with the great differences between the engines studied, which confirms the robustness of RCCI concept. For the sake of brevity, these results have not been included here, but a detailed explanation can be found in [14].

After the first pool of tests, the experimental procedure described in section 7.2.1 was carried out taking into account the constraints specified in section 7.3.2. The direct comparison between RCCI and CDC emissions at $25 \%$ and $35 \%$ load, which was the maximum operable load with RCCI considering the imposed constraints, is shown in figure 7.18. In addition, the maximum in-cylinder pressure and the maximum pressure rise rate are 
depicted in the figure. Since the analysis is performed using indicated parameters, the EURO VI limits are included only as reference.

The results demonstrate again the ability of RCCI to avoid the classical NOx-soot trade-off, providing a simultaneous reduction of both emissions up to values under the limits imposed. The higher benefits of RCCI versus CDC are observed in NOx emissions, while the major improvements in soot emissions are observed at high engine speeds. As it can be seen, the high values of PRR and $\mathrm{P}_{\max }$ were found as limiting factors to increase the maximum operable load, which was limited to $35 \%$ for all the engine speeds. Moreover, the comparison between the RCCI results at $25 \%$ and $35 \%$ load reveals a great reduction in $\mathrm{CO}$ and $\mathrm{HC}$ emissions as load increases, providing $\mathrm{CO}$ levels near EURO VI limits in some cases. Lastly, it is seen that at $35 \%$ load the soot levels are also very near the limitation of $0.01 \mathrm{~g} / \mathrm{kWh}$ imposed for this pollutant.
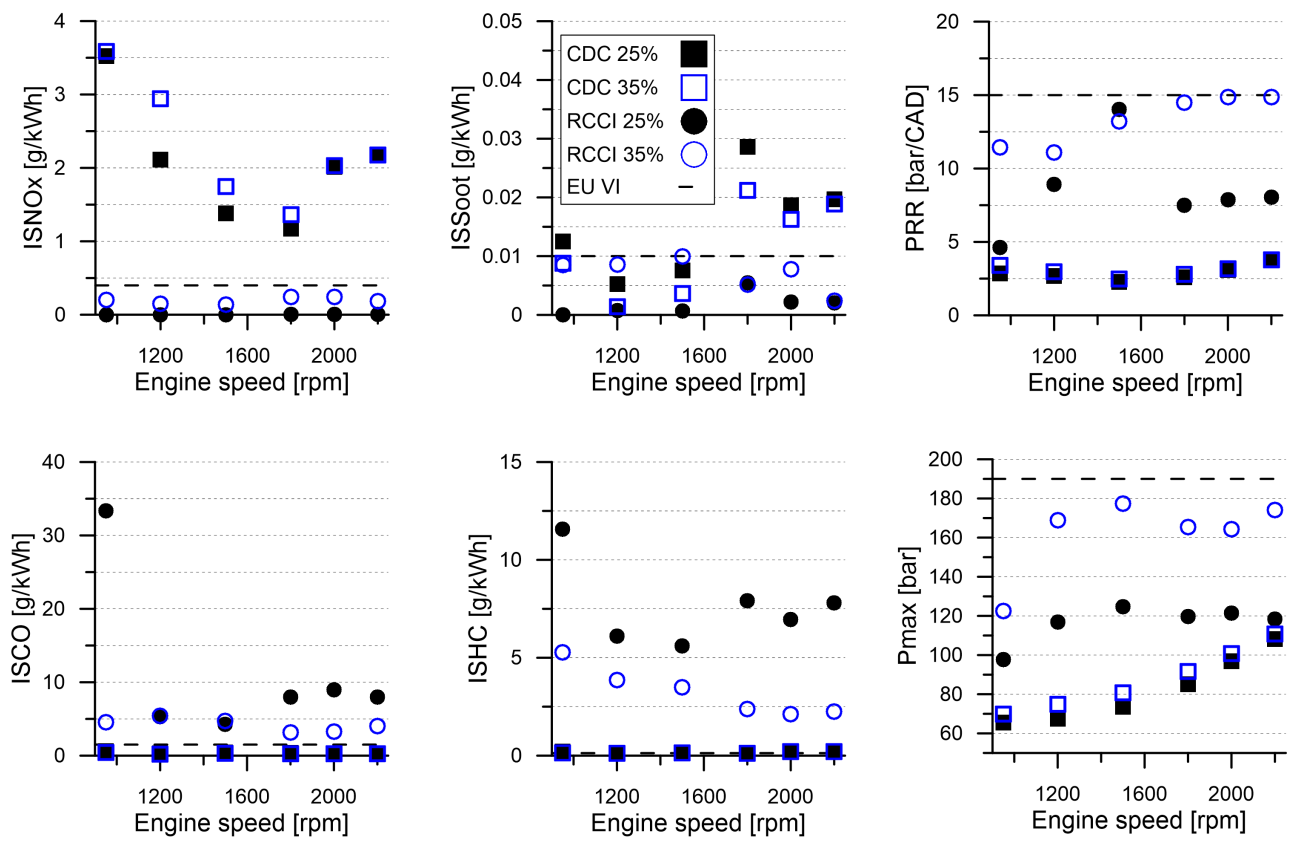

Figure 7.18. Comparison of RCCI and CDC emissions, maximum in-cylinder pressure and PRR at 25\% and 35\% load in the whole engine speed range of the engine.

Figure 7.19 summarizes the main engine settings used to reach the previous RCCI results. At $25 \%$ load, the average GF used was $85 \%$ with a peak of $95 \%$ at $1500 \mathrm{rpm}$. The majority of tests were obtained using a combination of an advanced pilot injection and a main injection near TDC. In some conditions, 
this was found an effective strategy to reduce $\mathrm{HC}$ and $\mathrm{CO}$ emissions due to the better diesel fuel stratification [14]. At 35\% RCCI operation, the GF was reduced around $5 \%$ in average as compared to $25 \%$ load due to the increasing knocking tendency, but the trends observed versus engine speed are very similar. At this load, the RCCI operation was achieved through an early single pulse of diesel fuel between -45 and -70 CAD ATDC. The diesel SOI was advanced as engine speed increased to compensate the lower duration of the engine cycle. Finally, it is interesting to remark that the EGR and intake pressure levels used in all the cases are representative of those found during CDC operation with OEM settings, which showed maximum values of $\approx 30 \%$ and 3 bar, respectively. Moreover, diesel injection pressure was fixed at 1000 bar to minimize the variables included in the experimental procedure. However, in one operating condition it was necessary to increase this value up to 1300 bar to reduce soot emissions up to the limit of $0.01 \mathrm{~g} / \mathrm{kWh}$.
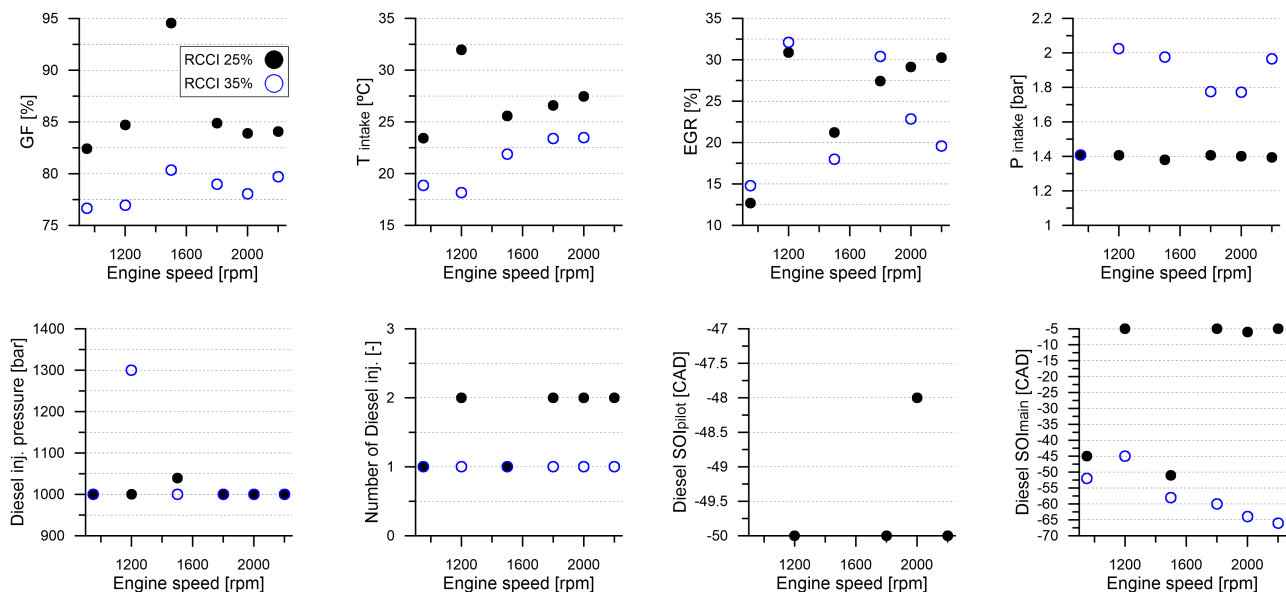

Figure 7.19. Different engine settings corresponding to the RCCI tests at $25 \%$ and $35 \%$ load in the whole engine speed range.

\subsubsection{Dual-mode engine operation approach}

Previous section demonstrated that RCCI concept is capable of providing EURO VI NOx levels and ultra-low soot emissions simultaneously, even using a high $\mathrm{CR}$ engine. In addition, $\mathrm{CO}$ and $\mathrm{HC}$ emissions are much lower than those obtained in the heavy-duty engine for both compression ratios 14.4:1 and 11:1. To illustrate better these results, the maps of regulated gaseous emissions and soot are shown in figure 7.20. In spite of offering low engine-out emissions, the 
maximum $\mathrm{PRR}$ and $\mathrm{P}_{\max }$ constraints restrict the maximum operable load of RCCI concept to $35 \%$ at all engine speeds. Thus, the potential of combining RCCI and CDC concepts to cover all the engine operating range is discussed next.
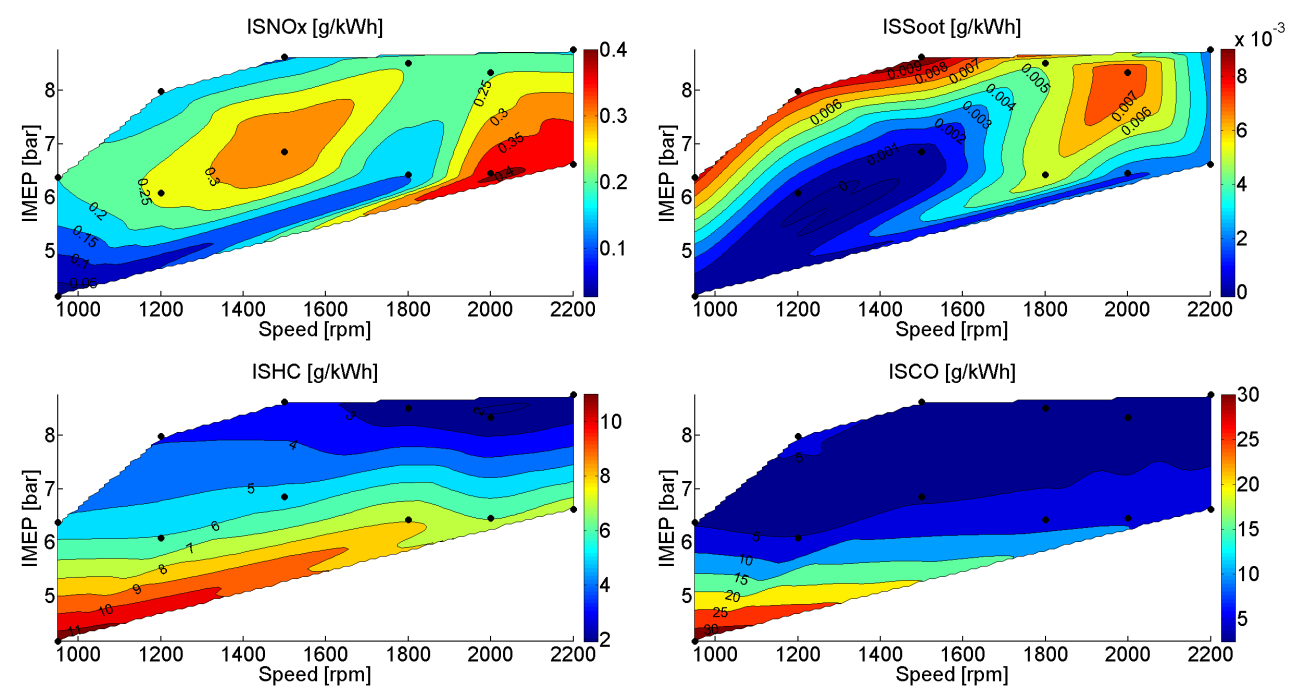

Figure 7.20. RCCI emissions mapping in the high compression ratio EURO VI engine. The maximum operable load under RCCI conditions is limited by the excessive PRR and maximum in-cylinder pressure.

As shown in figure 7.19, the boost pressure levels and EGR rates used to promote RCCI conditions in the current experiments are quite similar to those used in the production engine. Thus, these two variables do not represent technological limitations in this case. In addition, the results shown in figure 7.21 reveal that all the operating conditions provide exhaust temperatures above $200^{\circ} \mathrm{C}$, thus ensuring the catalytic activity during RCCI operation. The higher exhaust temperatures compared to those of the heavyduty engine are well related to the higher compression ratio of the current engine. This fact also explains the great reduction in $\mathrm{CO}$ and $\mathrm{HC}$ emissions observed when comparing the mapping results of both engines. Moreover, it is worthy to note that the exhaust temperatures showed in the figure should be even higher when the engine run in dual-mode due to the heating up of the exhaust line during CDC operation. Thus, taking into account that the exhaust temperatures are near $300^{\circ} \mathrm{C}$ in the most portion of the map, this additional heating up will ensure a great conversion efficiency of the 
DOC. Finally, it is possible to see that combustion noise levels of the present experiments do not exceed those obtained in the heavy-duty engine.
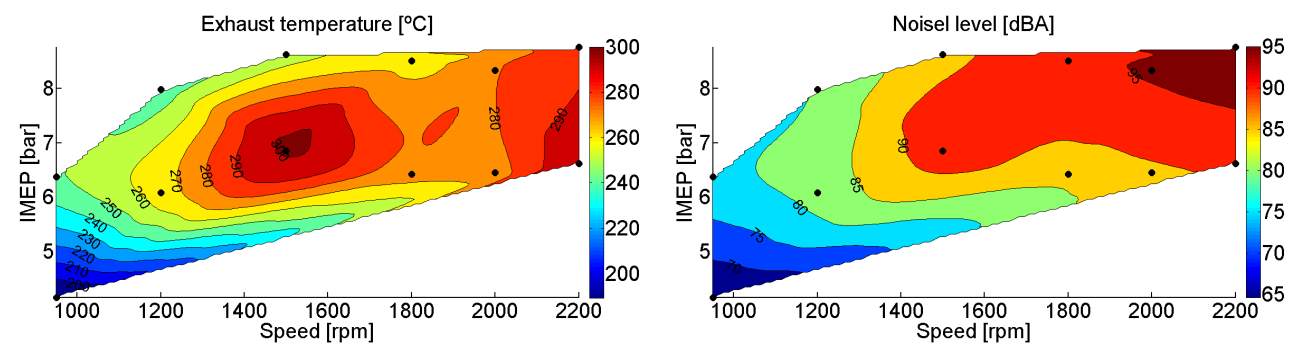

Figure 7.21. Exhaust temperature and combustion noise levels experienced during $R C C I$ operation in the high compression ratio EURO VI engine.

As it has been already remarked, the dual-mode RCCI/CDC engine operation does not offer the possibility of removing the SCR and DPF aftertreatment systems, which questions the potential of the concept. Thus, its technological implementation only could be justified if RCCI provides enough increase in efficiency versus CDC to reduce considerably the fuel consumption in its operative portion of the engine map. As described in chapter 1, to fulfill the limits imposed by the EURO VI regulation, the current production engines inject additional fluids into the exhaust line for improving the efficiency of the aftertreatment systems. This fact must be considered to perform a more realistic approach about the possible fuel economy advantages of the dual-mode concept. In this sense, the configuration of the aftertreatment systems in the exhaust line of the VOLVO D5K240 engine is illustrated in the figure $7.22[15]$.

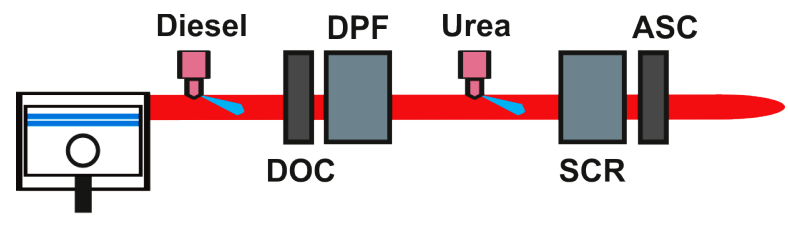

Figure 7.22. Scheme of the exhaust line of the VOLVO D5K240 engine used in this study.

As can be seen in the figure, two different fluids are injected into the exhaust system. First, diesel fuel is injected upwards the DOC for heat management purposes as well as to ensure the efficiency of the DPF and 
good SCR functionality. Later, an injection of urea (commercially known as AdBlue) takes place upwards the SCR to improve the catalytic efficiency. Since these two injections provide no useful work, they can be considered as an additional "fuel" consumption. Urea consumption can be estimated at $1 \%$ of the fuel consumption per $\mathrm{g} / \mathrm{kWh}$ reduction in NOx emissions [16]. Thus, the mass of urea required to reduce the engine-out NOx up to the EURO VI target can be estimated as shown in equation 7.1. Since RCCI operation provides NOx levels under the EURO VI limit, the consumption of urea will be avoided during RCCI operation.

$$
m_{\text {urea }}=\left(N O x_{\text {engine-out }}-N O x_{E U R O V I}\right) \cdot 0.01 \cdot m_{\text {diesel }}
$$

To account this extra "fuel" consumption, the GIE values for CDC can be corrected on a cost-basis as shown in equation 7.2. This estimation considers the same prices for urea and diesel fuel. However, if the urea and diesel fuel prices were very different, the total GIE should be recalculated based on the weighted masses of urea and diesel fuel.

$$
G I E_{S C R_{-} \text {corr }}=\frac{W_{i}}{\left(m_{\text {urea }}+m_{\text {diesel }}\right) \cdot L H V}
$$

As can be seen in figure 7.23, depending on the engine speed and load, this correction entails a reduction in GIE ranging from $0.5 \%$ to $4 \%$ of the baseline value.

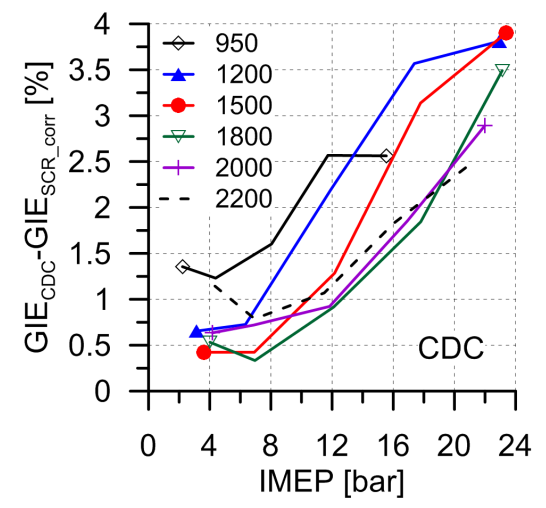

Figure 7.23. Reduction in GIE for CDC at different engine speeds and loads when considering the urea consumption. 
Considering this new scenario, figure 7.24 shows the load-speed map of the GIE for RCCI and another one accounting the GIE difference between RCCI and the corrected CDC operation.
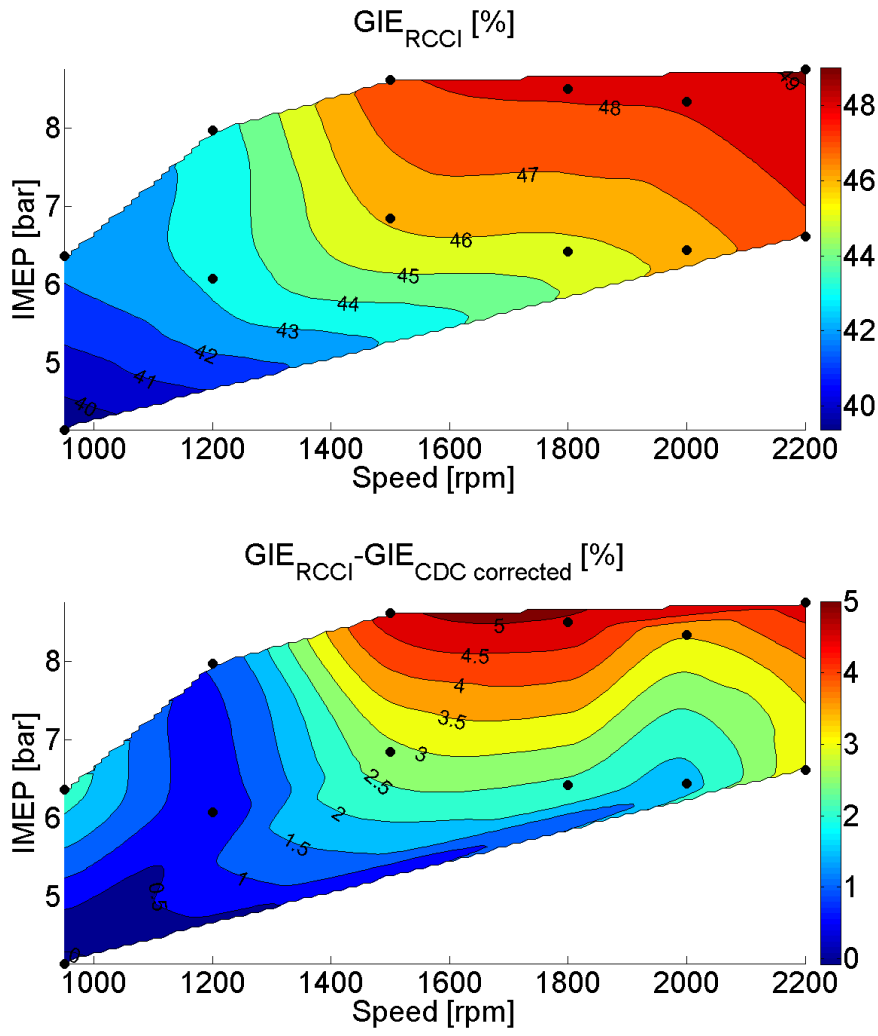

Figure 7.24. GIE map for RCCI and GIE difference between RCCI and corrected $C D C$.

The second map shows that RCCI concept is capable of improving the GIE up to $5 \%$ in the mid-to-high speed portion of the engine map, while in the low speed region shows equal efficiency than CDC operation. Thus, the potential fuel economy gain of dual-mode versus CDC will depend on the drive cycle applied to the engine.

On the other hand, during dual-mode operation, the diesel injection ahead the DOC would be still necessary to regenerate the DPF. However, since RCCI promotes a great reduction in soot emissions versus CDC (see figure 7.25), the time between regenerations during dual-mode operation could be significantly extended depending on the drive cycle applied to the engine. 


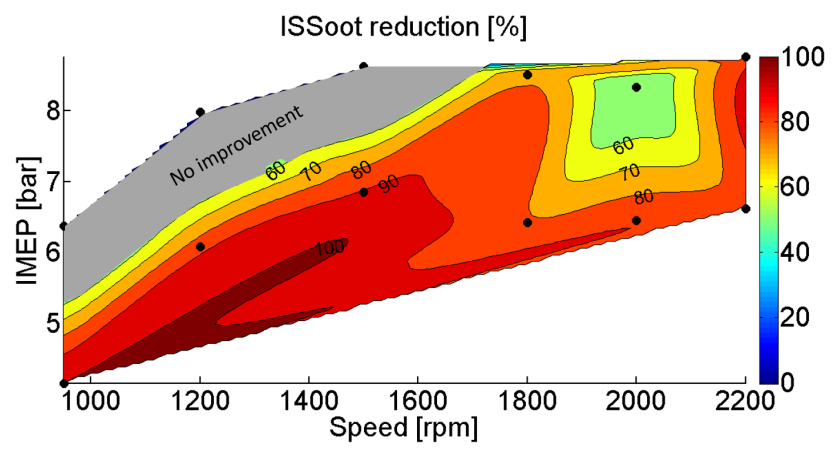

Figure 7.25. Reduction in soot emissions promoted by RCCI compared to CDC operation.

To perform a rough estimation about the exhaust diesel fuel saved due to the lower demand of DPF regenerations when the engine run in dual-mode, the world harmonized stationary cycle (WHSC) proposed by the EURO VI regulation has been considered. Thus, figure 7.26 shows the different loadspeed tests proposed in the WHSC, where the size of the symbols determines the weight of each test in the cycle. In addition, the actual engine tests performed to obtain the CDC results are depicted in the figure. As it can be seen, the experimental tests are slightly shifted to higher engine speeds than the tests proposed by the WHSC. Since the objective is to perform a rough estimation, it has been preferred to use the exact experimental soot measurements than extrapolate the values of the specific WHSC conditions from the maps. Another difference versus the WHSC is that no operating point has been tested at $650 \mathrm{rpm}$.

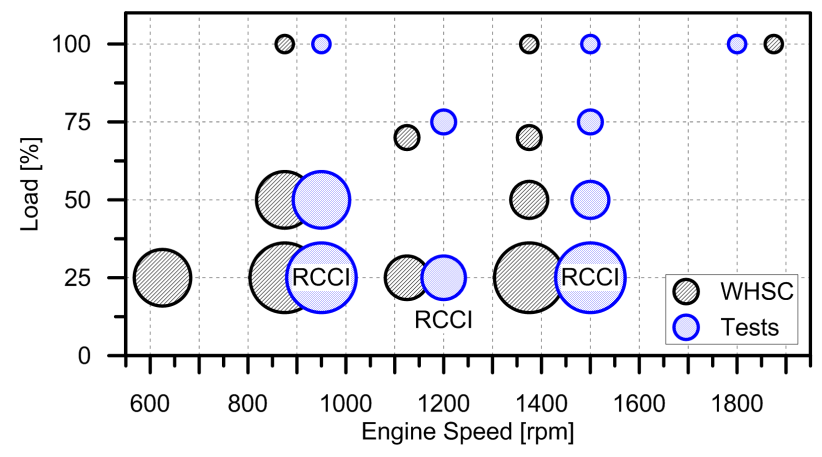

Figure 7.26. Tests proposed in the world harmonized stationary cycle (WHSC) and tests experimentally measured with RCCI and CDC. 
To estimate the differences in soot emissions, the engine cycle has been calculated twice. In the first case, all the operating points correspond to CDC. In the second case, the soot from a dual-mode cycle has been calculated considering that the three operating conditions at $25 \%$ load correspond to RCCI conditions, while the remaining points belong to CDC operation. These data are summarized in table 7.3.

Table 7.3. CDC and dual-mode conditions considered to calculate the soot emissions from the engine cycle proposed.

\begin{tabular}{cccccc}
\hline \hline $\begin{array}{c}\text { Speed } \\
{[\mathrm{rpm}]}\end{array}$ & $\begin{array}{c}\text { Load } \\
{[\%]}\end{array}$ & $\begin{array}{c}\text { time } \\
{[\mathrm{s}]}\end{array}$ & $\begin{array}{c}\mathrm{N}_{i} \\
{[\mathrm{~kW}]}\end{array}$ & $\begin{array}{c}\text { ISSoot }_{C D C} \\
{[\mathrm{~g} / \mathrm{kWh}]}\end{array}$ & $\begin{array}{c}\text { ISSoot }_{\text {dual }} \\
{[\mathrm{g} / \mathrm{kWh}]}\end{array}$ \\
\hline 950 & 25 & 250 & 17.69 & 0.0125 & $\mathbf{0 . 0 0 0 0}$ \\
950 & 50 & 200 & 32.47 & 0.0041 & 0.0041 \\
950 & 100 & 50 & 62.76 & 0.0024 & 0.0024 \\
1200 & 25 & 150 & 32.32 & 0.0052 & $\mathbf{0 . 0 0 0 7}$ \\
1200 & 75 & 75 & 88.62 & 0.0012 & 0.0012 \\
1500 & 25 & 250 & 44.07 & 0.0075 & $\mathbf{0 . 0 0 0 7}$ \\
1500 & 50 & 125 & 77.57 & 0.0029 & 0.0029 \\
1500 & 75 & 75 & 113.38 & 0.0006 & 0.0006 \\
1500 & 100 & 50 & 149.03 & 0.0016 & 0.0016 \\
1800 & 100 & 50 & 176.89 & 0.0015 & 0.0015 \\
\hline
\end{tabular}

The calculation of the cycle results in 0.073 grams of engine-out soot for single CDC operation and 0.0308 grams for the dual-mode cycle. The great reduction in soot emissions obtained with the dual-mode strategy versus CDC $(\approx 58 \%)$ is explained by two reasons. The first reason is because the operating conditions at $25 \%$ load have the highest weight in the WHSC cycle. The second is that RCCI promotes the greatest soot reduction versus CDC at this engine load (see figure 7.25). These results suggest that, practically, the regeneration periods for an engine working with dual-mode RCCI/CDC strategy can be reduced more than twice compared to single CDC operation.

As literature demonstrates, the selection of the optimal regeneration strategy must consider the increase in BSFC due to both the backpressure increase and the extra fuel injected in the exhaust line. In this sense, the average effect of backpressure on fuel consumption will have similar magnitude during CDC or dual-mode operation, which is estimated in around $1.5 \%$ to $2.5 \%$ of BSFC [17]. On the other hand, the increase in BSFC due to the 
fuel amount injected in the exhaust during the regeneration periods has been estimated in around $2 \%$ to $4 \%[18,19]$. Thus, depending on the drive cycle considered, the reduction of regeneration periods can have a considerable effect on total fuel consumption.

The estimates performed in this section hint that dual-mode concept has promising potential as compared to $\mathrm{CDC}$ operation. However, to maximize the benefits of this concept, it is necessary to develop a dedicated optimization work for fitting better the RCCI concept into the dual-mode engine map. This procedure must take into account some additional factors than those considered for achieving the widest possible isolated RCCI operation. In this sense, aside from modifications in engine settings and fuel properties to tailor the GIE in the most appropriate zones of the engine map, the different trade-offs between the urea necessity, exhaust diesel consumption and RCCI operation coverage should be studied in detail. This means that the emissions restrictions imposed to RCCI could be relieved looking for optimizing the engine settings and maximize the GIE bearing in mind the future application of the engine. Another important factor to be optimized for broaden the RCCI operation coverage is the compression ratio of the engine, which has shown a clear effect on the maximum load achievable: $70 \%$ (11:1), 50\% (14.4:1) and $35 \%(17.5: 1)$. In this regard, the trade-off appearing between the RCCI coverage and CDC efficiency as the engine CR is reduced should be examined minutely.

\subsection{Summary and conclusions}

The first part of the present chapter evaluated the potential of RCCI concept to reach EURO VI NOx levels and ultra-low soot emissions over the whole engine map. For this purpose, a detailed experimental methodology was defined and applied to obtain maps of the engine performance, emissions and several other parameters using two different compression ratios (14.4:1 and 11:1). To perform this study, the constrained value for the maximum PRR was relieved up to $25 \mathrm{bar} / \mathrm{CAD}$.

From the experimental procedure, it was found that the key variables to reach stable RCCI operation are the diesel injection timing and gasoline fraction. The modification of both variables allows to modulate the combustion pashing while maintaining the PRR under the limit value with a high GF in the blend. In a second step, aimed at introducing the potential RCCI engine operating points under the NOx and soot limitations, the EGR rate was also found as key variable. In addition, the limitation in $\mathrm{COV}_{\text {IMEP }}$ 
introduced in this step allows to control the emission levels of unburned products. Finally, a rough optimization step was needed to minimize CO and $\mathrm{HC}$ emission levels.

Following the defined experimental procedure, it has been demonstrated the ability of RCCI concept to operate under the NOx and soot restrictions in great part of the engine map. The key conclusions from the analysis of the different results presented in the maps are summarized as follows:

- In order to avoid excessive PRR with the nominal CR (14.4:1), it was necessary to delay the diesel SOI progressively as load increased. This action resulted in higher soot emissions, which limited the RCCI operation to $50 \%$ load.

- The use of a reduced CR (11:1) allowed to extend the RCCI operation towards the upper portion of the engine map without exceeding the limits of NOx and soot emissions, maximum PRR and COV IMEP.

- NOx emissions trend showed a greater dependency on engine speed than the other pollutant emissions. In this case, all the values were below the EURO VI limitation with both compression ratios.

- Gross indicated efficiency increased with engine speed and load. In addition, the regions in the map of maximum GIE values correspond with the highest GF levels. A 48.2\% peak of GIE at $1200 \mathrm{rpm}$ and almost full load was found with CR 11:1.

- For both compression ratios, $\mathrm{HC}$ and $\mathrm{CO}$ emissions were reduced as BMEP increased. In addition, the lowest $\mathrm{HC}$ and $\mathrm{CO}$ emissions were located in the region of the map with great combustion stability and PRR. The comparison of the best balanced operating conditions for both CR suggested that the extension in load range allowed with CR 11:1 results in a great improvement of both emissions.

The analysis of the results obtained for both compression ratios revealed several technological challenges that could arise when trying to implement the RCCI concept in a real engine application. In particular, the low exhaust temperatures not allowed the direct use of conventional DOCs for oxidizing the $\mathrm{HC}$ and $\mathrm{CO}$ emissions from RCCI combustion, requiring more effort in understanding what prevents a catalyst from lighting off, why, and how it may be mitigated. In addition, despite combustion noise levels are in the range of those used in literature for preliminary combustion studies, they should be 
reduced to reduce the engine packaging costs. Moreover, the air-management results suggested that specific turbo-machinery and EGR systems should be developed to supply the required air and exhaust gas amounts at high engine loads.

Considering $15 \mathrm{bar} / \mathrm{CAD}$ as reasonable limit for the maximum in-cylinder PRR, the application of RCCI concept becomes restricted to $70 \%$ load in the best case (CR 11:1). Thus, the capabilities of implementing a dual-mode RCCI/CDC concept to cover all the engine map were evaluated. This study was performed using a EURO VI production engine with compression ratio of 17.5:1. Considering the restrictions imposed in NOx, soot and PRR, the RCCI operation was found possible from $25 \%$ to $35 \%$ load at all engine speeds. In this operating range, the technological limitations observed in the first part of the chapter were avoided. In particular, the turbocharging demands and EGR were found achievable with the stock hardware. In addition, the high exhaust temperature observed due to the high $\mathrm{CR}$ of the engine ensure great catalytic conversion of $\mathrm{CO}$ and $\mathrm{HC}$ emissions during RCCI operation.

Finally, to evaluate the possible benefits of the dual-mode concept, an estimation to account all the fluids consumed during CDC operation was done. Firstly, the GIE was corrected on a cost-basis to account the amount of urea necessary to reduce the NOx emissions during CDC operation. The comparison versus RCCI at these conditions suggested that RCCI can provide up to $5 \%$ increased GIE at medium engine speeds, leading to similar efficiency than CDC in the low speed portion of the map. Later, considering the WHSC cycle as reference, it was demonstrated that the regeneration periods of the DPF during dual-mode operation can be reduced more than twice, which entails a great reduction of the diesel fuel amount injected in the exhaust line. In addition, it should be considered that the size of both aftertreatment systems (SCR and DPF) could be reduced, thus contributing to the total cost saving. 


\section{Bibliography}

[1] Splitter D., Hanson R., Kokjohn S., Wissink M. and Reitz R.D. "Injection Effects in Low Load RCCI Dual-Fuel Combustion". SAE Technical Paper, no 2011-24-0047, 2011.

[2] Kokjohn S., Hanson R., Splitter D. and Reitz R.D. "Fuel reactivity controlled compression ignition (RCCI): a pathway to controlled high-efficiency clean combustion". International Journal of Engine Research, Vol. 12 n 3, pp. 209-226, 2011.

[3] Splitter D., Wissink M.L., Hendricks T.L., Ghandhi J.B. and Reitz R.D. "Comparison of RCCI, HCCI, and CDC Operation from Low to Full Load". THIESEL Conference on Thermo- and Fluid Dynamic Processes in Direct Injection Engines, 2012.

[4] Prikhodko V., Curran S., Parks J. and Wagner R. "Effectiveness of Diesel Oxidation Catalyst in Reducing $\mathrm{HC}$ and CO Emissions from Reactivity Controlled Compression Ignition". SAE Int. J. Fuels Lubr., Vol. 6 no 2013-01-0515, pp. 329-335, 2013.

[5] Bartley G.J. "Identifying Limiters to Low Temperature Catalyst Activity". SAE Technical Paper, $\mathrm{n}^{\circ}$ 2015-01-1025, 2015.

[6] Shahlari A.J., Hocking C., Kurtz E. and Ghandhi J. "Comparison of Compression Ignition Engine Noise Metrics in Low-Temperature Combustion Regimes". SAE Int. J. Engines, Vol. 6, pp. 541-552, 2013.

[7] Sellnau M., Foster M., Hoyer K., Moore W., Sinnamon J. and Husted H. "Development of a Gasoline Direct Injection Compression Ignition (GDCI) Engine". SAE Int. J. Engines, Vol. 7, pp. 835-851, 2014.

[8] Sellnau M., Sinnamon J., Hoyer K., Kim J., Cavotta M. and Husted H. "Part-Load Operation of Gasoline Direct-Injection Compression Ignition (GDCI) Engine". SAE Technical Paper, $\mathrm{n}^{\circ}$ 2013-01-0272, 2013.

[9] Splitter D., Wissink M., Vescovo D. Del and Reitz R.D. "Improving the Understanding of Intake and Charge Effects for Increasing RCCI Engine Efficiency". SAE Int. J. Engines, Vol. 7, pp. 913-927, 2014.

[10] "Regulation (EU) no 540/2014 of the European parliament and of the council of 16 April 2014 on the sound level of motor vehicles and of replacement silencing systems, and amending Directive 2007/46/EC and repealing Directive 70/157/EEC". In http://eurlex.europa.eu.

[11] "Commission Directive (EU) 2015/996 of 19 May 2015 establishing common noise assessment methods according to Directive 2002/49/EC of the European Parliament and of the Council". In http://eur-lex.europa.eu.

[12] Yu S. and Zheng M. "Ethanol-diesel premixed charge compression ignition to achieve clean combustion under high loads". Proceedings of the Institution of Mechanical Engineers, Part D: Journal of Automobile Engineering, pág. 0954407015589870, 2015.

[13] Klos D., Janecek D. and Kokjohn S. "Investigation of the Combustion Instability-NOx Tradeoff in a Dual Fuel Reactivity Controlled Compression Ignition (RCCI) Engine". SAE International Journal of Engines, Vol. 8 n $^{\circ}$ 2, pp. 821-830, 2015.

[14] Benajes J., García A., Monsalve-Serrano J., Balloul I. and Pradel G. "Operational limits assessment of RCCI combustion in a high compression ratio medium-duty diesel engine using near-term available biofuels". THIESEL Conference on Thermo- and Fluid Dynamic Processes in Direct Injection Engines, 2016.

[15] "http://www.volvotrucks.com/trucks/uk-market/en-gb/trucks/volvo-fl/productfeatures/Pages/d5k-and-d8k-engines.aspx". 
[16] Johnson T.V. "Diesel Emissions in Review". SAE International Journal of Engines, Vol. $4 \mathrm{n}^{\circ}$ 1, pp. 143-157, 2011.

[17] Singh N., Rutland C.J., Foster Da.E., Narayanaswamy K. and He Y. "Investigation into Different DPF Regeneration Strategies Based on Fuel Economy Using Integrated System Simulation". SAE Technical Paper, no 2009-01-1275, 2009.

[18] Gong J. and Rutland C.J. "Pulsed Regeneration for DPF Aftertreatment Devices". SAE Technical Paper, $\mathrm{n}^{\circ}$ 2011-24-0182, 2011.

[19] Prikhodko V. and Parks J. "Implications of Low Particulate Matter Emissions on System Fuel Efficiency for High Efficiency Clean Combustion". SAE Technical Paper, n $2009-01-2709,2009$. 


\title{
Chapter 8
}

\section{Conclusions and suggestions for future work}

\author{
Contents
}

$8.1 \quad$ Introduction...................... 262

8.2 Summary and conclusions $\ldots \ldots \ldots \ldots \ldots \ldots \ldots 2$

8.3 Suggestions for future work ............. 269 


\subsection{Introduction}

This chapter aims at drawing the main conclusions of the work carried out in this thesis, thus providing a global view of the whole investigation performed. This will allow to check how the results obtained along the chapters have contributed to reach the objectives initially proposed. Finally, based on several suggestions that have emerged during the analysis, a proposal of future works is presented in the last section of this chapter.

\subsection{Summary and conclusions}

The present work has been developed within the general framework of improving the efficiency and reduce the most relevant engine-out emissions of diesel engines, $\mathrm{NOx}$ and soot. The more promising combustion strategies to improve the efficiency of compression ignition engines while reducing these two pollutants are the low temperature combustion (LTC) modes. The current knowledge of these advanced combustion processes was reviewed in chapter 2 .

The literature survey stated that major drawbacks of the LTC concepts are the poor combustion control in terms of cycle-to-cycle variation and combustion phasing, and the excessive mechanical stress provoked to the engine. These disadvantages reduce the effective operating range of these strategies to very narrow ranges, which limits their practical application. To overcome this shortcoming, several approaches were investigated. Specifically, the influence of the charge preparation, partial fuel stratification, fuel reactivity and spark assistance were studied in detail by many researchers. The studies concluded that those methods can increase slightly the operating range and suggested that, for promoting a proper operation, fuels with different reactivity are required depending on the operating conditions.

More recent experimental and computational studies proved that Reactivity Controlled Compression Ignition (RCCI) is a more promising LTC technique than HCCI and PPC. In particular, it was shown that the ability of RCCI concept to modulate the in-cylinder equivalence ratio and reactivity stratification in the combustion chamber through the gasoline fraction and diesel injection timing variation, provides an effective control on the rate of heat release. That flexibility allows minimizing the drawbacks found with the single-fuel LTC concepts. Moreover, some works have proved that RCCI achieves very high GIE at medium load conditions with ultra-low NOx and soot emission levels. However, the combustion efficiency was found to be poor at low load conditions, which limits the efficiency advantages over CDC at 
this load. In addition, the considerably higher $\mathrm{HC}$ and $\mathrm{CO}$ emissions levels than those emitted during CDC operation may compromise the efficiency of the aftertreatment systems during RCCI operation.

Based on the conclusions extracted from the literature review, the present thesis has investigated different paths to increase the efficiency of RCCI concept at low load and has also evaluated the capabilities of each path to extend the RCCI operating range towards higher loads. The search for high efficiency has been conditioned by three constraints, which defined the requirements demanded to RCCI regime. Specifically, two of them were aimed at ensuring EURO VI NOx compliance with ultra-low soot levels, while the third constraint intended to preserve the mechanical integrity of the engine by limiting the maximum pressure rise rate in the combustion chamber. The main findings about each strategy studied are summarized next:

\section{Combination of engine settings}

The first strategy explored to improve RCCI efficiency at low load was the combination of engine settings. Prior to perform the study, a baseline injection strategy for the diesel fuel was selected. Based on previous experimental background, the pilot diesel injection was set at -60 CAD ATDC. By means of computational simulations, it was demonstrated that this highly advanced injection timing allows increasing the reactivity at crevice region, which enhances the gasoline burning and reduces the unburned hydrocarbon emissions. The main injection timing showed great effect on NOx emissions, while soot emissions were below the detection limit of the smoke meter in all cases due to the very early pilot injection used. Thus, a dedicated study showed that main diesel injection set at -50 CAD ATDC provides NOx levels under EURO VI limits in a wide range of engine conditions (GF, EGR and intake temperature). Moreover, the EURO VI NOx compliance was found to be related to the CA50 position of the combustion cycle. In particular, combustion phasing values near +5 CAD ATDC showed a proper trade-off between engine performance and NOx emissions levels.

With the diesel injection timing fixed for both events (-60/-50 CAD ATDC), two different strategies were tested to modulate the in-cylinder reactivity while providing constant combustion phasing at +5.5 CAD ATDC. First, the simultaneous variation of EGR and gasoline fraction (GF) was studied. Later, it was explored the simultaneous variation of the intake charge temperature and GF. Both strategies were effective in controlling RCCI combustion, and showed great potential to decrease combustion losses and increase thermal efficiency. In this regard, the experimental results confirmed 
that the selection of the proper engine settings can allow to increase the combustion efficiency in around 1.5\% and the indicated efficiency from $3 \%$ to $4 \%$ if compared with the worst combination of settings.

The computational results showed that the cases with the lowest combustion efficiency for both strategies were consequence of the nonprogression of combustion towards the center of the cylinder. This fact was explained due to the highly advanced injection strategy selected for diesel fuel, which increased considerably the fuel reactivity in the crevice zone but resulted in poor spatial stratification of diesel fuel towards the center of the cylinder. Thus, working under low reactive intake charge conditions (high EGR rates or low intake charge temperatures), a great mass fraction of unburned gasoline was identified around this zone, which promoted high amount of $\mathrm{CO}$ and $\mathrm{HC}$ emissions during the late combustion period.

Finally, the direct comparison of all the operating points for both strategies suggested that, under conditions investigated, the strategy of combining EGR+GF provided slight improvements in GIE than using the $\mathrm{T}+\mathrm{GF}$ strategy. Moreover, the relationship between the intake temperature and EGR rate with GF to maintain fixed CA50 showed linear response in the range of the operating conditions tested, which is desirable if a combustion control algorithm based on these variables were required.

\section{Heat transfer reduction}

A review into the literature suggested that heat transfer $(\mathrm{HT})$ reduction offers great potential for increasing the efficiency of RCCI concept. With the aim of understanding the main sources of in-cylinder HT losses in this combustion mode, three operating conditions corresponding to low, medium and high load were studied by means of computational modeling. The analysis of the results revealed that, for all the engine loads, the heat flux through the piston wall is the dominant mechanism of in-cylinder HT losses during RCCI operation, accounting for more than half of the total in-cylinder HT. Thus, as second way for improving the efficiency of RCCI, two bowl geometries aimed at reducing the wall heat transfer were evaluated by means of experimental tests.

The two bowl geometries were defined following the guidelines found in literature for reducing in-cylinder HT, i.e. to promote lower surface-to-volume ratio and more quiescent combustion chamber. The main goal of the first geometry (tapered) was to limit the squish flow velocities and therefore the HT coefficient in the squish region. To achieve this, the squish height was increased by conferring a tapered shape. Additionally, this geometry resulted 
in $5.7 \%$ lower piston surface than the stock piston. The design of the second geometry (bathtub) focused on achieving the maximum possible reduction in the bowl surface area. Thus, a more flat geometry with near $16 \%$ less bowl surface area than the stock piston was proposed. Both geometries kept equal compression ratio than the stock piston.

The experimental results demonstrated that bathtub piston provides higher gross indicated efficiency than the stock geometry in all the load range, but unfortunately, its flatter bowl geometry resulted in unacceptable soot emissions when using single injection strategies at high load. Since the use of single injection patterns was found to be mandatory to reach moderated PRR as load increases, this limitation implied that bathtub geometry was not suitable for extending the RCCI concept up to full load conditions. The analysis of the computational results proved that the increase in indicated efficiency was directly related to the reduction in total HT due to the lower piston surface area. On the other hand, the tapered geometry showed very similar values of emissions and efficiency than the stock piston from low to high load conditions.

\section{Low reactivity fuel properties modification}

Some studies found in literature showed that reducing the reactivity gradient between the low reactivity fuel (LRF) and high reactivity fuel (HRF) improves RCCI performance at low load, but it is not adequate solution to extend the operation to higher loads. To achieve this, the use of ethanol E85 as LRF was found to be favorable due to its high octane number and charge cooling effect. These characteristics, however, make it unsuitable for low load operation. These findings suggested that more research is needed to find a proper combination of LRF and HRF that allows the improvement of efficiency at low load, but without limiting the operation towards higher loads.

The previous statements motivated the modification of the LRF properties as third option to increase the efficiency of RCCI concept. The study focused on the LRF because, as confirmed in the previous part of the thesis, this must be the major fuel source to achieve a simultaneous improvement of efficiency, NOx and soot emissions. This suggests that the physicochemical properties of the LRF may play a fundamental role on local reactivity, and therefore, in RCCI combustion characteristics.

To evaluate this option, four different fuel blends varying the ethanol content and gasoline octane number were investigated. Three of them were intermediate ethanol-gasoline blends, which considering the current regulations could be near-term available in the petrol stations (E10-95, E10-98 
and E20-95). The fourth fuel grade was E85, which was already investigated by many other researchers due to its particular characteristics and its public availability in the fuel distribution network of some countries. The results demonstrated that the three intermediate blends allow reaching NOx under the EURO VI limit with ultra-low soot emissions and acceptable PRR from low to high load, which demonstrates the capabilities of RCCI as flexible-fuel concept. However, fuel consumption was better than CDC only from low to medium load, thus requiring further optimization at high load conditions. From these fuels, E10-95 showed the highest potential to be used in all the engine load range due to its capacity for lowering $\mathrm{HC}$ and $\mathrm{CO}$ emissions together with higher gross indicated efficiency.

Lastly, a comparison between the best tests (highest efficiency with emissions under imposed limits) of E10-95 with the best ones obtained in the chapter 4 (using regular diesel and gasoline fuels) was performed. This analysis confirmed that the use of near-term available biofuels is an effective strategy for decreasing the petroleum energy consumption through both, the direct displacement of petroleum fuels usage and the increase of RCCI efficiency.

\section{Operational limits of RCCI concept}

Since the different studies performed along the thesis were executed at a fixed engine speed of $1200 \mathrm{rpm}$, the last chapter was aimed at finding the operational limits of RCCI over the whole load-speed operating range.

As a first approach, it was evaluated the possibility of extending the use of the RCCI concept to cover the whole engine map. For this purpose, a detailed experimental methodology considering the emissions limits and the mechanical constraints of the engine was defined and applied using two different compression ratios (14.4:1 and 11:1). The LRF used was E1095 as it previously showed benefits in all the load range. Moreover, the stock piston was used because the bathtub geometry showed high sooting tendency at high load, and the benefits of the tapered piston were not such clear to justify its use. Under these conditions, the maximum operable load was found to be around $50 \%$ and $70 \%$ for the high and low compression ratio, respectively. In addition, some technological challenges related to the low exhaust temperatures and the high performance demanded to the turbocharger and EGR systems, were identified. Thus, it was concluded that the whole engine map cannot be covered by only operating in RCCI regime, at least if the simultaneous compliance of the three constraints imposed in this thesis is required. 
Considering this limitation, the capabilities of implementing a dual-mode RCCI/CDC concept to cover all the engine map were evaluated. This study was performed using a EURO VI calibrated production engine with compression ratio of 17.5:1. Considering this high CR and taking into account the capabilities of ethanol to reduce the maximum in-cylinder pressure rise rates, the LRF selected for performing this study was E20-95. Thus, with the pertinent restrictions imposed in NOx, soot and PRR, the RCCI operation was found to be possible from $25 \%$ to $35 \%$ load at all engine speeds. Taking into account all the exhaust fluids consumed during CDC operation, the dualmode concept showed promising results in this operating range. These results suggested that to extract the maximum benefits of this technology, the RCCI operating conditions must be optimized particularly for a dedicated dual-mode application.

Finally, in order to provide a global view of the work previously described, a graphical summary is presented in figure 8.1: 


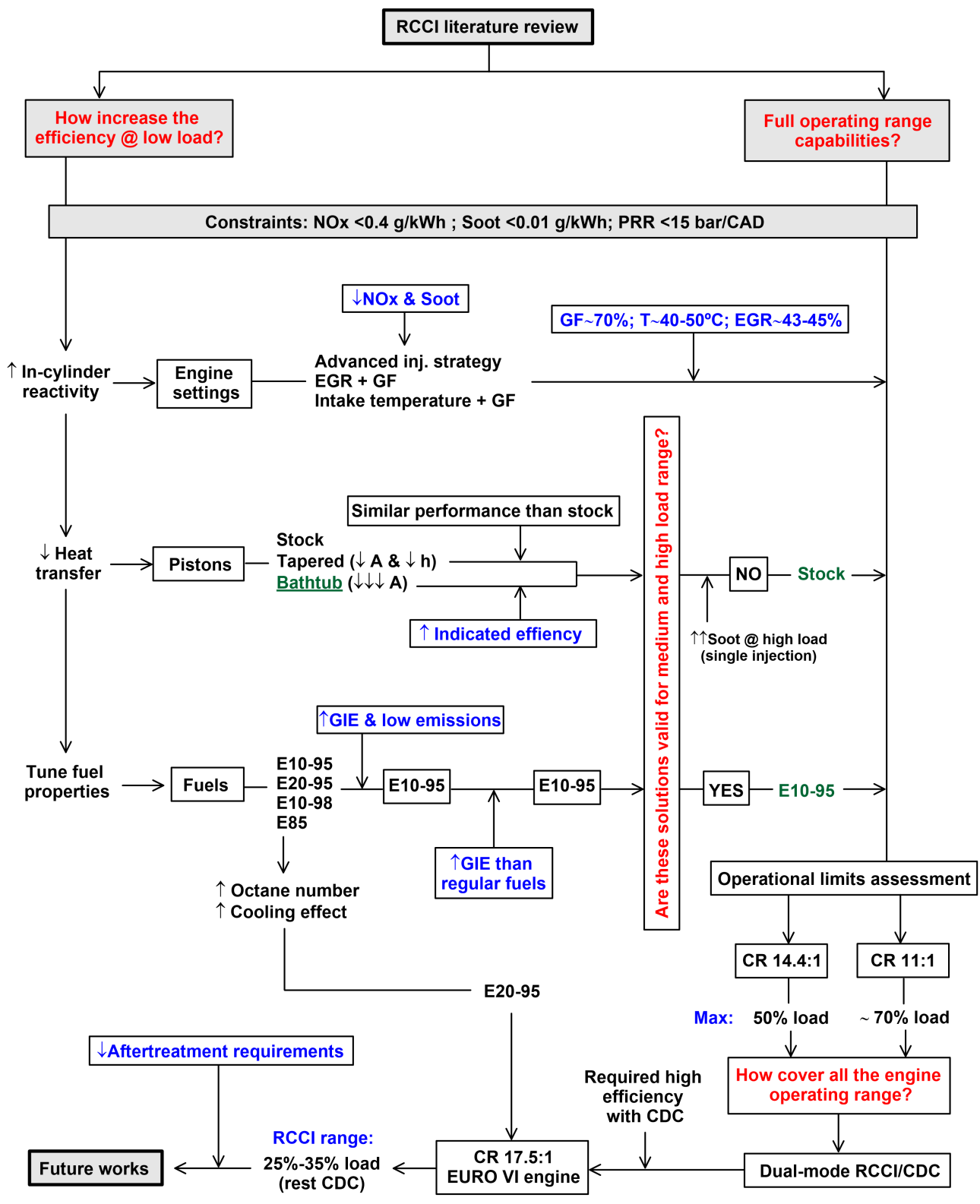

Figure 8.1. General view of the different studies and main results of this thesis. 


\subsection{Suggestions for future work}

Throughout the research described in this thesis, several remarks and suggestions about future works were brought to light, which could not be considered either due to hardware limitations, time constraints or budget restrictions. These could potentially provide the basis for prospective studies that are still necessary to evaluate the real opportunities of applying a dualfuel technology in compression ignition engines. Thus, the proposal for this future work is divided into three different but complementary paths: to improve the fundamental knowledge about RCCI emissions characteristics and aftertreatment demands, to evaluate the capabilities of applying the combustion concept in a multi-cylinder engine platform and to expand the operational limits of RCCI concept intended for dual-mode operation.

\section{Emissions analysis and aftertreatment systems modeling}

One important part of the proposal for future work is to get deeper knowledge on the emissions characteristics of RCCI concept. On one hand, a rigorous analysis of the particulate matter (PM) that reveals the total particle number concentration in the whole engine map is needed to ensure the compliance of the EURO VI regulation for this pollutant. In addition, the particle number-size distribution and their characteristics must be studied to ensure the filtering effectiveness of the conventional DPFs. In this sense, it is interesting to remark that DPFs are effective in controlling the solid fraction of diesel particulates, including elemental carbon (soot) and the related black smoke emission, but may have limited effectiveness, or be totally ineffective, in controlling the non-solid fractions of PM, such as the soluble organic fraction (SOF) present in the emitted particles during RCCI operation. Regarding $\mathrm{CO}$ and $\mathrm{HC}$ emissions, it is necessary to improve the understanding of the mechanisms causing the catalytic activity limitation at low temperature conditions of the DOC, with the ultimate goal of reducing the light-off temperatures.

In parallel, it is necessary to perform a detailed modeling work of the exhaust aftertreatment line, including all the subsystems used in current production engines, to predict more accurately the operational advantages of RCCI when compared to CDC. In particular, the simulation tool should help to predict the regeneration intervals of the DPF during the dual-mode operation, thus quantifying the total fluid saving versus CDC depending on the drive cycle considered. A key parameter to be considered for studying the aftertreatment effectiveness in a dual-mode operation cycle is the exhaust 
temperature, which should be monitored experimentally and studied in detail to provide accurate data to the computational model.

\section{Implementation of RCCI concept in a multi-cylinder engine}

In the present work, the robustness of RCCI has been proved in two different single-cylinder engine configurations. Thus, a proposal for future work is to investigate the ability of RCCI to be implemented in a multicylinder engine platform. The following tasks could be performed using the multi-cylinder medium-duty engine used in the last chapter of this thesis:

- To study the transient operation of RCCI in both engine speed and load. As a first approach, the steps proposed can be done inside the RCCI operable area obtained in chapter 7 . First, it is necessary to perform a batch of tests aimed at obtaining steady-state operating conditions with the stock hardware. Thus, the engine controller can be fed with tables containing the engine control parameters obtained. Later, openloop and closed-loop control strategies must be investigated to assess their effectiveness in reducing the deviance versus the steady-state results during the transient response of the engine.

- To develop control strategies and study the engine transient performance during the RCCI/CDC mode switching.

Once confirmed that RCCI operation is possible over transient conditions, dedicated control strategies must be developed to perform real transient cycles such as the World Harmonized Transient Cycle (WHTC).

\section{Expand the limits of RCCI concept for dual-mode operation}

Attending to the results presented in chapter 7 , it can be concluded that RCCI cannot cover the full engine operating range fulfilling simultaneously the three constraints imposed (NOx, soot and PRR). Thus, it is necessary to continue exploring strategies for expanding the operational load limits of RCCI concept to be applied in a dual-mode concept. This objective can suggest two ways of working: to maximize the RCCI coverage without modifying the stock engine hardware and to optimize the engine hardware to expand the RCCI load limits.

The first path entails defining new in-cylinder strategies to cover higher portion of the speed-load engine map. The dual-mode results presented in chapter 7 were focused on demonstrating the potential of the concept, 
without optimizing rigorously the RCCI results. Since the concept showed good capabilities to improve the efficiency versus CDC, some additional tasks can be considered as future works in this subject:

- To perform RCCI mappings in the high compression ratio EURO VI engine described in chapter 7, but using E85 as low reactivity fuel. The high octane number and great cooling effect of this fuel could extend the operable limits towards higher load than E20-95. In addition, the lower EGR requirements should also improve the efficiency of the engine cycle. However, some drawbacks can be found at low load conditions due to the low reactivity of this fuel grade. Another problem is that this ethanol-gasoline blend is less expected to be near-term available in the fuel market in Europe.

- A specific work to optimize the injection strategy is needed. As was demonstrated in the exploratory mapping of the current production engine showed in chapter 7 , the high $\mathrm{CR}$ of the engine allows reducing $\mathrm{CO}$ and $\mathrm{HC}$ to very low levels, which indicates improved gasoline burning. This fact suggests that high GF can be possible over the whole engine map. Thus, a possibility for escaping from the high PRRs experienced due to the very early diesel injection (needed to diminish engine-out soot emissions) is to change the injection strategy to higher GF and near TDC pilot diesel injections. To evaluate this possibility, a dedicated study to assess the EGR- $\phi$-T relationship governing gasoline burning is needed. This study should provide an overview about the misfire and knocking limits, the thermal efficiency and the validity of this strategy to fulfill the emissions targets imposed.

- Finally, it is interesting to bear in mind the possibility of relieving the emissions restrictions imposed to RCCI at the expense of more efficient combustion. In this case, the different trade-offs between the urea necessity, DPF regeneration intervals and the potential improvement of GIE should be studied in detail to evaluate the net potential of RCCI versus CDC.

Another path to maximize the load range operable with RCCI can be focused on optimizing the engine hardware. This work would imply an iterative process involving different tasks:

- To reduce the stock compression ratio (17.5:1). This can be achieved by defining a new piston geometry or a new camshaft profile. Since the 
$\mathrm{CR}$ required to extend the concept up to higher loads than $35 \%$ may be substantially lower than the stock one, the definition of a new geometry may entail emissions problems. Thus, a computational work based on design of experiments (DoE) will be necessary to optimize the piston geometry. On the other hand, if the reduction of CR is promoted by designing a new camshaft to reduce the intake event (Miller strategy), the demands to the boosting system will increase, which could penalize the brake efficiency of the concept. Thus, the combination of both methods should be also studied as possible way to reduce the $\mathrm{CR}$ of the engine.

- To optimize the swirl ratio (SR). Despite that the study of this parameter was out of the scope of the current thesis, its modification should affect the heat transfer and the in-cylinder mixing conditions, thus having possible repercussions on the brake engine efficiency and the engine-out emissions of the concept that must be understood.

- To perform experimental RCCI mappings in the SCE version following the experimental procedure provided in chapter 7 . This work will identify the maximum operable limits and the turbocharging/EGR demands for the engine configuration proposed.

- To define a dedicated turbocharger and EGR systems that allow supplying the required levels of air and EGR. This step must be studied carefully because depending on the turbocharger architecture, the brake efficiency of the concept could be penalized.

- Finally, the complete configuration (piston, camshaft and turbocharger) must be tested in the multi-cylinder engine to check if RCCI provides lower emissions and fuel consumption than CDC operation.

\section{Additional long-term studies}

Along the thesis, it has been proved that, in order to promote the desired simultaneous NOx and soot emissions reduction, RCCI concept relies on feeding the engine with as much gasoline as possible. This implies problems when trying to extend the concept up to high load due to the increased knocking tendency. Since all the gasoline mass has to be injected at the same time in the cycle, a homogeneous equivalence ratio distribution is attained at the autoignition time. Then, the knocking phenomenon can occur under high pressure and temperature conditions if enough reactive gasoline equivalence ratio is delivered to the cylinder. 
A possibility to overcome this problem may be moving from PFI to direct injection of gasoline. In this case, the total amount of gasoline could be injected in separated pulses, thus promoting an equivalence ratio stratification also for the gasoline fuel. This strategy should improve the control over the rate of heat release and thus reduce the in-cylinder PRR. Since the equivalence ratio stratification will result in less constant volume-like combustion, it is expected that this strategy be less efficient from the thermodynamic point of view. However, up to reach the PRR limit, similar mixture conditions to the ones achieved with PFI can be promoted using very early DI of gasoline. Finally, it is thought that this strategy could help to reduce the unburned products coming from the premixed gasoline trapped in the crevice regions. Thus, despite this solution has less technological advantages than the configuration used in the present thesis (PFI+DI), this can be an interesting future academic research. 



\section{Bibliography}

AVL $733 S$ fuel balance.

Technical information available at http://www.avl.com.

(cited on p. 80)

Commission Directive (EU) 2015/996 of 19 May 2015 establishing common noise assessment methods according to Directive 2002/49/EC of the European Parliament and of the Council. In http://eur-lex.europa.eu.

(cited on p. 242)

Converge CFD software.

Technical information available at http://www.convergecfd.com.

(cited on p. 89)

Directive 2009/28/EC of the European parliament and of the council of 23 April 2009 on the promotion of the use of energy from renewable sources.

Technical report, http://eur-lex.europa.eu. (cited on p. 178)

Directive 2009/30/EC of the European parliament and of the council of 23 April 2009.

Technical report, http://eur-lex.europa.eu. (cited on p. 178)

European Emission Standards: Heavy-Duty Truck and Bus Engines.

More information available at www.dieselnet.com.

(cited on p.4)

http://www.volvotrucks.com/trucks/uk-market/en-gb/trucks/volvo-fl/product-features/Pages/d5kand-d8k-engines.aspx. (cited on p. 251)

Regulation (EC) No 595/2009 of the European Parliament and of the Council of 18 June 2009 on type-approval of motor vehicles and engines with respect to emissions from heavy duty vehicles (Euro VI) and on access to vehicle repair and maintenance information and amending Regulation (EC) No 715/2007 and Directive 2007/46/EC and repealing Directives 80/1269/EEC, 2005/55/EC and 2005/78/EC. Official Journal of the European Union, Vol. 52 no L275, pp. 1-14, 2009.

http://eur-lex.europa.eu.

(cited on pp. 4, 81) 
Regulation (EU) no 540/2014 of the European parliament and of the council of 16 April 2014 on the sound level of motor vehicles and of replacement silencing systems, and amending Directive 2007/46/EC and repealing Directive 70/157/EEC.

In http://eur-lex.europa.eu.

(cited on p. 242)

VOLVO D13K engine features.

Technical information available at http://www.volvotrucks.com. $\quad$ (cited on p.6)

Measurement of intake air or exhaust gas flow of Diesel engines.

SAE Standards J244, 1992.

(cited on p. 74)

Sandia laboratories CFR Newsletter: Imaging of advanced low-temperature diesel combustion.

Technical report, Combustion Research facility, Sandia Laboratories, 2005, Livermore, CA, USA, Vol. 25, $\mathrm{n}^{\circ}$ 5, Page $2 . \quad$ (cited on pp. 22, 23)

Agarwal A.K., Pandey A., Gupta A.K., Aggarwal S.K. and Kushari A.

Novel Combustion Concepts for Sustainable Energy Development.

Springer, p.122, 2014.

(cited on p. 110)

Albrecht W., Dohle U., Gombert R., Krauss J., Leonhard R. and Wannenwetsch $P$.

Innovative BOSCH common rail injection system CRSN4.2 for the new generation of Daimler-Chrysler heavy duty diesel-engines.

$28^{\text {th }}$ International Vienna Motor Symposium, $200 \%$.

(cited on p.69)

Alperstein M., Swim W.B. and Schweitzer P.H.

Fumigation kills smoke - improves diesel performance.

SAE Technical Paper, $\mathrm{n}^{\circ}$ 580058, 1958.

(cited on p. 24)

Amsden A.A., O'Rourke P.J. and Butler T.D.

KIVA-II: A Computer Program for Chemically Reactive Flows with Sprays.

Los Alamos National Laboratory Report, Vol. LA-11560-MS no UC-96, May 1989.

(cited on p. 92)

Andersen V.F., Anderson J.E., Wallington T.J., Mueller S.A. and Nielsen O.J. Vapor Pressures of Alcohol-Gasoline Blends.

Energy \& Fuels, Vol. 24 n ${ }^{\circ}$ 6, pp. 3647-3654, $2010 . \quad$ (cited on p. 179)

Ando H., Sakai Y. and Kuwahara K.

Universal Rule of Hydrocarbon Oxidation.

SAE Technical Paper, $\mathrm{n}^{\circ}$ 2009-01-0948, 2009.

(cited on p. 39)

Asad U., Kumar R., Zheng M. and Tjong J.

Ethanol-fueled low temperature combustion: A pathway to clean and efficient diesel engine cycles.

Applied Energy, Vol. 157, pp. 838-850, 2015.

(cited on p. 181)

Assanis D.N., Wiese K., Schwarz E. and Bryzik W.

The Effects of Ceramic Coatings on Diesel Engine Performance and Exhaust Emissions. SAE Technical Paper, $\mathrm{n}^{\circ}$ 910460, 1991.

(cited on p. 136) 
Babajimopoulos A., Assanis D.N., Flowers D.L., Aceves S.M. and Hessel R.P. A fully coupled computational fluid dynamics and multi-zone model with detailed chemical kinetics for the simulation of premixed charge compression ignition engines.

International Journal of Engine Research, Vol. 6 n ${ }^{\circ}$ 5, pp. 497-512, 2005.

(cited on p. 92)

Bakenhus M. and Reitz R.D.

Two-Color Combustion Visualization of Single and Split Injections in a Single-Cylinder Heavy-Duty D.I. Diesel Engine Using an Endoscope-Based Imaging System.

SAE Technical Paper, $\mathrm{n}^{\circ}$ 1999-01-1112, 1999.

(cited on p. 9)

Balki M.K., Sayin C. and Canakci M.

The effect of different alcohol fuels on the performance, emission and combustion characteristics of a gasoline engine.

Fuel, Vol. 115, pp. 901-906, 2014.

(cited on p. 179)

Bartley G.J.

Identifying Limiters to Low Temperature Catalyst Activity.

SAE Technical Paper, $\mathrm{n}^{\circ}$ 2015-01-1025, 2015.

(cited on pp. 25, 241)

\section{Belarte E.}

Estudio del proceso de combustión premezclada controlada por la reactividad del combustible en un motor de encendido por compresión.

Doctoral Thesis, Universitat Politècnica de València, Departamento de Máquinas y Motores Térmicos, 2015.

(cited on pp. 46, 105, 106)

Benajes J., García A., Domenech V. and Durrett R.

An investigation of partially premixed compression ignition combustion using gasoline and spark assistance.

Applied Thermal Engineering, Vol. 52 n ${ }^{\circ}$ 2, pp. 468-477, 2013.

(cited on p. 34)

Benajes J., García A., Monsalve-Serrano J., Balloul I. and Pradel G.

Operational limits assessment of RCCI combustion in a high compression ratio medium-duty diesel engine using near-term available biofuels.

THIESEL Conference on Thermo- and Fluid Dynamic Processes in Direct Injection Engines, 2016.

(cited on pp. 247, 249)

Benajes J., López J.J. and R. Novella A. García.

Advanced methodology for improving testing efficiency in a single-cylinder research diesel engine.

Experimental Techniques, Vol. $32 \mathrm{n}^{\circ}$ 6, pp. 41-47, 2008.

(cited on pp. 83, 84)

Benajes J., Molina S., García A., Monsalve-Serrano J. and Durrett R.

Performance and engine-out emissions evaluation of the double injection strategy applied to the gasoline partially premixed compression ignition spark assisted combustion concept.

Applied Energy, Vol. 134, pp. 90-101, 2014.

(cited on p. 34)

Benajes J., Molina S., Novella R. and Amorim R.

Study on Low Temperature Combustion for Light-Duty Diesel Engines.

Energy $\&$ Fuels, Vol. $24 \mathrm{n}^{\circ}$ 1, pp. 355-364, 2010

(cited on p. 194)

Benajes J., Molina S., Novella R. and Belarte E.

Evaluation of massive exhaust gas recirculation and Miller cycle strategies for mixingcontrolled low temperature combustion in a heavy duty diesel engine.

Energy, Vol. 71, pp. 355-366, 2014.

(cited on p. 23) 
Bessonette P.W., Schleyer C.H., Duffy K.P., Hardy W.L. and Liechty M.P. Effects of Fuel Property Changes on Heavy-Duty HCCI Combustion. SAE Technical Paper, $\mathrm{n}^{\circ}$ 2007-01-0191, 2007.

(cited on pp. 35, 37)

Bittle J.A., Knight B.M. and Jacobs T.J.

Heat Release Parameters to Assess Low Temperature Combustion Attainment.

SAE Technical Paper, $\mathrm{n}^{\circ}$ 2011-01-1350, 2011.

(cited on p. 10)

Blasio G. Di, Beatrice C. and Molina S.

Effect of Port Injected Ethanol on Combustion Characteristics in a Dual-Fuel Light Duty Diesel Engine.

SAE Technical Paper, $\mathrm{n}^{\circ}$ 2013-01-1692, 2013.

(cited on p. 181)

Borgqvist P., Tunestål P. and Johansson B.

Investigation and Comparison of Residual Gas Enhanced HCCI using Trapping (NVO HCCI) or Rebreathing of Residual Gases.

SAE Technical Paper, $\mathrm{n}^{\circ}$ 2011-01-1772, 2011.

(cited on p. 33)

Borgqvist P., Tunestål P. and Johansson B.

Gasoline Partially Premixed Combustion in a Light Duty Engine at Low Load and Idle Operating Conditions.

SAE Technical Paper, ${ }^{\circ}$ 2012-01-0687, 2012.

(cited on p. 33)

Borgqvist P., Tunestål P. and Johansson B.

Comparison of Negative Valve Overlap (NVO) and Rebreathing Valve Strategies on a Gasoline PPC Engine at Low Load and Idle Operating Conditions.

SAE Int. J. Engines, Vol. 6 n $^{\circ}$ 2013-01-0902, pp. 366-378, $2013 . \quad$ (cited on p. 33)

Brijesh P., Chowdhury A. and Sreedhara S.

Effect of Ultra-Cooled EGR and Retarded Injection Timing on Low Temperature Combustion in CI Engines.

SAE Technical Paper, $\mathrm{n}^{\circ}$ 2013-01-0321, 2013.

(cited on p. 10)

Bruns L., Bryzik W. and Kamo R.

Performance Assessment of US. Army Truck with Adiabatic Diesel Engine.

SAE Technical Paper, $\mathrm{n}^{\circ}$ 890142, 1989.

(cited on p. 136)

\section{Caton J.A.}

Thermodynamic Advantages of Low Temperature Combustion (LTC) Engines Using Low Heat Rejection (LHR) Concepts.

SAE Technical Paper, $\mathrm{n}^{\circ}$ 2011-01-0312, 2011.

(cited on p. 10)

\section{Celik M.B.}

Experimental determination of suitable ethanol-gasoline blend rate at high compression ratio for gasoline engine.

Applied Thermal Engineering, Vol. 28 n ${ }^{\circ}$ 5-6, pp. 396-404, $2008 . \quad$ (cited on p. 179)

Cengel Y. and Boles M.

Thermodynamics: An Engineering Approach Sixth Edition (SI Units).

McGraw-Hill, 2007.

(cited on p. 130)

Chang K., Babajimopoulos A., Lavoie G.A., Filipi Z. and Assanis D.N.

Analysis of Load and Speed Transitions in an HCCI Engine Using 1-D Cycle Simulation and Thermal Networks.

SAE Technical Paper, $\mathrm{n}^{\circ}$ 2006-01-1087, 2006.

(cited on p. 33) 
Chen R-H., Chiang L-B., Chen C-N. and Lin T-H.

Cold-start emissions of an SI engine using ethanol-gasoline blended fuel.

Applied Thermal Engineering, Vol. 31 n 8-9, pp. 1463-1467, 2011.

(cited on p. 179)

Cheng A.S. (Ed), Upatnieks A. and Mueller C.J.

Investigation of Fuel Effects on Dilute, Mixing-Controlled Combustion in an Optical DirectInjection Diesel Engine.

Energy \& Fuels, Vol. 21 n 4 , pp. 1989-2002, 2007.

(cited on pp. 122, 168, 214)

Cheng W.K., Wong V.W. and Gao F.

Heat Transfer Measurement Comparisons in Insulated and Non-Insulated Diesel Engines. SAE Technical Paper, $\mathrm{n}^{\circ}$ 890570, 1989.

(cited on p. 136)

Christensen M., Hultqvist A. and Johansson B.

Demonstrating the Multi Fuel Capability of a Homogeneous Charge Compression Ignition Engine with Variable Compression Ratio.

SAE Technical Paper, $\mathrm{n}^{\circ}$ 1999-01-3679, 1999.

(cited on p. 26)

Christian R., Knopf F., Jasmek A. and Schindler W.

A new method for the filter smoke number measurement with improved sensitivity.

MTZ Motortechnische Zeitschift, Vol. 54, pp. 16-22, 1993.

(cited on p. 82)

Curran S., Hanson R. and Wagner R.

Effect of E85 on RCCI Performance and Emissions on a Multi-Cylinder Light-Duty Diesel Engine.

SAE Technical Paper, $\mathrm{n}^{\circ}$ 2012-01-0376, 2012.

(cited on pp. 51, 181)

Curran S., Hanson R., Wagner R. and Reitz R.D.

Efficiency and Emissions Mapping of RCCI in a Light-Duty Diesel Engine.

SAE Technical Paper, $\mathrm{n}^{\circ}$ 2013-01-0289, 2013.

(cited on p. 182)

Curran S., Prikhodko V., Cho K., Sluder C.S., Parks J., Wagner R., Kokjohn S. and Reitz R.D.

In-Cylinder Fuel Blending of Gasoline/Diesel for Improved Efficiency and Lowest Possible Emissions on a Multi-Cylinder Light-Duty Diesel Engine.

SAE Technical Paper, $\mathrm{n}^{\circ}$ 2010-01-2206, 2010.

(cited on p. 109)

Dargay J. and Gately D.

Income's effect on car and vehicle ownership, worldwide: 1960-2015.

Transportation Research Part A: Policy and Practice, Vol. $33 \mathrm{n}^{\circ}$ 2, pp. 101-138, 1999.

(cited on p. 2)

de Rudder $\mathbf{K}$.

An approach to low-temperature combustion in a small HSDI diesel engine.

Doctoral Thesis, Universitat Politècnica de València, Departamento de Máquinas y Motores

Térmicos, 2007.

(cited on p. 76)

Dec J.E.

A Conceptual Model of DI Diesel Combustion Based on Laser-Sheet Imaging*.

SAE Technical Paper, $\mathrm{n}^{\circ}$ 970873, 1997.

(cited on pp. 19, 20, 23)

Dec J.E. and Sjöberg M.

Isolating the Effects of Fuel Chemistry on Combustion Phasing in an HCCI Engine and the Potential of Fuel Stratification for Ignition Control.

SAE Technical Paper, $\mathrm{n}^{\circ}$ 2004-01-0557, 2004.

(cited on p. 27) 
Dec J.E. and Yang Y.

Boosted HCCI for High Power without Engine Knock and with Ultra-Low NOx Emissions using Conventional Gasoline.

SAE Int. J. Engines, Vol. 3, pp. 750-767, 2010.

(cited on pp. 49, 104, 196)

Degobert P.

Automobiles and pollution.

SAE International, 1995.

(cited on p. 80)

\section{Degraeuwe B.}

Contribution to the thermal management of DI Diesel engines.

Doctoral Thesis, Universitat Politècnica de València, Departamento de Máquinas y Motores

Térmicos, 2007.

(cited on p. 86)

Dempsey A.B., Curran S. and Reitz R.D.

Characterization of Reactivity Controlled Compression Ignition (RCCI) Using Premixed Gasoline and Direct-Injected Gasoline with a Cetane Improver on a Multi-Cylinder Engine. SAE International Journal of Engines, Vol. 8 n $^{\circ}$ 2, pp. 859-877, 2015. $\quad$ (cited on p. 49)

Dempsey A.B., Walker N.R. and Reitz R.D.

Effect of Cetane Improvers on Gasoline, Ethanol, and Methanol Reactivity and the Implications for RCCI Combustion.

SAE International Journal of Fuels and Lubricants, Vol. $6 \mathrm{n}^{\circ}$ 1, pp. 170-187, 2013.

(cited on pp. 47, 48)

Desantes J.M., J. Arrègle J.J., López and García A.

A Comprehensive Study of Diesel Combustion and Emissions with Post-injection.

SAE Technical Paper, ${ }^{\circ}$ 2007-01-0915, 2007.

(cited on p. 9)

Desantes J.M., Payri R., García A. and Monsalve-Serrano J.

Evaluation of Emissions and Performances from Partially Premixed Compression Ignition Combustion using Gasoline and Spark Assistance.

SAE Technical Paper, $\mathrm{n}^{\circ}$ 2013-01-1664, 2013.

(cited on p. 34)

Dickey D.W.

The Effect of Insulated Combustion Chamber Surfaces on Direct-Injected Diesel Engine Performance, Emissions and Combustion.

SAE Technical Paper, $\mathrm{n}^{\circ}$ 890292, 1989.

(cited on p. 136)

Dolak J.G., Shi Y. and Reitz R.D.

A Computational Investigation of Stepped-Bowl Piston Geometry for a Light Duty Engine Operating at Low Load.

SAE Technical Paper, $\mathrm{n}^{\circ}$ 2010-01-1263, $2010 . \quad$ (cited on pp. 139, 140)

Dronniou N., Lejeune M., Balloul I. and Higelin P.

Combination of High EGR Rates and Multiple Injection Strategies to Reduce Pollutant Emissions.

SAE Technical Paper, $\mathrm{n}^{\circ}$ 2005-01-3726, 2005.

(cited on p. 9)

Dukowicz J.K.

A particle-fluid numerical model for liquid sprays.

Journal of Computational Physics, Vol. $35 \mathrm{n}^{\circ}$ 2, pp. 229-253, $1980 . \quad$ (cited on p. 91)

Engineer Commercial Vehicle.

Euro 6 the inside story.

Technical report, March 2012. (cited on p. 5) 
Environmental European Agency.

Emissions of primary PM2.5 and PM10 particulate matter.

Technical report. (cited on p. 3)

Environmental Protection Agency.

Nitrogen Oxides (NOx), Why and How They Are Controlled.

Technical report, 1999. (cited on p. 3)

European Automobile Manufacturers' Association.

The Automobile Industry Pocket Guide 2014-2015.

Technical report. (cited on p. 3)

European Commission.

Strategy for reducing Heavy-Duty Vehicles' fuel consumption and $\mathrm{CO}_{2}$ emissions.

Technical report, 2014. (cited on p. 4)

Foong T.M., Morganti K.J., Brear M.J., da Silva G., Yang Y. and Dryer F.L. The Effect of Charge Cooling on the RON of Ethanol/Gasoline Blends.

SAE Int. J. Fuels Lubr., Vol. 6 n 2013-01-0886, pp. 34-43, 2013.

(cited on p. 192)

Fraioli V., Mancaruso E., Migliaccio M. and Vaglieco B.

Ethanol effect as premixed fuel in dual-fuel CI engines: Experimental and numerical investigations.

Applied Energy, Vol. 119, pp. 394-404, $2014 . \quad$ (cited on p. 181)

French C.C.J.

Ceramics in Reciprocating Internal Combustion Engines.

SAE Technical Paper, $\mathrm{n}^{\circ}$ 841135, 1984.

(cited on p. 136)

Ganesh D. and Nagarajan G.

Homogeneous charge compression ignition (HCCI) combustion of diesel fuel with external mixture formation.

Energy, Vol. 35 n $^{o}$ 1, pp. 148-157, 2010.

(cited on p. 25)

Ganesh D., Nagarajan G. and Mohamed Ibrahim M.

Study of performance, combustion and emission characteristics of diesel homogeneous charge compression ignition (HCCI) combustion with external mixture formation.

Fuel, Vol. $87 \mathrm{n}^{\circ} 17-18$, pp. 3497-3503, 2008.

(cited on pp. 25, 26)

Gense N.L.J., Riemersma, Such C. and Ntziachristos L.

Euro VI technologies and costs for Heavy Duty vehicles.

Technical report, Delft: TNO Science and Industry report 06.OR.PT.023.2/NG, 2006. p. 56. (cited on p. 8)

Gerdes K.R. and Suppes G.J.

Miscibility of Ethanol in Diesel Fuels.

Industrial ES Engineering Chemistry Research, Vol. 40 n 3, pp. 949-956, 2001.

(cited on p. 180)

Giakoumis E.G.

Cylinder wall insulation effects on the first- and second-law balances of a turbocharged diesel engine operating under transient load conditions.

Energy Conversion and Management, Vol. $48 \mathrm{n}^{\circ}$ 11, pp. 2925-2933, 2007. 
Gnanam G., Sobiesiak A., Reader G. and Zhang C.

An HCCI Engine Fuelled with Iso-octane and Ethanol.

SAE Technical Paper, $\mathrm{n}^{\circ}$ 2006-01-3246, 2006.

(cited on p. 181)

Gnanamoorthi V. and Devaradjane G.

Effect of compression ratio on the performance, combustion and emission of DI diesel engine fueled with ethanol-Diesel blend.

Journal of the Energy Institute, Vol. $88 \mathrm{n}^{\circ}$ 1, pp. 19-26, 2015. ～(cited on p. 180)

Gong J. and Rutland C.J.

Pulsed Regeneration for DPF Aftertreatment Devices.

SAE Technical Paper, $\mathrm{n}^{\circ}$ 2011-24-0182, 2011.

(cited on p. 256)

Guezennec Y., Midlam-Mohler S. and Rizzoni G.

A mixed mode HCCI/DI engine based on a novel heavy fuel atomizer.

Proceedings of $8^{\text {th }}$ diesel engine emission reduction conference, 2002, San Diego, USA.

(cited on p. 26)

Han Z. and Reitz R.D.

Turbulence Modeling of Internal Combustion Engines Using RNG $k-\epsilon$ Models.

Combustion Science and Technology, Vol. $106 \mathrm{n}^{\circ}$ 4-6, pp. 267-295, 1995. (cited on p. 92)

Han Z. and Reitz R.D.

A temperature wall function formulation for variable-density turbulent flows with application to engine convective heat transfer modeling.

International Journal of Heat and Mass Transfer, Vol. 40 n $^{\circ}$ 3, pp. 613-625, 1997.

(cited on p. 92)

Hanson R., Curran S., Wagner R., Kokjohn S., Splitter D. and Reitz R.D.

Piston Bowl Optimization for RCCI Combustion in a Light-Duty Multi-Cylinder Engine.

SAE International Journal of Engines, Vol. $5 \mathrm{n}^{\circ}$ 2, pp. 286-299, 2012. $\quad$ (cited on p. 143)

Hanson R., Kokjohn S., Splitter D. and Reitz R.D.

An Experimental Investigation of Fuel Reactivity Controlled PCCI Combustion in a HeavyDuty Engine.

SAE Int. J. Engines, Vol. 3, pp. 700-716, 2010.

(cited on pp. 48, 107)

Hanson R., Kokjohn S., Splitter D. and Reitz R.D.

Fuel Effects on Reactivity Controlled Compression Ignition (RCCI) Combustion at Low Load.

SAE International Journal of Engines, Vol. $4 \mathrm{n}^{\circ}$ 1, pp. 394-411, 2011.

(cited on pp. 48, 104)

Hasegawa R. and Yanagihara $\mathbf{H}$.

HCCI Combustion in DI Diesel Engine.

SAE Technical Paper, $\mathrm{n}^{\circ}$ 2003-01-0745, $2003 . \quad$ (cited on p. 30)

Hashimoto $\mathrm{K}$.

Inhibition Effect of Ethanol on Homogeneous Charge Compression Ignition of Heptane. SAE Technical Paper, $\mathrm{n}^{\circ}$ 2008-01-2504, 2008.

(cited on p. 194)

Hashizume T., Miyamoto T., Hisashi A. and Tsujimura K.

Combustion and Emission Characteristics of Multiple Stage Diesel Combustion.

SAE Technical Paper, $\mathrm{n}^{\circ}$ 980505, 1998.

(cited on p. 29) 
Havstad P.H., Garwin I.J. and Wade W.R.

A Ceramic Insert Uncooled Diesel Engine.

SAE Technical Paper, $\mathrm{n}^{\circ}$ 860447, 1986.

(cited on p. 136)

Heywood J.B.

Internal Combustion Engine Fundamentals.

McGraw-Hill, Inc., p.674, 1988.

(cited on p. 139)

Higgins B., Siebers D., Mueller C. and Aradi A.

Effects of an ignition-enhancing, diesel-fuel additive on diesel-spray evaporation, mixing, ignition, and combustion.

Symposium (International) on Combustion, Vol. 27 n ${ }^{\circ}$ 2, pp. 1873-1880, 1998.

(cited on p. 47)

Hoffman M.A.

Characterization of combustion chamber deposits formed during homogeneous charge compression ignition and the impact of a thermal barrier coating on deposit accumulation and HCCI operability.

Doctoral Thesis, The University of Michigan, 2012.

(cited on p. 138)

Hoffman M.A., Lawler B.J., Güralp O.A., Najt P.M. and Filipi Z.S.

The impact of a magnesium zirconate thermal barrier coating on homogeneous charge compression ignition operational variability and the formation of combustion chamber deposits.

International Journal of Engine Research, Vol. 16 nº 8, pp. 968-981, 2015.

(cited on p. 138)

Huang Y., Hong G., Cheng X. and Huang R.

Investigation to Charge Cooling Effect of Evaporation of Ethanol Fuel Directly Injected in a Gasoline Port Injection Engine.

SAE Technical Paper, $\mathrm{n}^{\circ}$ 2013-01-2610, 2013.

(cited on p. 192)

Idicheria C.A. and Pickett L.M.

Soot Formation in Diesel Combustion under High-EGR Conditions.

SAE Technical Paper, ${ }^{\circ}$ 2005-01-3834, 2005.

(cited on p. 8)

Inagaki K., Fuyuto T., Nishikawa K., Nakakita K. and Sakata I.

Dual-Fuel PCI Combustion Controlled by In-Cylinder Stratification of Ignitability.

SAE Technical Paper, $\mathrm{n}^{\circ}$ 2006-01-0028, $2006 . \quad$ (cited on pp. 36, 37, 38, 39, 40)

Iorio S. Di, Mancaruso E. and Vaglieco B.M.

Characterization of Soot Particles Produced in a Transparent Research CR DI Diesel Engine Operating with Conventional and Advanced Combustion Strategies.

Aerosol Science and Technology, Vol. $46 \mathrm{n}^{\circ}$ 3, pp. 272-286, $2012 . \quad$ (cited on p. 24)

Issa R.I., Ahmadi-Befrui B., Beshay K.R. and Gosman A.D.

Solution of the implicitly discretised reacting flow equations by operator-splitting.

Journal of Computational Physics, Vol. $93 \mathrm{n}^{\circ}$ 2, pp. 388-410, $1991 . \quad$ (cited on p. 89)

Iwabuchi Y., Kawai K., Shoji T. and Takeda Y.

Trial of New Concept Diesel Combustion System - Premixed Compression-Ignited Combustion.

SAE Technical Paper, $\mathrm{n}^{\circ}$ 1999-01-0185, 1999.

(cited on p. 28)

Jaichandar S. and Tamilporai P.

Low Heat Rejection Engines - An Overview.

SAE Technical Paper, $\mathrm{n}^{\circ}$ 2003-01-0405, 2003.

(cited on p. 136) 
Johnson T.V.

Review of $\mathrm{CO}_{2}$ Emissions and Technologies in the Road Transportation Sector.

SAE Int. J. Engines, Vol. 3, pp. 1079-1098, 2010.

(cited on p. 5)

Johnson T.V.

Diesel Emissions in Review.

SAE International Journal of Engines, Vol. $4 \mathrm{n}^{\circ}$ 1, pp. 143-157, 2011. (cited on p. 252)

Johnson T.V.

Vehicular Emissions in Review.

SAE Int. J. Engines, Vol. 5, pp. 216-234, 2012.

(cited on p. 8)

Johnson T.V.

Vehicular Emissions in Review.

SAE Int. J. Engines, Vol. 7, pp. 1207-1227, 2014.

(cited on p. 5)

Jung Y., Qi D. and Bae C.

Assessment of Soot Particles in an Exhaust Gas for Low Temperature Diesel Combustion with High EGR in a Heavy Duty Compression Ignition Engine.

SAE Technical Paper, $\mathrm{n}^{\circ}$ 2013-01-2572, 2013.

(cited on p. 10)

Kalghatgi G.T., Risberg P. and Ångström H-E.

Advantages of Fuels with High Resistance to Auto-ignition in Late-injection, Lowtemperature, Compression Ignition Combustion.

SAE Technical Paper, $\mathrm{n}^{\circ}$ 2006-01-3385, 2006.

(cited on pp. 31, 180)

Kalghatgi G.T., Risberg P. and Ångström H-E.

Partially Pre-Mixed Auto-Ignition of Gasoline to Attain Low Smoke and Low NOx at High Load in a Compression Ignition Engine and Comparison with a Diesel Fuel.

SAE Technical Paper, $\mathrm{n}^{\circ}$ 2007-01-0006, 2007.

(cited on pp. 31, 180)

Kamimoto T. and Bae M.

High Combustion Temperature for the Reduction of Particulate in Diesel Engines.

SAE Technical Paper, $\mathrm{n}^{\circ}$ 880423, 1988.

(cited on pp. 19, 21)

Kamo R. and Bryzik W.

Adiabatic Turbocompound Engine Performance Prediction.

SAE Technical Paper, $\mathrm{n}^{\circ}$ 780068, 1978.

(cited on p. 136)

Kamo R. and Bryzik W.

Cummins/TACOM Advanced Adiabatic Engine.

SAE Technical Paper, $\mathrm{n}^{\circ}$ 840428, 1984.

(cited on p. 136)

Kampman B., Verbeek R., van Grinsven A., van Mensch P., Croezen H. and Patuleia A.

Bringing biofuels on the market: options to increase EU biofuels volumes beyond the current blending limits.

In CE Delft, 2013.

(cited on p. 178)

Kastner L.J.

An investigation of the airbox method of measuring the air consumption of internal combustion engines.

Proceedings of the Institution of Mechanical Engineers, Vol. $157 \mathrm{n}^{\circ}$ 1, pp. 387-404, 1947.

(cited on p. 74) 
Kimura S., Aoki O., Kitahara Y. and Aiyoshizawa E.

Ultra-Clean Combustion Technology Combining a Low-Temperature and Premixed Combustion Concept for Meeting Future Emission Standards.

SAE Technical Paper, $\mathrm{n}^{\circ}$ 2001-01-0200, 2001.

(cited on p. 30)

Kimura S., Aoki O., Ogawa H., Muranaka S. and Enomoto Y.

New Combustion Concept for Ultra-Clean and High-Efficiency Small DI Diesel Engines.

SAE Technical Paper, $\mathrm{n}^{\circ}$ 1999-01-3681, 1999.

(cited on p. 30)

Klos D., Janecek D. and Kokjohn S.

Investigation of the Combustion Instability-NOx Tradeoff in a Dual Fuel Reactivity Controlled Compression Ignition (RCCI) Engine.

SAE International Journal of Engines, Vol. $8 \mathrm{n}^{\circ}$ 2, pp. 821-830, 2015. $\quad$ (cited on p. 245)

Kokjohn S., Hanson R., Splitter D. and Reitz R.D.

Experiments and Modeling of Dual-Fuel HCCI and PCCI Combustion Using In-Cylinder Fuel Blending.

SAE Int. J. Engines, Vol. 2, pp. 24-39, $2009 . \quad$ (cited on pp. 38, 39, 40, 47, 90, 92)

Kokjohn S., Hanson R., Splitter D. and Reitz R.D.

Fuel reactivity controlled compression ignition (RCCI): a pathway to controlled highefficiency clean combustion.

International Journal of Engine Research, Vol. 12 n 3, pp. 209-226, 2011.

(cited on pp. 35, 90, 92, 104, 107, 131, 183, 230, 232)

Kokjohn S., Musculus M. and Reitz R.D.

Evaluating temperature and fuel stratification for heat-release rate control in a reactivitycontrolled compression-ignition engine using optical diagnostics and chemical kinetics modeling.

Combustion and Flame, Vol. $162 \mathrm{n}^{\circ}$ 6, pp. 2729-2742, 2015.

(cited on pp. 104, 195)

Kokjohn S., Reitz R.D., Splitter D. and Musculus M.

Investigation of Fuel Reactivity Stratification for Controlling PCI Heat-Release Rates Using High-Speed Chemiluminescence Imaging and Fuel Tracer Fluorescence.

SAE Int. J. Engines, Vol. 5, pp. 248-269, 2012.

(cited on p. 195)

Kokjohn S.L. and Reitz R.D.

A modeling study of charge preparation in an HCCI engine using a variable pressure pulse (VPP) injection system and optimized PRF Blends.

The $11^{\text {th }}$ International Conference on Liquid Atomization and Spray Systems, Vail, Colorado, July $30^{\text {th }}, 2009$.

(cited on p. 107)

Kolodziej C., Ciatti S., Vuilleumier D., Adhikary B. Das and Reitz R.D.

Extension of the Lower Load Limit of Gasoline Compression Ignition with 87 AKI Gasoline by Injection Timing and Pressure.

SAE Technical Paper, $\mathrm{n}^{\circ}$ 2014-01-1302, 2014.

(cited on p. 33)

Kolodziej C., Kodavasal J., Ciatti S., Som S., Shidore N. and Delhom J.

Achieving Stable Engine Operation of Gasoline Compression Ignition Using 87 AKI Gasoline Down to Idle.

SAE Technical Paper, $\mathrm{n}^{\circ}$ 2015-01-0832, 2015.

(cited on p. 33)

Kondo M., Kimura S., Hirano I., Uraki Y. and Maeda R.

Development of noise reduction technologies for a small direct-injection diesel engine.

Society of automotive engineers of Japan, Vol. 21, Page 327-333, 2000. （cited on p. 31) 
Kono M., Basaki M., Ito M., Hashizume T., Ishiyama S. and Inagaki K. Cooling Loss Reduction of Highly Dispersed Spray Combustion with Restricted In-Cylinder Swirl and Squish Flow in Diesel Engine.

SAE Int. J. Engines, Vol. 5, pp. 504-515, $2012 . \quad$ (cited on pp. 139, 140, 141)

Koopmans L. and Denbratt I.

A Four Stroke Camless Engine, Operated in Homogeneous Charge Compression Ignition Mode with Commercial Gasoline.

$\mathrm{n}^{o}$ 2001-01-3610, 2001. (cited on p. 33)

Kosaka H., Wakisaka Y., Nomura Y., Hotta Y., Koike M., Nakakita K. and Kawaguchi A.

Concept of "Temperature Swing Heat Insulation" in Combustion Chamber Walls, and Appropriate Thermo-Physical Properties for Heat Insulation Coat.

SAE Int. J. Engines, Vol. 6, pp. 142-149, 2013.

(cited on p. 138)

Kumar C., Athawe M., Aghav Y.V., Babu M.K. Gajendra and Das L.M.

Effects of Ethanol Addition on Performance, Emission and Combustion of DI Diesel Engine Running at Different Injection Pressures.

SAE Technical Paper, $\mathrm{n}^{\circ}$ 2007-01-0626, 2007.

(cited on p. 180)

Ladommatos N., Abdelhalim S. and Zhao H.

The effects of exhaust gas recirculation on diesel combustion and emissions.

International Journal of Engine Research, Vol. $1 \mathrm{n}^{\circ}$ 1, pp. 107-126, 2000. $\quad$ (cited on p. 8)

Lapuerta M., Armas O. and Hernández J.J.

Diagnosis of DI Diesel combustion from in-cylinder pressure signal by estimation of mean thermodynamic properties of the gas.

Applied Thermal Engineering, Vol. 19 n $^{\circ}$ 5, pp. 513-529, 1999. $\quad$ (cited on pp. 85, 86)

Lapuerta M., Ballesteros R. and Agudelo J.R.

Effect of the gas state equation on the thermodynamic diagnostic of diesel combustion. Applied Thermal Engineering, Vol. 26 n $^{\circ}$ 14-15, pp. 1492-1499, $2006 . \quad$ (cited on p. 86)

Lee J., Lee S., Kim J. and Kim D.

Bowl Shape Design Optimization for Engine-Out PM Reduction in Heavy Duty Diesel Engine.

$\mathrm{n}^{\circ}$ 2015-01-0789, 2015. (cited on p. 9)

Leermakers C.A., Somers L.M. and Johansson B.

Combustion Phasing Controllability with Dual Fuel Injection Timings.

SAE Technical Paper, $\mathrm{n}^{\circ}$ 2012-01-1575, 2012.

(cited on p. 109)

Lei J., Bi Y. and Shen L.

Performance and Emission Characteristics of Diesel Engine Fueled with Ethanol-Diesel Blends in Different Altitude Regions.

BioMed Research International, Vol. 2011, pp. 417-421, 2010. ～(cited on p. 180)

Li T. and Ogawa $\mathbf{H}$.

Analysis of the Trade-off between Soot and Nitrogen Oxides in Diesel-Like Combustion by Chemical Kinetic Calculation.

SAE Int. J. Engines, Vol. 5, pp. 94-101, 2011.

(cited on p. 20)

Liu H., Zheng Z., Yao M., Zhang P., Zheng Z., He B. and Qi Y.

Influence of temperature and mixture stratification on HCCI combustion using chemiluminescence images and CFD analysis.

Applied Thermal Engineering, Vol. 33-34, pp. 135-143, 2012.

(cited on p. 26) 
Lombard B. and Le Forrestier R.

Advanced combustion and engine integration of a Hydraulic Valve Actuation system (camless).

Proceedings of the SIA Conference on Variable Valve Actuation, 2006. $\quad$ (cited on p.68)

Ma S., Zheng Z., Liu H., Zhang Q. and M.Yao.

Experimental investigation of the effects of diesel injection strategy on gasoline/diesel dualfuel combustion.

Applied Energy, Vol. 109, pp. 202-212, $2013 . \quad$ (cited on pp. 43, 44, 45, 105)

Machrafi H. and Cavadiasa S.

An experimental and numerical analysis of the influence of the inlet temperature, equivalence ratio and compression ratio on the HCCI auto-ignition process of Primary Reference Fuels in an engine.

Fuel Processing Technology, Vol. 89 n $^{o}$ 11, pp. 1218-1226, 2008.

(cited on p. 26)

Mancaruso E. and Vaglieco B.M.

UV - Visible imaging of PCCI engine running with ethanol/diesel fuel.

SAE Technical Paper, $\mathrm{n}^{\circ}$ 2012-01-1238, 2012.

(cited on p. 180)

Mancaruso E. and Vaglieco B.M.

Characterization of PCCI combustion in a single cylinder CI engine fuelled with RME and bio-ethanol.

SAE Technical Paper, $\mathrm{n}^{\circ}$ 2013-01-1672, 2013.

(cited on p. 180)

Mancaruso E. and Vaglieco B.M.

Spectroscopic analysis of the phases of premixed combustion in a compression ignition engine fuelled with diesel and ethanol.

Applied Energy, Vol. 143, pp. 164-175, 2015.

(cited on p. 180)

Manente V., Zander C-G., Johansson B., Tunestål P. and Cannella W.

An Advanced Internal Combustion Engine Concept for Low Emissions and High Efficiency from Idle to Max Load Using Gasoline Partially Premixed Combustion.

SAE Technical Paper, $\mathrm{n}^{\circ}$ 2010-01-2198, 2010.

(cited on p. 32)

Maritati M.

EURO VI Technologies and Strategies.

Technical report, IVECO Body Builders. (cited on p. 5)

\section{Martín J.}

Aportación al diagnóstico de la combustión en motores Diesel de inyección directa.

Doctoral Thesis, Universitat Politècnica de València, Departamento de Máquinas y Motores Térmicos, 2007.

(cited on p. 87)

Mehl M., Pitz W., Sarathy M., Yang Y. and Dec J.E.

Detailed Kinetic Modeling of Conventional Gasoline at Highly Boosted Conditions and the Associated Intermediate Temperature Heat Release.

SAE Technical Paper, $\mathrm{n}^{\circ}$ 2012-01-1109, 2012.

(cited on p. 50)

Midlam-Mohler S., Guezennec Y. and Rizzoni G.

Mixed-mode diesel HCCI with external mixture formation.

Deer 2003 Newport, August 26 ${ }^{\text {th }}, 2003$.

(cited on p. 26)

Millam D.

Final Report for Caterpillar/DOE Heavy Truck Clean Diesel Cooperative Research 
Program.

Technical report, Heavy Truck Engine Program, March $31^{\text {st }}, 2007 . \quad$ (cited on p. 41)

Miyairi Y.

Computer Simulation of an LHR DI Diesel Engine.

SAE Technical Paper, $\mathrm{n}^{\circ}$ 880187, 1988.

(cited on p. 136)

\section{Molina S.}

Estudio de la influencia de los parámetros de inyección y la recirculación de gases de escape sobre el proceso de combustión, las prestaciones y las emisiones de un motor diesel de 1.8 litros de cilindrada.

Doctoral Thesis, Universitat Politècnica de València, Departamento de Máquinas y Motores

Térmicos, $2003 . \quad$ (cited on pp. 80, 83)

Molina S., Desantes J.M., García A. and Pastor J.M.

A Numerical Investigation on Combustion Characteristics with the use of Post Injection in DI Diesel Engines.

SAE Technical Paper, $\mathrm{n}^{\circ}$ 2010-01-1260, $2010 . \quad$ (cited on p.9)

Mueller C.J. and Upatnieks A.

Dilute clean diesel combustion achieves low emissions and high efficiency while avoiding control problems of HCCI.

Proceedings of $11^{\text {th }}$ diesel engine emission reduction conference, 2005, Chicago, USA.

(cited on p. 24)

Murcak A., Haşimoğlu C., Çevik İ. and H. Kahraman Hüseyin.

Effect of injection timing to performance of a diesel engine fuelled with different dieselethanol mixtures.

Fuel, Vol. 153, pp. 569-577, 2015.

(cited on p. 180)

\section{Musculus M.}

Multiple Simultaneous Optical Diagnostic Imaging of Early-Injection Low-Temperature Combustion in a Heavy-Duty Diesel Engine.

SAE Technical Paper, $\mathrm{n}^{\circ}$ 2006-01-0079, 2006.

(cited on pp. 22, 23)

Neely G.D., Sasaki S., Huang Y., Leet J.A. and Stewart D.W.

New Diesel Emission Control Strategy to Meet US Tier 2 Emissions Regulations.

SAE Technical Paper, $\mathrm{n}^{\circ}$ 2005-01-1091, 2005.

(cited on pp. 20, 21)

Nishijima Y., Asaumi Y. and Aoyagi Y.

Impingement Spray System with Direct Water Injection for Premixed Lean Diesel Combustion Control.

SAE Technical Paper, $\mathrm{n}^{\circ}$ 2002-01-0109, 2002.

(cited on p. 28)

\section{Novella R.}

Estudio de la influencia de los ciclos Atkinson y Miller sobre el proceso de combustión y la formación de emisiones contaminantes en un motor Diesel.

Doctoral Thesis, Universitat Politècnica de València, Departamento de Máquinas y Motores Térmicos, 2009.

(cited on pp. $76,83,84$ )

O'Connor J. and Musculus M.

Post Injections for Soot Reduction in Diesel Engines: A Review of Current Understanding.

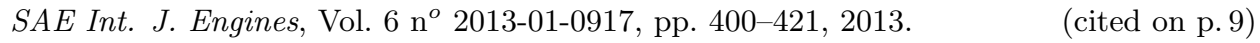


O'Connor J. and Musculus M.

In-Cylinder Mechanisms of Soot Reduction by Close-Coupled Post-Injections as Revealed by Imaging of Soot Luminosity and Planar Laser-Induced Soot Incandescence in a Heavy-Duty Diesel Engine.

SAE Int. J. Engines, Vol. 7, pp. 673-693, 2014.

(cited on p. 9)

O'Connor J. and Musculus M.

Optical Investigation of Multiple Injections for Unburned Hydrocarbon Emissions Reduction with Low-Temperature Combustion in a Heavy-Duty Diesel Engine.

$8^{\text {th }}$ US National Combustion Meeting, May 19-22, 2013.

(cited on p. 22)

Okude K., Mori K., Shiino S. and Moriya T.

Premixed Compression Ignition (PCI) Combustion for Simultaneous Reduction of NOx and Soot in Diesel Engine.

SAE Technical Paper, $\mathrm{n}^{\circ}$ 2004-01-1907, 2004.

(cited on p. 29)

O'Rourke P.J.

Statistical properties and numerical implementation of a model for droplet dispersion in a turbulent gas.

Journal of Computational Physics, Vol. 83 n n $^{\circ}$, pp. 345-360, $1989 . \quad$ (cited on p. 92)

O'Rourke P.J. and Amsden A.A.

A Spray/Wall Interaction Submodel for the KIVA-3 Wall Film Model.

SAE Technical Paper, $\mathrm{n}^{\circ}$ 2000-01-0271, 2000.

(cited on p. 92)

Owen K., Coley T. and Weaver C.S.

Automotive fuels reference book.

Society of Automotive Engineers, 1995.

(cited on p. 179)

Payri F., Benajes J., Molina S. and Riesco J.M.

Reduction of Pollutant Emissions in a HD Diesel Engine by Adjustment of Injection Parameters, Boost Pressure and EGR.

SAE Technical Paper, $\mathrm{n}^{\circ}$ 2003-01-0343, 2003.

(cited on p. 8)

Payri F. and Desantes J.M.

Motores de combustión interna alternativos.

Editorial Reverté, 2011.

(cited on pp. 67, 130)

Payri F., Margot X., Gil A. and Martín J.

Computational Study of Heat Transfer to the Walls of a DI Diesel Engine.

SAE Technical Paper, $\mathrm{n}^{\circ}$ 2005-01-0210, 2005.

(cited on p. 86)

Pearson R.J. and Turner J.W.G.

2 - The role of alternative and renewable liquid fuels in environmentally sustainable transport A2 - Folkson, Richard.

In Alternative Fuels and Advanced Vehicle Technologies for Improved Environmental Performance, pp. 19-51. Woodhead Publishing, 2014.

(cited on p. 178)

Persson H., Agrell M., Olsson J., Johansson B. and Ström H.

The Effect of Intake Temperature on HCCI Operation Using Negative Valve Overlap.

SAE Technical Paper, $\mathrm{n}^{\circ}$ 2004-01-0944, 2004.

(cited on p. 33)

Persson H., Johansson B. and Remón A.

The Effect of Swirl on Spark Assisted Compression Ignition (SACI).

SAE Technical Paper, $\mathrm{n}^{\circ}$ 2007-01-1856, 2007. 
Pickett L.M. and Siebers D.L.

Non-Sooting, Low Flame Temperature Mixing-Controlled DI Diesel Combustion.

SAE Technical Paper, $\mathrm{n}^{\circ}$ 2004-01-1399, 2004.

(cited on pp. 21, 23)

\section{Pickett L.M. and Siebers D.L.}

Soot in diesel fuel jets: effects of ambient temperature, ambient density, and injection pressure.

Combustion and Flame, Vol. 138 n $^{\circ}$ 1-2, pp. 114-135, $2004 . \quad$ (cited on p.9)

Posada F., Chambliss S. and Blumberg K.

Costs of emission reduction technologies for heavy-duty diesel vehicles.

ICCT White paper, 2016.

(cited on p. 7)

Prikhodko V., Curran S., Barone T., Lewis S., Storey J., Cho K., Wagner R. and Parks J.

Emission characteristics of a diesel engine operating with in-cylinder gasoline and diesel fuel blending.

Technical report, SAE Technical Paper, 2010. (cited on p. 82)

Prikhodko V., Curran S., Parks J. and Wagner R.

Effectiveness of Diesel Oxidation Catalyst in Reducing $\mathrm{HC}$ and $\mathrm{CO}$ Emissions from Reactivity Controlled Compression Ignition.

SAE Int. J. Fuels Lubr., Vol. $6 \mathrm{n}^{\circ}$ 2013-01-0515, pp. 329-335, 2013. （cited on p. 240)

Prikhodko V. and Parks J.

Implications of Low Particulate Matter Emissions on System Fuel Efficiency for High Efficiency Clean Combustion.

SAE Technical Paper, $\mathrm{n}^{\circ}$ 2009-01-2709, 2009 . (cited on p. 256)

Ra Y. and Reitz R.D.

A reduced chemical kinetic model for IC engine combustion simulations with primary reference fuels.

Combustion and Flame, Vol. 155 n $^{\circ}$ 4, pp. 713-738, 2008.

(cited on pp. 92, 95)

Ra Y., Yun J.E. and Reitz R.D.

Numerical simulation of gasoline-fuelled compression ignition combustion with late direct injection.

International Journal of Vehicle Design, Vol. $50 \mathrm{n}^{\circ}$ 1, pp. 3, $2009 . \quad$ (cited on p. 92)

Reitz R.D. and Beale J.C.

Modeling spray atomization with the Kelvin-Helmholtz/Rayleigh-Taylor hybrid model.

Atomization and Sprays, Vol. $9 \mathrm{n}^{\circ}$ 6, pp. 623-650, 1999.

(cited on p. 92)

Reuss D.L., Kuo T.W., Silvas G., Natarajan V. and Sick V.

Experimental metrics for identifying origins of combustion variability during spark-assisted compression ignition.

International Journal of Engine Research, Vol. 9 n ${ }^{o}$ 5, pp. 409-434, 2008.

(cited on p. 33)

Reveille B., Kleemann A., Knop V. and Habchi C.

Potential of Narrow Angle Direct Injection Diesel Engines for Clean Combustion: 3D CFD Analysis.

SAE Technical Paper, $\mathrm{n}^{\circ}$ 2006-01-1365, 2006.

(cited on p. 30)

Ricardo.

Report to the European Commission: Reduction and Testing of GHG emissions from Heavy 
Duty Vehicles - Lot 1: Strategy.

Technical report, February 2011. (cited on p.4)

Saad D., Saad P., Kamo L., Mekari M., Bryzik W., Schwarz E. and Tasdemir J. Thermal Barrier Coatings for High Output Turbocharged Diesel Engine.

SAE Technical Paper, $\mathrm{n}^{\circ}$ 2007-01-1442, 2007.

(cited on p. 137)

Saravana T., Abu A. and Farid A.

Review on bioethanol as alternative fuel for spark ignition engines.

Renewable and Sustainable Energy Reviews, Vol. 56, pp. 820-835, 2016. （cited on p. 179)

Sarjovaara T. and Larmi M.

Dual fuel diesel combustion with an E85 ethanol/gasoline blend.

Fuel, Vol. 139, pp. 704-714, 2015.

(cited on pp. 51, 181)

Sarjovaara T., Larmi M. and Vuorinen V.

Effect of charge air temperature on E85 dual-fuel diesel combustion.

Fuel, Vol. 153, pp. 6-12, 2015.

(cited on pp. 51, 181)

Schwab S.D., Guinther G.H., Henly T.J. and Miller K.T.

The Effects of 2-Ethylhexyl Nitrate and Di-Tertiary-Butyl Peroxide on the Exhaust

Emissions from a Heavy-Duty Diesel Engine.

SAE Technical Paper, ${ }^{\circ}$ 1999-01-1478, 1999.

(cited on p.49)

Sellnau M., Foster M., Hoyer K., Moore W., Sinnamon J. and Husted H.

Development of a Gasoline Direct Injection Compression Ignition (GDCI) Engine.

SAE Int. J. Engines, Vol. 7, pp. 835-851, 2014.

(cited on pp. 241, 242)

Sellnau M., Sinnamon J., Hoyer K., Kim J., Cavotta M. and Husted H.

Part-Load Operation of Gasoline Direct-Injection Compression Ignition (GDCI) Engine.

SAE Technical Paper, $\mathrm{n}^{\circ}$ 2013-01-0272, 2013.

(cited on pp. 241, 242)

Senecal P.K., Richards K.J., Pomraning E., Yang T., Dai M.Z., McDavid R.M., Patterson M.A., Hou S. and Shethaji T.

A New Parallel Cut-Cell Cartesian CFD Code for Rapid Grid Generation Applied to InCylinder Diesel Engine Simulations.

SAE Technical Paper, $\mathrm{n}^{\circ}$ 2007-01-0159, 2007.

(cited on p. 89)

Serrano J.R., Arnau F.J., Martín J., Hernández M. and Lombard B. Analysis of Engine Walls Thermal Insulation: Performance and Emissions.

$\mathrm{n}^{o}$ 2015-01-1660, 2015. (cited on p. 137)

Shabir M.F., Authars S., Ganesan S., Karthik R. and Kumar Madhan S.

Low Heat Rejection Engines - Review.

SAE Technical Paper, $\mathrm{n}^{\circ}$ 2010-01-1510, 2010.

(cited on p. 130)

Shahlari A.J., Hocking C., Kurtz E. and Ghandhi J.

Comparison of Compression Ignition Engine Noise Metrics in Low-Temperature Combustion Regimes.

SAE Int. J. Engines, Vol. 6, pp. 541-552, 2013.

(cited on p. 241)

Sherman M.T., Chase R., Mauti A., Rauker Z. and Silvis W.

Evaluation of Horiba MEXA 7000 Bag Bench Analyzers for Single Range Operation.

SAE Technical Paper, $\mathrm{n}^{\circ}$ 1999-01-0147, 1999.

(cited on p. 80) 
Sherman M.T., Mauti A., Rauker Z. and Dageforde A.

Evaluation of Mass Flow Controller Gas Divider For Linearizing Emission Analytical Equipment.

SAE Technical Paper, $\mathrm{n}^{\circ}$ 1999-01-0148, 1999.

(cited on p. 80)

Silvis W.M.

An Algorithm for Calculating the Air/Fuel Ratio from Exhaust Emissions.

SAE Technical Paper, $\mathrm{n}^{\circ}$ 2016-04-05, 1997.

(cited on p. 81)

Singh N., Rutland C.J., Foster Da.E., Narayanaswamy K. and He Y. Investigation into Different DPF Regeneration Strategies Based on Fuel Economy Using Integrated System Simulation.

SAE Technical Paper, $\mathrm{n}^{\circ}$ 2009-01-1275, 2009.

(cited on p. 255)

Sjöberg M. and Dec J.E.

Smoothing HCCI Heat-Release Rates Using Partial Fuel Stratification with Two-Stage Ignition Fuels.

SAE Technical Paper, $\mathrm{n}^{\circ}$ 2006-01-0629, 2006.

(cited on pp. 27, 28)

Sjöberg M. and Dec J.E.

Ethanol Autoignition Characteristics and HCCI Performance for Wide Ranges of Engine Speed, Load and Boost.

SAE International Journal of Engines, Vol. $3 \mathrm{n}^{\circ}$ 1, pp. 84-106, 2010. (cited on p. 181)

Sjöberg M. and Dec J.E.

Smoothing HCCI Heat Release with Vaporization-Cooling-Induced Thermal Stratification using Ethanol.

SAE International Journal of Fuels and Lubricants, Vol. $5 \mathrm{n}^{\circ}$ 1, pp. 7-27, 2011.

(cited on p. 192)

Splitter D., Hanson R., Kokjohn S. and Reitz R.D.

Reactivity Controlled Compression Ignition (RCCI) Heavy-Duty Engine Operation at Midand High-Loads with Conventional and Alternative Fuels.

SAE Technical Paper, $\mathrm{n}^{\circ}$ 2011-01-0363, 2011.

(cited on p. 50)

Splitter D., Hanson R., Kokjohn S., Wissink M. and Reitz R.D.

Injection Effects in Low Load RCCI Dual-Fuel Combustion.

SAE Technical Paper, $\mathrm{n}^{\circ}$ 2011-24-0047, 2011.

(cited on pp. 105, 227)

Splitter D., Kokjohn S., Rein K., Hanson R., Sanders S. and Reitz R.D.

An Optical Investigation of Ignition Processes in Fuel Reactivity Controlled PCCI Combustion.

SAE Int. J. Engines, Vol. 3, pp. 142-162, $2010 . \quad$ (cited on pp. 39, 47)

Splitter D., Reitz R.D. and Hanson R.

High Efficiency, Low Emissions RCCI Combustion by Use of a Fuel Additive.

SAE International Journal of Fuels and Lubricants, Vol. $3 \mathrm{n}^{\circ}$ 2, pp. 742-756, 2010.

(cited on pp. 47, 48)

Splitter D., Wissink M., Kokjohn S. and Reitz R.D.

Effect of Compression Ratio and Piston Geometry on RCCI Load Limits and Efficiency.

SAE Technical Paper, $\mathrm{n}^{\circ}$ 2012-01-0383, $2012 . \quad$ (cited on pp. 140, 141, 143, 144, 183)

Splitter D., Wissink M., Vescovo D. Del and Reitz R.D.

Improving the Understanding of Intake and Charge Effects for Increasing RCCI Engine Efficiency.

SAE Int. J. Engines, Vol. 7, pp. 913-927, 2014.

(cited on p. 241) 
Splitter D., Wissink M.L., Hendricks T.L., Ghandhi J.B. and Reitz R.D. Comparison of RCCI, HCCI, and CDC Operation from Low to Full Load. THIESEL Conference on Thermo- and Fluid Dynamic Processes in Direct Injection Engines, 2012. (cited on pp.40, 41, 42, 232)

Stanglmaier R.H. and Roberts C.E.

Homogeneous Charge Compression Ignition (HCCI): Benefits, Compromises, and Future Engine Applications.

SAE Technical Paper, $\mathrm{n}^{\circ}$ 1999-01-3682, 1999.

(cited on p. 25)

Stein R.A., Anderson J.E. and Wallington T.J.

An Overview of the Effects of Ethanol-Gasoline Blends on SI Engine Performance, Fuel Efficiency, and Emissions.

SAE Int. J. Engines, Vol. 6, pp. 470-487, 2013.

(cited on p. 180)

Styron J., Baldwin B., Fulton B., Ives D. and Ramanathan S.

Ford 2011 6.7L Power Stroke ${ }^{\circledR}$ Diesel Engine Combustion System Development.

SAE Technical Paper, $\mathrm{n}^{\circ}$ 2011-01-0415, 2011.

(cited on pp. 138, 139, 140)

Takeda Y., Keiichi N. and Keiichi N.

Emission Characteristics of Premixed Lean Diesel Combustion with Extremely Early Staged Fuel Injection.

SAE Technical Paper, $\mathrm{n}^{\circ}$ 961163, 1996.

(cited on p. 28)

Tao F., Foster D.E. and Reitz R.D.

Soot Structure in a Conventional Non-Premixed Diesel Flame.

SAE Technical Paper, $\mathrm{n}^{\circ}$ 2006-01-0196, 2006.

(cited on p. 9)

The European Commission.

Energy, Transport and Environment Indicators.

Technical report, 2014. (cited on pp. 2, 3, 178)

Torregrosa A., Olmeda P., Degraeuwe B. and Reyes M.

A concise wall temperature model for DI Diesel engines.

Applied Thermal Engineering, Vol. 26 n $^{\circ}$ 11-12, pp. 1320-1327, $2006 . \quad$ (cited on p. 86)

Tricoire A., Bjellman B., Wigren J., Vanvolsem M. and Aixala L.

Insulated Piston Heads for Diesel Engines.

Journal of Thermal Spray Technology, Vol. $18 \mathrm{n}^{\circ}$ 2, pp. 217-222, 2009. （cited on p. 137)

Tricoire A., Bjellman B., Wigren J., Vanvolsem M., Aixala L. and Serrano J.R. Insulated piston fire face for diesel engines.

International Thermal Spray Conference ITSC. (cited on p. 137)

Tunèr M., Johansson T., Aulin H., Tunestål P., Johansson B. and Cannella W. Multi Cylinder Partially Premixed Combustion Performance Using Commercial Light-Duty Engine Hardware.

$\mathrm{n}^{\circ}$ 2014-01-2680, 2014. (cited on p. 33)

Turner C.W., Babbitt G.R., Balton C.S., Raimao M.A. and Giordano D.D. Design and Control of a Two-stage Electro-hydraulic Valve Actuation System.

SAE Technical Paper, $\mathrm{n}^{\circ}$ 2004-01-1265, 2004.

(cited on p.67)

Turner C.W., Raimao M.A. and Babbitt G.R.

Hydraulic valve actuation systems and methods.

US Patent App. 10/164,046, Patent Number 6739293, 2002.

(cited on p.67) 


\section{Tutak W.}

Bioethanol E85 as a fuel for dual fuel diesel engine.

Energy Conversion and Management, Vol. 86, pp. 39-48, 2014. (cited on pp. 51, 181)

Wade W.R., Havstad P.H., Ounsted E.J., Trinkler F.H. and Garwin I.J.

Fuel Economy Opportunities with an Uncooled DI Diesel Engine.

C432, pp.11-24, ImechE/SAE 1984, 1984.

(cited on p. 136)

Wagner R.M., Green J.B., Dam T.Q., Edwards K.D. and Storey J.M.

Simultaneous Low Engine-Out NOx and Particulate Matter with Highly Diluted Diesel Combustion.

SAE Technical Paper, $\mathrm{n}^{\circ}$ 2003-01-0262, 2003.

(cited on p. 9)

Walter B. and Gatellier B.

Development of the High Power NADI ${ }^{\mathrm{TM}}$ Concept Using Dual Mode Diesel Combustion to Achieve Zero NOx and Particulate Emissions.

SAE Technical Paper, $\mathrm{n}^{\circ}$ 2002-01-1744, 2002.

(cited on p. 30)

Wanhua S., Tiejian L. and Yiqiang P.

A Compound Technology for HCCI Combustion in a DI Diesel Engine Based on the MultiPulse Injection and the BUMP Combustion Chamber.

SAE Technical Paper, ${ }^{\circ}$ 2003-01-0741, 2003.

(cited on p. 30)

Wickman D.D., Senecal P.K. and Reitz R.D.

Diesel Engine Combustion Chamber Geometry Optimization Using Genetic Algorithms and Multi-Dimensional Spray and Combustion Modeling.

SAE Technical Paper, $\mathrm{n}^{\circ}$ 2001-01-0547, 2001.

(cited on p. 9)

Willand J., Nieberding R-G., Vent G. and Enderle C.

The Knocking Syndrome - Its Cure and Its Potential.

SAE Technical Paper, $\mathrm{n}^{\circ}$ 982483, 1998.

(cited on p. 25)

Woschni G.

A Universally Applicable Equation for the Instantaneous Heat Transfer Coefficient in the Internal Combustion Engine.

SAE Technical Paper, $\mathrm{n}^{\circ}$ 670931, 1967.

(cited on p. 86)

Woschni G., Spindler W. and Kolesa K.

Heat Insulation of Combustion Chamber Walls - A Measure to Decrease the Fuel Consumption of I.C. Engines?

SAE Technical Paper, $\mathrm{n}^{\circ}$ 870339, 1987.

(cited on p. 136)

Xing-cai L., Jian-guang Y., Wu-gao Z. and Zhen $\mathbf{H}$.

Effect of cetane number improver on heat release rate and emissions of high speed diesel engine fueled with ethanol-diesel blend fuel.

Fuel, Vol. 83 n $^{\circ} 14-15$, pp. 2013-2020, 2004

(cited on p. 180)

Yang Y., Dec J.E., Dronniou N. and Cannella W.

Boosted HCCI Combustion Using Low-Octane Gasoline with Fully Premixed and Partially Stratified Charges.

SAE International Journal of Engines, Vol. 5 n ${ }^{\circ}$ 3, pp. 1075-1088, 2012. （cited on p. 27)

Yang Y., Dec J.E., Dronniou N. and Sjöberg M.

Tailoring HCCI heat-release rates with partial fuel stratification: Comparison of two-stage and single-stage-ignition fuels.

Proceedings of the Combustion Institute, Vol. $33 \mathrm{n}^{\circ}$ 2, pp. 3047-3055, 2011.

(cited on p. 27) 
Yang Y., Dec J.E., Dronniou N., Sjöberg M. and Cannella W.

Partial Fuel Stratification to Control HCCI Heat Release Rates: Fuel Composition and Other Factors Affecting Pre-Ignition Reactions of Two-Stage Ignition Fuels.

SAE International Journal of Engines, Vol. $4 \mathrm{n}^{\circ}$ 1, pp. 1903-1920, 2011. (cited on p. 27)

Yokota H., Kudo Y., Nakajima H., Kakegawa T. and Suzuki T.

A New Concept for Low Emission Diesel Combustion.

SAE Technical Paper, $\mathrm{n}^{\circ}$ 970891, 1997.

(cited on p. 29)

Yoon S.H. and Lee C.S.

Effect of undiluted bioethanol on combustion and emissions reduction in a SI engine at various charge air conditions.

Fuel, Vol. 97, pp. 887-890, 2012.

(cited on p. 179)

Yu S. and Zheng M.

Ethanol-diesel premixed charge compression ignition to achieve clean combustion under high loads.

Proceedings of the Institution of Mechanical Engineers, Part D: Journal of Automobile Engineering, pág. 0954407015589870, 2015.

(cited on p. 245)

Zhang W., Tian J-P. and Nishida K.

Effects of Nozzle Hole Diameter and Injection Pressure on Flame Lift-Off and Soot Formation in D.I. Diesel Combustion.

SAE Technical Paper, $\mathrm{n}^{\circ}$ 2011-01-1813, 2011.

(cited on p. 9)

Zhang Y., He B-Q., Xie H. and Zhao H.

The Combustion and Emission Characteristics of Ethanol on a Port Fuel Injection HCCI Engine.

SAE Technical Paper, $\mathrm{n}^{\circ}$ 2006-01-0631, 2006.

(cited on p. 181) 